\title{
Sampling procedure and sample details for the New Zealand Attitudes and Values Study
}

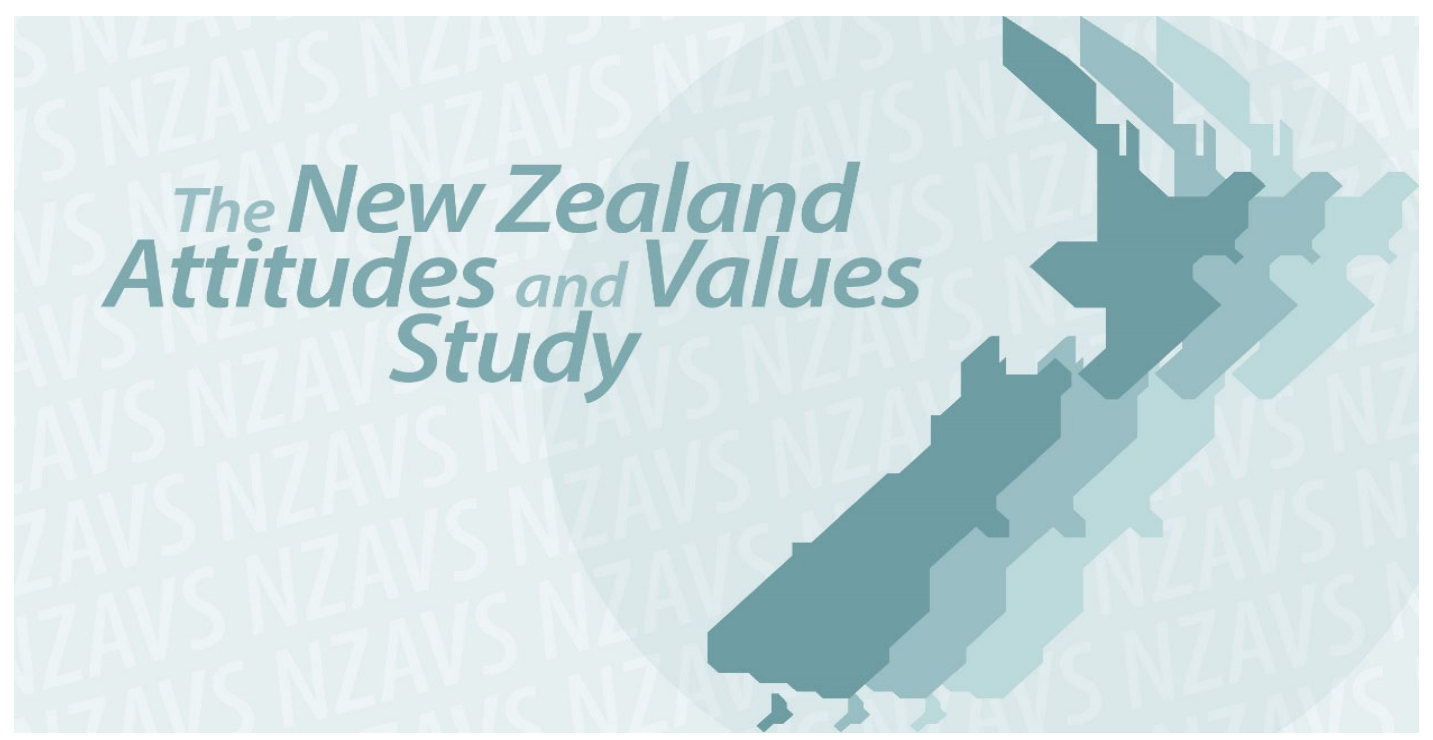

Sibley, C. G. (2021) Sampling procedure and sample details for the New Zealand Attitudes and Values Study. https://doi.org/10.31234/osf.io/wgqvy

Version 4

Updated 16 February 2022

Chris Sibley

New Zealand Attitudes and Values Study

School of Psychology | University of Auckland

c.sibley@auckland.ac.nz |www.nzavs.auckland.ac.nz

www.psych.auckland.ac.nz/people/c-sibley 


\section{Contents}

Preamble

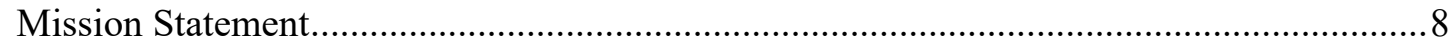

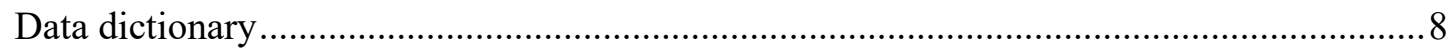

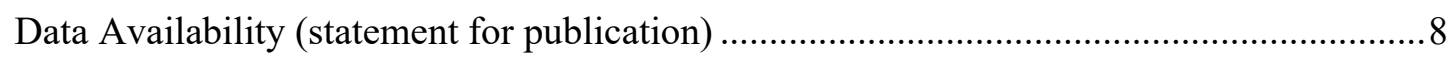

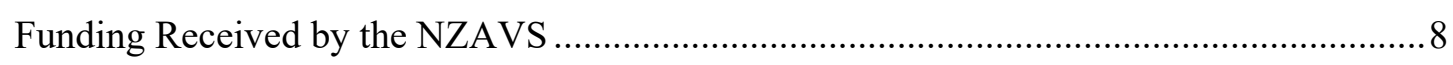

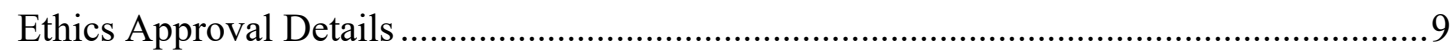

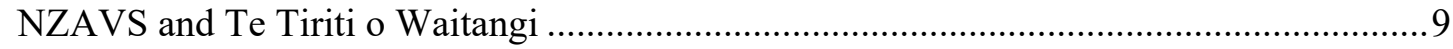

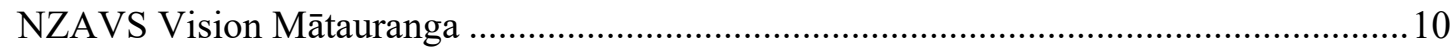

Some thoughts about researcher degrees of freedom in the NZAVS ................................ 10

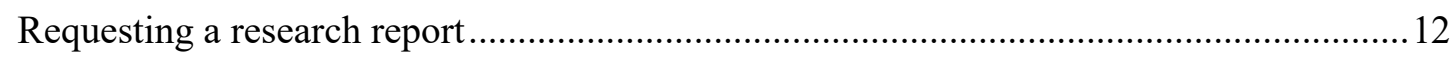

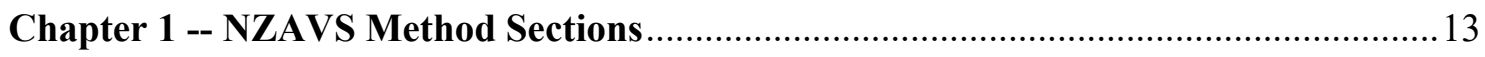

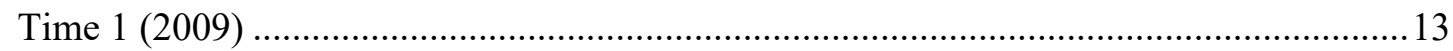

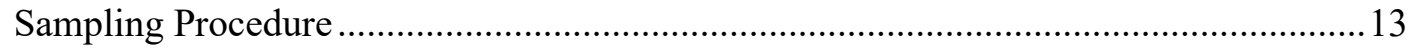

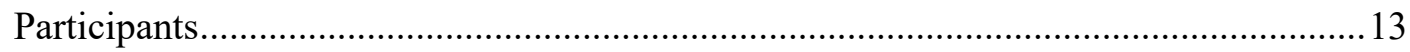

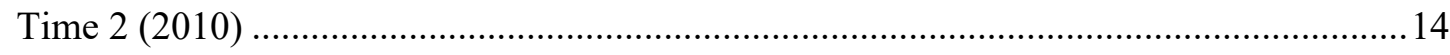

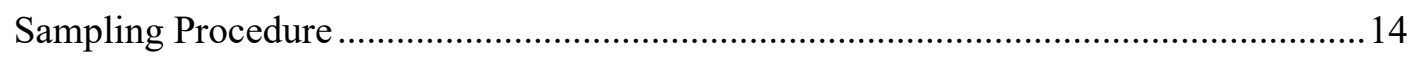

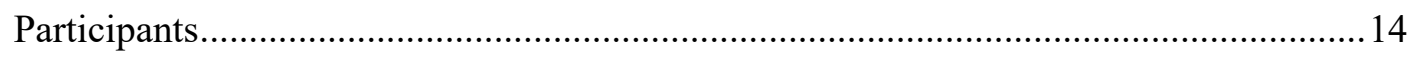

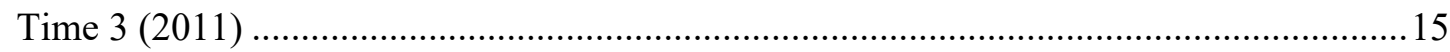

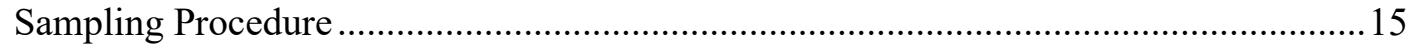

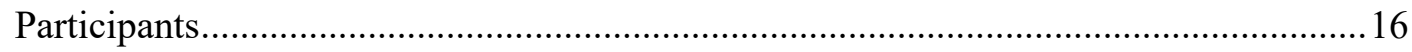

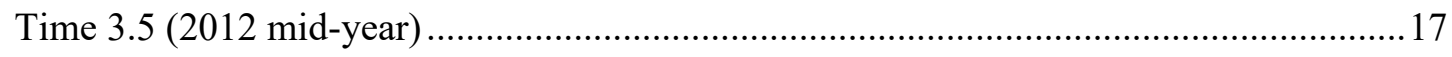

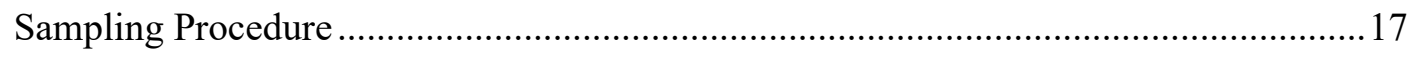

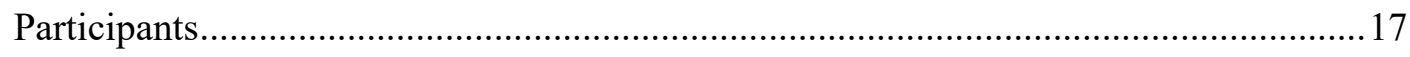

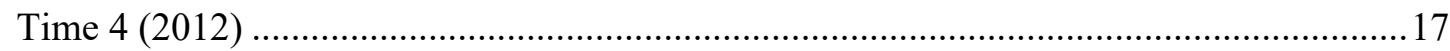

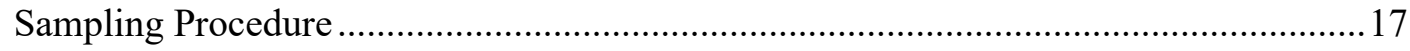

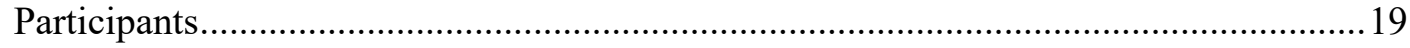

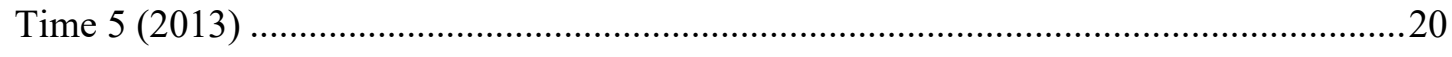

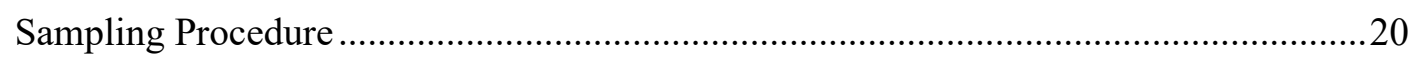

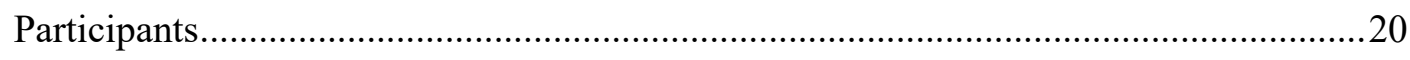

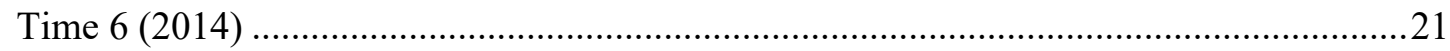

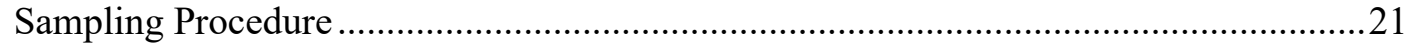

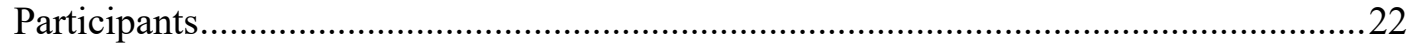

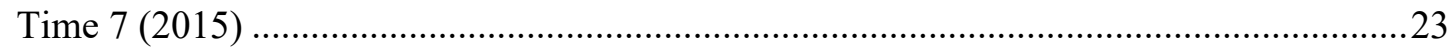

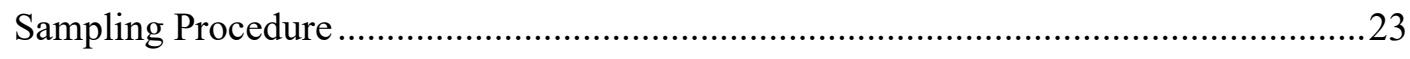

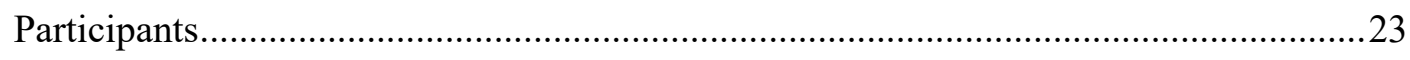

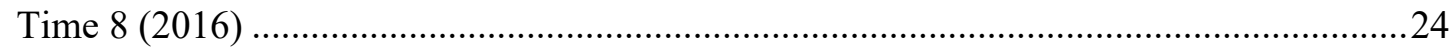




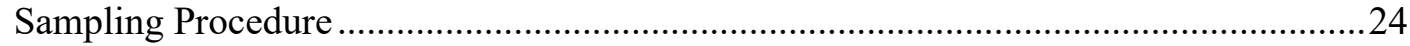

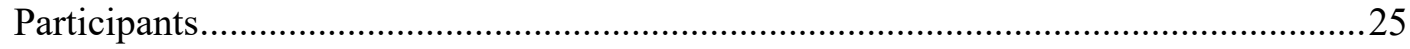

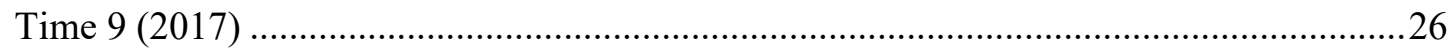

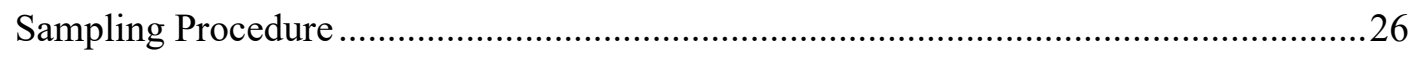

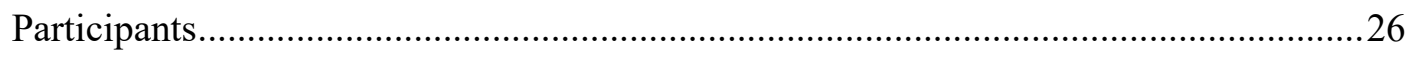

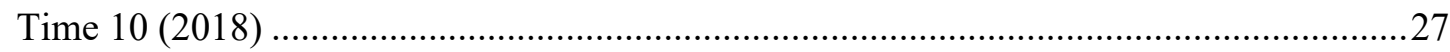

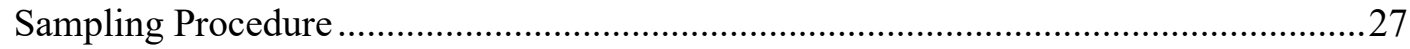

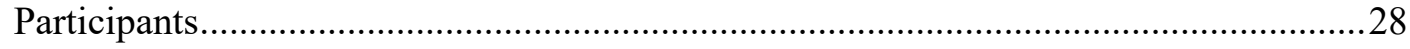

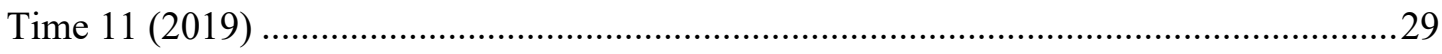

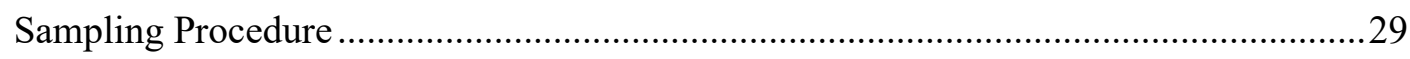

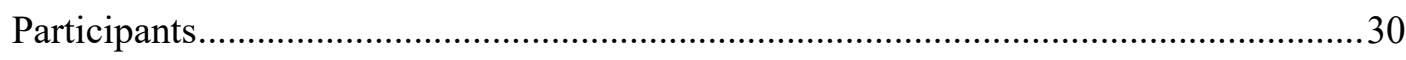

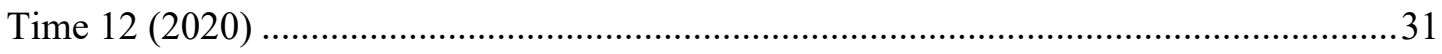

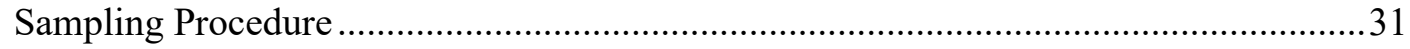

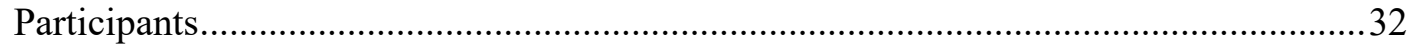

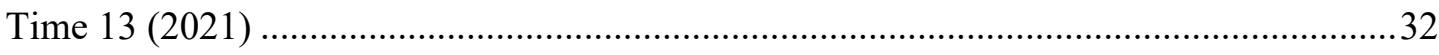

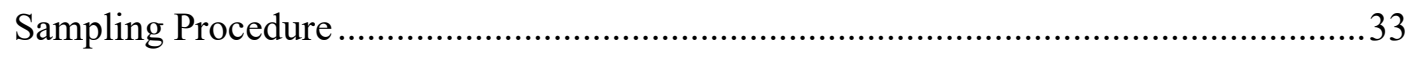

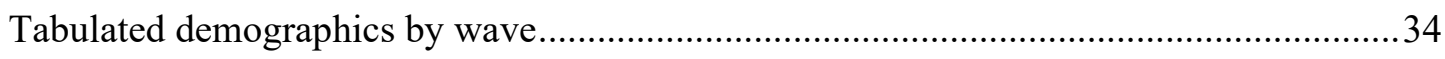

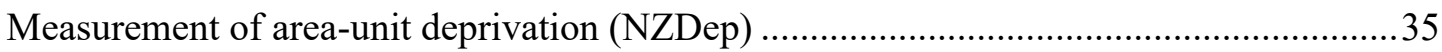

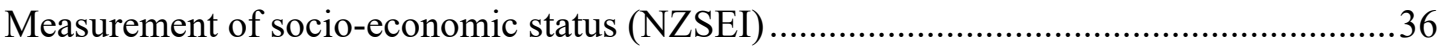

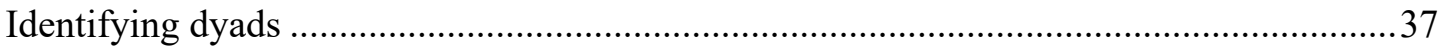

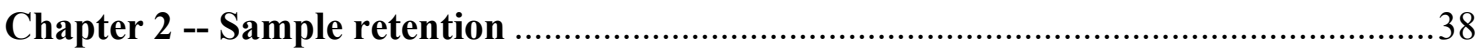

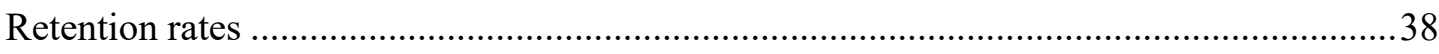

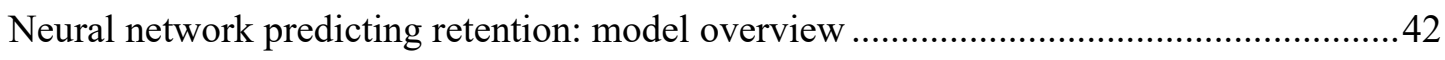

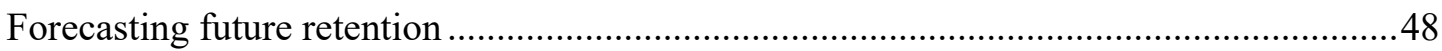

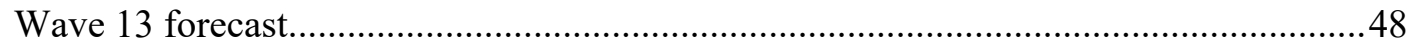

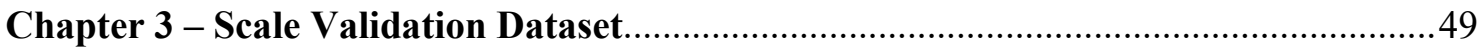

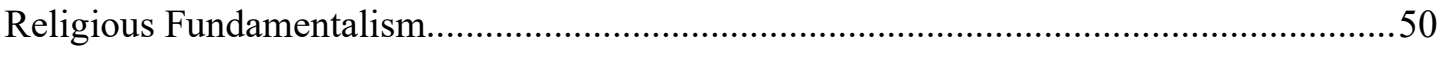

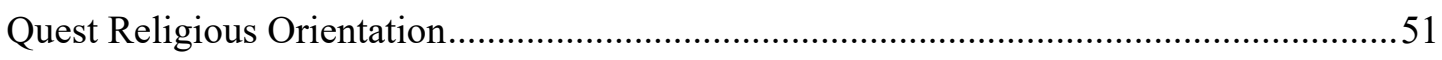

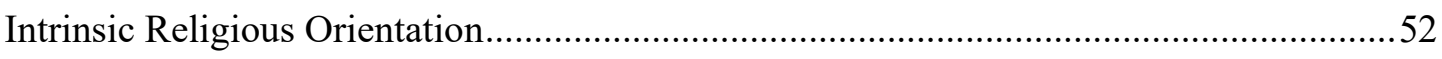

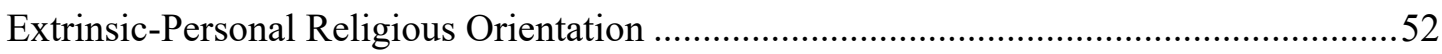

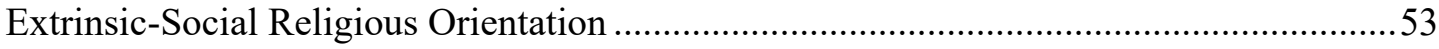

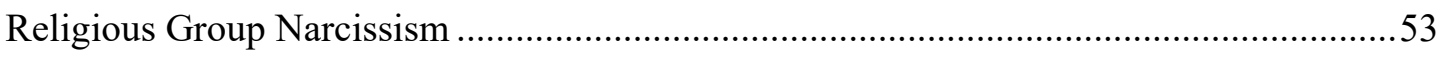

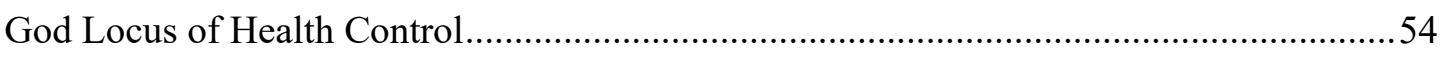

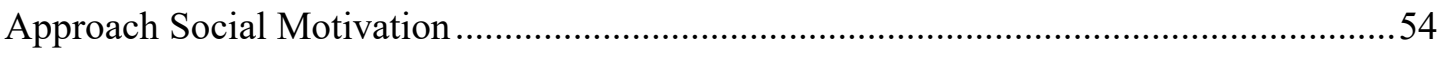

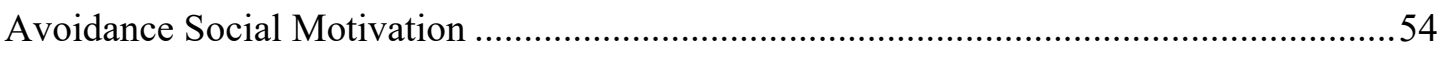

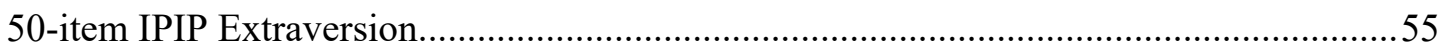

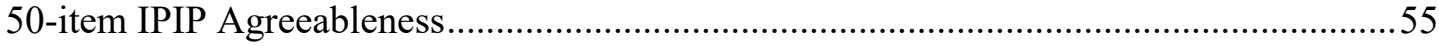




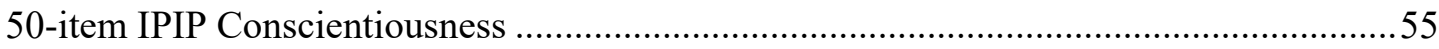

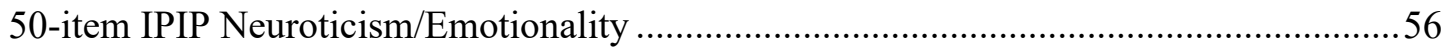

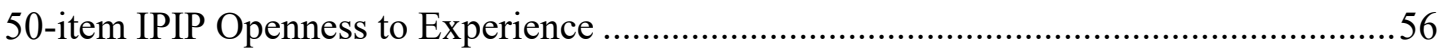

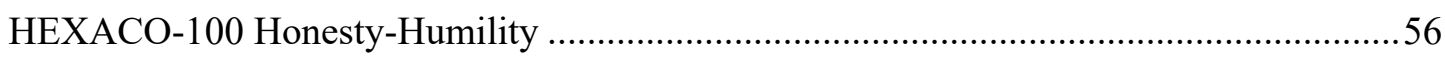

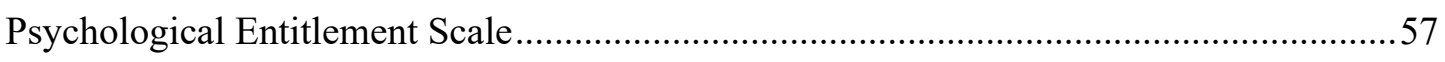

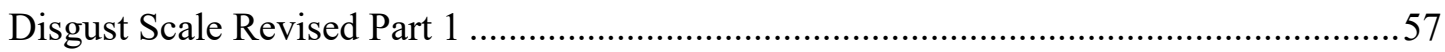

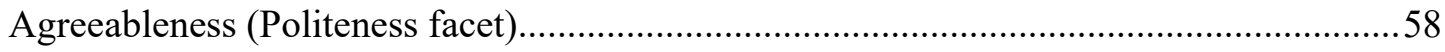

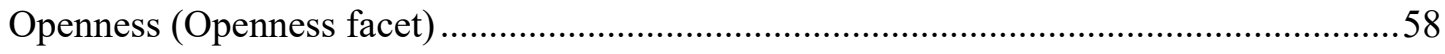

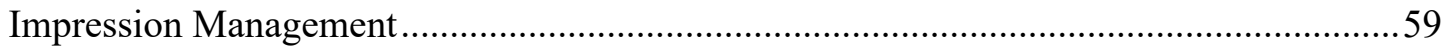

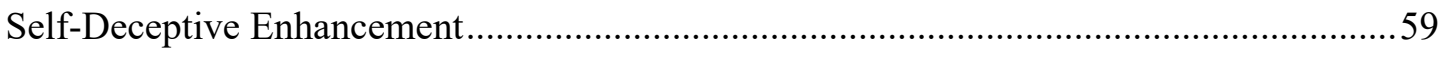

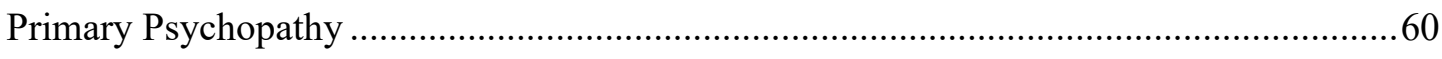

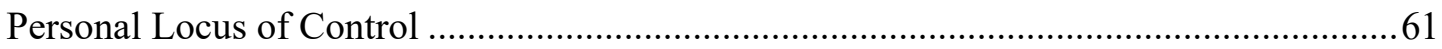

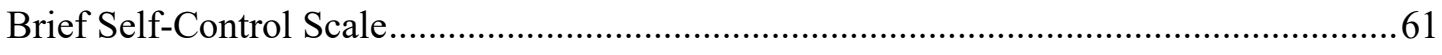

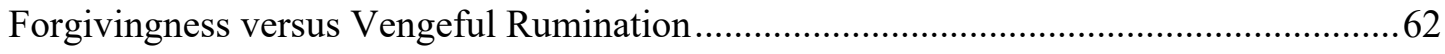

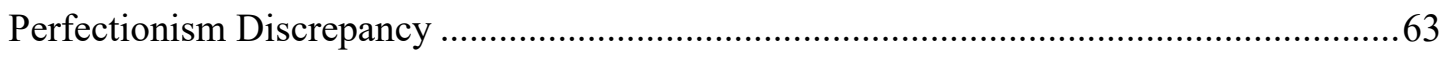

Subjective Health (General health perceptions subscale) ...............................................6 63

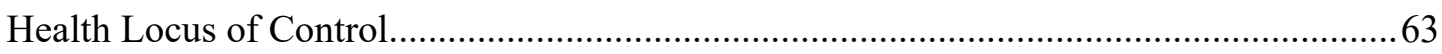

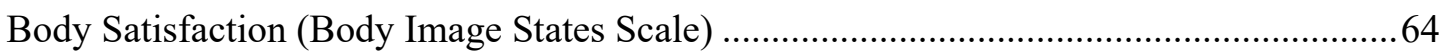

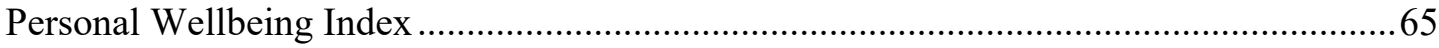

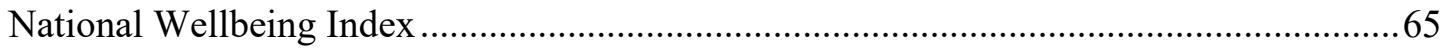

Perceived Social Support (Social Provisions Scale) ........................................................65

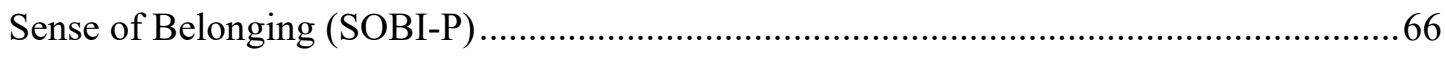

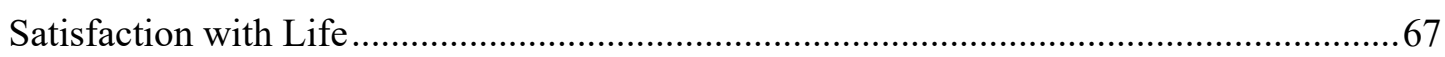

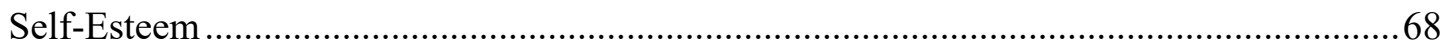

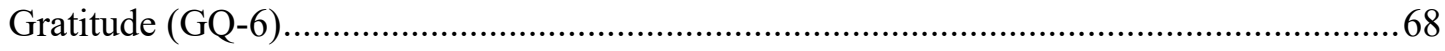

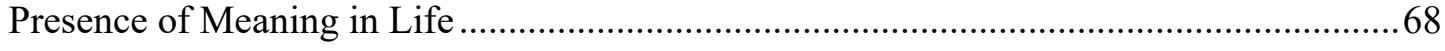

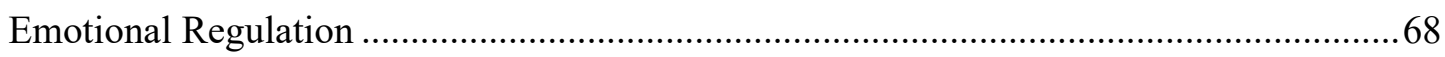

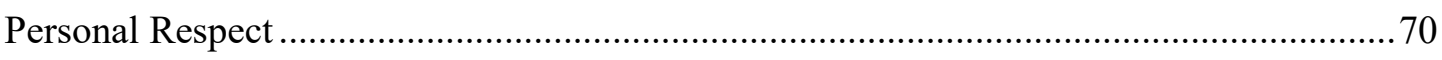

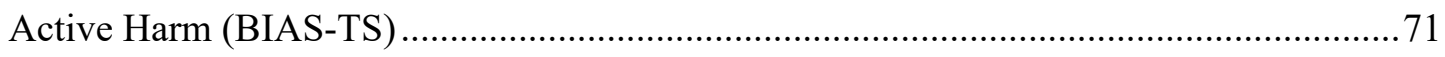

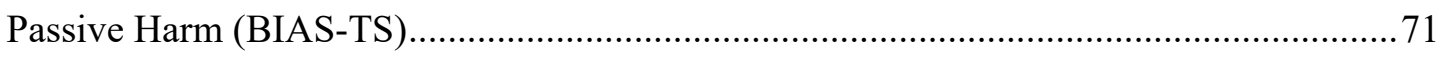

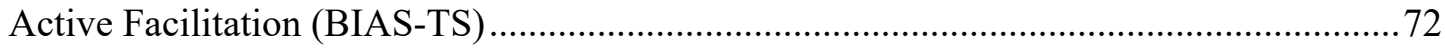

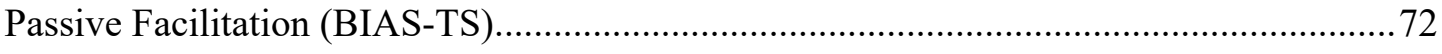

Political Locus of Control/ Political Efficacy ............................................................... 72

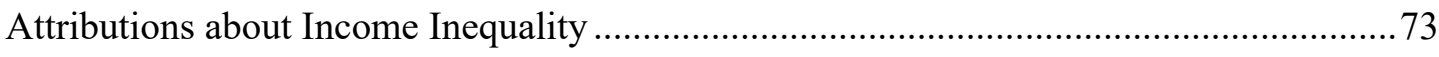

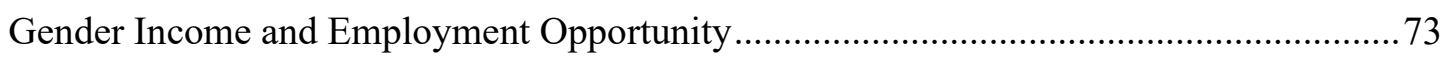

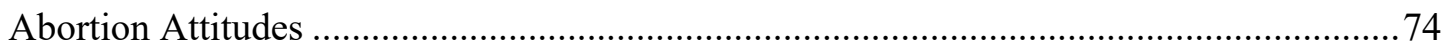

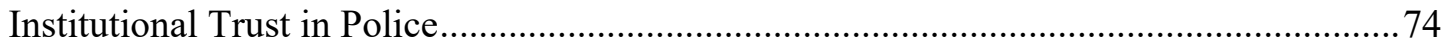




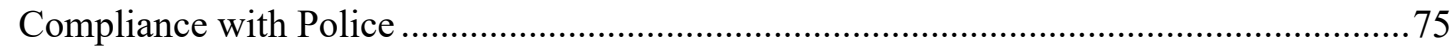

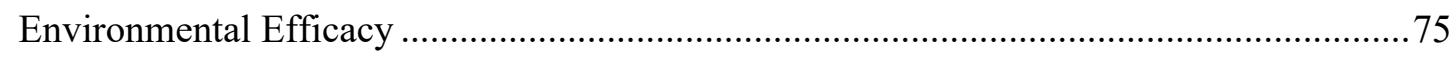

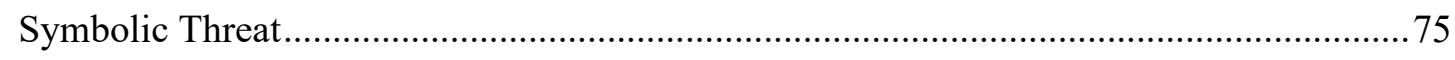

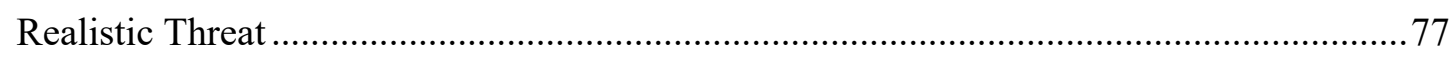

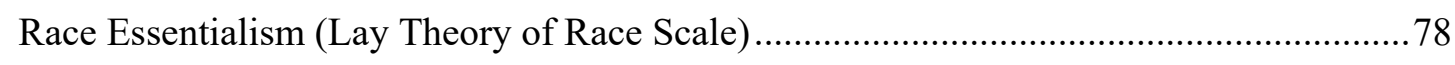

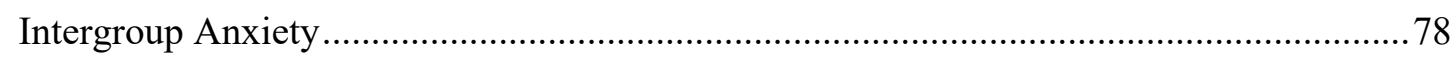

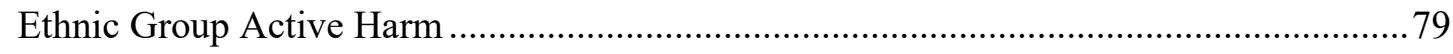

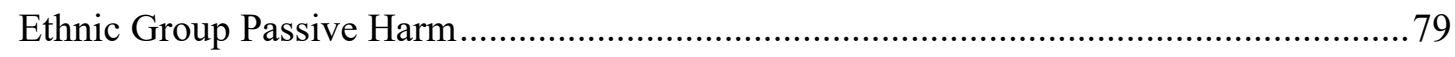

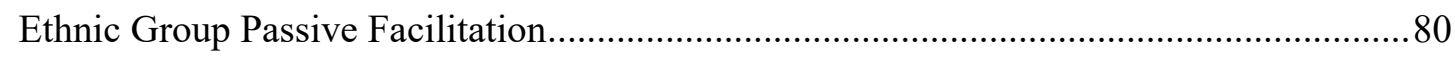

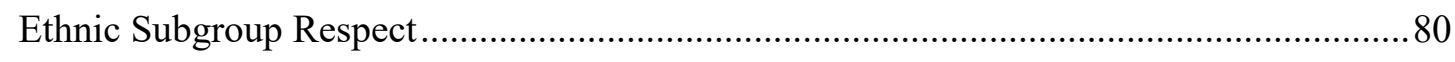

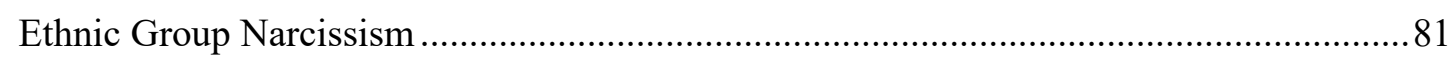

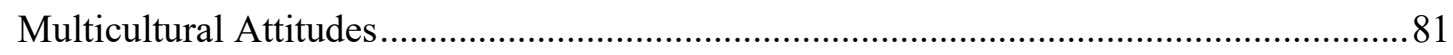

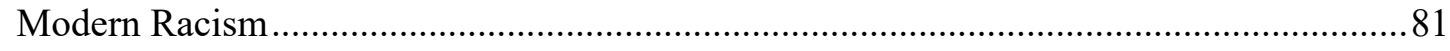

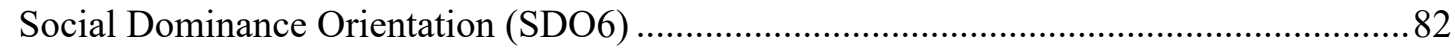

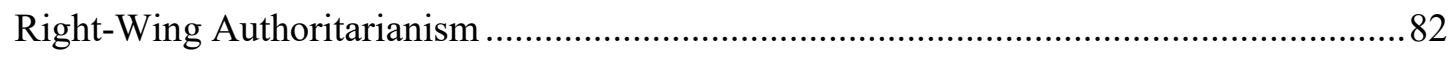

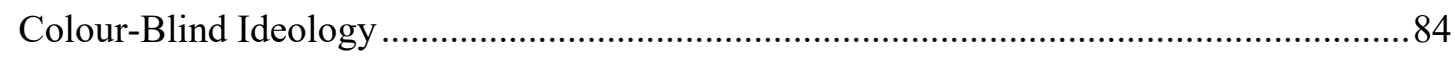

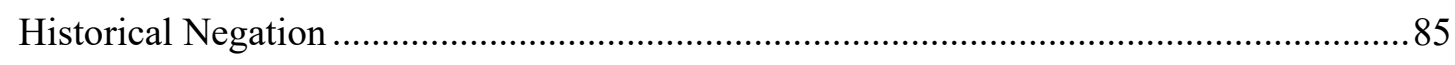

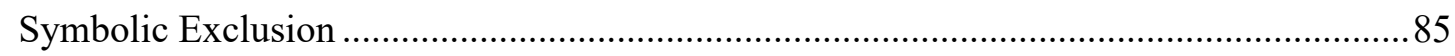

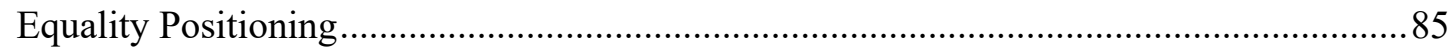

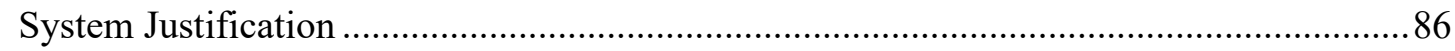

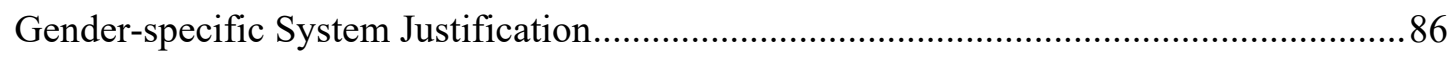

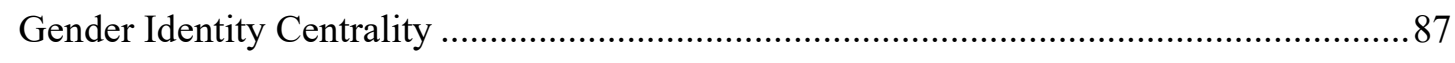

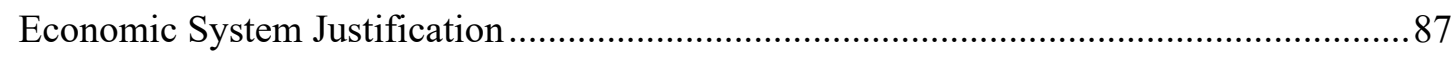

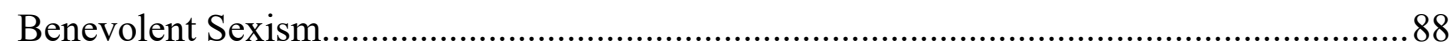

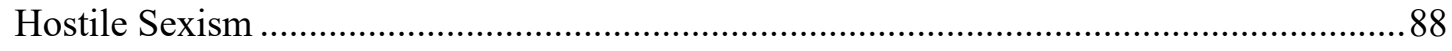

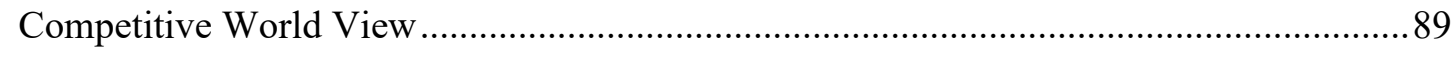

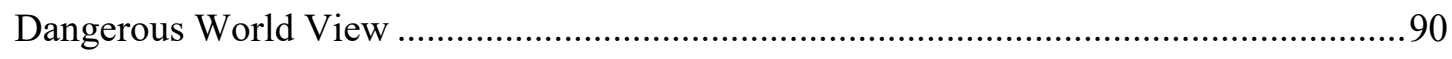

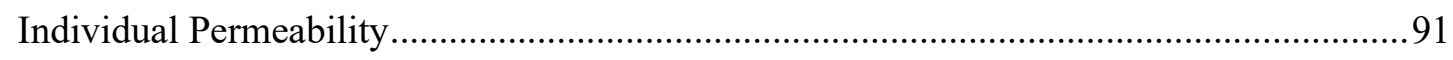

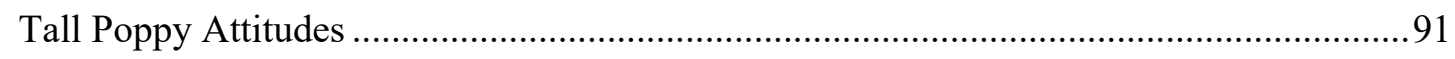

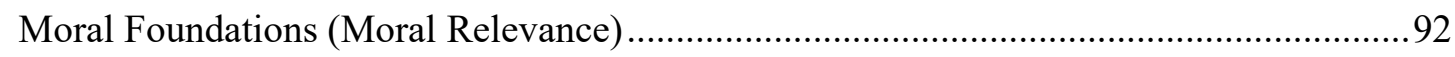

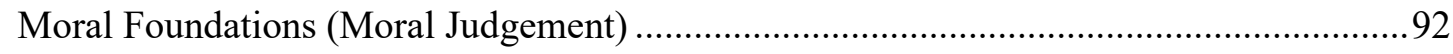

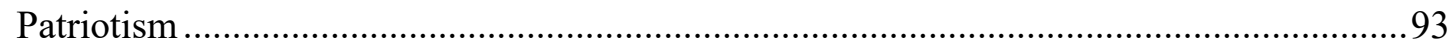

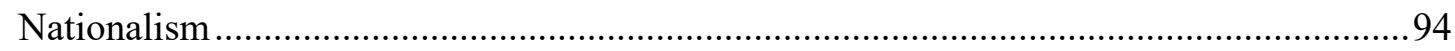

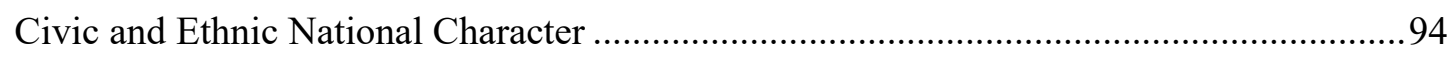

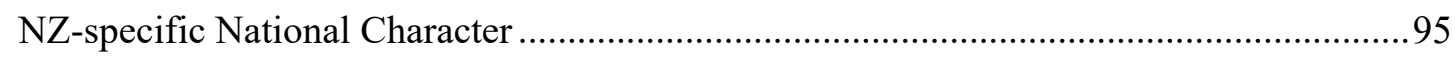

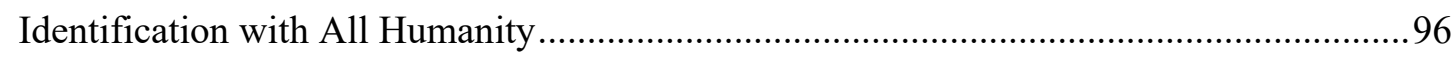

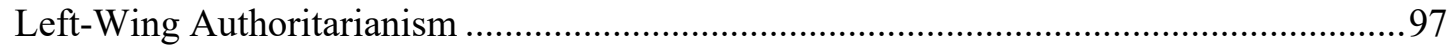




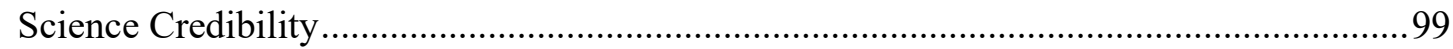

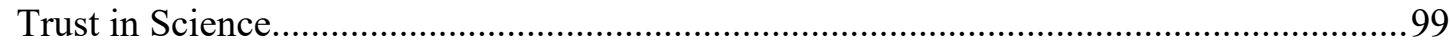

Chapter 4 -- NZAVS Economic Decisions Project......................................................... 100

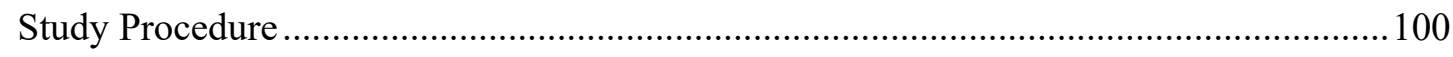

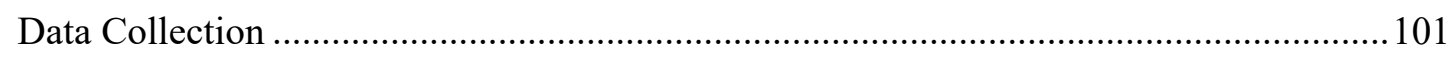

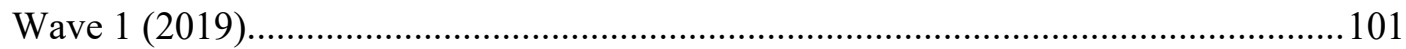

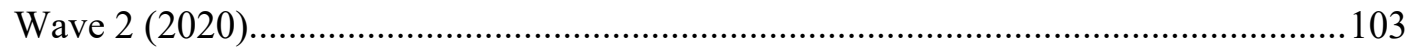

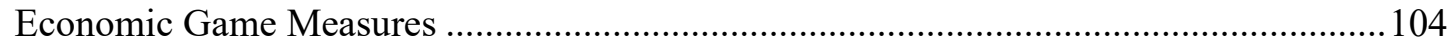

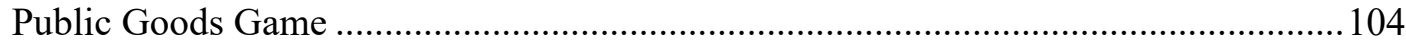

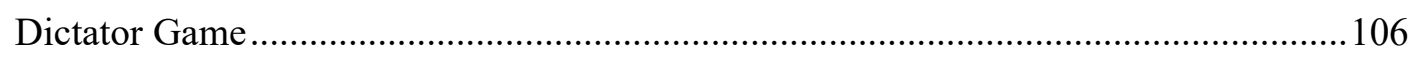

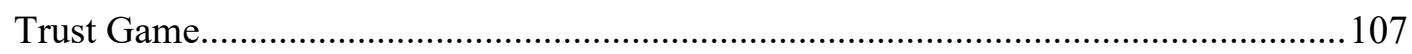

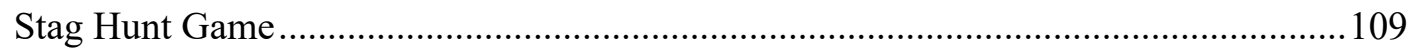

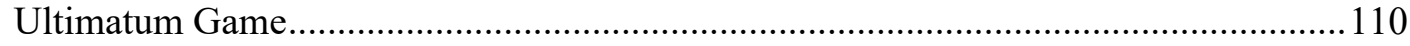

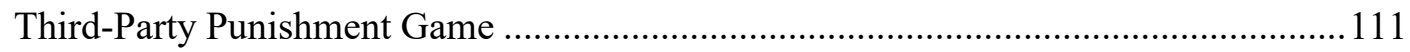

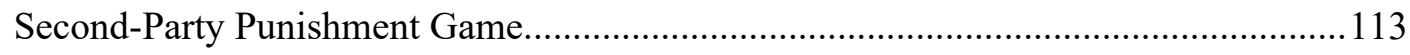

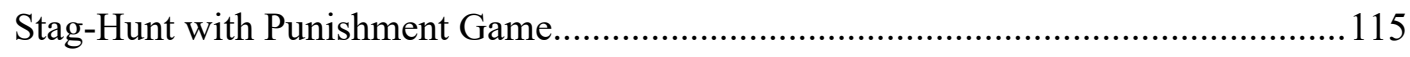

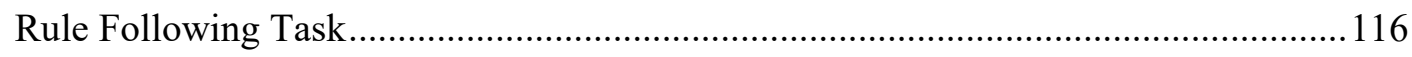

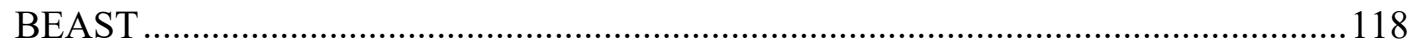

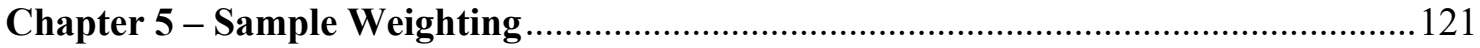

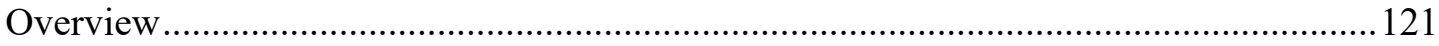

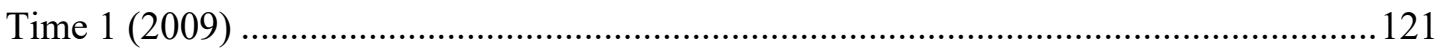

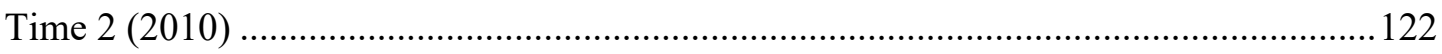

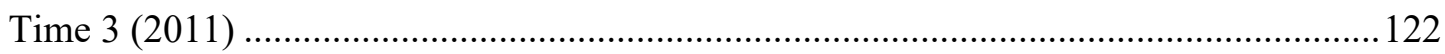

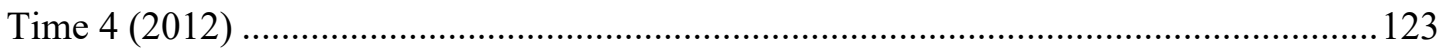

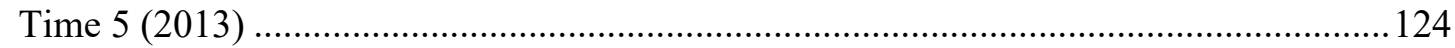

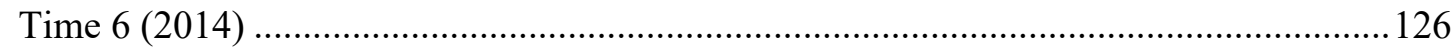

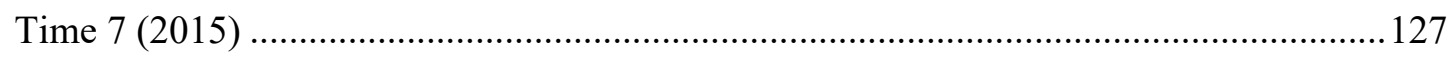

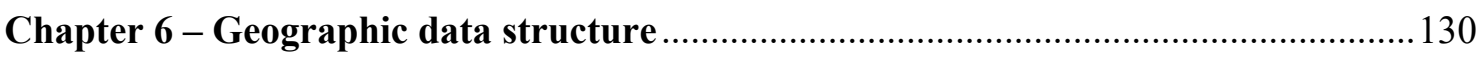

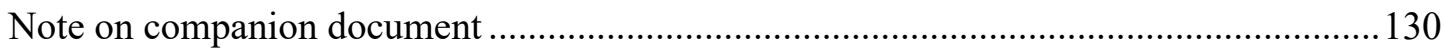

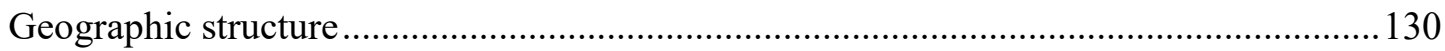

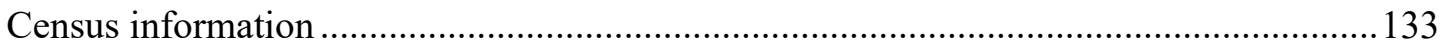

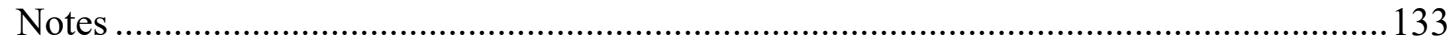

Chapter 7 - Power Estimation of Slope Growth Factors in the NZAVS using Monte

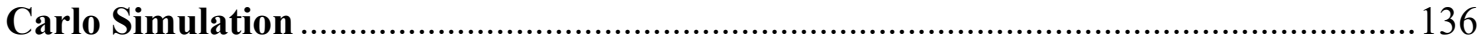

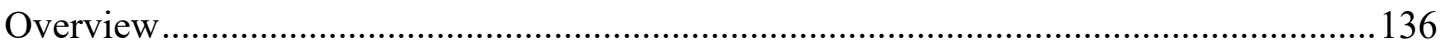

Power Estimation Using Monte Carlo Simulation in Mplus: A Brief Overview ...............136

Known and Projected NZAVS Data Characteristics ..................................................... 137 


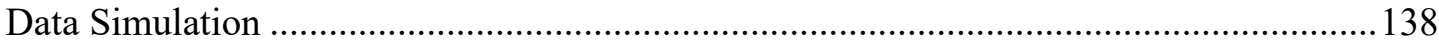

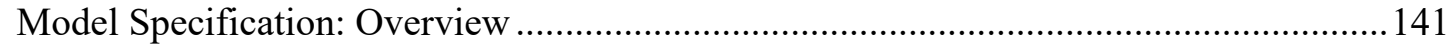

Model 1: LGM without covariates, varying the random effect of slope ....................... 142

Model 2: LGM without covariates, varying the mean of slope ................................... 145

Model 3: LGM with time-invariant covariate, varying the conditional effect of covariate

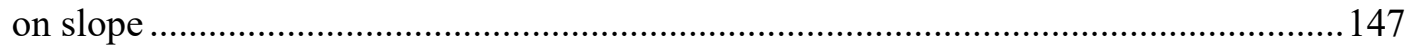

Model 4: LGM with six time-invariant covariates, varying the conditional effect of focal

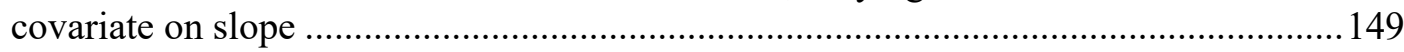

Model 5: LGM with second-order polynomial, varying the random effect of the quadratic component of the slope

Model 6: LGM with second-order polynomial, varying the mean of the quadratic component of the slope

Model 7: LGM with six covariates, varying the conditional effect of focal covariate on quadratic component of slope

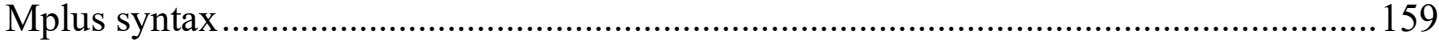

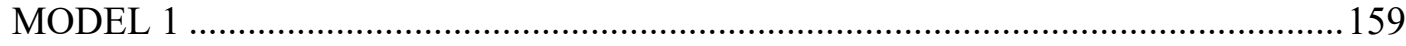

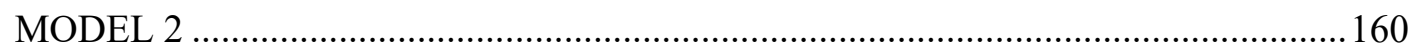

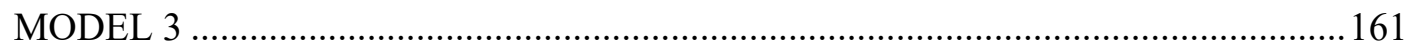

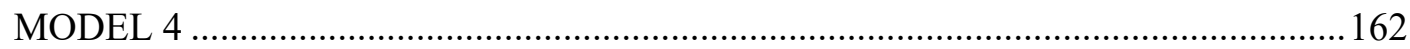

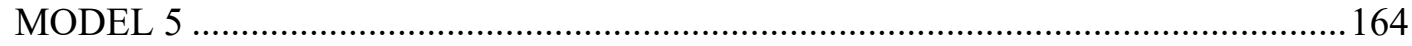

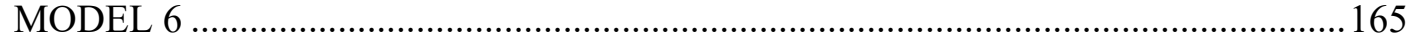

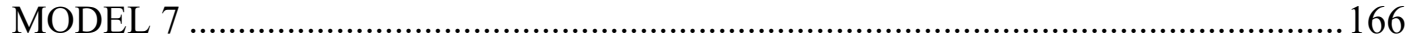

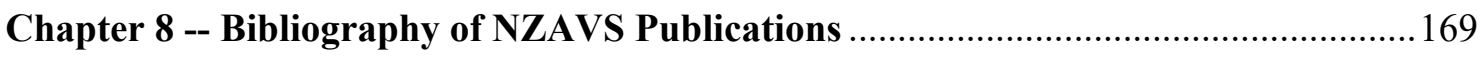

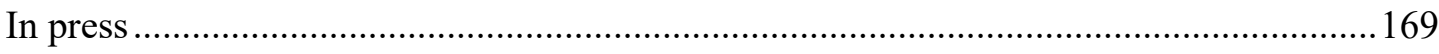

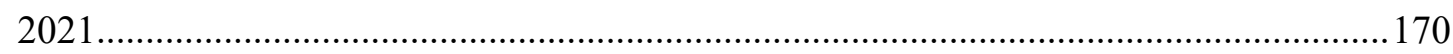

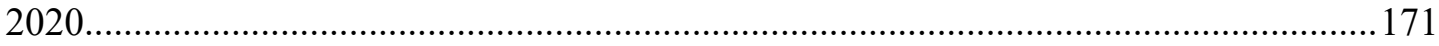

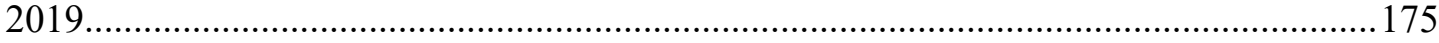

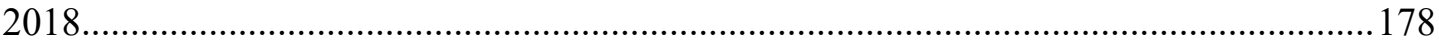

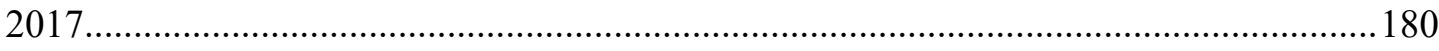

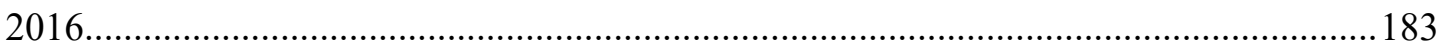

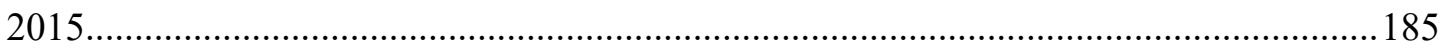

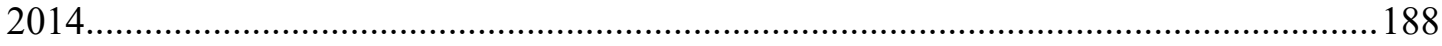

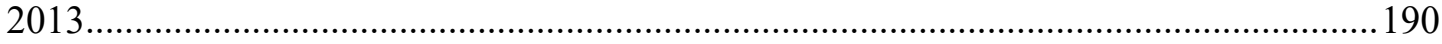

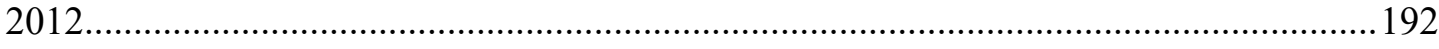

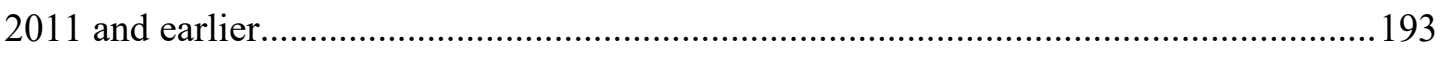

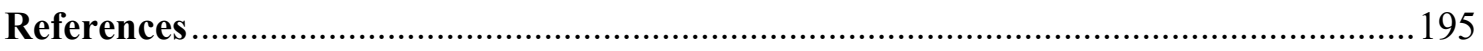

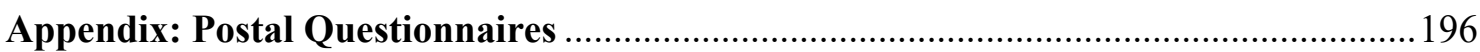




\section{Preamble}

Overview

The New Zealand Attitudes and Values Study (NZAVS) is a 20-year longitudinal national study of social attitudes, personality and health outcomes of more than $60,000 \mathrm{New}$ Zealanders. The study is broad-ranging and includes researchers from a number of New Zealand universities, including the University of Auckland, Victoria University of Wellington, the University of Canterbury, the University of Otago, and Waikato University. The NZAVS extends our understanding of how New Zealanders' life circumstances, attitudes, values, and beliefs change over time. The study is university-based, not-for-profit and independent of political or corporate funding.

The NZAVS is curated by Professor Chris Sibley.

\section{Mission Statement}

The NZAVS is a scientific study led by New Zealanders, for New Zealanders, and about New Zealanders. Broadly stated, the study aims to extend our understanding of how people and their life circumstances change over time.

The NZAVS aims to track changes in various social, psychological and health factors over a twenty-year period, from 2009 to 2029. The study aims to provide information about how the personality, attitudes and values of New Zealanders may be changing over time. This is important because we currently know very little about how peoples' opinions, values and levels of satisfaction with their lives may change gradually over time, and perhaps also change rapidly in response to current events in society. Another key aim of the study is to examine how changes in attitudes and values may relate to changes in health and wellbeing over time. Because the annual survey uses repeat respondents, it can track subtle changes in attitudes and values over time, and is becoming an important tool for researchers.

\section{Data dictionary}

Please note that this document is not the NZAVS data dictionary. If you are looking for the data dictionary, it is available at: www.nzavs.auckland.ac.nz. The data dictionary is the companion to this document, and contains a list of all items included in each wave of the NZAVS, variable names and so forth for the various NZAVS datasets, etc. It is much easier to search the data dictionary for items, and see what has been included in each wave.

\section{Data Availability (statement for publication)}

The data described in the paper are part of the New Zealand Attitudes and Values Study (NZAVS). Full copies of the NZAVS data files are held by all members of the NZAVS management team and advisory board. A de-identified dataset containing the variables analysed in this manuscript is available upon request from Chris Sibley (c.sibley@auckland.ac.nz), or any member of the NZAVS advisory board for the purposes of replication or checking of any published study using NZAVS data. The Mplus syntax used to test all models reported in this manuscript are available on the NZAVS website:

www.nzavs.auckland.ac.nz

\section{Funding Received by the NZAVS}

The NZAVS is funded from various not-for-profit research granting agencies, research trusts, and internal University funding from year-to-year. Our funders have no role in NZAVS study design, data collection and analysis, decision to publish, or preparation of scientific reports or manuscripts for publication using NZAVS data. A full and complete list of all the funding received by the NZAVS is provided in the next paragraph. 
The NZAVS has received funding from the following sources: University of Auckland Faculty Research Development Grants awarded to Chris Sibley in $2009(\$ 30,000)$ and $2014(\$ 25,000)$. A University of Auckland Early Career Research Excellence Award to Chris Sibley in 2010 (\$25,000). A Strategic Fund Grant from the School of Psychology, University of Queensland awarded to Fiona Kate Barlow in 2013 (\$10,000). A Te Whare Kura New Knowledge Acquisition Grant awarded to Carla Houkamau and Chris Sibley in 2013 (\$10,000). Faculty Research Development Grants awarded to Danny Osborne in 2011 $(\$ 30,000)$ and $2015(\$ 50,000)$. A University of Auckland Early Career Research Excellence Award to Danny Osborne in 2015 (\$25,000). A University of Auckland Research Excellence Award to the NZAVS research group (\$5000). A grant from the Templeton World Charity Foundation awarded to Chris Sibley, Joseph Bulbulia and Geoff Troughton in 2013 (\$601,235; \#0077). A Marsden Fund grant from the Royal Society of New Zealand awarded to Joseph Bulbulia in 2013 (\$769,565). A grant from the Templeton Religion Trust awarded to Chris Sibley, Joseph Bulbulia, Geoff Troughton and Don E. Davis in 2018 (\$4,569,114; TRT0196). A COVID-19 Project Grant from the Auckland Medical Research Foundation, awarded to Danny Osborne and Chris Sibley in 2020 (\$81,878; AMRF 1720006). An extension grant from the Templeton Religion Trust awarded to Chris Sibley, Joseph Bulbulia, Geoff Troughton and Don E. Davis in 2021 (\$700,184; TRT0196 one-year extension).

The NZAVS has also received annual support (in the range of \$2000-\$6000 each year) from School of Psychology internal Performance Based Research Funds awarded to Chris Sibley and Danny Osborne, and internal yearly publication incentive funds awarded to Chris Sibley and Danny Osborne, from 2009-2018.

\section{Ethics Approval Details}

The NZAVS is reviewed every three years by the University of Auckland Human Participants Ethics Committee. Our most recent ethics approval statement is as follows: The New Zealand Attitudes and Values Study was approved by the University of Auckland Human Participants Ethics Committee on 26/05/2021 for three years, Reference Number UAHPEC22576.

Our previous ethics approval statement for the 2015-2021 period is: The New Zealand Attitudes and Values Study was approved by The University of Auckland Human Participants Ethics Committee on 03-June-2015 until 03-June-2018, and renewed on 05September-2017 until 03-June-2021. Reference Number: 014889.

Our previous ethics approval statement for the 2009-2015 period is: The New Zealand Attitudes and Values Study was approved by The University of Auckland Human

Participants Ethics Committee on 09-September-2009 until 09-September-2012, and renewed on 17-February-2012 until 09-September-2015. Reference Number: 6171.

For any queries regarding ethical concerns, you may contact the Chair, University of Auckland Human Participants Ethics Committee, Ethics and Integrity Team, University of Auckland, Private Bag 92019, Auckland 1142. Telephone 09 373-7599 ext. 83711. Email: humanethics@auckland.ac.nz

\section{NZAVS and Te Tiriti o Waitangi}

In keeping with Te Tiriti o Waitangi/The Treaty of Waitangi ("the Treaty") the New Zealand Attitudes and Values Study recognises the unique status accorded Māori as tangata whenua (people of the land) in Aotearoa/New Zealand. Three key principles underpin the relationship between the Government and Māori under the Treaty: partnership, participation and protection.

The NZAVS recognises these three principles and strives to uphold them in the following ways: 
Protection: As a research team we are committed to respecting and protecting data gathered from all our participants and take confidentiality seriously (please see confidentiality statement here). We have a protocol for managing how data relating to Māori is prepared for publication. Any papers which focus specifically on Māori issues or data require review from our senior Māori academic advisor Associate Professor Carla Houkamau (and/or appropriate nominated reviewers). This ensures that data relating to Māori is reported in a respectful way considering the socio-political, cultural and historical context of Māori.

Participation: Māori representation is an important part of our research, and we invest in ensuring Māori representation within our samples. The NZAVS is also committed to enhancing the research capacity of Māori. We work closely with Māori collaborators to plan and implement strategies for Māori research development. Toward these goals, the NZAVS also works in partnership with our sister study, Te Rangahau o Te Tuakiri Māori me Ngā Waiaro ā-Pūtea | The Māori Identity and Financial Attitudes Study.

Partnership: In carrying out our research we are attentive to patterns in our data which are relevant to the interests of Māori. We actively seek research opportunities for emerging Māori researchers and explore co-publication options with Māori scholars. We take a proactive role in nurturing Māori undergraduate and graduate students who indicate an interest in accessing NZAVS data for research in their own post graduate theses or dissertations.

\section{NZAVS Vision Mātauranga}

In keeping with Vision Mātauranga, we understand that Māori success is New Zealand's success. The NZAVS is committed to upholding Vision Mātauranga as another way of strengthening our commitment to making a positive, long-term contribution to New Zealand. We do this by:

- Proactively seeking patterns in our data which is of interest and relevance to Māori and encouraging co-publication with Māori students and scholars.

- Developing Māori research capability through supporting Māori undergraduate and postgraduate students seeking employment, research and study opportunities with the NZAVS team.

- Fostering connections with Māori researchers through the Māori Identity and Financial Attitudes Study.

\section{Some thoughts about researcher degrees of freedom in the NZAVS}

This section is just some of my (Chris') personal reflections about researcher degrees of freedom in analyses of the NZAVS. I have included this section because I get asked about this rather frequently, and so thought it worth stating a position. First, I distinguish between (a) the decisions that I make in terms of data collection and building the NZAVS database itself and (b) decisions that get made in analyses of the NZAVS data to answer a particular research question.

With regard to the first point, I have literally been making decisions every day for more than 10 years now about how to build and manage the NZAVS database, collect and process the data, items to include in a given wave, screen for matching errors, set thresholds for the numerous algorithms I have written to help process and match data, improve retention, etc. Those are all researcher degrees of freedom, but in the sense of building the database itself. Some obvious ones: people might ask about are things like stopping criteria for data collection, sample size, and power. Simply put, I do everything I can to retain as many people 
as possible in the wave up until October each year, at which point the wave is closed, and collection of the next wave begins. Our sample size is determined by our funding, in terms of how large an initial sample, and booster samples, we were able to collect, and how well we perform at retaining as many people as possible. I see these decisions as independent from decisions that people make about any specific analyses of the NZAVS data to answer specific research questions, as all of my decisions about how the sample is collected and the database is built are determined in advance, and finalized before any data is analysed each year. I spend the majority of my time focused on building the NZAVS database and making it excellent, rather than thinking about its use for specific research questions (that said, my primary interest is in tracking change in prejudice over time, and my primary goal in setting up the NZAVS in the first place was to look at factors predicting within-person change in prejudice and ideology over time).

Now, my thoughts with regard to researcher degrees of freedom for data analyses... First, as mentioned above, there is no prior determination of statistical power for a given analysis. The sample size is as large as it was possible for our team to achieve. All decisions about data processing, data matching, screening for errors, and so forth in the baseline NZAVS dataset have already been made in isolation by me before the data is made available to anyone else in the research team for analysis.

Note that statistical outliers have not been deleted. However, things I judge to be improbable income values, such as where a participant reported $\$ 50,000 \mathrm{k}$ income for 4 years in a row, then $\$ 500,000$ one year, then back to $\$ 50,000 \mathrm{k}$, and kept the same occupation, at the same job, and the same residence, with the same partner (as this is household income) the whole time have been assumed as a typo made by the participant on the questionnaire and the $\$ 500,000$ value changed to $\$ 50,000$ (I also check for all of these sorts of things in terms of data entry errors on the paper questionnaires). Another interesting example is screening for cases where there might seem to be a large number of logical contradictions, such as consistently strongly agreeing with equivalent portrait and contrait statements. This is uncommon, but does happen. Inspection of these cases indicates that most participants who respond in this way also tend to report some form of head injury or other brain trauma in the open-ended section asking about their health. These cases have been retained, as in my view they represent part of the target population (i.e., adults in New Zealand). Where participants have made obvious patterns in their responses, such as a zig-zag pattern across all the pages, and writing nonsensical responses into the open-ended options, they have been deleted (this might be 5 or so people each year, but is decreasing as we follow the sample people over time). I mention these by way of example, as there are many factors like this that I have considered in advance of the data being released to the team for analysis.

With regard to how researcher degrees of freedom in data analysis are managed, I have two suggestions. The first obvious one is (a) some form of pre-registration. The second possibly less obvious one in our field is (b) the use of a holdout sample replicating the analysis (as an aside a lot of the neural networks and other algorithms I have written to help process the NZAVS dataset have been trained or calibrated using holdout samples, so I like this approach).

With regard to pre-registration, you are welcome to pre-register your analysis plan before working with the NZAVS data. One option that I quite like when developing complex models with many assumptions and choices along the way is to plan out a model, and check that it works - at least in principle - using random (or less focal) outcome variables. Similarly, you could plan out the model and test convergence, etc., using Monte Carlo simulation, then pre-register the Mplus code for your model, along with a list of the variables you plan to analyse as outcomes in your model. As an example, a while back I developed a piecewise growth model that can be used to study the onset of an event, where that event can 
occur during different years for different participants and hence y0 (first measurement postonset) differs across participants (such as birth of first child, or retirement). I got the general version of the model and code for it working using one outcome measure and then planned to pre-register the model, with a statement that no additional changes will be made to the code for the model itself, apart from using it to test for effects on the focal DVs, which have not yet been analysed.

Personally, I would lean toward the use of holdout samples in analyses of the NZAVS dataset where possible (i.e., where $\mathrm{n}$ is not an issue). For a start, the NZAVS sample size is very large relative to many datasets in psychology. Our total participant base is over 67,000, and at Wave 10 in particular (for cross-sectional models) we have $n$ greater than 47,000 (one could also increase cross-sectional $n$ by taking the first wave during which each participant completed the measure of interest and the also including which wave they were drawn from as a covariate). Where possible, and in particular if post-hoc decisions have been made in terms of model building, I think it is worth considering randomly selecting $30 \%$ of the sample (or maybe 50\% depending) as a holdout sample, and once your model is finalized, re-running the model on the holdout sample and checking that it replicates. The analyses of the holdout sample could then be presented in a second set of columns in parameter tables, or as a supplement, depending. To assist in this, there is a variable RANDOM in the dataset, which contains randomly generated values from a normal distribution with $\mathrm{M}=0$ and $\mathrm{SD}=1$. In Mplus (where random case section is not currently possible), one could simply select cases less than or greater than some value of this variable, of some section of the SD range for the holdout sample. Even if analyses for the full sample are presented, I suggest at least using a training/holdout sample approach initially and even just footnoting it. Another related option that some NZAVS researchers have used is to replicate a cross-sectional analysis using data from a second timepoint.

Finally, these are just some personal thoughts and suggestions, and certainly not intended as rules for how analyses should or must be conducted using the NZAVS. In the end, we all need to make our own informed decisions.

\section{Requesting a research report}

Research reports using anonymous data from the study may be requested for the purposes of not-for-profit social and health research in New Zealand. We do not charge for use of or access to the NZAVS data itself. To cover the cost of data analysis and preparing the report itself, typically a post-graduate would be employed on a short-term contract. In some cases, we are also open to preparing reports on important social issues free of charge.

The NZAVS is a university-based, scientific not-for-profit study. The NZAVS is not affiliated with or funded by any political organization or government body. Our study is independent of government or corporate interests.

Results and publication of all NZAVS data are independent of any specific funding agency, corporate or government body. To request a report using NZAVS data please contact: Professor Chris Sibley 


\title{
Chapter 1 -- NZAVS Method Sections
}

\author{
Time 1 (2009)
}

\section{Sampling Procedure}

The Time 1 (2009) NZAVS contained responses from 6,518 participants sampled from the 2009 New Zealand electoral roll, who were currently residing in New Zealand (one can be registered to vote in New Zealand but living overseas). The electoral roll is publicly available for scientific research and in 2009 contained 2,986,546 registered voters. This represented all citizens over 18 years of age who were eligible to vote regardless of whether they chose to vote, barring people who had their contact details removed due to specific caseby-case concerns about privacy. The sample frame was spilt into three parts. Sample Frame 1 constituted a sample of 25,000 people from the electoral roll (4,060 respondents). Sample Frame 2 constituted a further 10,000 people from the electoral roll (1,609 respondents). Sample Frame 3 constituted 5,500 people randomly selected from meshblock area units of the country with a high proportion of Māori, Pacific Nations and Asian peoples (671 respondents). ${ }^{1}$ All three samples were drawn using a stratified random procedure in which 25,000, 10,000 and 5,500 unique households (postal addresses) were first drawn, and then one person per household was randomly selected. A further 178 people responded but did not provide contact details and so could not be matched to a sample frame.

In sum, postal questionnaires were sent to 40,500 registered voters or roughly $1.36 \%$ of all registered voters in New Zealand. The overall response rate (adjusting for the address accuracy of the electoral roll and including anonymous responses) was $16.6 \%$.

\section{Participants}

The Time 1 wave included 3,879 women and 2,639 men, with a mean age of 48.10 years $(\mathrm{SD}=15.75)$. With regard to ethnicity, 5,340 people identified as European, 1,168 as Māori, 280 were Pacific Nations peoples, and 322 identified with an Asian ethnic group. Note that people could identify with multiple ethnic groups (and hence be counted multiple times). Education $(\mathrm{M}=4.04, \mathrm{SD}=2.78)$ was coded using the New Zealand Qualifications Authority scheme, which ranged from 0 (none) to 10 (doctoral degree or equivalent). Deprivation $(\mathrm{M}=5.06, \mathrm{SD}=2.85)$ was coded using the New Zealand Deprivation index for the meshblock level (approx. 100 person-sized geographic units), with a decile rank from 1 (low) 10 (high; Atkinson, Salmond \& Crampton, 2014). Socioeconomic status $(\mathrm{M}=49.75$, $\mathrm{SD}=15.77$ ) was scored from 10 (low) to 90 (high) using the New Zealand Socioeconomic Index, which assigned a score based on occupation and derived from census data (Fahy, Lee, \& Milne, 2017). Mean household income was NZ\$81,055 $(\mathrm{SD}=\mathrm{NZ} \$ 65,579$, median $=$ NZ\$70,000). Of the 6,518 people sampled, 2,826 were religious; 4,888 were parents; 4,558 had a romantic partner; 4,742 were employed; 3,839 lived in an urban or suburban area; and 5,138 were born in New Zealand.

\footnotetext{
${ }^{1}$ Statistics New Zealand (2013) define the meshblock as "the smallest geographic unit for which statistical data is collected and processed by Statistics New Zealand. A meshblock is a defined geographic area, varying in size from part of a city block to large areas of rural land. Each meshblock abuts against another to form a network covering all of New Zealand including coasts and inlets, and extending out to the two-hundred-mile economic zone. Meshblocks are added together to 'build up' larger geographic areas such as area units and urban areas. They are also the principal unit used to draw-up and define electoral district and local authority boundaries." Meshblocks were selected using ethnic group proportions based on 2006 national census data.
} 


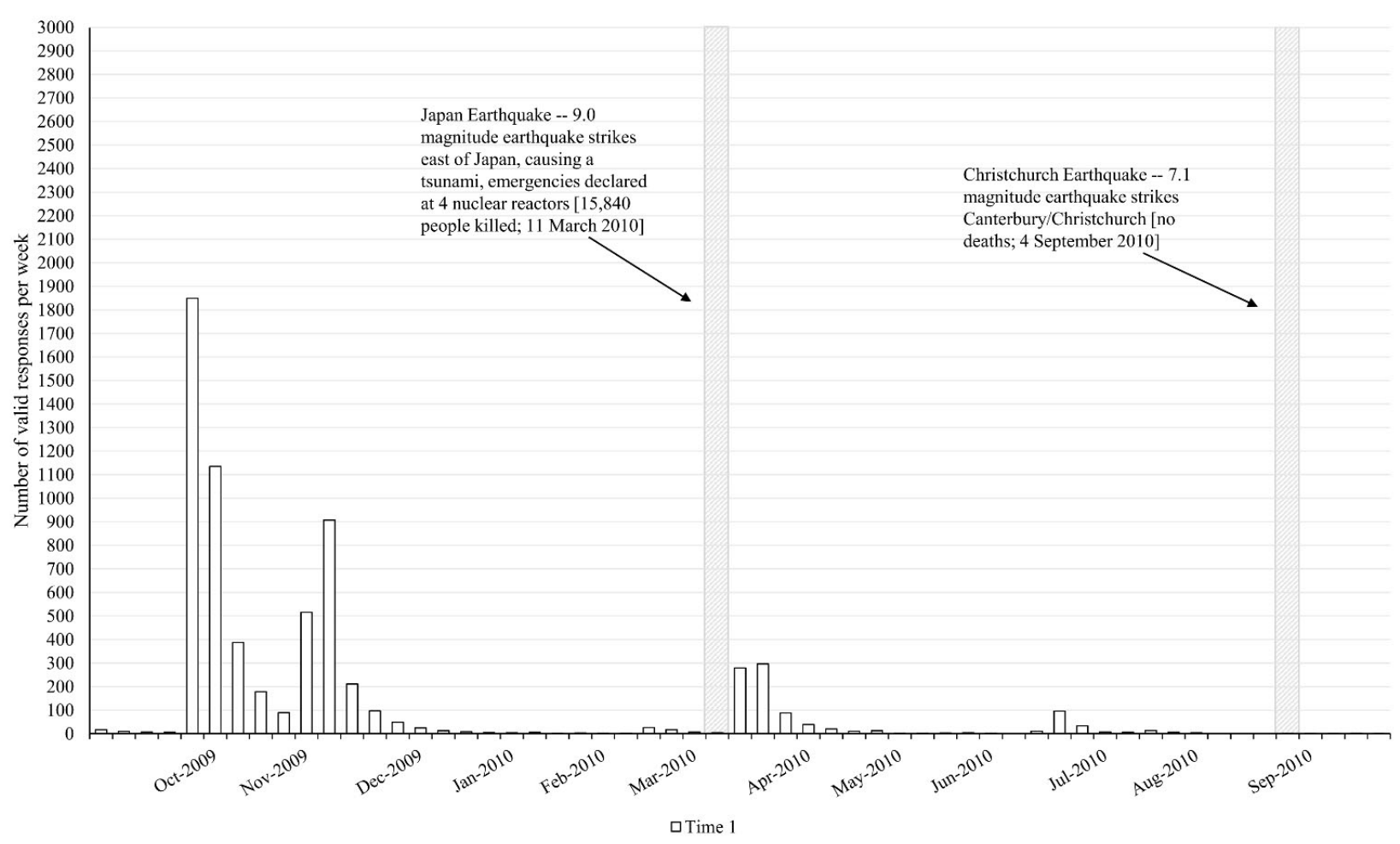

Figure 1. Histogram of weekly survey completions for Time 1 conducted from 01.07.200914.10.2010 (x-axis ranges from October 2009 to October 2010, some responses to this wave may be presented on the graph for the following year; select national and international events that occurred during this data collection wave are also included for context).

Time 2 (2010)

Sampling Procedure

The Time 2 (2010) NZAVS contained responses from 4,441 participants. The Time 2 (2010) NZAVS retained 4,425 from the initial Time 1 (2009) NZAVS sample of 6,518 participants, and included an additional 16 respondents who could not be matched to the Time 1 participant database (a retention rate of $67.9 \%$ over one year). Participants in the initial Time 1 (2009) sample were randomly selected from the New Zealand electoral roll (a national registry of registered voters). The response rate in the initial Time 1 sample, adjusting for the accuracy of the electoral roll and including anonymous responses, was $16.6 \%$. Participants were posted a copy of the questionnaire, with a second postal follow-up two months later. Participants who provided an email address were also emailed and invited to complete an online questionnaire if they preferred.

\section{Participants}

The Time 2 wave included 2,735 women and 1,706 men, with a mean age of 50.99 years $(\mathrm{SD}=15.23)$. With regard to ethnicity, 3,815 people identified as European, 690 as Māori, 161 were Pacific Nations peoples, and 179 identified with an Asian ethnic group. Note that people could identify with multiple ethnic groups (and hence be counted multiple times). Deprivation $(\mathrm{M}=5.03, \mathrm{SD}=2.78)$ was coded using the New Zealand Deprivation index for the meshblock level (approx. 100 person-sized geographic units), with a decile rank from 1 (low) 10 (high; Atkinson, Salmond \& Crampton, 2014). Socioeconomic status ( $\mathrm{M}=$ 
53.48, $\mathrm{SD}=17.48$ ) was scored from 10 (low) to 90 (high) using the New Zealand Socioeconomic Index, which assigned a score based on occupation and derived from census data (Fahy, Lee, \& Milne, 2017). Mean household income was NZ\$80,282 (SD = NZ\$71,329, median $=$ NZ\$67,000). Of the 4,441 people sampled, 1,941 were religious; 3,477 were parents; 3,215 had a romantic partner; 3,155 were employed; 2,625 lived in an urban or suburban area; and 3,549 were born in New Zealand (education level was not measured at Time 2).

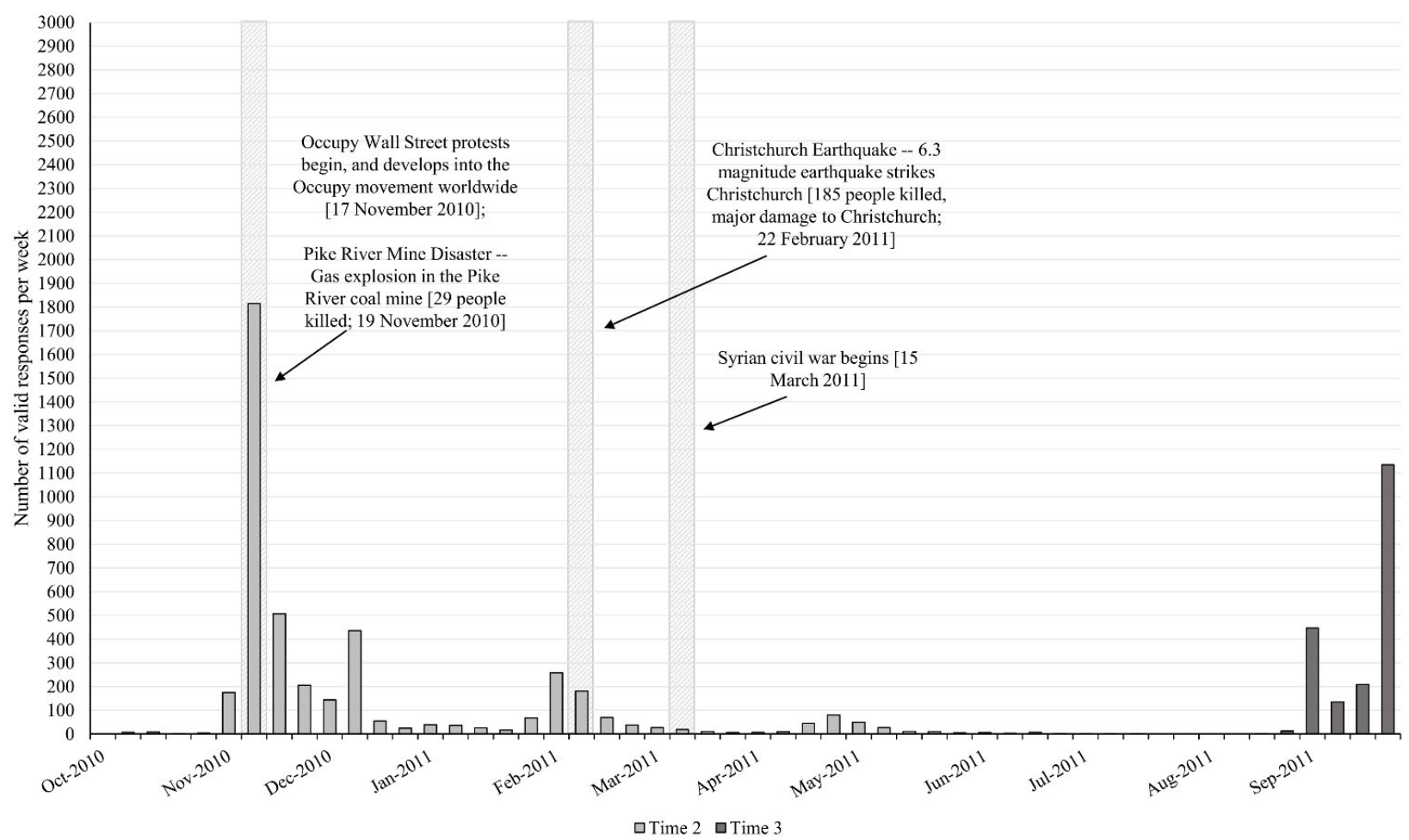

Figure 2. Histogram of weekly survey completions for Time 2 conducted from 15.10.201026.08.2011 (x-axis ranges from October 2010 to October 2011, some responses to this wave may be presented on the graph for the following year; select national and international events that occurred during this data collection wave are also included for context).

Time 3 (2011)

Sampling Procedure

The Time 3 (2011) NZAVS contained responses from 6,884 participants $(3,918$ retained from one or more previous wave, 2,966 new additions from booster sampling, and 4 unmatched participants or unsolicited opt-ins). The Time 3 (2011) NZAVS retained 3,918 from the initial Time 1 national probability sample (a $60.1 \%$ retention rate over two years). A further three participants who joined at Time 2 were also retained. Participants were posted a copy of the questionnaire, with a second postal follow-up two months later. Participants who provided an email address were also emailed and invited to complete an online version if they preferred.

To boost sample size at Time 3 and compensate for sample attrition, a booster sample was recruited through an unrelated survey posted on the website of a major New Zealand newspaper in 2011. A total of 3,208 participants registered an initial expression of interest in being contacted to participate in the NZAVS via this survey. Participants in this non-random 
booster sample were emailed an invitation to participate in an online version of the NZAVS, and those who did not respond to the email were also sent a postal version of the questionnaire. A total of 2,966 participants completed the questionnaire when subsequently contacted (92.5\%). This yielded a total sample size for the Time 3 (2012) NZAVS of 6,884 (3,918 retained from Time 1, 3 additions retained from opt-ins at Time 2, 2,966 recruited from the newspaper website at Time 3, and 4 opt-ins at Time 3).

Participants

The Time 3 wave included 4,303 women and 2,578 men, with a mean age of 50.75 years $(\mathrm{SD}=15.95)$. With regard to ethnicity, 5,147 people identified as European, 745 as Māori, 177 were Pacific Nations peoples, and 252 identified with an Asian ethnic group. Note that people could identify with multiple ethnic groups (and hence be counted multiple times). Deprivation $(\mathrm{M}=4.73, \mathrm{SD}=2.74)$ was coded using the New Zealand Deprivation index for the meshblock level (approx. 100 person-sized geographic units), with a decile rank from 1 (low) 10 (high; Atkinson, Salmond \& Crampton, 2014). Socioeconomic status ( $\mathrm{M}=$ $56.27, \mathrm{SD}=16.75$ ) was scored from 10 (low) to 90 (high) using the New Zealand Socioeconomic Index, which assigned a score based on occupation and derived from census data (Fahy, Lee, \& Milne, 2017). Mean household income was NZ\$91,715 (SD = $\mathrm{NZ} \$ 108,260$, median $=\mathrm{NZ} \$ 78,000)$. Of the 6,884 people sampled, 2,683 were religious; 4,997 were parents; 4,769 had a romantic partner; 5,075 were employed; 4,147 lived in an urban or suburban area; and 5,189 were born in New Zealand (education level was not measured at Time 3).

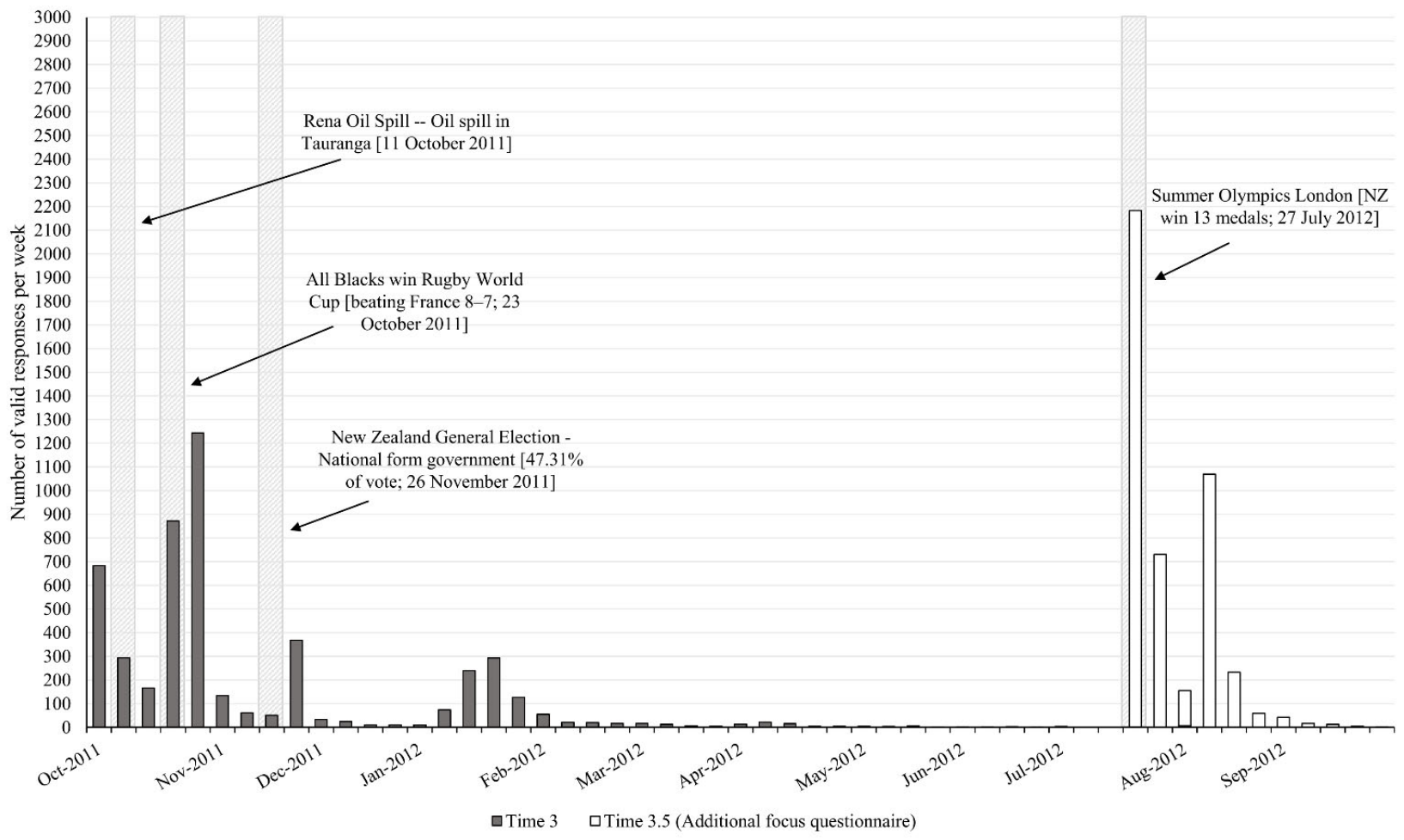

Figure 3. Histogram of weekly survey completions for Time 3 conducted from 27.08.201118.09.2012 (x-axis ranges from October 2011 to October 2012, some responses to this wave may be presented on the graph for the following year; select national and international events 
that occurred during this data collection wave are also included for context).

Time 3.5 (2012 mid-year)

Sampling Procedure

The Time 3.5 (2012 mid-year) NZAVS contained responses from 4,514 participants who completed a follow-up online-only questionnaire administered roughly six months following the full Time 3 (2011) questionnaire. The Time 3.5 sample was supplementary to the full Time 3 (2011) NZAVS. The sample frame included those participants who had provided an email address when completing the full Time 3 questionnaire earlier that year, as well as approximately 400-450 Pacific participants who were recruited informally via Pasifika networks. The sample included 1,977 retained participants from the initial Time 1 (2009) NZAVS random electoral roll sample, 2,113 participants from the non-random online newspaper website sample collected as part of the Time 3 (2011) NZAVS, a further 50 participants online newspaper website sample who has initially indicated but had not responded initially at T3 (but did respond when contacted again at Time 3.5), 197 participants who self-selected into the study or who were unable to be matched to a sample frame, and 177 additional Pacific participants recruited via Pasifika networks who complete a different version of the questionnaire focusing on Pacific identity and wellbeing.

Participants

The Time 3.5 wave included 2,811 women and 1,569 men, with a mean age of 49.12 years $(\mathrm{SD}=15.67)$. With regard to ethnicity, 3,968 people identified as European, 434 as Māori, 275 were Pacific Nations peoples, and 164 identified with an Asian ethnic group. Note that people could identify with multiple ethnic groups (and hence be counted multiple times). Deprivation ( $\mathrm{M}=4.57, \mathrm{SD}=2.73$ ) was coded using the New Zealand Deprivation index for the meshblock level (approx. 100 person-sized geographic units), with a decile rank from 1 (low) 10 (high; Atkinson, Salmond \& Crampton, 2014). Of the 4,514 people sampled, 1,690 were religious.

Time 4 (2012)

\section{Sampling Procedure}

The Time 4 (2012) NZAVS contained responses from 12,179 participants $(6,807$ retained from one or more previous wave, 5,107 new additions from booster sampling, and 265 unmatched participants or unsolicited opt-ins). Informal analysis indicates that unsolicited opt-ins were often the partners of existing participants. The sample retained 4,053 participants from the initial Time 1 (2009) NZAVS of 6,518 participants (a retention rate of $62.2 \%$ over three years). The sample retained 5,762 participants from the full Time 3 (2011) sample (a retention rate of $83.7 \%$ from the previous year). Participants were posted a copy of the questionnaire, with a second postal follow-up two months later. Participants who provided an email address were also emailed and invited to complete an online version if they preferred.

Non-respondents were emailed a follow-up reminder email approximately two months later. Three attempts were then made using each provided phone number (typically home and cell phone) to contact non-respondents to encourage participation. These attempts were made on separate days, approximately one week apart. When possible, a phone message was left for each phone number after the third attempt. Participants were also posted a pamphlet outlining recent findings from the study mid-way through the year. Finally, 
participants were posted a Season's Greetings from the NZAVS research team, and informed that they had been automatically entered into a bonus seasonal grocery voucher prize draw for a total pool of $\$ N Z 1,000$. Participants were informed that the draw would happen automatically, and winners contacted. The Season's Greetings card also asked participants to contact us (online, email or phone) to let us know if any of their contact details had changed before the prize draw was conducted. These additional materials are presented by Huang, Greaves, and Sibley (2014) in an online NZAVS technical report.

To boost sample size at Time 4 and increase sample diversity for subsequent waves, five independent booster samples using different sample frames were also conducted. Booster sampling was conducted without replacement (i.e., all people included in previous sample frames were identified and removed from the electoral roll before generation of the new sample frames). The first sample frame consisted of a randomly selected sample of 20,000 people aged from 18-70 randomly selected from the 2012 New Zealand electoral roll, and who were currently residing in New Zealand (one can be registered to vote in New Zealand but living overseas). A total of 2,429 participants responded to this booster sample (response rate $=12.33 \%$ when adjusting for the $98.5 \%$ accuracy of the 2012 electoral roll).

The second sample frame consisted of a regional booster of 10,000 people aged from 18-70 randomly selected randomly selected from people listed in the 2012 electoral roll who lived in the Auckland region. A total of 890 participants responded to this booster sample (adjusted response rate $=9.04$ ). The Auckland region was oversampled because it is the fastest growing and most ethnically diverse region of the country with an increasing number of Asian and Pacific peoples in particular. The questionnaire used for this Auckland sample was longer than the standard NZAVS questionnaire, and contained additional unrelated questions that are not included in the NZAVS dataset (these related to the use of community facilities). Exit interviews conducted during Time 5 indicated that the longer length of this questionnaire may have contributed to the low response rate in this case.

The third sample frame consisted of 3,000 people aged from 18-60 randomly selected randomly selected from the 2012 electoral roll who lived in the Christchurch region. A total of 332 participants responded to this booster sample (adjusted response rate $=11.24 \%$ ). The Christchurch region was oversampled because it has experienced significant hardship and change due to the Christchurch earthquakes of 2010 and 2011 with many people moving out of the region (Statistics New Zealand, 2013) and problems with mail delivery with some city zones being placed under restricted entry due to safety concerns and considerable infrastructure destroyed.

The fourth sample frame consisted of 9,000 respondents selected from meshblock area units across the country that were moderate-to-high in deprivation according to the index developed by Salmond, Crampton and Atkinson (2007). Regions with levels of deprivation were selected using scores on the decile-ranked NZ Deprivation index from 6-10, with 10 being the most deprived. This sample frame used scaled weighting so that people in increasingly deprived regions were increasingly more likely to be selected (with random sampling of people aged from 18-75 randomly selected within regions that had a given level of deprivation). The scaling factor was as follows: $n_{i}=n_{\text {base }} *$ weight $i$, where $n_{\text {base }}=600$, and

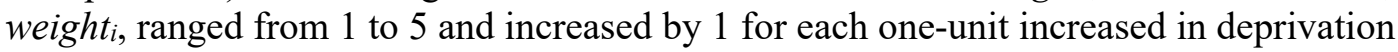
score. Thus, 600 people were randomly selected from regions with a deprivation score of 6 , 1,200 people were randomly selected from regions with a deprivation score of 7 , and so on. This sampling strategy was designed to increase the representativeness of the sample across regions with different levels of deprivation, as the NZAVS showed increased attrition in increasingly more deprived regions over the first three years of the study. A total of 767 participants responded to this booster sample (adjusted response rate $=8.65 \%$ ). 
The fifth sample frame consisted of 9,000 people aged from 18-70 randomly selected randomly selected from those who indicated on the 2012 electoral roll that they were of Māori ethnicity (ethnic affiliation as Māori is listed on the roll, but other ethnic affiliations are not). A total of 689 participants responded to this booster sample (adjusted response rate $=7.78 \%$ ). The questionnaire administered to the Māori booster sample included additional questions specifically referring to Māori identity.

\section{Participants}

The Time 4 wave included 7,621 women and 4,554 men, with a mean age of 49.11 years $(\mathrm{SD}=15.02)$. With regard to ethnicity, 10,281 people identified as European, 2,025 as Māori, 610 were Pacific Nations peoples, and 619 identified with an Asian ethnic group. Note that people could identify with multiple ethnic groups (and hence be counted multiple times). Education $(\mathrm{M}=4.70, \mathrm{SD}=2.84)$ was coded using the New Zealand Qualifications Authority scheme, which ranged from 0 (none) to 10 (doctoral degree or equivalent). Deprivation $(\mathrm{M}=5.02, \mathrm{SD}=2.85)$ was coded using the New Zealand Deprivation index for the meshblock level (approx. 100 person-sized geographic units), with a decile rank from 1 (low) 10 (high; Atkinson, Salmond \& Crampton, 2014). Socioeconomic status $(\mathrm{M}=52.30$, $\mathrm{SD}=16.27$ ) was scored from 10 (low) to 90 (high) using the New Zealand Socioeconomic Index, which assigned a score based on occupation and derived from census data (Fahy, Lee, \& Milne, 2017). Mean household income was NZ\$96,071 $(\mathrm{SD}=\mathrm{NZ} \$ 90,936$, median $=$

NZ\$80,000). Of the 12,179 people sampled, 4,934 were religious; 8,856 were parents; 8,314 had a romantic partner; 8,464 were employed; 7,871 lived in an urban or suburban area; and 9,421 were born in New Zealand.

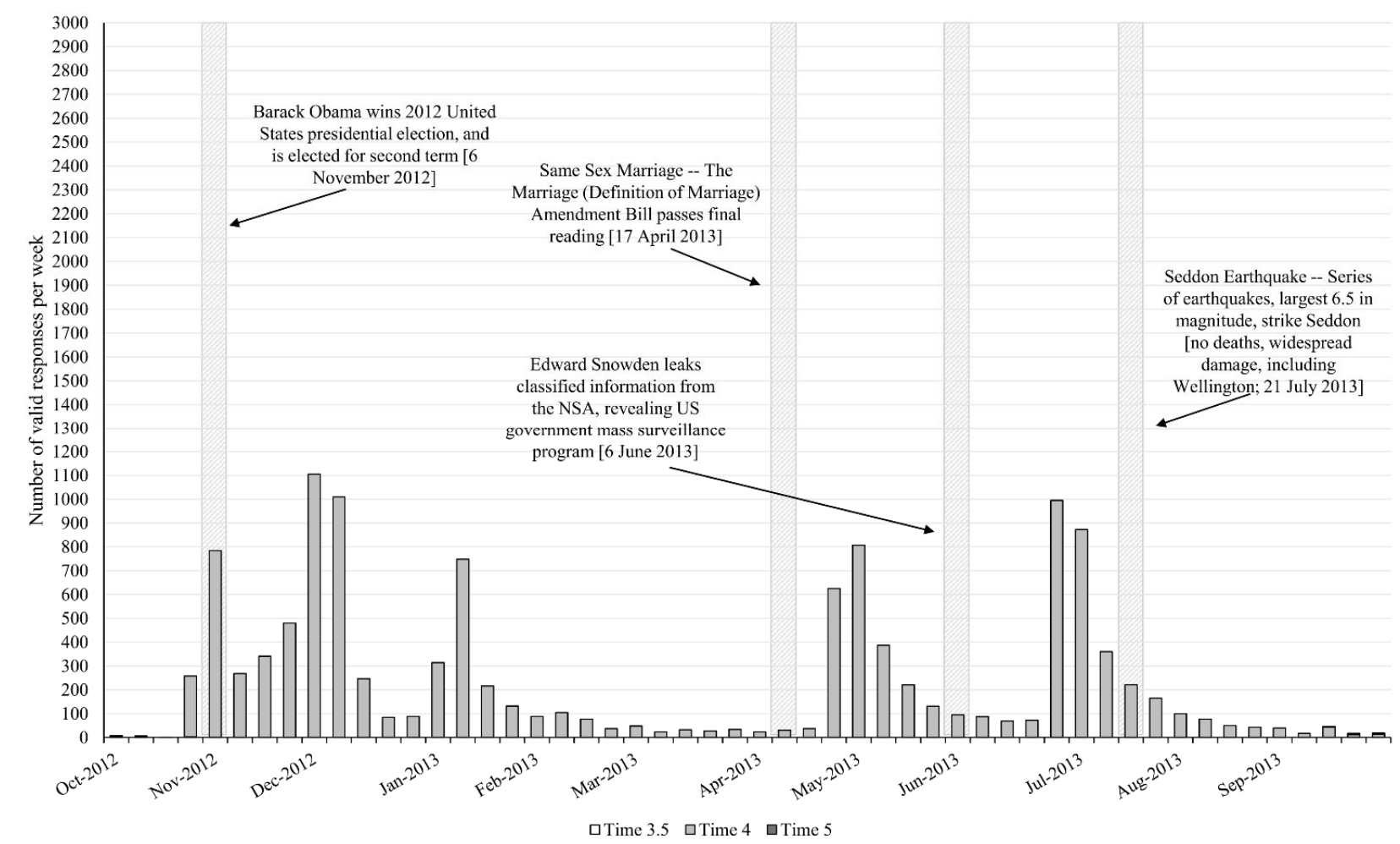

Figure 4. Histogram of weekly survey completions for Time 4 conducted from 19.09.201216.09.2013 (x-axis ranges from October 2012 to October 2013, some responses to this wave may be presented on the graph for the following year; select national and international events 
that occurred during this data collection wave are also included for context).

Time 5 (2013)

Sampling Procedure

The Time 5 (2013) NZAVS contained responses from 18,261 participants (10,502 retained from one or more previous wave, 7,579 new additions from booster sampling, and 179 unmatched participants or unsolicited opt-ins). Informal analysis indicates that unsolicited opt-ins were often the partners of existing participants. The sample retained 3,934 participants from the initial Time 1 (2009) NZAVS of 6,518 participants (a retention rate of $60.4 \%$ over four years). The sample retained 9,844 participants from the full Time 4 (2011) sample (a retention rate of $80.8 \%$ from the previous year). Participants were posted a copy of the questionnaire, with a second postal follow-up two months later. Participants who provided an email address were also emailed and invited to complete an online version if they preferred. As described in the Time 4 procedure, we offered a prize draw for participation, non-respondents were emailed and phoned multiple times, and all participants were posted a Season's Greetings card from the NZAVS research team and informed that they had been automatically entered into a bonus seasonal grocery voucher prize draw. We also posted our yearly pamphlet summarizing key research findings published during the current wave of the study.

To boost sample size and increase sample diversity for subsequent waves, two booster samples were also conducted by selecting people from the New Zealand electoral roll. As with previous booster samples, sampling was conducted without replacement (i.e., all people included in previous sample frames were identified and removed from the 2014 roll). The first sample frame consisted of 70,000 people aged from 18-60 randomly selected from the 2014 New Zealand electoral roll, who were currently residing in New Zealand (one can be registered to vote in New Zealand but living overseas). The New Zealand electoral roll contains participants' date of birth (within a one-year window), and we limited our frame to people who 60 or younger, due to our aim of retaining participants for the following 15 years. A total of 7,487 participants responded to this booster sample (response rate $=10.9 \%$ when adjusting for the $98.6 \%$ accuracy of the 2014 electoral roll). The second sample frame consisted of 1,500 people who were listed on the electoral roll as being of Māori ancestry, aged between 18-60 years of age, and currently residing in New Zealand. A total of 92 participants responded to this booster sample (response rate $=6.2 \%$ adjusting for electoral roll accuracy).

Participants

The Time 5 wave included 11,460 women and 6,798 men, with a mean age of 47.65 years $(\mathrm{SD}=14.07)$. With regard to ethnicity, 15,607 people identified as European, 2,328 as Māori, 625 were Pacific Nations peoples, and 814 identified with an Asian ethnic group. Note that people could identify with multiple ethnic groups (and hence be counted multiple times). Education $(\mathrm{M}=4.93, \mathrm{SD}=2.82)$ was coded using the New Zealand Qualifications Authority scheme, which ranged from 0 (none) to 10 (doctoral degree or equivalent).

Deprivation $(\mathrm{M}=4.81, \mathrm{SD}=2.79)$ was coded using the New Zealand Deprivation index for the meshblock level (approx. 100 person-sized geographic units), with a decile rank from 1 (low) 10 (high; Atkinson, Salmond \& Crampton, 2014). Socioeconomic status $(\mathrm{M}=52.94$, $\mathrm{SD}=16.46$ ) was scored from 10 (low) to 90 (high) using the New Zealand Socioeconomic Index, which assigned a score based on occupation and derived from census data (Fahy, Lee,

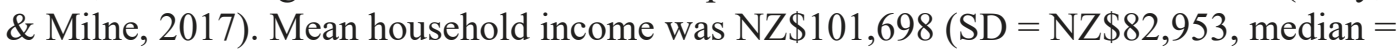


NZ\$85,000). Of the 18,261 people sampled, 6,879 were religious; 13,084 were parents; 12,984 had a romantic partner; 13,578 were employed; 12,151 lived in an urban or suburban area; and 14,225 were born in New Zealand.

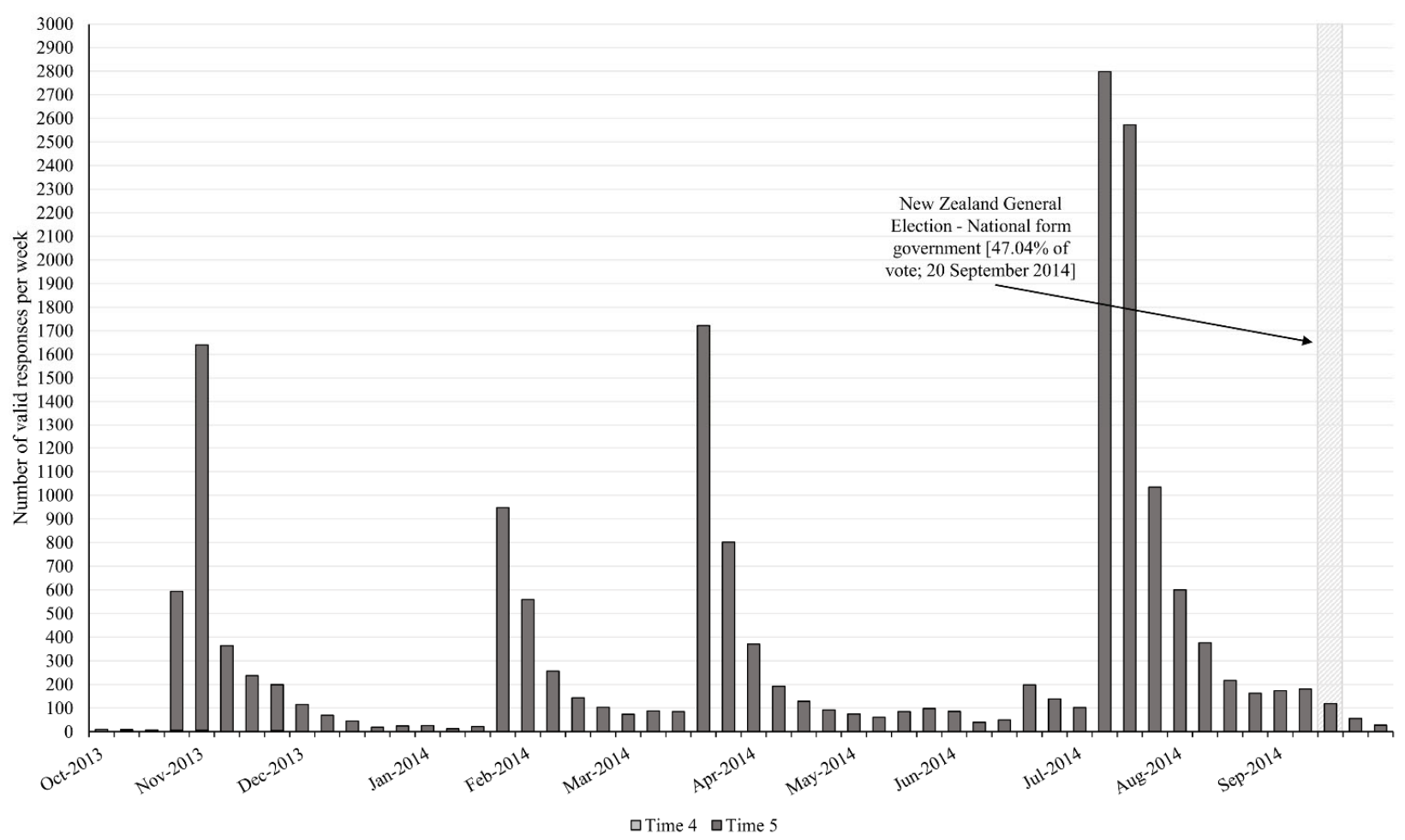

Figure 5. Histogram of weekly survey completions for Time 5 conducted from 17.09.201320.10.2014 (x-axis ranges from October 2013 to October 2014, some responses to this wave may be presented on the graph for the following year; select national and international events that occurred during this data collection wave are also included for context).

Time 6 (2014)

\section{Sampling Procedure}

The Time 6 (2014) NZAVS contained responses from 15,820 participants (15,740 retained from one or more previous wave, and 82 unmatched participants or unsolicited optins). The sample retained 3,728 participants from the initial Time 1 (2009) NZAVS of 6,518 participants (a retention rate of $57.2 \%$ over five years). The sample retained 14,878

participants from the full Time 5 (2013) sample (a retention rate of $81.5 \%$ from the previous year). Participants who provided an email address were first emailed and invited to complete an online version if they preferred. Participants who did not complete the online version (or did not provide an email) were then posted a copy of the questionnaire, with a second postal follow-up two months later. We staggered the time of contact, so that participants who had completed the previous wave were contacted approximately one year after they last completed the questionnaire. As described in the Time 4 procedure, we offered a prize draw for participation, non-respondents were emailed and phoned multiple times, and all participants were posted a Season's Greetings card from the NZAVS research team and informed that they had been automatically entered into a bonus seasonal grocery voucher 
prize draw. We also emailed participants an online pamphlet containing a series of video interviews with the researchers summarizing different research findings.

Participants

The Time 6 wave included 10,002 women, 5,798 men, and 20 people who identified as gender diverse, with a mean age of 49.33 years $(\mathrm{SD}=14.03)$. With regard to ethnicity, 14,161 people identified as European, 1,977 as Māori, 526 were Pacific Nations peoples, and 684 identified with an Asian ethnic group. Note that people could identify with multiple ethnic groups (and hence be counted multiple times). Education $(\mathrm{M}=5.08, \mathrm{SD}=2.81$ ) was coded using the New Zealand Qualifications Authority scheme, which ranged from 0 (none) to 10 (doctoral degree or equivalent). Deprivation $(\mathrm{M}=4.71, \mathrm{SD}=2.76)$ was coded using the New Zealand Deprivation index for the meshblock level (approx. 100 person-sized geographic units), with a decile rank from 1 (low) 10 (high; Atkinson, Salmond \& Crampton, 2014). Socioeconomic status ( $M=53.73, \mathrm{SD}=16.26$ ) was scored from 10 (low) to 90 (high) using the New Zealand Socioeconomic Index, which assigned a score based on occupation and derived from census data (Fahy, Lee, \& Milne, 2017). Mean household income was $\mathrm{NZ} \$ 104,852(\mathrm{SD}=\mathrm{NZ} \$ 92,822$, median $=\mathrm{NZ} \$ 90,000)$. Of the 15,820 people sampled, 6,030 were religious; 11,655 were parents; 11,354 had a romantic partner; 12,037 were employed; 10,454 lived in an urban or suburban area; and 12,497 were born in New Zealand.

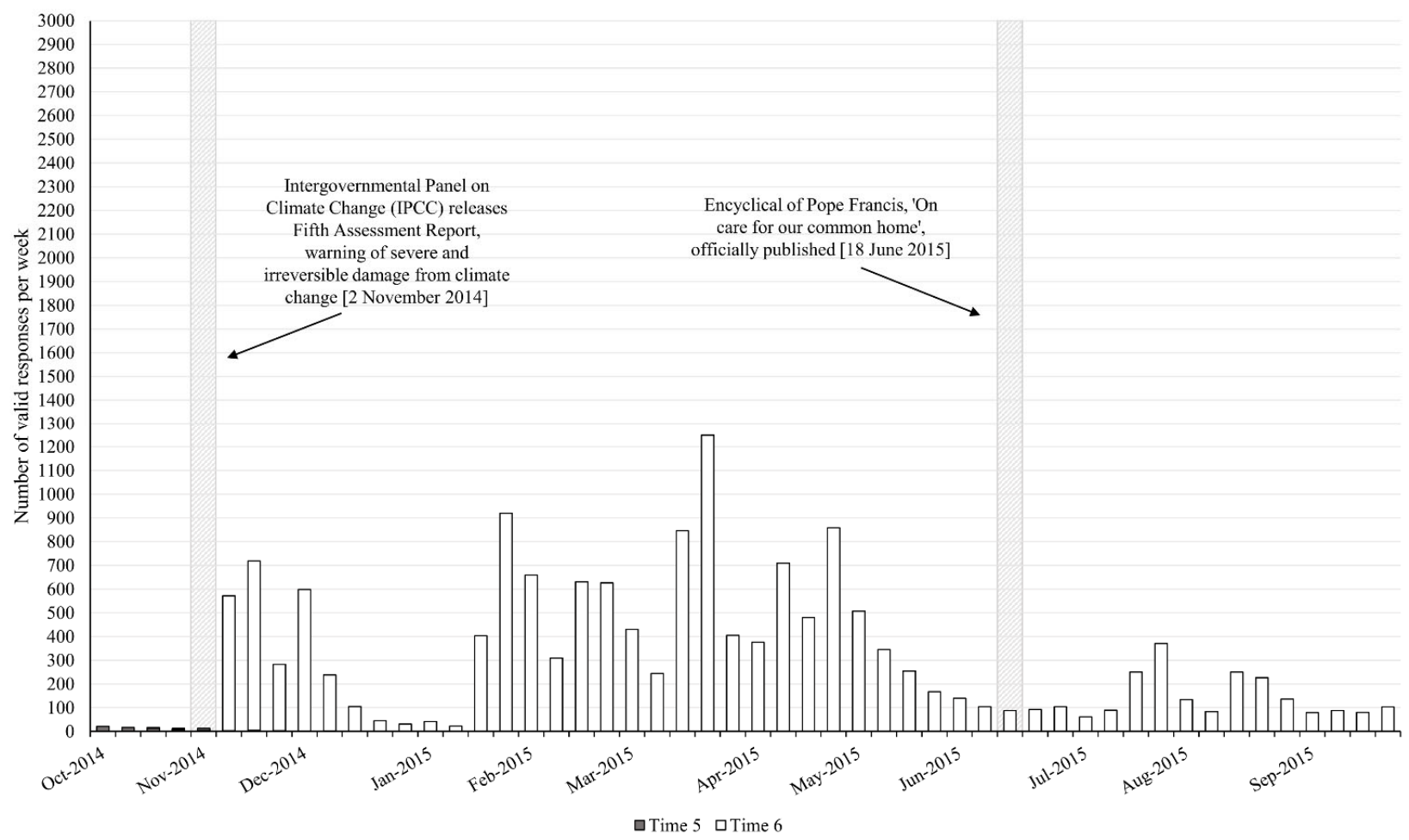

Figure 6. Histogram of weekly survey completions for Time 6 conducted from 21.10.201419.08.2015 (x-axis ranges from October 2014 to October 2015, some responses to this wave may be presented on the graph for the following year; select national and international events that occurred during this data collection wave are also included for context). 
Time 7 (2015)

Sampling Procedure

The Time 7 (2015) NZAVS contained responses from 13,942 participants (13,941

retained from one or more previous wave, and 1 unmatched participant or unsolicited opt-in). The sample retained 3,344 participants from the initial Time 1 (2009) NZAVS of 6,518 participants (a retention rate of 51.3\% over five years). The sample retained 12,550 participants from the full Time 6 (2014) sample (a retention rate of $79.3 \%$ from the previous year). Participants who provided an email address were first emailed and invited to complete an online version if they preferred. Participants who did not complete the online version (or did not provide an email) were then posted a copy of the questionnaire, with a second postal follow-up two months later. We staggered the time of contact, so that participants who had completed the previous wave were contacted approximately one year after they last completed the questionnaire. As described in the Time 4 procedure, we offered a prize draw for participation, non-respondents were emailed and phoned multiple times, and all participants were posted a Season's Greetings card from the NZAVS research team and informed that they had been automatically entered into a bonus seasonal grocery voucher prize draw.

Participants

The Time 7 wave included 8,726 women, 5,197 men, and 17 participants identified as gender diverse, with a mean age of 50.79 years $(\mathrm{SD}=13.90)$. With regard to ethnicity, 12,506 people identified as European, 1,672 as Māori, 427 were Pacific Nations peoples, and 545 identified with an Asian ethnic group. Note that people could identify with multiple ethnic groups (and hence be counted multiple times). Education $(\mathrm{M}=5.19, \mathrm{SD}=2.78$ ) was coded using the New Zealand Qualifications Authority scheme, which ranged from 0 (none) to 10 (doctoral degree or equivalent). Deprivation $(\mathrm{M}=4,70, \mathrm{SD}=2.78)$ was coded using the New Zealand Deprivation index for the meshblock level (approx. 100 person-sized geographic units), with a decile rank from 1 (low) 10 (high; Atkinson, Salmond \& Crampton, 2014). Socioeconomic status ( $M=54.36, \mathrm{SD}=16.04$ ) was scored from 10 (low) to 90 (high) using the New Zealand Socioeconomic Index, which assigned a score based on occupation and derived from census data (Fahy, Lee, \& Milne, 2017). Mean household income was $\mathrm{NZ} \$ 106,980(\mathrm{SD}=\mathrm{NZ} \$ 86,722$, median $=\mathrm{NZ} \$ 90,000)$. Of the 13,942 people sampled, 5,844 were religious; 10,511 were parents; 10,090 had a romantic partner; 10,457 were employed; 8,994 lived in an urban or suburban area; and 10,624 were born in New Zealand. 


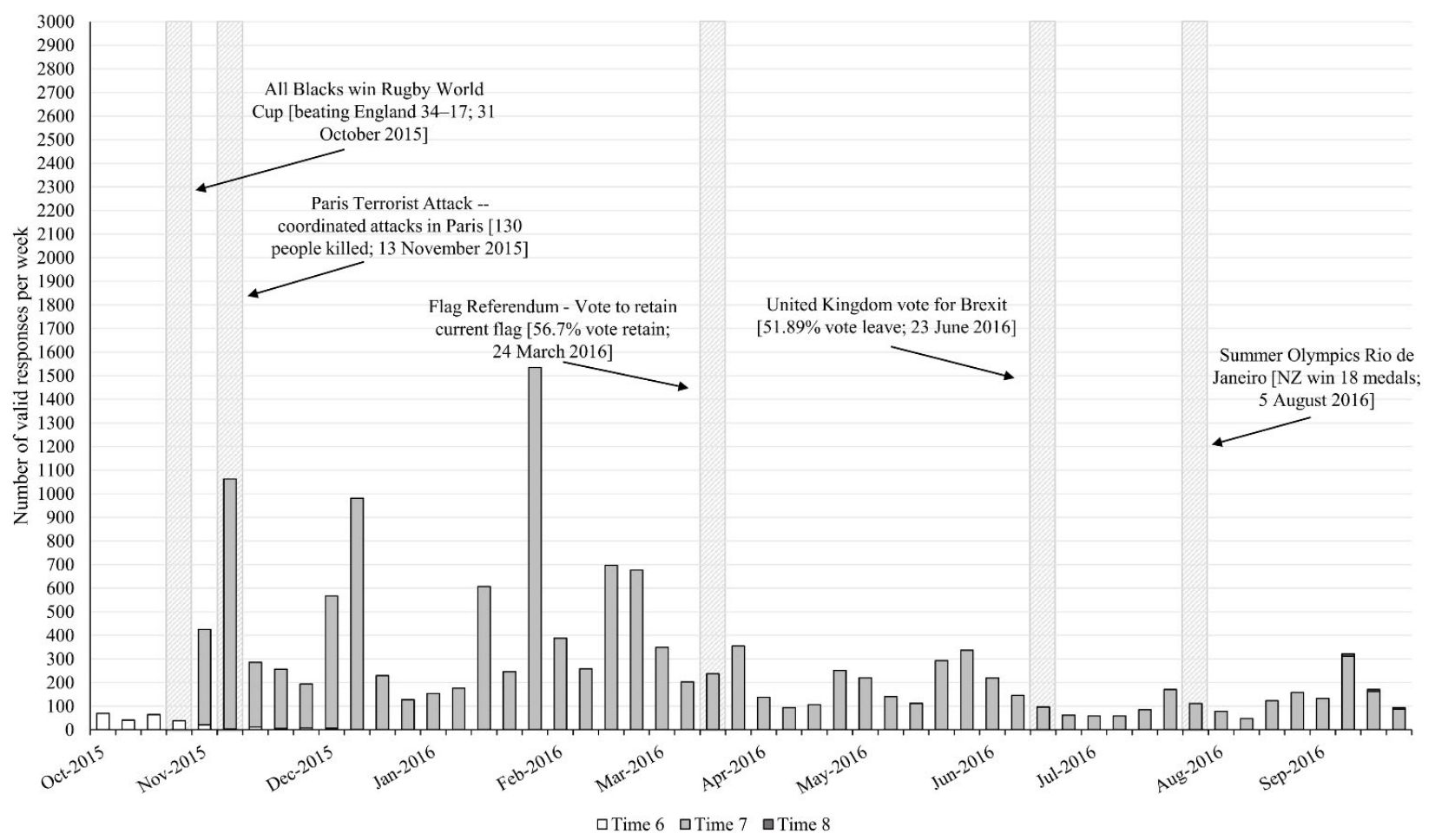

Figure 7. Histogram of weekly survey completions for Time 7 conducted from 20.08.201510.09.2016 (x-axis ranges from October 2015 to October 2016, some responses to this wave may be presented on the graph for the following year; select national and international events that occurred during this data collection wave are also included for context).

\section{Time 8 (2016)}

\section{Sampling Procedure}

The Time 8 (2016) NZAVS contained responses from 21,936 participants $(13,781$ retained from one or more previous wave, 7,667 new additions from booster sampling, and 488 unmatched participants or unsolicited opt-ins). The sample retained 3,347 participants from the initial Time 1 (2009) NZAVS of 6,518 participants (a retention rate of 51.4\%). The sample retained 11,933 participants from the full Time 7 (2015) sample (a retention rate of $85.6 \%$ from the previous year). Participants who provided an email address were first emailed and invited to complete an online version if they preferred. Participants who did not complete the online version (or did not provide an email) were then posted a copy of the questionnaire, with a second postal follow-up two months later. We staggered the time of contact, so that participants who had completed the previous wave were contacted approximately one year after they last completed the questionnaire. As described in the Time 4 procedure, we offered a prize draw for participation, non-respondents were emailed and phoned multiple times, and all participants were posted a Season's Greetings card from the NZAVS research team and informed that they had been automatically entered into a bonus seasonal grocery voucher prize draw.

To boost sample size and increase sample diversity for subsequent waves, a booster sample was also conducted by selecting people from the New Zealand electoral roll. As with previous booster samples, sampling was conducted without replacement (i.e., all people included in previous sample frames were identified and removed from the 2016 roll). The 
sample frame consisted of 80,000 people aged from 18-65 randomly selected from the 2016 New Zealand electoral roll, who were currently residing in New Zealand (one can be registered to vote in New Zealand but living overseas). The New Zealand electoral roll contains participants' date of birth (within a one-year window), and we limited our frame to people who 65 or younger, due to our aim of retaining participants longitudinally. A total of 7,667 participants responded to this booster sample (response rate $=9.7 \%$ when adjusting for the $98.6 \%$ accuracy of the 2016 electoral roll).

\section{Participants}

The Time 8 wave included 13,722 women, 8,171 men, and 41 participants identified as gender diverse, with a mean age of 49.62 years $(\mathrm{SD}=13.93)$. With regard to ethnicity, 19,478 people identified as European, 2,473 as Māori, 574 were Pacific Nations peoples, and 1,001 identified with an Asian ethnic group. Note that people could identify with multiple ethnic groups (and hence be counted multiple times). Education $(\mathrm{M}=5.30, \mathrm{SD}=2.75)$ was coded using the New Zealand Qualifications Authority scheme, which ranged from 0 (none) to 10 (doctoral degree or equivalent). Deprivation $(\mathrm{M}=4,67, \mathrm{SD}=2.75)$ was coded using the New Zealand Deprivation index for the meshblock level (approx. 100 person-sized geographic units), with a decile rank from 1 (low) 10 (high; Atkinson, Salmond \& Crampton, 2014). Socioeconomic status $(\mathrm{M}=54.30, \mathrm{SD}=16.29)$ was scored from 10 (low) to 90 (high) using the New Zealand Socioeconomic Index, which assigned a score based on occupation and derived from census data (Fahy, Lee, \& Milne, 2017). Mean household income was $\mathrm{NZ} \$ 108,624(\mathrm{SD}=\mathrm{NZ} \$ 97,306$, median $=\mathrm{NZ} \$ 90,000)$. Of the 21,936 people sampled, 8,274 were religious; 15,883 were parents; 15,885 had a romantic partner; 17,119 were employed; 14,074 lived in an urban or suburban area; and 17,157 were born in New Zealand.

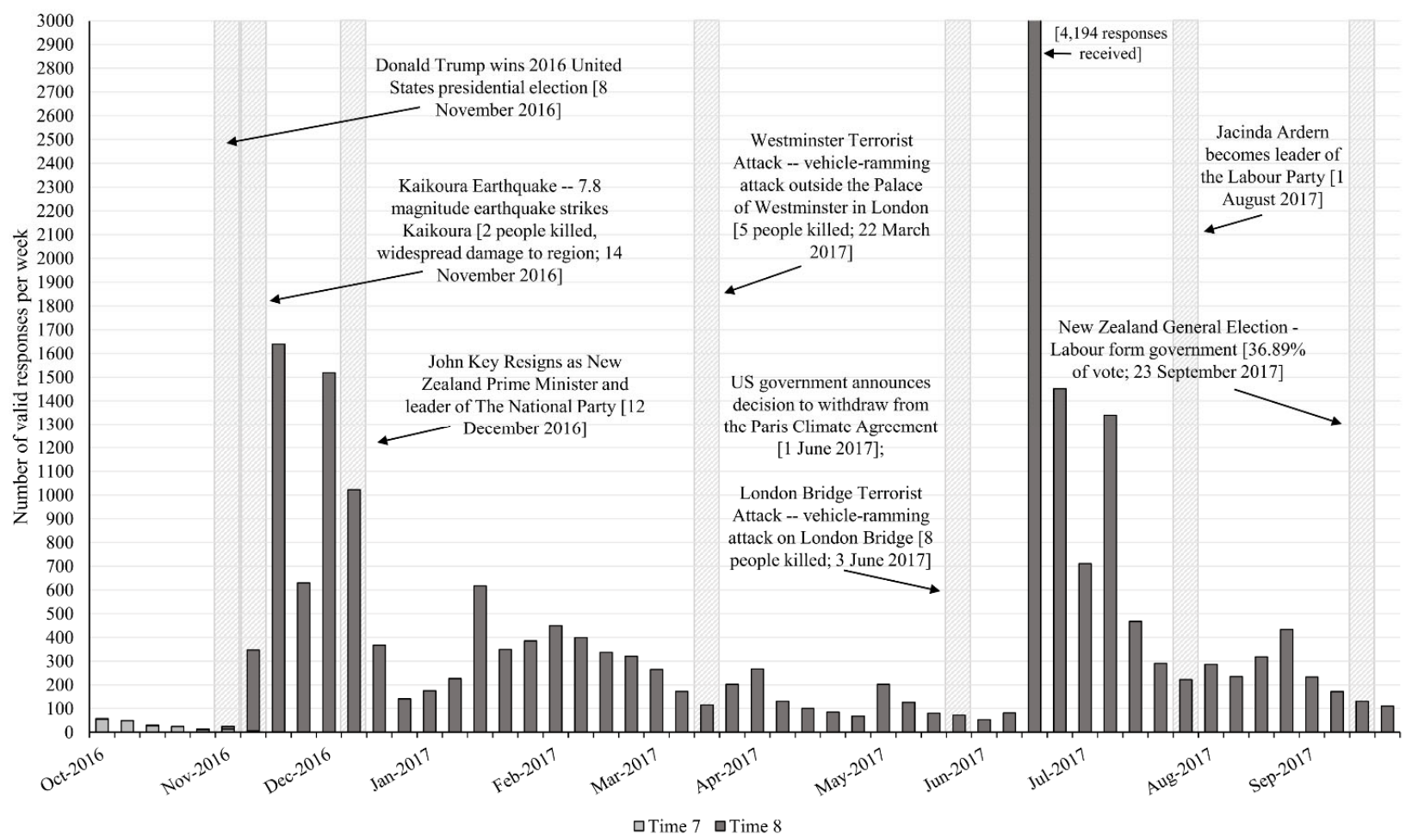

Figure 8. Histogram of weekly survey completions for Time 8 conducted from 11.09.201612.08.2017 (x-axis ranges from October 2016 to October 2017, some responses to this wave 
may be presented on the graph for the following year; select national and international events that occurred during this data collection wave are also included for context).

Time 9 (2017)

\section{Sampling Procedure}

The Time 9 (2017) NZAVS contained responses from 17,072 participants (16,931 retained from one or more previous wave, and 141 unmatched participants or unsolicited optins). The sample retained 2,771 participants from the initial Time 1 (2009) NZAVS of 6,518 participants (a retention rate of $42.5 \%$ over five years). The sample retained 15,784 participants from the full Time 8 (2016) sample (a retention rate of $72.0 \%$ from the previous year). Participants who provided an email address were first emailed and invited to complete an online version if they preferred. Participants who did not complete the online version (or did not provide an email) were then posted a copy of the questionnaire, with a second postal follow-up two months later. We staggered the time of contact, so that participants who had completed the previous wave were contacted approximately one year after they last completed the questionnaire. We offered a prize draw for participation (five draws each for $\$ 1000$ grocery vouchers, $\$ 5000$ total prize pool). All participants were posted a Season's Greetings card from the NZAVS research team and informed that they had been automatically entered into a bonus seasonal grocery voucher prize draw.

The retention rate from Time 8 to Time 9 of $72 \%$ was notably lower than the $\sim 80 \%$ achieved in previous few years. We had opted not to phone non-respondents during the Time 9 wave of data collection, and instead decided to let one year pass and then intensify phoning of non-respondents the following year. We decided on this approach in the hope that it might reduce 'contact fatigue', and hence increase the recovery rate and give more time (two years) for intermittent and non-respondents to become re-enthused about participating in the study. We thus decided to risk a lower retention rate in Time 9 with the hopes of getting a bounce back in the recovery rate during the following wave of data collection amongst these most hard-to-retain participants (see Satherley et al. 2015, for a detailed analysis of the demographic and individual difference factors predicting retention, non-response and intermittent response). Our decision to reduce the risk of contact fatigue during Time 9 was also compounded by a major telecommunications carrier in New Zealand opting to discontinue their email servers in November 2017. Many of our participants had used these email services, and hence a large number of the emails in our database were rendered invalid. This increased the subsequent load on attempting to contact participants via postal mail and phone until contact could be made and our email database could be updated with participants' new email addresses.

\section{Participants}

The Time 9 wave included 10,802 women, 6,246 men, and 24 participants identified as gender diverse, with a mean age of 51.33 years $(\mathrm{SD}=13.77)$. With regard to ethnicity, 15,606 people identified as European, 2,007 as Māori, 466 were Pacific Nations peoples, and 700 identified with an Asian ethnic group. Note that people could identify with multiple ethnic groups (and hence be counted multiple times). Education $(\mathrm{M}=5.26, \mathrm{SD}=2.77)$ was coded using the New Zealand Qualifications Authority scheme, which ranged from 0 (none) to 10 (doctoral degree or equivalent). Deprivation $(\mathrm{M}=4.59, \mathrm{SD}=2.72$ ) was coded using the New Zealand Deprivation index for the meshblock level (approx. 100 person-sized geographic units), with a decile rank from 1 (low) 10 (high; Atkinson, Salmond \& Crampton, 2014). Socioeconomic status $(\mathrm{M}=54.88, \mathrm{SD}=16.16)$ was scored from 10 (low) to 90 (high) using the New Zealand Socioeconomic Index, which assigned a score based on occupation 
and derived from census data (Fahy, Lee, \& Milne, 2017). Mean household income was $\mathrm{NZ} \$ 113,625(\mathrm{SD}=\mathrm{NZ} \$ 94,464$, median $=\mathrm{NZ} \$ 98,000)$. Of the 17,072 people sampled, 6,137 were religious; 12,628 were parents; 12,770 had a romantic partner; 13,136 were employed; 13,732 lived in an urban or suburban area; and 13,517 were born in New Zealand.

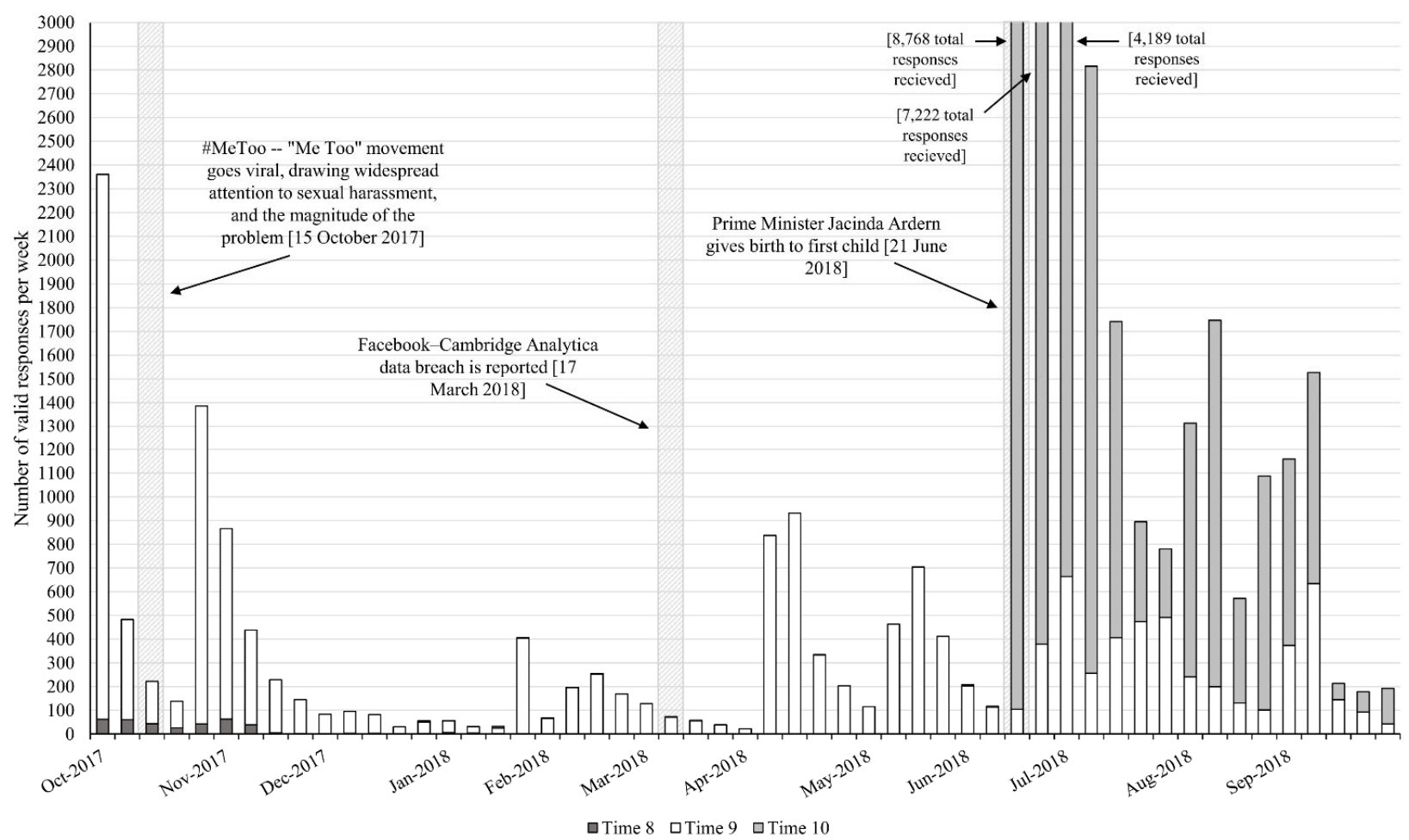

Figure 9. Histogram of weekly survey completions for Time 9 conducted from 13.08.201717.06.2018 (x-axis ranges from October 2017 to October 2018, some responses to this wave may be presented on the graph for the following year; select national and international events that occurred during this data collection wave are also included for context).

\section{Time $10(2018)$}

\section{Sampling Procedure}

The Time 10 (2018) NZAVS contained responses from 47,951 participants $(18,010$ retained from one or more previous wave). The sample retained 2,964 participants from the Time 1 (2009) sample (a retention rate of 45.5\%). The sample retained 14,049 participants from Time 9 (2017; a retention rate of $82.3 \%$ from the previous year). Participants who provided an email address were first emailed and invited to complete an online version if they preferred. Participants who did not complete the online version (or did not provide an email) were then posted a copy of the questionnaire, with a second postal follow-up two months later. We staggered the time of contact, so that participants who had completed the previous wave were contacted approximately one year after they last completed the questionnaire. We offered a prize draw for participation (five draws each for $\$ 1000$ grocery vouchers, $\$ 5000$ total prize pool). All participants were posted a Season's Greetings card from the NZAVS research team and informed that they had been automatically entered into a bonus seasonal grocery voucher prize draw. Participants were also emailed an eight-page newsletter about the study. 
To boost sample size and increase sample diversity for subsequent waves, a booster sample was conducted by selecting people from the New Zealand electoral roll. As with previous booster samples, sampling was conducted without replacement (i.e., people included in previous sample frames were identified and removed from the 2018 roll). The sample frame consisted of 325,000 people aged from 18-65 randomly selected from the 2018 New Zealand electoral roll, who were currently residing in New Zealand (one can be registered to vote in New Zealand but living overseas). The electoral roll contained $\sim 3,250,000$ registered voters. The New Zealand electoral roll contains participants' date of birth (within a one-year window), and we limited our frame to people who 65 or younger, due to our aim of retaining participants longitudinally. We concurrently advertised the survey on Facebook via a $\$ 5000$ paid promotion of a link to a YouTube video describing the NZAVS and the large booster sample we were conducting. The advertisement targeted men and women aged 18-65+ who lived in New Zealand and ran for 14 days. This paid promotion reached 147,296 people, with 4,721 link clicks (i.e., clicking to watch the video), according to Facebook. The goal of the paid promotion was twofold: (a) to increase name recognition of the NZAVS during the period in which questionnaires were being posted, and (b) to help improve retention by potentially reaching previous participants who happened to see the advertisement. A total of 29,293 participants who were contained in our sample frame completed the questionnaire (response rate $=9.2 \%$ when adjusting for the $98.2 \%$ accuracy of the 2018 electoral roll). A further 648 participants completed the questionnaire, but were unable to be matched to our sample frame (for example, due to a lack of contact information) or were unsolicited opt-ins. Informal analysis indicates that unsolicited opt-ins were often the partners of existing participants.

Participants

The Time 10 wave included 30,021 women, 17,811 men, and 101 participants identified as gender diverse, with a mean age of 48.59 years $(\mathrm{SD}=13.86)$. With regard to ethnicity, 42,495 people identified as European, 4,691 as Māori, 1,037 were Pacific Nations peoples, and 2,538 identified with an Asian ethnic group. Note that people could identify with multiple ethnic groups (and hence be counted multiple times). Education ( $\mathrm{M}=5.33, \mathrm{SD}$ $=2.73$ ) was coded using the New Zealand Qualifications Authority scheme, which ranged from 0 (none) to 10 (doctoral degree or equivalent). Deprivation $(\mathrm{M}=4.62, \mathrm{SD}=2.71)$ was coded using the New Zealand Deprivation index for the meshblock level (approx. 100 person-sized geographic units), with a decile rank from 1 (low) 10 (high; Atkinson, Salmond $\&$ Crampton, 2014). Socioeconomic status $(\mathrm{M}=54.05, \mathrm{SD}=16.46)$ was scored from 10 (low) to 90 (high) using the New Zealand Socioeconomic Index, which assigned a score based on occupation and derived from census data (Fahy, Lee, \& Milne, 2017). Mean household income was NZ\$115,295 (SD = NZ\$95,686, median $=\mathrm{NZ \$ 100,000).} \mathrm{Of} \mathrm{the}$ 47,949 people sampled, 16,907 were religious; 32,730 were parents; 34,199 had a romantic partner; 36,493 were employed; 38,637 lived in an urban or suburban area; and 36,409 were born in New Zealand. 


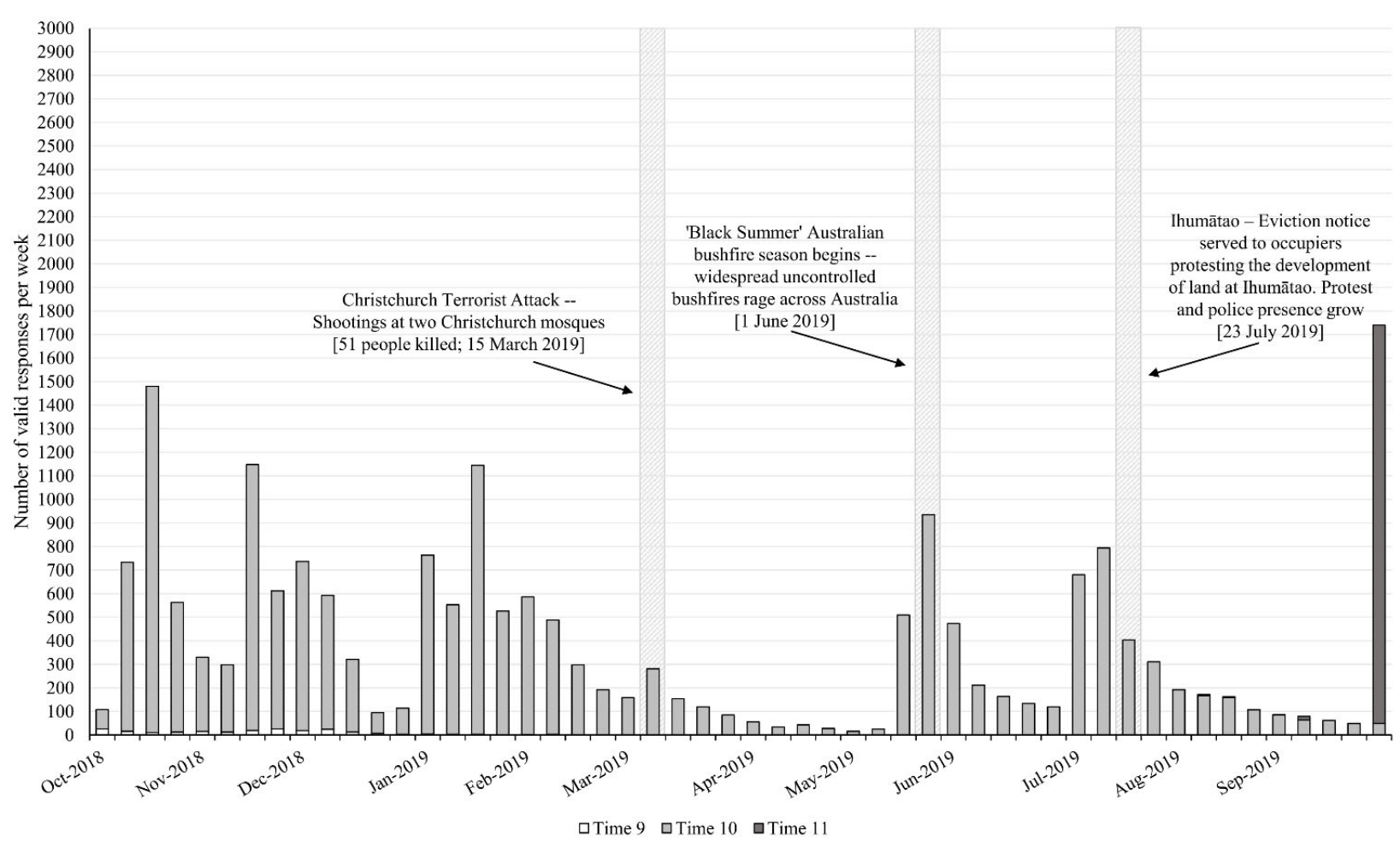

Figure 10. Histogram of weekly survey completions for Time 10 conducted from 18.06.201828.09.2019 (x axis ranges from October 2018 to October 2019, some responses to this wave may be presented on the graph for the following year; select national and international events that occurred during this data collection wave are also included for context).

\section{Time 11 (2019)}

\section{Sampling Procedure}

The Time 11 wave was conducted during COVID-19 pandemic. Procedures thus differed in that there was an increased focus on online deliver using email reminders and extensive Facebook advertising, no Christmas card, and incomplete phoning of nonrespondents.

The Time 11 (2019) NZAVS contained responses from 42,684 participants $(36,522$ retained from one or more previous wave). The sample retained 2,506 participants from the Time 1 (2009) sample (a retention rate of 38.4\%). The sample retained 34,782 participants from Time 10 (2018; a retention rate of $72.5 \%$ from the previous year). Participants who provided an email address were first emailed and invited to complete an online version if they preferred. Participants who did not complete the online version (or did not provide an email) were then posted a copy of the questionnaire, with a second postal follow-up two months later. We staggered the time of contact, so that participants who had completed the previous wave were contacted approximately one year after they last completed the questionnaire. A second reminder email was sent approximately four months following the first email attempt. We offered a prize draw for participation (five draws each for $\$ 1000$ grocery vouchers, $\$ 5000$ total prize pool). Participants were also emailed an eight-page newsletter about the study. As in past years, three attempts were made to phone non-respondents using each available cell and landline number. However, due to the university closure during COVID-19 
lockdowns, phoning attempts were made for only $54 \%$ of the phoning pool (11,687 from a total of 21,636 non-respondents who provided at least one phone number).

Two additional forms of recruitment were also introduced during Time 11 . The first was a large information box in the questionnaire (taking a full page on the paper version), which asked people: 'Do you have a partner who would also like to join the NZAVS?' with additional details for how partners might join the study (see questionnaire for the full text). The second was a Facebook advertisement. The advertisement targeted men and women aged $18-65+$ who lived in New Zealand and ran from and $4^{\text {th }}$ April $2020-4^{\text {th }}$ July 2020 (overlapping with New Zeeland's first lockdown period and recovery), and again from $18^{\text {th }}$ August $2020-4^{\text {th }}$ September (during the second Auckland lockdown). Given the unprecedented nature of the COVID-19 lockdowns, we thought it important to maximise sampling during these periods. The goal of the Facebook advertisement was threefold: (a) to increase name recognition of the NZAVS and remind people to complete the paper/online version already posted/emailed to them, (b) to help improve retention by potentially reaching previous lost participants who happened to see the advertisement, and (c) to recruit new participants (and also the partners of existing participants) while people were at home with some possibly having more free time during lockdown. This last goal was indirect and not explicitly stated it in the advertisement.

The Facebook advertisement read as follows: "Participate in the New Zealand Attitudes and Values Study. Complete the 2020 Questionnaire online" with the body of text: "If you are part of the NZAVS, but have not heard from us in the last year, then please consider completing the 2020 questionnaire online. The study is more important than ever as we aim to understand the impact of COVID-19 on mental health, wellbeing and resilience in our communities. Note that the advertisement referred to the year 2020 as this was conducted early in that year, as part of the Time 11 (2019 wave. We wish you all the best at this time and hope you keep well and stay safe." This paid promotion reached 883,969 people, with 37,850 link clicks (i.e., clicking the link for the Qualtrics survey) according to Facebook. A total of 6106 people continued complete the questionnaire and provide full contact details, and were thus included in the dataset (4734 were new participants opting in to the study, and 1372 were previously 'lost' participants).

\section{Participants}

The Time 11 wave included 27,221 women, 15,260 men, and 203 participants identifying as gender diverse, with a mean age of 52.05 years $(\mathrm{SD}=13.87)$. With regard to ethnicity, 39,527 people identified as European, 4,315 as Māori, 1,149 were Pacific Nations peoples, and 1900 identified with an Asian ethnic group. Note that people could identify with multiple ethnic groups (and hence be counted multiple times). Education $(\mathrm{M}=5.69, \mathrm{SD}=$ 2.66) was coded using the New Zealand Qualifications Authority scheme, which ranged from 0 (none) to 10 (doctoral degree or equivalent). Deprivation $(\mathrm{M}=4.75, \mathrm{SD}=2.72$ ) was coded using the New Zealand Deprivation index for the meshblock level (approx. 100 person-sized geographic units), with a decile rank from 1 (low) 10 (high; Atkinson, Salmond \& Crampton, 2014). Socioeconomic status $(\mathrm{M}=55.56, \mathrm{SD}=16.01)$ was scored from 10 (low) to 90 (high) using the New Zealand Socioeconomic Index, which assigned a score based on occupation and derived from census data (Fahy, Lee, \& Milne, 2017). Mean household income was $\mathrm{NZ} \$ 119,342(\mathrm{SD}=\mathrm{NZ} \$ 125,545$, median $=\mathrm{NZ} \$ 100,000)$. Of the 42,684 people sampled, 14,062 were religious; 31,177 were parents; 31,108 had a romantic partner; 31,858 were employed; 34,499 lived in an urban or suburban area; and 33,275 were born in New Zealand. 


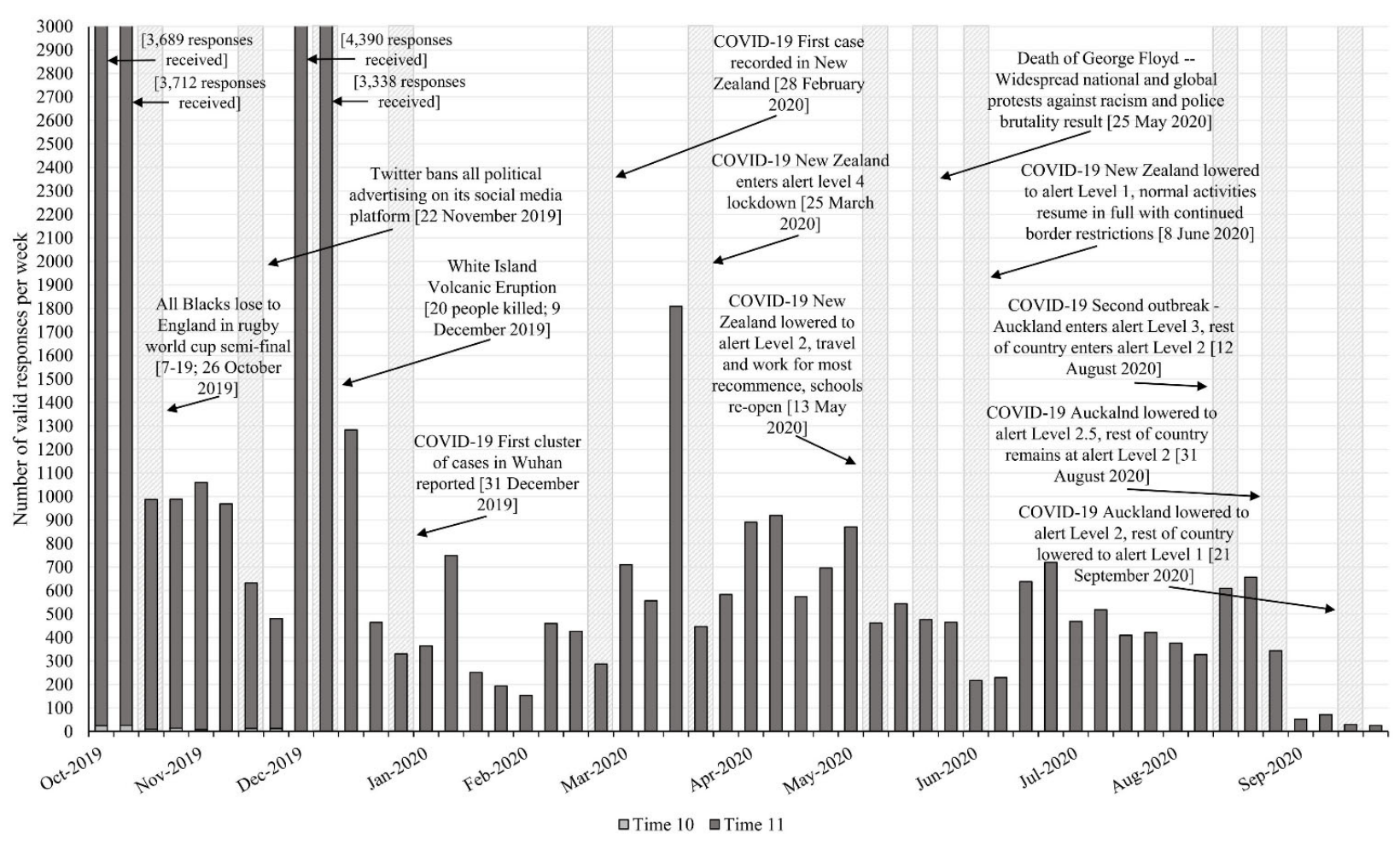

Figure 11. Histogram of weekly survey completions for Time 11 (x axis ranges from October 2019 to October 2020, some responses to this wave may be presented on the graph for the following year; select national and international events that occurred during this data collection wave are also included for context).

\section{Time 12 (2020)}

\section{Sampling Procedure}

The Time 12 (2020) wave was conducted during COVID-19 pandemic. For most of this wave, New Zealand successfully managed it COVID-19 eradication policy. Toward the end of this Wave (on August 17) the delta variant was detected and New Zealand moved into lockdown. This lasted for the remainder of the wave, and thus resulted in cancellation of the annual newsletter and Christmas cards, and incomplete phoning of non-respondents.

The Time 12 (2020) NZAVS contained responses from 38,551 participants $(38,345$ retained from one or more previous wave). The sample retained 2,107 participants from the Time 1 (2009) sample (a retention rate of 37.30\%). The sample retained 33,318 participants from Time 11 (2018; a retention rate of 78.10\% from the previous year). Participants who provided an email address were first emailed and invited to complete an online version if they preferred. Participants who did not complete the online version (or did not provide an email) were then posted a copy of the questionnaire, with a second postal follow-up two months later (note that the final postal reminder was mailed 2 or 3 days before the nationwide lockdown). We staggered the time of contact, so that participants who had completed the previous wave were contacted approximately one year after they last completed the questionnaire. A second reminder email was sent approximately four months following the first email attempt. We offered a prize draw for participation (five draws each for $\$ 1000$ grocery vouchers, $\$ 5000$ total prize pool). 


\section{Participants}

The Time 12 wave included 24,542 women, 13,815 men, and 194 participants identifying as gender diverse, with a mean age of 52.96 years $(\mathrm{SD}=13.70)$. With regard to ethnicity, 35,544 people identified as European, 3,374 as Māori, 857 were Pacific Nations peoples, and 1,558 identified with an Asian ethnic group. Note that people could identify with multiple ethnic groups (and hence be counted multiple times). Education ( $\mathrm{M}=5.56, \mathrm{SD}$ $=2.76$ ) was coded using the New Zealand Qualifications Authority scheme, which ranged from 0 (none) to 10 (doctoral degree or equivalent). Deprivation $(\mathrm{M}=4.70, \mathrm{SD}=2.73)$ was coded using the New Zealand Deprivation index for the meshblock level (approx. 100 person-sized geographic units), with a decile rank from 1 (low) 10 (high; Atkinson, Salmond $\&$ Crampton, 2014). Socioeconomic status $(M=59.92, S D=16.40)$ was scored from 10 (low) to 90 (high) using the New Zealand Socioeconomic Index, which assigned a score based on occupation and derived from census data (Fahy, Lee, \& Milne, 2017). Mean household income was NZ\$121,771 $(\mathrm{SD}=\mathrm{NZ} \$ 115,732$, median $=\mathrm{NZ} \$ 100,000)$. Of the 38,551 people sampled, 12,610 were religious; 28,687 were parents; 28,267 had a romantic partner; 29,303 were employed; 30,882 lived in an urban or suburban area; and 30,211 were born in New Zealand.

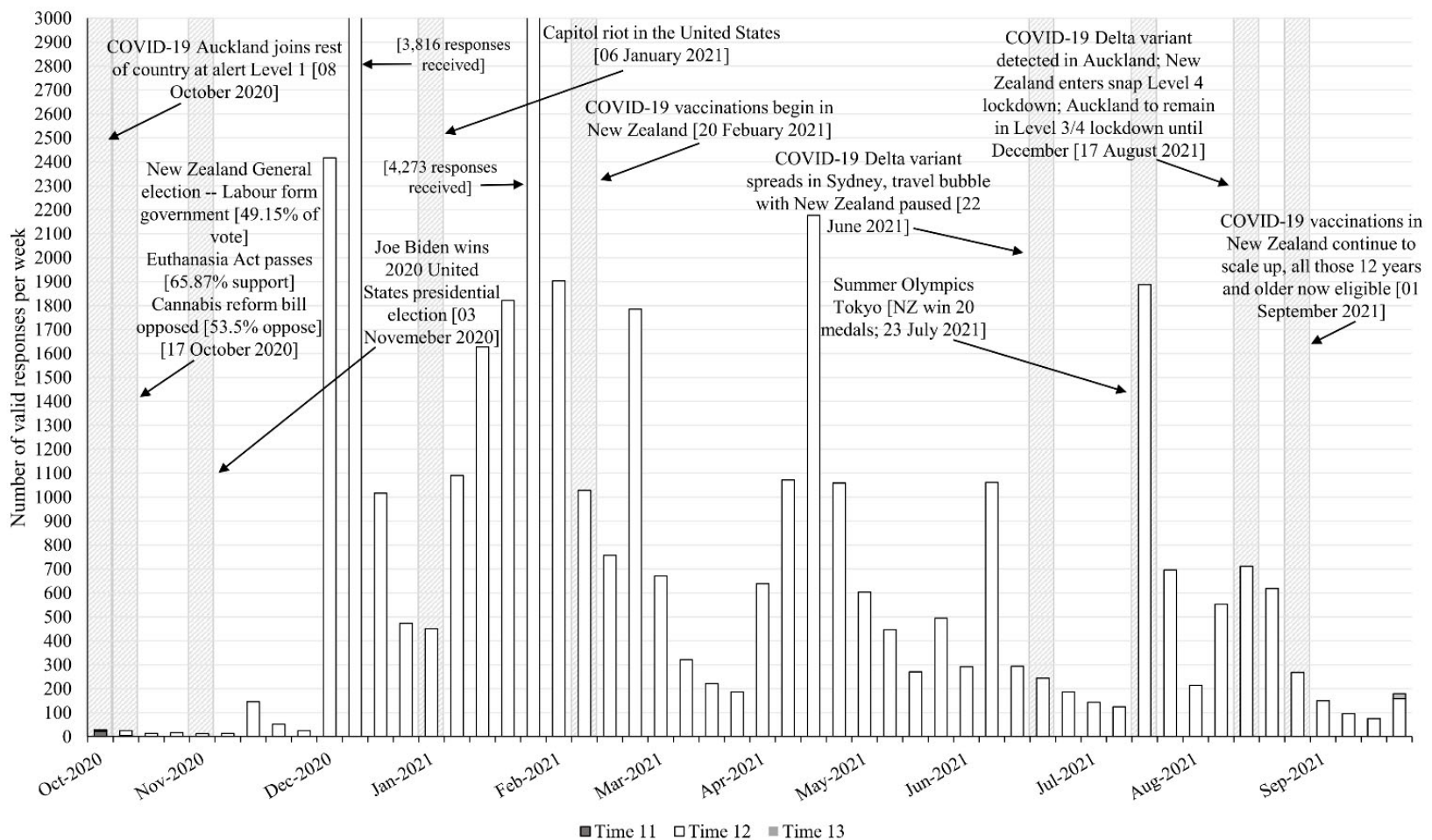

Figure 12. Histogram of weekly survey completions for Time 12 (x axis ranges from October 2019 to October 2020, some responses to this wave may be presented on the graph for the following year; select national and international events that occurred during this data collection wave are also included for context).

Time 13 (2021) 
[Time 13 is currently being conducted]

Sampling Procedure

The Time 13 (2021) wave began on 29-Oct-2021, eight weeks after New Zealand went into a nationwide lockdown following detection of the COVID-19 delta variant in the community. During this time vaccination rates for COVID-19 were massively scaled up, and New Zealand ultimately moved to managing COVID-19 in the community.

The Time 13 (2021) sampling procedure introduced two new procedures: (a) a prenotification Facebook advertisement, and (b) a shortened online questionnaire employing a planned missing design sent to non-respondents.

The Facebook pre-notification advertisement was identical to that used during the Time 11 wave, just referring to the 2021 year. The advertisement ran for one month before the first email survey invitations were sent to existing participants (four weeks after the country entered lockdown), and then ran for a further two weeks. The advertisement was framed as 'did we miss you this year?' despite being shown at the start of Time 13 wave (keep in mind that sampling is rolling throughout each year, with the aim to re-contact each person approximately one year after their last completion). The goal of the Facebook advertisement was to (a) increase name recognition of the NZAVS (and hence hopefully the retention rate) prior to sending initial email and postal letters inviting people to complete the annual questionnaire, (b) to reach previous lost participants who happened to see the advertisement, and (c) to recruit new participants (and also the partners of existing participants) while people were at home with some possibly having more free time during lockdown.

The Facebook advertisement read as follows: "Participate in the New Zealand Attitudes and Values Study. Complete the 2021 Questionnaire online" with the body of text: "If you are part of the NZAVS, but have not heard from us in the last year, then please consider completing the 2020 questionnaire online. The study is more important than ever as we aim to understand the impact of COVID-19 on mental health, wellbeing and resilience in our communities. We wish you all the best at this time and hope you keep well and stay safe." This paid promotion reached 249,767 people, with 9,715 link clicks (i.e., clicking the link for the Qualtrics survey) according to Facebook. A total of xx existing NZAVS participants completed the questionnaire, and an additional $\mathrm{xx}$ people opted in to the study and completed the questionnaire for the first time.

The most commonly stated reason for participant withdrawal in past years has been that the questionnaire was too long. In an attempt to reduce attrition, a shortened version of the online questionnaire was employed when emailing the invitation to participants for whom any of the following were true: (a) the neural network forecast their probability of responding to be less than .50 , (b) they had not responded during the previous wave, (c) they had provided only a partial completion during the last wave, or (d) they had participated in last wave, but that did not did not respond to the initial email invitation for the current wave. The shortened questionnaire employed a planned missing design that randomly presented only $68 \%$ of the Likert questions (those on a 1-7 strongly disagree to strongly agree scale) and $68 \%$ of the personality-style items (those on a 1-7 scale from very inaccurate to very accurate scale) included in the full T13 questionnaire. All other rating scales (e.g., warmth ratings, satisfaction ratings) and demographic questions were presented in full. 
Tabulated demographics by wave

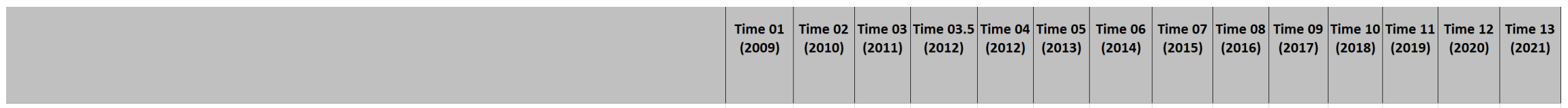

Gender
Women

Men

Gender Diverse

Ethnicity (Note. Does not sum to 100\%, as people could identify with multiple groups).

European

Pacific Nations peoples

Pacific Nations
Asian penples

Age
Mean

Standard Deviation

Education (NZReg 0-10)

Mean

Standard Deviation

Household Income (Log)

Mean

Standard Deviatio

NZDep (1-10)

Mean
Standard Deviation

Socio-Economic Index (2013) [SEI 10-90)

Mean

Standard Deviation

Categorical Demographics

Religious

Partner

Employed

Urban

Born in New Zealand

\begin{tabular}{|c|c|c|c|c|c|c|c|c|c|c|c|c|}
\hline 3,879 & 2,735 & 4,303 & 2,811 & 7,621 & 11,460 & 10,002 & 8,726 & 13,722 & 10,802 & 30,021 & 27,221 & 24,542 \\
\hline 2,639 & 1,706 & 2,578 & 1,569 & 4,554 & 6,798 & 5,798 & 5,197 & 8,171 & 6,246 & 17,811 & 15,260 & 13,815 \\
\hline ---- & --- & - & - & - & $\cdots$ & 20 & 17 & 41 & 24 & 101 & 203 & 194 \\
\hline 5,340 & 3,815 & 5,147 & 3,968 & 10,281 & 15,607 & 14,161 & 12,506 & 19,478 & 15,606 & 42,495 & 39,527 & 35,544 \\
\hline 1,168 & 690 & 745 & 434 & 2,025 & 2,328 & 1,977 & 1,672 & 2,473 & 2,007 & 4,691 & 4,315 & 3,374 \\
\hline 280 & 161 & 177 & 275 & 610 & 625 & 526 & 427 & 574 & 466 & 1,037 & 1,149 & 857 \\
\hline 372 & 179 & 25? & 164 & 619 & 814 & 684 & 545 & 1,001 & 700 & , ,538 & 1,900 & 1,558 \\
\hline 48.10 & 50.99 & 50.95 & 49.12 & 49.11 & 47.65 & 49.33 & 50.79 & 49.62 & 51.33 & 48.59 & 52.05 & 52.96 \\
\hline 15.75 & 15.23 & 15.95 & 15.67 & 15.02 & 14.07 & 14.03 & 13.90 & 13.93 & 13.77 & 13.86 & 13.87 & 13.70 \\
\hline 4.04 & - -..- & --.-- & ---ב- & 4.70 & 4.93 & 5.08 & 5.19 & 5.30 & 5.26 & 5.33 & 5.69 & 5.56 \\
\hline 2.78 & $\ldots$ & -- & -- & 2.84 & 2.82 & 2.81 & 2.78 & 2.75 & 2.77 & 2.73 & 2.66 & 2.76 \\
\hline 11.04 & 10.99 & 11.08 & --.- & 11.23 & 11.30 & 11.25 & 11.30 & 11.29 & 11.37 & 11.39 & 11.39 & 11.42 \\
\hline 0.91 & 1.02 & 1.22 & --- & 0.80 & 0.79 & 1.14 & 0.97 & 1.04 & 0.85 & 0.78 & 0.83 & 0.83 \\
\hline 5.06 & 5.03 & 4.73 & 4.57 & 5.02 & 4.81 & 4.71 & 4.70 & 4.67 & 4.59 & 4.62 & 4.75 & 4.70 \\
\hline 2.85 & 2.78 & 2.74 & 2.73 & 2.85 & 2.79 & 2.76 & 2.78 & 2.75 & 2.72 & 2.71 & 2.72 & 2.73 \\
\hline 49.75 & 53.48 & 56.27 & - & 52.30 & 52.94 & 53.73 & 54.36 & 54.30 & 54.88 & 54.05 & 55.56 & 59.92 \\
\hline 15.77 & 17.48 & 16.75 & - & 16.27 & 16.46 & 16.26 & 16.04 & 16.29 & 16.16 & 16.46 & 16.01 & 16.40 \\
\hline 2,826 & 1,941 & 2,683 & 1,690 & 4,934 & 6,879 & 6,030 & 5,844 & 8,274 & 6,137 & 16,907 & 14,062 & 12,610 \\
\hline 4,888 & 3,477 & 4,997 & - & 8,856 & 13,084 & 11,655 & 10,511 & 15,883 & 12,628 & 32,730 & 31,177 & 28,687 \\
\hline 4,558 & 3,215 & 4,769 & - & 8,314 & 12,984 & 11,354 & 10,090 & 15,885 & 12,770 & 34,199 & 31,108 & 28,267 \\
\hline 4,742 & 3,155 & 5,075 & ---- & 8,464 & 13,578 & 12,037 & 10,457 & 17,119 & 13,136 & 36,493 & 31,858 & 29,303 \\
\hline 3,839 & 2,625 & 4,147 & $\ldots$ & 7,871 & 12,151 & 10,454 & 8,994 & 14,074 & 13,732 & 38,637 & 34,499 & 30,882 \\
\hline 5,138 & 3,549 & 5,189 & --- & 9,421 & 14,225 & 12,497 & 10,624 & 17,157 & 13,517 & 36,409 & 33,275 & 30,211 \\
\hline
\end{tabular}




\section{Measurement of area-unit deprivation (NZDep)}

We measured the deprivation of participants' immediate (small area) neighborhood using the 2013 New Zealand Deprivation Index (Atkinson, Salmond, Crampton, 2014; see also Salmond, Crampton \& Atkinson, 2007). New Zealand is unusual in having rich census information about each area unit/neighborhood of the country available for research purposes. The smallest of these area units are meshblocks. The NZAVS includes the meshblock code for each participant.

The geographic size of these meshblock units differs depending on population density. Each unit tends to cover a region containing a median of roughly 81 residents $(\mathrm{M}=$ $95.95, \mathrm{SD}=73.49$, range $=0-1899)$. In 2013, at the time of the latest census, there were a total of 44,211 meshblocks for which data was available. The distribution of usually resident population of the 44,211 meshblocks for which data were available from the $2013 \mathrm{New}$ Zealand National Census is presented in Figure 1.

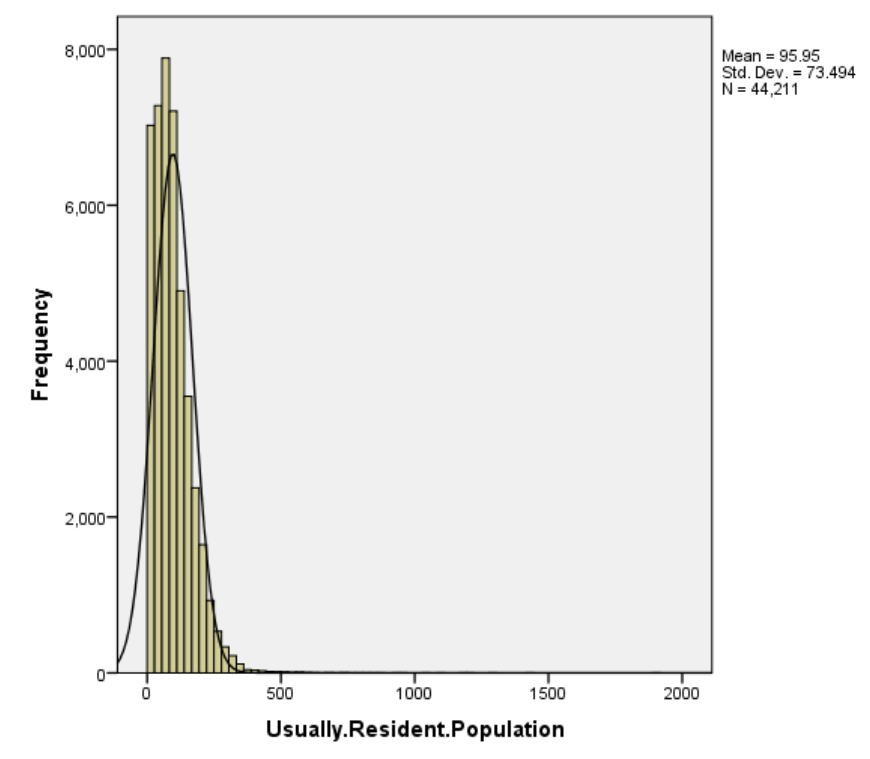

Figure 1. Histogram showing distribution of Usually Resident Population of 44,211 meshblocks based on the 2013 New Zealand National Census.

Statistics New Zealand (2013) defined a meshblock as "a defined geographic area, varying in size from part of a city block to large areas of rural land. Each meshblock abuts against another to form a network covering all of New Zealand including coasts and inlets, and extending out to the two-hundred-mile economic zone. Meshblocks are added together to 'build up' larger geographic areas such as area units and urban areas."

The New Zealand Deprivation Index (Atkinson et al., 2013; Salmond et al., 2007) uses aggregate census information about the residents of each meshblock to assign a decilerank index from 1 (least deprived) to 10 (most deprived) to each meshblock unit. Because it is a decile-ranked index, the $10 \%$ of meshblocks that a most deprived are most affluent are given a score of 1 , the next $10 \%$ a score of 2 , and so on. The index is based on a Principal Components Analysis of the following nine variables (in weighted order): proportion of adults who received a means-tested benefit, household income, proportion not owning own home, proportion single-parent families, proportion unemployed, proportion lacking 
qualifications, proportion household crowding, proportion no telephone access, and proportion no car access.

The New Zealand Deprivation Index thus reflects the average level of deprivation for small neighborhood-type units (or small community areas of about 80-90 people each) across the entire country. The index is a well-validated index of the level of deprivation of small area units, and has been widely used in health and social policy research examining numerous health outcomes, including mortality, rates of hospitalization, smoking, cot death, and access to health care, to name just a few examples (e.g., HURA Research Alliance et al., 2006; Mitchell, Stewart, Crampton, \& Salmond, 2000; Salmond \& Crampton, 2000; Crampton, Salmond, Woodward \& Reid, 2000). The index is also widely used in service planning by government and local council, and is a key indicator used identify high needs areas and allocate resources such as health funding (see Salmond \& Crampton, 2012, White, Gunston, Salmond, Atkinson, \& Crampton, 2008, for review).

\section{Measurement of socio-economic status (NZSEI)}

Socioeconomic status was calculated using the New Zealand Socioeconomic Index (NZSEI) which is a Census-derived, occupation-based measure of a person's socioeconomic status. Occupation is likely to capture a person's opportunities in life as it is an intermediary between educational attainment and income (see Fahy, Lee, \& Milne, 2017; Ganzeboom, DeGraaf, Treiman, \& De-Leeuw, 1992; Milne, Byun, \& Lee, 2013). Participants were asked to respond to an open-ended question asking what their current occupation was and these unique strings were classified according to the Australian and New Zealand Standard Classification of Occupations (ANZSCO) Level 3. In line with prior research, missing values for the NZSEI were imputed using a combination of education and age. 


\section{Identifying dyads}

The NZAVS aimed to sample individuals, but over time some people's partners have self-selected to join the study and in other cases both partners have been randomly sampled. We identified couples in cohabiting, serious relationships by first identifying people who share a postal address (or in the case of one person providing a residential address and other a postal box in the same region, those sharing a landline or email address). Of those sharing these contact details, to be flagged as a dyad, both couple members must have also reported one or more of the following characteristics: (a) same relationship type and similar relationship duration, (d) if married, then same date of marriage, (c) both partners' genders consistent with reported sexual orientation. If there was more than 12 years difference in age (increasing the possibility of a parent-adult child dyad), then one or more of the following additional factors was also required to be considered a dyad: (a) same date of marriage, (b) if parents, same birthdate of one or more children.

Table.1 Number of complete dyads in each wave.

\begin{tabular}{lr}
\hline & N complete dyads \\
\hline Time 01 & 10 \\
Time 02 & 7 \\
Time 03 & 53 \\
Time 035 & 33 \\
Time 04 & 67 \\
Time 05 & 136 \\
Time 06 & 115 \\
Time 07 & 93 \\
Time 08 & 202 \\
Time 09 & 139 \\
Time 10 & 864 \\
Time 11 & 822 \\
\hline
\end{tabular}

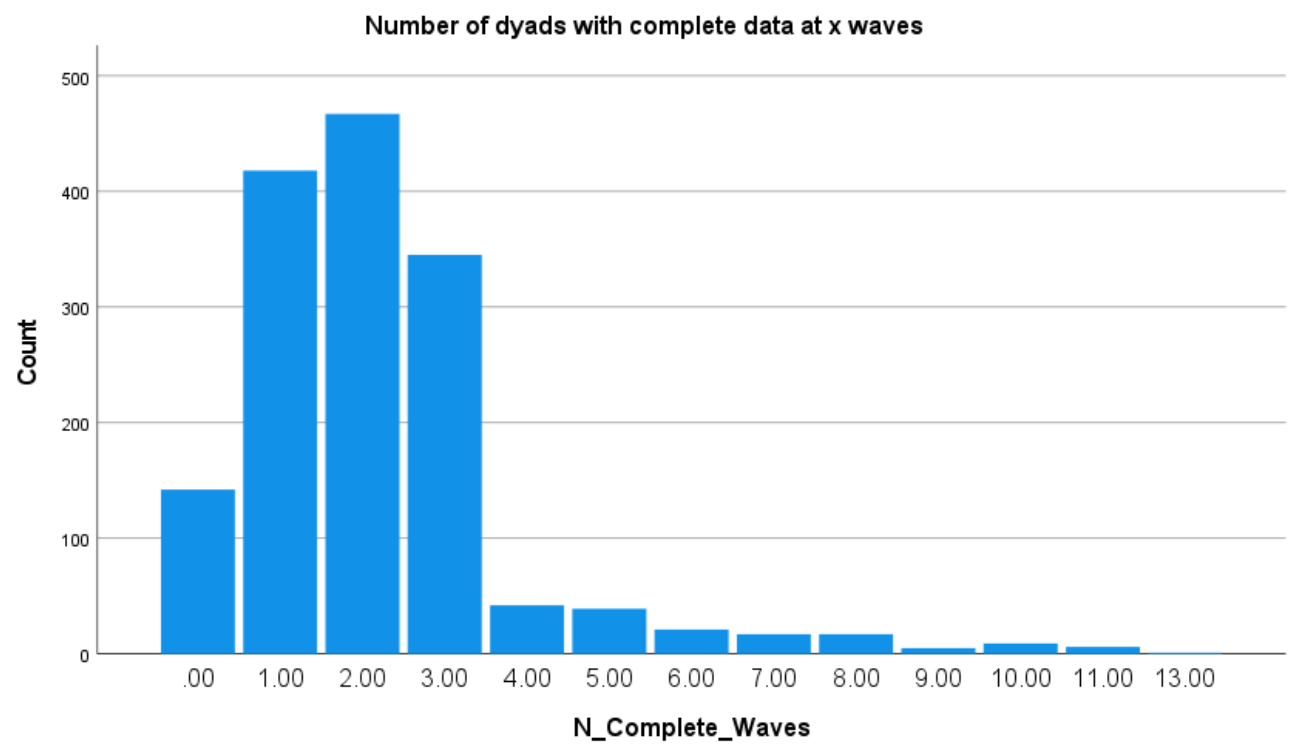




\section{Chapter 2 -- Sample retention}

Retention rates

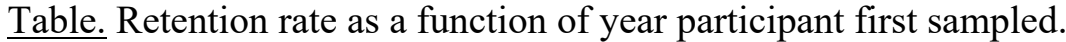

\begin{tabular}{|c|c|c|c|c|c|c|c|c|c|c|c|c|c|}
\hline & $\begin{array}{c}2009 \\
(\mathrm{~N}-6518)\end{array}$ & $\begin{array}{c}2010 \\
(\mathrm{~N}-6534)\end{array}$ & $\begin{array}{c}2011 \\
(\mathrm{~N}-9500)\end{array}$ & $\begin{array}{c}2011.5 \\
(\mathrm{~N}-9923)\end{array}$ & $\begin{array}{c}2012 \\
(\mathrm{~N}-15294)\end{array}$ & $\begin{array}{c}2013 \\
(\mathrm{~N}-23052)\end{array}$ & $\begin{array}{c}2014 \\
(\mathrm{~N}-23130)\end{array}$ & $\begin{array}{c}2015 \\
(\mathrm{~N}-23195)\end{array}$ & $\begin{array}{c}2016 \\
(\mathrm{~N}-31463)\end{array}$ & $\begin{array}{c}2017 \\
(\mathrm{~N}-31602)\end{array}$ & $\begin{array}{c}2018 \\
(\mathrm{~N}-61525)\end{array}$ & $\begin{array}{c}2019 \\
(\mathrm{~N}-67684)\end{array}$ & $\begin{array}{c}2020 \\
(\mathrm{~N}-67856)\end{array}$ \\
\hline \multicolumn{14}{|l|}{ States } \\
\hline 2009 & $\begin{array}{c}6518 \\
(100 \%)\end{array}$ & $\begin{array}{c}4425 \\
(67.7 \%)\end{array}$ & $\begin{array}{c}3916 \\
(41.2 \%)\end{array}$ & $\begin{array}{c}1977 \\
(19.9 \%)\end{array}$ & $\begin{array}{c}4054 \\
(26.5 \%)\end{array}$ & $\begin{array}{c}3936 \\
(17.1 \%)\end{array}$ & $\begin{array}{c}3728 \\
(16.1 \%)\end{array}$ & $\begin{array}{c}3345 \\
(14.4 \%)\end{array}$ & $\begin{array}{c}3349 \\
(10.6 \%)\end{array}$ & $2771(8.8 \%)$ & $2967(4.8 \%)$ & $2506(3.7 \%)$ & $2224(3.3 \%)$ \\
\hline 2010 & $0(0 \%)$ & $16(0.2 \%)$ & $2(0.036)$ & $0(0 \%)$ & $4(0.0 \%)$ & $3(0.0 \%)$ & $2(0.0 \%)$ & $2(0.096)$ & $1(0.0 \% 6)$ & $1(0.0 \%)$ & $2(0.0 \%)$ & $3(0.0 \%)$ & $1(0.0 \%)$ \\
\hline 2011 & $0(0 \%)$ & $0(0 \%)$ & $\begin{array}{c}2966 \\
(31.2 \%)\end{array}$ & $\begin{array}{c}2114 \\
(21.3 \%)\end{array}$ & $\begin{array}{c}2430 \\
(15.996)\end{array}$ & $\begin{array}{c}2337 \\
(10.1 \%)\end{array}$ & $2270(9.8 \%)$ & $2041(8.8 \%)$ & $2038(6.5 \%)$ & $1759(5.6 \%)$ & $1875(3.066)$ & $1719(2.5 \%)$ & $1583(2.3 \%)$ \\
\hline 2011.5 & $0(0 \%)$ & $0(0 \%)$ & $0(0 \% 6)$ & $423(4.3 \%)$ & $320(2.1 \%)$ & 253 (1.1\%) & $238(1.0 \%)$ & $204(0.9 \%)$ & $204(0.6 \%)$ & $164(0.5 \%)$ & $177(0.3 \%)$ & $153(0.2 \%)$ & $133(0.2 \%)$ \\
\hline 2012 & $0(0 \%)$ & $0(0 \%)$ & $0(036)$ & $0(036)$ & $\begin{array}{c}5371 \\
(35.1 \%)\end{array}$ & $\begin{array}{c}3974 \\
(17.2 \%)\end{array}$ & $\begin{array}{c}3505 \\
(15.2 \%)\end{array}$ & $\begin{array}{c}3202 \\
{[13.8 \%)}\end{array}$ & 3108 (9.9\%) & 2511 (7.9\%) & 2699 (4.4\%) & $2295(3.4 \%)$ & 2081 (3.1\%) \\
\hline 2013 & $0(0 \%)$ & $O(0 \%)$ & $0(0 \% 6)$ & $0(0 \%)$ & $0(0 \%)$ & $\begin{array}{c}7758 \\
(33.7 \%)\end{array}$ & $\begin{array}{c}5999 \\
(25.996)\end{array}$ & $\begin{array}{c}5033 \\
(21.7 \%)\end{array}$ & $\begin{array}{c}4882 \\
(15.5 \%)\end{array}$ & $\begin{array}{c}4066 \\
(12.9 \%)\end{array}$ & $4420(7.2 \%)$ & $3657(5.4 \%)$ & $3341(4.996)$ \\
\hline 2014 & $0(0 \%)$ & $0(0 \%)$ & $0(036)$ & $0(0 \%)$ & $0(0 \%)$ & $0(0 \%)$ & $78(0.3 \%)$ & $50(0.2 \%)$ & $40(0.1 \%)$ & $33(0.1 \%)$ & $43(0.1 \%)$ & $40(0.1 \%)$ & $32(0.086)$ \\
\hline 2015 & $0(0 \%)$ & $0(0 \%)$ & $0(0 \%)$ & $0(036)$ & $0(0 \%)$ & $0(0 \%)$ & $0(0 \%)$ & $65(0.3 \%)$ & $46(0.1 \%)$ & $36(0.1 \%)$ & $43(0.1 \%)$ & $37(0.1 \%)$ & $33(0.0 \%)$ \\
\hline 2016 & $0(0 \%)$ & $0(0 \%)$ & $0(03)$ & $0(036)$ & $0(0 \%)$ & $0(0 \%)$ & $0(0 \%)$ & $0(036)$ & $\begin{array}{c}8268 \\
(26.3 \%)\end{array}$ & $\begin{array}{c}5592 \\
(17.7 \%)\end{array}$ & 5715 (9.3\%) & 4838 (7.1\%) & $4324(6.4 \%)$ \\
\hline 2017 & $0(0 \%)$ & $0(0 \%)$ & $0(0 \%)$ & $0(0 \%)$ & $0(0 \%)$ & $0(0 \%)$ & $0(0 \%)$ & $0(036)$ & $0(0 \%)$ & $139(0.4 \%)$ & $84(0.1 \%)$ & $85(0.1 \%)$ & $77(0.1 \%)$ \\
\hline 2018 & $0(0 \%)$ & $0(0 \%)$ & $0(0 \%)$ & $0(0 \%)$ & $0(0 \%)$ & $0(0 \%)$ & $0(0 \%)$ & $0(036)$ & $0(0 \%)$ & $0(0 \%)$ & $\begin{array}{c}29923 \\
(48.696)\end{array}$ & $\begin{array}{c}21188 \\
(31.3 \%)\end{array}$ & $\begin{array}{c}17150 \\
(25.3 \%)\end{array}$ \\
\hline 2019 & $0(0 \%)$ & $0(0 \%)$ & $0(0 \% 6)$ & $0(0 \%)$ & $0(0 \%)$ & $0(0 \%)$ & $0(0 \%)$ & $0(0 \%)$ & $0(096)$ & $0(036)$ & $0(0 \%)$ & $6159(9.1 \%)$ & $4219(6.2 \%)$ \\
\hline 2020 & $0(0 \%)$ & $0(0 \%)$ & $0(036)$ & $0[036)$ & $0(0 \%)$ & $0(0 \%)$ & $0(0 \%)$ & $0(0 \%)$ & $0(036)$ & $0[0 \%)$ & $0(0 \%)$ & $0(0 \%)$ & $172(0.3 \%)$ \\
\hline missing & $0(0 \%)$ & $\begin{array}{c}2068 \\
(31.6 \%)\end{array}$ & $\begin{array}{c}2545 \\
(26.8 \%)\end{array}$ & $\begin{array}{c}5294 \\
(53.4 \%)\end{array}$ & $\begin{array}{c}2966 \\
(19.4 \%)\end{array}$ & $\begin{array}{c}4574 \\
(19.8 \%)\end{array}$ & $\begin{array}{c}7019 \\
(30.3 \%)\end{array}$ & $\begin{array}{c}8865 \\
(38.2 \%)\end{array}$ & $\begin{array}{c}9043 \\
(28.7 \%)\end{array}$ & $\begin{array}{c}13947 \\
(44.1 \%)\end{array}$ & $\begin{array}{c}12904 \\
(21.0 \%)\end{array}$ & $\begin{array}{c}24174 \\
(35.7 \%)\end{array}$ & $\begin{array}{c}31569 \\
(46.5 \%)\end{array}$ \\
\hline deceased & $0(0 \%)$ & $25(0.4 \%)$ & $71(0.7 \%)$ & $115(1.2 \%)$ & $149(1.0 \%)$ & $217(0.9 \%)$ & $291(1.3 \%)$ & $388(1.7 \%)$ & $484(1.5 \%)$ & $583(1.8 \%)$ & 673 (1.1\%) & $830(1.2 \%)$ & $917(1.4 \%)$ \\
\hline
\end{tabular}


NZAVS alluvial retention graph: waves 2009-2020

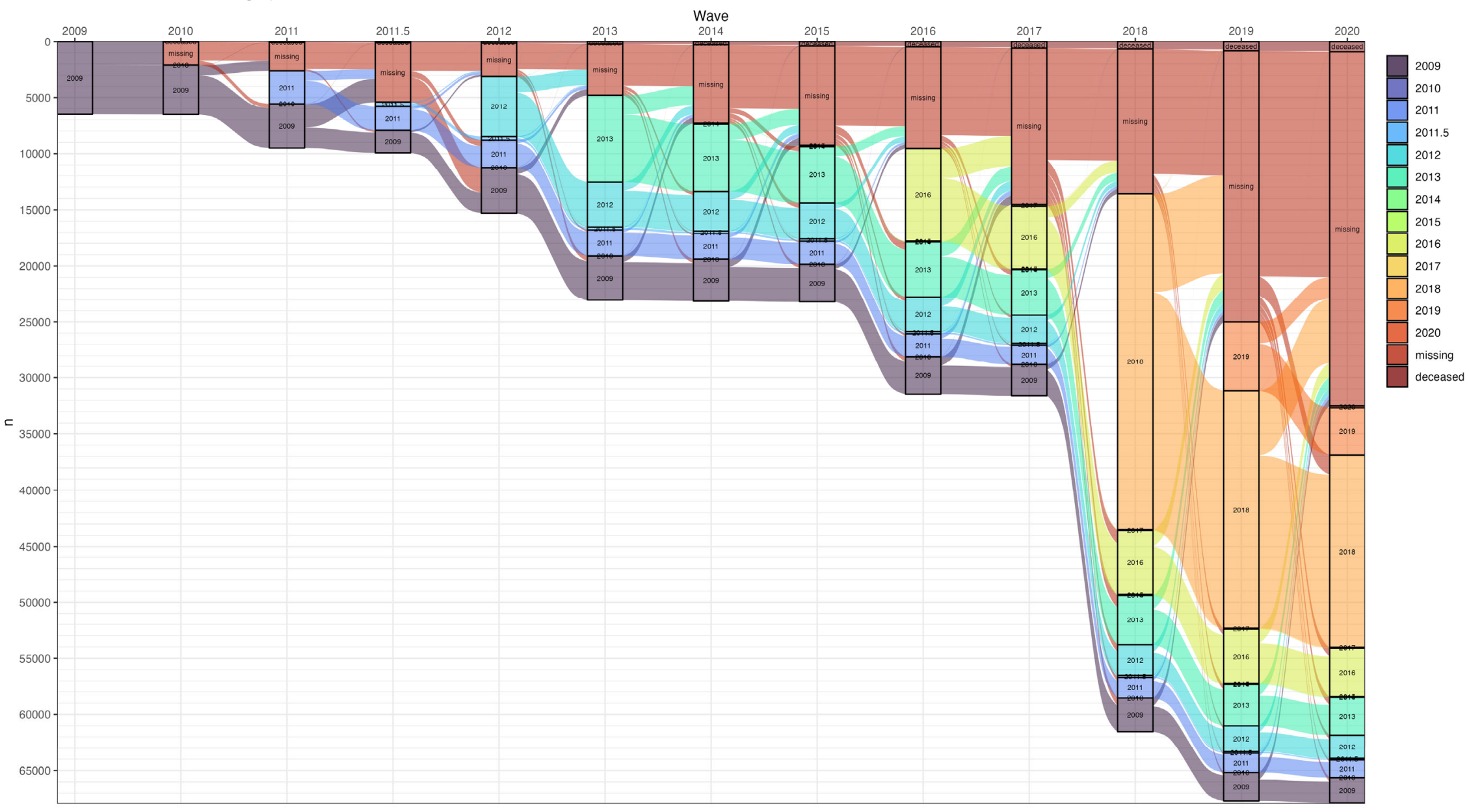

Figure. Retention over time as a function of sample origin year. 
NZAVS alluvial retention graph: waves 2009-2020

Facets are sample frames

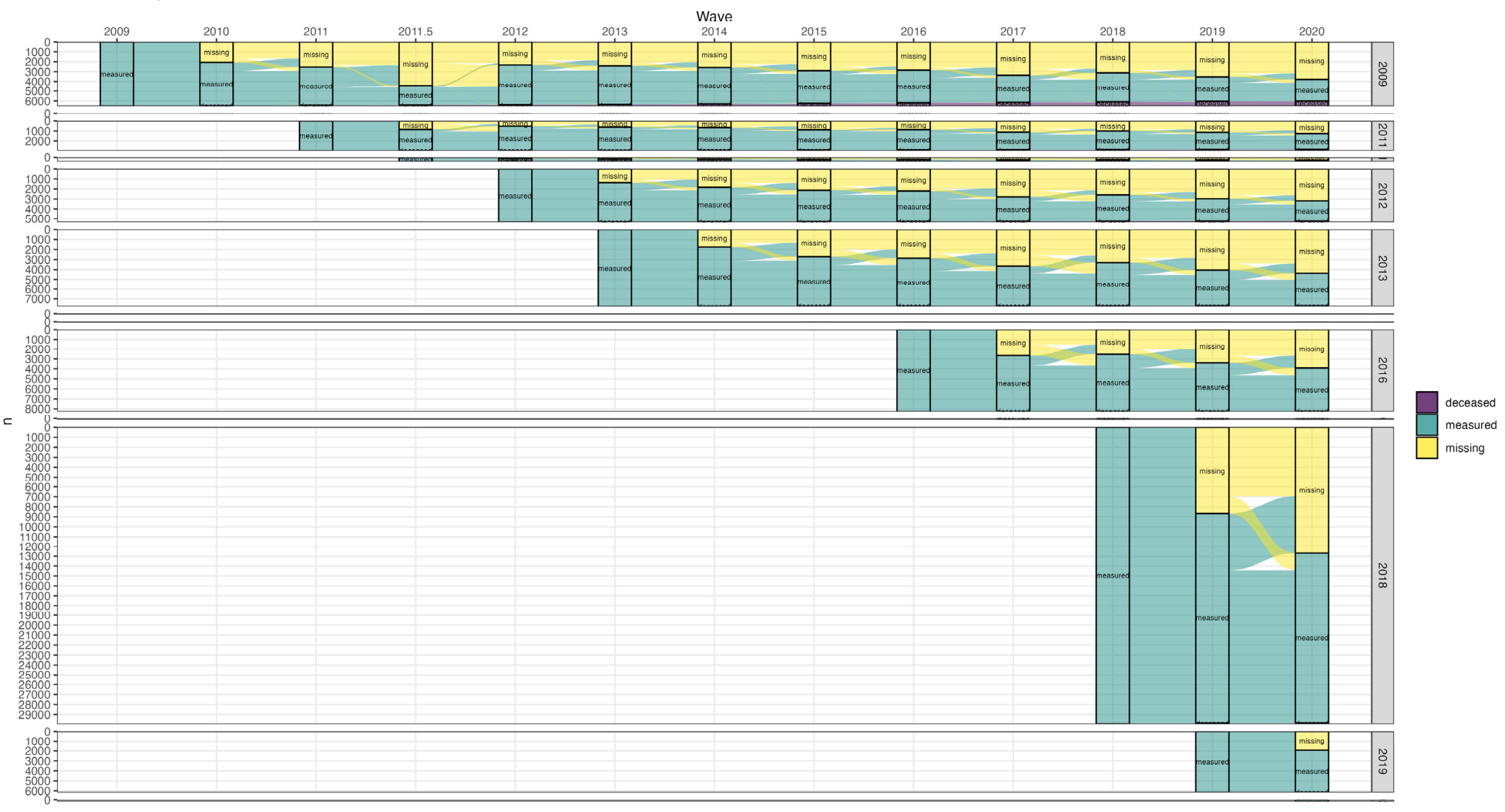

Figure. Retention over time separately for each origin year. 


\begin{tabular}{|c|c|c|c|c|c|c|c|c|c|c|c|c|c|c|}
\hline & $\begin{array}{c}\text { Time } 01 \\
(2009)\end{array}$ & $\mid \begin{array}{c}\text { Time 02 } \\
\text { (2010) }\end{array}$ & $\left|\begin{array}{c}\text { Time 03 } \\
(2011)\end{array}\right|$ & $\begin{array}{c}\text { Time } 03.5 \\
\text { (2012) }\end{array} \mid$ & \begin{tabular}{|c|} 
Time 04 \\
(2012)
\end{tabular} & $\begin{array}{c}\text { Time 05 } \\
\text { (2013) }\end{array}$ & \begin{tabular}{|c|} 
Time 06 \\
(2014)
\end{tabular} & $\mid$\begin{tabular}{c|} 
Time 07 \\
(2015)
\end{tabular} & $\mid$\begin{tabular}{c|} 
Time 08 \\
(2016)
\end{tabular} & $\mid \begin{array}{c}\text { Time 09 } \\
\text { (2017) }\end{array}$ & $\left|\begin{array}{c}\text { Time 10 } \\
(2018)\end{array}\right|$ & $\left|\begin{array}{c}\text { Time 11 } \\
(2019)\end{array}\right|$ & $\begin{array}{c}\text { Time 12 } \\
(\mathbf{2 0 2 0 )}\end{array}$ & \begin{tabular}{|l|} 
Time 13 \\
(2021)
\end{tabular} \\
\hline \multicolumn{15}{|l|}{ SAMPLE SIZE DETAILS } \\
\hline Sample size (n) & 6.518 & 4,441 & 6,884 & 4.514 & 12,179 & 18,261 & 15,820 & 13,942 & 21.936 & 17.072 & 47.949 & 42,684 & & \\
\hline Retained sample (from previous wave or earlier) & 0 & 4,425 & 3,918 & 4,091 & 6,808 & 10,503 & 15,742 & 13,877 & 13,668 & 16,932 & 18,025 & 36,522 & & \\
\hline Additions during that particular wave (booster sampling, partners of existing participants) & 6,518 & 16 & 2,966 & 423 & 5,371 & 7,758 & 78 & 65 & 8,268 & 140 & 29,924 & 6,162 & & \\
\hline Previous wave retention & $\ldots$ & 4,425 & 3,530 & $\ldots$ & 5,762 & 9,844 & 14,878 & 12,550 & 11,933 & 15,784 & 14,049 & 34,782 & & \\
\hline$\%$ Previous wave retention & $\ldots$ & $67.89 \%$ & $79.47 \%$ & -..-- & $83.70 \%$ & $80.81 \%$ & $81.46 \%$ & $79.30 \%$ & $85.59 \%$ & $71.95 \%$ & $82.30 \%$ & $72.50 \%$ & & \\
\hline$\%$ Previous wave retention [Mortality Adjusted] & $\ldots$ & $68.15 \%$ & $79.88 \%$ & $\ldots$ & $84.13 \%$ & $81.00 \%$ & $81.65 \%$ & $79.58 \%$ & $85.99 \%$ & $72.05 \%$ & $85.00 \%$ & $73.50 \%$ & & \\
\hline$\%$ Wave 1 Retention & $\ldots$ & $67.89 \%$ & $60.08 \%$ & $\ldots$ & $62.18 \%$ & $60.36 \%$ & $57.20 \%$ & $51.32 \%$ & $51.35 \%$ & $42.51 \%$ & $45.50 \%$ & $38.40 \%$ & & \\
\hline$\%$ Wave 1 Retention [Mortality Adjusted] & $\ldots$ & $68.15 \%$ & $60.74 \%$ & $\ldots$ & $63.26 \%$ & $61.84 \%$ & $58.96 \%$ & $53.32 \%$ & $54.24 \%$ & $44.95 \%$ & $48.20 \%$ & $40.30 \%$ & & \\
\hline \multicolumn{15}{|l|}{ Cross-tabulation of retained sample across each assessment period } \\
\hline $\begin{array}{l}\text { Lross-aburation or retainea sampie across eacn assessment period } \\
\text { Iime } 1\end{array}$ & 6,518 & 4,423 & 3,916 & $1,9 / 1$ & 4,053 & 3,934 & $3, / 28$ & 3,343 & $3,34 /$ & $2, / / 1$ & 2,961 & 2,506 & & \\
\hline Time 2 & & 4,441 & 3,530 & 1,825 & 3,464 & 3,352 & 3,185 & 2,878 & 2,855 & 2,390 & 2,527 & 2,183 & & \\
\hline Time 3 & & & 6,884 & 3,918 & 5,762 & 5,550 & 5,310 & 4,813 & 4,790 & 4,066 & 4,286 & 3,811 & & \\
\hline Time 3.5 & & & & 4,514 & 4,013 & 3,814 & 3,671 & 3,346 & 3,340 & 2,902 & 3,028 & 2,739 & & \\
\hline Time 4 & & & & & 12,179 & 9,844 & 9,095 & 8,260 & 8,140 & 6,776 & 7,161 & 6,217 & & \\
\hline Time 5 & & & & & & 18,261 & 14,878 & 13,044 & 12,806 & 10,687 & 11,376 & 9,740 & & \\
\hline Time 6 & & & & & & & 15,820 & 12,550 & 12,398 & 10,366 & 10,911 & 9,419 & & \\
\hline Time 7 & & & & & & & & 13,942 & 11,933 & 10,049 & 10,435 & 9,073 & & \\
\hline Time 8 & & & & & & & & & 21,936 & 15,784 & 16,333 & 14,086 & & \\
\hline Time 9 & & & & & & & & & & 17,072 & 14,049 & $\begin{array}{l}14,000 \\
12,369\end{array}$ & & \\
\hline Time 10 & & & & & & & & & & & 47,949 & 34,782 & & \\
\hline Time 11 & & & & & & & & & & & & 42,684 & & \\
\hline \multicolumn{15}{|l|}{ Time 12} \\
\hline Time 13 & & & & & & & & & & & & & & \\
\hline
\end{tabular}

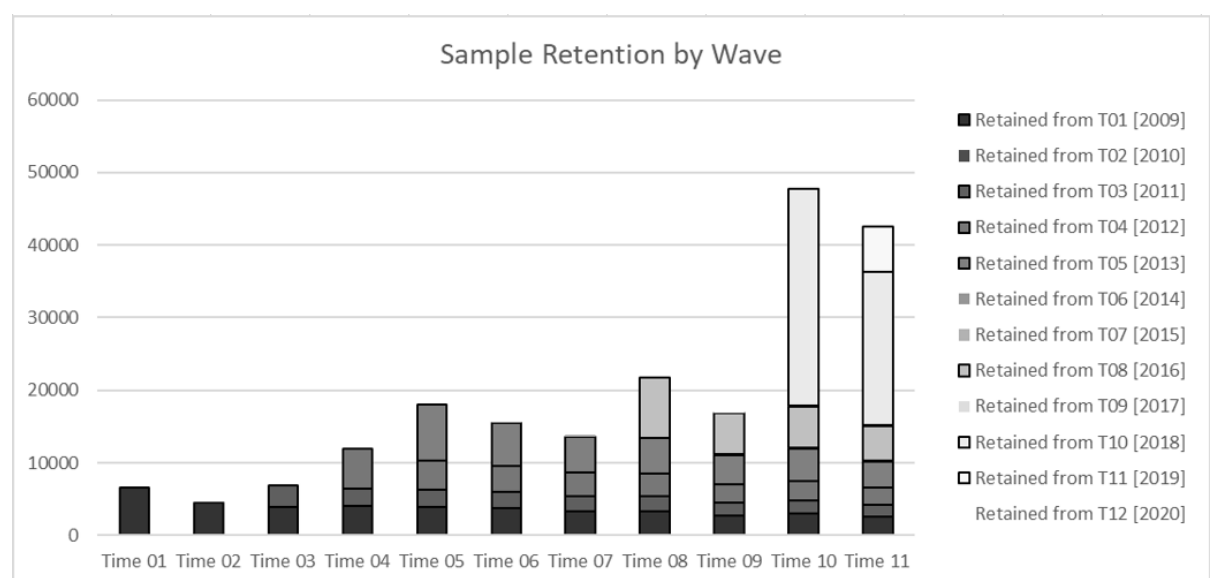




\section{Neural network predicting retention: model overview}

The NZAVS uses a neural network to forecast future retention. The structure of the NZAVS is fairly complex in terms of sampling, as it contains various booster samples conducted during different waves, and of different sizes, and sometimes using different sample frames, as well as including self-selected opt-in participants (often the partners of existing participants).

The retention neural network is a fairly simple multilayer perceptron with 2 hidden layers (with 110 and 60 nodes, respectively). The network was trained using 99,217 cases, which comprised a snapshot of the NZAVS dataset at Wave 9 (with the outcome being completion or not of the Wave 9 sample) and again at Wave 12 (again, with the outcome being completion or not at Wave 12). I opted to combine these two samples (and hence replicate all $\sim 33,000$ participants in the Wave 9 dataset at Wave 12 in the training dataset for a few reasons (a) obviously to increase the size of the training dataset, (b) so that each booster sample was not being training using only one constant lag predicting retention, so for example, the booster sample conducted at Wave 5 has a four year lag when predicting retention at Wave 9, but a 7 year lag when predicting retention at Wave 9, and (c) because in extensive testing and training of various alternatives, the model trained on this composite dataset was more accurate at forecasting actual Wave 12 retention than one trained using only Wave 12 data.

The input layer contained 24 continuous covariates, and 145 categorical units (these were made up of 52 variables, with some variables having multiple categories. A full list of the variables included in the model is provided in the model syntax below.

Syntax used to train the multilayer perceptron:

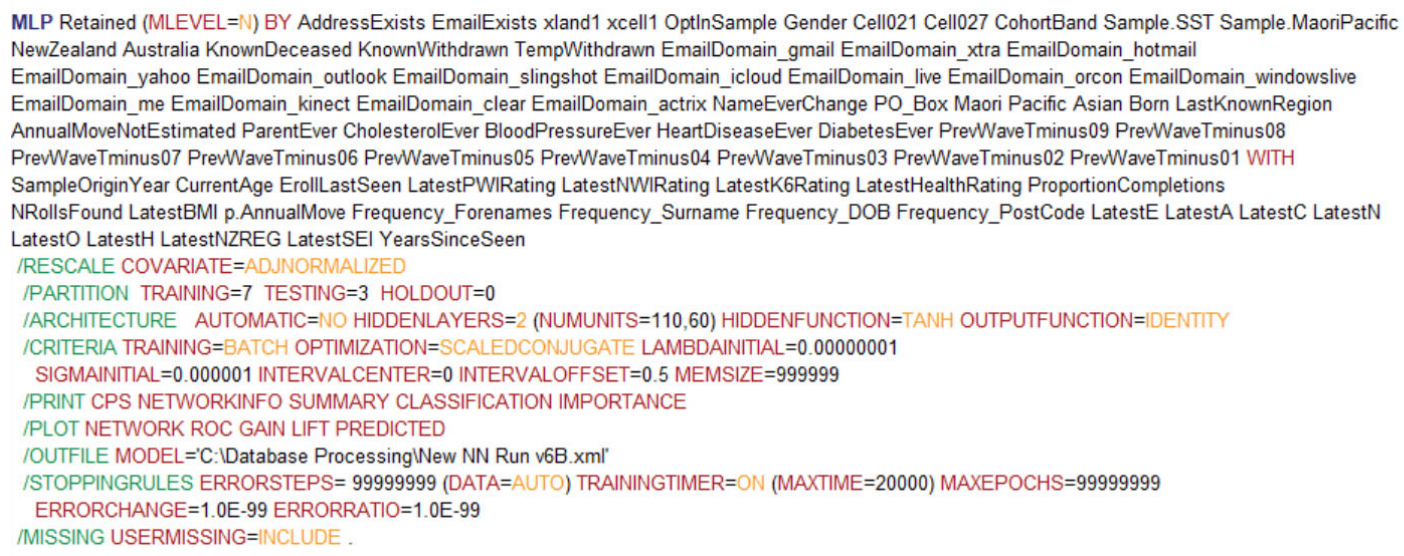


The model summary and classification tables are presented below. As can be seen the model had an overall rate of incorrect prediction of $19.4 \%$, with about $88.4 \%$ accuracy in predicting whether someone would respond, and a lower $71.0 \%$ accuracy in predicting whether someone would not respond.

\section{Model Summary}

\begin{tabular}{|c|c|c|}
\hline \multirow[t]{4}{*}{ Training } & Sum of Squares Error & 9565.212 \\
\hline & $\begin{array}{l}\text { Percent Incorrect } \\
\text { Predictions }\end{array}$ & $19.3 \%$ \\
\hline & Stopping Rule Used & $\begin{array}{l}\text { Maximum } \\
\text { training time } \\
(20000 \\
\text { minutes) } \\
\text { exceeded }\end{array}$ \\
\hline & Training Time & $333: 20: 18.05$ \\
\hline \multirow[t]{2}{*}{ Testing } & Sum of Squares Error & 4177.730 \\
\hline & $\begin{array}{l}\text { Percent Incorrect } \\
\text { Predictions }\end{array}$ & $19.4 \%$ \\
\hline
\end{tabular}

\section{Classification}

\begin{tabular}{lll|r|r} 
& & & \multicolumn{3}{c}{ Predicted } \\
Sample & Observed & \multicolumn{1}{c}{.00} & 1.00 & $\begin{array}{c}\text { Percent } \\
\text { Correct }\end{array}$ \\
\hline Training & \multicolumn{1}{c}{.00} & 22609 & 8771 & $72.0 \%$ \\
\cline { 2 - 5 } & 1.00 & 4635 & 33440 & $87.8 \%$ \\
\cline { 2 - 5 } & Overall Percent & $39.2 \%$ & $60.8 \%$ & $80.7 \%$ \\
\hline \multirow{2}{*}{ Testing } & .00 & 9478 & 3874 & $71.0 \%$ \\
\cline { 2 - 5 } & 1.00 & 1906 & 14504 & $88.4 \%$ \\
\cline { 2 - 5 } & Overall Percent & $38.3 \%$ & $61.7 \%$ & $80.6 \%$ \\
\hline
\end{tabular}

Dependent Variable: Retained 


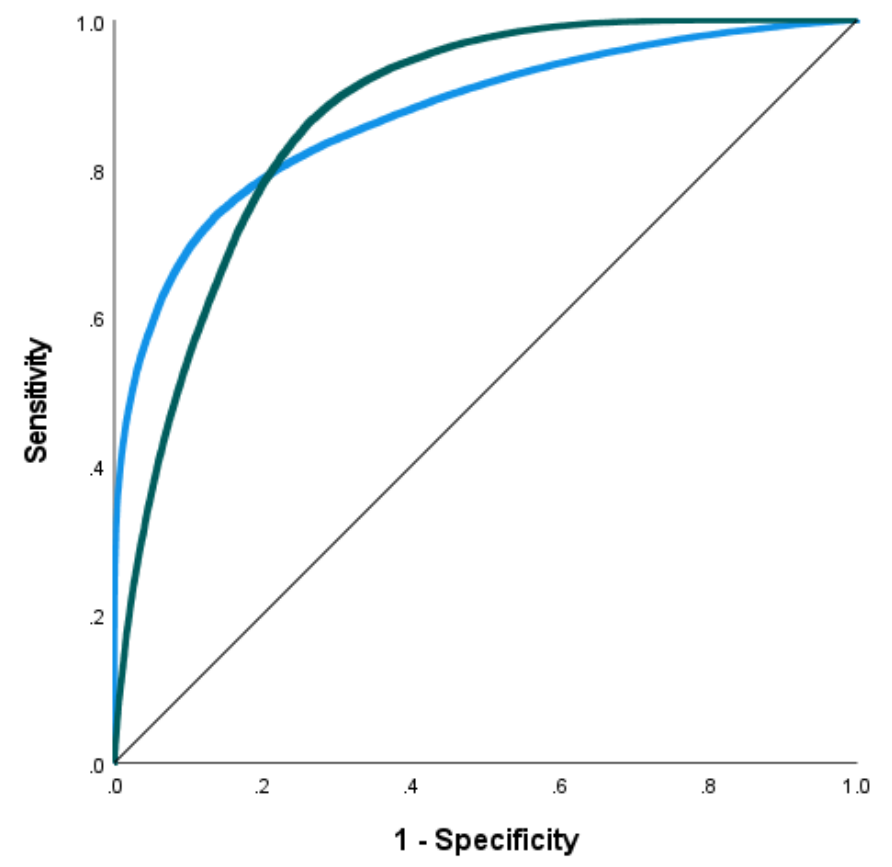

$=.00$

Dependent Variable: Retained

\section{Area Under the Curve}

\begin{tabular}{lll} 
& \multicolumn{2}{c}{ Area } \\
\hline Retained & .00 & .872 \\
\cline { 2 - 3 } & 1.00 & .872 \\
\hline
\end{tabular}

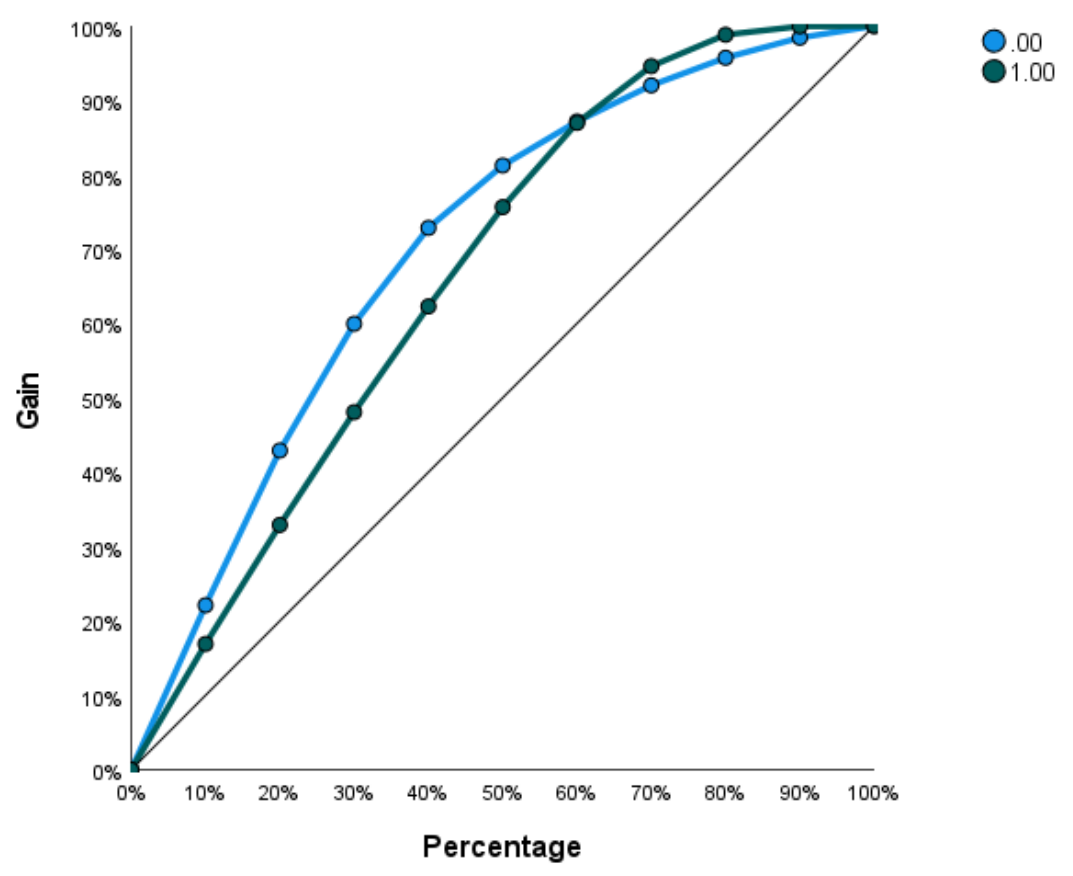

Dependent Variable: Retained 
Independent Variable Importance

\begin{tabular}{|c|c|c|}
\hline & Importance & $\begin{array}{l}\text { Normalized } \\
\text { Importance }\end{array}$ \\
\hline AddressExists & .006 & $7.1 \%$ \\
\hline EmailExists & .049 & $53.5 \%$ \\
\hline xland1 & .005 & $5.6 \%$ \\
\hline xcell1 & .017 & $18.8 \%$ \\
\hline OptinSample & .005 & $5.1 \%$ \\
\hline Gender & .004 & $4.6 \%$ \\
\hline Cello21 & .004 & $4.1 \%$ \\
\hline Cell027 & .003 & $3.0 \%$ \\
\hline CohortBand & .011 & $12.3 \%$ \\
\hline Sample.SST & .003 & $3.7 \%$ \\
\hline Sample.MaoriPacific & .005 & $5.0 \%$ \\
\hline NewZealand & .006 & $7.0 \%$ \\
\hline Australia & .006 & $6.9 \%$ \\
\hline KnownDeceased & .088 & $97.1 \%$ \\
\hline KnownWithdrawn & .091 & $100.0 \%$ \\
\hline TempWithdrawn & .082 & $89.8 \%$ \\
\hline EmailDomain_gmail & .004 & $4.2 \%$ \\
\hline EmailDomain_xtra & .003 & $3.1 \%$ \\
\hline EmailDomain_hotmail & .004 & $4.4 \%$ \\
\hline EmailDomain_yahoo & .004 & $4.1 \%$ \\
\hline EmailDomain_outlook & .004 & $4.7 \%$ \\
\hline EmailDomain_slingshot & .005 & $5.6 \%$ \\
\hline EmailDomain_icloud & .005 & $5.4 \%$ \\
\hline EmailDomain_live & .005 & $5.4 \%$ \\
\hline EmailDomain_orcon & .004 & $4.6 \%$ \\
\hline $\begin{array}{l}\text { EmailDomain_windowsli } \\
\text { ve }\end{array}$ & .005 & $5.1 \%$ \\
\hline EmailDomain_me & .003 & $3.7 \%$ \\
\hline EmailDomain_kinect & .005 & $5.9 \%$ \\
\hline EmailDomain_clear & .006 & $6.3 \%$ \\
\hline EmailDomain_actrix & .003 & $3.2 \%$ \\
\hline NameEverChange & .006 & $7.0 \%$ \\
\hline PO_Box & .004 & $4.5 \%$ \\
\hline Maori & .005 & $5.4 \%$ \\
\hline Pacific & .003 & $3.8 \%$ \\
\hline Asian & .007 & $7.7 \%$ \\
\hline Born & .004 & $4.6 \%$ \\
\hline LastKnownRegion & .014 & $15.1 \%$ \\
\hline AnnualMoveNotEstimated & .004 & $4.0 \%$ \\
\hline ParentEver & .005 & $5.1 \%$ \\
\hline CholesterolEver & .003 & $3.5 \%$ \\
\hline BloodPressureEver & .004 & $4.3 \%$ \\
\hline HeartDiseaseEver & .003 & $2.8 \%$ \\
\hline DiabetesEver & .004 & $4.3 \%$ \\
\hline PrevWaveTminus 09 & .013 & $14.7 \%$ \\
\hline PrewWaveTminus 08 & .013 & $14.6 \%$ \\
\hline PrewWaveTminus 07 & .014 & $15.1 \%$ \\
\hline PrewWaveTminus 06 & .012 & $13.1 \%$ \\
\hline PrevWaveTminus 05 & .010 & $10.5 \%$ \\
\hline PrevWaveTminus 04 & .013 & $14.6 \%$ \\
\hline PrevWaveTminus 03 & .018 & $20.1 \%$ \\
\hline PrevWaveTminus 02 & .018 & $19.9 \%$ \\
\hline PrevWaveTminus 01 & .064 & $70.5 \%$ \\
\hline SampleOriginYear & .051 & $55.6 \%$ \\
\hline CurrentAge & .032 & $35.2 \%$ \\
\hline ErollLastSeen & .008 & $8.6 \%$ \\
\hline LatestPWIRating & .008 & $8.7 \%$ \\
\hline LatestNWIRating & .004 & $4.6 \%$ \\
\hline LatestK6Rating & .005 & $5.9 \%$ \\
\hline LatestHealthRating & .007 & $7.6 \%$ \\
\hline ProportionCompletions & .053 & $58.1 \%$ \\
\hline NRollsfound & .007 & $8.1 \%$ \\
\hline LatestBMI & .006 & $7.0 \%$ \\
\hline p.AnnualMove & .007 & $7.5 \%$ \\
\hline Frequency_Forenames & .010 & $10.6 \%$ \\
\hline Frequency_Surname & .007 & $7.8 \%$ \\
\hline Frequency_DOB & .027 & $29.9 \%$ \\
\hline Frequency_PostCode & .006 & $6.9 \%$ \\
\hline LatestE & .009 & $9.9 \%$ \\
\hline LatestA & .005 & $5.6 \%$ \\
\hline LatestC & .011 & $12.2 \%$ \\
\hline LatestN & .005 & $5.3 \%$ \\
\hline Latesto & .006 & $6.1 \%$ \\
\hline LatestH & .010 & $10.5 \%$ \\
\hline LatestNZREG & .011 & $12.2 \%$ \\
\hline LatestSEI & .007 & $7.2 \%$ \\
\hline YearsSinceSeen & .011 & $12.1 \%$ \\
\hline
\end{tabular}

This table lists the importance of each variable in the model. From this you can get a sense of the overall contribution or importance of each variable to the prediction of retention, in the relative sense of how much each variable contributed to minimizing the sum of squares error. 


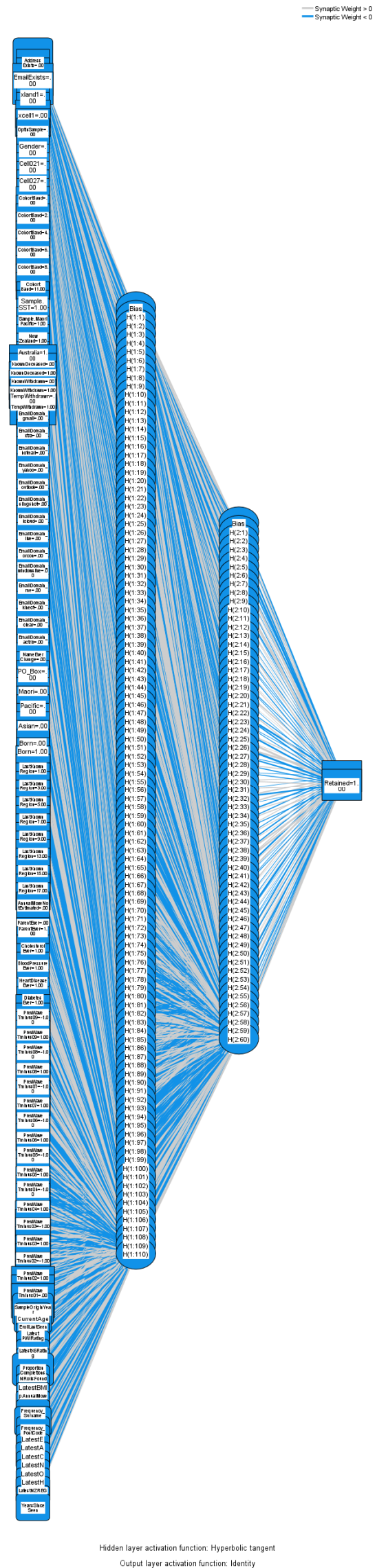

Representation of the neural network used to forecast retention in the NZAVS.

Lines in blue represent synaptic weights $<0$.

Lines in grey represent synaptic weights $>0$. 


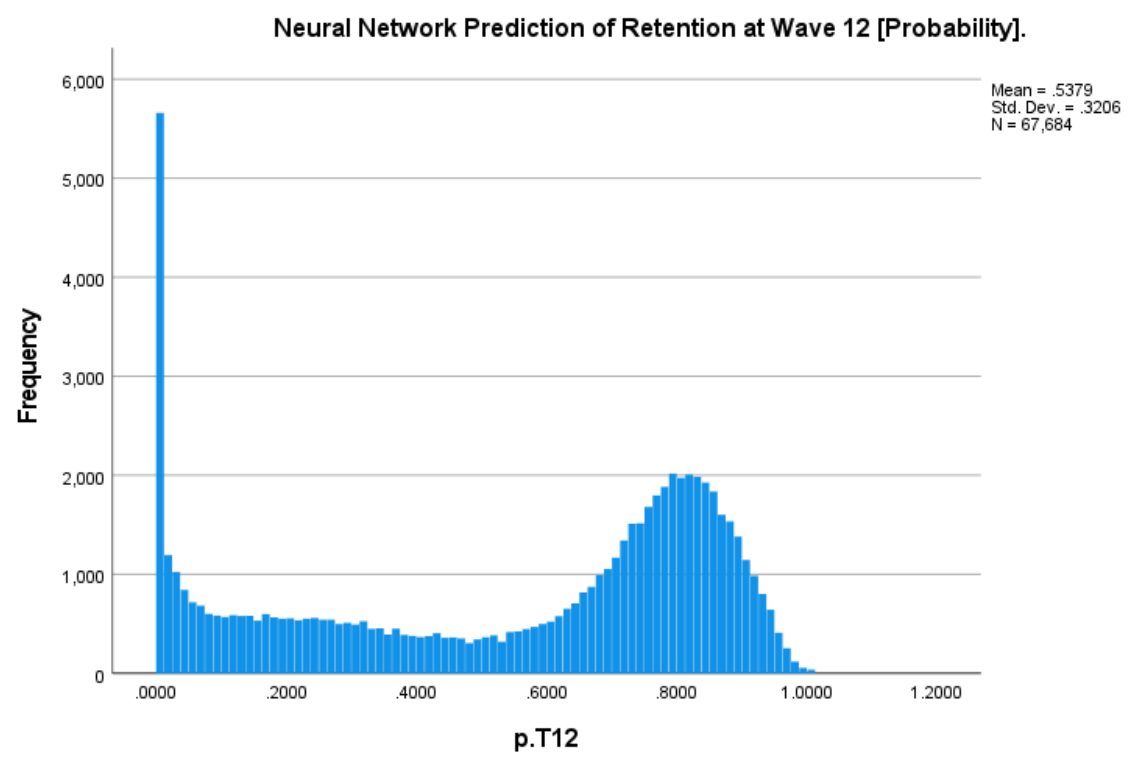

Figure. Distribution of the probability that each participant will complete Wave 12.

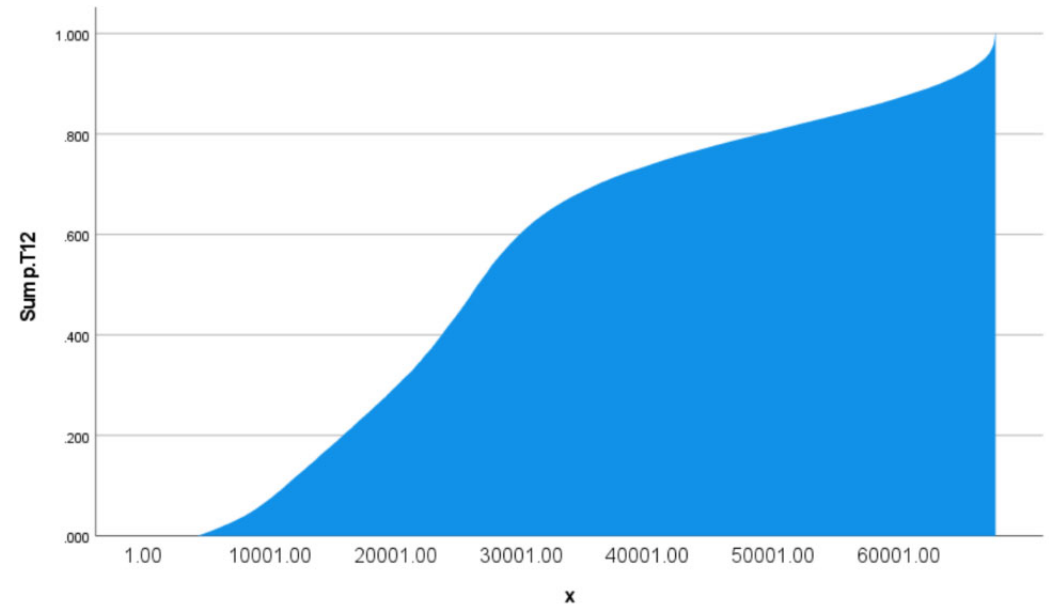

Figure. Area under the curve represents the sum of individual probabilities that each participant will complete Wave 12.

\section{Descriptive Statistics}

\begin{tabular}{l|c|r|r|c|c|r} 
& $\mathrm{N}$ & Minimum & Maximum & \multicolumn{1}{c}{ Sum } & Mean & Std. Deviation \\
\hline p.T12 & 67684 & .0000 & 1.0000 & 36404.7646 & .537864 & .3205866 \\
\hline Valid N (listwise) & 67684 & & & & & \\
\hline
\end{tabular}

Predicted retention at $\mathrm{T} 12=36,404$. This was calculated as the sum of individual probabilities, or area under the curve from the graph above.

Note that T12 was used as part of the training dataset, so this is not a forecast. $\mathrm{N}$ responses to $\mathrm{T} 12$ at the time a snapshot of the data was taken to train the neural network $=36,702$. 
Forecasting future retention

Wave 13 forecast

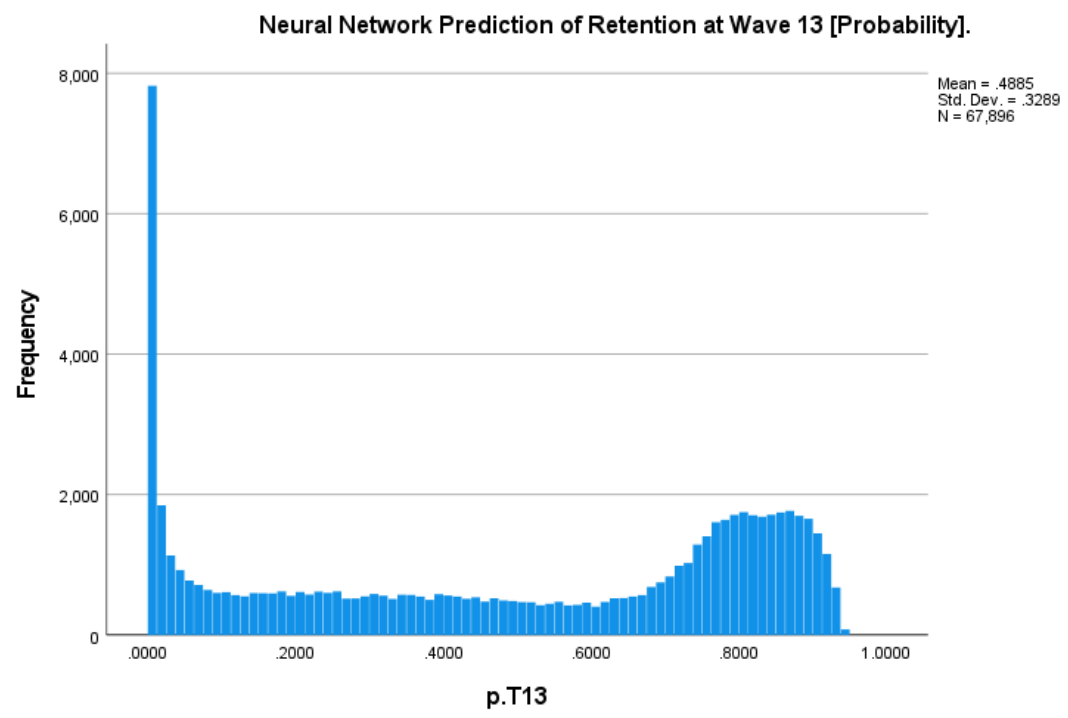

Figure. Distribution of the probability that each participant will complete Wave 13.

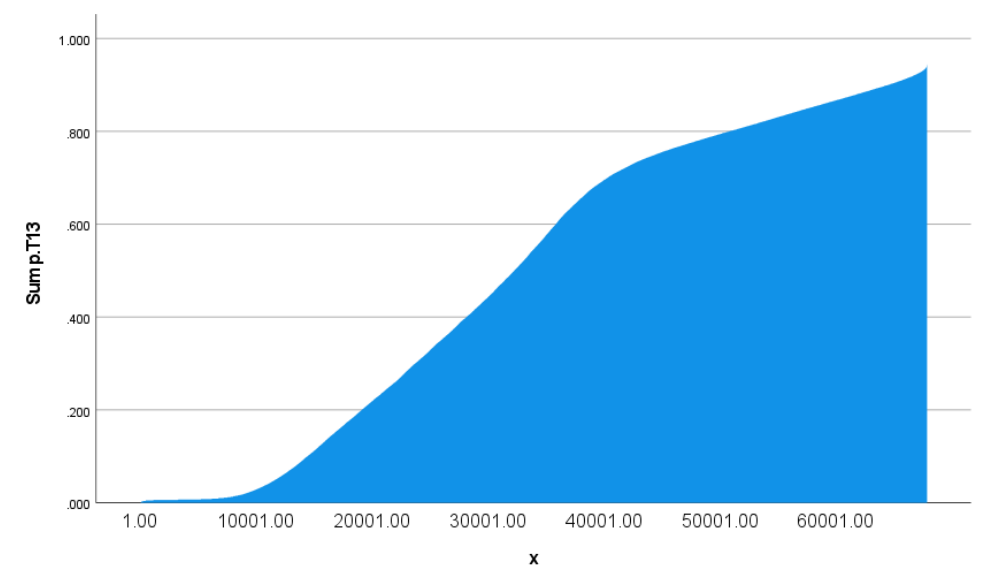

Figure. Area under the curve represents the sum of individual probabilities that each participant will complete Wave 13.

\section{Descriptive Statistics}

\begin{tabular}{l|c|r|r|c|c|r} 
& N & Minimum & Maximum & \multicolumn{1}{c}{ Sum } & Mean & Std. Deviation \\
\hline p.T13 & 67896 & .0000 & .9846 & 33169.1459 & .488529 & .3288685 \\
\hline Valid N (listwise) & 67896 & & & & & \\
\hline
\end{tabular}

Forecast retention at Wave 13: $\mathbf{n}=\mathbf{3 3 , 1 6 9}$

Calculated as the sum of individual probabilities, or area under the curve above.

This forecast was made on October $22^{\text {nd }} 2021$, at the very start of Wave 13. 


\section{Chapter 3 - Scale Validation Dataset}

Please note that this document is not the NZAVS data dictionary. If you are looking for the data dictionary, it is available at: www.nzavs.auckland.ac.nz.

The data dictionary is the companion to this document, and contains a list of all items included in each wave of the NZAVS, variable names and so forth for the various NZAVS datasets, etc. It is much easier to search the data dictionary for items, and see what has been included in each wave.

This section contains full scales (all items) for every short-form scale included in the NZAVS from Time 01-13, for the purposes of scale validation. All scales have been adapted for the New Zealand context and formatted to fit with existing NZAVS questions. Bolded items have been included in the NZAVS at one or more time points. Struck-through items were not measured due to item overlap or their unsuitability for the New Zealand context.

The NZAVS necessarily uses very short-form scales, or in some cases single items to index broad dimensions of attitudes and values. The NZAVS Scale Validation Study is a database combining samples to provide psychometric information comparing the full and short-form versions of all scales included in the NZAVS. The database is built on a primary validation sample (or foundation) that employed a planned missing design, where participants completed a random selection of $\sim 66 \%$ of the items randomly drawn from the full-scale versions for all scales included in the NZAVS. The primary sample is a rolling online questionnaire completed by undergraduates at various universities in New Zealand. The NZAVS Scale Validation Study also includes various other validation samples that have included the full versions of two or more scales used in the NZAVS. A detailed breakdown of which scales have been included in which samples is provided in the NZAVS data dictionary.

This dataset can thus leverage FIML and other estimation methods allowing for missing data to test CFAs and other measurement models of the full item sets for each scale and compare them to the shortened or single item versions included in the primary NZAVS dataset. Note. This validation dataset is designed explicitly for psychometric analysis of full versus shortform scales used in the NZAVS, rather than inferences about the mean level of some attitude or value in the New Zealand population (for that I recommend using the NZAVS). Further documentation is provided in Chapter 3 of the companion document 'Sampling procedure and sample details for the New Zealand Attitudes and Values Study.' The full item list and breakdown of which items were included in each specific sample are provided in the NZAVS data dictionary.

Note that all contrait items have been recoded. All scales have been adapted for the New Zealand context and formatted to fit with existing NZAVS questions (for example, some items developed in other nations have been revised to refer to the New Zealand context). Items included within the NZAVS are indicated by "---" in front of the item description. An annotated list of all variables organized by scale is also included in this Mplus syntax below the VARIABLE list. This is useful for quickly copying the text listing all items in a given scale for analysis. The NZAVS scale validation dataset contains data from the full versions of all these scales. 
The primary validation study employs a missing by design analysis, where each participant completed a random set of (at most) 668 items out of 978 total items $(69.44 \%)$. Items were selected for presentation at random, and were presented in random order. Due to differing scales of measurement, all participants completed the Body Image States Scale, the Identification with All Humanity Scale, 1 item from the SF-36 Scale (In general, would you say your health is poor-excellent), the Personal Wellbeing Index, the National Wellbeing Index, the BIAS Treatment Scale, the Moral Foundations Moral Relevance subscale, and measures of ethnic subgroup respect, intergroup anxiety, national character, and support/opposition to policies. In total, 203 items from these scales were always presented to all participants. A further 709 items (including 16 attention check) were presented randomly to all participants, with a missing rate of $40 \%$. Participants were presented with 435 of these items (638 items in total). A further 50 items were presented randomly to participants who indicated they were religious, with a missing rate of $40 \%$. Religious participants were presented with 30 of these items (668 items in total). Note, Left-Wing Authoritarianism, Trust in Science and Science Credibility were added during Version 2.

\section{Religious \\ Fundamentalism}

(1 Strongly Disagree - 7

Strongly Agree)

Altemeyer, B., \& Hunsberger, B. (1992). Authoritarianism, religious fundamentalism, quest, and prejudice. International Journal for the Psychology of Religion, 2, 113-133.

\section{God has given mankind a complete, unfailing guide to} happiness and salvation, which must be totally followed.

All of the religions in the world have flaws and wrong teachings. (r)

Of all the people on this earth, one group has a special relationship with God because it believes the most in his revealed truths and tries the hardest to follow his laws.

The long-established traditions in religion show the best way to honour and serve God, and should never be compromised.

Religion must admit all its past failings, and adapt to modem life if it is to benefit humanity. (r)

When you get right down to it, there are only two kinds of people in the world: the Righteous, who will be rewarded by God; and the rest, who will not.

\section{Different religions and philosophies have different versions of the truth, and may be equally right in their own way. (r)}

The basic cause of evil in this world is Satan, who is still constantly and ferociously fighting against God.

It is more important to be a good person than to believe in God and the right religion. (r)

No one religion is especially close to God, nor does God favour any particular group of believers. (r)

God will punish most severely those who abandon his true 


\begin{tabular}{|c|c|}
\hline & religion. \\
\hline & $\begin{array}{l}\text { No single book of religious writings contains all the important } \\
\text { truths about life. (r) }\end{array}$ \\
\hline & $\begin{array}{l}\text { It is silly to think people can be divided into "the Good" and } \\
\text { "the Evil." Everyone does some good, and some bad things. } \\
\text { (r) }\end{array}$ \\
\hline & $\begin{array}{l}\text { God's true followers must remember that he requires them to } \\
\text { constantly fight Satan and Satan's allies on this earth. }\end{array}$ \\
\hline & $\begin{array}{l}\text { Parents should encourage their children to study all religions } \\
\text { without bias, then make up their own minds about what to } \\
\text { believe. (r) }\end{array}$ \\
\hline & $\begin{array}{l}\text { There is a religion on this earth that teaches, without error, } \\
\text { God's truth. }\end{array}$ \\
\hline & $\begin{array}{l}\text { "Satan" is just the name people give to their own bad } \\
\text { impulses. There really is no such thing as a diabolical "Prince } \\
\text { of Darkness" who tempts us. (r) }\end{array}$ \\
\hline & $\begin{array}{l}\text { Whenever science and sacred scripture conflict, science must } \\
\text { be wrong. }\end{array}$ \\
\hline & $\begin{array}{l}\text { There is no body of teachings, or set of scriptures, which is } \\
\text { completely without error. (r) }\end{array}$ \\
\hline & $\begin{array}{l}\text { To lead the best, most meaningful life, one must belong to the } \\
\text { one, true religion. }\end{array}$ \\
\hline Quest Religious & $\begin{array}{l}\text { I was not very interested in religion until I began to ask } \\
\text { questions about the meaning and purpose of my life. }\end{array}$ \\
\hline $\begin{array}{l}\text { (1 Strongly Disagree }-7 \\
\text { Strongly Agree) }\end{array}$ & $\begin{array}{l}\text { I have been driven to ask religious questions out of a growing } \\
\text { awareness of the tensions in my world and in my relation to } \\
\text { the world. }\end{array}$ \\
\hline Batson, C. D., \& & $\begin{array}{l}\text { My life experiences have led me to rethink my religious } \\
\text { convictions. }\end{array}$ \\
\hline $\begin{array}{l}\text { Schoenrade, P. A. (1991). } \\
\text { Measuring religion as quest: }\end{array}$ & $\begin{array}{l}\text { God wasn't very important for me until I began to ask } \\
\text { questions about the meaning of my own life. }\end{array}$ \\
\hline $\begin{array}{l}\text { Journal for the Scientific } \\
\text { Study of Religion, } 30,430 \text { - }\end{array}$ & $\begin{array}{l}\text { It might be said that I value my religious doubts and } \\
\text { uncertainties. }\end{array}$ \\
\hline 44 & $\begin{array}{l}\text { For me, doubting is an important part of what it means to be } \\
\text { religious. }\end{array}$ \\
\hline & I find religious doubts upsetting. (r) \\
\hline & $\begin{array}{l}\text { Questions are far more central to my religious experiences } \\
\text { than are answers. }\end{array}$ \\
\hline
\end{tabular}


As I grow and change, I expect my religion also to grow and change.

I am constantly questioning my religious beliefs.

I do not expect my religious convictions to change in the next few years. (r)

There are many religious issues on which my views are still changing.

Intrinsic Religious

Orientation

(1 Strongly Disagree - 7

Strongly Agree)

Batson, C. D., \&

Schoenrade, P. A. (1991).

Measuring religion as quest:

2) reliability concerns.

Journal for the Scientific

Study of Religion, 30, 430-

447.
It is important for me to spend periods of time in private thought and meditation.

(original) It is important for me to spend periods of time in private religious thought and meditation.

If not prevented by unavoidable circumstances, I attend church.

\section{I try hard to carry my religion over into all my other dealings in life.}

The prayers I say when I am alone carry as much meaning and personal emotion as those said by me during services.

Quite often I have been keenly aware of the presence of God or the Divine Being.

I read literature about my faith (or church).

If I were to join a church group I would prefer to join a Bible study group rather than a social fellowship.

My religious beliefs are what really lie behind my whole approach to life.

Religion is especially important to me because it answers many questions about the meaning of life.

Although I believe in my religion, I feel there are many more important things in my life.

It doesn't matter so much what I believe so long as I lead a moral life.

The purpose of prayer is to gain relief and protection.

(original) The primary purpose of prayer is to gain relief and protection.

Schoenrade, P. A. (1991).

Measuring religion as quest:

2) reliability concerns.

Journal for the Scientific

Study of Religion, 30, 430-
The church is most important as a place to formulate good social relationships.

What religion offers me most is comfort when sorrows and misfortune strike. 
447.

Extrinsic-Social

Religious Orientation

(1 Strongly Disagree - 7

Strongly Agree)

Gorsuch, R. L., \&

McPherson, S. E. (1989).

Intrinsic/extrinsic

measurement: I/E revised and single item scales.

Journal for the Scientific

Study of Religion, 28, 348-

354.

\section{Religious Group \\ Narcissism}

(1 Strongly Disagree - 7

Strongly Agree)

\section{ADAPTED FROM de}

Zavala, A. G., Cichocka, A., Eidelson, R., \& Jayawickreme, N. (2009). Collective narcissism and its social consequences. Journal of Personality and Social Psychology, 97, 1074-1096.
I pray chiefly because I have been taught to pray.

Although I am a religious person I refuse to let religious considerations influence my everyday affairs.

A primary reason for my interest in religion is that my church is a congenial social activity.

Occasionally I find it necessary to compromise my religious beliefs in order to protect my social and economic well-being.

One reason for my being a church member is that such membership helps to establish a person in the community.

The purpose of prayer is to secure a happy and peaceful life.

\section{I go to church because it helps me to make friends.}

I go to church mostly to spend time with my friends.

I go to church mainly because I enjoy seeing people I know there.

I wish other groups would more quickly recognize the authority of my religious group/denomination.

My religious group/denomination deserves special treatment.

I will never be satisfied until my religious group/denomination gets all it deserves.

\section{I insist upon my religious group/denomination getting the respect that is due to it.}

It really makes me angry when others criticize my religious group/denomination.

If my religious group/denomination had a major say in the world, the world would be a much better place.

I do not get upset when people do not notice achievements of my religious group/denomination. (r)

Not many people seem to fully understand the importance of my religious group/denomination. 
The true worth of my religious group/denomination is often misunderstood.

\section{God Locus of Health} Control

(1 Strongly Disagree - 7

Strongly Agree)

Wallston, K. A., Malcarne, V. L., Flores, L., Hansdottir, I., Smith, C. A., Stein, M. H., ... \& Clements, P. J. (1999). Does God determine your health? The God locus of health control scale. Cognitive Therapy and Research, 23, 131-142.

\section{Approach Social}

Motivation

(1 Strongly Disagree - 7

Strongly Agree)

Elliot, A.J., Gable, S.L., \& Mapes, R.R. (2006). Approach and Avoidance Motivation in the Social Domain. Personality and Social Psychology Bulletin, 32, 378-391.

\section{Avoidance Social Motivation}

(1 Strongly Disagree - 7

Strongly Agree)

Elliot, A.J., Gable, S.L., \& Mapes, R.R. (2006).

Approach and Avoidance Motivation in the Social Domain. Personality and Social Psychology Bulletin, 32, 378-391.
If my health worsens, it is up to God to determine whether I will feel better again.

Most things that affect my health happen because of God.

God is directly responsible for my health getting better or worse.

Whatever happens to my health is God's will.

Whether or not my health improves is up to God.

God is in control of my health.
I try to deepen my relationships with my friends.

I try to move toward growth and development in my close relationships.

I try to enhance the bonding and intimacy in my close relationships.

I try to share many fun and meaningful experiences with people I am close to.
I try to avoid disagreement and conflict in my close relationships.

I try to stay away from situations that would harm my close relationships.

I try to avoid getting embarrassed, betrayed, or hurt by any of my friends.

I try to make sure that nothing bad happens to my close relationships. 


\section{0-item IPIP}

Extraversion

(1 Very Inaccurate - 7 Very Accurate)

Goldberg, L. R. (1999). A broad-bandwidth, public domain, personality inventory measuring the lower-level facets of several five-factor models. Personality Psychology in Europe, 7(1), 7-28.

\section{I don't talk a lot. (r)}

I feel comfortable around people.

\section{I keep in the background. (r)}

I start conversations.

I have little to say. (r)

I talk to a lot of different people at parties.

I don't like to draw attention to myself. (r)

I don't mind being the centre of attention.

I am quiet around strangers. (r)

\section{0-item IPIP}

Agreeableness

(1 Very Inaccurate -7 Very Accurate)

Goldberg, L. R. (1999). A domain, personality inventory measuring the lower-level facets of several five-factor models.

Personality Psychology in Europe, 7(1), 7-28.
I feel little concern for others. (r)

I am interested in people.

Iinsult people. (f) (duplicated in Agreeableness Politeness

facet)

\section{I sympathize with others' feelings.}

\section{I am not interested in other people's problems. (r)}

I have a soft heart.

\section{I am not really interested in others. (r)}

I take time out for others.

\section{I feel others' emotions.}

I make people feel at ease.

I am always prepared.

50-item IPIP

Conscientiousness

I leave my belongings around. (r)

I pay attention to details.

(1 Very Inaccurate -7 Very Accurate)

\section{I make a mess of things. (r)}

\section{I get chores done right away.}

Goldberg, L. R. (1999). A broad-bandwidth, public domain, personality inventory measuring the lower-level facets of several five-factor models.

Personality Psychology in Europe, 7(1), 7-28.

\section{I often forget to put things back in their proper place. (r)}

\section{I like order.}

I shirk my duties. (r)

I follow a schedule.

I am exacting in my work.

I get stressed out easily. 
50-item IPIP
Neuroticism/Emotionality
(1 Very Inaccurate - 7 Very
Accurate)
Goldberg, L. R. (1999). A
broad-bandwidth, public
domain, personality
inventory measuring the
lower-level facets of several
five-factor models.
Personality Psychology in
Europe, 7(1), 7-28.
50-item IPIP Openness to
Experience

(1 Very Inaccurate -7 Very Accurate)

Goldberg, L. R. (1999). A broad-bandwidth, public domain, personality inventory measuring the lower-level facets of several five-factor models. Personality Psychology in Europe, 7(1), 7-28.

\section{HEXACO-100 Honesty- Humility}

(1 Very Inaccurate -7 Very Accurate)

Ashton, M. C., Lee, K., Perugini, M., Szarota, P., De Vries, R. E., Di Blas, L., ... \& De Raad, B. (2004). A six-factor structure of personality-descriptive adjectives: solutions from psycholexical studies in seven languages. Journal of Personality and Social Psychology, 86(2), 356.

\section{I am relaxed most of the time. (r)}

I worry about things.

I seldom feel blue. (r)

I am easily disturbed.

\section{I get upset easily.}

I change my mood a lot.

\section{I have frequent mood swings.}

I get irritated easily.

I often feel blue.

I have a rich vocabulary.

\section{I have difficulty understanding abstract ideas. (r)}

\section{I have a vivid imagination.}

\section{I am not interested in abstract ideas. (r)}

I have excellent ideas.

\section{I do not have a good imagination. (r)}

I am quick to understand things.

I use difficult words.

I spend time reflecting on things.

I am full of ideas.

If I want something from a person I dislike, I will act very nicely toward that person in order to get it. (r)

If I knew that I could never get caught, I would be willing to steal a million dollars. (r)

Having a lot of money is not especially important to me.

I am an ordinary person who is no better than others.

I wouldn't use flattery to get a raise or promotion at work, even if I thought it would succeed.

I would be tempted to buy stolen property if I were financially tight. (r)

I would like to live in a very expensive, high-class neighbourhood. (r)

I wouldn't want people to treat me as though I were superior to them. 
If I want something from someone, I will laugh at that person's worst jokes. (r)

I would never accept a bribe, even if it were very large.

I would like to be seen driving around in a very expensive car. (r)

I think that I am entitled to more respect than the average person is. (r)

I wouldn't pretend to like someone just to get that person to do favours for me.

I'd be tempted to use counterfeit money, if I were sure I could get away with it. (r)

I would get a lot of pleasure from owning expensive luxury goods. (r)

I want people to know that I am an important person of high status. (r)

Psychological

Entitlement Scale

(1 Very Inaccurate -7 Very Accurate)

Campbell, W. K., Bonacci, A. M., Shelton, J., Exline, J. J., \& Bushman, B. J. (2004). Psychological entitlement: Interpersonal consequences and validation of a self-report measure. Journal of Personality Assessment, 83(1), 29-45.

\section{Disgust Scale Revised}

Part 1

(1 Strongly Disagree - 7

Strongly Agree)

Olatunji, B. O., Williams, N. L., Tolin, D. F., Sawchuck, C. N., Abramowitz, J. S., Lohr, J.
I honestly feel I'm just more deserving than others.

Great things should come to me.

If I were on the Titanic, I would deserve to be on the first lifeboat.

\section{I demand the best because I'm worth it.}

I do not necessarily deserve special treatment. (r)

I deserve more things in life.

(original) I deserve more things in my life.

People like me deserve an extra break now and then.

Things should go my way.

I feel entitled to more of everything.

I might be willing to try eating monkey meat, under some circumstances. ( $r$ )

It would bother me to see a rat run across my path in a park.

Seeing a cockroach in someone else's house doesn't bother me. (r)

It bothers me to hear someone clear a throat full of mucus.

If I see someone vomit, it makes me sick to my stomach.

It would bother me to be in a science class, and see a human hand in a jar. 
M., et al. (2007). The disgust scale: Item analysis, factor structure, and suggestions for refinement. Psychological Assessment, 19, 281-297.
It would not upset me at all to watch a person with a glass eye take the eye out of the socket. (r)

It would bother me tremendously to touch a dead body.

I would go out of my way to avoid walking through a graveyard.

I never let any part of my body touch the toilet seat in a public washroom.

I probably would not go to my favourite restaurant if I found out the cook had a cold.

Even if I was hungry, I would not drink a bowl of my favourite soup it had been stirred with a used but thoroughly washed flyswatter.

It would bother me to sleep in a nice hotel room if I knew that man had died of a heart attack in that room the night before.

Bad smells, messes, dead animals and rotten food absolutely disgust me. (NZAVS item)

I respect authority.

\section{I insult people. (r)}

\section{I hate to seem pushy.}

(1 Very Inaccurate -7 Very Accurate)

I believe that I am better than others. (r)

I avoid imposing my will on others.

DeYoung, C.G., Quilty, L.C., \& Peterson, J.B. I rarely put people under pressure.

I take advantage of others. (r)

I seek conflict. (r)

\section{I love a good fight. (r)}

I am out for my own personal gain. (r)

Psychology, 93, 880-896.

I enjoy the beauty of nature.

Openness (Openness facet)

(1 Very Inaccurate -7 Very Accurate)

DeYoung, C.G., Quilty, L.C., \& Peterson, J.B. (2007). Between facets and domains: 10 aspects of the Big-Five. Journal of Personality and Social Psychology, 93, 880-896.

\section{I believe in the importance of art.}

I love to reflect on things.

\section{I get deeply immersed in music.}

I do not like poetry. (r)

I see beauty in things that others might not notice.

I need a creative outlet.

I seldom get lost in thought. (r)

I seldom daydream. (r)

I seldom notice the emotional aspects of paintings and 
pictures. (r)

\section{Impression Management}

(1 Very Inaccurate -7 Very Accurate)

Paulhus, D. L. (1991). Measurement and control of response bias. In J. P. Robinson, P. Shaver, \& L. S. Wrightsman (Eds.), Measures of Personality and Social Psychological Attitudes. San Diego: Academic Press.

I sometimes tell lies if I have to. (r)

I never cover up my mistakes.

There have been occasions when I have taken advantage of someone. (r)

I never swear.

I sometimes try to get even rather than forgive and forget. (r)

I always obey laws, even if I'm unlikely to get caught.

I have said something bad about a friend behind his or her back. (r)

When I hear people talking privately, I avoid listening.

I have received too much change from a salesperson without telling him or her. (r)

I always declare everything at customs.

When I was young I sometimes stole things. (r)

I have never dropped litter on the street.

I sometimes drive faster than the speed limit. (r)

I never read sexy books or magazines.

I have done things that I don't tell other people about. (r)

I never take things that don't belong to me.

I have taken sick-leave from work or school even though I wasn't really sick. (r)

I have never damaged a library book or store merchandise without reporting it.

I have some pretty awful habits. (r)

\section{I don't gossip about other people's business.}

My first impressions of people usually turn out to be right.

Self-Deceptive

Enhancement

(1 Very Inaccurate -7 Very Accurate)

Paulhus, D. L. (1991).

Measurement and control of
It would be hard for me to break any of my bad habits. (r)

\section{I don't care to know what other people really think of me.}

I have not always been honest with myself. (r)

I always know why I like things.

When my emotions are aroused, it biases my thinking. (r) 
response bias. In J. P. Robinson, P. Shaver, \& L. S. Wrightsman (Eds.), Measures of Personality and Social Psychological Attitudes. San Diego: Academic Press.
Once I've made up my mind, other people can seldom change my opinion.

I am not a safe driver when I exceed the speed limit. (r)

I am fully in control of my own fate.

It's hard for me to shut off a disturbing thought. (r)

I never regret my decisions.

I sometimes lose out on things because I can't make up my mind soon enough. (r)

The reason I vote is because my vote can make a difference.

My parents were not always fair when they punished me. (r)

I am a completely rational person.

I rarely appreciate criticism. (r)

I am very confident of my judgments.

I have sometimes doubted my ability as a lover. (r)

It's all right with me if some people happen to dislike me.

I don't always know the reasons why I do the things I do. (r)

\section{Primary Psychopathy}

(1 Strongly Disagree - 7

Strongly Agree)

Levenson M. R., Kiehl, K. A., \& Fitzpatrick, C. M. (1995). Assessing Psychopathic Attributes in a Non-institutionalised Population. Journal of Personality and Social Psychology, 68 (1), 151158.

\section{Success is based on survival of the fittest; I am not concerned about the losers.}

For me, what's right is whatever I can get away with. In today's world, I feel justified in doing anything I can get away with to succeed.

My main purpose in life is getting as many goodies as I can.

Making a lot of money is my most important goal.

I let others worry about higher values; my main concern is with the bottom line.

People who are stupid enough to get ripped off usually deserve it.

Looking out for myself is my top priority.

I tell other people what they want to hear so that they will do what I want them to do.

I would be upset if my success came at someone else's expense. (r)

I often admire a really clever scam.

I make a point of trying not to hurt others in pursuit of my goals. (r) 
I enjoy manipulating other people's feelings.

I feel bad if my words or actions cause someone else to feel emotional pain. (r)

Even if I were trying very hard to sell something, I wouldn't lie about it. (r)

Cheating is not justified because it is unfair to others. (r) Control

(1 Strongly Disagree - 7 Strongly Agree)

Paulhus, D. L., \& Van Selst, M. (1990). The Spheres of Control Scale: 10 Years of Research. Personality and Individual Differences, 11, 1029-1036.
Personal Locus of

I can usually achieve what I want when I work hard for it.

Once I make plans I am almost certain to make them work. I prefer games involving some luck over games of pure skill. (r)

\section{I can learn almost anything if I set my mind to it.}

My major accomplishments are entirely due to my hard work and ability.

I usually do not set goals because I have a hard time following through on them. (r)

Bad luck has sometimes prevented me from achieving things.

(r)

\section{Almost anything is possible for me if I really want it.}

Most of what will happen in my career is beyond my control.

I find it pointless to keep working on something that is too difficult for me. (r)

I am good at resisting temptation.

Brief Self-Control Scale

I have a hard time breaking bad habits. (r)

(1 Strongly Disagree - 7

Strongly Agree)

I am lazy. (r)

I say inappropriate things. (r)

Tangney, J. P., Baumeister, I do certain things that are bad for me, if they are fun. (r)

R. F., \& Boone, A. L. (2004). High self-control predicts good adjustment, less pathology, better grades, and interpersonal success. Journal of Personality, 72, 271-322.
I refuse things that are bad for me.

\section{I wish I had more self-discipline. (r)}

People would say that I have iron self- discipline.

Pleasure and fun sometimes keep me from getting work done. (r)

I have trouble concentrating. (r)

I am able to work effectively toward long-term goals.

Sometimes I can't stop myself from doing something, even if I know it is wrong. (r)

I often act without thinking through all the alternatives. (r)

In general, I have a lot of self-control. (NZAVS item) 
Forgivingness versus

Vengeful Rumination

(1 Strongly Disagree - 7

Strongly Agree)

ADAPTED from Caprara, G. V. (1986). Indicators of aggression: The dissipationrumination scale.

Personality and Individual

Differences, 7(6), 763-769.

ADAPTED from Berry, $\mathrm{J}$. W., Worthington, E. L., O'Connor, L. E., Parrott, L., $\&$ Wade, N. G. (2005). Forgivingness, vengeful rumination, and affective traits. Journal of Personality, 73(1), 183-226.
I never help those who do me wrong. (r)

I will always remember the injustices I have suffered. (r)

The more time that passes, the more satisfaction I get from revenge. (r)

It takes many years for me to get rid of a grudge. (r)

When somebody offends me, sooner or later I retaliate. (r)

I do not forgive easily once I am offended. (r)

I won't accept excuses for certain offenses. (r)

I hold a grudge, for a very long time, towards people who have offended me. (r)

I remain aloof towards people who annoy me, in spite of any excuses. (r)

I can remember very well the last time I was insulted. (r)

I still remember the offenses I have suffered, even after many years. (r)

If somebody harms me, I am not at peace until I can retaliate. (r)

When I am outraged, the more I think about it, the angrier I feel. (r)

I am often sulky. (r)

\section{Sometimes I can't sleep because of thinking about past wrongs I have suffered. (r)}

(original) Sometimes I can't sleep because of a wrong done to me. (r)

People close to me probably think I hold a grudge too long. (r)

I can forgive a friend for almost anything.

If someone treats me badly, I treat him or her the same. (r)

I try to forgive others even when they don't feel guilty for what they did. (r)

\section{I can usually forgive and forget it when someone does me wrong.}

I feel bitter about many of my relationships. (r)

Even after I forgive someone, things often come back to me that I resent. (r)

There are some things for which I could never forgive even a loved one. (r)

I have always forgiven those who have hurt me.

I am a forgiving person. 
I find myself regularly thinking about past times that I have been wronged. (r) (NZAVS item)

Perfectionism

Discrepancy

(1 Strongly Disagree - 7

Strongly Agree)

Rice, K. G., Richardson, C. M., \& Tueller, S. (2014). The short form of the revised almost perfect scale. Journal of Personality Assessment, 96(3), 368-379.

I often feel frustrated because I can't meet my goals.

My best just never seems to be good enough for me.

I rarely live up to my high standards.

Doing my best never seems to be enough.

I am never satisfied with my accomplishments.

I often worry about not measuring up to my own expectations. My performance rarely measures up to my standards.

I am not satisfied even when I know I have done my best.

I am seldom able to meet my own high standards for performance.

I am hardly ever satisfied with my performance.

I hardly ever feel that what I've done is good enough.

I often feel disappointment after completing a task because I know I could have done better.

Subjective Health

(General health perceptions subscale)

(1 Poor - 7 Excellent) (1 Strongly Disagree - 7

Strongly Agree)

Ware Jr, J. E., \& Sherbourne, C. D. (1992). The MOS 36-item shortform health survey (SF-36):

I. Conceptual framework and item selection. Medical Care, 30, 473-483.

\section{Health Locus of Control}

(1 Strongly Disagree - 7

Strongly Agree)

Wallston, K. A., Wallston, B. S., DeVellis, R. (1978). Development of the multidimensional health locus of control (MHLC)

\section{In general, would you say your health is:}

I seem to get sick a little easier than other people.

I am as healthy as anybody I know.

\section{I expect my health to get worse.}

My health is excellent.
If I get sick, it is my own behaviour which determines how soon I get well again.

I am in control of my health.

When I get sick I am to blame.

The main thing which affects my health is what I myself do.

\section{If I take care of myself I can avoid illness.}

If I take the right actions, I can stay healthy.

If I become sick, I have the power to make myself well again. 
scales. Health Education

Monographs, 6, 160-170.
I am directly responsible for my health.

Whatever goes wrong with my health is my own fault.

My physical wellbeing depends on how well I take care of myself.

When I feel ill, I know it is because I have not been taking care of myself properly.

I can pretty much stay healthy by taking good care of myself.

\section{I am satisfied with the appearance, size and shape of my} body. (NZAVS item)

Body Satisfaction (Body Image States Scale)

Right now I feel . . .

(1 Very Inaccurate - 7 Very Accurate)

Cash, T. F., Fleming, E. C., Alindogan, J., Steadman, L., \& Whitehead, A. (2002). Beyond body image as a trait: The development and validation of the Body Image States Scale. Eating Disorders, 10(2), 103-113.

- Extremely dissatisfied with my physical appearance

- Mostly dissatisfied with my physical appearance

- Moderately dissatisfied with my physical appearance

- Slightly dissatisfied with my physical appearance

- Neither dissatisfied nor satisfied with my physical appearance

- Slightly satisfied with my physical appearance

- Moderately satisfied with my physical appearance

- Mostly satisfied with my physical appearance

- Extremely satisfied with my physical appearance
Right now I feel.... extremely satisfied with my body size and shape

Right now I feel.... extremely satisfied with my weight

Right now I feel....

- Extremely physically attractive

- Very physically attractive

- Moderately physically attractive

- Slightly physically attractive

- Neither attractive nor unattractive

- Slightly physically unattractive

- Moderately physically unattractive

- Very physically unattractive

- Extremely physically unattractive

Right now I feel...

- A great deal worse about my looks than I usually feel

- Much worse about my looks than I usually feel

- Somewhat worse about my looks than I usually feel

- Just slightly worse about my looks than I usually feel

About the same about my looks as usual

- Just slightly better about my looks than I usually feel

- Somewhat better about my looks than I usually feel

- Much better about my looks than I usually feel

- A great deal better about my looks than I usually feel

Right now I feel that I look... 
A great deal better than the average person looks

Much better than the average person looks

Somewhat better than the average person looks

Just slightly better than the average person looks

About the same as the average person looks

Just slightly worse than the average person looks

Somewhat worse than the average person looks

Much worse than the average person looks

A great deal worse than the average person looks

Personal Wellbeing Index

(0 Completely Dissatisfied

- 10 Completely Satisfied)

Cummins, R.A., Eckersley, R., Pallant, J., van Vugt, J. \& Misajon, R. (2003).

Development of a national index of subjective wellbeing: The Australian Unity Wellbeing Index. Social Indicators Research, 64, 159-190.

Please rate your level of satisfaction with the following aspects of your life and New Zealand.

\section{National Wellbeing Index}

(0 Completely Dissatisfied - 10 Completely Satisfied)

Tiliouine, H., Cummins, R.A., \& Davern, M. (2006). Measuring wellbeing in developing countries: The case of Algeria. Social Indicators Research, 75, 130.

Please rate your level of satisfaction with the following aspects of your life and New Zealand.

\section{Your standard of living.}

\section{Your health.}

What you are achieving in life.

\section{Your personal relationships}

How safe you feel.

Feeling part of your community.

Your future security.

Your spirituality or religion.
The performance of the current New Zealand government.

The economic situation in New Zealand.

Business in New Zealand.

The social conditions in New Zealand.

National security in New Zealand.

The quality of New Zealand's natural environment.

John Key's leadership as The Prime Minister of New

Zealand. (NZAVS item)

There are people I can depend on to help me if I really 


\section{(Social Provisions Scale)}

(1 Strongly Disagree - 7

Strongly Agree)

Cutrona, C.E., \& Russell, D.W. (1987). The provisions of social relationships and adaptation to stress. Advances in Personal Relationships, 1 , 37-67.

(original) There are people I know will help me if I really need it.

I do not have close relationships with other people. (r)

There is no one I can turn to for guidance in times of stress. (r)

(original) There is no one I can turn to in times of stress. (r)

There are people who call on me to help them.

There are people who like the same social activities I do.

Other people do not think I am good at what I do. (r)

I feel responsible for taking care of someone else.

I am with a group of people who think the same way I do about things.

I do not think that other people respect what I do. (r)

If something went wrong, no one would help me. (r)

I have close relationships that make me feel good.

I have someone to talk to about decisions in my life.

There are people who value my skills and abilities.

There is no one who has the same interests and concerns as me. (r)

There is no one who needs me to take care of them. (r)

I have a trustworthy person to turn to if I have problems.

I feel a strong emotional tie with at least one other person.

There is no one I can count on for help if I really need it. (r)

There is no one I feel comfortable talking about problems with. (r)

There are people who admire my talents and abilities.

I do not have a feeling of closeness with anyone. (r)

There is no one who likes the things I do. (r)

There are people I can count on in an emergency.

No one needs me to take care of them. (r)

I know there are people I can turn to when I need help. (NZAVS item)

I wonder if there is any place on earth where I really fit in. (r)

Sense of Belonging (SOBI-P)

(1 Very Inaccurate -7 Very
I am just not sure if I fit in with my friends. (r)

I would describe myself as a misfit in most social situations. 
Accurate)

Hagerty, B. M., \& Patusky, K. (1995). Developing a measure of sense of belonging. Nursing Research, 44, 9-13.
I generally feel that people accept me.

I feel like a piece of a jig-saw puzzle that doesn't fit into the puzzle. (r)

I would like to make a difference to people or things around me, but I don't feel that what I have to offer is valued. (r)

\section{I feel like an outsider. (r)}

(original) I feel like an outsider in most situations.

I am troubled by feeling like I have no place in this world. (r)

I could disappear for days and it wouldn't matter to my family. (r)

In general, I don't feel a part of the mainstream of society. (r)

I feel like I observe life rather than participate in it. (r)

If I died tomorrow, very few people would come to my funeral. (r)

I feel like a square peg trying to fit into a round hole. (r)

I don't feel that there is any place where I really fit in this world. (r)

I am uncomfortable that my background and experiences are so different from those who are usually around me. (r)

I could not see or call my friends for days and it wouldn't matter to them. (r)

I feel left out of things. (r)

I am not valued by or important to my friends. (r)

I know that people in my life accept and value me. (NZAVS item)

I know that people around me share my attitudes and beliefs. (NZAVS item)

\section{In most ways my life is close to ideal.}

(original) In most ways my life is close to my ideal.

(1 Strongly Disagree - 7

Strongly Agree)

The conditions of my life are excellent.

\section{I am satisfied with my life.}

Diener, E., Emmons, R. A., So far I have gotten the important things I want in life. Larsen, R. J., \& Griffin, S. (1985). The Satisfaction If I could live my life over, I would change almost nothing. with Life Scale.

Psychological Assessment, 49, 71-75. 


\section{Self-Esteem}

(1 Very Inaccurate -7 Very Accurate)

Rosenberg, M. (1965).

Society and the Adolescent Self-image. Princeton, NJ:

Princeton University Press.
At times I think I am no good at all. (r)

I feel that I have a number of good qualities.

I am able to do things as well as most other people.

I feel I do not have much to be proud of. (r)

I certainly feel useless at times. (r)

I feel that I'm a person of worth, at least on an equal plane with others.

I wish I could have more respect for myself. (r)

I am inclined to feel that $I$ am a failure. (r)

(original) All in all, I am inclined to feel that I am a failure. (r)

I take a positive attitude toward myself.

\section{I have so much in life to be thankful for.}

Gratitude (GQ-6)

If I had to list everything that I felt grateful for, it would be a very long list.

(1 Strongly Disagree - 7

Strongly Agree)

McCullough, M. E., When I look at the world, I don't see much to be grateful for. (r)

Emmons, R. A., \& Tsang, J. I am grateful to a wide variety of people.

A. (2002). The grateful disposition: a conceptual and empirical topography. Journal of Personality and Social Psychology, 82(1), 112.

As I get older I find myself more able to appreciate the people, events, and situations that have been part of my life history.

Long amounts of time can go by before I feel grateful to something or someone. (r)

I understand my life's meaning.

Presence of Meaning in Life

\section{My life has a clear sense of purpose.}

I have a good sense of what makes my life meaningful.

(1 Strongly Disagree - 7 Strongly Agree)

Steger, M. F., Frazier, P., I have discovered a satisfying life purpose.

My life has no clear purpose. (r)

Oishi, S., \& Kaler, M. (2006). The Meaning in Life Questionnaire: Assessing the presence of and search for meaning in life. Journal of Counseling Psychology, 53, 80-93.

\section{Emotional Regulation}

When I'm upset, I feel guilty for feeling that way. (r)

When I'm upset, I feel ashamed with myself for feeling that way. (r) 
(1 Strongly Disagree - 7

Strongly Agree)

ADAPTED from Gratz, K. L., \& Roemer, L. (2004).

Multidimensional assessment of emotion regulation and dysregulation:

Development, factor structure, and initial validation of the difficulties in emotion regulation scale. Journal of Psychopathology and Behavioral Assessment, 26(1), 41-54.

ADAPTED from Gross, J. J., \& John, O. P. (2003). Individual differences in two emotion regulation processes: Implications for affect, relationships, and well-being. Journal of Personality and Social Psychology, 85(2), 348-362.
When I'm upset, I become embarrassed for feeling that way. (r)

When I'm upset, I become angry with myself for feeling that way. (r)

When I'm upset, I become irritated with myself for feeling that way. (r)

When I'm upset, I feel like I am weak. (r)

When I'm upset, I have difficulty concentrating. (r)

When I'm upset, I have difficulty focusing on other things. (r)

When I'm upset, I have difficulty getting work done. (r)

When I'm upset, I have difficulty thinking about anything else. (r)

When I'm upset, I can still get things done.

When I'm upset, I lose control over my behaviours. (r)

When I'm upset, I have difficulty controlling my behaviours. (r)

When I'm upset, I become out of control. (r)

When I'm upset, I feel out of control. (r)

I experience my emotions as overwhelming and out of control. (r)

When I'm upset, I feel like I can remain in control of my behaviours.

I am attentive to my feelings.

I pay attention to how I feel.

When I'm upset, I acknowledge my emotions.

When I'm upset, I believe that my feelings are valid and important.

I care about what I am feeling.

When I'm upset, I take time to figure out what I'm really feeling.

When I'm upset, I believe that I'll end up feeling very depressed. (r)

When I'm upset, I believe that I will remain that way for a long time. (r)

When I'm upset, I believe that wallowing in it is all I can do. (r)

When I'm upset, it takes me a long time to feel better. (r) When I'm upset, I believe that there is nothing I can do to 
make myself feel better. (r)

When I'm upset, I know that I can find a way to eventually feel better.

When I'm upset, my emotions feel overwhelming. (r)

When I'm upset, I start to feel very bad about myself. (r)

I have difficulty making sense out of my feelings. (r)

I have no idea how I am feeling. (r)

I am confused about how I feel. (r)

I know exactly how I am feeling.

I am clear about my feelings.

I control my emotions by changing the way I think about the situation I'm in.

When I want to feel less negative emotion, I change the way I'm thinking about the situation.

When I want to feel more positive emotion, I change the way I'm thinking about the situation.

When I want to feel more positive emotion (such as joy or amusement), I change what I'm thinking about.

When I want to feel less negative emotion (such as sadness or anger), I change what I'm thinking about.

When I'm faced with a stressful situation, I make myself think about it in a way that helps me stay calm.

I control my emotions by not expressing them.

When I am feeling negative emotions, I make sure not to express them.

I keep my emotions to myself.

When I am feeling positive emotions, I am careful not to express them.

When I feel negative emotions, my emotions feel out of control. (NZAVS item) (r)

When I feel negative emotions, I suppress or hide my emotions. (NZAVS item)

When I feel negative emotions, I change the way I think to help me stay calm. (NZAVS item)

Personal Respect

(1 Strongly Disagree - 7

Strongly Agree)
If they knew me well, most members of my group would respect my values.

\section{If they knew me, most NZers would respect what I have accomplished in life.}

(original) If they knew me well, most members of my group 
ADAPTED FROM: Tyler,

T. R., Degoey, P., \& Smith,

H. J. (1996). Understanding why the justice of group procedures matters: A test of the psychological dynamics of the groupvalue model. Journal of Personality and Social Psychology, 70(5), 913-930. doi: 10.1037/00223514.70.5.913

\section{Active Harm (BIAS-TS)}

(1 Have never experienced this - 7 Often experience this)

Sibley, C. G. (2011). The BIAS Treatment Scale (BIAS-TS): A measure of the subjective experience of active and passive harm and facilitation. Journal of Personality Assessment, 93, 300-315.

In your day-to-day life, how often do people in New Zealand act toward you in the following ways?

\section{Passive Harm (BIAS-TS)}

(1 Have never experienced this -7 Often experience this)

Sibley, C. G. (2011). The BIAS Treatment Scale (BIAS-TS): A measure of the subjective experience of active and passive harm and facilitation. Journal of Personality Assessment, 93, 300-315. would think highly of my accomplishments in life.

If they knew me well, most members of my group would approve of how I live my life.

I believe that most members of my group respect me.

I believe I make a good impression on other members of my group.

\section{Do things to threaten you.}

Act in a threatening manner toward you.

Threaten or harass you.

Attack you, or make you fear that they might.

\section{Make threatening gestures toward you.}

Call you names or insult you.

Make you feel unsafe.

Deliberately try to make you feel unsafe.

Offer advice and opinions even when you don't want it. Insist that they know what is best for you.

Act as if they know what's best for you.

Try to help you with things you'd rather do for yourself.

Try to do things for you that you would rather do for yourself.

Act as if you need help when you don't.

Insist on helping you even when you don't need it.

Tell you what you should do, despite what you might want. 
Active Facilitation

(BIAS-TS)

(1 Have never experienced this -7 Often experience this)

Sibley, C. G. (2011). The BIAS Treatment Scale (BIAS-TS): A measure of the subjective experience of active and passive harm and facilitation. Journal of

Personality Assessment, 93, 300-315.

Passive Facilitation (BIAS-TS)

(1 Have never experienced this -7 Often experience this)

Sibley, C. G. (2011). The BIAS Treatment Scale (BIAS-TS): A measure of the subjective experience of active and passive harm and facilitation. Journal of Personality Assessment, 93, 300-315.

Political Locus of

Control/ Political

Efficacy

(1 Strongly Disagree - 7

Strongly Agree)

Paulhus, D. L., \& Van

Selst, M. (1990). The Spheres of Control Scale: 10 Years of Research. Personality and Individual Differences, 11, 1029-1036.
Are happy to hear your opinions about things.

Make you feel welcome when they meet you.

Actively listen to your opinions about things.

Do their best to make you feel comfortable.

Are friendly toward you and make you feel welcome.

\section{Are friendly and willing to help you.}

Volunteer to help you out.

Actively listen to what you want.

Only interact with you when they need something from you.

Only socialize or interact with you when it suits their purposes.

Only associate with you when they need something done.

Happily interact with you in formal situations but not social ones.

Seem to only want you around when you can help them somehow.

Are happy to associate with you, but only when it benefits them.

\section{Treat you with respect, but avoid socializing with you.}

Are happy to work with you, but not socialize with you.

By taking an active part in political and social affairs we, the people, can control world events.

The average citizen can have an influence on government decisions.

It is difficult for us to have much control over the things politicians do in office. (r)

Bad economic conditions are caused by world events that are beyond our control. (r)

\section{With enough effort we can wipe out political corruption.}

One of the major reasons we have wars is because people don't take enough interest in politics.

There is nothing we, as consumers, can do to keep the cost of living from going higher. (r)

It is impossible to have any real influence over what big 
businesses do. (r)

I prefer to concentrate my energy on other things rather than on solving the world's problems. (r)

In the long run we, the voters, are responsible for bad government on a national as well as a local level.

Attributions about Income Inequality

(1 Strongly Disagree - 7 Strongly Agree)

Kluegel, J. E, Smith. 1986. Beliefs about Inequality: Americans' Views of What is and What Ought to Be. New York: Aldine de Gruyter.
Gender Income and Employment Opportunity

(1 Strongly Oppose - 7 Strongly Support)

Sibley, C. G., \& Perry, R. (2010). An Opposing Process Model of Benevolent Sexism. Sex Roles, 62, 438-452.
More equality of incomes would allow my family to live better. ( $\mathrm{r}$ )

More equality of incomes would avoid conflicts between people at different levels. (r)

Incomes should be more equal because every family's needs for food, housing, and so on, are the same. (r)

Incomes should be more equal, because everybody's contribution to society is equally important. (r)

If incomes were more equal, people would be less motivated to work hard.

(original) If incomes were more equal, nothing would motivate people to work hard.

Incomes cannot be made more equal since people's abilities and talents are unequal.

Incomes should not be more equal since the rich invest in the economy, creating jobs and benefits for everyone.

If incomes were more equal, life would be boring because people would all live in the same way.

Incomes cannot be made more equal since its human nature to always want more than others have.

Incomes should not be made more equal since that would keep people from dreaming of someday becoming a real success.

Making incomes more equal means socialism, and that deprives people of individual freedoms.

Monitoring women's representation and participation at senior levels in business and the education sector to ensure their participation in leadership and decision-making roles.

Introduce a program to enhance sustainable business growth among businesses owned and operated by women.

\section{Affirmative action policies for women promoting entry into female-under represented occupations, such as construction and the trades.}

A government plan to increase women's average pay to the same level as men's average pay within the next 5 years. Incentives specifically targeting women in order to increase 
The following scale lists a variety of actual or proposed policy changes and initiatives.

Please rate how strongly you oppose or support each of the following policies.

\section{Abortion Attitudes}

(1 Strongly Oppose - 7

Strongly Support)

Smith, T. W., Marsden, P. V., Hout, M., \& Kim, J. (2011). General Social Surveys, 1972-2010:

Cumulative Codebook. University of Chicago: National Opinion Research Center.

Please rate how strongly you oppose or support each of the following possible policies or issues. women's uptake of retirement savings schemes.

Incentives to increase women's participation in the paid workforce (paid for by government).

Legalized abortion when there is a strong chance of serious defect in the baby.

(original) Should it be possible for a pregnant woman to obtain a legal abortion if there is a strong chance of serious defect in the baby?

Legalized abortion when the woman is married and does not want any more children.

(original) Should it be possible for a pregnant woman to obtain a legal abortion if she is married and does not want any more children?

\section{Legalized abortion when the woman's life is endangered.}

(original) Should it be possible for a pregnant woman to obtain a legal abortion if the woman's own health is seriously endangered by the pregnancy?

Legalized abortion when the family has a very low income and cannot afford any more children.

(original) Should it be possible for a pregnant woman to obtain a legal abortion if the family has a very low income and cannot afford any more children?

Legalized legal abortion when the woman became pregnant as a result of rape.

(original) Should it be possible for a pregnant woman to obtain a legal abortion if she became pregnant as a result of rape?

Legalized abortion when the woman is not married and does not want to marry the man.

(original) Should it be possible for a pregnant woman to obtain a legal abortion if she is not married and does not want to marry the man?

\section{Legalized abortion for women, regardless of the reason.}

(original) Should it be possible for a pregnant woman to obtain a legal abortion if the woman wants it for any reason?

Institutional Trust in Police
I have confidence that the New Zealand Police can do its job well.

I trust the leaders of the New Zealand Police to make decisions that are good for everyone in the city. 
(1 Strongly Disagree - 7

Strongly Agree)

Tyler, T. R. (2005).

Policing in black and white:

Ethnic group differences in trust and confidence in the police. Police

quarterly, 8(3), 322-342.
Overall, the New Zealand Police is a legitimate institution and people should obey the decisions that New Zealand Police officers make.

There are many things about the New Zealand Police and its policies that need to be changed. (r)

People's basic rights are well protected by the New Zealand Police.

The New Zealand Police care about the well-being of everyone they deal with.

The New Zealand Police are often dishonest. (r)

Some of the things the New Zealand Police do embarrass the country. (r)

I would always call the police to report a crime that was occurring in my neighbourhood.

(original) How likely would you be to call the police to report a crime that was occurring in your neighbourhood?

I would always provide information to the police to help them find someone suspected of committing a crime.

(original) How likely would you be to help the police to find someone suspected of committing a crime by providing them with information?

police. Police

Quarterly, 8(3), 322-342.

I would always report dangerous or suspicious activities occurring in my neighbourhood to the police.

(original) How likely would you be to report dangerous or suspicious activities in your neighbourhood to the police?

\section{Environmental Efficacy}

\section{I feel I can make a difference to the state of the} environment.

(1 Strongly Disagree - 7

Strongly Agree)

Sharma, S. (2008) Where do we stand? One Auckland secondary school's journey toward sustainability. I am able to find ways to tackle environmental problems in everyday life.

\section{By taking personal action I believe I can make a positive} difference to environmental problems.

I don't feel I have the ability to do things for the environment. (r)

Unpublished MA thesis, The University of Auckland, Auckland, NZ.

I don't think I can make a difference to global environmental problems. (r)

The actions I can take to protect the environment are too small to make a difference. (r)

Asian immigrants should learn to conform to the rules and

Symbolic Threat norms of New Zealand society as soon as possible after they arrive.

(1 Strongly Disagree - 7 Immigration from Asia is undermining New Zealand culture. 
Strongly Agree)

Stephan, W. G., Boniecki, K. A., Ybarra, O., Bettencourt, A., Ervin, K. S., Jackson, L. A., McNatt, P. S., \& Renfro, C. L. (2002). The role of threats in the racial attitudes of Blacks and Whites.

Personality and Social Psychology Bulletin, 28, 1242-1254.

Items are not the full 12item scale which is not available; taken from

Stephan, W. G., Ybarra, O., \& Bachman, G. (1999).

Prejudice toward immigrants. Journal of Applied Social Psychology, 29(11), 2221-2237.
The values and beliefs of Asians regarding work are basically quite similar to those of most NZers. (r)

The values and beliefs of Asians regarding moral and religious issues are not compatible with the beliefs and values of most NZers.

The values and beliefs of Asians regarding family issues and socializing children are basically quite similar to those of most NZers. (r)

The values and beliefs of Asians regarding social relations are not compatible with the beliefs and values of most NZers.

Asian immigrants should not have to accept New Zealand ways. (r)

Asians have different values and morals compared to most other NZers. (NZAVS item)

Pacific Islander immigrants should learn to conform to the rules and norms of New Zealand society as soon as possible after they arrive.

Immigration from the Pacific Islands is undermining New Zealand culture.

The values and beliefs of Pacific Islanders regarding work are basically quite similar to those of most NZers. (r)

The values and beliefs of Pacific Islanders regarding moral and religious issues are not compatible with the beliefs and values of most NZers.

The values and beliefs of Pacific Islanders regarding family issues and socializing children are basically quite similar to those of most NZers. (r)

The values and beliefs of Pacific Islanders regarding social relations are not compatible with the beliefs and values of most NZers. 7

Pacific Islander immigrants should not have to accept New Zealand ways. (r)

Pacific Islanders have different values and morals compared to most other NZers. (NZAVS item)

The values and beliefs of NZ Europeans regarding work are basically quite similar to those of most NZers. (r) 
The values and beliefs of NZ Europeans regarding moral and religious issues are not compatible with the beliefs and values of most NZers.

The values and beliefs of NZ Europeans regarding family issues and socializing children are basically quite similar to those of most NZers. (r)

The values and beliefs of NZ Europeans regarding social relations are not compatible with the beliefs and values of most NZers.

NZ Europeans have different values and morals compared to most other NZers. (NZAVS item)

The values and beliefs of Māori regarding work are basically quite similar to those of most NZers. (r)

The values and beliefs of Māori regarding moral and religious issues are not compatible with the beliefs and values of most NZers.

The values and beliefs of Māori regarding family issues and socializing children are basically quite similar to those of most NZers. (r)

The values and beliefs of Māori regarding social relations are not compatible with the beliefs and values of most NZers.

Māori have different values and morals compared to most other NZers. (NZAVS item)

Realistic Threat

(1 Strongly Disagree - 7

Strongly Agree)

Bobo, L. (1998). Race, interests, and beliefs about affirmative action. American Behavioral Scientist, 41, 985-1003.
In my opinion, more good jobs for Asians means fewer good jobs for members of other groups in New Zealand.

The more influence Asians have in local politics the less influence members of other groups will have in local politics.

As more good housing and neighbourhoods go to Asians, the fewer good houses and neighbourhoods there will be for members of other groups.

Many Asians have been trying to get ahead economically at the expense of other groups.

In my opinion, more good jobs for Pacific Islanders means fewer good jobs for members of other groups in New Zealand.

The more influence Pacific Islanders have in local politics the less influence members of other groups will have in local politics.

As more good housing and neighbourhoods go to Pacific Islanders, the fewer good houses and neighbourhoods there will be for members of other groups.

Many Pacific Islanders have been trying to get ahead 
economically at the expense of other groups.

In my opinion, more good jobs for NZ Europeans means fewer good jobs for members of other groups in New Zealand.

The more influence NZ Europeans have in local politics the less influence members of other groups will have in local politics.

As more good housing and neighbourhoods go to NZ Europeans, the fewer good houses and neighbourhoods there will be for members of other groups.

Many NZ Europeans have been trying to get ahead economically at the expense of other groups.

In my opinion, more good jobs for Māori means fewer good jobs for members of other groups in New Zealand.

The more influence Māori have in local politics the less influence members of other groups will have in local politics.

As more good housing and neighbourhoods go to Māori, the fewer good houses and neighbourhoods there will be for members of other groups.

Many Māori have been trying to get ahead economically at the expense of other groups.

Race Essentialism (Lay Theory of Race Scale)

(1 Strongly Disagree - 7 Strongly Agree)

No, S., Hong, Y-Y., Liao, H-Y., Lee, K., Wood, D., \& Chao, M. M. (2008). Lay theory of race affects and moderated Asian Americans' responses toward American culture. Journal of Personality and Social Psychology, 95, 9911004.

\section{Intergroup Anxiety}

(1 Strongly Disagree - 7 Strongly Agree)
To a large extent, a person's race biologically determines his or her abilities and traits.

Although a person can adapt to different cultures, it is hard if not impossible to change the dispositions of a person's race.

How a person is like (e.g., his or her abilities, traits) is deeply ingrained in his or her race. It cannot be changed much.

A person's race is something very basic about them and it can't be changed much.

Races are just arbitrary categories and can be changed if necessary. (r)

Racial categories are constructed totally for economic, political, and social reasons. If the socio-political situation changes, the racial categories will change as well. (r)

Race does not have an inherent biological basis, and thus can be changed. (r)

Racial categories are fluid, malleable constructs. (r)

\section{I feel anxious about interacting with people from other} races. (NZAVS item)

certain

awkward 


\begin{tabular}{|c|c|}
\hline (multiple & 10 \\
\hline $\begin{array}{l}\text { Stephan, W. G., \& Stephan, } \\
\text { C. W. (1985). Intergroup } \\
\text { anxiety. Journal of Social } \\
\text { Issues, 41(3), 157-175. }\end{array}$ & $\begin{array}{l}\text { happy } \\
\text { accepted } \\
\text { confident }\end{array}$ \\
\hline $\begin{array}{l}\text { If you were the only } \\
\text { member of your ethnic } \\
\text { group and you were } \\
\text { interacting with people } \\
\text { from a different racial or } \\
\text { ethnic group (e.g., talking } \\
\text { with them, working on a } \\
\text { project with them), how } \\
\text { would you feel compared to } \\
\text { occasions when you are } \\
\text { interacting with people } \\
\text { from your own ethnic } \\
\text { group? More or less: }\end{array}$ & $\begin{array}{l}\text { irritated } \\
\text { impatient } \\
\text { defensive } \\
\text { suspicious } \\
\text { careful }\end{array}$ \\
\hline
\end{tabular}

Ethnic Group Active Harm

(1 Have never experienced this -7 Often experience this)

Sibley, C. G. (2011). The BIAS Treatment Scale (BIAS-TS): A measure of the subjective experience of active and passive harm and facilitation. Journal of Personality Assessment, 93, 300-315.

In your day-to-day life, how often do PEOPLE FROM OTHER ETHNIC GROUPS act towards you in the following ways?

\section{Ethnic Group Passive} Harm

(1 Have never experienced this -7 Often experience this)

\section{Do things to threaten you.}

Act in a threatening manner toward you.

Threaten or harass you.

Attack you, or make you fear that they might.

Make threatening gestures toward you.

Call you names or insult you.

Make you feel unsafe.

Deliberately try to make you feel unsafe.
Offer advice and opinions even when you don't want it.

Insist that they know what is best for you.

Act as if they know what's best for you.

Try to help you with things you'd rather do for yourself.

Try to do things for you that you would rather do for yourself. 
Sibley, C. G. (2011). The BIAS Treatment Scale (BIAS-TS): A measure of the subjective experience of active and passive harm and facilitation. Journal of Personality Assessment, 93, 300-315.
Act as if you need help when you don't.

Insist on helping you even when you don't need it.

Tell you what you should do, despite what you might want.

\section{Ethnic Group Passive} Facilitation

(1 Have never experienced this -7 Often experience this)

Sibley, C. G. (2011). The BIAS Treatment Scale (BIAS-TS): A measure of the subjective experience of active and passive harm and facilitation. Journal of Personality Assessment, 93, 300-315.

In your day-to-day life, how often do people from other ethnic groups act towards you in the following ways?

\section{Ethnic Subgroup Respect}

(1 Definitely NO - 7

Definitely YES)

ADAPTED FROM: Huo, Y. J., Molina, L. E., Binning, K. R., \& Funge, S. P. (2010). Subgroup respect, social engagement, and well-being: A field study of an ethnically diverse high school. Cultural Diversity and Ethnic Minority Psychology, 16, 427-436.
Only interact with you when they need something from you.

\section{Only socialize or interact with you when it suits their purposes.}

Only associate with you when they need something done.

\section{Happily interact with you in formal situations but not social ones.}

Seem to only want you around when you can help them somehow.

Are happy to associate with you, but only when it benefits them.

\section{Treat you with respect, but avoid socializing with you.}

Are happy to work with you, but not socialize with you.

\section{Do you think most New Zealanders respect the achievements of your ethnic group?}

(original) Most of the time I feel that New Zealanders respect the achievements of my ethnic group.

Do you think most New Zealanders value the opinions and ideas of your ethnic group?

(original) Most of the time I feel that New Zealanders value the opinions and ideas of my ethnic group.

Do you think most New Zealanders approve of how members of your ethnic group live their lives?

(original) Most of the time I feel that New Zealanders approve of how members of my ethnic group live their lives. 


\section{Ethnic Group Narcissism}

(1 Strongly Disagree - 7

Strongly Agree)

de Zavala, A. G., Cichocka, A., Eidelson, R., \& Jayawickreme, N. (2009). Collective narcissism and its social consequences. Journal of Personality and Social Psychology, 97, 1074-1096.
I wish other ethnic groups would more quickly recognize authority of my group.

My ethnic group deserves special treatment.

I will never be satisfied until my ethnic group gets all it deserves.

I insist upon my ethnic group getting the respect that is due to it.

It really makes me angry when others criticize my ethnic group.

If my ethnic group had a major say in the world, the world would be a much better place.

I do not get upset when people do not notice achievements of my ethnic group. (r)

Not many people seem to fully understand the importance of my ethnic group.

The true worth of my ethnic group is often misunderstood.

I think that it is good for New Zealand to have different groups with a distinct cultural background living in this country.

(1 Strongly Disagree - 7

Strongly Agree)

Breugelmans, S. M., \& van de Vijver, F. J. R. (2004). Antecedents and components of majority attitudes toward multiculturalism in the Netherlands. Applied Psychology: An International Review, 53, 400-422.

I do not like being in a bus or train in which there are many immigrants. (r)

\section{The unity of New Zealand is weakened by too many} immigrants. (r)

(original) I think that the unity of New Zealand is weakened by non-natives. (r)

I think that city districts in New Zealand with many immigrants are less safe. (r)

There are too many immigrants living in New Zealand. (original) I think that too many non-natives are living in New Zealand. (r)

I think that it is the best for New Zealand that immigrants keep their own culture and customs.

I feel at ease when I am in a city district in New Zealand with many immigrants.

\section{Modern Racism}

Discrimination against Māori is no longer a problem in New Zealand.

(1 Strongly Disagree - 7 Strongly Agree)

It is easy to understand the anger of Māori people in New Zealand. (r)

Māori have more influence upen-schooldesegregation plans than they ought to have.

McConahay, J. B. (1986). 
Modern racism, ambivalence, and the Modern Racism Scale. In J. Dovidio \& S. Gaertner (Eds.), Prejudice, discrimination, and racism (pp. 91-125). Orlando, FL: Academic Press.

Social Dominance

Orientation (SDO6)

(1 Strongly Disagree - 7

Strongly Agree)

Sidanius, J., \& Pratto, F. (1999). Social dominance: An intergroup theory of social hierarchy and oppression. Cambridge: Cambridge University

Press.
Māori are getting too demanding in their push for equal rights. Māori should not push themselves where they are not wanted. Over the past few years, Māori have gotten more economically than they deserve.

Over the past few years, the government and news media have shown more respect to Māori than they deserve.

Some groups of people are simply inferior to other groups.

In getting what you want, it is sometimes necessary to use force against other groups.

It's OK if some groups have more of a chance in life than others.

To get ahead in life, it is sometimes necessary to step on other groups.

If certain groups stayed in their place, we would have fewer problems.

It's probably a good thing that certain groups are at the top and other groups are at the bottom.

Inferior groups should stay in their place.

Sometimes other groups must be kept in their place.

It would be good if groups could be equal. (r)

Group equality should be our ideal. (r)

All groups should be given an equal chance in life. (r)

We should do what we can to equalise conditions for different groups. (r)

We should have increased social equality. (r)

We would have fewer problems if we treated people more equally. (r)

We should strive to make incomes as equal as possible. (r)

No one group should dominate in society. (r)

Our country desperately needs a mighty leader who will do

\section{Right-Wing}

Authoritarianism

what has to be done to destroy the radical new ways and sinfulness that are ruining us.

Gays and lesbians are just as healthy and moral as anybody else. (r)

It is always better to trust the judgment of the proper authorities in government and religion than to listen to the noisy rabble rousers in our society who are trying to create doubt in people's minds.

Atheists and others who have rebelled against the 
established religions are no doubt every bit as good and virtuous as those who attend church regularly. (r)

The only way our country can get through the crisis ahead is to get back to our traditional values, put some tough leaders in power, and silence the troublemakers spreading bad ideas.

There is absolutely nothing wrong with nudist camps. (r)

Our country needs free thinkers who will have the courage to defy traditional ways, even if this upsets many people. (r)

Our country will be destroyed someday if we do not smash the perversions eating away at our moral fibre and traditional beliefs.

Everyone should have their own life-style, religious beliefs, and sexual preferences, even if it makes them different from everyone else. (r)

The "old-fashioned ways" and "old-fashioned values" still show the best way to live.

You have to admire those who challenged the law and the majority's view by protesting for women's abortion rights, for animal rights, or to abolish school prayer. (r)

What our country really needs is a strong, determined leader who will crush evil, and take us back to our true path.

Some of the best people in our country are those who are challenging our government, criticizing religion, and ignoring the "normal way things are supposed to be done." (r)

God's laws about abortion, pornography, and marriage must be strictly followed before it is too late, and those who break them must be strongly punished.

It would be best for everyone if the proper authorities censored magazines so that people could not get their hands on trashy and disgusting material.

There is nothing wrong with premarital sexual intercourse. (r)

Our country will be great if we honour the ways of our forefathers, do what the authorities tell us to do, and get rid of the "rotten apples" who are ruining everything.

There is no "ONE right way" to live life; everybody has to create their own way. (r)

Homosexuals and feminists should be praised for being brave enough to defy "traditional family values." (r)

This country would work a lot better if certain groups of troublemakers would just shut up and accept their group's traditional place in society. 
There are many radical, immoral people in our country today, who are trying to ruin it for their own godless purposes, whom the authorities should put out of action.

People should pay less attention to the Bible and the other old forms of religious guidance, and instead develop their own personal standards of what is moral and immoral. (r)

What our country needs most is discipline, with everyone following our leaders in unity.

It's better to have trashy magazines and radical pamphlets in our communities than to let the government have the power to censor them. (r)

The facts on crime, sexual immorality, and the recent public disorders all show we have to crack down harder on deviant groups and troublemakers if we are going to save our moral standards and preserve law and order.

A lot of our rules regarding modesty and sexual behaviour are just customs which are not necessarily any better or holier than those which other people follow. (r)

The situation in our country is getting so serious, the strongest methods would be justified if they eliminated the troublemakers and got us back to our true path.

A "woman's place" should be wherever she wants to be. The days when women are submissive to their husbands and social conventions belong strictly in the past. (r)

It is wonderful that young people today have greater freedom to protest against things they don't like, and to make their own "rules" to govern their behaviour. (r)

Once our government leaders give us the "go ahead," it will be the duty of every patriotic citizen to help stomp out the rot that is poisoning our country from within.

\section{Colour-Blind Ideology}

(1 Strongly Disagree - 7 Strongly Agree)

Knowles, E.D., Lowery, B.S., Hogan, C.M., \& Chow, R.M. (2009). On the malleability of ideology: motivated construals of color blindness. Journal of Personality and Social Psychology, 96, 857-869.

\section{I wish people in this society would stop obsessing so much} about race.

People who become preoccupied by race are forgetting that we are all just human.

Putting racial labels on people obscures the fact that everyone is a unique individual.

Race is an artificial label that keeps people from thinking freely as individuals. 


\section{Historical Negation}

(1 Strongly Disagree - 7

Strongly Agree)

Sibley, C. G., Liu, J. H., Duckitt, J., \& Khan, S. S. (2008). Social

representations of history and the legitimation of social inequality: The form and function of historical negation. European Journal of Social Psychology, 38, 542-565.
Grievances for past injustices should be recognised and due compensation offered to the descendants of those who suffered from such injustices. (r)

New Zealand law needs to recognise that certain ethnic minorities have been treated unfairly in the past. People belonging to those groups should be entitled to certain benefits and compensation. (r)

I believe that I should take part in the efforts to help repair the damage to others caused by earlier generations of people from my ethnic group. (r)

We as a nation have a responsibility that see that due settlement is offered to Māori in compensation for past injustices. ( $\mathrm{r}$ )

We should not have to pay for the mistakes of our ancestors.

We should all move on as one nation and forget about past differences and conflicts between ethnic groups.

It is true that many things happened to Māori people in the past that should not have happened, but it is unfair to hold current generations of Pākehā/NZ Europeans accountable for things that happened so long ago.

People who were not around in previous centuries should not feel accountable for the actions of their ancestors.

\section{Symbolic Exclusion}

(1 Strongly Disagree - 7 Strongly Agree)

Sibley, C. G. (2010). The dark duo of post-colonial ideology: A model of symbolic exclusion and historical negation.

International Journal of Conflict and Violence, 4 , 106-123.

\section{I think that Māori culture helps to define New Zealand in} positive ways. (r)

I reckon Māori culture should stay where it belongs-with Māori. It doesn't concern other New Zealanders.

Māori culture is something that all New Zealanders can share in, even if they are not themselves Māori by descent. (r)

I reckon New Zealand would be a much better place if it stopped trying to promote Māori culture and just got on with other things.

I think Māori culture is just as important as European culture for defining what true "New Zealandness" is. (r)

When we're honest about it, Māori culture has very little to do with what it actually means to be a true New Zealander.

New Zealand would be a much more boring place to live if it was all just based on White/European culture. (r)

New Zealand would be a better place to live if we forgot about trying to promote Māori culture to everyone.

We are all one nation and we should all be treated the Equality Positioning same. No one should be entitled to anything more than the 
(1 Strongly Disagree - 7

Strongly Agree)

Sibley, C. G., \& Wilson, M. S. (2007). Political attitudes and the ideology of equality: Differentiating support for liberal and conservative political parties in New Zealand. New Zealand Journal of Psychology, 36, 72-84.

\section{System Justification}

(1 Strongly Disagree - 7 Strongly Agree)

Kay, A. C., \& Jost, J. T. (2003). Complementary justice: effects of "poor but happy" and "poor but honest" stereotype exemplars on system justification and implicit activation of the justice motive. Journal of Personality and Social Psychology, 85, 823-837. rest of us simply because they belong to one particular ethnic group.

It is wrong for any one minority to be provided with additional resources because of their ethnicity. Equality means treating all people equally regardless of whether they identify as Māori, NZ European, Asian, or any other ethnic group currently living in New Zealand.

We should provide additional resources and opportunities to ethnic minorities with a history of disadvantage in order to promote genuine equality in the future. (r)

True equality can only be achieved once we recognize that some ethnic groups are currently more disadvantaged than others and require additional assistance from the government. (r)

Given that the economic playing field in New Zealand is not truly level, it is only fair to provide disadvantaged ethnic minorities with additional resources in the here and now so as to make things more equal in the long term. (r)

Everyone should be judged solely on their individual merits. People should not be given additional rights simply because of their ethnicity, even if they do belong to a 'disadvantaged' group.

We are all New Zealanders and the law should not make provision for minority groups because of their ethnicity.

The government should devote extra resources to disadvantaged ethnic groups in order to help them overcome the effects of past discrimination and inequality. (r)

In general, I find New Zealand society to be fair.

In general, the New Zealand political system operates as it should.

New Zealand society needs to be radically restructured. (r)

New Zealand is the best country in the world to live in.

Most of New Zealand's policies serve the greater good.

Everyone has a fair shot at wealth and happiness in New Zealand.

New Zealand society is getting worse every year. (r)

New Zealand society is set up so that people usually get what they deserve. 


\section{Justification}

(1 Strongly Disagree - 7

Strongly Agree)

Jost, J.T., \& Kay, A.C. (2005). Exposure to benevolent sexism and complementary gender stereotypes: Consequences for specific and diffuse forms of system justification. Journal of Personality and Social Psychology, 88, 498-509.

\section{Gender Identity}

Centrality

(1 Strongly Disagree - 7

Strongly Agree)

Leach, C.W., van Zomeren, M., Zebel, S., Vliek, M. L. W., Pennekamp, S. F., Doosje, B.,... Spears, R. (2008). Group-level selfdefinition and selfinvestment: A hierarchical (multicomponent) model of ingroup identification. Journal of Personality and Social Psychology, 95, 144165.

\section{Economic System Justification}

(1 Strongly Disagree - 7 Strongly Agree)

Jost, J. T., \& Thompson, E. P. (2000). Group-based dominance and opposition to equality as independent predictors of self-esteem,
The division of labour in families generally operates as it should.

Gender roles need to be radically restructured. (r)

For women, New Zealand is the best country in the world to live in.

Most policies relating to gender and the sexual division of labour serve the greater good.

\section{Men and women both have a fair shot at wealth and} happiness in New Zealand.

(original) Everyone (male or female) has a fair shot at wealth and happiness

Sexism in society is getting worse every year. (r)

Society is set up so that men and women usually get what they deserve.

I often think about the fact that I am a woman/man.

The fact that I am a woman/man is an important part of my identity.

\section{Being a woman/man is an important part of how I see} myself.

If people work hard, they almost always get what they want.

The existence of widespread economic differences does not mean that they are inevitable. (r)

Laws of nature are responsible for differences in wealth in society.

There are many reasons to think that the economic system is unfair. (r)

It is virtually impossible to eliminate poverty.

Poor people are not essentially different from rich people. (r)

Most people who don't get ahead in our society should not 
ethnocentrism, and social policy attitudes among African Americans and European Americans. Journal of Experimental Social Psychology, 36(3), 209-232. blame the system; they have only themselves to blame.

Equal distribution of resources is a possibility for our society. (r)

Social class differences reflect differences in the natural order of things.

Economic differences in the society reflect an illegitimate distribution of resources. (r)

There will always be poor people, because there will never be enough jobs for everybody.

\section{Economic positions are legitimate reflections of people's achievements.}

If people wanted to change the economic system to make things equal, they could. (r)

Equal distribution of resources is unnatural.

It is unfair to have an economic system which produces extreme wealth and extreme poverty at the same time. (r)

There is no point in trying to make incomes more equal.

There are no inherent differences between rich and poor; it is purely a matter of the circumstances into which you are born. (r)

No matter how accomplished he is, a man is not truly complete as a person unless he has the love of a woman.

Benevolent Sexism In a disaster, women ought not necessarily to be rescued before men. (r)

(1 Strongly Disagree - 7

Strongly Agree)
Glick, P., \& Fiske, S. T. (1996). The Ambivalent Sexism Inventory: Differentiating hostile and benevolent sexism. Journal of Personality and Social Psychology, 70, 491-512.

People are often truly happy in life without being romantically involved with a member of the other sex. (r)

Many women have a quality of purity that few men possess.

\section{Women should be cherished and protected by men.}

Every man ought to have a woman whom he adores.

Men are complete without women. (r)

A good woman should be set on a pedestal by her man.

Women, compared to men, tend to have a superior moral sensibility.

Men should be willing to sacrifice their own wellbeing in order to provide financially for the women in their lives.

Women, as compared to men, tend to have a more refined sense of culture and good taste.

Many women are actually seeking special favours, such as 
(1 Strongly Disagree - 7 Strongly Agree)

Glick, P., \& Fiske, S. T. (1996). The Ambivalent Sexism Inventory: Differentiating hostile and benevolent sexism. Journal of Personality and Social Psychology, 70, 491-512. asking for "equality."

Most women interpret innocent remarks or acts as being sexist.

\section{Women are too easily offended.}

Feminists are not seeking for women to have more power than men. (r)

Most women fail to appreciate fully all that men do for them.

Women seek to gain power by getting control over men.

Women exaggerate problems they have at work.

Once a woman gets a man to commit to her, she usually tries to put him on a tight leash.

When women lose to men in a fair competition, they typically complain about being discriminated against.

There are actually very few women who get a kick out of teasing men by seeming sexually available and then refusing male advances. ( $\mathrm{r}$ )

Feminists are making entirely reasonable demands of men. (r)

Winning is not the first thing; it's the only thing.

Competitive World View

(1 Strongly Disagree - 7

Strongly Agree)

Duckitt, J., Wagner, C., du Plessis, I., \& Birum, I. (2002). The psychological bases of ideology and prejudice: Testing a dual process model. Journal of Personality and Social Psychology, 83, 75-93.
The best way to lead a group under one's supervision is to show them kindness, consideration, and treat them as fellow workers, not as inferiors. (r)

If one has power in a situation, one should use it however one has to in order to get one's way.

If it's necessary to be cold blooded and vengeful to reach one's goals, then one should do it.

Life is not governed by the "survival of the fittest." We should let compassion and moral laws be our guide. (r)

Money, wealth and luxury are what really count in life.

It is better to be loved than to be feared. (r)

It is much more important in life to have integrity in your dealings with others than to have money and power. (r)

It's a dog-eat-dog world where you have to be ruthless at times.

Charity (i.e., giving somebody something for nothing) is admirable not stupid. (r)

You know that most people are out to "screw" you, so you have to get them first when you get the chance.

All in all it is better to be humble and honest than important and dishonest. (r) 
My knowledge and experience tells me that the social world we live in is basically a competitive "jungle" in which the fittest survive and succeed, in which power, wealth, and winning are everything, and might is right.

Honesty is the best policy in all cases. (r)

There is really no such thing as "right" and "wrong." It all boils down to what you can get away with.

Do unto to others as you would have them do unto you, and never do anything unfair to someone else. (r)

One of the most useful skills a person should develop is how to look someone straight in the eye and lie convincingly.

Basically people are objects to be quietly and coolly manipulated for one's own benefit.

One should give others the benefit of the doubt. Most people are trustworthy if you have faith in them. (r)

We can make a society based on unselfish cooperation, sharing and people generously helping each other, and NOT on competition and acquisitiveness. (r)

\section{Dangerous World View}

(1 Strongly Disagree - 7 Strongly Agree)

Duckitt, J., Wagner, C., du Plessis, I., \& Birum, I. (2002). The psychological bases of ideology and prejudice: Testing a dual process model. Journal of Personality and Social Psychology, 83, 75-93.
Although it may appear that things are constantly getting more dangerous and chaotic, it really isn't so. Every era has its problems, and a person's chances of living a safe, untroubled life are better today than ever before. (r)

Any day now chaos and anarchy could erupt around us. All the signs are pointing to it.

\section{There are many dangerous people in our society who will attack someone out of pure meanness, for no reason at all.}

Despite what one hears about "crime in the street," there probably isn't any more now than there ever has been. (r)

If a person takes a few sensible precautions, nothing bad is likely to happen to him or her; we do not live in a dangerous world. (r)

Every day as society become more lawless and bestial, a person's chances of being robbed, assaulted, and even murdered go up and up.

My knowledge and experience tells me that the social world we live in is basically a safe, stable and secure place in which most people are fundamentally good. (r)

It seems that every year there are fewer and fewer truly respectable people, and more and more persons with no morals at all who threaten everyone else.

The "end" is not near. People who think that earthquakes, wars, and famines mean God might be about to destroy the 


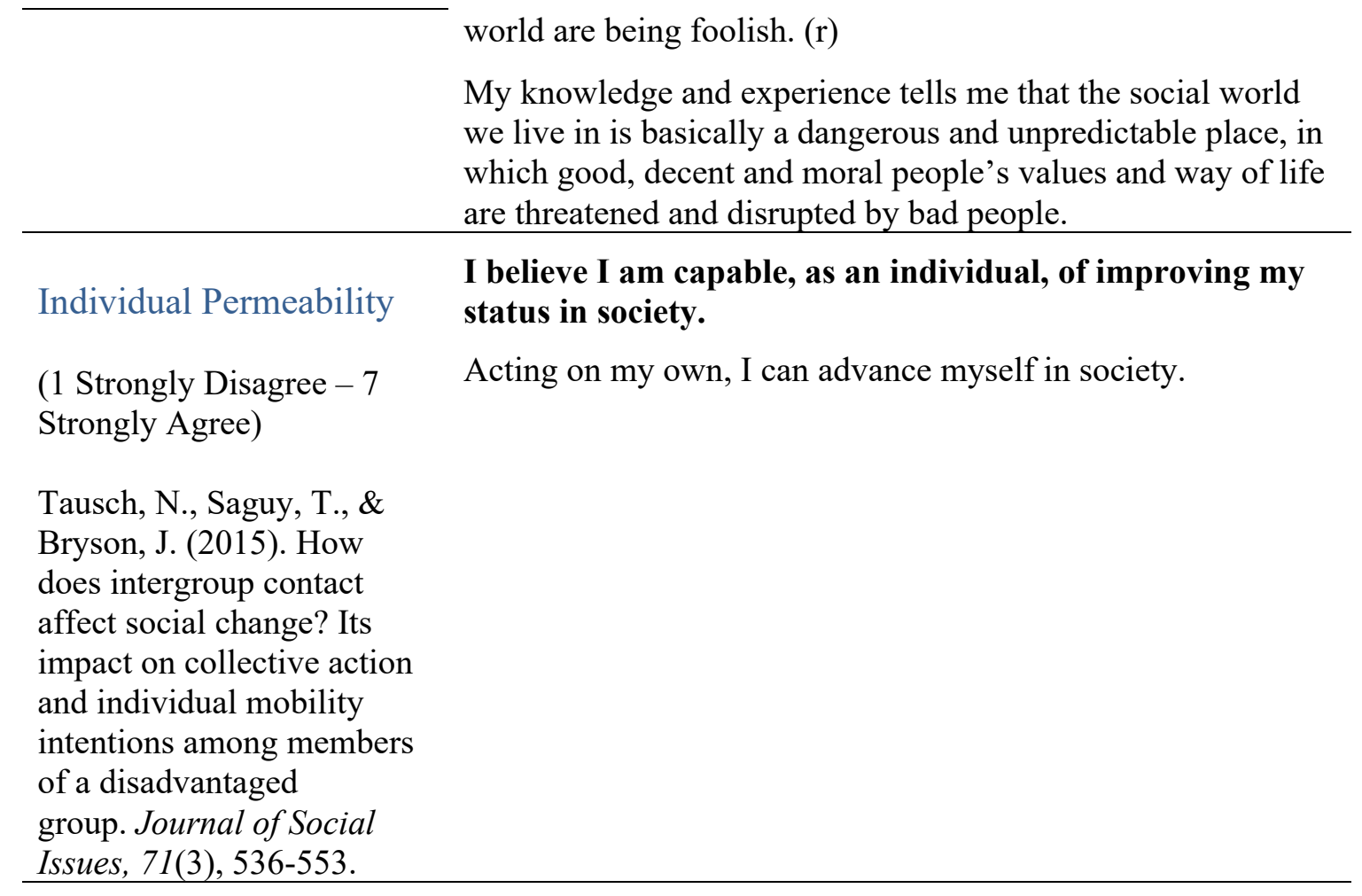

People who are very successful deserve all the rewards they

Tall Poppy Attitudes get for their achievements. (r)

(1 Strongly Disagree - 7 Strongly Agree)

Feather, N. T. (1989). Attitudes towards the high achiever: The fall of the tall poppy. Australian Journal of Psychology, 41(3), 239267.

\section{It's good to see very successful people fail occasionally.}

Very successful people often get too big for their boots.

People who are successful in what they do are usually friendly and helpful to others. (r)

At school it's probably better for students to be near the middle of the class than the very top student.

People shouldn't criticise or knock the very successful. (r)

Very successful people who fall from the top usually deserve their fall from grace.

Those who are very successful ought to come down off their pedestals and be like other people.

The very successful person should receive public recognition for his/her accomplishments. (r)

\section{People who are "tall poppies" should be cut down to size.}

One should always respect the person at the top. (r)

One ought to be sympathetic to very successful people when they experience failure and fall from their very high positions. (r)

Very successful people sometimes need to be brought down a peg or two, even if they have done nothing wrong. 
Society needs a lot of very high achievers. (r)

People who always do a lot better than others need to learn what it's like to fail.

People who are right at the top usually deserve their high position. (r)

It's very important for society to support and encourage people who are very successful. (r)

People who are very successful get too full of their own importance.

Very successful people usually succeed at the expense of other people.

Very successful people who are at the top of their field are usually fun to be with. (r)

Moral Foundations

(Moral Relevance)

(1 Not at all relevant -7

Extremely relevant)

Graham, J., Haidt, J., \&

Nosek, B. A. (2009).

Liberals and conservatives rely on different sets of moral foundations. Journal of Personality and Social Psychology, 96, 1029-1046.

\section{Whether or not someone suffered emotionally}

Whether or not some people were treated differently than others

Whether or not someone's action showed love for his or her country

Whether or not someone showed a lack of respect for authority

Whether or not someone violated standards of purity and decency

Whether or not someone cared for someone weak or vulnerable

Whether or not someone acted unfairly

Whether or not someone did something to betray his or her group

Whether or not someone conformed to the traditions of society

Whether or not someone did something disgusting

Whether or not someone was cruel

Whether or not someone was denied his or her rights

Whether or not someone showed a lack of loyalty

Whether or not an action caused chaos or disorder

Whether or not someone acted in a way that God would approve of

Compassion for those who are suffering is the most crucial virtue.

When the government makes laws, the number one
Moral Foundations

(Moral Judgement) 
(1 Strongly Disagree - 7

Strongly Agree)

Graham, J., Haidt, J., \& Nosek, B. A. (2009). Liberals and conservatives rely on different sets of moral foundations. Journal of Personality and Social Psychology, 96, 1029-1046. principle should be ensuring that everyone is treated fairly.

I am proud of my country's history.

Respect for authority is something all children need to learn.

People should not do things that are disgusting, even if no one is harmed.

One of the worst things a person could do is hurt a defenceless animal.

Justice is the most important requirement for a society.

People should be loyal to their family members, even when they have done something wrong.

Men and women each have different roles to play in society.

I would call some acts wrong on the grounds that they are unnatural.

It can never be right to kill a human being.

I think it's morally wrong that rich children inherit a lot of money while poor children inherit nothing.

It is more important to be a team player than to express oneself.

If I were a soldier and disagreed with my commanding officer's orders, I would obey anyway because that is my duty.

Chastity is an important and valuable virtue.

I love my country.

Patriotism

I am proud to be a New Zealander.

(1 Strongly Disagree - 7

Strongly Agree)

Kosterman, R., \& Feshbach, S. (1989). Toward a measure of patriotic and nationalistic attitudes.

Political Psychology, 10, 257-274.
In a sense, I am emotionally attached to my country and emotionally affected by its actions.

Although at times I may not agree with the government, my commitment to New Zealand always remains strong.

I feel a great pride in that land that is our New Zealand.

It is not important for me to serve my country. (r)

When I see the New Zealand flag flying I feel great.

The fact that I am a New Zealander is an important part of my identity.

It is not constructive for one to develop an emotional attachment to his/her country. (r)

In general, I have very little respect for New Zealanders. (r) 
It bothers me to see children made to pledge allegiance to the flag or sing the national anthem or otherwise induced to adopt such strong patriotic attitudes. $(\mathrm{r})$

New Zealand is just an institution, big and powerful yes, but just an institution. (r)

\section{Nationalism}

(1 Strongly Disagree - 7

Strongly Agree)

Kosterman, R., \& Feshbach, S. (1989). Toward a measure of patriotic and nationalistic attitudes. Political Psychology, 10, 257-274.
In view of New Zealand's moral and material superiority, it is only right that we should have the biggest say in deciding United Nations policy.

The first duty of every young New Zealander is to honour national New Zealand history and heritage.

The important thing for the New Zealand foreign aid program is to see to it that New Zealand gains a political advantage.

Other countries should try to make their government as much like ours as possible.

Generally, the more influence New Zealand has on other nations, the better off they are.

Foreign nations have done some very fine things but they are still not as good as New Zealand.

(original) Foreign nations have done some very fine things but it takes New Zealand to do things in a big way.

It important that New Zealand win in international sporting competition like the Olympics.

It is really not important that New Zealand be number one in whatever it does. (r)

To believe in God.

Civic and Ethnic National Character

To vote in elections.

To treat people of all races and backgrounds equally.

(1 Not Important - 7 Very Important)

To have Māori or European ancestry. (NZAVS item)
Citrin, J., Reingold, B., \& Green, D.P. (1990).

American identity and the politics of ethnic change. Journal of Politics, 52, 1124-1154.

Some people say that there are certain qualities that make someone a 'true' New Zealander. Others say there are not. How important do you personally think the following qualities are for 
being a 'true' New

Zealander?

\section{Overlap Character Items}

(Items included within both Civic and Ethnic National Character and NZ-specific National Character full scales)

\section{NZ-specific National} Character

(1 Not Important - 7 Very Important)

Sibley, C. G., Hoverd, W. J., \& Liu, J. H. (2011). Pluralistic and monocultural facets of New Zealand national character and identity. New Zealand Journal of Psychology, 40, 19-29.

Some people say that there are certain qualities that make someone a 'true' New Zealander. Others say there are not. How important do you personally think the following qualities are for being a 'true' New Zealander?
To try to get ahead on one's own efforts.

\section{To have New Zealand citizenship.}

\section{To be able to speak English.}

To defend New Zealand when it is criticized.

To respect New Zealand's political institutions and laws.

To be friendly and approachable.

To be friendly.

To respect other cultures and ethnic groups.

To be environmentally friendly.

\section{To be egalitarian - believe in equality.}

Treat all people of all races equally.

To be tolerant of other cultures.

\section{To have a 'clean and green' attitude.}

To be a hard worker.

To appreciate nature and the outdoors.

To support a nuclear-free New Zealand.

To be innovative and creative.

To like beer and rugby.

To enjoy sports.

To like rugby.

To feel a sense of rivalry with Australia.

To support New Zealand sports teams.

To have strong ties with The Commonwealth.

\section{To have a knowledge of Māori culture.}

To know about the Treaty of Waitangi.

To identify with Māori culture.

To have a knowledge of New Zealand history.

To know at least a few Māori words.

To have an opinion about the Treaty of Waitangi. 
To identify with Pacific Nations cultures.

To be born in New Zealand.

To have lived in New Zealand for most of one's life.

To have a parent born in New Zealand.

To have a New Zealand accent.

To be patriotic.

To recognize the New Zealand flag.

To know the New Zealand national anthem.

Identification with All Humanity

(1 Not at all -5 Very much)

McFarland, S., Webb, M., \& Brown, D. (2012). All humanity is my ingroup: A measure and studies of identification with all humanity. Journal of Personality and Social Psychology, 103, 830-853.
How close do you feel to each of the following groups? (1 Not at all close -5 Very close)

- People in my community

- New Zealanders

- People all over the world

How often do you use the word "we" to refer to the following groups of people? ( 1 Almost never -5 Very often)

- People in my community

- New Zealanders

- People all over the world

How much would you say you have in common with the following groups? ( 1 Almost nothing in common -5 Very much in common)

- People in my community

- New Zealanders

- People all over the world

Sometimes people think of those who are not a part of their immediate family as "family." To what degree do you think of the following groups of people as "family"?

- People in my community

New Zealanders

People all over the world

How much do you identify with (that is, feel a part of, feel love toward, have concern for) each of the following?

People in my community

New Zealanders

People all over the world

How much would you say you care (feel upset, want to help) when bad things happen to:

People in my community

New Zealanders

People all over the world 


\section{How much do you want to be:}

- A responsible citizen of my community

- A responsible New Zealand citizen

- A responsible citizen of the world

\section{How much do you believe in:}

Being loyal to my community

- Being loyal to New Zealand

- Being loyal to all mankind

When they are in need, how much do you want to help:

- People in my community

- New Zealanders

- People all over the world

\section{Left-Wing}

Authoritarianism

(1 Strongly Disagree -7

Strongly Agree)

Costello, T. H., Bowes, S., Stevens, S. T., Waldman, I., Tasimi, A., \& Lilienfeld, S. O. (2020). Clarifying the structure and nature of leftwing authoritarianism. Journal of Personality and Social Psychology.
The rich should be stripped of their belongings and status.

Rich people should be forced to give up virtually all of their wealth.

\section{If I could remake society, I would put people who} currently have the most privilege at the very bottom.

New Zealand would be much better off if all of the rich people were at the bottom of the social ladder.

When the tables are turned on the oppressors at the top of society, I will enjoy watching them suffer the violence that they have inflicted on so many others.

Most rich Wall Street executives deserve to be thrown in prison.

Constitutions and laws are just another way for the powerful to destroy our dignity and individuality.

The current system is beyond repair.

We need to replace the established order by any means necessary.

Political violence can be constructive when it serves the cause of social justice.

Certain elements in our society must be made to pay for the violence of their ancestors.

If a few of the worst conservative politicians were assassinated, it wouldn't be the end of the world.

I would prefer a far-left leader with absolute authority over a right-wing leader with limited power.

Schools should be required by law to teach children about our country's history of racism, classism, sexism, and homophobia.

Anyone who opposes gay marriage must be homophobic. 
Deep down, just about all conservatives are racist, sexist, and homophobic.

People are truly worried about terrorism should shift their focus to the nutjobs on the far-right.

The "old-fashioned ways" and "old-fashioned values" need to be abolished.

Radical and progressive moral values can save our society.

\section{All political conservatives are fools.}

I cannot imagine myself becoming friends with a political conservative.

Conservatives are morally inferior to liberals.

It is important that we destroy the West's nationalist, imperialist values.

I try to expose myself to conservative news sources. (r)

There is nothing wrong with Bible camps. (r)

I hate being around non-progressive people.

Classroom discussions should be safe places that protect students from disturbing ideas.

University authorities are right to ban hateful speech from campus.

I should have the right not to be exposed to offensive views.

To succeed, a workplace must ensure that its employees feel safe from criticism.

We must line up behind strong leaders who have the will to stamp out prejudice and intolerance.

When we spend all of our time protecting the right to "free speech" we're protecting the rights of sexists, racists, and homophobes at the cost of marginalized people.

I am in favor of allowing the government to shut down rightwing internet sites and blogs that promote nutty, hateful positions.

Colleges and universities that permit speakers with intolerant views should be publicly condemned.

Getting rid of inequality is more important than protecting the so-called "right" to free speech.

Right-wing talk radio, and other conservative media outlets should be prohibited from broadcasting their hateful views.

Even books that contain racism or racial language should not be censored. (r) 
I don't support shutting down speakers with sexist, homophobic, or racist views. (r)

Neo-Nazis ought to have a legal right to their opinions. (r)

People trust scientists a lot more than they should. (r)

Science Credibility

(1 Strongly Disagree - 7

Strongly Agree)

Hartman, R. O., Dieckmann, N. F., Sprenger, A. M., Stastny, B. J., \& DeMarree, K. G. (2017). Modeling attitudes toward science: development and validation of the credibility of science scale. Basic and Applied Social Psychology, 39(6), 358-371.

\section{Trust in Science}

(1 Strongly Disagree - 7 Strongly Agree)

Nisbet, E. C., Cooper, K. E., \& Garrett, R. K. (2015). The partisan brain: How dissonant science messages lead conservatives and liberals to (dis) trust science. The ANNALS of the American Academy of Political and Social Science, 658(1), 36-66.
I have a high degree of confidence in the scientific community.

Information from the scientific community is trustworthy. I trust the scientific community to do what is right.

The scientific community often does not tell the public the truth. (r)

I am suspicious of the scientific community. (r) 


\section{Chapter 4 -- NZAVS Economic Decisions Project}

This technical document describes the methodology for the NZAVS Economic Decisions Project. The project is an online behavioural study that runs alongside the main New Zealand Attitudes and Values Study questionnaire and sampling approximately 1000 participants from the NZAVS to particate in additional online experiments.

The project uses a series of real-time one-shot anonymised incentivised economic games to tap into participants' social preferences. The study's methodology was initially adapted from Peysakhovich, Nowak, \& Rand (2014), but has since expanded to include more behavioural measures. The games are designed to measure social preferences like altruism, trust, reciprocity, cooperation, norm-enforcing punishment, conformity, and rule following. The study was designed by Professor Chris Sibley, Professor Ananish Chaudhuri, Professor Quentin Atkinson, and PhD student Scott Claessens.

This chapter was written by Scott Claessens and should be cited as:

Claessens, S. (2020). The NZAVS Economic Decisions Project. NZAVS Technical Documents.

\section{Study Procedure}

The study is coded using oTree software (Chen, Schonger, \& Wickens, 2016). In the study, participants who agree to take part are booked into an hour-long online session on a midweek evening. As the study is conducted in real time, participants must be present at the beginning of the session and focused throughout. After clicking the oTree link to begin the study, participants sequentially work through a series of eight one-shot economic games in a randomised order (see Data Collection and Economic Games Measures for more information). For each game, they first read through instructions for the game, then complete a comprehension question to check their understanding, and then submit their decisions for the game. Participants are given the correct answer after answering the comprehension question. For the main decisions, we used the strategy method, where participants submit decisions for all roles in multi-role games. In the games, participants played for "points" which were converted to NZD at a rate of 1 point $=\$ 0.035$.

Once participants submit their decisions for all eight games, they must wait for everyone else in the session to complete the games too, and then (in real time) the computer randomly matches all participants in the session into groups and executes the decisions that the participants made. These decisions ultimately determine the participants' payment for the study. Participants earn a show-up fee of \$20 for taking part, plus anywhere between $\$ 10$ and $\$ 35$ based on the decisions they make in the study. Name and bank account details are collected at the end of the study. For security purposes, this information is encrypted while stored online and later decrypted on a local computer for payment.

Participants have a 55 minute time limit to complete the games. As the study involves realtime matching between participants, participants cannot pause their completion of the questionnaire and return to it later, as other participants would be left waiting to match with them. If participants take longer than 55 minutes, the software skips them ahead to the waiting lobby and treats them as if they were simulated players (i.e., submitting median 
responses from past research). Timeouts are still paid the $\$ 20$ show-up fee, but no bonus payment.

Ethical approval for this project was given on $16^{\text {th }}$ July 2018 for three years (ref: 021666), with an ethics amendment for the second wave of data collection approved on $4^{\text {th }}$ September 2020 .

\section{Data Collection}

Wave 1 (2019)

In the first wave of data collection for this project, we included the following economic games: Public Goods Game, Dictator Game, Trust Game, Stag Hunt Game, Ultimatum Game, Third-Party Punishment Game, Second-Party Punishment Game, and StagHunt with Punishment Game (see Economic Games Measures for more information).

We included participants in our sample frame who: had completed Wave 4 of the NZAVS ( $n=12,189)$; had also completed Wave 9 and/or Wave $10(n=8,095)$; had not subsequently withdrawn from the NZAVS at the time of sampling $(n=7,833)$; had consistently indicated at Wave 9 and 10 that they would be willing to participate in an additional online study $(n=4,181)$; had a valid email address $(n=4,040)$; were living in New Zealand $(n=3,955)$; were younger than 70 at the time of sampling $(n=3,374)$; and had a valid cell or landline number $(n=3,345)$. Of these 3,345 participants, we attempted to contact 3,063 about an additional study involving "economic decision-making in groups". We managed to successfully contact 2,731 about the study.

Participants were contacted initially by phone and then, if they agreed to participate, over email in the days leading up to their allocated study session. 1,662 participants did not participate and 24 participants either were not paid or did not complete the study in time, resulting in a final sample of 1,045 participants (631 females; age $M=50.5$ years, $S D=12$ years).

The first wave of data collection for this project was conducted between $18^{\text {th }}$ February and $25^{\text {th }}$ July 2019 (though we took a break mid-way through data collection due to the Christchurch terrorist attack in March 2019). Study sessions contained between 14 and 97 participants, and were conducted on midweek evenings (between 6pm and 8pm). Participants knew that they were playing with others recruited from the New Zealand Attitudes and Values Study, but were not aware of how many people were present in any particular session. On average, participants took 22 minutes to complete the eight economic games $(\mathrm{SD}=7.49$ mins, range $=6-52$ mins; Figure 1). 


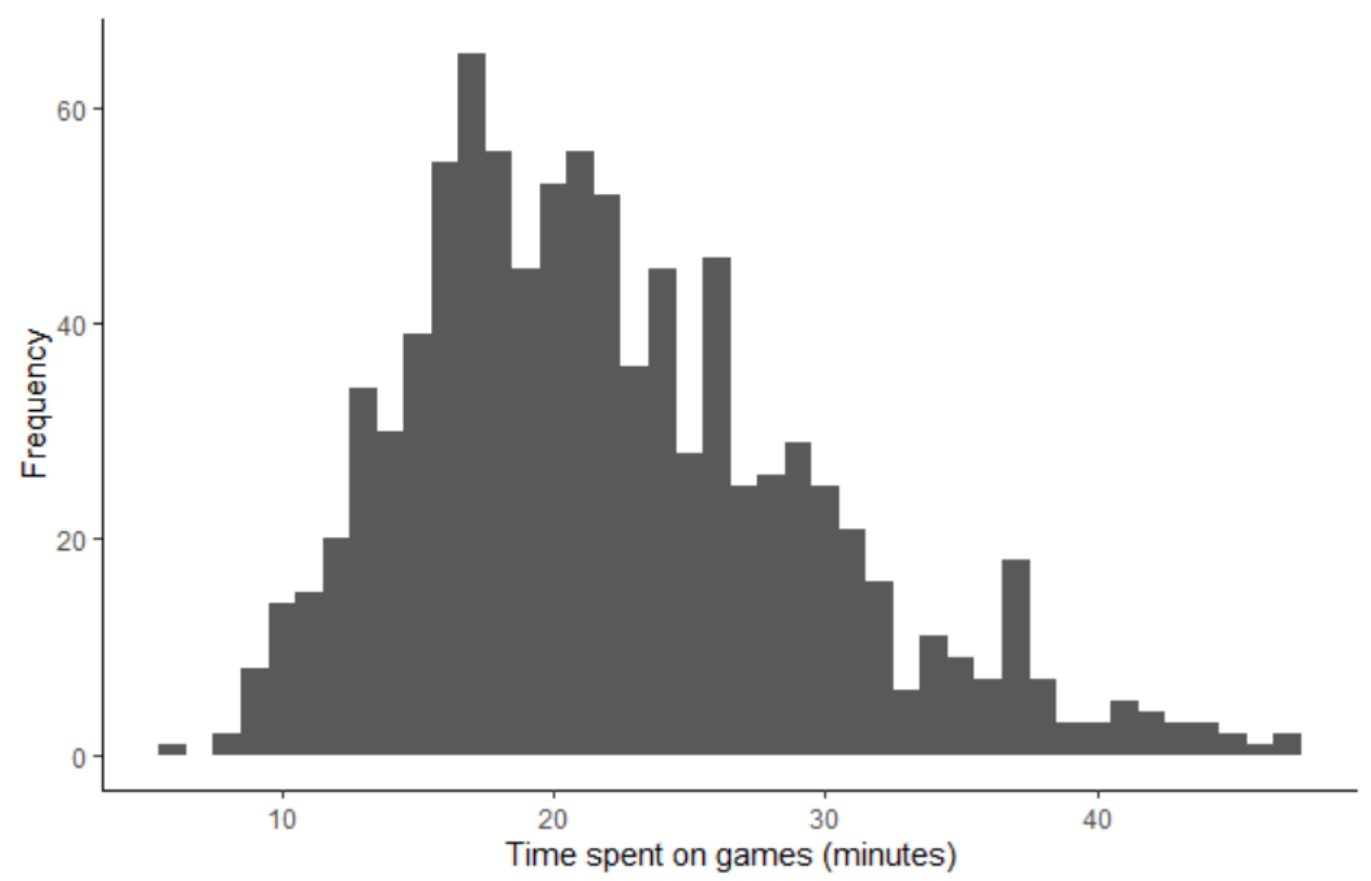

Figure 1. Time spent on economic games in Wave 1.

Participants were paid a fixed \$20 NZD show-up fee, plus a bonus payment of between $\$ 10$ - $35(\mathrm{M}=\$ 25.17, \mathrm{SD}=\$ 2.47$; Figure 2$)$ depending on the decisions of themselves and others. In total, we spent $\$ 41,826$ on participant reimbursements in Wave 1.

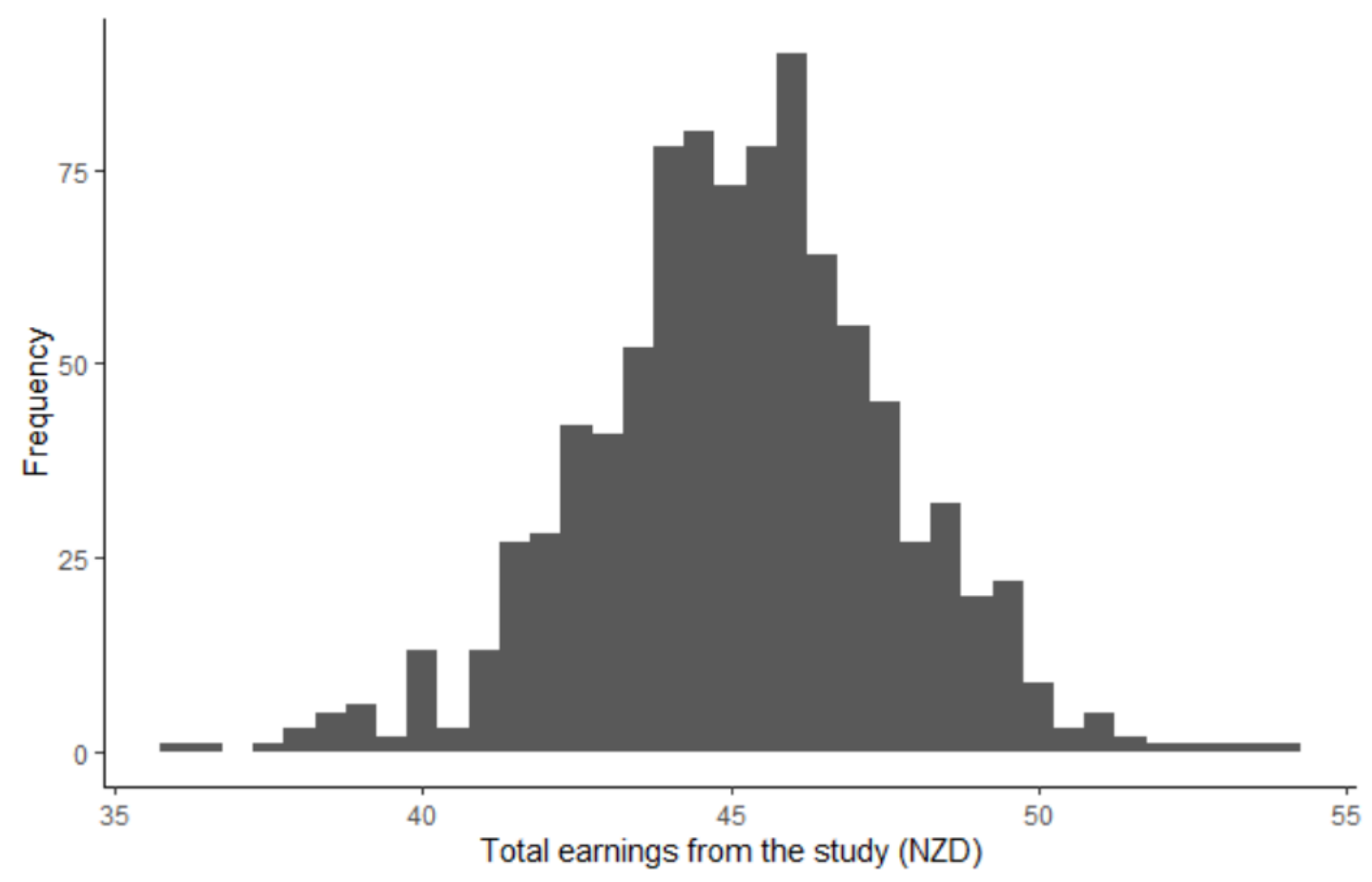

Figure 2. Total earnings from the study (NZD) in Wave 1. 
Wave 2 (2020)

In the second wave of data collection for this project, we included the following economic games: Public Goods Game, Dictator Game, Trust Game, Ultimatum Game, ThirdParty Punishment Game, Second-Party Punishment Game, Rule Following Task, and BEAST (see Economic Games Measures for more information). In other words, we swapped out the Stag Hunt Game and Stag-Hunt with Punishment Game for the Rule Following Task and BEAST.

In the second wave, we attempted to contact every participant who had participated in the first wave and had not since withdrawn from the NZAVS Economic Decisions Project or the NZAVS more generally. This resulted in a sample frame with 997 participants. In this wave, we did not call participants directly but instead emailed them with another invitation to participate in the same study. Of the participants we emailed, 636 participants completed the second wave (64\% retention rate). 5 of these participants did not complete the study in time, resulting in a final sample of 631 participants (414 females; age $M=50.6$ years, $S D=12.5$ years).

The second wave of data collection was conducted between $19^{\text {th }}$ October and $11^{\text {th }}$ November 2020. Study sessions contained between 26 and 128 participants, and were again conducted on midweek evenings (between $6 \mathrm{pm}$ and $8 \mathrm{pm}$ ). On average, participants took 24 minutes to complete the eight economic games $(\mathrm{SD}=8$ mins, range $=9$ - 55 mins; Figure 3 ).

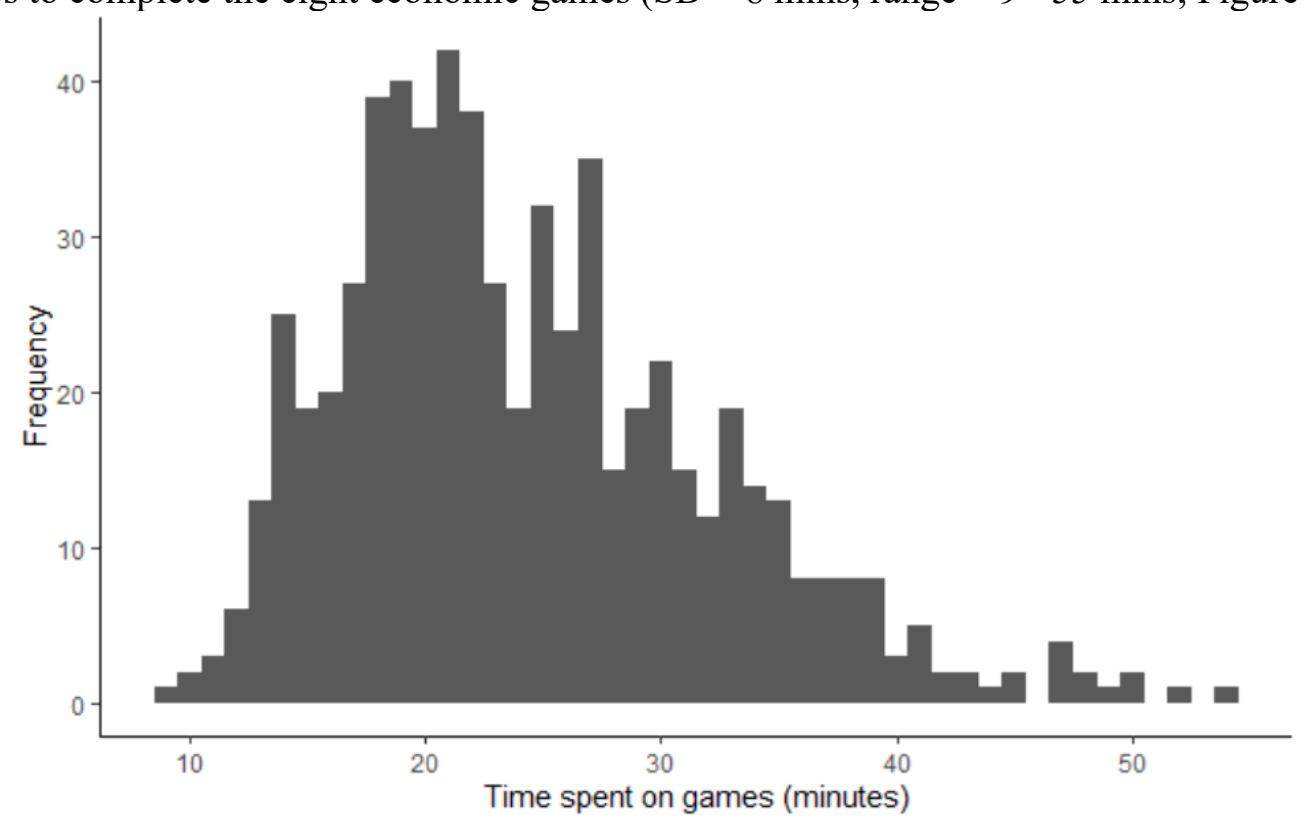

Figure 3. Time spent on economic games in Wave 2.

Participants were paid a fixed \$20 NZD show-up fee, plus a bonus payment of between $\$ 10$ $35(\mathrm{M}=\$ 21.39, \mathrm{SD}=\$ 2.63$; Figure 4) depending on the decisions of themselves and others. In total, we spent $\$ 26,219$ on participant reimbursements in Wave 2. 


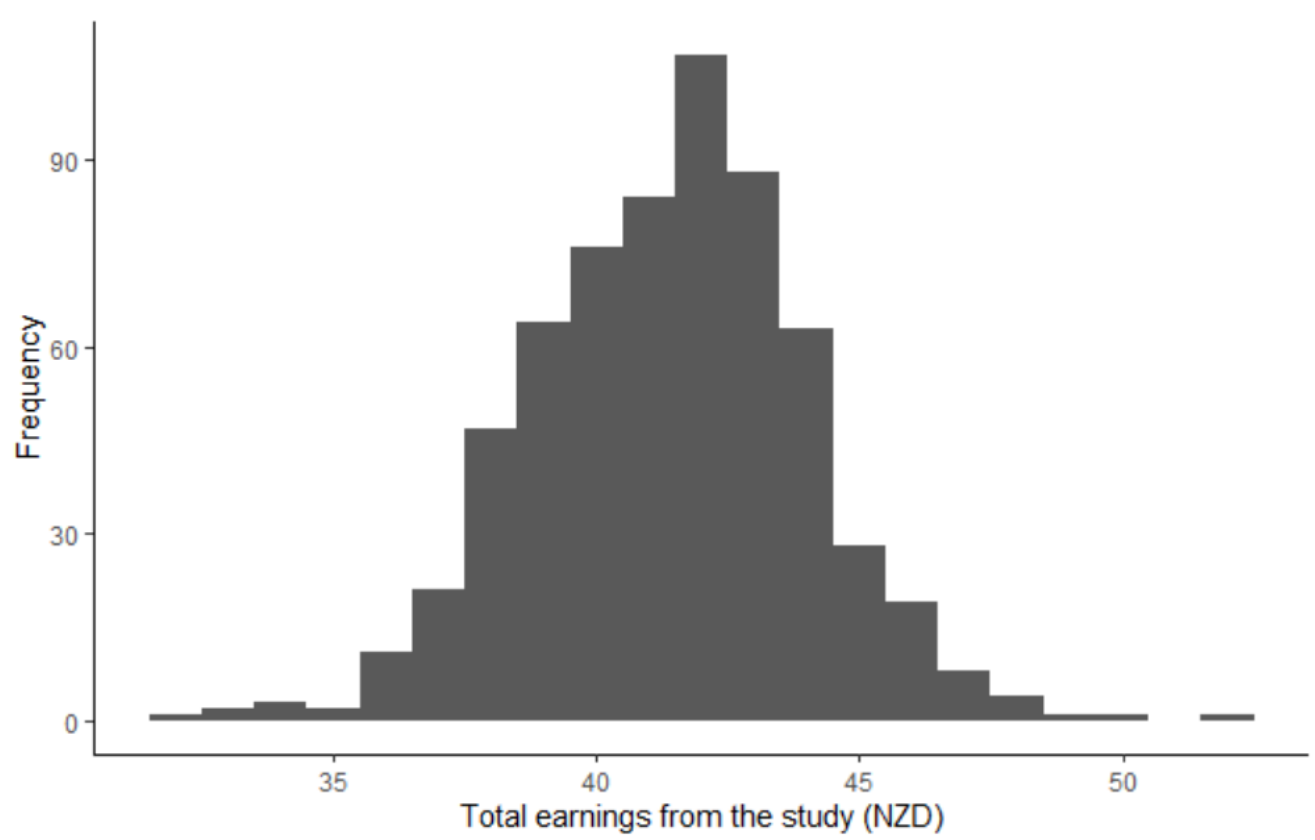

Figure 4. Total earnings from the study (NZD) in Wave 2.

\section{Economic Game Measures}

\section{Public Goods Game}

The Public Goods Game is a measure of collective action and cooperation in social dilemmas. This game was copied verbatim from Peysakhovich et al. (2014). This variable loads onto the "cooperation" latent variable. We used this game in both Wave 1 (egame.PGG.T10) and Wave 2 (egame.PGG.T11).

On the first page, participants read the following instructions:

In this task you are matched with three other people.

All of you start with 100 points.

Each of you will choose how much of these 100 points to contribute to a group project, and how much to keep for yourself.

All individuals decide at the same time.

All contributed points are doubled and split evenly among the group.

Thus, for every 2 points you contribute, you only receive one point from the project. So contributing more points always increases your groups' total payoff, but you always end up with more money if you contribute less.

On the next page, participants answer the following comprehension question (correct answer is $\mathrm{C})$ :

What contribution BY YOU maximises payoffs for the GROUP? What about for yourself?

(A) Contributing 100 maximises payoffs for both the group and myself

(B) Contributing 0 maximises payoffs for both the group and myself

(C) Contributing 100 maximises payoffs for the group but contributing 0 maximises my own payoff

On the final page, participants make their decision: 
How many points do you wish to contribute to the group project? [0 - 100]

In Wave 1, participants contributed an average of 49 points $(\mathrm{SD}=32$ points, range $=0$ 100 points; Figure 5). In Wave 2, participants contributed an average of 50 points $(\mathrm{SD}=31$ points, range $=0-100$ points; Figure 6 ).

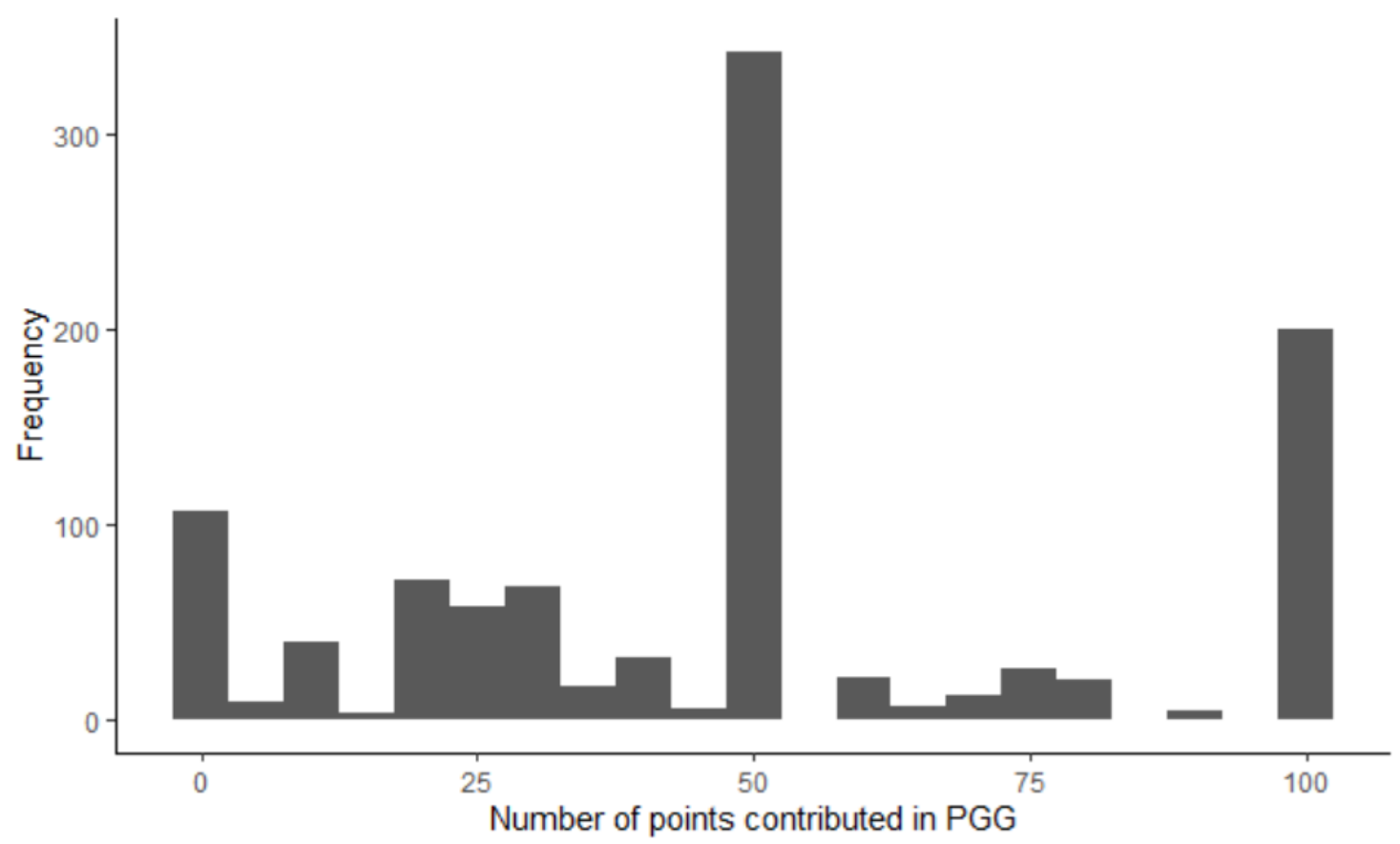

Figure 5. Number of points contributed in the Public Goods Game in Wave 1.

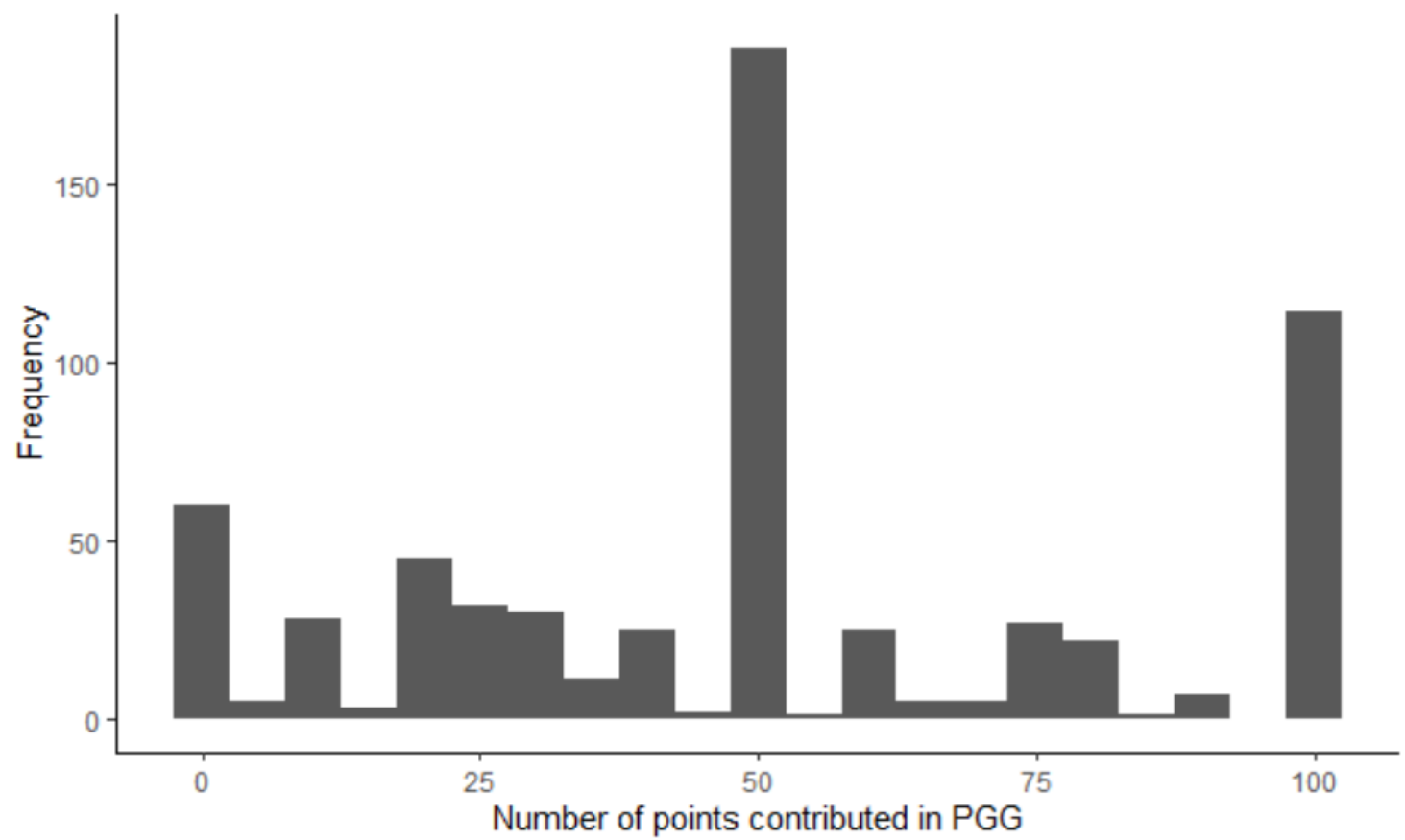

Figure 6. Number of points contributed in the Public Goods Game in Wave 2. 


\section{Dictator Game}

The Dictator Game is a measure of altruistic giving. This game was copied verbatim from Peysakhovich et al. (2014). This variable loads onto the "cooperation" latent variable. We used this game in both Wave 1 (egame.DG.T10) and Wave 2 (egame.DG.T11).

On the first page, participants read the following instructions:

In this task you are matched with one other person.

One of you will be Person A, one of you will be Person B.

Person A starts with 100 points, and Person B starts with 0 points.

This task has one single decision: Person A will choose how many of the 100 points to transfer to Person $B$.

Person B will get the number of points Person A transfers, and Person A will get to keep the rest.

On the next page, participants answer the following comprehension question (correct answer is A):

What happens if Person A transfers 20 points?

(A) A keeps 80 points and $B$ gets 20 points

(B) Both get 20 points

On the final page, participants make their decision:

If you are Person A, how many points will you transfer to Person B? [0 - 100]

In Wave 1 , participants gave an average of 38 points $(\mathrm{SD}=20$ points, range $=0-100$ points; Figure 7). In Wave 2, participants gave an average of 36 points $(\mathrm{SD}=20$ points, range $=0-$ 100 points; Figure 8).

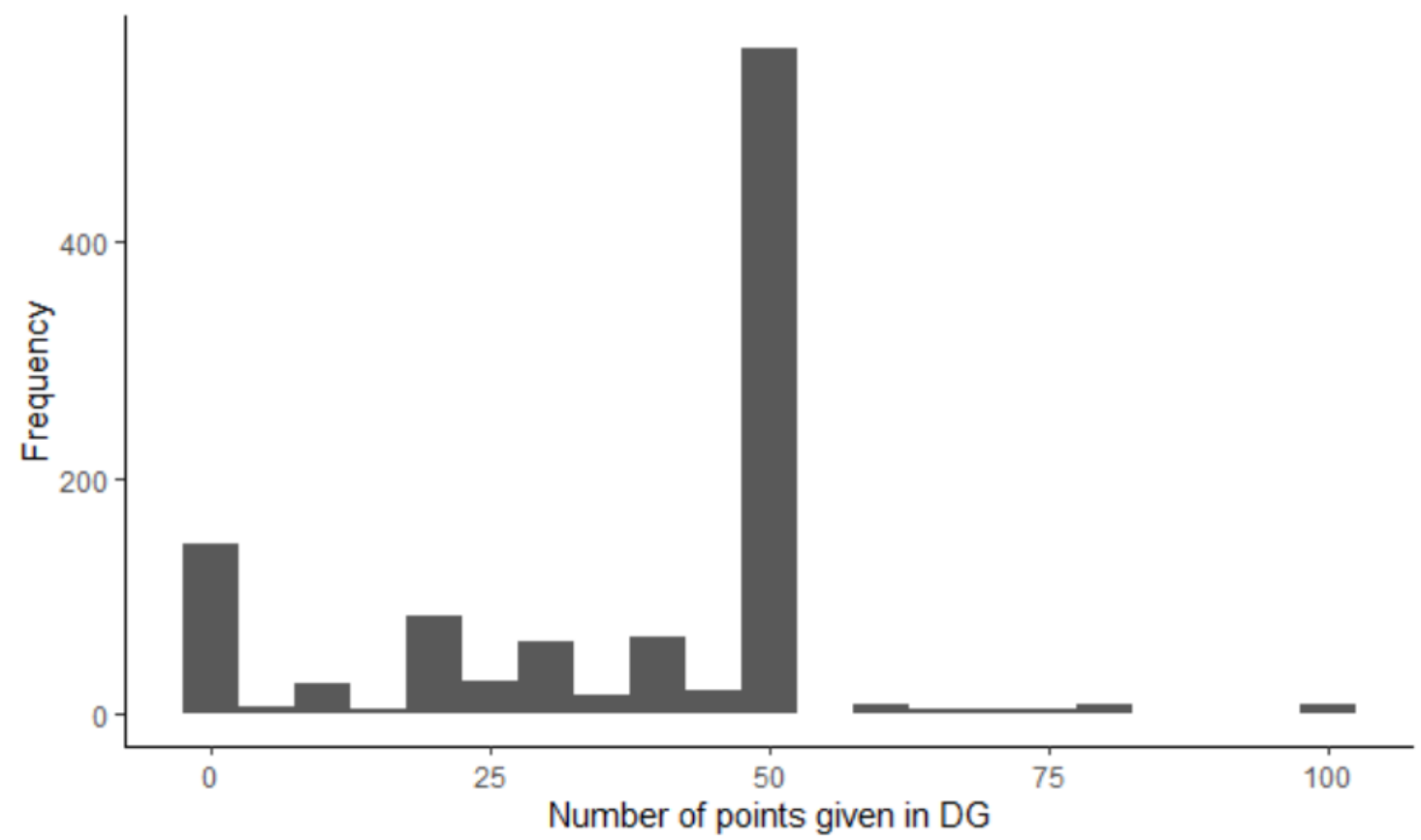

Figure 7. Number of points given in the Dictator Game in Wave 1. 


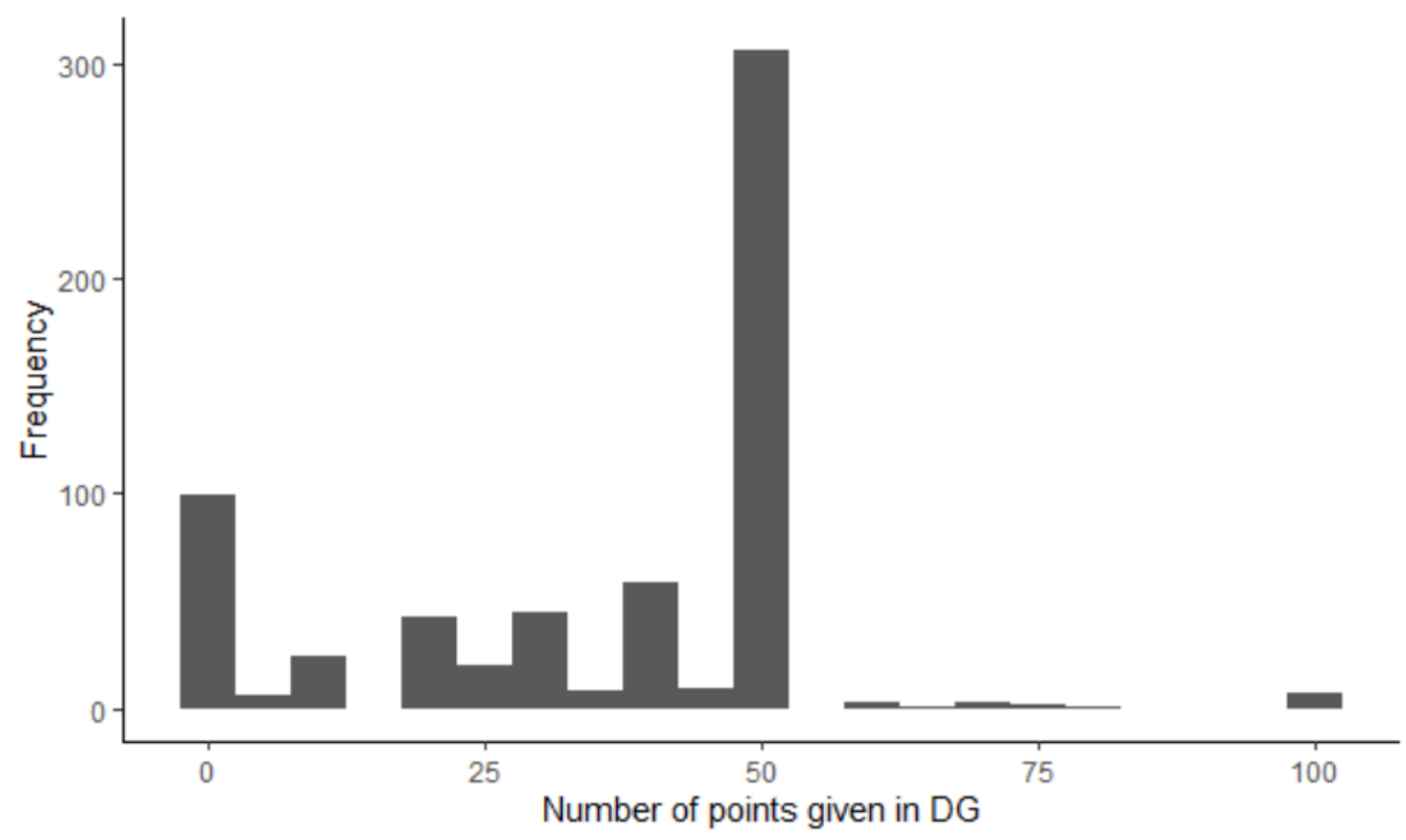

Figure 8. Number of points given in the Dictator Game in Wave 2.

\section{Trust Game}

The Trust Game is a measure of trust and reciprocal giving. This game was copied verbatim from Peysakhovich et al. (2014). This game creates two variables as there are two roles: the "first move" initial giving decision, and the "second move" returning decision. These variables both load onto the "cooperation" latent variable. We used this game in both Wave 1 (egame.TG1.T10 / egame.TG2.T10) and Wave 2 (egame.TG1.T11 / egame.TG2.T11).

On the first page, participants read the following instructions:

In this task you are matched with one other person.

One of you will be Person A, the other will be Person B.

Both of you start with 50 points.

First, Person A makes a choice, then Person B responds.

1. Person A can choose to transfer their 50 points or not. If Person A transfers 50 points then it is TRIPLED and given to Person B (so Person B now has 200 points).

2. Person $B$ can then choose how many of the points they want to transfer back to Person $A$ (between 0 and 150). This latter amount is not tripled.

On the next page, participants answer the following comprehension question (correct answer is A):

What happens if Person A transfers 50 points and Person B transfers back 25 points?

(A) Person A earns 25 points, Person B earns 175 points

(B) Person A earns 50 points, Person B earns 50 points

(C) Person A earns 100 points, Person B earns 100 points

On the next page, participants make their decision in the Person A (giving) role:

If you are Person A, do you want to transfer your 50 points to Person B?

- No transfer 
On the final page, participants make their decision in the Person B (returning) role:

If you are Person B and Person A transfers you 50 points (which is tripled to 150), how many points do you want to transfer back to A? [0 - 150]

In Wave 1, 733 / 1,045 participants (70\%) transferred the 50 points in the Person A role, and participants returned an average of 77 points in the Person B role $(\mathrm{SD}=29$ points, range $=0-150$ points; Figure 9). In Wave 2, 454 / 636 participants $(71 \%)$ transferred the 50 points in the Person A role, and participants returned an average of 77 points in the Person B role $(\mathrm{SD}=32$ points, range $=0-150$ points; Figure 10$)$.

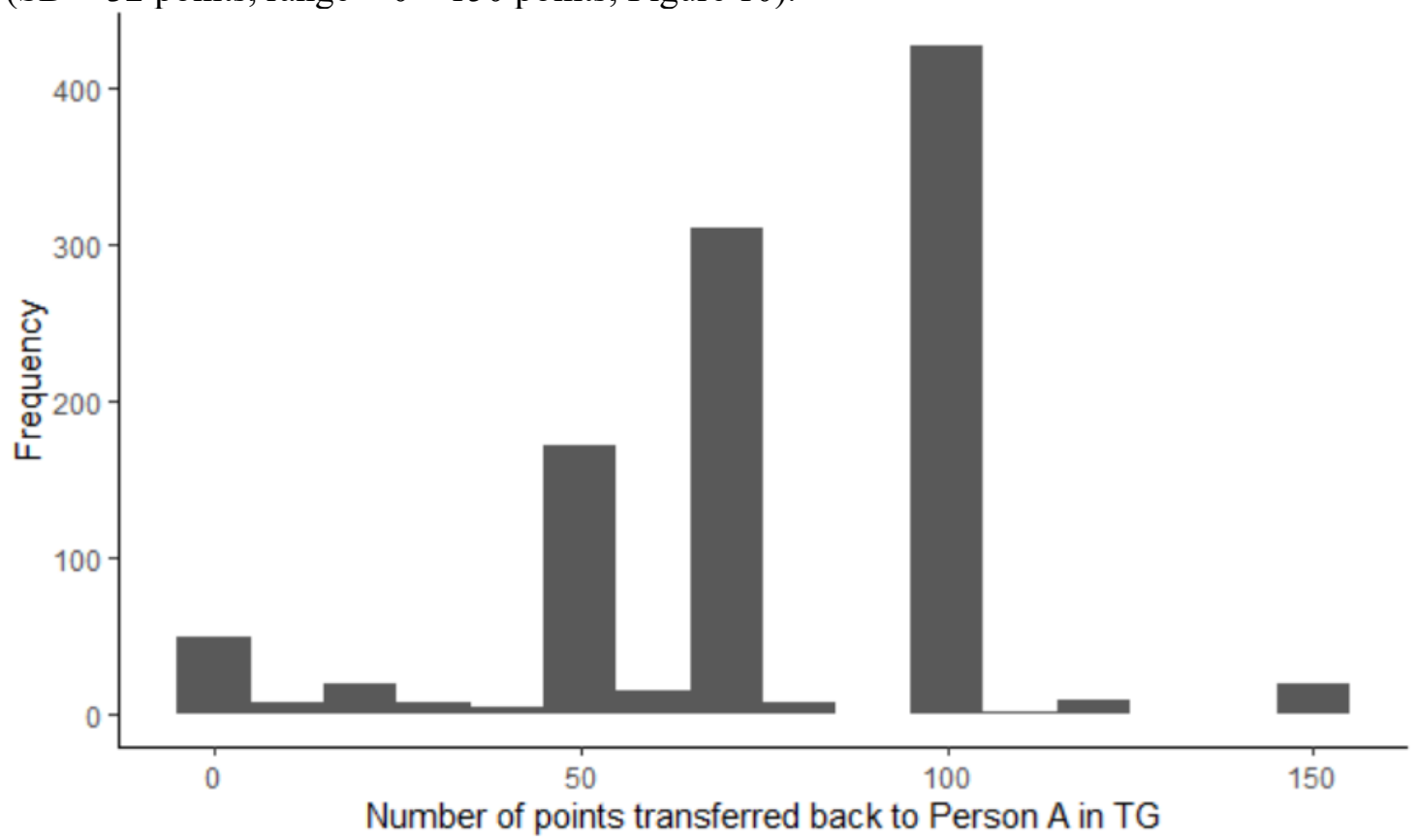

Figure 9. Number of points transferred back to Person A in the Trust Game in Wave 1. 


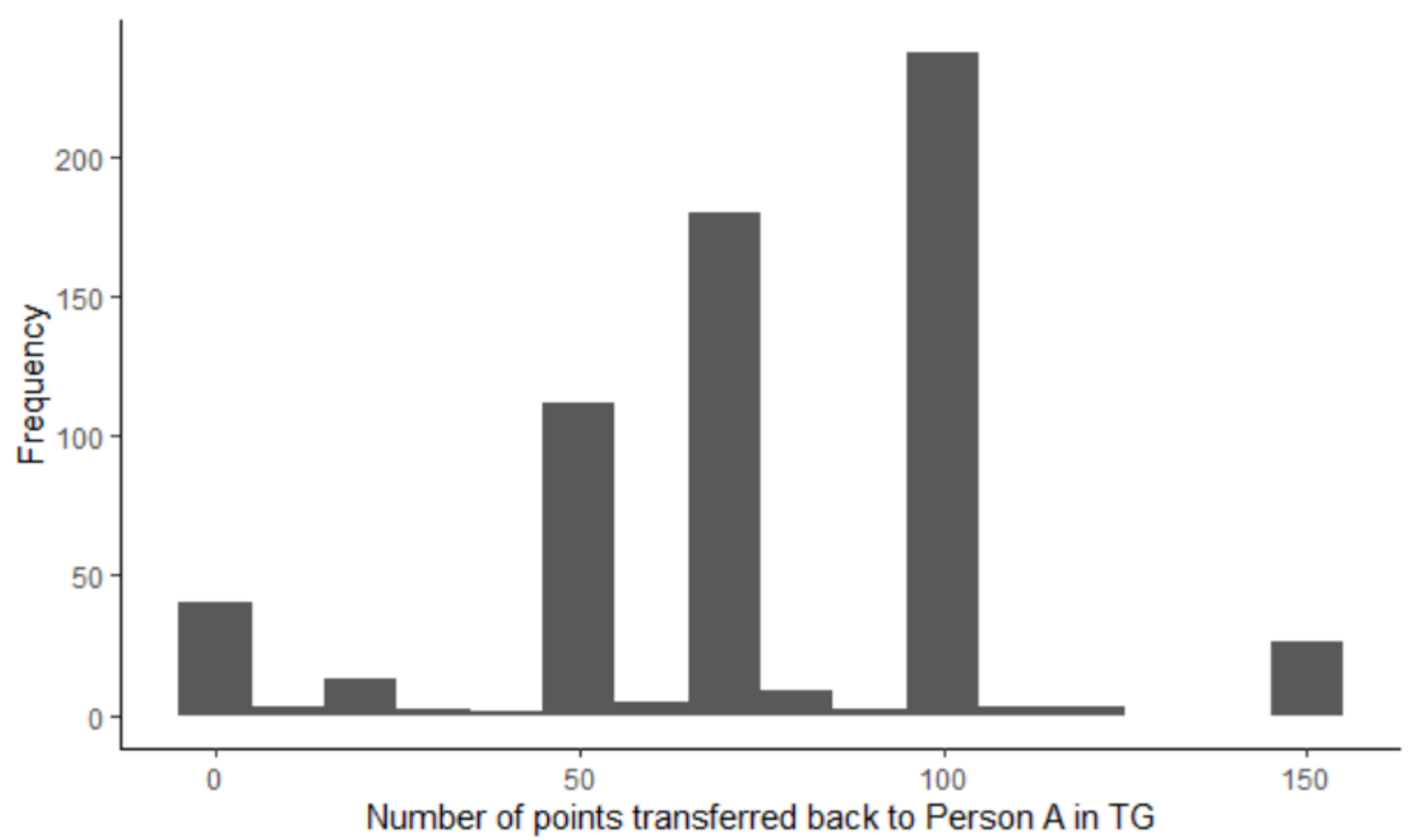

Figure 10. Number of points transferred back to Person A in the Trust Game in Wave 2.

\section{Stag Hunt Game}

The Stag Hunt Game is a measure of coordination. This game was adapted from the Public Goods Game by our research team, changing the payoff matrix to create a coordination problem rather than a social dilemma. This variable loads onto the "cooperation" latent variable. We only used this game in Wave 1 (egame.SH.T10).

On the first page, participants read the following instructions:

In this task you are matched with three other people.

All of you start with 100 points.

Each of you will choose whether to contribute 30 points to a group project.

All individuals decide at the same time.

If all people contribute, the group project is successful. In this case, all contributed points will be doubled and split evenly among the group.

If only one, two, or three people contribute, the group project is not successful, and all the points in it are lost.

On the next page, participants answer the following comprehension question (correct answer is $\mathrm{C})$ :

If you contribute 30 points to the group project, but no one else does, how many points do you end this task with?

(A) 130 points (100 start +30$)$

(B) 100 points (100 start +0$)$

(C) 70 points (100 start - 30)

On the final page, participants make their decision:

Will you contribute 30 points to the group project?

- Contribute 30 points

- Do not contribute 30 points 
In Wave 1, $951 / 1,045$ participants (91\%) contributed 30 points to the group project.

\section{Ultimatum Game}

The Ultimatum Game is a measure of cooperation, fairness, and altruistic punishment. This game was copied verbatim from Peysakhovich et al. (2014). This game creates two variables as there are two roles: the offer decision, and the minimum-acceptable-offer decision. This second variable loads onto the "punishment" latent variable. We used this game in both Wave 1 (egame.UG1.T10 / egame.UG2.T10) and Wave 2 (egame.UG1.T11/ egame.UG2.T11).

On the first page, participants read the following instructions:

In this task you are matched with one other person.

One of you will be Person A, one of you will be Person B.

Person A starts with 100 points and Person B starts with 0 points.

First Person A makes a choice, then Person B responds.

Person A will make an offer on how to split the 100 points with Person $B$.

Person $B$ will either accept or reject this offer. If Person $B$ accepts the offer, then $B$ will get the offered amount and $A$ will keep the rest. If Person $B$ rejects the offer then both individuals will get 0 points.

On the next page, participants answer the following comprehension question (correct answer is $\mathrm{C})$ :

What happens if Person B accepts an offer of 20 points? What happens if Person B rejects this offer?

(A) If $B$ accepts this offer then $A$ gets 80 and $B$ gets 20 , if $B$ rejects then $A$ gets 80 and $B$ gets 0

(B) If $B$ accepts this offer than $A$ gets 0 and $B$ gets 0 , if $B$ rejects then $A$ gets 0 and $B$ gets 0

(C) If $B$ accepts this offer then $A$ gets 80 and $B$ gets 20 , if $B$ rejects then both get 0

On the next page, participants make their decision in the Person A (offer) role:

If you are Person A, what amount will you offer to Person B? [0 - 100]

On the final page, participants make their decision in the Person B (minimum-acceptableoffer) role:

If you are Person $B$, what is your minimum acceptable offer? That is, if the offer that Person A gives you is below this, you would reject and if the offer A gives you is above or equal to this, you would accept. [0 - 100]

In Wave 1 , participants offered 46 points on average $(\mathrm{SD}=13$ points, range $=0-100$ points) and gave a minimum-acceptable-offer of 36 points on average ( $\mathrm{SD}=17$ points, range $=0-100$ points; Figure 11). In Wave 2, participants offered 46 points on average $(\mathrm{SD}=12$ points, range $=0-100$ points) and gave a minimum-acceptable-offer of 34 points on average $(\mathrm{SD}=17$ points, range $=0-100$ points; Figure 12$)$. 

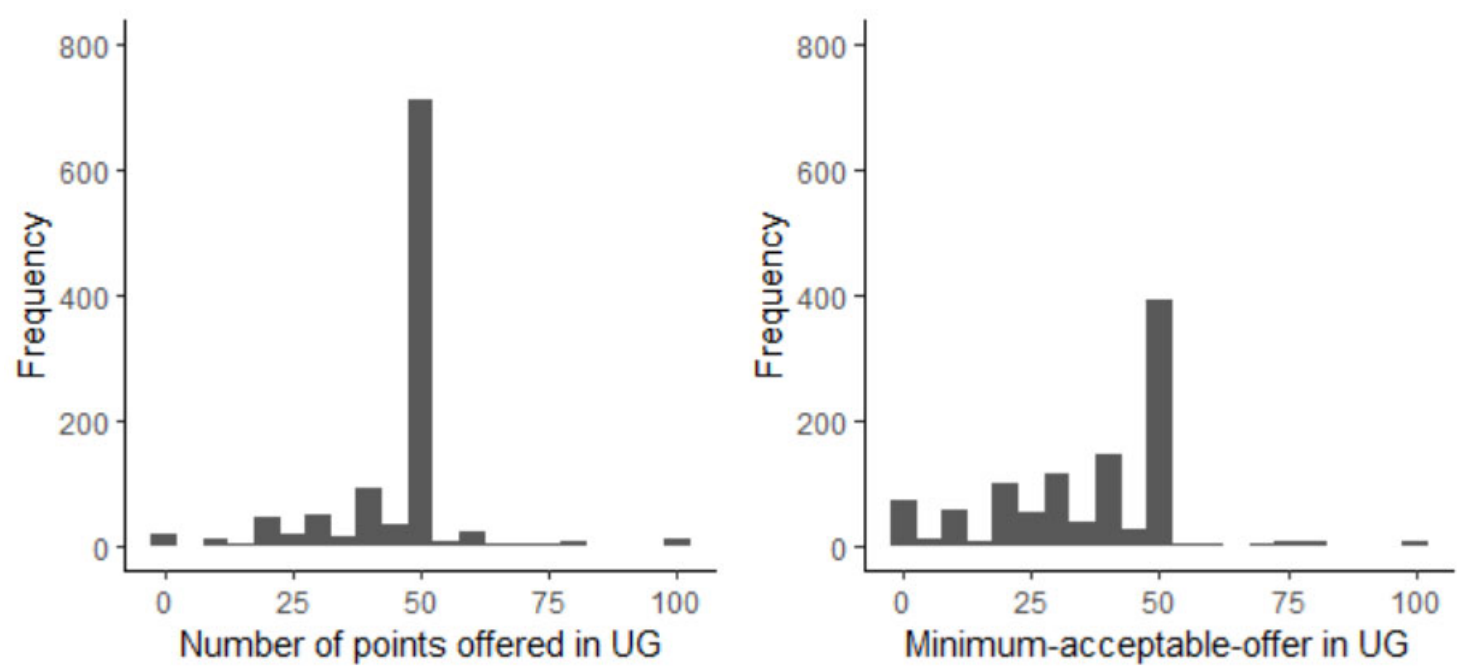

Figure 11. Distribution of decisions in the Ultimatum Game in Wave 1.
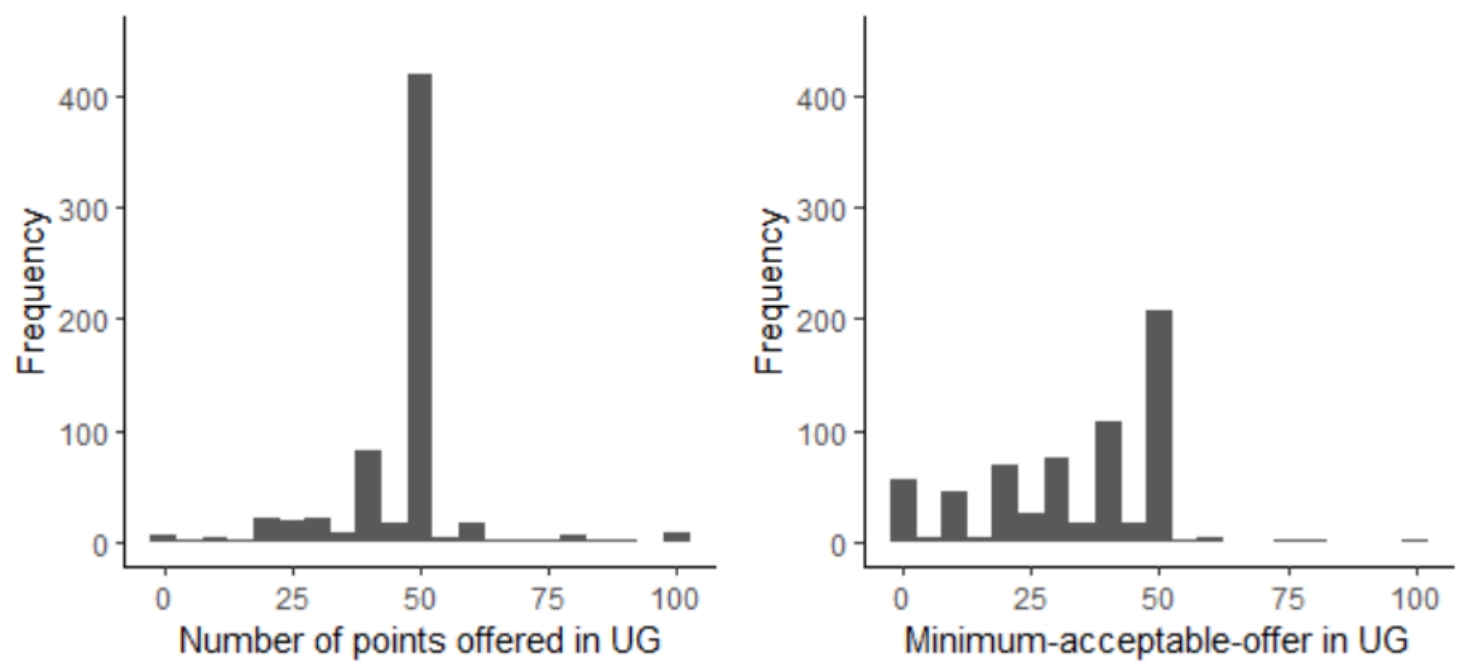

Figure 12. Distribution of decisions in the Ultimatum Game in Wave 2.

Third-Party Punishment Game

The Third-Party Punishment Game is a measure of altruistic punishment from third parties. This game was copied verbatim from Peysakhovich et al. (2014). This game creates two variables: the decision to take or not take, and the punishment decision. This second variable loads onto the "punishment" latent variable. We used this game in both Wave 1 (egame.TPP1.T10 / egame.TPP2.T10) and Wave 2 (egame.TPP1.T11 / egame.TPP2.T11).

On the first page, participants read the following instructions:

In this task you are matched with two other people.

One of you will be Person A, one of you will be Person B, one of you will be Person C.

All individuals start with 100 points.

First, Person A makes a choice, then Person C responds.

Person A can choose to take or not take from Person $B$.

If A takes, Person B loses 50 points and A gains 30 points. 
If A takes, then Person $C$ can choose to remove points from A. Person $C$ can remove up to 100 points from $A$.

Person $C$ must pay 1 point for every 5 points they remove from A. Person $B$ is passive in this task and makes no decisions.

NOTE: Removed points are completely removed from the task, they are not 'taken' by Person $C$.

On the next page, participants answer the following comprehension question (correct answer is $\mathrm{A})$ :

When can Person $C$ remove points from Person $A$ ?

(A) $C$ can only choose to remove points from $A$ if $A$ chooses to take

(B) C can always remove points from $A$

(C) C can never remove points from $A$

On the next page, participants make their decision in the Person A (taking) role:

If you are Person A, will you take from Person B?

- Don't take

- Take

On the final page, participants make their decision in the Person $\mathrm{C}$ (punishing) role:

If you are Person $C$, how many points will you remove from Person $A$ if they take? [0 100] (Reminder: if $A$ chooses to take, $B$ loses 50 points and $A$ gains 30 points.)

In Wave 1, 190 / 1,045 participants (18\%) chose to take in the Person A role, and participants removed an average of 44 points in the Person $\mathrm{C}$ role $(\mathrm{SD}=34$ points, range $=0$ - 100 points; Figure 13). In Wave 2, 118 / 636 participants (19\%) chose to take in the Person A role, and participants removed an average of 45 points in the Person $\mathrm{C}$ role $(\mathrm{SD}=34$ points, range $=0-100$ points; Figure 14).

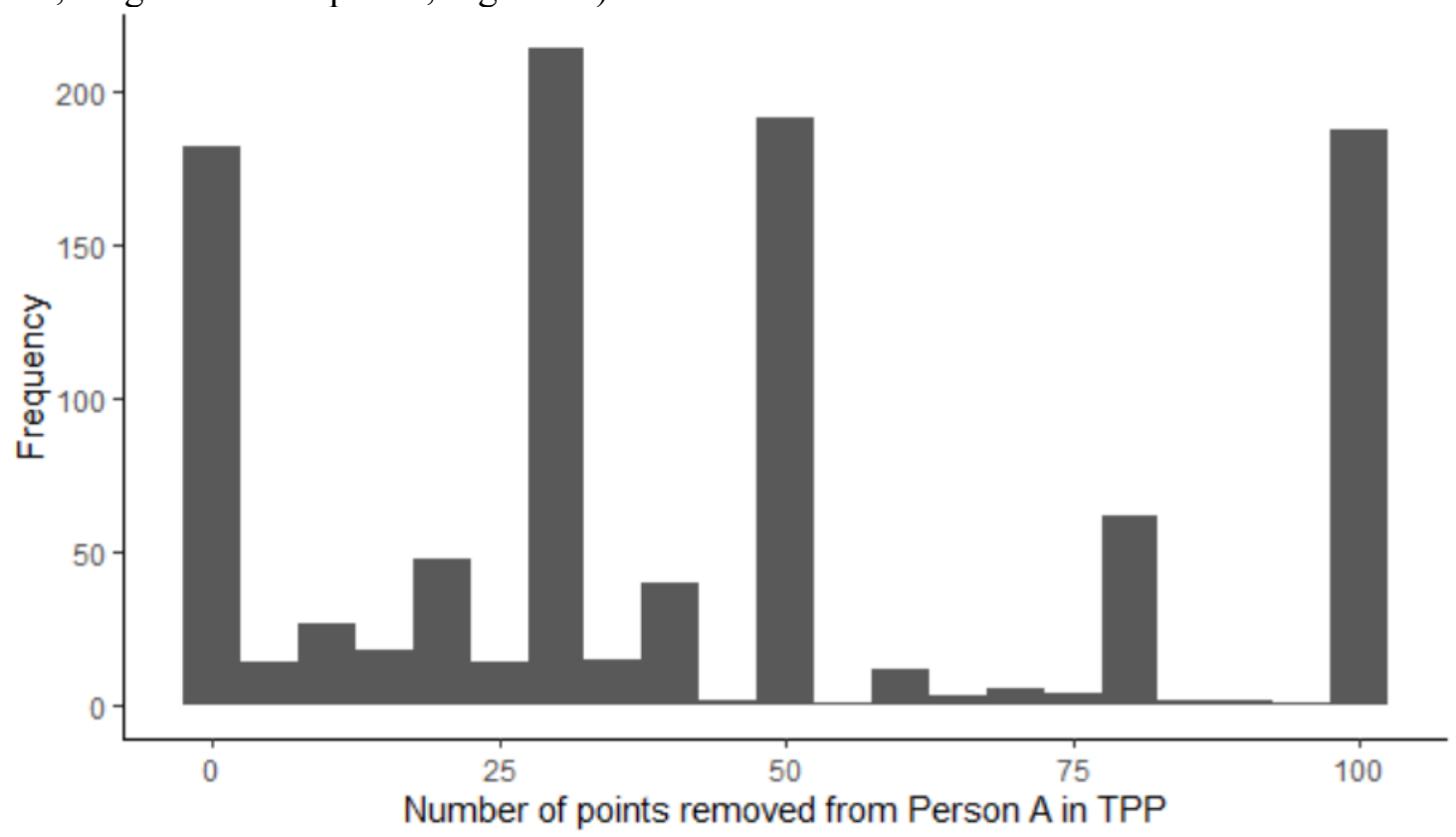

Figure 13. Number of points removed from Person A in the Third-Party Punishment Game in Wave 1. 


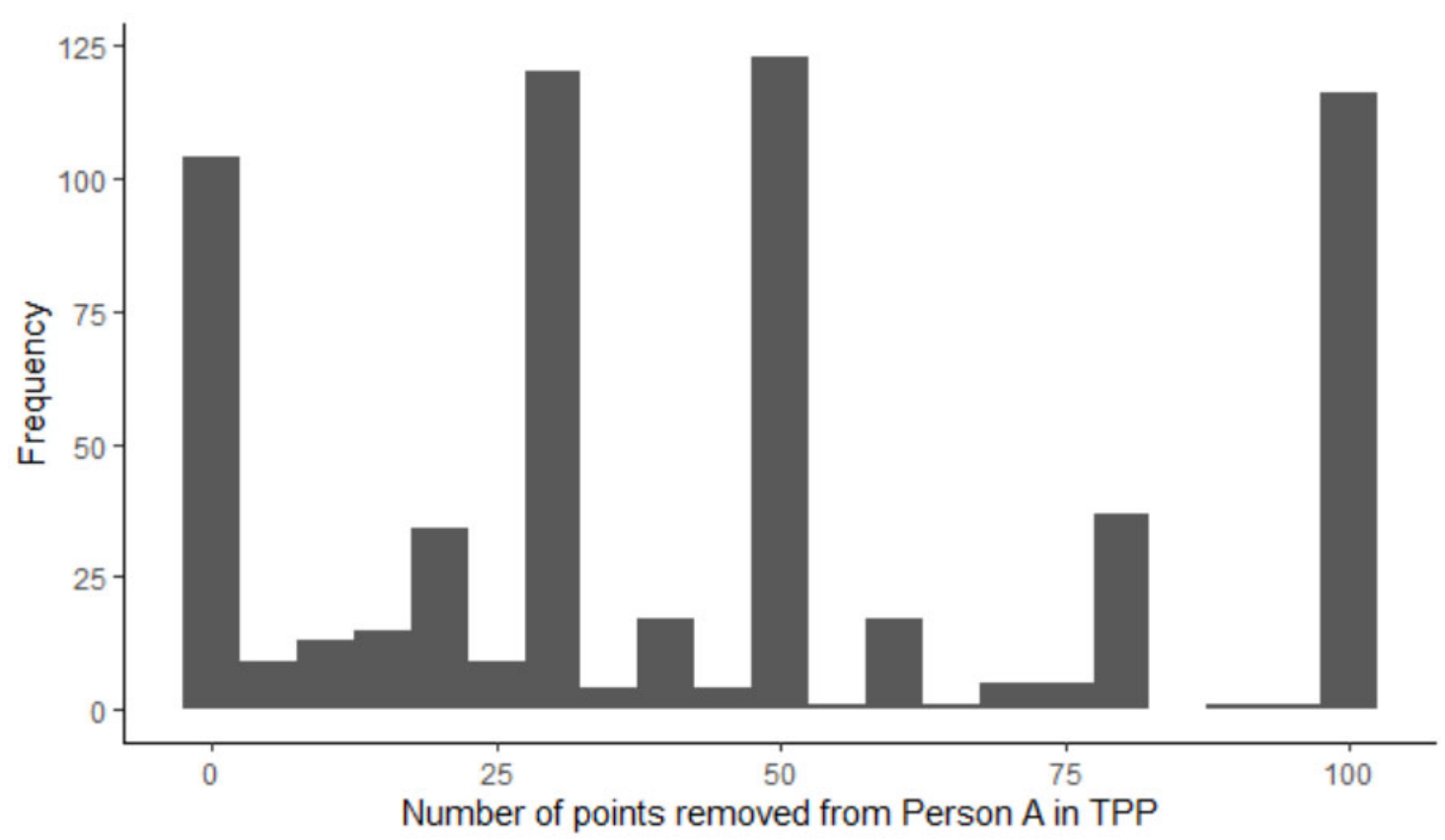

Figure 14. Number of points removed from Person A in the Third-Party Punishment Game in Wave 2.

\section{Second-Party Punishment Game}

The Second-Party Punishment Game is a measure of cooperation and altruistic punishment. This game was copied verbatim from Peysakhovich et al. (2014). This game creates three variables: the decision to cooperate or defect in a Prisoner's Dilemma, punishment of cooperators, and punishment of defectors. This third variable (punishment of defectors) loads onto the "punishment" latent variable. We used this game in both Wave 1 (egame.SPP1.T10 / egame.SPP2.T10 / egame.SPP3.T10) and Wave 2 (egame.SPP1.T11/ egame.SPP2.T11 / egame.SPP3.T11).

On the first page, participants read the following instructions:

In this task you are matched with one other person.

One of you will be Person A, one of you will be Person B.

Both individuals start with 100 points.

This task has two phases. In each phase, both people choose at the same time.

\section{The transfer phase}

In the transfer phase, both people will choose to transfer 30 of their points to the other person or not. Any points transferred are doubled and given to the other person.

\section{The penalty phase}

In the penalty phase, each person then chooses whether they want to remove up to 50 points from the other person, based on the other person's decision in the transfer phase. For every 5 points someone wants to remove from the other person, they must pay 1 point. NOTE: Removed points are completely removed from the task, they are not 'taken' by you.

On the next page, participants answer the following comprehension question (correct answer is $\mathrm{B})$ : 
If Person B transfers and Person A doesn't, how many points will they each have at the end of the transfer phase?

(A) A will have 100 (100 start - 0 transferred), B will have 130 (100 start - 30 transferred +60 received)

(B) A will have 160 (100 start +60 received - 0 transferred), B will have 70 (100 start - 30 transferred)

(C) Both will have 130

On the next page, participants make their transfer phase decision:

Will you transfer 30 points to the other person?

- Transfer

- Don't transfer

On the final page, participants make their penalty phase decisions:

Depending on if the other person transfers, how many points would you like to remove from them?

If the other DOES TRANSFER, I will remove this many points... [0 - 50]

If the other DOESN'T TRANSFER, I will remove this many points... [0 - 50]

In Wave 1, $891 / 1,045$ participants $(85 \%)$ chose to cooperate in the transfer phase.

Participants removed an average of 9 points from cooperators $(\mathrm{SD}=16$ points, range $=0-50$ points) and removed an average of 27 points from defectors $(S D=21$ points, range $=0-50$ points; Figure 15). In Wave 2, 537 / 636 participants (84\%) chose to cooperate in the transfer phase. Participants removed an average of 11 points from cooperators $(\mathrm{SD}=16$ points, range $=0-50$ points $)$ and removed an average of 28 points from defectors $(\mathrm{SD}=20$ points, range $=0-50$ points; Figure 16).
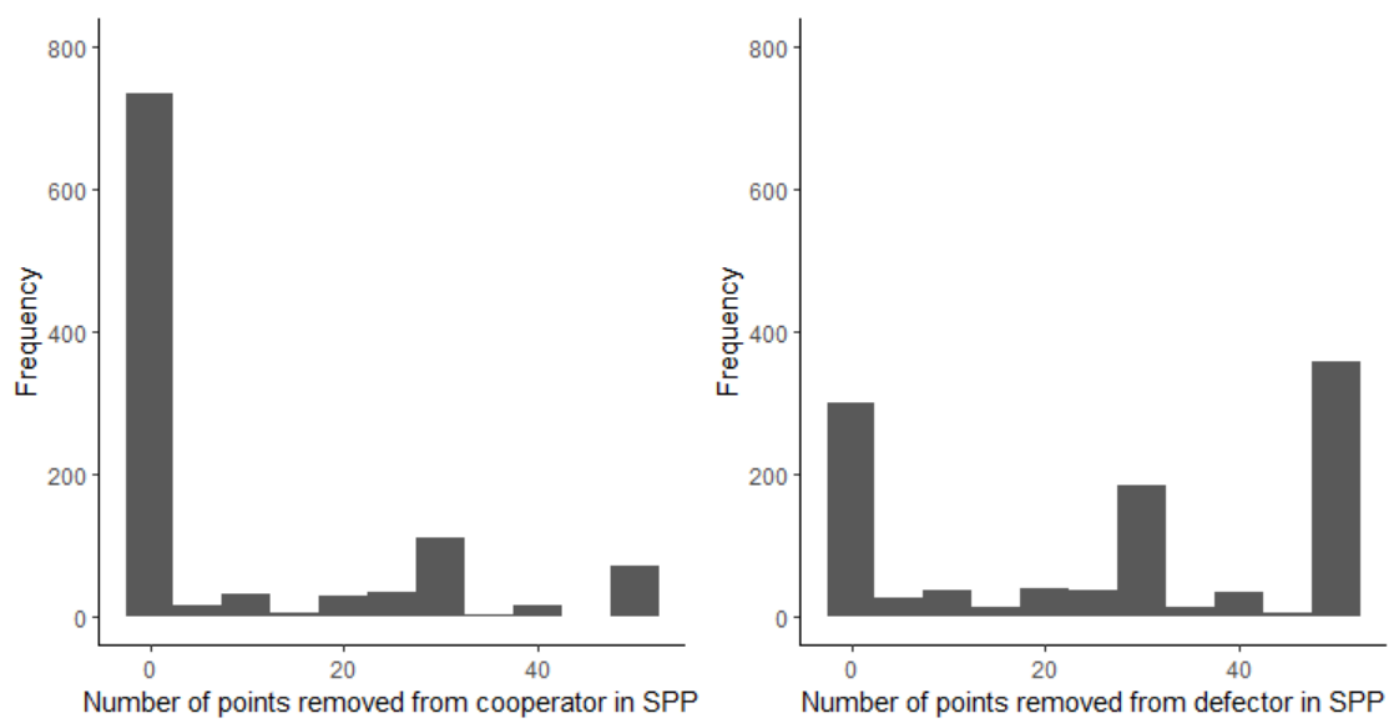

Figure 15. Number of points removed in the Second-Party Punishment Game in Wave 1. 


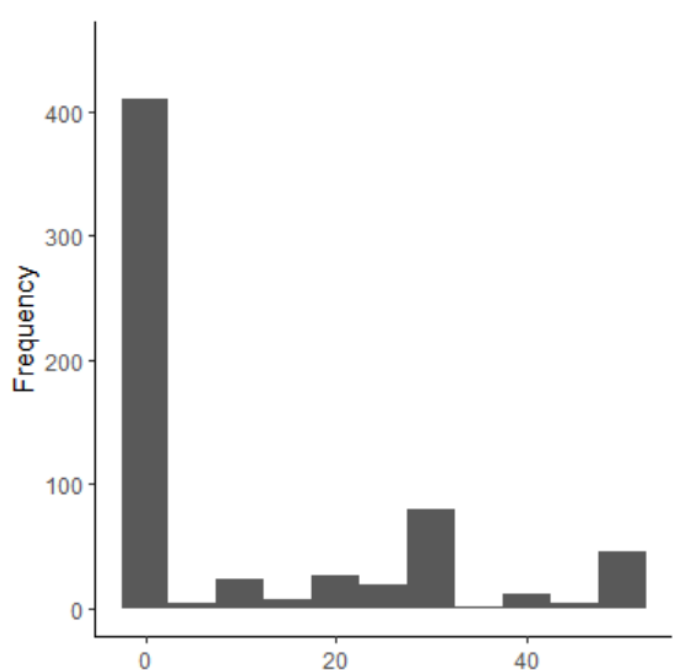

Number of points removed from cooperator in SPP

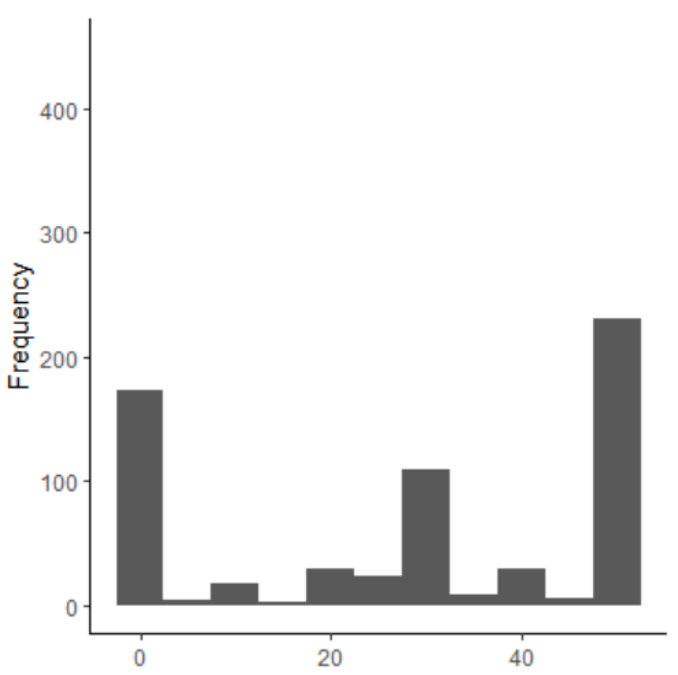

Number of points removed from defector in SPP

Figure 16. Number of points removed in the Second-Party Punishment Game in Wave 2.

\section{Stag-Hunt with Punishment Game}

The Stag-Hunt with Punishment Game is a measure of coordination and altruistic punishment. This game was adapted from the Second-Party Punishment Game by our research team, changing the payoff matrix for the transfer phase to create a coordination problem rather than a social dilemma. This game creates three variables: the decision to coordinate or defect in a Stag Hunt, punishment of coordinators, and punishment of defectors. This third variable (punishment of defectors) loads onto the "punishment" latent variable. We only used this game in Wave 1 (egame.SHP1.T10 / egame.SHP2.T10 / egame.SHP3.T10).

On the first page, participants read the following instructions:

In this task you are matched with one other person.

One of you will be Person A, one of you will be Person B.

Both individuals start with 100 points.

This task has two phases. In each phase, both people choose at the same time.

\section{The transfer phase}

In the transfer phase, both people will choose whether to transfer 30 of their points to a group project or not. The group project is only successful if both people transfer points to it, in which case the 60 points in it will be doubled to 120 and distributed evenly between both people. If only one person transfers, the group project is not successful, and the points in it are lost.

\section{The penalty phase}

In the penalty phase, each person then chooses whether they want to remove up to 50 points from the other person, based on the other person's decision in the transfer phase. For every 5 points someone wants to remove from the other person, they must pay 1 point. NOTE: Removed points are completely removed from the task, they are not 'taken' by you.

On the next page, participants answer the following comprehension question (correct answer is $\mathrm{C})$ : 
If you transfer 30 points to the group project, but the other person does not, how many points will you have at the end of the transfer phase?

(A) 130 points (100 start +30$)$

(B) 100 points (100 start +0$)$

(C) 70 points (100 start - 30)

On the next page, participants make their transfer phase decision:

Will you transfer 30 points to the group project?

- Transfer 30 points

- Don't transfer

On the final page, participants make their penalty phase decisions:

Depending on the other person's decision in the transfer phase, how many points would you like to remove from them?

If the other DOES TRANSFER, I will remove this many points... [0 - 50]

If the other DOESN'T TRANSFER, I will remove this many points... [0 - 50]

In Wave $1,1,001 / 1,045$ participants $(96 \%)$ chose to coordinate in the transfer phase.

Participants removed an average of 6 points from coordinators $(\mathrm{SD}=14$ points, range $=0-$ 50 points) and removed an average of 25 points from defectors $(\mathrm{SD}=19$ points, range $=0$ 50 points; Figure 17).
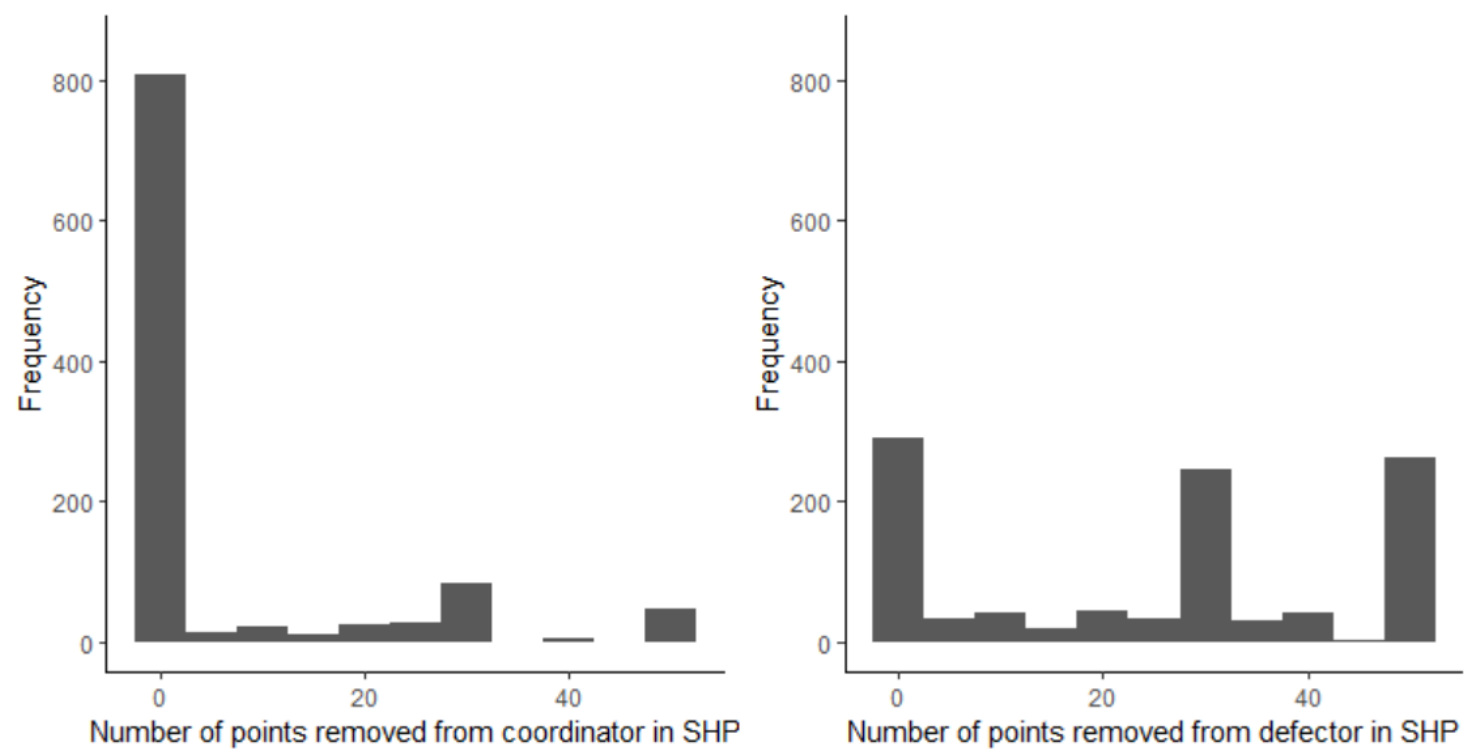

Figure 17. Number of points removed in the Stag-Hunt with Punishment Game in Wave 1.

\section{Rule Following Task}

The Rule Following Task is a measure of rule following and norm adherence. This task was adapted from the protocol in Kimbrough \& Vostroknutov (2018). This task creates 31 variables: 30 sequential binary decisions (egame.RFTXX.T11), and a final variable capturing the sum of all these decisions (egame.RFT_Sum.T11). We only used this task in Wave 2. The task implemented counterbalancing, such that the rule following bucket was randomly allocated to be either Bucket A or Bucket B. 
On the first page, participants read the following instructions:

In this solo task, you will decide how to allocate 30 balls between two buckets.

Your task is to put each of the balls, one-by-one, into the two buckets on the screen.

You will allocate each ball by clicking either the button for Bucket A or the button for

Bucket B.

For each ball you put in Bucket A you will receive 2 points, and for each ball you put in

Bucket $B$ you will receive 1 points.

The rule is to put the balls in Bucket B.

On the next page, participants answer the following comprehension question (correct answer is A):

How many points will you receive for each ball you put in Bucket A?

(A) 2 points

(B) 1 points

On subsequent pages, participants make 30 sequential binary rule-following decisions:

Remember, for each ball you put in Bucket A you will receive 2 points, and for each ball you put in Bucket B you will receive 1 point.

The rule is to put the balls in Bucket B.

Please now allocate the balls to the buckets you choose using the buttons below. You must allocate all the balls to continue.

Balls remaining: 30/30 Bucket $A$ Bucket $B$

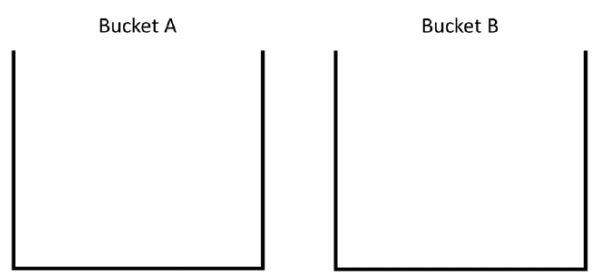

In Wave 2, 263 / 636 participants (41\%) never broke the rule, 78 / 636 participants (12\%) always broke the rule, while other participants fell somewhere in between (Figure 18). 


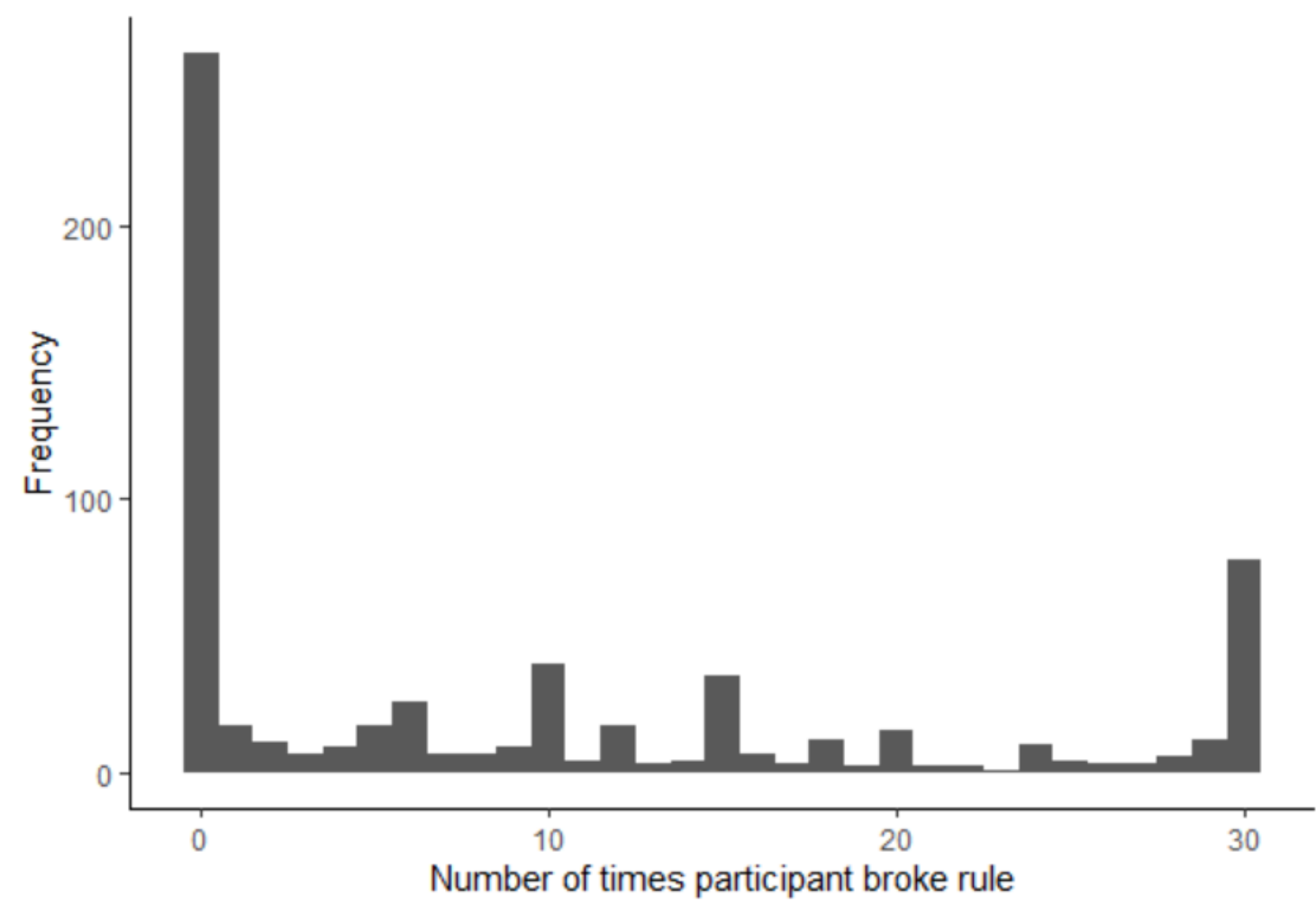

Figure 18. Number of times participants broke the rule in the Rule Following Task in Wave 2.

\section{BEAST}

The BEAST (Berlin Estimate AdjuStment Task) is a measure of conformity and social information use. This task was adapted from the protocol in Molleman, Kurvers, \& van den Bos (2019). We only used this task in Wave 2. The task consists of five rounds, and each round creates three variables: a first estimate (egame.BEAST_RXE1.T11), the social information (egame.BEAST RXPE.T11), and a second estimate (egame.BEAST RXE2.T11). Together, these variables are combined to calculate the final BEAST score for that round (egame.BEASTRXscore.T11; calculation explained below).

On the first page, participants read the following instructions:

In this task, you have to make a number of estimates. The number of points you earn in this task depends on how accurate your estimates are.

The task consists of 5 rounds. At the beginning of each round, you will observe an image showing a number of animals. The image will disappear after 6 seconds. Once the image has disappeared, you have to enter an estimate of how many animals were displayed within 15 seconds. The more accurate your estimate, the more points you can earn. This is your estimate for Part $A$ of a round.

Once you have entered your estimate, Part B of the round begins. You can observe the estimate of another participant. Over 100 people participated in a previous session in which they completed this task. In each round, you can observe the Part A estimate of one of these previous participants. Previous participants saw the same image as you. They also saw it for six seconds. After the image disappeared, they also had to estimate how many animals were displayed. They could also earn more points if their estimate was more accurate. 
You then have to enter a second estimate within 45 seconds. You can enter the same estimate as before, or adjust it as you wish. This is your estimate for Part B of a round. Once you have entered your Part B estimate, the round is over and a new round begins. Note: if you do not enter your estimate within the time limit, you will earn 0 points for this task.

To calculate your earnings, the computer will randomly select 1 of the 5 rounds of this task. Then, the computer will randomly select Part A or B. Your estimate for that part is used to calculate your earnings for this task. If you estimated the number of animals exactly right, you earn 100 points. For each number that you are off, we subtract 5 points. Your earnings cannot become negative. For example, if the actual number of animals in the image was 60, and you estimate 53, you were 7 off. We subtract $7 \times 5=35$ points, so you would earn $100-35=65$ points.

On the next page, participants answer the following comprehension question (correct answer is A):

Once you have entered your estimate, you can observe the estimate of a previous participant who completed this task before, and then make a second estimate.

(A) True

(B) False

On the subsequent pages, participants complete the five rounds of the BEAST task. In an example round, they are first shown an image with a number of animals on them for six seconds, like this:

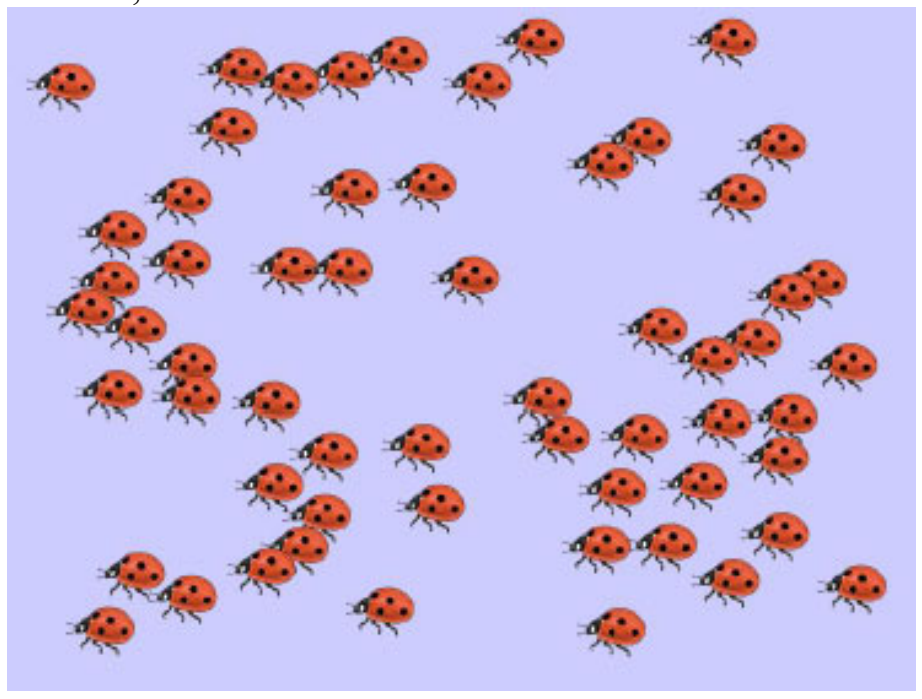

On the next page, they are then asked to provide their first estimate $\left(E_{1}\right)$ :

How many [animals] were shown in the image?

On the next page, they are shown social information $(s)$ and asked to provide their second estimate $\left(E_{2}\right)$ :

Your Part A estimate of [first estimate] has been recorded.

Now, we show you the Part A estimate of a participant who has completed this task before. This previous participant saw the same image that you just did. They also saw it for 6 seconds. Their estimate was [social information]. You can now enter your Part B estimate below.

How many [animals] were shown in the image? 
This then repeats for four more rounds, with different numbers of different animals in each round.

Social information $(s)$ is determined by searching a real database of estimates from 100 previous participants sampled by Molleman, Kurvers, \& van den Bos (2019) in their original paper. The computer searches for an estimate in this database that is (1) in the direction of the true (correct) answer (e.g. if participant guesses 50 and true answer is 60, social information will be higher than 50) and (2) deviates from the participant's first estimate according to a parameter $\Delta: s=E_{1} *(1 \pm \Delta)$. Replicating the original paper, this $\Delta$ parameter varied across the five rounds, taking values of $0.25,0.15,0.20,0.15$, and 0.25 respectively.

Based on participants' two estimates and the social information they were provided, we calculate a BEAST score for that round using the following equation:

$$
\text { BEAST score }=\frac{E_{2}-E_{1}}{s-E_{1}}
$$

We remove cases where (1) participants moved their second estimate away from the social information, (2) where participants moved their second estimate further than the social information, or (3) participants ran out of time to make their estimate. The BEAST score varies between 0 and 1 , where 0 implies that the participant did not shift their estimate after receiving social information and 1 implies that the participant shifted their estimate completely towards the social information.

Plotting the distribution of BEAST scores (averaged over all five rounds) reveals that participants are generally biased towards sticking with their first estimate, though there is substantial variation (Figure 19).

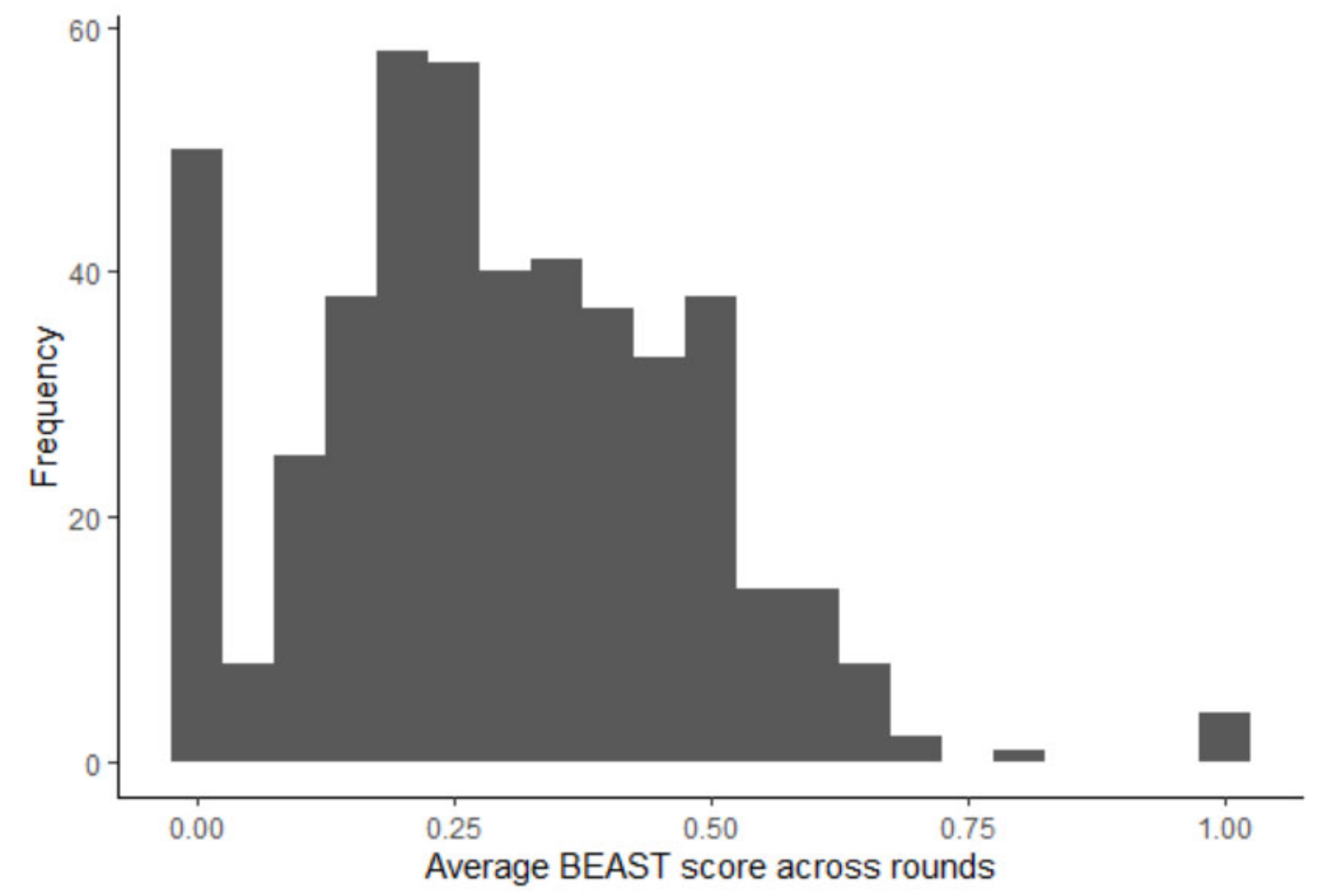

Figure 19. Average BEAST score across all five rounds in Wave 2. 


\section{Chapter 5 - Sample Weighting}

\section{Overview}

This chapter outlines how the post-stratification weights provided in each NZAVS data file were calculated. Details on how to apply post-stratification sample weighting procedures are provided in Groves, Fowler, Couper, Lepkowski, and Tourangeau (2004). These post-stratification weights are provided as standard in the data files for each wave of the NZAVS. Research papers using NZAVS data that have applied these or other more specific post-stratification weighting procedures explicitly state that they have done so.

\section{Time 1 (2009)}

To estimate representative population proportions, the NZAVS provides a poststratification weight that adjusted for sample bias in gender (male versus female), ethnic identification as Māori (yes, no), identification as Pacific (yes, no), identification as Asian (yes, no), and identification as European or another ethnic group (yes, no). The combined weighting factor adjusting for gender and ethnic group sampling bias is expressed in Equation (1.0):

Sample Weight ${ }_{i}=W_{i \text { (Gender) }} * W_{i \text { (European \& Other) }} * W_{i \text { (Māori) }} * W_{i \text { (Pacific) }} * W_{i \text { (Asian) }}+c$

where $c$ was a constant value added to the weight for each participant so that the average weight across participants was 1.00. The weighting value for a given demographic factor, $W_{i}$, was defined as a ratio of the known proportion of that demographic group in the population,

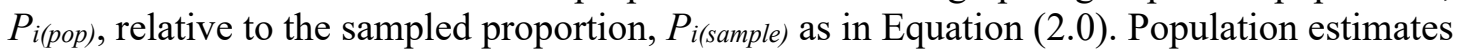
used to calculate these weights were based on 2006 New Zealand Census data for people 15 years of age and over.

$W_{i}=P_{i(p o p)} / P_{i(\text { sample })}$

Sample and population proportions for each demographic variable on which sample weights were based are presented in Table 1 . The weighting values for each demographic variable are also reported.

Table 1. Weighting values provided for the Time 1 (2009) NZAVS.

\begin{tabular}{lccr}
\hline & $P_{i(\text { pop })}$ & $P_{i(\text { sample })}$ & \multicolumn{1}{c}{$W_{i}$} \\
\hline Gender & & & \\
Male & .488 & .407 & 1.199 \\
Female & .512 & .593 & .864 \\
Māori & & & \\
$\quad$ Yes & .140 & .179 & .784 \\
$\quad$ No & .860 & .821 & 1.047 \\
Pacific & & & \\
$\quad$ Yes & .066 & .043 & 1.536 \\
No & .934 & .957 & .976 \\
Asian & & & \\
$\quad$ Yes & .088 & .049 & 1.796 \\
$\quad$ No & .912 & .951 & .959 \\
European/Other & & &
\end{tabular}




$\begin{array}{llll}\text { Yes } & .754 & .849 & .888\end{array}$

$\begin{array}{llll}\text { No } & .256 & .151 & 1.632\end{array}$

Time $2(2010)$

Comparable post-stratification weights that adjusted for sample bias in gender (male versus female), ethnic identification as Māori (yes, no), identification as Pacific (yes, no), identification as Asian (yes, no), and identification as European or another ethnic group (yes, no) are also provided for the Time 2 (2010) NZAVS. Estimation of the post-stratification weights using in the Time 2 sample also employed Equations 1.0 and 2.0. Sample and population proportions for each demographic variable on which sample weights were based are presented in Table 2. The weighting values for each demographic variable are also reported in Table 2.

Table 2. Weighting values provided the Time 2 (2010) NZAVS.

\begin{tabular}{lrrr}
\hline & $P_{i(\text { pop })}$ & $P_{i(\text { sample })}$ & \multicolumn{1}{c}{$W_{i}$} \\
\hline Gender & & & \\
Male & .488 & .387 & 1.260 \\
Female & .512 & .613 & .836 \\
Māori & & & \\
$\quad$ Yes & .140 & .155 & .906 \\
$\quad$ No & .860 & .845 & 1.017 \\
Pacific & & & \\
$\quad$ Yes & .066 & .036 & 1.834 \\
$\quad$ No & .934 & .964 & .969 \\
Asian & & & \\
$\quad$ Yes & .088 & .040 & 2.201 \\
$\quad$ No & .912 & .960 & .950 \\
European/Other & & & \\
$\quad$ Yes & .754 & .889 & .848 \\
$\quad$ No & .256 & .111 & 2.220 \\
\hline
\end{tabular}

Time 3 (2011)

Comparable post-stratification weights that adjusted for sample bias in gender (male versus female), ethnic identification as Māori (yes, no), identification as Pacific (yes, no), identification as Asian (yes, no), and identification as European or another ethnic group (yes, no) are also provided for the Time 3 (2011) NZAVS. Estimation of the post-stratification weights using in the Time 3 sample also employed Equations 1.0 and 2.0. Sample and population proportions for each demographic variable on which sample weights were based are presented in Table 3. The weighting values for each demographic variable are also reported in Table 3.

Table 3. Weighting values provided for the Time 3 (2011) NZAVS.

Gender

\begin{tabular}{lll}
$P_{i(\text { pop })}$ & $P_{i(\text { sample })}$ & $W_{i}$ \\
\hline
\end{tabular}




\begin{tabular}{lrrr} 
Male & .488 & .375 & 1.301 \\
Female & .512 & .624 & .821 \\
Māori & & & \\
$\quad$ Yes & .140 & .108 & 1.230 \\
No & .860 & .892 & .964 \\
Pacific & & & \\
Yes & .066 & .026 & 2.539 \\
$\quad$ No & .934 & .974 & .959 \\
Asian & & & \\
$\quad$ Yes & .088 & .037 & 2.379 \\
$\quad$ No & .912 & .963 & .947 \\
European/Other & & & \\
$\quad$ Yes & .754 & .909 & .829 \\
No & .256 & .091 & 2.708 \\
\hline
\end{tabular}

Time 4 (2012) onwards.

The NZAVS post-stratification weighting procedure was changed from Time 4

The Time 4 NZAVS sample included various regional booster samples. Because of this, the Time 4 NZAVS post-stratification weighting included regional information. Regions of residence were coded by identifying which of the 16 mutually exclusive and nonoverlapping council zones of New Zealand each participant listed as their primary residential address. The post-stratification weighting procedure was also revised to weight men and women from each of the four primary ethnic groups separately.

The combined weighting factor adjusting for gender and ethnic group sampling bias and region is expressed in Equation (3.0):

Sample $W_{\text {eight }}=W_{i \text { (Male European \& Other) }}{ }^{*} W_{i \text { (Female European \& Other) }} * W_{i \text { (Male Māori) }} * W_{i}$ (Female Māori) $* W_{i \text { (Male Pacific) }} * W_{i \text { (Female Pacific) }} * W_{i \text { (Male Asian) }} * W_{i \text { (Female Asian) }}+W_{i \text { (Council }}$ Region) $+c$

where $c$ was a constant value added to the weight for each participant so that the average weight across participants was 1.00. The weighting value for a given demographic factor, $W_{i}$, was defined as a ratio of the known proportion of that demographic group in the population, $P_{i(p o p)}$, relative to the sampled proportion, $P_{i(\text { sample })}$ as in Equation (4.0).

$W_{i}=P_{i(p o p)} / P_{i(\text { sample })}$

Population estimates used to calculate these weights were based on $2013 \mathrm{New}$ Zealand Census data for people 15 years of age and over. The census provided information in the age bracket from 15-19. Because our sample included those aged 18 and older, to adjust for this bias, we estimated census proportions for those over 18 by down-weighting the frequencies for this age bracket by a factor of $2 / 5$. Sample and population proportions for each demographic variable on which sample weights were based are presented in Table 4. The weighting values for each demographic variable and residential location are also reported.

Table 4. Weighting values provided for the Time 4 (2012) NZAVS.

\begin{tabular}{lccc}
\hline & $P_{i(\text { pop })}$ & $P_{i(\text { sample })}$ & $W_{i}$ \\
\hline $\begin{array}{l}\text { Māori Male } \\
\text { Yes }\end{array}$ & 0.0515 & 0.0583 & 0.8844
\end{tabular}




\begin{tabular}{|c|c|c|c|}
\hline No & 0.9485 & 0.9417 & 1.0072 \\
\hline \multicolumn{4}{|l|}{ Māori Female } \\
\hline Yes & 0.0598 & 0.1079 & 0.5544 \\
\hline No & 0.9402 & 0.8921 & 1.0539 \\
\hline \multicolumn{4}{|l|}{ Pacific Male } \\
\hline Yes & 0.0253 & 0.0159 & 1.5892 \\
\hline No & 0.9747 & 0.9841 & 0.9905 \\
\hline \multicolumn{4}{|l|}{ Pacific Female } \\
\hline Yes & 0.0277 & 0.0341 & 0.8131 \\
\hline No & 0.9723 & 0.9659 & 1.0066 \\
\hline \multicolumn{4}{|l|}{ Asian Male } \\
\hline Yes & 0.0511 & 0.0184 & 2.7799 \\
\hline No & 0.9489 & 0.9816 & 0.9667 \\
\hline \multicolumn{4}{|l|}{ Asian Female } \\
\hline Yes & 0.0576 & 0.0324 & 1.7751 \\
\hline No & 0.9424 & 0.9676 & 0.9740 \\
\hline \multicolumn{4}{|l|}{ European/Other Male } \\
\hline Yes & 0.3470 & 0.3237 & 1.0722 \\
\hline No & 0.6530 & 0.6763 & 0.9655 \\
\hline \multicolumn{4}{|l|}{ European/Other Female } \\
\hline Yes & 0.3799 & 0.5420 & 0.7009 \\
\hline No & 0.6201 & 0.4580 & 1.3540 \\
\hline \multicolumn{4}{|l|}{ Council Region } \\
\hline Auckland Region & 0.3337 & 0.3652 & 0.9140 \\
\hline Bay of Plenty Region & 0.0631 & 0.0562 & 1.1226 \\
\hline Canterbury Region & 0.1272 & 0.1338 & 0.9506 \\
\hline Gisbourne Region & 0.0103 & 0.0084 & 1.2300 \\
\hline Hawke's Bay Region & 0.0356 & 0.0338 & 1.0544 \\
\hline Manawatu-Wanganui Region & 0.0525 & 0.0491 & 1.0688 \\
\hline Marlborough Region & 0.0102 & 0.0100 & 1.0194 \\
\hline Nelson Region & 0.0109 & 0.0134 & 0.8178 \\
\hline Northland Region & 0.0358 & 0.0304 & 1.1774 \\
\hline Otago Region & 0.0477 & 0.0443 & 1.0764 \\
\hline Southland Region & 0.0220 & 0.0151 & 1.4530 \\
\hline Taranaki Region & 0.0258 & 0.0208 & 1.2453 \\
\hline Tasman Region & 0.0111 & 0.0096 & 1.1554 \\
\hline Waikato Region & 0.0952 & 0.0746 & 1.2765 \\
\hline Wellington Region & 0.1111 & 0.1289 & 0.8618 \\
\hline West Coast Region & 0.0076 & 0.0064 & 1.1919 \\
\hline
\end{tabular}

Time 5 (2013)

The NZAVS post-stratification weighting procedure followed that implemented at Time 4, and weighted men and women from each of the four primary ethnic groups separately as well as region of residence. Regions were coded by identifying which of the 16 mutually exclusive and non-overlapping council zones of New Zealand each participant listed as their primary residential address.

The combined weighting factor adjusting for gender and ethnic group sampling bias and region is expressed in Equation (5.0): 
Sample Weight $t_{i}=W_{i \text { (Male European \& Other) }} * W_{i \text { (Female European \& Other })} * W_{i \text { (Male Māori })} * W_{i}$

(Female Māori) $* W_{i \text { (Male Pacific) }} * W_{i \text { (Female Pacific) }} * W_{i \text { (Male Asian) }} * W_{i \text { (Female Asian })}+W_{i \text { (Council }}$

Region) $+c$

where $c$ was a constant value added to the weight for each participant so that the average weight across participants was 1.00. The weighting value for a given demographic factor, $W_{i}$, was defined as a ratio of the known proportion of that demographic group in the population, $P_{i(p o p)}$, relative to the sampled proportion, $P_{i(\text { sample })}$ as in Equation (6.0).

$W_{i}=P_{i(p o p)} / P_{i(\text { sample })}$

Population estimates used to calculate these weights were based on $2013 \mathrm{New}$

Zealand Census data for people 15 years of age and over. The census provided information in the age bracket from 15-19. Because our sample included those aged 18 and older, to adjust for this bias, we estimated census proportions for those over 18 by down-weighting the frequencies for this age bracket by a factor of $2 / 5$. Sample and population proportions for each demographic variable on which sample weights were based are presented in Table 5. The weighting values for each demographic variable and residential location are also reported.

Table 5. Weighting values provided for the Time 5 (2013) NZAVS.

\begin{tabular}{|c|c|c|c|}
\hline & $P_{i(\text { pop })}$ & $P_{i(\text { sample })}$ & $W_{i}$ \\
\hline \multicolumn{4}{|l|}{ Māori Male } \\
\hline Yes & 0.0515 & 0.0417 & 1.2354 \\
\hline No & 0.9485 & 0.9583 & 0.9898 \\
\hline \multicolumn{4}{|l|}{ Māori Female } \\
\hline Yes & 0.0598 & 0.0857 & 0.6980 \\
\hline No & 0.9402 & 0.9143 & 1.0283 \\
\hline \multicolumn{4}{|l|}{ Pacific Male } \\
\hline Yes & 0.0253 & 0.0107 & 2.3583 \\
\hline No & 0.9747 & 0.9893 & 0.9853 \\
\hline \multicolumn{4}{|l|}{ Pacific Female } \\
\hline Yes & 0.0277 & 0.0235 & 1.1793 \\
\hline No & 0.9723 & 0.9765 & 0.9957 \\
\hline \multicolumn{4}{|l|}{ Asian Male } \\
\hline Yes & 0.0511 & 0.0163 & 3.1328 \\
\hline No & 0.9489 & 0.9837 & 0.9646 \\
\hline \multicolumn{4}{|l|}{ Asian Female } \\
\hline Yes & 0.0576 & 0.0284 & 2.0294 \\
\hline No & 0.9424 & 0.9716 & 0.9700 \\
\hline \multicolumn{4}{|l|}{ European/Other Male } \\
\hline Yes & 0.3470 & 0.3354 & 1.0346 \\
\hline No & 0.6530 & 0.6646 & 0.9825 \\
\hline \multicolumn{4}{|l|}{ European/Other Female } \\
\hline Yes & 0.3799 & 0.5646 & 0.6729 \\
\hline No & 0.6201 & 0.4354 & 1.4242 \\
\hline \multicolumn{4}{|l|}{ Council Region } \\
\hline Auckland Region & 0.3337 & 0.3169 & 1.0532 \\
\hline Bay of Plenty Region & 0.0631 & 0.0586 & 1.0773 \\
\hline Canterbury Region & 0.1272 & 0.1380 & 0.9215 \\
\hline Gisbourne Region & 0.0103 & 0.0078 & 1.3161 \\
\hline Hawke's Bay Region & 0.0356 & 0.0338 & 1.0541 \\
\hline
\end{tabular}




\begin{tabular}{llll} 
Manawatu-Wanganui Region & 0.0525 & 0.0509 & 1.0317 \\
Marlborough Region & 0.0102 & 0.0106 & 0.9630 \\
Nelson Region & 0.0109 & 0.0136 & 0.8049 \\
Northland Region & 0.0358 & 0.0328 & 1.0896 \\
Otago Region & 0.0477 & 0.0544 & 0.8782 \\
Southland Region & 0.0220 & 0.0191 & 1.1516 \\
Taranaki Region & 0.0258 & 0.0228 & 1.1334 \\
Tasman Region & 0.0111 & 0.0132 & 0.8447 \\
Waikato Region & 0.0952 & 0.0815 & 1.1684 \\
Wellington Region & 0.1111 & 0.1385 & 0.8026 \\
West Coast Region & 0.0076 & 0.0076 & 0.9973 \\
\hline
\end{tabular}

Time 6 (2014)

The NZAVS post-stratification weighting procedure followed that implemented at Time 4, and weighted men and women from each of the four primary ethnic groups separately as well as region of residence. Regions were coded by identifying which of the 16 mutually exclusive and non-overlapping council zones of New Zealand each participant listed as their primary residential address.

The combined weighting factor adjusting for gender and ethnic group sampling bias and region is expressed in Equation (5.0):

Sample Weight $t_{i}=W_{i \text { (Male European \& Other) }} * W_{i \text { (Female European \& Other) }} * W_{i \text { (Male Māori) }} * W_{i}$ (Female Māori) $* W_{i \text { (Male Pacific) }} * W_{i \text { (Female Pacific })} * W_{i \text { (Male Asian) }} * W_{i \text { (Female Asian })}+W_{i \text { (Council }}$ Region) $+c$

where $c$ was a constant value added to the weight for each participant so that the average weight across participants was 1.00. The weighting value for a given demographic factor, $W_{i}$, was defined as a ratio of the known proportion of that demographic group in the population, $P_{i(p o p)}$, relative to the sampled proportion, $P_{i(\text { sample })}$ as in Equation (6.0).

$W_{i}=P_{i(p o p)} / P_{i(\text { sample })}$

Population estimates used to calculate these weights were based on $2013 \mathrm{New}$ Zealand Census data for people 15 years of age and over. The census provided information in the age bracket from 15-19. Because our sample included those aged 18 and older, to adjust for this bias, we estimated census proportions for those over 18 by down-weighting the frequencies for this age bracket by a factor of $2 / 5$. Sample and population proportions for each demographic variable on which sample weights were based are presented in Table 6 . The weighting values for each demographic variable and residential location are also reported.

Table 6. Weighting values provided for the Time 6 (2014) NZAVS.

\begin{tabular}{lccc}
\hline & $P_{i(\text { pop })}$ & $P_{i(\text { sample })}$ & $W_{i}$ \\
\hline $\begin{array}{l}\text { Māori Male } \\
\text { Yes }\end{array}$ & 0.0515 & 0.0405 & 1.2723 \\
$\quad$ No & 0.9485 & 0.9595 & 0.9885 \\
$\begin{array}{l}\text { Māori Female } \\
\quad \text { Yes }\end{array}$ & & \\
$\quad$ No & 0.0598 & 0.0842 & 0.7104 \\
Pacific Male & 0.9402 & 0.9158 & 1.0266 \\
$\quad$ Yes & & & \\
No & 0.0253 & 0.0103 & 2.4568 \\
$\quad$ & 0.9747 & 0.9897 & 0.9848
\end{tabular}




\begin{tabular}{|c|c|c|c|}
\hline \multicolumn{4}{|l|}{ Pacific Female } \\
\hline Yes & 0.0277 & 0.0229 & 1.2075 \\
\hline No & 0.9723 & 0.9771 & 0.9951 \\
\hline \multicolumn{4}{|l|}{ Asian Male } \\
\hline Yes & 0.0511 & 0.0149 & 3.4272 \\
\hline No & 0.9489 & 0.9851 & 0.9633 \\
\hline \multicolumn{4}{|l|}{ Asian Female } \\
\hline Yes & 0.0576 & 0.0284 & 2.0284 \\
\hline No & 0.9424 & 0.9716 & 0.9700 \\
\hline \multicolumn{4}{|l|}{ European/Other Male } \\
\hline Yes & 0.3470 & 0.3336 & 1.0402 \\
\hline No & 0.6530 & 0.6664 & 0.9799 \\
\hline \multicolumn{4}{|l|}{ European/Other Female } \\
\hline Yes & 0.3799 & 0.5732 & 0.6627 \\
\hline No & 0.6201 & 0.4268 & 1.4530 \\
\hline \multicolumn{4}{|l|}{ Council Region } \\
\hline Auckland Region & 0.3337 & 0.3101 & 1.0761 \\
\hline Bay of Plenty Region & 0.0631 & 0.0585 & 1.0795 \\
\hline Canterbury Region & 0.1272 & 0.1379 & 0.9223 \\
\hline Gisbourne Region & 0.0103 & 0.0077 & 1.3280 \\
\hline Hawke's Bay Region & 0.0356 & 0.0352 & 1.0137 \\
\hline Manawatu-Wanganui Region & 0.0525 & 0.0502 & 1.0468 \\
\hline Marlborough Region & 0.0102 & 0.0114 & 0.8978 \\
\hline Nelson Region & 0.0109 & 0.0145 & 0.7564 \\
\hline Northland Region & 0.0358 & 0.0323 & 1.1057 \\
\hline Otago Region & 0.0477 & 0.0546 & 0.8737 \\
\hline Southland Region & 0.0220 & 0.0184 & 1.1972 \\
\hline Taranaki Region & 0.0258 & 0.0232 & 1.1146 \\
\hline Tasman Region & 0.0111 & 0.0133 & 0.8346 \\
\hline Waikato Region & 0.0952 & 0.0828 & 1.1500 \\
\hline Wellington Region & 0.1111 & 0.1424 & 0.7801 \\
\hline West Coast Region & 0.0076 & 0.0075 & 1.0114 \\
\hline
\end{tabular}

Time 7 (2015)

The NZAVS post-stratification weighting procedure followed that implemented at Time 4, and weighted men and women from each of the four primary ethnic groups separately as well as region of residence. Regions were coded by identifying which of the 16 mutually exclusive and non-overlapping council zones of New Zealand each participant listed as their primary residential address.

The combined weighting factor adjusting for gender and ethnic group sampling bias and region is expressed in Equation (5.0):

Sample Weight $t_{i}=W_{i \text { (Male European \& Other) }} * W_{i \text { (Female European \& Other) }} * W_{i \text { (Male Māori) }} * W_{i}$

(Female Māori) $* W_{i \text { (Male Pacific) }} * W_{i \text { (Female Pacific) }} * W_{i \text { (Male Asian) }} * W_{i \text { (Female Asian) }}+W_{i \text { (Council }}$ Region) $+c$

where $c$ was a constant value added to the weight for each participant so that the average weight across participants was 1.00 . The weighting value for a given demographic factor, $W_{i}$, was defined as a ratio of the known proportion of that demographic group in the population, $P_{i(p o p)}$, relative to the sampled proportion, $P_{i(\text { sample })}$ as in Equation (6.0). 
$W_{i}=P_{i(p o p)} / P_{i(\text { sample })}$

Population estimates used to calculate these weights were based on $2013 \mathrm{New}$ Zealand Census data for people 15 years of age and over. The census provided information in the age bracket from 15-19. Because our sample included those aged 18 and older, to adjust for this bias, we estimated census proportions for those over 18 by down-weighting the frequencies for this age bracket by a factor of $2 / 5$. Sample and population proportions for each demographic variable on which sample weights were based are presented in Table 7. The weighting values for each demographic variable and residential location are also reported.

Table 7. Weighting values provided for the Time 7 (2015) NZAVS.

\begin{tabular}{|c|c|c|c|}
\hline & $P_{i(p o p)}$ & $P_{i \text { (sample) }}$ & $W_{i}$ \\
\hline \multicolumn{4}{|l|}{ Māori Male } \\
\hline Yes & 0.0515 & 0.0401 & 1.2858 \\
\hline No & 0.9485 & 0.9559 & 0.9881 \\
\hline \multicolumn{4}{|l|}{ Māori Female } \\
\hline Yes & 0.0598 & 0.0795 & 0.7532 \\
\hline No & 0.9402 & 0.9205 & 1.0213 \\
\hline \multicolumn{4}{|l|}{ Pacific Male } \\
\hline Yes & 0.0253 & 0.0100 & 2.5209 \\
\hline No & 0.9747 & 0.9900 & 0.9846 \\
\hline \multicolumn{4}{|l|}{ Pacific Female } \\
\hline Yes & 0.0277 & 0.0206 & 1.3459 \\
\hline No & 0.9723 & 0.9794 & 0.9927 \\
\hline \multicolumn{4}{|l|}{ Asian Male } \\
\hline Yes & 0.0511 & 0.0147 & 3.4771 \\
\hline No & 0.9489 & 0.9853 & 0.9630 \\
\hline \multicolumn{4}{|l|}{ Asian Female } \\
\hline Yes & 0.0576 & 0.0244 & 2.3607 \\
\hline No & 0.9424 & 0.9756 & 0.9660 \\
\hline \multicolumn{4}{|l|}{ European/Other Male } \\
\hline Yes & 0.3470 & 0.3410 & 1.0177 \\
\hline No & 0.6530 & 0.6590 & 0.9908 \\
\hline \multicolumn{4}{|l|}{ European/Other Female } \\
\hline Yes & 0.3799 & 0.5766 & 0.6588 \\
\hline No & 0.6201 & 0.4234 & 1.4647 \\
\hline \multicolumn{4}{|l|}{ Council Region } \\
\hline Auckland Region & 0.3337 & 0.2956 & 1.1291 \\
\hline Bay of Plenty Region & 0.0631 & 0.0606 & 1.0417 \\
\hline Canterbury Region & 0.1272 & 0.1355 & 0.9389 \\
\hline Gisbourne Region & 0.0103 & 0.0088 & 1.1668 \\
\hline Hawke's Bay Region & 0.0356 & 0.0349 & 1.0227 \\
\hline Manawatu-Wanganui Region & 0.0525 & 0.0504 & 1.0414 \\
\hline Marlborough Region & 0.0102 & 0.0118 & 0.8651 \\
\hline Nelson Region & 0.0109 & 0.0139 & 0.7870 \\
\hline Northland Region & 0.0358 & 0.0338 & 1.0566 \\
\hline Otago Region & 0.0477 & 0.0529 & 0.9020 \\
\hline Southland Region & 0.0220 & 0.0184 & 1.1987 \\
\hline Taranaki Region & 0.0258 & 0.0222 & 1.1662 \\
\hline
\end{tabular}


Tasman Region

Waikato Region

Wellington Region

West Coast Region
0.0111

0.0952

0.1111

0.0076
0.0138

0.0802

0.1426

0.0073
0.8075

1.1859

0.7791

1.0362 


\section{Chapter 6 - Geographic data structure}

\section{Note on companion document}

This document is in two parts. This document (Part A) provides an overview of the structure of geographic data files used by the New Zealand census and linked to the NZAVS. Part B (the associated excel file) provides an exhaustive geographic key and variable names for aggregate information from the 2001, 2006 and 2014 census about area and regional characteristics included in the NZAVS). The companion document is available at www.nzavs.auckland.ac.nz

\section{Geographic structure}

New Zealand is unusual in having rich census information about each area unit/neighborhood of the country available for research purposes. The smallest of these area units are meshblocks. The geographic size of these meshblock units differs depending on population density. Each unit tends to cover a region containing a median of roughly 81 residents $(\mathrm{M}=95.95, \mathrm{SD}=73.49$, range $=0-1899)$. In 2013, at the time of the latest census, there were a total of 44,211 meshblocks for which data were available. The distribution of usually resident population of the 44,211 meshblocks for which data were available from the 2013 New Zealand National Census is presented in Figure 1.

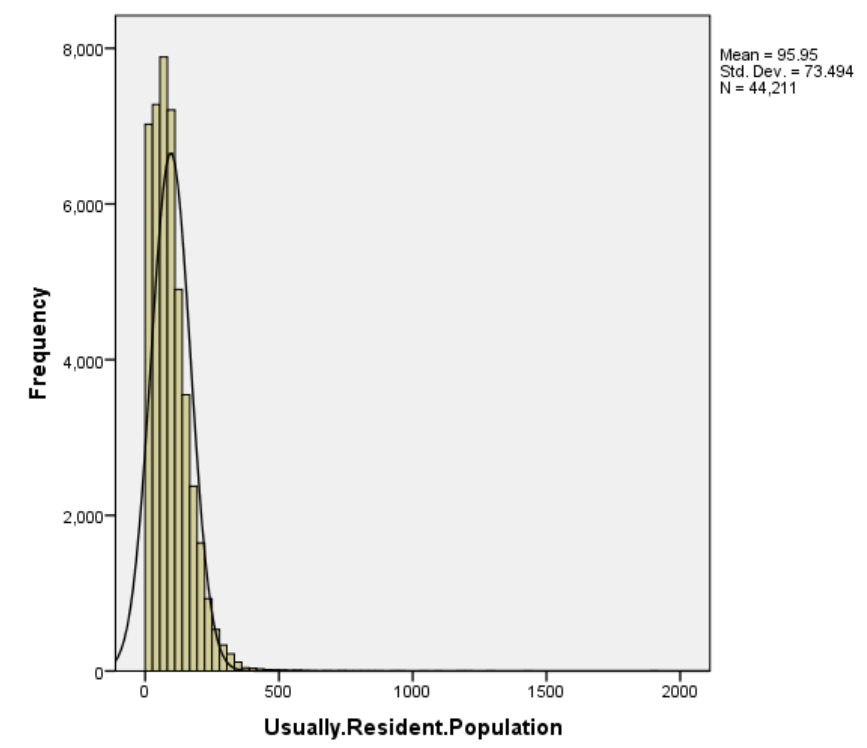

Figure 1. Histogram showing distribution of Usually Resident Population of 44,211 meshblocks based on the 2013 New Zealand National Census.

Statistics New Zealand (2013) define a meshblock as "a defined geographic area, varying in size from part of a city block to large areas of rural land. Each meshblock abuts against another to form a network covering all of New Zealand including coasts and inlets, and extending out to the two hundred mile economic zone. Meshblocks are added together to 'build up' larger geographic areas such as area units and urban areas." These units (in order of their size) are presented in Table 1 . The mean and median usually resident population of 
these areas based on 2013 census data are also reported. The organization of these and other geographic areas used in New Zealand is presented in Figure 1.

Table 1. Mean and median resident population of geographic areas based on 2013 Census

Data.

\begin{tabular}{llll}
\hline & \multirow{2}{*}{ Num. Units } & \multicolumn{2}{c}{ Usually resident population } \\
Median
\end{tabular}

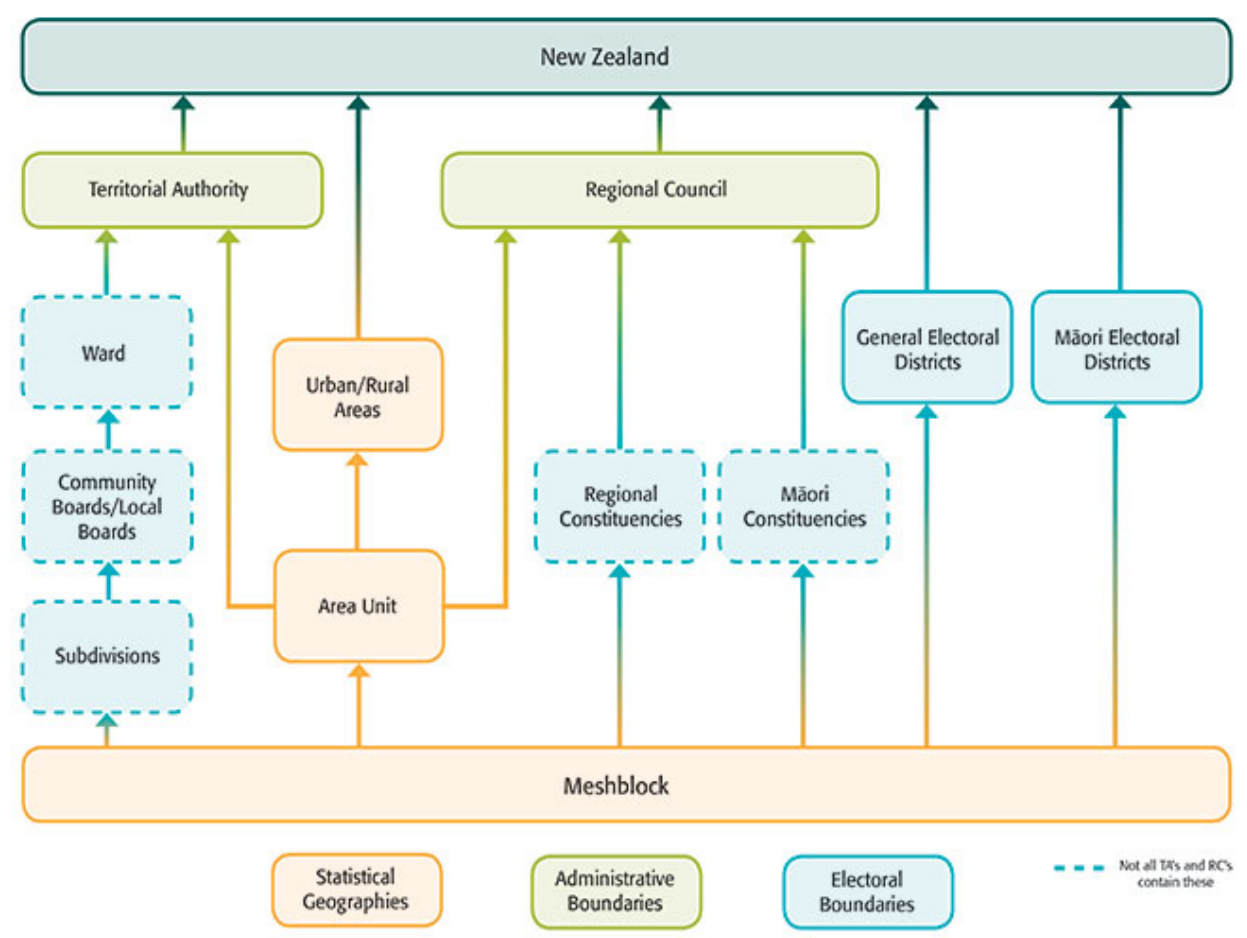

Figure 1. Geographic hierarchy of areas in New Zealand. (Available at:

http://www.stats.govt.nz/methods/classifications-and-standards/geographic-hierarchy.aspx)

The NZAVS includes meshblock area unit information for each participant. Building up from these meshblock codes, the NZAVS also includes information for the complete set of geographic areas presented in Figure 1. 


\section{Territorial authorities}

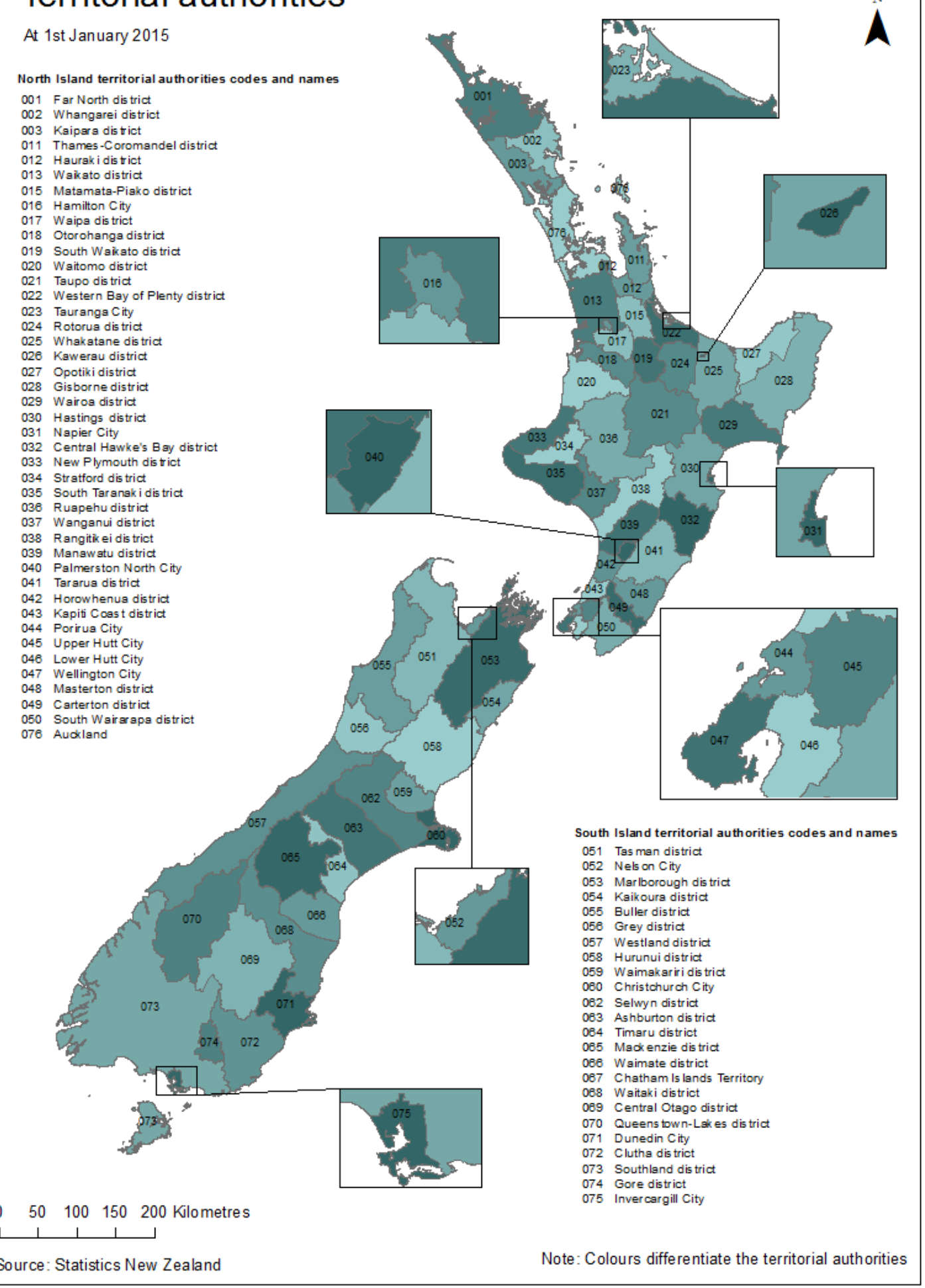

Figure 2. Map of New Zealand with territorial authorities (source: Statistics New Zealand http://www.stats.govt.nz/browse for_stats/Maps and_geography/Geographic-areas/digitalboundary-layers.aspx). 


\section{Census information}

New Zealand is also fairly unusual in that extensive aggregate demographic data from our national census is available for each area unit. At its most fine-grained this information is available for all meshblock area units (with rounding or missing data for areas in which a very small number of people reside in order to protect individual privacy). The NZAVS dataset also includes the full and complete set of publicly available data from the 2001, 2006 and 2013 New Zealand national censuses about the geographic area of each participant. This information is included for two area classifications:

- Area Units (2020 units, median $=1977$ residents per unit)

- Wards (257 units, median $=6378$ residents per unit)

We opted to include information about these two area classifications because such information provides viable-sized samples when estimating regional clustering effects using multilevel random coefficient models, and so forth. The geographic unit of interest will of course depend on the nature of the theoretical question aiming to be answered, but we generally recommend that Area Units are appropriate for analyses seeking to look at the links between NZAVS sample responses and fine-grained information about immediate area units (and where one is modelling fixed-effects). In contrast, for research questions focused on the broader overall contextual effects of neighborhoods, we recommend that Wards be used as the grouping variable. The NZAVS sample size provides enough participants nested within each ward to pursue viable estimates of random effects (something not always viable when analyzing area unit clustering due to the limited number of participants per area unit).

The completed list of demographic information available in the NZAVS dataset at both the Area Unit and Ward level is provided in Part B of this document.

Notes

Further information about available census data and geographic area files is available on Statistics New Zealand website:

http://www.stats.govt.nz/browse for_stats/people_and_communities/Geographicareas/geographic-area-files.aspx\#customisedgeog

Note that the New Zealand Attitudes and Values Study (NZAVS) is not associated with the Census or with Statistics New Zealand. The views in the document are the opinion of the NZAVS research team. Data from the New Zealand census about geographic areas are publicly available and we have integrated them with the NZAVS at the meshblock and area unit level. NZAVS data, however, are not publicly available. 
Geographic Information

Census Year Availability

New Zealand Deprivation Index (Area Unit only)

Census usually resident population count

2001

2001

2006

2006

2013

Census night population count

Sex, for the census usually resident population count

Age in five year groups, for the census usually resident population count

2001

2006

20012006

20012006

Age in broad groups, for the census usually resident population count

Years at usual residence, for the census usually resident population count

20012006

Usual residence five years ago (2008) indicator, for the census usually resident population count

Birthplace, for the census usually resident population count

Years since arrival in New Zealand, for the overseas-born census usually resident population count

Ethnic group (grouped total responses), for the census usually resident population count

Six languages (total responses), for the census usually resident population count

Mãori descent, for the census usually resident population count

Religious affiliation (total responses), for the census usually resident population count

Cigarette smoking behaviour, for the census usually resident population count aged 15 years and over

Legally registered relationship status, for the census usually resident population count aged 15 years and over

Partnership status in current relationship, for the census usually resident population count aged 15 years and over

Tenure holder, for the census usually resident population count aged 15 years and over

Number of children born alive, for the female census usually resident population count aged 15 years and over

Highest qualification, for the census usually resident population count aged 15 years and over

Study participation, for the census usually resident population count aged 15 years and over

Total personal income (grouped), for the census usually resident population count aged 15 years and over

Sources of personal income, for the census usually resident population count aged 15 years and over

Work and labour force status, for the census usually resident population count aged 15 years and over

Status in employment, for the employed census usually resident population count aged 15 years and over

Occupation (ANZSCO major group), for the employed census usually resident population count aged 15 years and over

Occupation (ANZSCO major group), for workplace address, for the employed census usually resident population count aged 15 years and over

Occupation (NZSCO99 major group), for the employed census usually resident population count aged 15 years and over

Occupation (NZSCO99 major group), for workplace address, for the employed census usually resident population count aged 15 years and over

$\begin{array}{lll}2001 & 2006 & 2013 \\ 2001 & 2006 & 2013 \\ 2001 & 2006 & 2013 \\ 2001 & 2006 & 2013 \\ 2001 & 2006 & 2013 \\ 2001 & 2006 & 2013 \\ & 2006 & 2013 \\ 2001 & 2006 & 2013 \\ 2001 & 2006 & 2013 \\ 2001 & 2006 & 2013 \\ & 2006 & 2013 \\ & 2006 & 2013 \\ & 2006 & 2013 \\ 2001 & 2006 & 2013 \\ 2001 & 2006 & 2013 \\ 2001 & 2006 & 2013 \\ 2001 & 2006 & 2013 \\ & 2006 & 2013 \\ & 2006 & 2013 \\ 2001 & 2006 & 2013 \\ 2001 & 2006 & 2013\end{array}$


Industry (ANZSIC06 division), for the employed census usually resident population count aged 15 years and over

Industry (ANZSIC06 division), for workplace address, for the employed census usually resident population count aged 15 years and over

Industry (ANZSIC96 division), for workplace address, for the employed census usually resident population count aged 15 years and over

Total household income (grouped), for households in occupied private dwellings

Sources of household income, for households in occupied private dwellings

Tenure of household, for households in occupied private dwellings

Family type, for families in occupied private dwellings

Total family income (grouped), for families in occupied private dwellings 


\section{Chapter 7 - Power Estimation of Slope Growth Factors in the NZAVS using Monte Carlo Simulation}

\section{Overview}

This chapter describes results from a series of models we have developed to estimate the statistical power of latent growth parameters in the NZAVS using Monte Carlo simulation. The models are tailored specifically for the NZAVS, and the simulated data approximate the actual NZAVS data structure. Specifically, our simulations approximate the NZAVS datasets in terms of sample size for previous waves (Waves 1-5), projected sample size for future waves (Waves 6-10), and the structure of missing data introduced by both sample attrition and booster sampling occurring at various points during the first five years of the study.

Sample size in these models is thus known, or can be predicted with reasonable accuracy, as can missing data (with some exceptions). These parameters are thus held constant in our models. This allows us to estimate the statistical power that the NZAVS can be expected to achieve under the following conditions:

(a) Depending on the effect size for the latent growth parameter of interest,

(b) given other reasonable default parameter settings in latent growth models of NZAVS data,

(c) the complexity of the latent growth model (e.g., number of time-invariant covariates, estimation of second-order polynomial curves, etc), and

(d) depending on whether the model is tested using the currently available (as of 2014) first five waves of the NZAVS, or whether one waits for a given number of subsequent waves of data to be collected.

It is this last parameter (d) that is of critical interest to us, because holding other parameters constant, our simulations can thus provide projections about how many waves of data are needed to test latent growth curve models of varying complexity and still achieve power of .80 (a typical default for acceptable power) to detect the parameter of interest given the expected size of that parameter.

\section{Power Estimation Using Monte Carlo Simulation in Mplus: A Brief Overview}

We adapted the procedures outlined by Muthén and Muthén (2002) to estimate statistical power. Muthén and Muthén (2002, p. 606) provide the following summary of power estimation in Mplus, and we repeat it here:

Power is evaluated using the information in the column "labelled \% Sig Coeff. This column gives the proportion of replications for which the null hypothesis that a parameter is equal to zero is rejected for each parameter at the .05 level (two-tailed test with a critical value of 1.96). The statistical test is the ratio of the parameter estimate to its standard error, an approximately normally distributed quantity (z-score) in large samples. For parameters with population values different from zero, this value is an estimate of power, that is, the probability of rejecting the null hypothesis when it is false. For parameters with population values equal 
to zero, this value is an estimate of Type I error, that is, the probability of rejecting the null hypothesis when it is true.

-- Muthén and Muthén (2002, p. 606)

We followed the general recommendations outlined by Muthén and Muthén (2002) for determining adequate models when estimating desired sample size. Muthén and Muthén $(2002$, p. 8) summarized these as follows, and we apply them to our estimates of power when varying different model parameters (rather than to estimate sample size): "The first criterion is that parameter and standard error biases do not exceed 10 percent for any parameter in the model. The second criterion is that the standard error bias for the parameter for which power is being assessed does not exceed 5 percent. The third criterion is that coverage remains between 0.91 and $0.98 . "$

\section{Known and Projected NZAVS Data Characteristics}

Because the first 5 waves of the NZAVS have been collected, we know quite a lot already about the structure of the data and thus aimed to approximate the actual NZAVS data structure in our models. As of the end of Wave 5, the NZAVS contains $\sim 23,000$ unique participants. There are currently about 3500 'loyal stayers' in the NZAVS, that is, people who have participated since Wave 1, and have completed all of the first 5 Waves. Many more people have completed at least 4 of the first 5 waves.

In 2009 , at Wave I, the NZAVS randomly sampled a total of 6,518 registered voters from the New Zealand electoral roll.

In 2010, the NZAVS sampled 4,423 people retained from Wave I (retention rate from Wave $\mathrm{I}=68 \%$ ).

In 2011, the NZAVS sampled 6,884 New Zealanders, with 3,916 people retained from Wave I and a booster sample of 2,961 new participants (retention rate from Wave I = $60 \%$, wave-to-wave retention from previous year $=80 \%$ ).

In 2012, the NZAVS sampled 12,182 New Zealanders, with 4,054 people retained from Wave I and a booster sample of 5,377 new participants (retention rate from Wave I = $62 \%$, wave-to-wave retention from previous year $=84 \%$ ).

In 2013, the NZAVS sampled 18,211 New Zealanders, with 3,941 people retained from Wave I and a booster sample of 7,639 new participants (retention rate from Wave I = $61 \%$, wave-to-wave retention from previous year $=81 \%$ ).

Sibley (2014, NZAVS Tech Docs, e18) derived Eq 1.0 predicting sample retention from Wave 6 onwards:

$$
\mathrm{y}_{\mathrm{w}}=22764 \mathrm{e}^{-0.223 \mathrm{w}}
$$

This simple model summarizes a rate of decay in the number of people sampled holding constant a wave-by-wave retention rate of $80 \%$, where: $y=$ the predicted number of people retained in the NZAVS at a given wave (w). For simplicity, Wave 1 in this model represents Time 5 as this was the current wave of the sample from which this model was derived. So setting $\mathrm{w}=2$ estimates the projected number of people who should complete Wave 6 (or the 2014 phase), $\mathrm{w}=3$ estimates the projected number of people who should complete Wave 7 (or the 2015 phase), and so forth. Sample projections are thus as follows: 
Table 1. Projected sample sizes (from Sibley, 2014).

\begin{tabular}{llrr}
\hline wave & year & w & \multicolumn{2}{c}{$\begin{array}{l}\text { sample } \\
\text { projection }\end{array}$} \\
\hline Wave 5 & 2013 & 1 & 18214 \\
Wave 6 & 2014 & 2 & 14573 \\
Wave 7 & 2015 & 3 & 11660 \\
Wave 8 & 2016 & 4 & 9329 \\
Wave 9 & 2017 & 5 & 7465 \\
Wave 10 & 2018 & 6 & 5973 \\
\hline
\end{tabular}

\section{Data Simulation}

All models were estimated using Mplus 7.3. Given the known and projected sample details outlined above, we generated simulation data with the following parameters:

- $\mathrm{N}=23,000$

- Variables are normally distributed.

- No missing data for $13 \%$ of cases. This ensures that the minimum possible number of loyal stayers is 3000 . This is a clear underestimate for models only using data from Wave $1-5$. Given random data generated for the remaining $87 \%$ of the sample, simulation data for Wave $1-5$ tended to give a number of loyal stayers of $\sim 3400$ 3500. Setting this value of 3000 also allows for a decrease in loyal stayers in subsequent waves.

- Data were generated with Missing at Random (MAR) for the remaining $87 \%$ of the total N. To allow for variation in sample size across time, we specified specific estimates of the proportion of missing data in this $87 \%$ at each wave. Note that this did not simply apply the decay function equation outlined in Eq. 1 because the data include independent booster samples conducted during Waves 3, 4 and 5.

- Table 2 presents the proportions of data missing completely at random that was specified for each wave for the $87 \%$ for which missing data were allowed, and the $13 \%$ which (by definition) did not have missing data. For example, at Wave 1, we calculated the proportion of missing data for the $87 \%$ for which missing data were allowed using Eq. 2.0:

1 - (Wave N - Loyal Stayer N) / Grand N, or

$1-(6518-3000) / 23000$

- For Wave 1-5, Wave $\mathrm{N}$ was a known value. For Waves $6-10$, Wave $\mathrm{N}$ was an estimate derived from $\mathrm{Eq} 1.0$ 
Table 2. Proportions of missing data estimated for each wave (T1 - T5 based on known values, T6-10 based on sample projections).

\begin{tabular}{|c|c|c|c|c|c|c|c|c|c|c|}
\hline Grand N & 23000.000 & & & & & & & & & \\
\hline Loyal Stayers & 3000.000 & & & & & & & & & \\
\hline \multirow[t]{2}{*}{ Prop Loyal Stayers } & 0.130 & & & & & & & & & \\
\hline & $\mathrm{T} 1$ & $\mathrm{~T} 2$ & $\mathrm{~T} 3$ & $\mathrm{~T} 4$ & $\mathrm{~T} 5$ & T6 & $\mathrm{T} 7$ & $\mathrm{~T} 8$ & T9 & $\mathrm{T} 10$ \\
\hline Wave $\mathrm{N}$ & 6518.000 & 4442.000 & 6884.000 & 12182.000 & 18211.000 & 14573.000 & 11660.000 & 9329.000 & 7465.000 & 5973.000 \\
\hline Wave N / Grand N & 0.283 & 0.193 & 0.299 & 0.530 & 0.792 & 0.634 & 0.507 & 0.406 & 0.325 & 0.260 \\
\hline Wave N - Loyal Stayers N & 0.153 & 0.063 & 0.169 & 0.399 & 0.661 & 0.503 & 0.377 & 0.275 & 0.194 & 0.129 \\
\hline Prop Loyal Stayers & 0.130 & 0.130 & 0.130 & 0.130 & 0.130 & 0.130 & 0.130 & 0.130 & 0.130 & 0.130 \\
\hline $\begin{array}{l}\text { Prop Missing from Grand N } \\
\text { (varying component) }\end{array}$ & 0.847 & 0.937 & 0.831 & 0.601 & 0.339 & 0.497 & 0.623 & 0.725 & 0.806 & 0.871 \\
\hline $\begin{array}{l}\text { Prop Missing from Grand N (loyal } \\
\text { stayer component) }\end{array}$ & 0.870 & 0.870 & 0.870 & 0.870 & 0.870 & 0.870 & 0.870 & 0.870 & 0.870 & 0.870 \\
\hline
\end{tabular}


- It is important to note that we simulated data as Missing at Random (MAR). While this mimics the obtained and projected sample sizes for each wave, our simulation did not include specific decay functions for the booster samples collected during Waves $3-5$.

- The NZAVS and simulated data have a comparable number of people who completed only one wave to those in the simulated data. However, in the NZAVS, these people completed only the wave in which they were initially booster sampled (and are thus most likely to be in Waves 1 or 5). In the simulated data, they are distributed across all waves. We thus tend to as a consequence under-estimate the $\mathrm{N}$ for unique cases in Wave 5 specifically.

The Mplus syntax for estimating missing data patterns in our simulations for the first 10 waves of the NZAVS was thus:

PATMISS = y1(.847) y2(.937) y3(.831) y4(.601) y5(.339) y6(.497) y7(.623) y8(.725) y9(.806) y10(.871) | y1(0) y2(0) y3(0) y4(0) y5(0) y6(0) y7(0) y8(0 y9(0) y10(0);

PATPROB $=.870 \mid .130$;

Where for PATMISS, y1 - y10 represent Waves $1-10$ of the study, and the values in parentheses represent the proportion of missing data.

PATPROB then extends this to specify that the first section of proportions should be estimated for $87 \%$ of simulated cases and the latter section of proportions (those with no missing values) should be simulated for $13 \%$ of cases.

Note that when estimating less than 10 waves of data, for e.g., 6 waves, the only the proportions for $\mathrm{y} 1-$ y6 would be included.

Table 3. Summary of missing data patterns for a simulated run using Waves $1-5$ and without covariates ( $\mathrm{x}=$ non-missing data).

\begin{tabular}{rrrrrr}
\hline $\mathrm{Y1}$ & $\mathrm{Y} 2$ & $\mathrm{Y3}$ & $\mathrm{Y} 4$ & $\mathrm{Y} 5$ & Sim. N \\
\hline & & & & $\mathrm{X}$ & 5853 \\
$\mathrm{X}$ & $\mathrm{X}$ & $\mathrm{X}$ & $\mathrm{X}$ & $\mathrm{X}$ & 4039 \\
& & & $\mathrm{X}$ & & 3402 \\
$\mathrm{X}$ & & $\mathrm{X}$ & & $\mathrm{X}$ & 1946 \\
& & & & $\mathrm{X}$ & 1243 \\
$\mathrm{X}$ & & $\mathrm{X}$ & $\mathrm{X}$ & $\mathrm{X}$ & 1100 \\
& & $\mathrm{X}$ & $\mathrm{X}$ & $\mathrm{X}$ & 717 \\
$\mathrm{X}$ & & & & & 598 \\
& $\mathrm{X}$ & & & $\mathrm{X}$ & 542 \\
& & $\mathrm{X}$ & $\mathrm{X}$ & & 406 \\
$\mathrm{X}$ & & & $\mathrm{X}$ & & 395 \\
& $\mathrm{X}$ & & $\mathrm{X}$ & $\mathrm{X}$ & 383 \\
& $\mathrm{X}$ & & & & 277 \\
$\mathrm{X}$ & & $\mathrm{X}$ & & $\mathrm{X}$ & 220 \\
$\mathrm{X}$ & & $\mathrm{X}$ & $\mathrm{X}$ & $\mathrm{X}$ & 203 \\
& $\mathrm{X}$ & & $\mathrm{X}$ & & 153 \\
$\mathrm{X}$ & & $\mathrm{X}$ & & & 118 \\
$\mathrm{X}$ & & $\mathrm{X}$ & $\mathrm{X}$ & & 113 \\
$\mathrm{X}$ & $\mathrm{X}$ & & & $\mathrm{X}$ & 73 \\
& $\mathrm{X}$ & $\mathrm{X}$ & & $\mathrm{X}$ & 63 \\
$\mathrm{X}$ & $\mathrm{X}$ & & $\mathrm{X}$ & $\mathrm{X}$ & 60 \\
& $\mathrm{X}$ & $\mathrm{X}$ & & & 44 \\
& $\mathrm{X}$ & $\mathrm{X}$ & $\mathrm{X}$ & $\mathrm{X}$ & 41
\end{tabular}




\begin{tabular}{rrrrrr}
$X$ & $X$ & & & & 33 \\
& $X$ & $X$ & $X$ & & 31 \\
$X$ & $X$ & & $X$ & & 22 \\
$X$ & $X$ & $X$ & & $X$ & 15 \\
$X$ & $X$ & $X$ & & & 11 \\
$X$ & $X$ & $X$ & $X$ & & 5 \\
\hline
\end{tabular}

\section{Model Specification: Overview}

We specified a series of Latent Growth models of varying complexity and estimated the statistical power achieved by each model when varying the size of key parameters of interest when analysed using the first 5 waves, first 6 waves, and so on up to Wave 10.

Models were estimated using between 10,000 and 50,000 replications and assuming normally distributed continuous indicators. We varied the number of replications within this range depending on the complexity of the model and closely monitored coverage and standard error biases to ensure an adequate replication (further details on the number of replication used in each model are available from the appendix).

Missing data were generated using MAR (as outlined in the section on missing data estimation above). We used Maximum Likelihood estimation. Latent Growth Models were estimated assuming a time-invariant and equally dispersed series. The means of indicators in our latent growth model were set at 0 , with variances $=.50$. The intercept of the latent growth models was fixed at 4.0 with variance $=1.0$. These default values were chosen because they generally approximate those observed in previous LGMs using NZAVS data. Syntax for a sample example of each model simulating 10 waves of data collection for each model type is included in the Appendix.

The models we estimated were:

- Model 1: LGM without covariates, varying the random effect of slope.

- Model 2: LGM without covariates, varying the mean of slope.

- Model 3: LGM with time-invariant covariate, varying the conditional effect of covariate on slope.

- Model 4: LGM with six time-invariant covariates, varying the conditional effect of focal covariate on slope.

- Model 5: LGM with second-order polynomial, varying the random effect of the quadratic component of the slope.

- Model 6: LGM with second-order polynomial, varying the mean of the quadratic component of the slope.

- Model 7: LGM with six covariates, varying the conditional effect of focal covariate on quadratic component of slope.

- Model 8: LGM where the effect of time-invariant covariate on the slope is moderated by the intercept of the growth factor.

- Model 9: Parallel process LGM, varying the regression of the intercept from one growth factor on the slope of the second growth factor. 
Model 1: LGM without covariates, varying the random effect of slope

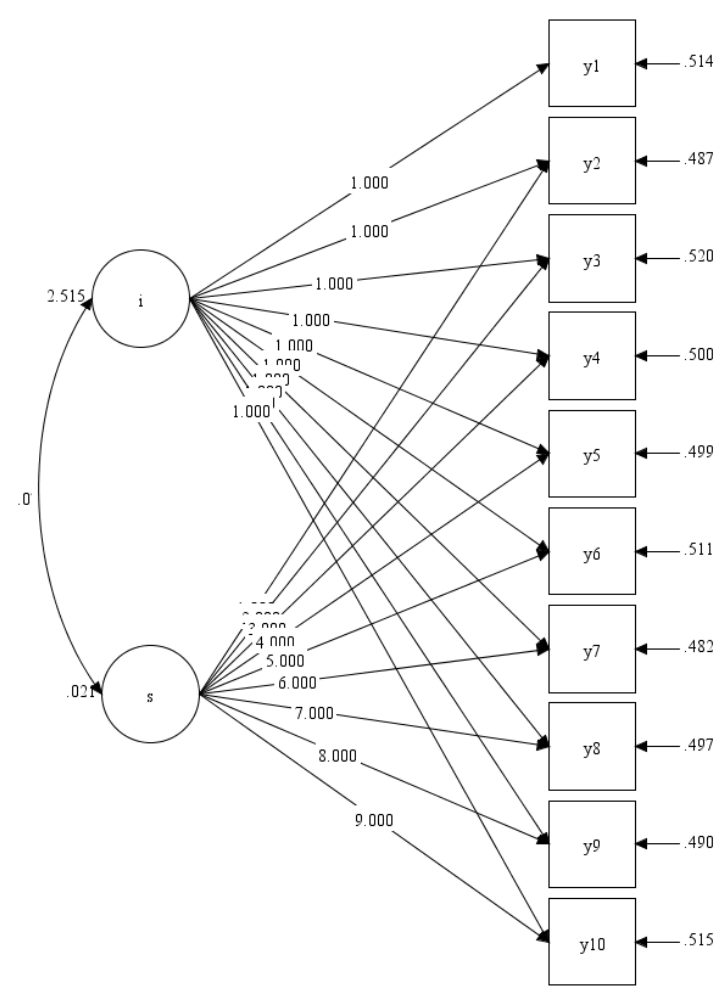

Figure 1. Example of Model 1 Simulating Waves $1-10$.

\section{Summary of model parameters}

- Equally dispersed fixed periods between each wave $(0,1,2$, etc)

- Models ranged from those simulating Waves 1-5 up to Waves 1-10

- Mean of y indicators set to 0 , residual variance of y indicators set to .50

- Intercept mean set to 4 , variance set to 1

- Slope mean set to 0 , variance ranged from .001 to .015

- Covariance of slope and intercept set to 0 (Refer to Appendix for Syntax) 


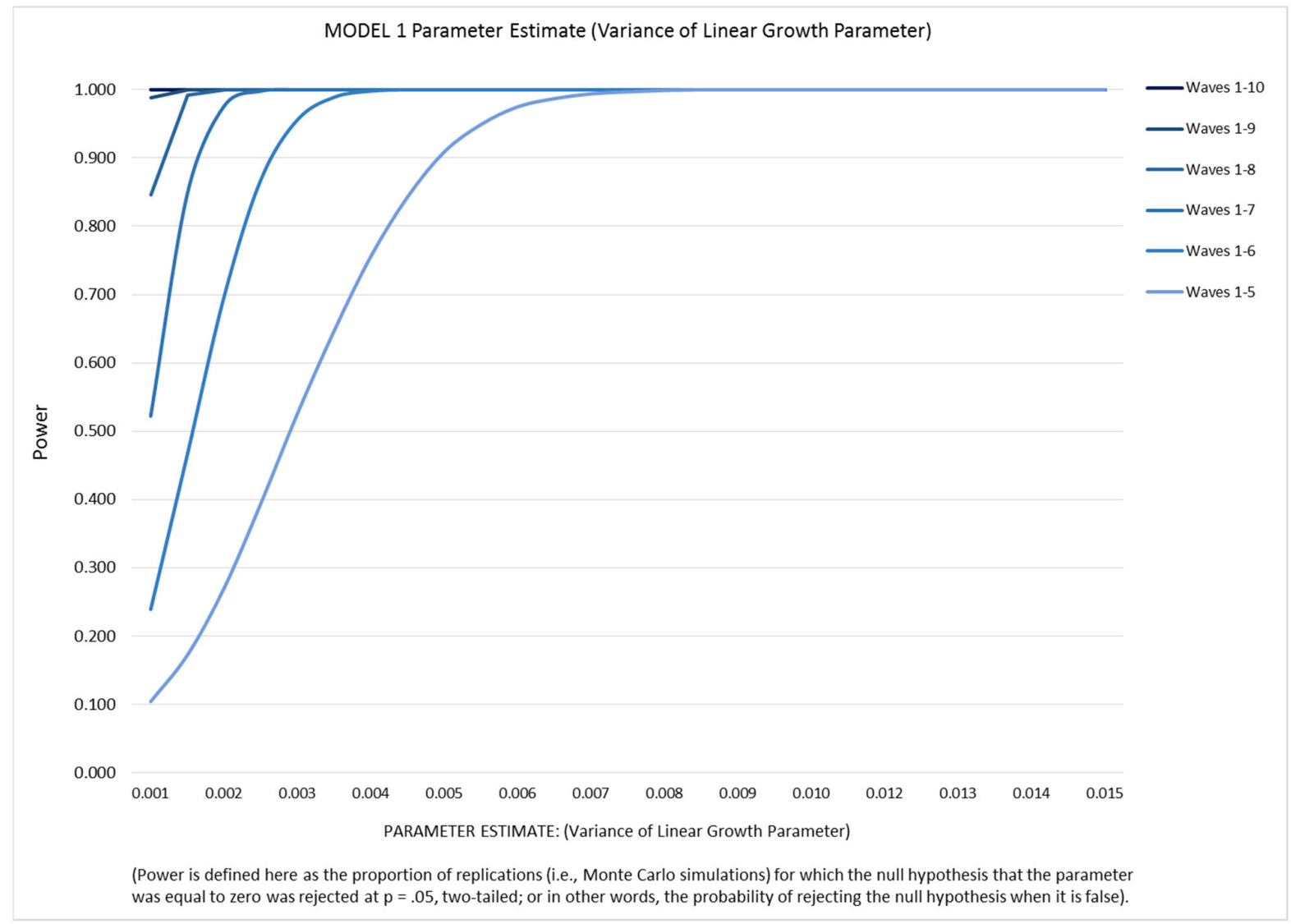

Figure 3. Power estimates for Model 1. 
Table 5. Tabulated power estimates for Model 1.

\begin{tabular}{|c|c|c|c|c|c|c|}
\hline $\begin{array}{l}\text { Effect } \\
\text { Size }\end{array}$ & Waves 1-5 & Waves 1-6 & Waves 1-7 & Waves 1-8 & Waves 1-9 & Waves $1-10$ \\
\hline .0010 & 0.104 & 0.239 & 0.522 & 0.846 & 0.988 & 1.000 \\
\hline .0015 & 0.172 & 0.466 & 0.848 & 0.992 & 1.000 & 1.000 \\
\hline .0020 & 0.270 & 0.697 & 0.976 & 1.000 & 1.000 & 1.000 \\
\hline .0025 & 0.394 & 0.868 & 0.998 & 1.000 & 1.000 & 1.000 \\
\hline .0030 & 0.526 & 0.956 & 1.000 & 1.000 & 1.000 & 1.000 \\
\hline .0035 & 0.647 & 0.989 & 1.000 & 1.000 & 1.000 & 1.000 \\
\hline .0040 & 0.756 & 0.998 & 1.000 & 1.000 & 1.000 & 1.000 \\
\hline .0045 & 0.843 & 1.000 & 1.000 & 1.000 & 1.000 & 1.000 \\
\hline .0050 & 0.909 & 1.000 & 1.000 & 1.000 & 1.000 & 1.000 \\
\hline .0055 & 0.949 & 1.000 & 1.000 & 1.000 & 1.000 & 1.000 \\
\hline .0060 & 0.975 & 1.000 & 1.000 & 1.000 & 1.000 & 1.000 \\
\hline .0065 & 0.987 & 1.000 & 1.000 & 1.000 & 1.000 & 1.000 \\
\hline .0070 & 0.994 & 1.000 & 1.000 & 1.000 & 1.000 & 1.000 \\
\hline .0075 & 0.997 & 1.000 & 1.000 & 1.000 & 1.000 & 1.000 \\
\hline .0080 & 0.999 & 1.000 & 1.000 & 1.000 & 1.000 & 1.000 \\
\hline .0085 & 1.000 & 1.000 & 1.000 & 1.000 & 1.000 & 1.000 \\
\hline .0090 & 1.000 & 1.000 & 1.000 & 1.000 & 1.000 & 1.000 \\
\hline .0095 & 1.000 & 1.000 & 1.000 & 1.000 & 1.000 & 1.000 \\
\hline .0100 & 1.000 & 1.000 & 1.000 & 1.000 & 1.000 & 1.000 \\
\hline .0105 & 1.000 & 1.000 & 1.000 & 1.000 & 1.000 & 1.000 \\
\hline .0120 & 1.000 & 1.000 & 1.000 & 1.000 & 1.000 & 1.000 \\
\hline .0125 & 1.000 & 1.000 & 1.000 & 1.000 & 1.000 & 1.000 \\
\hline .0130 & 1.000 & 1.000 & 1.000 & 1.000 & 1.000 & 1.000 \\
\hline .0135 & 1.000 & 1.000 & 1.000 & 1.000 & 1.000 & 1.000 \\
\hline .0140 & 1.000 & 1.000 & 1.000 & 1.000 & 1.000 & 1.000 \\
\hline .0145 & 1.000 & 1.000 & 1.000 & 1.000 & 1.000 & 1.000 \\
\hline .0150 & 1.000 & 1.000 & 1.000 & 1.000 & 1.000 & 1.000 \\
\hline
\end{tabular}


Model 2: LGM without covariates, varying the mean of slope

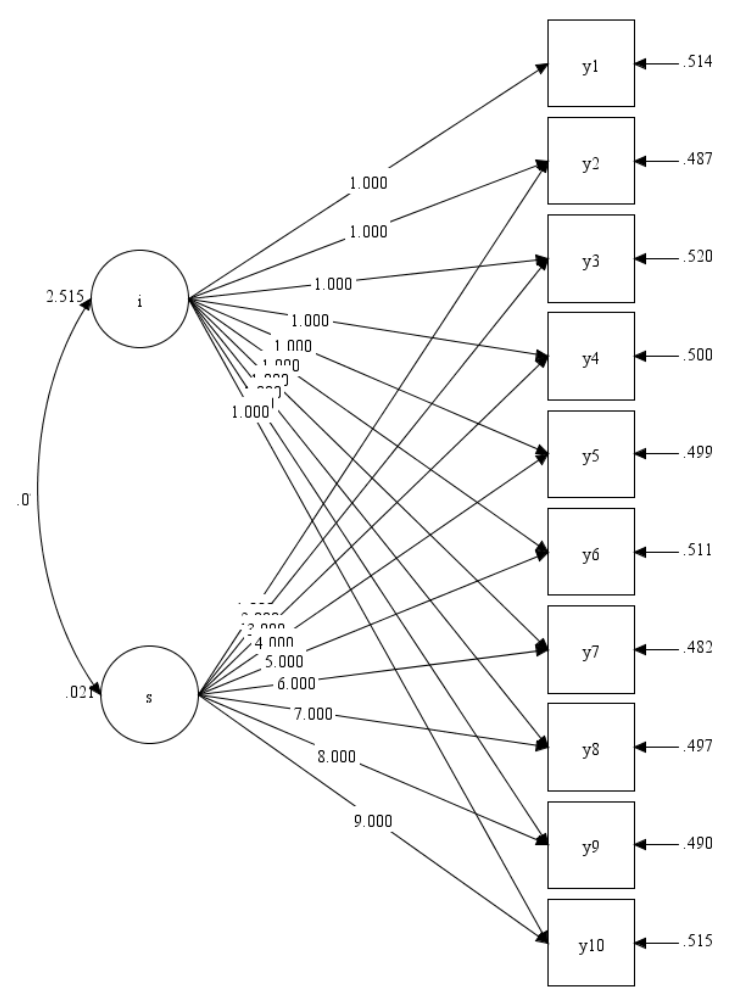

Figure 4. Example Model 2 Simulating Waves $1-10$.

\section{Summary of model parameters}

- Equally dispersed fixed periods between each wave $(0,1,2$, etc)

- Models ranged from those simulating Waves 1-5 up to Waves 1-10

- Mean of y indicators set to 0 , residual variance of y indicators set to .50

- Intercept mean set to 4 , intercept variance set to 1

- Slope mean set to 0 , slope variance ranged from .001 to .015

- Covariance of slope and intercept set to 0 (Refer to Appendix for Syntax) 


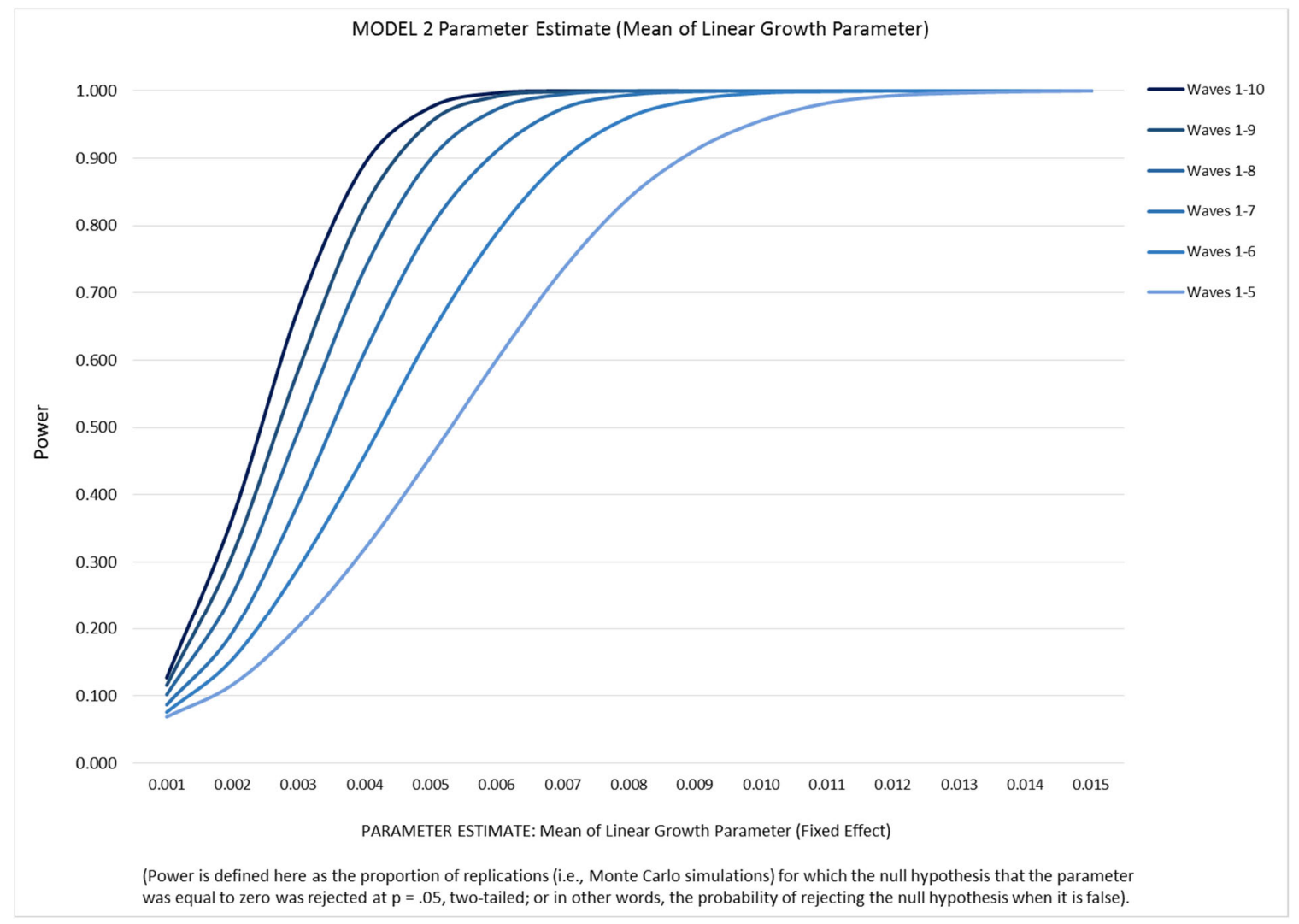

Figure 5. Power estimates for Model 2.

Table 6. Tabulated power estimates for Model 2.

\begin{tabular}{lrrrrrr}
\hline \multicolumn{1}{l}{$\begin{array}{l}\text { Effect } \\
\text { Size }\end{array}$} & Waves 1-5 & Waves 1-6 & Waves 1-7 & Waves 1-8 & Waves 1-9 & Waves 1-10 \\
\hline 0.001 & 0.069 & 0.076 & 0.087 & 0.102 & 0.116 & 0.127 \\
0.002 & 0.117 & 0.155 & 0.195 & 0.253 & 0.312 & 0.367 \\
0.003 & 0.204 & 0.292 & 0.389 & 0.496 & 0.587 & 0.678 \\
0.004 & 0.320 & 0.459 & 0.612 & 0.736 & 0.828 & 0.892 \\
0.005 & 0.457 & 0.639 & 0.798 & 0.899 & 0.954 & 0.976 \\
0.006 & 0.601 & 0.789 & 0.911 & 0.973 & 0.992 & 0.997 \\
0.007 & 0.735 & 0.899 & 0.974 & 0.995 & 0.999 & 1.000 \\
0.008 & 0.841 & 0.961 & 0.994 & 1.000 & 1.000 & 1.000 \\
0.009 & 0.912 & 0.987 & 0.999 & 1.000 & 1.000 & 1.000 \\
0.010 & 0.956 & 0.997 & 1.000 & 1.000 & 1.000 & 1.000 \\
0.011 & 0.982 & 0.999 & 1.000 & 1.000 & 1.000 & 1.000 \\
0.012 & 0.993 & 1.000 & 1.000 & 1.000 & 1.000 & 1.000 \\
0.013 & 0.997 & 1.000 & 1.000 & 1.000 & 1.000 & 1.000 \\
0.014 & 0.999 & 1.000 & 1.000 & 1.000 & 1.000 & 1.000 \\
0.015 & 1.000 & 1.000 & 1.000 & 1.000 & 1.000 & 1.000 \\
\hline
\end{tabular}


Model 3: LGM with time-invariant covariate, varying the conditional effect of covariate on slope

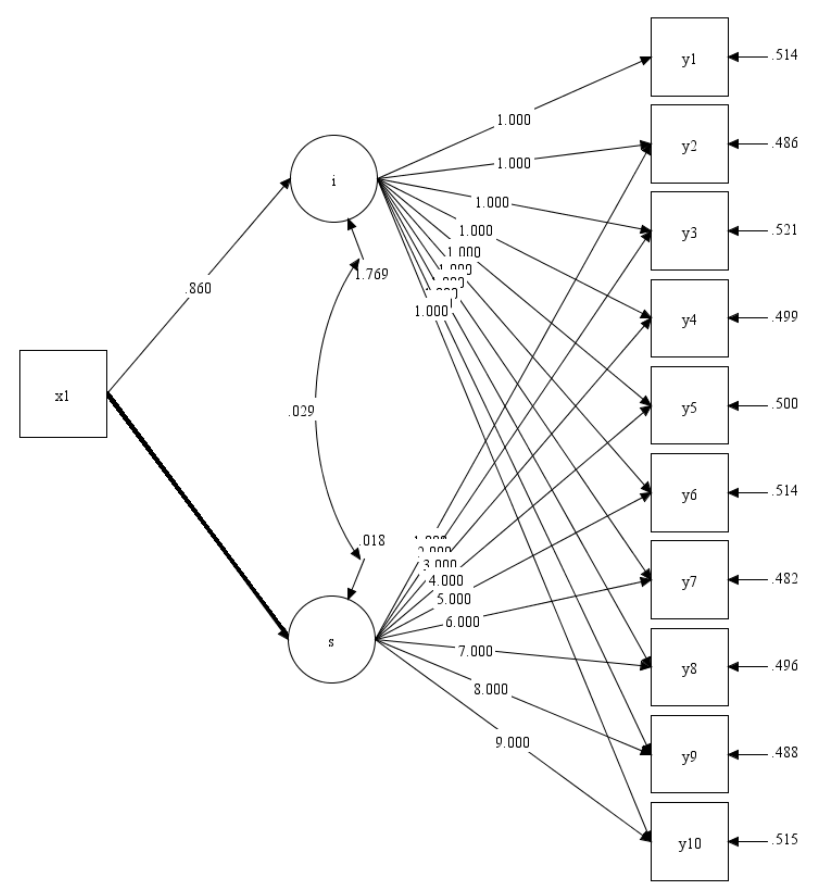

Figure 6. Example Model 3 Simulating Waves $1-10$.

\section{Summary of model parameters}

- Equally dispersed fixed periods between each wave $(0,1,2$, etc)

- Models ranged from those simulating Waves 1-5 up to Waves 1-10

- Mean of y indicators set to 0 , residual variance of y indicators set to .50

- Means of $x 1$ covariate set to 0 , variance of $\mathrm{x}$ indicators set to 1 .

- Intercept mean set to 4 , intercept variance set to 1

- Slope mean set to .01, slope variance set to .01

- Covariance of slope and intercept set to -.05

- Regression of intercept on time-invariant covariate set to .30

- Regression of slope on time-invariant covariate ranged from .001 to .015 (Refer to Appendix for Syntax) 


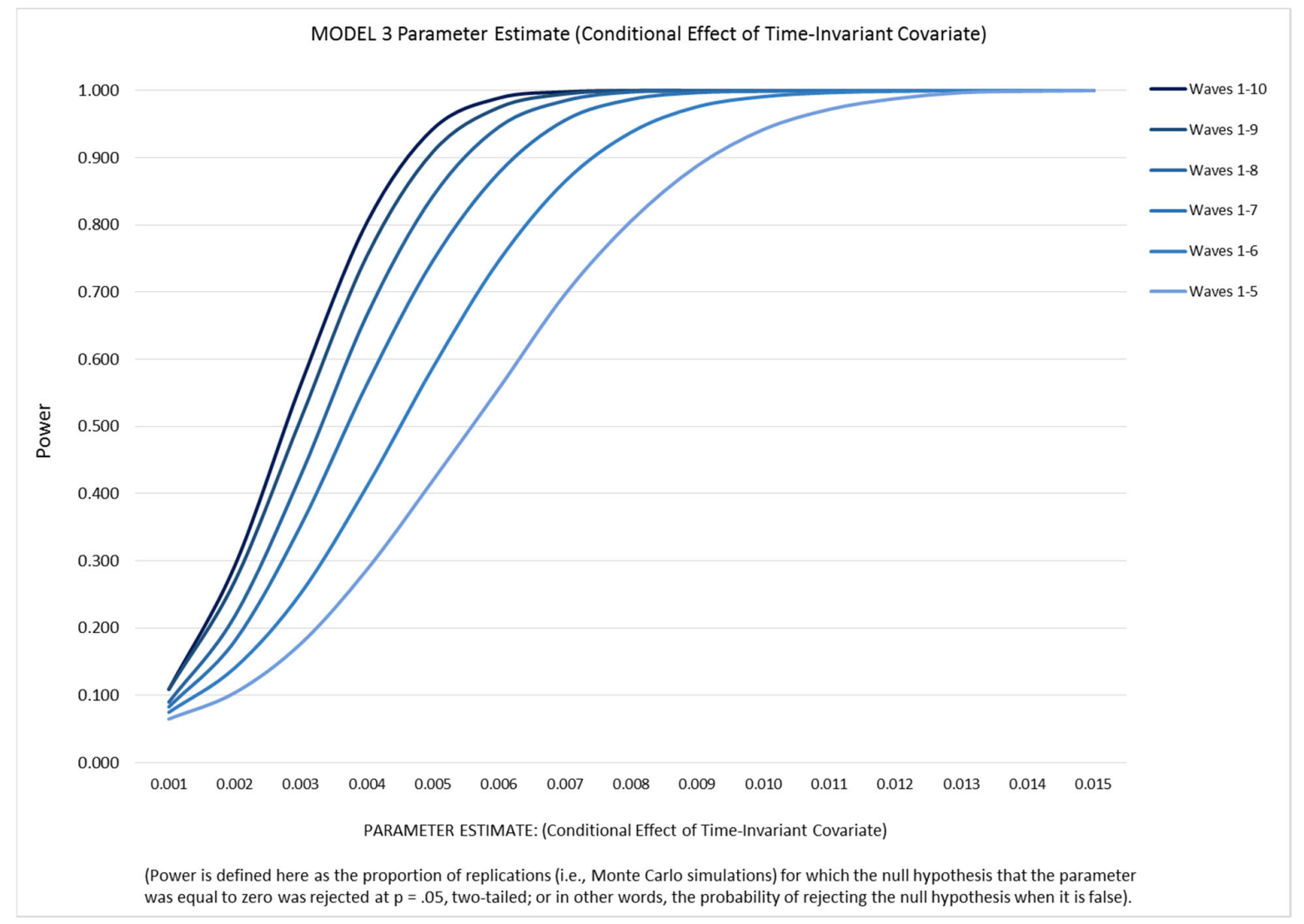

Figure 7. Power estimates for Model 3.

Table 7. Tabulated power estimates for Model 3.

\begin{tabular}{lrrrrrr}
\hline \multicolumn{1}{l}{$\begin{array}{l}\text { Effect } \\
\text { Size }\end{array}$} & Waves 1-5 & Waves 1-6 & Waves 1-7 & Waves 1-8 & Waves 1-9 & Waves 1-10 \\
\hline 0.001 & 0.065 & 0.075 & 0.083 & 0.090 & 0.109 & 0.109 \\
0.002 & 0.104 & 0.141 & 0.181 & 0.218 & 0.270 & 0.293 \\
0.003 & 0.177 & 0.252 & 0.353 & 0.428 & 0.512 & 0.563 \\
0.004 & 0.287 & 0.411 & 0.563 & 0.666 & 0.754 & 0.804 \\
0.005 & 0.420 & 0.588 & 0.747 & 0.843 & 0.909 & 0.943 \\
0.006 & 0.557 & 0.747 & 0.878 & 0.946 & 0.975 & 0.989 \\
0.007 & 0.697 & 0.865 & 0.956 & 0.985 & 0.995 & 0.998 \\
0.008 & 0.806 & 0.938 & 0.987 & 0.998 & 1.000 & 1.000 \\
0.009 & 0.888 & 0.976 & 0.997 & 0.999 & 1.000 & 1.000 \\
0.010 & 0.942 & 0.991 & 0.999 & 1.000 & 1.000 & 1.000 \\
0.011 & 0.972 & 0.997 & 1.000 & 1.000 & 1.000 & 1.000 \\
0.012 & 0.988 & 0.999 & 1.000 & 1.000 & 1.000 & 1.000 \\
0.013 & 0.997 & 1.000 & 1.000 & 1.000 & 1.000 & 1.000 \\
0.014 & 0.999 & 1.000 & 1.000 & 1.000 & 1.000 & 1.000 \\
0.015 & 1.000 & 1.000 & 1.000 & 1.000 & 1.000 & 1.000 \\
\hline
\end{tabular}


Model 4: LGM with six time-invariant covariates, varying the conditional effect of focal covariate on slope

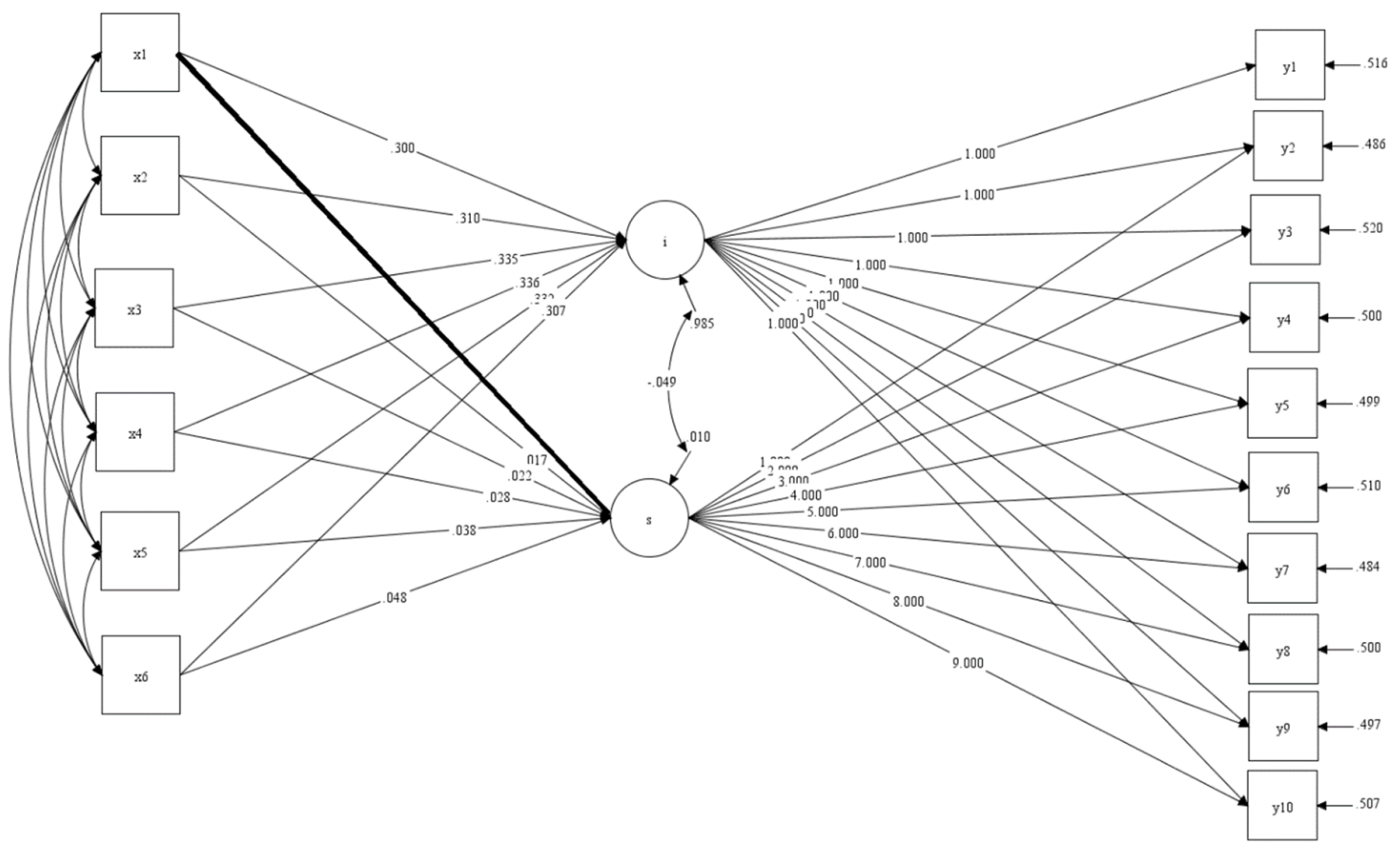

Figure 8. Example Model 4 Simulating Waves $1-10$.

\section{Summary of model parameters}

- Equally dispersed fixed periods between each wave (0,1,2, etc)

- Models ranged from those simulating Waves 1-5 up to Waves 1-10

- Mean of y indicators set to 0 , residual variance of y indicators set to .50

- Means of x1-x6 set to 0 , variance of $x$ indicators set to 1 .

- One $\mathrm{x}$ indicator specified as categorical.

- Intercept mean set to 4, slope variance set to 1

- Slope mean set to .01, slope variance set to .01

- Covariance of slope and intercept set to -.05

- Population covariances between x1-x6 time-invariant covariates set to .40

- Regression of intercept on time-invariant focal covariate set to .30

- Regression of intercept on time-invariant other covariates set to $.31, .32, .33, .34, .35$

- Regression of slope on time-invariant other covariates set to $.05, .04, .03, .02, .01$

- Regression of slope on time-invariant focal covariate ranged from .001 to .015 (Refer to Appendix for Syntax) 


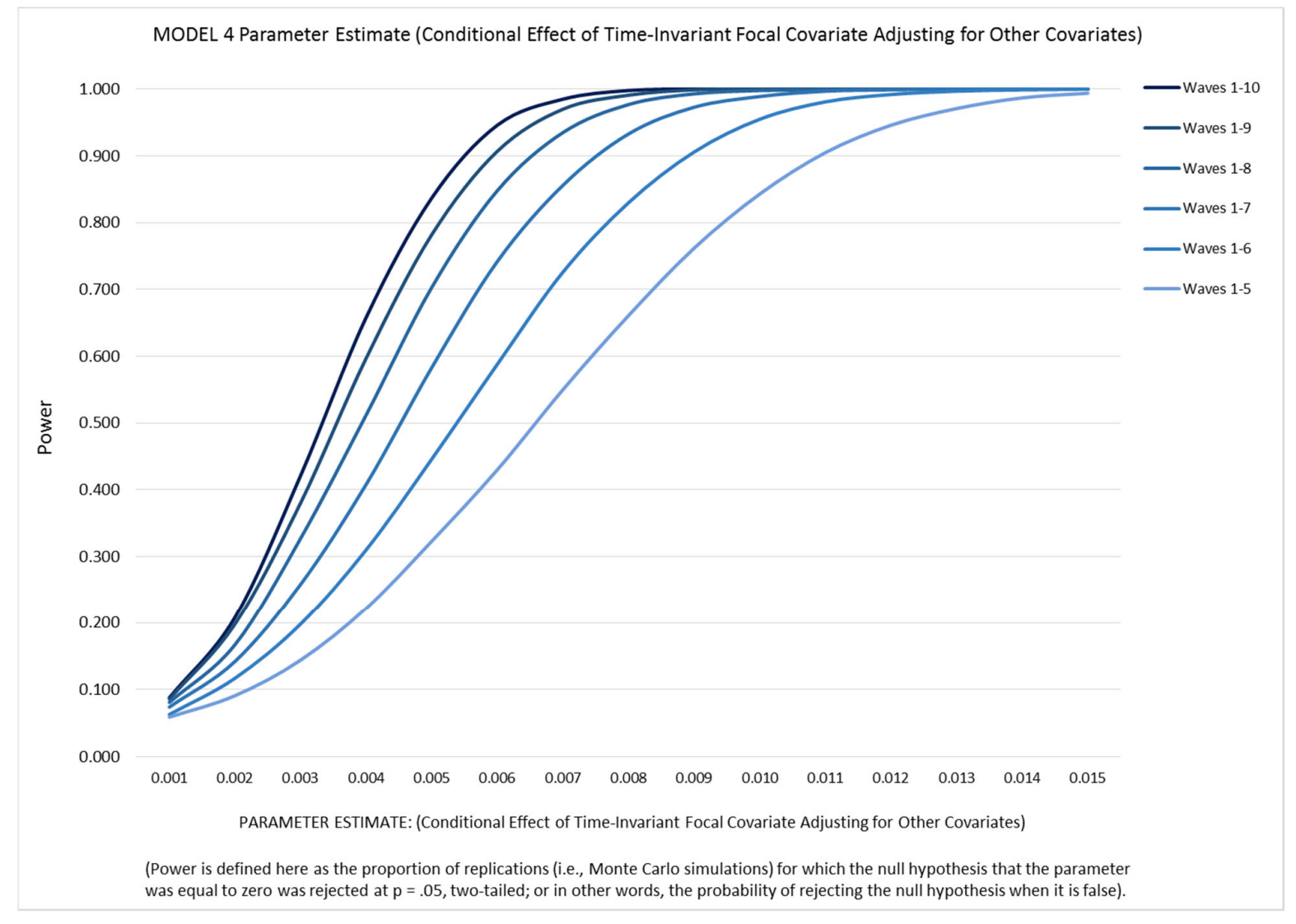

Figure 9. Power estimates for Model 4.

Table 8. Tabulated power estimates for Model 4.

\begin{tabular}{lrrrrrr}
\hline \multicolumn{1}{l}{$\begin{array}{l}\text { Effect } \\
\text { Size }\end{array}$} & Waves 1-5 & Waves 1-6 & Waves 1-7 & Waves 1-8 & Waves 1-9 & Waves 1-10 \\
\hline 0.001 & 0.059 & 0.063 & 0.074 & 0.081 & 0.086 & 0.088 \\
0.002 & 0.091 & 0.117 & 0.142 & 0.167 & 0.198 & 0.208 \\
0.003 & 0.144 & 0.198 & 0.258 & 0.327 & 0.380 & 0.421 \\
0.004 & 0.222 & 0.310 & 0.408 & 0.512 & 0.597 & 0.658 \\
0.005 & 0.323 & 0.446 & 0.583 & 0.703 & 0.782 & 0.837 \\
0.006 & 0.430 & 0.588 & 0.742 & 0.848 & 0.907 & 0.946 \\
0.007 & 0.550 & 0.726 & 0.856 & 0.935 & 0.970 & 0.985 \\
0.008 & 0.661 & 0.830 & 0.933 & 0.977 & 0.991 & 0.998 \\
0.009 & 0.762 & 0.906 & 0.973 & 0.993 & 0.999 & 1.000 \\
0.010 & 0.843 & 0.955 & 0.989 & 0.998 & 1.000 & 1.000 \\
0.011 & 0.905 & 0.981 & 0.997 & 0.999 & 1.000 & 1.000 \\
0.012 & 0.946 & 0.992 & 0.999 & 1.000 & 1.000 & 1.000 \\
0.013 & 0.971 & 0.997 & 1.000 & 1.000 & 1.000 & 1.000 \\
0.014 & 0.987 & 0.999 & 1.000 & 1.000 & 1.000 & 1.000 \\
0.015 & 0.994 & 1.000 & 1.000 & 1.000 & 1.000 & 1.000 \\
\hline
\end{tabular}


Model 5: LGM with second-order polynomial, varying the random effect of the quadratic component of the slope

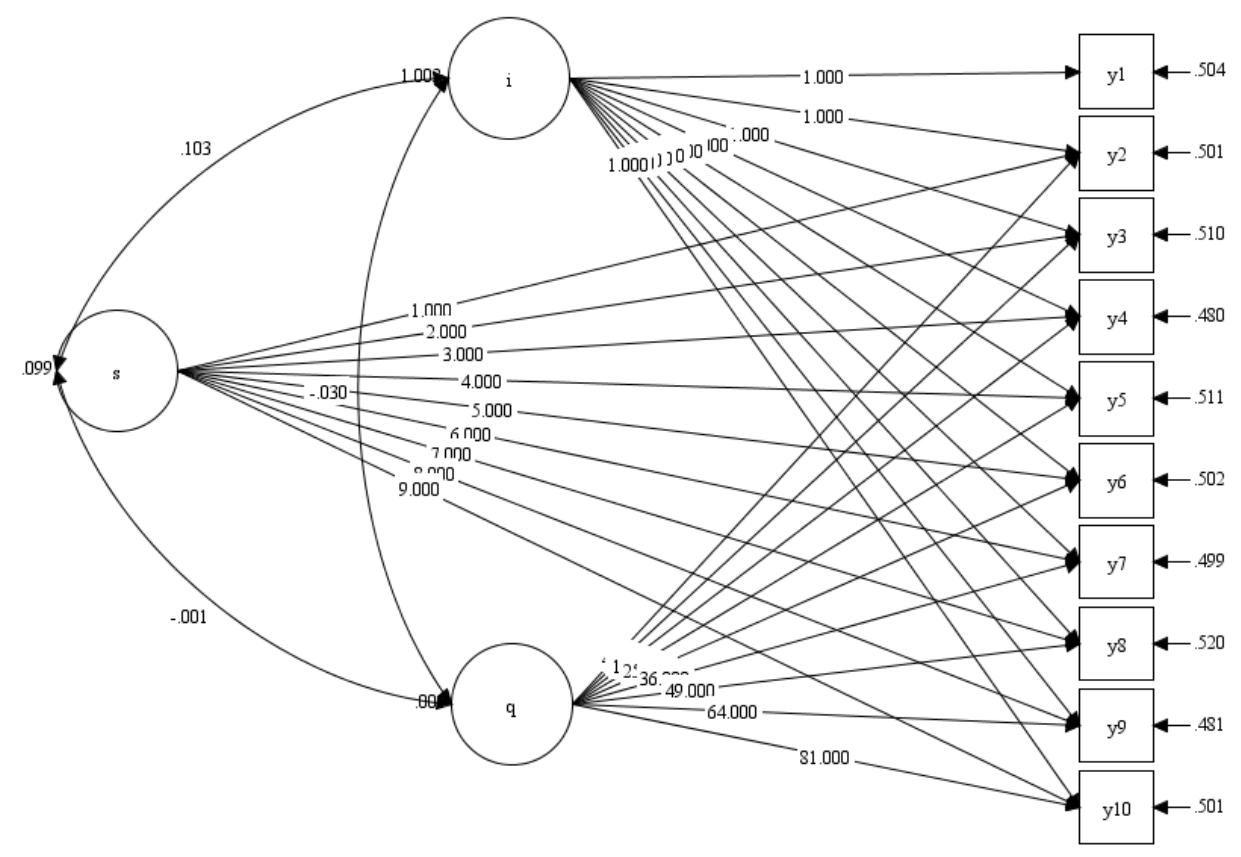

Figure 10. Example Model 5 Simulating Waves $1-10$.

\section{Summary of model parameters}

- Equally dispersed fixed periods between each wave $(0,1,2$, etc)

- Models ranged from those simulating Waves 1-5 up to Waves 1-10

- Mean of y indicators set to 0 , residual variance of y indicators set to .50

- Intercept mean set to 4 , variance set to 1

- Slope of linear effect mean set to .20, variance set to .10

- Slope of quadratic effect mean set to -.03, variance ranged from .001 to .015

- Covariance of intercept and linear effect set to .10

- Covariance of intercept and quadratic effect set to -.03

- Covariance of linear and quadratic effect set to -.001 (Refer to Appendix for Syntax) 


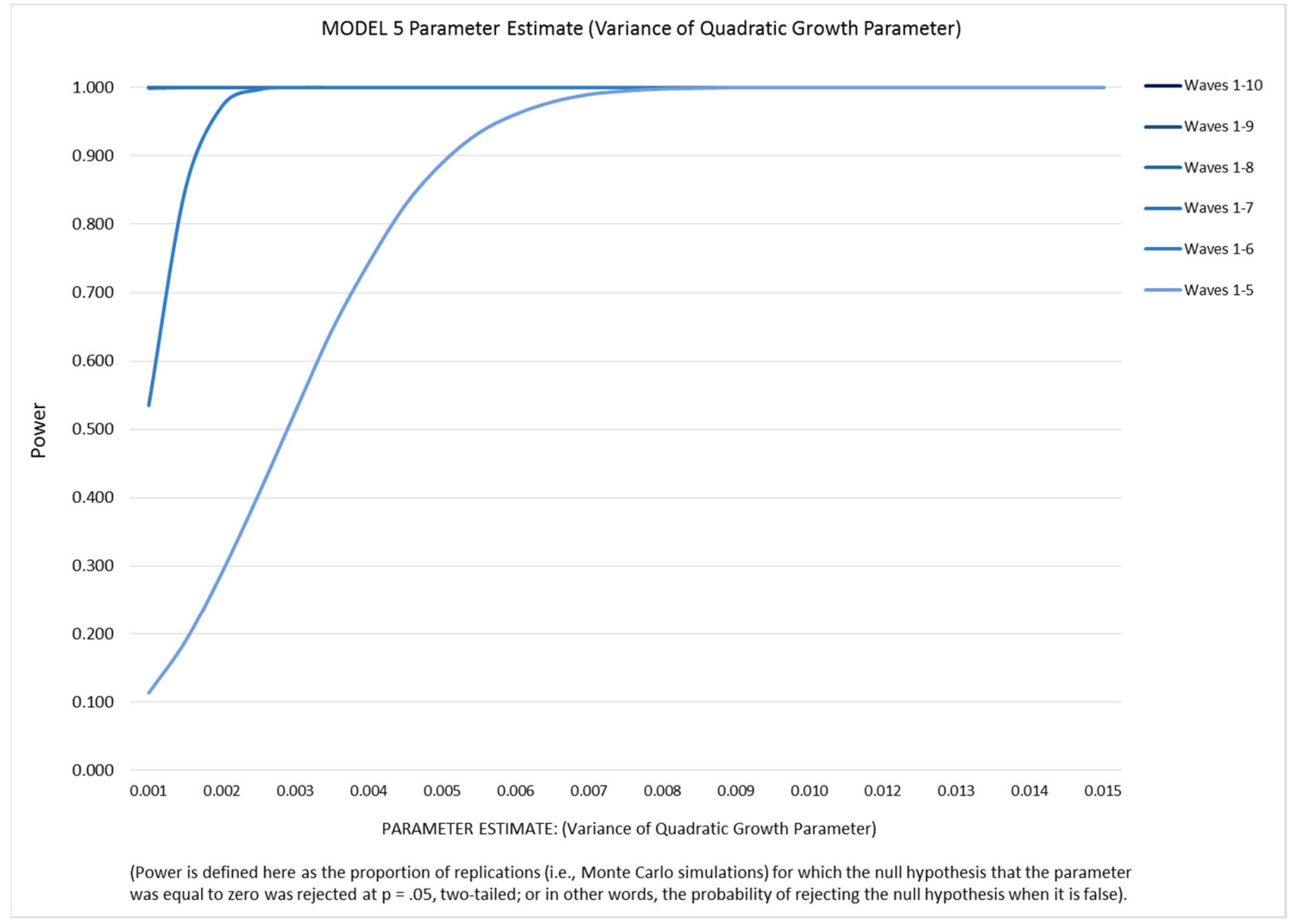

Figure 11. Power estimates for Model 5. 
Table 9. Tabulated power estimates for Model 5.

\begin{tabular}{|c|c|c|c|c|c|c|}
\hline $\begin{array}{l}\text { Effect } \\
\text { Size }\end{array}$ & Waves 1-5 & Waves 1-6 & Waves 1-7 & Waves 1-8 & Waves 1-9 & Waves $1-10$ \\
\hline .0010 & 0.113 & 0.535 & 0.999 & 1.000 & 1.000 & 1.000 \\
\hline .0015 & 0.189 & 0.852 & 1.000 & 1.000 & 1.000 & 1.000 \\
\hline .0020 & 0.291 & 0.973 & 1.000 & 1.000 & 1.000 & 1.000 \\
\hline .0025 & 0.406 & 0.997 & 1.000 & 1.000 & 1.000 & 1.000 \\
\hline .0030 & 0.527 & 1.000 & 1.000 & 1.000 & 1.000 & 1.000 \\
\hline .0035 & 0.646 & 1.000 & 1.000 & 1.000 & 1.000 & 1.000 \\
\hline .0040 & 0.744 & 1.000 & 1.000 & 1.000 & 1.000 & 1.000 \\
\hline .0045 & 0.829 & 1.000 & 1.000 & 1.000 & 1.000 & 1.000 \\
\hline .0050 & 0.890 & 1.000 & 1.000 & 1.000 & 1.000 & 1.000 \\
\hline .0055 & 0.934 & 1.000 & 1.000 & 1.000 & 1.000 & 1.000 \\
\hline .0060 & 0.961 & 1.000 & 1.000 & 1.000 & 1.000 & 1.000 \\
\hline .0065 & 0.979 & 1.000 & 1.000 & 1.000 & 1.000 & 1.000 \\
\hline .0070 & 0.990 & 1.000 & 1.000 & 1.000 & 1.000 & 1.000 \\
\hline .0075 & 0.995 & 1.000 & 1.000 & 1.000 & 1.000 & 1.000 \\
\hline .0080 & 0.998 & 1.000 & 1.000 & 1.000 & 1.000 & 1.000 \\
\hline .0085 & 0.999 & 1.000 & 1.000 & 1.000 & 1.000 & 1.000 \\
\hline .0090 & 1.000 & 1.000 & 1.000 & 1.000 & 1.000 & 1.000 \\
\hline .0095 & 1.000 & 1.000 & 1.000 & 1.000 & 1.000 & 1.000 \\
\hline .0100 & 1.000 & 1.000 & 1.000 & 1.000 & 1.000 & 1.000 \\
\hline .0105 & 1.000 & 1.000 & 1.000 & 1.000 & 1.000 & 1.000 \\
\hline .0120 & 1.000 & 1.000 & 1.000 & 1.000 & 1.000 & 1.000 \\
\hline .0125 & 1.000 & 1.000 & 1.000 & 1.000 & 1.000 & 1.000 \\
\hline .0130 & 1.000 & 1.000 & 1.000 & 1.000 & 1.000 & 1.000 \\
\hline .0135 & 1.000 & 1.000 & 1.000 & 1.000 & 1.000 & 1.000 \\
\hline .0140 & 1.000 & 1.000 & 1.000 & 1.000 & 1.000 & 1.000 \\
\hline .0145 & 1.000 & 1.000 & 1.000 & 1.000 & 1.000 & 1.000 \\
\hline .0150 & 1.000 & 1.000 & 1.000 & 1.000 & 1.000 & 1.000 \\
\hline
\end{tabular}


Model 6: LGM with second-order polynomial, varying the mean of the quadratic component of the slope

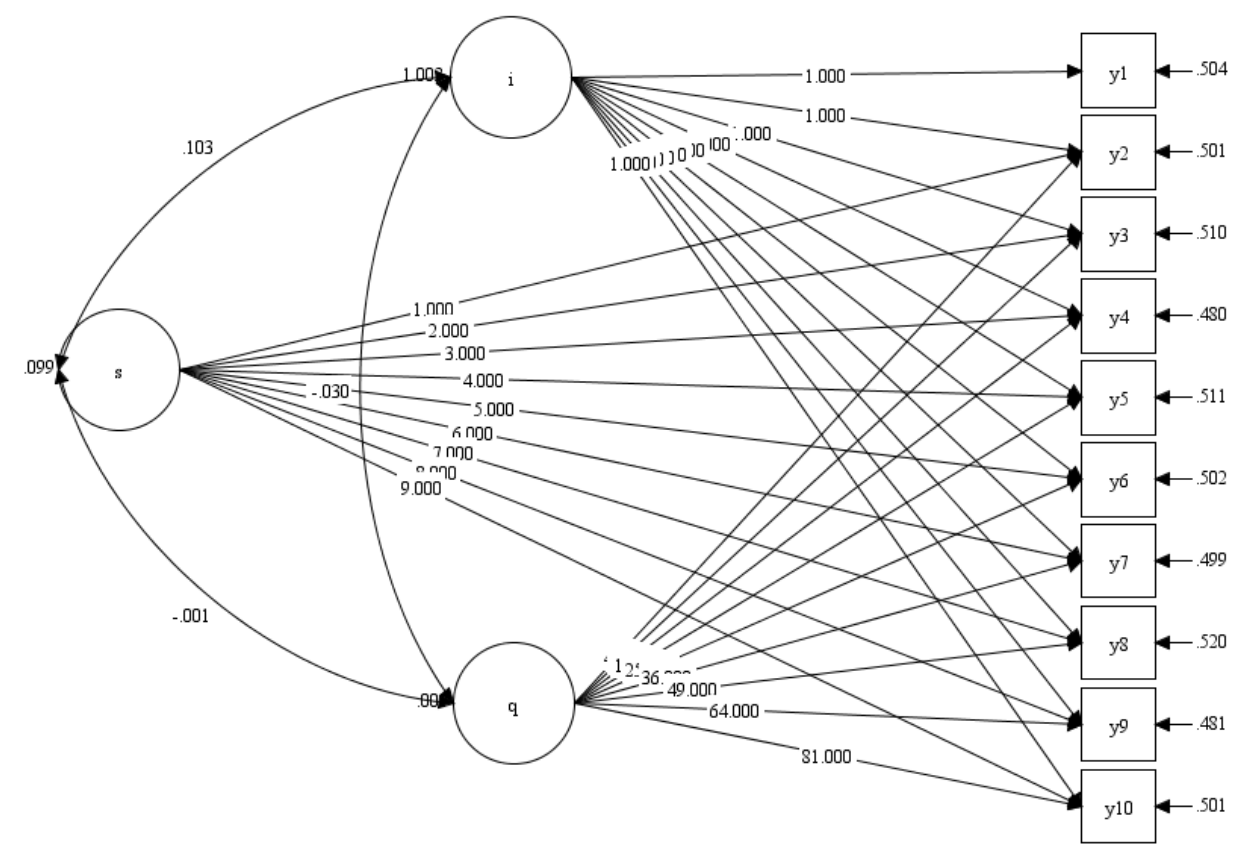

Figure 12. Example Model 6 Simulating Waves $1-10$.

\section{Summary of model parameters}

- Equally dispersed fixed periods between each wave $(0,1,2$, etc)

- Models ranged from those simulating Waves 1-5 up to Waves 1-10

- Mean of y indicators set to 0 , residual variance of y indicators set to .50

- Intercept mean set to 4 , variance set to 1

- Slope of linear effect mean set to .20, variance set to .10

- Slope of quadratic effect mean ranged from -.001 to -.015, variance set to .01

- Covariance of intercept and linear effect set to .10

- Covariance of intercept and quadratic effect set to -.03

- Covariance of linear and quadratic effect set to -.001 (Refer to Appendix for Syntax) 


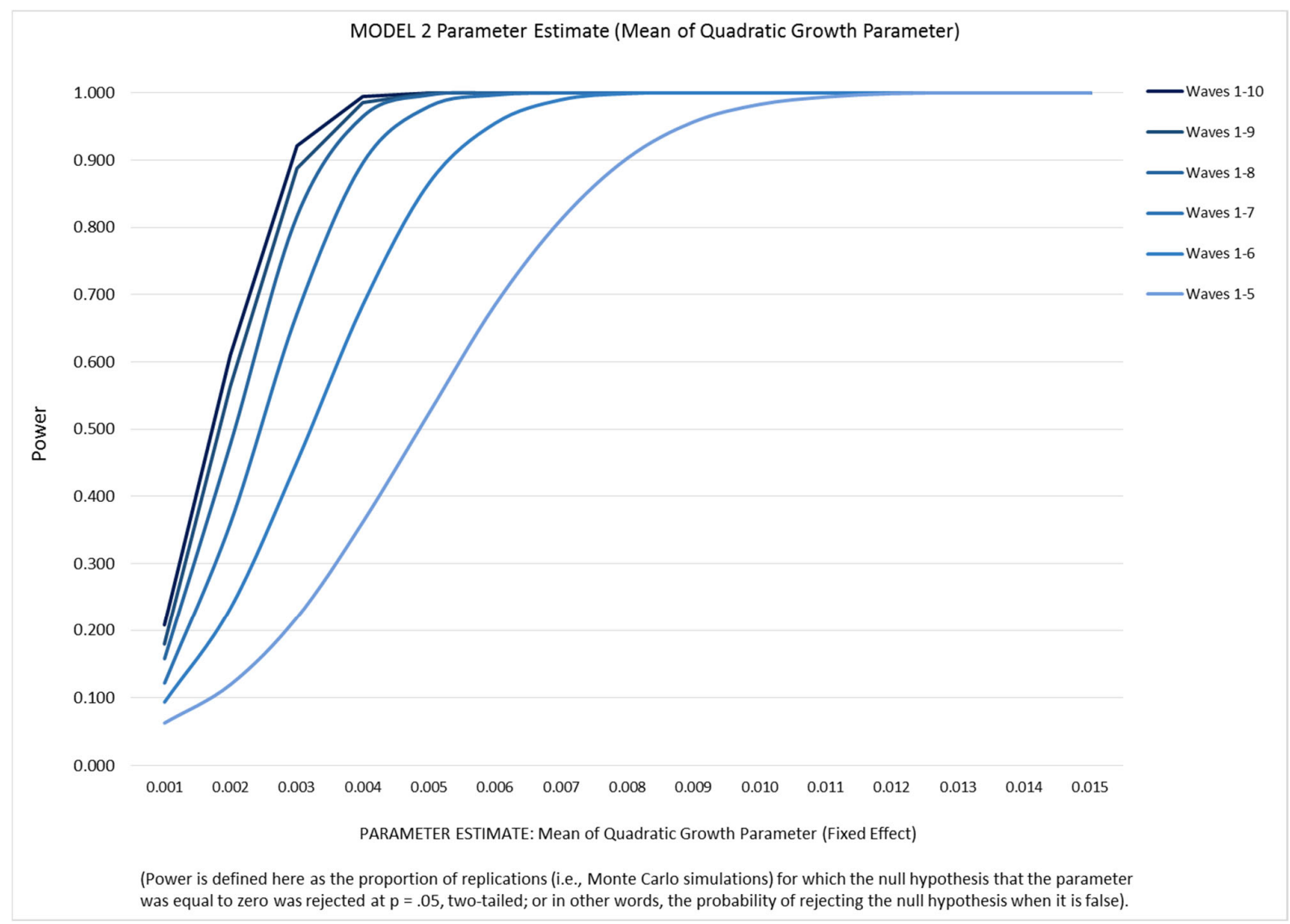

Figure 13. Power estimates for Model 6.

Table 10. Tabulated power estimates for Model 6.

\begin{tabular}{lrrrrrr}
\hline \multicolumn{1}{l}{$\begin{array}{l}\text { Effect } \\
\text { Size }\end{array}$} & Waves 1-5 & Waves 1-6 & Waves 1-7 & Waves 1-8 & Waves 1-9 & Waves 1-10 \\
\hline 0.001 & 0.063 & 0.094 & 0.122 & 0.158 & 0.180 & 0.208 \\
0.002 & 0.120 & 0.234 & 0.361 & 0.479 & 0.564 & 0.610 \\
0.003 & 0.219 & 0.451 & 0.671 & 0.816 & 0.888 & 0.921 \\
0.004 & 0.362 & 0.685 & 0.896 & 0.965 & 0.986 & 0.995 \\
0.005 & 0.524 & 0.866 & 0.980 & 0.997 & 1.000 & 1.000 \\
0.006 & 0.685 & 0.955 & 0.997 & 1.000 & 1.000 & 1.000 \\
0.007 & 0.812 & 0.990 & 1.000 & 1.000 & 1.000 & 1.000 \\
0.008 & 0.903 & 0.999 & 1.000 & 1.000 & 1.000 & 1.000 \\
0.009 & 0.957 & 1.000 & 1.000 & 1.000 & 1.000 & 1.000 \\
0.010 & 0.983 & 1.000 & 1.000 & 1.000 & 1.000 & 1.000 \\
0.011 & 0.994 & 1.000 & 1.000 & 1.000 & 1.000 & 1.000 \\
0.012 & 0.999 & 1.000 & 1.000 & 1.000 & 1.000 & 1.000 \\
0.013 & 1.000 & 1.000 & 1.000 & 1.000 & 1.000 & 1.000 \\
0.014 & 1.000 & 1.000 & 1.000 & 1.000 & 1.000 & 1.000 \\
0.015 & 1.000 & 1.000 & 1.000 & 1.000 & 1.000 & 1.000 \\
\hline
\end{tabular}


Model 7: LGM with six covariates, varying the conditional effect of focal covariate on quadratic component of slope

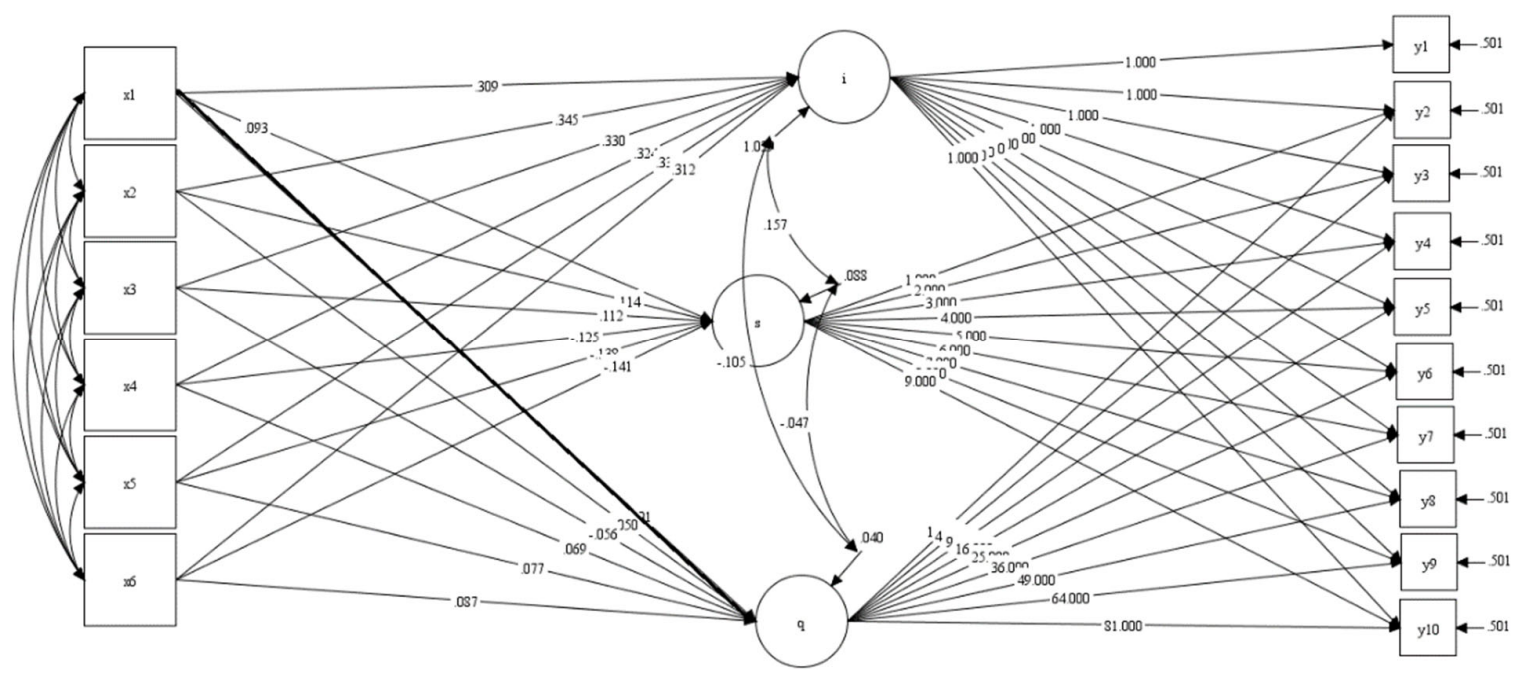

Figure 14. Example Model 7 Simulating Waves $1-10$.

\section{Summary of model parameters}

- Equally dispersed fixed periods between each wave (0,1,2, etc)

- Models ranged from those simulating Waves 1-5 up to Waves 1-10

- Mean of y indicators set to 0 , residual variance of y indicators set to .50

- Means of x1-x6 set to 0 , variance of x indicators set to 1 .

- One $\mathrm{x}$ indicator specified as categorical.

- Intercept mean set to 4, slope variance set to 1

- Slope of linear effect mean set to .20, variance set to .10

- Slope of quadratic effect mean set to -.03, variance set to .04

- Covariance of intercept and linear effect set to .15

- Covariance of intercept and quadratic effect set to -.10

- Covariance of linear and quadratic effect set to -.05

- Population covariances between x1-x6 time-invariant covariates set to .40

- Regression of intercept on time-invariant focal covariate set to .30

- Regression of linear slope on time-invariant focal covariate set to .10

- Regression of intercept on time-invariant covariates set to $.35, .34, .33, .32, .31$

- Regression of linear slope on time-invariant covariates set to .11,.12, -.13, -.14, -.15

- Regression of quad slope on time-invariant covariates set to -.05, -.06, .07, .08, .09

- Regression of quadratic slope on time-invariant focal covariate ranged from -.001 to --.015 (Refer to Appendix for Syntax) 


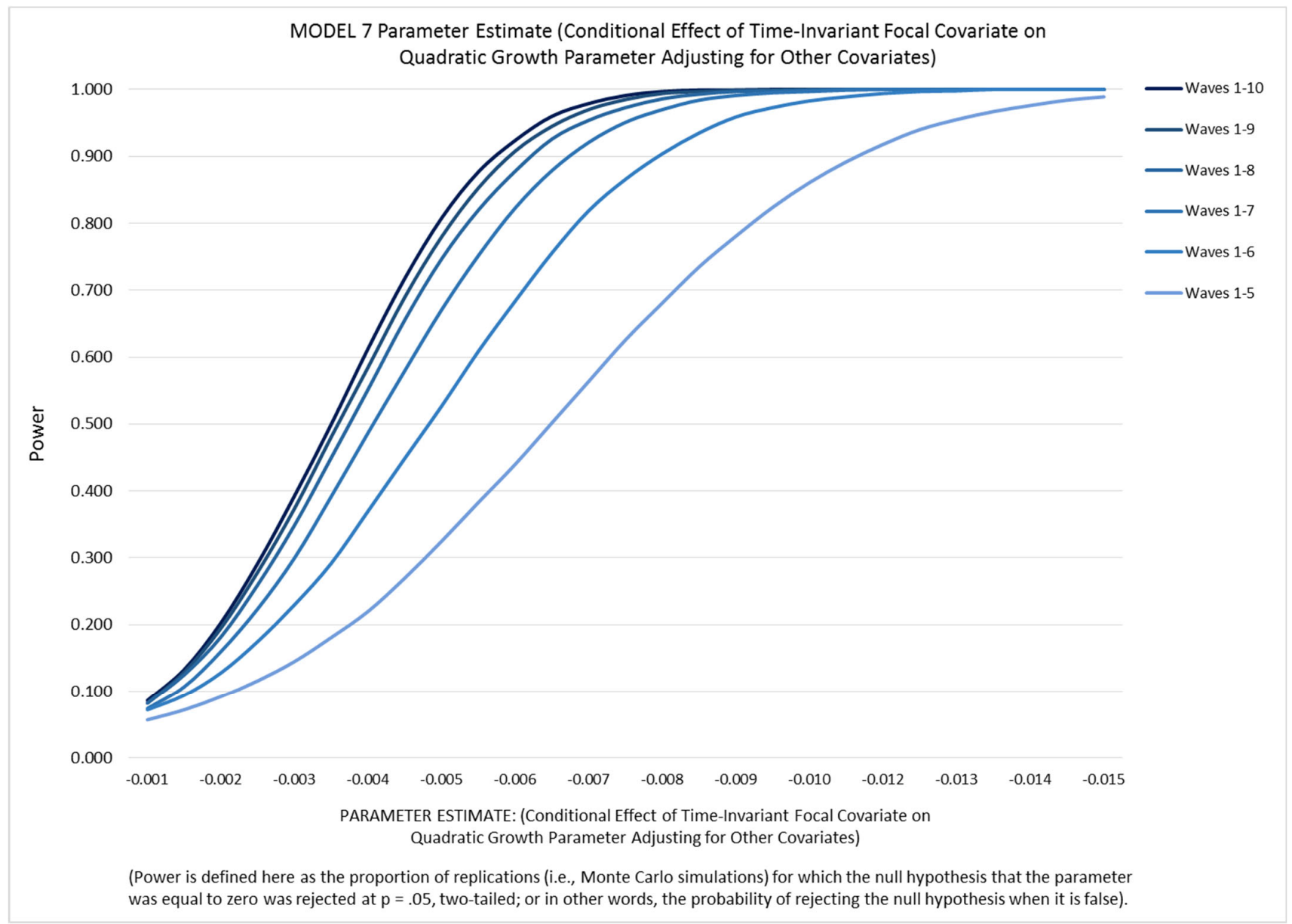

Figure 15. Example Model 7 Simulating Waves $1-10$. 
Table 11. Tabulated power estimates for Model 7.

\begin{tabular}{|c|c|c|c|c|c|c|}
\hline $\begin{array}{l}\text { Effect } \\
\text { Size }\end{array}$ & Waves 1-5 & Waves 1-6 & Waves 1-7 & Waves $1-8$ & Waves 1-9 & Waves $1-10$ \\
\hline-.0010 & 0.057 & 0.072 & 0.074 & 0.082 & 0.082 & 0.086 \\
\hline-.0015 & 0.072 & 0.094 & 0.107 & 0.125 & 0.129 & 0.133 \\
\hline-.0020 & 0.092 & 0.128 & 0.160 & 0.182 & 0.195 & 0.203 \\
\hline-.0025 & 0.116 & 0.175 & 0.224 & 0.260 & 0.279 & 0.292 \\
\hline-.0030 & 0.145 & 0.230 & 0.300 & 0.349 & 0.374 & 0.393 \\
\hline-.0035 & 0.181 & 0.292 & 0.392 & 0.450 & 0.481 & 0.500 \\
\hline-.0040 & 0.220 & 0.370 & 0.487 & 0.552 & 0.585 & 0.613 \\
\hline-.0045 & 0.270 & 0.449 & 0.580 & 0.656 & 0.690 & 0.718 \\
\hline-.0050 & 0.325 & 0.527 & 0.671 & 0.747 & 0.780 & 0.808 \\
\hline-.0055 & 0.383 & 0.609 & 0.752 & 0.820 & 0.853 & 0.877 \\
\hline-.0060 & 0.440 & 0.684 & 0.823 & 0.878 & 0.908 & 0.924 \\
\hline-.0065 & 0.502 & 0.756 & 0.879 & 0.926 & 0.945 & 0.960 \\
\hline-.0070 & 0.564 & 0.819 & 0.921 & 0.954 & 0.970 & 0.979 \\
\hline-.0075 & 0.626 & 0.866 & 0.951 & 0.973 & 0.985 & 0.991 \\
\hline-.0080 & 0.681 & 0.904 & 0.970 & 0.986 & 0.994 & 0.997 \\
\hline-.0085 & 0.735 & 0.935 & 0.984 & 0.993 & 0.997 & 0.999 \\
\hline-.0090 & 0.781 & 0.959 & 0.991 & 0.997 & 0.999 & 0.999 \\
\hline-.0095 & 0.824 & 0.973 & 0.995 & 0.998 & 0.999 & 1.000 \\
\hline-.0100 & 0.861 & 0.983 & 0.997 & 0.999 & 1.000 & 1.000 \\
\hline-.0105 & 0.892 & 0.989 & 0.999 & 1.000 & 1.000 & 1.000 \\
\hline-.0120 & 0.918 & 0.994 & 1.000 & 1.000 & 1.000 & 1.000 \\
\hline-.0125 & 0.940 & 0.997 & 1.000 & 1.000 & 1.000 & 1.000 \\
\hline-.0130 & 0.955 & 0.998 & 1.000 & 1.000 & 1.000 & 1.000 \\
\hline-.0135 & 0.967 & 1.000 & 1.000 & 1.000 & 1.000 & 1.000 \\
\hline-.0140 & 0.976 & 1.000 & 1.000 & 1.000 & 1.000 & 1.000 \\
\hline-.0145 & 0.984 & 1.000 & 1.000 & 1.000 & 1.000 & 1.000 \\
\hline-.0150 & 0.989 & 1.000 & 1.000 & 1.000 & 1.000 & 1.000 \\
\hline
\end{tabular}


Mplus syntax

MODEL 1

TITLE:

Monte Carlo Simulations used to estimate the statistical

power of latent growth parameters in the NZAVS.

Chris Sibley and Petar Milojev, 06-11-2014

MONTECARLO:

NAMES ARE y1-y10;

NOBSERVATIONS $=23000 ;$ ! Total $\mathrm{N}$ ever sampled

NREPS $=10000 ; \quad$ !Number of replications

SEED $=65474 ; \quad$ !Random Seed

CLASSES $=\mathrm{C}(1) ; \quad$ !Used for extending to non-normal models

GENCLASSES $=\mathrm{C}(1)$;

PATMISS $=$ y1(.847) y2(.937) y3(.831) y4(.601) y5(.339) y6(.497)

y7(.623) y $8(.725)$ y $9(.806)$ y10(.871)

!.870 of sample have missing data according to these proportions

y1(0) y2(0) y3(0) y4(0) y5(0) y6(0)

y7(0) y8(0) y $9(0)$ y10(0);

!.130 have 0 missing data

!y1(.847) y2(.937) y3(.831) y4(.601) y5(.339) y6(.497) y7(.623) y8(.725) y9(.806) y10(.871) |

PATPROB $=.870 \mid .130$

ANALYSIS:

TYPE = MIXTURE;

ESTIMATOR $=$ ML;

MODEL MONTECARLO:

$\%$ OVERALL $\%$

is |y1@0y2@1 y3@2 y4@3 y5@4y6@5 y7@6y8@7y9@8 y10@9;

[y1-y10@0]; y1-y10*.5;

[i*4]; i*1.0;

$\left[\mathrm{s}^{*} 0\right] ; \mathrm{s}^{*} .001 ;$ !Values we change

i WITH s*0;

$\% \mathrm{C} \# 1 \%$

[i*4];

$[\mathrm{s} * 0]$; 
MODEL:

$\%$ OVERALL \%

i s|y1@0y2@1y3@2y4@3 y5@4y6@5y7@6y8@7y9@8y10@9;

[y1-y10@0]; y1-y10*.5;

[i*4]; i*1.0;

$\left[\mathrm{s}^{*} 0\right] ; \mathrm{s}^{*} .001 ;$ !Values we change

i WITH s*0;

$\% \mathrm{C} \# 1 \%$

$[i * 4]$

$[\mathrm{s} * 0]$

MODEL 2

TITLE:

Monte Carlo Simulations used to estimate the statistical power of latent growth parameters in the NZAVS.

Chris Sibley and Petar Milojev, 06-11-2014

MONTECARLO:

NAMES ARE y1-y10;

NOBSERVATIONS $=23000 ;$ !Total $\mathrm{N}$ ever sampled

NREPS $=10000 ; \quad$ !Number of replications

SEED $=65474 ; \quad$ !Random Seed

CLASSES $=\mathrm{C}(1) ; \quad$ !Used for extending to non-normal models

GENCLASSES $=\mathrm{C}(1)$;

PATMISS $=\mathrm{y} 1(.847) \mathrm{y} 2(.937) \mathrm{y} 3(.831) \mathrm{y} 4(.601) \mathrm{y} 5(.339)$

y6(.497) y7(.623) y8(.725) y9(.806) y10(.871)

!.870 of sample have missing data according to these proportions

$\mathrm{y} 1(0) \mathrm{y} 2(0) \mathrm{y} 3(0) \mathrm{y} 4(0) \mathrm{y} 5(0)$

y6(0) y7(0) y $8(0)$ y9(0) y $10(0)$;

!.130 have 0 missing data

PATPROB $=.870 \mid .130 ;$

ANALYSIS:

TYPE = MIXTURE;

ESTIMATOR $=$ ML;

MODEL MONTECARLO:

\%OVERALL \% 
is |y1@0y2@1 y3@2y4@3 y5@4 y6@5 y7@6y8@7 y9@8y10@9;

[y1-y10@0]; y1-y10*.5;

[i*4]; i*1.0;

[s*.001]; $\mathrm{s}^{*} .005 ;$ !Values we change

i WITH s*0;

$\% \mathrm{C} \# 1 \%$

[i*4];

[s*.001]; !Values we change

MODEL:

$\%$ OVERALL \%

is |y1@0y2@1 y3@2y4@3 y5@4y6@5 y7@6y8@7 y9@8 y10@9;

[y1-y10@0]; y1-y10*.5;

[i*4]; i*1.0;

$\left[\mathrm{s}^{*} .001\right] ; \mathrm{s}^{*} .005 ;$ !Values we change

i WITH s*0;

$\% \mathrm{C} \# 1 \%$

[i*4];

[s*.001]; !Values we change

MODEL 3

TITLE:

Monte Carlo Simulations used to estimate the statistical power of latent growth parameters in the NZAVS.

Chris Sibley and Petar Milojev, 06-11-2014

MONTECARLO:

NAMES ARE y1-y10 x1;

!CUTPOINTS $=\mathrm{x} 1(0) ; \quad$ !Specifies Categorical $\mathrm{x}$ var NOBSERVATIONS $=23000$; !Total $\mathrm{N}$ ever sampled

NREPS $=10000 ; \quad$ !Number of replications

SEED $=35479 ; \quad$ !Random Seed

CLASSES $=\mathrm{C}(1) ; \quad$ !Used for extending to non-normal models

GENCLASSES $=\mathrm{C}(1)$;

PATMISS $=\mathrm{y} 1(.847) \mathrm{y} 2(.937) \mathrm{y} 3(.831) \mathrm{y} 4(.601) \mathrm{y} 5(.339)$

y6(.497) y7(.623) y $8(.725)$ y9(.806) y $10(.871) \mid$

y1(0) y2(0) y3(0) y4(0) y5(0) y6(0) y7(0) y8(0) y9(0) y10(0); 
PATPROB $=.870 \mid .130$;

!SAVE = data out.txt;

ANALYSIS:

TYPE $=$ MIXTURE;

ESTIMATOR $=$ ML;

MODEL MONTECARLO:

$\%$ OVERALL $\%$

[x1@0]; x1@1;

is|y1@0y2@1y3@2y4@3 y5@4y6@5 y7@6y8@7y9@8y10@9;

[y1-y10@0]; y1-y10*.5;

$\left[i^{*} 4\right] ; \mathrm{i}^{*} 1.0$;

$\left[\mathrm{s}^{*} .01\right] ; \mathrm{s}^{*} .01$;

i WITH s*-.05;

i ON x1*.30;

s ON x1*.001; !Varying this parameter

$\% \mathrm{C} \# 1 \%$

$[i * 4]$

[s*.01];

MODEL:

$\%$ OVERALL $\%$

is |y1@0y2@1 y3@2y4@3 y5@4y6@5y7@6y8@7y9@8y10@9;

[y1-y10@0]; y1-y10*.5;

$[i * 4] ; \mathrm{i}^{*} 1.0$

[s*.01]; s*.01;

i WITH s*-.05;

i ON x1*.30;

s ON x1*.001; !Varying this parameter

$\% \mathrm{C} \# 1 \%$

$[i * 4]$

[s*.01];

MODEL 4

TITLE:

Monte Carlo Simulations used to estimate the statistical 
power of latent growth parameters in the NZAVS.

Chris Sibley and Petar Milojev, 06-11-2014

MONTECARLO:

NAMES ARE y1-y10 x1-x6;

CUTPOINTS $=\mathrm{x} 2(0) ; \quad$ !Specifies Categorical $\mathrm{x}$ var

NOBSERVATIONS $=23000 ; \quad$ !Total $\mathrm{N}$

NREPS $=10000 ; \quad$ !Number of replications

SEED $=66449 ; \quad$ !Random Seed

CLASSES $=\mathrm{C}(1)$;

GENCLASSES $=\mathrm{C}(1)$;

PATMISS $=$ y1(.847) y2(.937) y3(.831) y4(.601) y5(.339)

y6(.497) y7(.623) y8(.725) y9(.806) y10(.871)

y1(0) y2(0) y3(0) y4(0) y5(0) y6(0) y7(0) y8(0) y9(0) y10(0);

PATPROB $=.870 \mid .130$

!SAVE = data out.txt;

ANALYSIS:

TYPE = MIXTURE;

ESTIMATOR $=$ ML;

MODEL MONTECARLO:

$\%$ OVERALL $\%$

[x1-x6@0]; x1-x6*1;

x1 WITH x2*.4; x1 WITH x3*.4; x1 WITH x4*.4;

$\mathrm{x} 1$ WITH x $5^{*} .4$; $\mathrm{x} 1$ WITH $\mathrm{x} 6 * .4$; 2 WITH x $3 * .4$;

$\mathrm{x} 2$ WITH x4*.4; x2 WITH x $5^{*} .4$; 2 WITH x6*.4;

x3 WITH $x 4^{*} .4$; 33 WITH x $5^{*} .4$; 33 WITH x6*.4;

x 4 WITH x $5 * .4$; 4 WITH x6*.4; x 5 WITH x6*.4;

is $\mid$ y1@0y2@1 y3@2y4@3 y5@4 y6@5 y7@6y8@7 y9@8 y10@9;

[y1-y10@0]; y1-y10*.5;

$\left[i^{*} 4\right] ; i^{*} 1.0 ;\left[\mathrm{s}^{*} .01\right] ; \mathrm{s}^{*} .01$;

i WITH s*-.05;

i ON x1*.30; s ON x1*.001; !Varying this parameter

i ON x2*.35; s ON x $2 * .01$;

i ON x $3 * .34$; s ON x $3 * .02$;

i ON x $4 * .33$; s ON x $4^{*} .03$;

i ON x $5 * .32$; s ON x $5 * .04$;

i ON x6*.31; s ON x6*.05;

$\% \mathrm{C} \# 1 \%$

$[i * 4] ;\left[s^{*} .01\right]$ 
MODEL:

$\%$ OVERALL $\%$

i s|y1@0y2@1y3@2y4@3 y5@4y6@5y7@6y8@7y9@8y10@9;

[y1-y10@0]; y1-y10*.5;

$\left[i^{*} 4\right] ; i^{*} 1.0 ;\left[\mathrm{s}^{*} .01\right] ; \mathrm{s} * .01$

i WITH s*-.05;

i ON x1*.30; s ON x1*.001; !Varying this parameter

i ON x $2 * .35$; S ON x $2 * .01$;

i ON x $3 * .34$; s ON x $3 * .02$;

i ON x $4 * .33$; s ON x $4 * .03$;

i ON x $5^{*} .32$; s ON x $5^{*} .04$;

i ON x6*..31; s ON x6*.05;

$\% \mathrm{C} \# 1 \%$

$[i * 4] ;\left[\mathrm{s}^{*} .01\right]$;

MODEL 5

TITLE:

Monte Carlo Simulations used to estimate the statistical power of latent growth parameters in the NZAVS.

Chris Sibley and Petar Milojev, 06-11-2014

MONTECARLO:

NAMES ARE y1-y10;

NOBSERVATIONS $=23000 ;$ !Total $\mathrm{N}$ ever sampled

NREPS $=10000 ; \quad$ !Number of replications

SEED $=45348 ; \quad$ !Random Seed

CLASSES $=\mathrm{C}(1) ; \quad$ !Used for extending to non-normal models

GENCLASSES $=\mathrm{C}(1)$;

PATMISS $=\mathrm{y} 1(.847) \mathrm{y} 2(.937) \mathrm{y} 3(.831) \mathrm{y} 4(.601) \mathrm{y} 5(.339) \mathrm{y} 6(.497)$

y7(.623) y8(.725) y9(.806) y10(.871)

!.870 of sample have missing data according to these proportions

y1(0) y2(0) y3(0) y4(0) y5(0) y6(0)

y7(0) y8(0) y9(0) y10(0);

!.130 have 0 missing data

PATPROB $=.870 \mid .130$

ANALYSIS:

TYPE $=$ MIXTURE;

ESTIMATOR $=$ ML; 
MODEL MONTECARLO:

$\%$ OVERALL $\%$

is q|y1@0y2@1y3@2y4@3y5@4y6@5y7@6y8@7y9@8y10@9;

[y1-y10@0]; y1-y10*.5;

[i*4]; i*1.0;

[s*.20]; s*.10;

[q*-.03]; $\mathrm{q}^{*} .001 ;$ !Values we change

i WITH s*.10;

i WITH q*-.03;

s WITH q*-.001;

MODEL:

$\%$ OVERALL \%

is q |y1@0y2@1 y3@2y4@3 y5@4y6@5 y7@6y8@7y9@8 y10@9;

[y1-y10@0]; y1-y10*.5;

[i*4]; i*1.0;

[s*.20]; s*.10;

[q*-.03]; $\mathrm{q}^{*} .001 ;$ !Values we change

i WITH s*.10;

i WITH q*-.03;

s WITH q*-.001;

MODEL 6

TITLE:

Monte Carlo Simulations used to estimate the statistical power of latent growth parameters in the NZAVS.

Chris Sibley and Petar Milojev, 06-11-2014

MONTECARLO:

NAMES ARE y1-y10;

NOBSERVATIONS $=23000 ;$ !Total $\mathrm{N}$ ever sampled

NREPS $=10000 ; \quad$ !Number of replications

SEED $=65474 ; \quad$ !Random Seed

CLASSES $=\mathrm{C}(1) ; \quad$ !Used for extending to non-normal models

GENCLASSES $=\mathrm{C}(1)$;

PATMISS $=\mathrm{y} 1(.847) \mathrm{y} 2(.937) \mathrm{y} 3(.831) \mathrm{y} 4(.601) \mathrm{y} 5(.339) \mathrm{y} 6(.497)$

y7(.623) y $8(.725)$ y $9(.806)$ y $10(.871)$

!.870 of sample have missing data according to these proportions 
y1(0) y2(0) y3(0) y4(0) y5(0) y6(0)

y7(0) y8(0) y9(0) y10(0);

!.130 have 0 missing data

PATPROB $=.870 \mid .130 ;$

ANALYSIS:

TYPE $=$ MIXTURE;

ESTIMATOR $=$ ML;

MODEL MONTECARLO:

$\%$ OVERALL $\%$

is q|y1@0y2@1 y3@2 y4@3 y5@4 y6@5 y7@6y8@7y9@8y10@9;

[y1-y10@0]; y1-y10*.5;

[i*4]; i*1.0;

$\left[\mathrm{s}^{*} .20\right] ; \mathrm{s}^{*} .10$

[q*-.001]; $\mathrm{q}^{*} .01 ;$ !Values we change

i WITH s*.10;

i WITH q*-.03;

s WITH q*-.001;

MODEL:

$\%$ OVERALL $\%$

is q|y1@0y2@1y3@2y4@3 y5@4y6@5y7@6y8@7y9@8y10@9;

[y1-y10@0]; y1-y10*.5;

[i*4]; i*1.0;

[s*.20]; s*.10;

[q*-.001]; $\mathrm{q}^{*} .01 ;$ !Values we change

i WITH s*.10;

i WITH q*-.03;

s WITH q*-.001;

MODEL 7

TITLE:

Monte Carlo Simulations used to estimate the statistical power of latent growth parameters in the NZAVS.

Chris Sibley and Petar Milojev, 06-11-2014

MONTECARLO:

NAMES ARE y1-y10 x1-x6; 
CUTPOINTS $=\mathrm{x} 2(0) ; \quad$ !Specifies Categorical $\mathrm{x}$ var NOBSERVATIONS $=23000 ;$ !Total $\mathrm{N}$ ever sampled

NREPS $=10000 ; \quad$ !Number of replications

SEED $=198327 ; \quad$ !Random Seed

CLASSES $=\mathrm{C}(1) ; \quad$ !Used for extending to non-normal models

GENCLASSES $=\mathrm{C}(1)$;

PATMISS $=\mathrm{y} 1(.847) \mathrm{y} 2(.937) \mathrm{y} 3(.831) \mathrm{y} 4(.601) \mathrm{y} 5(.339) \mathrm{y} 6(.497)$

y7(.623) y8(.725) y9(.806) y10(.871)

!.870 of sample have missing data according to these proportions

y1(0) y2(0) y3(0) y4(0) y5(0) y6(0)

y7(0) y8(0) y $9(0)$ y10(0);

!.130 have 0 missing data

PATPROB $=.870 \mid .130$

!SAVE = data out.txt;

ANALYSIS:

TYPE $=$ MIXTURE;

ESTIMATOR $=$ ML;

MODEL MONTECARLO:

$\%$ OVERALL $\%$

[x1-x6@0]; x1-x6*1;

$\mathrm{x} 1$ WITH x $2^{*} .4 ; \mathrm{x} 1$ WITH x $3 * .4 ; \mathrm{x} 1$ WITH $\mathrm{x} 4 * .4$;

$\mathrm{x} 1$ WITH $\mathrm{x} 5^{*} .4$; $\mathrm{x} 1$ WITH $\mathrm{x} 6 * .4$; 2 WITH x $3 * .4$;

x 2 WITH x4*.4; x2 WITH x $5^{*} .4$; 2 WITH x6*.4;

x3 WITH $x 4^{*} .4$; 33 WITH $x 5^{*} .4$; 33 WITH $x 6^{*} .4$;

x4 WITH x5*.4; x4 WITH x6*.4; x5 WITH x6*.4;

is q|y1@0y2@1y3@2y4@3 y5@4y6@5 y7@6y8@7y9@8y10@9;

[y1-y10@0]; y1-y10*.5;

[i*4]; i*1.0;

[s*.20]; s*.10;

[q*-.03]; q*.04;

i WITH s*.15;

i WITH q*-.10;

s WITH q*-.05;

i ON x1*.30; s ON x1*.10; q ON x1*-.001; !Varying this parameter

i ON x2*.35; s ON x2*.11; q ON x2*-.05;

i ON x $3 * .34$; s ON x3*.12; q ON x3*-.06;

i ON x $4 * .33$; $\mathrm{s} \mathrm{ON} \mathrm{x} 4 *-.13$; q ON x $4 * .07$;

i ON x $5 * .32$; $\mathrm{ONN} \times 5^{*}$-. 14 ; q ON x $5^{*} .08$;

i ON x6*.31; s ON x6*-.15; q ON x6*.09;

MODEL: 
$\%$ OVERALL \%

is q|y1@0y2@1y3@2y4@3y5@4y6@5y7@6y8@7y9@8y10@9;

[y1-y10@0]; y1-y10*.5;

$\left[i^{*} 4\right] ; \mathrm{i}^{*} 1.0$;

$\left[\mathrm{s}^{*} .20\right] ; \mathrm{s}^{*} .10$

$\left[q^{*}-.03\right] ; q^{*} .04$;

i WITH s*.15;

i WITH q*-.10;

s WITH q*-.05;

i ON x1*.30; s ON x1*.10; q ON x1*-.001; !Varying this parameter i ON x $2 * .35$; s ON x $2 * .11$; q ON x $2 *-.05$;

i ON x3*.34; s ON x3*.12; q ON x3*-.06;

i ON x $4 * .33$; s ON x $4 *$-.13; q ON x $4 * .07$;

i ON x $5 * .32$; s ON x $5 *$-.14; q ON x $5^{*} .08$;

i ON x6*.31; s ON x6*-.15; q ON x6*.09; 


\section{Chapter 8 -- Bibliography of NZAVS Publications}

* denotes student author

In press

*Cross, E., Jayamaha, S., Overall, N. O., \& Sibley, C. G. (in press). Does low self-esteem predict lower wellbeing following relationship dissolution? Journal of Personal and Social Relationships. https://doi.org/10.1177/02654075211005843.

Funding: Templeton Religion Trust (TRT0196, Sibley).

*Deak, C. K., Hammond, M. D., Sibley, C. G., \& Bulbulia, J. (in press). Individuals' number of children is associated with benevolent sexism. PLoS ONE.

Funding: Templeton Religion Trust (TRT0196, Sibley).

Greaves, L. M., Stronge, S., Sibley, C. G., \& Barlow, F. K. (in press). Asexual identity, personality, and social motivations in a New Zealand national sample. Archives of Sexual Behavior

Funding: Templeton Religion Trust (TRT0196, Sibley).

Hammond, M. D., \& Sibley, C. G. (in press). Romantic partners are similar in their wellbeing and sociopolitical attitudes but change independently over time. Social Psychology and Personality Science.

Funding: Templeton Religion Trust (TRT0196, Sibley).

*Highland, B. R., Worthington, E. L., Davis, D. E., Sibley, C. G., \& Bulbulia, J. A. (in press). National longitudinal evidence for growth in subjective wellbeing from spiritual beliefs. Journal of Health Psychology. https://doi.org/10.1177/13591053211009280.

Funding: Templeton Religion Trust (TRT0196, Sibley).

Hopwood, C. J., Schwaba, T., Milfont, T. L., Sibley, C. G., \& Bleidorn, W. (in press). Personality change and sustainability attitudes and behaviors. European Journal of Personality.

Funding: Templeton Religion Trust (TRT0196, Sibley).

Marques, M. D., Wright, B. J., *Lee, C. H. J., \& Sibley, C. G. (in press). Increased sleep predicts annual decreases in psychological distress: results from a six-year longitudinal panel sample. Sleep Health. https://doi.org/10.1016/j.sleh.2020.12.005.

Funding: Templeton Religion Trust (TRT0196, Sibley).

*Matika, C. M., Manuela, S., Houkamau, C. A., \& Sibley, C. G. (in press). Māori and Pasifika language, identity, and wellbeing in Aotearoa New Zealand. Kōtuitui: New Zealand Journal of Social Sciences Online. https://doi.org/10.1080/1177083X.2021.1900298.

Funding: Templeton Religion Trust (TRT0196, Sibley).

Milfont, T. L., *Zubielevitch, E., Milojev, P., \& Sibley, C. G. (in press). Ten-year panel data confirms generation gap but climate beliefs are increasing across ages. Nature Communications. 
Funding: Templeton Religion Trust (TRT0196, Sibley, Bulbulia).

Osborne, D., *Satherley, N., Little, T. D., \& Sibley, C. G. (in press). Authoritarianism and social dominance predict annual increases in generalized prejudice. Social Psychological and Personality Science. https://doi.org/10.1177/1948550620969608

Funding: Templeton Religion Trust (TRT0196, Sibley).

*Satherley, N., Shanaah, S., Yogeeswaran, K., Osborne, D., \& Sibley, C. G. (in press). Investigating the effects of right-wing terrorism on government satisfaction: A time course analysis of the 2019 Christchurch terror attack. Studies in Conflict and Terrorism. https://doi.org/10.1080/1057610X.2021.1913819

Funding: Templeton Religion Trust (TRT0196, Sibley).

Shanaah, S., Yogeeswaran, K., Greaves, L., Bulbulia, J., Osborne, D., Afzali, U., \& Sibley, C. G. (in press). Hate begets warmth? the impact of an anti-Muslim terrorist attack on public attitudes toward Muslims. Terrorism and Political Violence. https://doi.org/10.1080/09546553.2021.1877673

Funding: Templeton Religion Trust (TRT0196, Sibley).

Stronge, S., Bulbulia, J., Davis, D. E., \& Sibley, C. G. (in press). Religion and the development of character: personality changes before and after religious conversion and deconversion. Social Psychology and Personality Science. https://doi.org/10.1177/1948550620942381

Funding: Templeton Religion Trust (TRT0196, Sibley).

*Zubielevitch, E., Cheung, G. W., Sibley, C. G., Sengupta, N. K., \& Osborne, D. (in press). People and the place: social dominance orientation is reciprocally associated with hierarchy-enhancing occupations over time. Journal of Management. https://doi.org/10.1177/01492063211004993

Funding: Templeton Religion Trust (TRT0196, Sibley).

\section{1}

*Bahamondes-Correa, J., Sibley, C. G., \& Osborne, D. (in press). System justification and perceptions of group-based discrimination: Investigating the temporal order of the ideologically motivated minimization (or exaggeration) of discrimination across low- and high-status groups. Social Psychological and Personality Science, 12(4), 431-441. https://doi.org/10.1177/1948550620929452.

Funding: Templeton Religion Trust (TRT0196, Sibley).

Ejova, A., Milojev, P., Worthington, E., Sibley, C. G., \& Bulbulia, J. (2021). Church attendance buffers against longer-term mental distress. Religion, Brain and Behavior, 11(2), 123-138.

https://doi.org/10.1080/2153599X.2020.1831580

Funding: Templeton Religion Trust (TRT0196, Sibley).

Houkamau, C. A., Milojev, P., Greaves, L. M., Dell, K., Sibley, C. G., \& Phinney, J. (2021). Indigenous ethnic identity, in-group warmth, and psychological wellbeing: A longitudinal study of Māori. Current Psychology. https://doi.org/10.1007/s12144-021-01636-4 
Funding: Templeton Religion Trust (TRT0196, Sibley).

*Matika, C. M., Houkamau, C. A., \& Sibley, C. G. (2021). New Zealand's Waitangi Day divided? Support for national day predicts in-group and out-group warmth for Pākehā but only in-group warmth for Māori. International Journal of Intercultural Relations, 80, 64-77.

https://doi.org/10.1016/j.ijintrel.2020.11.008

Funding: Templeton Religion Trust (TRT0196, Sibley).

*Panditharatne, S., Chant, L., Sibley, C. G., \& Osborne, D. (2021). At the intersection of disadvantage: Socioeconomic status heightens ethnic group differences in trust in the police. Race and Justice, 11(2), 160-182. https://doi.org/10.1177/2153368718796119.

Funding: University of Auckland FRDF (\#3709123, Osborne); School of Psychology PBRF (Osborne, Sibley); Templeton Religion Trust (TRT0196, Sibley).

*Satherley, N., Osborne, D., \& Sibley, C. G. (2021). Ideology before party: social dominance orientation and right-wing authoritarianism temporally precede political party support. British Journal of Social Psychology, 60(2), 509-523. https://doi.org/10.1111/bjso.12414

Funding: Templeton Religion Trust (TRT0196, Sibley).

Turner-Zwinkels, F. M., Johnson, C., Sibley, C. G., \& Brandt, M. J. (2021). Conservatives’ moral foundations are more densely connected than liberals' moral foundations. Personality and Social Psychology Bulletin, 47(2), 167-184. https://doi.org/10.1177/0146167220916070

Funding: European Research Council (ERC) under the European Union's Horizon 2020 research and innovation program (759320, Brandt); U.S. National Science Foundation (1644853, Johnson); Templeton Religion Trust (TRT0196, Sibley).

Van Tongeren, D. R., DeWall, C. N., Chen, Z., Sibley, C. G., \& Bulbulia, J. (2021). Religious residue: Cross-cultural evidence that religious psychology and behavior persist following deidentification. Journal of Personality and Social Psychology, 120(2), 484-503. https://doi.org/10.1037/pspp0000288

Funding: The John Templeton Foundation (\#60734, Van Tongeren, DeWall); Templeton Religion Trust (TRT0196, Sibley, Bulbulia).

\section{0}

*Andrews, N. P., Yogeeswaran, K., *Wang, M-J., Nash, K., Hawi, D., \& Sibley, C. G. (2020). Is social media use changing who we are? Examining the bidirectional relationship between personality and social media use. Cyberpsychology, Behavior, and Social Networking, 23(11), 752-760.

https://doi.org/10.1089/cyber.2019.0744

Funding: Templeton Religion Trust (TRT0196, Sibley).

*Basabas, M., \& Sibley, C. G. (2020). It's all just fun and games... right? habitual gaming links with body dissatisfaction, psychological distress, and lower self-esteem. New Zealand Journal of Psychology, 49(2), 23-33.

Funding: Templeton Religion Trust (TRT0196, Sibley). 
*Brownhalls, J., Duffy, A., Erikkson, L., Overall, N. O., Sibley, C. G., Radke, H., \& Barlow, F. K. (2020). Make it safe at night or teach women to fight? Sexism predicts views on men's and women's responsibility to reduce men's violence toward women. Sex Roles. https://doi.org/10.1007/s11199-02001159-5.

Funding: Templeton Religion Trust (TRT0196, Sibley).

Bulbulia, J. A., Troughton, J., *Highland, B., \& Sibley, C. G. (2020). A national-scale typology of orientations to religion poses new challenges for the cultural evolutionary study of religious groups. Religion, Brain and Behavior, 10(3), 239-251. https://doi.org/10.1080/2153599X.2019.1678516

Funding: Templeton World Charity Foundation Grant (ID: 0077, Sibley, Bulbulia); Templeton Religion Trust (TRT0196, Sibley, Bulbulia).

Devos, T., Yogeeswaran, K., Milojev, P., \& Sibley, C. G. (2020). Conceptions of national identity and opposition to bicultural policies in New Zealand: a comparison of majority and minority perspectives. International Journal of International Relations, 78, 33-42. https://doi.org/10.1016/j.ijintrel.2020.04.004.

Funding: Erskine Programme at the University of Canterbury (Devos, Yogeeswaran); Templeton Religion Trust (TRT0196, Sibley).

Ejova, A., Milojev, P., Worthington, E. L., Bulbulia, J., \& Sibley, C. G. (2020). The Big Six personality traits and mental distress: dynamic modelling in a population panel study reveals bidirectional relationships involving Neuroticism, Extraversion and Conscientiousness. Personality and Social Psychology Bulletin, 46(9), 1287-1302. https://doi.org/10.1177/0146167219895349.

Funding: Templeton Religion Trust (TRT0196, Sibley).

*Fraser, G., Bulbulia, J. A., Greaves, L., Wilson, M. S., \& Sibley, C. G. (2020). Coding responses to an open-ended gender measure in a New Zealand national sample. Journal of Sex Research, 57, 979-986. https://doi.org/10.1080/00224499.2019.1687640

Funding: Templeton Religion Trust (TRT0196, Sibley).

*Fraser, G., Huang, Y., *Robinson, K., Wilson, M. S., Bulbulia, J., \& Sibley, C. G. (2020). New Zealand pet owners' demographic characteristics, personality, and health and wellbeing: More than just a fluff piece. Anthrozoös, 33(4), 561-578.

Funding: Templeton Religion Trust (TRT0196, Sibley).

*Hamley, L., Houkamau, C. A., Osborne, D., Barlow, F. K., \& Sibley, C. G. (2020). Ingroup love or outgroup hate (or both)? Mapping distinct bias profiles in the population. Personality and Social Psychology Bulletin, 46(2), 171-188. https://doi.org/10.1177/0146167219845919

Funding: Templeton Religion Trust (TRT0196, Sibley)

Houkamau, C. A., Stronge, S., Osborne, D., Sibley, C. G., \& Dell, K. (2020). Exploring the relationship between support for protest and psychological well-being for Maori. New Zealand Journal of Psychology, $49,38-47$.

Funding: Templeton Religion Trust (TRT0196, Sibley). 
*Huang, Y., Sibley, C. G., \& Osborne, D. (2020). Breast is best, but where? Benevolent and hostile sexism underlies women's opposition to public breastfeeding. Journal of Social Issues, 76(2), 219-238. https://doi.org/10.1111/josi.12379

Funding: University of Auckland Doctoral Scholarship (Huang); Templeton Religion Trust (TRT0196, Sibley).

*Kapeli, S. A., Manuela, S., Milojev, P., \& Sibley, C. G. (2020). Trends in social support experienced by Pacific men and women over the adult lifespan: an age-based latent growth model. Trends in Pacific Health, 3, 1-16.

Funding: Templeton Religion Trust (TRT0196, Sibley).

*Kapeli, S. A., Manuela, S., \& Sibley, C. G. (2020). Perceived discrimination is associated with poorer health and well-being outcomes among Pacific peoples in New Zealand. Journal of Community and Applied Social Psychology, 30(2), 132-150. https://doi.org/10.1002/casp.2433

Funding: Templeton Religion Trust (TRT0196, Sibley).

*Lee, C. H. J., Overall, N. C., \& Sibley, C. G. (2020). Maternal and paternal confidence in vaccine safety: Whose attitudes are predictive of children's vaccination? Vaccine, 38(45), 7052-7062. https://doi.org/10.1016/j.vaccine.2020.09.020

Funding: University of Auckland Doctoral Scholarship (Lee); Templeton Religion Trust (TRT0196, Sibley).

*Lee, C. H. J., \& Sibley, C. G. (2020). Attitudes toward vaccinations are becoming more polarized in New Zealand: Findings from a longitudinal survey. EClinicalMedicine, 23, 100387. https://doi.org/10.1016/j.eclinm.2020.100387.

Funding: University of Auckland Doctoral Scholarship (Lee); Templeton Religion Trust (TRT0196, Sibley).

*Lee, C. H. J., \& Sibley, C. G. (2020). Correlates of New Zealanders' drinking status, frequency and intensity: Evidence from the New Zealand Attitudes and Values Study. New Zealand Journal of Psychology, 49(2), 46-58.

Funding: Templeton Religion Trust (TRT0196, Sibley).

*Lee, C. H. J., \& Sibley, C. G. (2020). Ethnic disparities in vaccine safety attitudes and perceptions of family doctors/general practitioners. Vaccine, 38(45), 7024-7032.

Funding: University of Auckland Doctoral Scholarship (Lee); Templeton Religion Trust (TRT0196, Sibley).

*Lockhart, C., Sibley, C. G., \& Osborne, D. (2020). Religion makes - and unmakes - the status quo: religiosity and spirituality have opposing effects on conservatism via RWA and SDO. Religion, Brain and Behaviour, 10(4), 379-392. https://doi.org/10.1080/2153599x.2019.1607540.

Funding: Templeton Religion Trust (TRT0196, Sibley). 
*Milfont, T. L., Osborne, D., Yogeeswaran, K., \& Sibley, C. G. (2020). The role of national identity in collective pro-environmental action. Journal of Environmental Psychology, 72, 101522.

https://doi.org/10.1016/j.jenvp.2020.101522.

Funding: Templeton Religion Trust (TRT0196, Sibley).

Milfont, T. L., Poortinga, W., \& Sibley, C. G. (2020). Does having children increase environmental concern? Testing parenthood effects with longitudinal data from the New Zealand Attitudes and Values Study. PLOS One, 15(3), e0230361. https://doi.org/10.1371/journal.pone.0230361

Funding: Templeton Religion Trust (TRT0196, Sibley).

Osborne, D., \& Sibley, C. G. (2020). Does Openness to Experience predict changes in conservatism? A nine-wave longitudinal investigation into the personality roots to ideology. Journal of Research in Personality, 87, 103979.

Funding: University of Auckland FRDF (3709123, Osborne); University of Auckland PBRF (Osborne, Sibley); Templeton Religion Trust (TRT0196, Sibley).

*Satherley, N., Greaves, L. K., Osborne, D., \& Sibley, C. G. (2020). State of the nation: Trends in New Zealand voters' polarization from 2009-2018. Political Science, 72(1), 1-23.

https://doi.org/10.1080/00323187.2020.1818587

Funding: Templeton Religion Trust (TRT0196, Sibley).

*Satherley, N., Osborne, D., \& Sibley, C. G. (2020). Identity, ideology, and personality: Examining moderators of affective polarization in New Zealand. Journal of Research in Personality, 87, 103961. https://doi.org/10.1016/j.jrp.2020.103961

Funding: Templeton Religion Trust (TRT0196, Sibley).

Sibley, C. G., *Afzali, M. U., *Satherley, N., Ejova, A., Stronge, S., Yogeeswaran, K., Grimshaw, M., Hawi, D., *Mirnajafi, Z., Barlow, F. K., Milojev, P., Greaves, L. M., *Kapeli, S., *Zubielevitch, E., *Hamley, L., *Basabas, M. C., Wu, M. H., *Howard, C., *Lee, C. H. J., *Huang, Y., *Lockhart, C., *Bahamondes, J., Manuela, S., Milfont, T. L., Perry, R., Sengupta, N. K., Overall, N. C., Shaver, J. H., Troughton, G., Osborne, D., \& Bulbulia, J. (2020). Prejudice toward Muslims in New Zealand: Insights from the New Zealand Attitudes and Values Study. New Zealand Journal of Psychology, 49, 48-72.

Funding: Templeton Religion Trust (TRT0196, Sibley).

Sibley, C. G., Greaves, L. M., *Satherley, N., Wilson, M. S., Overall, N. C., *Lee, C. H. J., Milojev, P., Bulbulia, J., Osborne, D., Milfont, T. L., Houkamau, C. A., Duck, I. M., *Vickers-Jones, R., \& Barlow, F. K. B. (2020). Effects of the COVID-19 pandemic and nationwide lockdown on trust, attitudes towards government, and wellbeing. American Psychologist, 75(5), 618-630. https://doi.org/10.1037/amp0000662

Funding: Templeton Religion Trust (TRT0196, Sibley, Bulbulia); Australian Research Council Future Fellowship grant (FT150100147, Barlow)

Thomas, E., *Zubielevitch, E., Sibley, C. G., \& Osborne, D. (2020). Testing the social identity model of collective action longitudinally and across structurally disadvantaged and advantaged groups. Personality and Social Psychology Bulletin, 46(6), 823-838. https://doi.org/10.1177/0146167219879111

Funding: Templeton Religion Trust (TRT0196, Sibley). 
Vilar, R., Milfont, T. L., \& Sibley, C. G. (2020). The role of social desirability responding in the longitudinal relations between intention and behaviour. Journal of Environmental Psychology, 70, 101457

Funding: Templeton Religion Trust (TRT0196, Sibley).

*Zubielevitch, E., Sibley, C. G., \& Osborne, D. (2020). Chicken or the egg? A cross-lagged panel analysis of group identification and group-based relative deprivation. Group Processes and Intergroup Relations, 23(7), 1032-1048. https://doi.org/10.1177/1368430219878782.

Funding: University of Auckland Doctoral Scholarship (Zubielevitch); University of Auckland FRDF grant (3709123, Osborne); University of Auckland PBRF (Osborne, Sibley); Templeton Religion Trust (TRT0196, Sibley).

\section{9}

*Bahamondes, J., Sibley, C. G., \& Osborne, D. (2019). 'We look (and feel) better through system justifying lenses': Evidence of the palliative function of ideology among the disadvantaged. Personality and Social Psychology Bulletin, 45, 1391-1408.

Funding: Templeton Religion Trust (TRT0196, Sibley).

Barlow, F. K., Hornsey, M., Hayward, L., Houkamau, C. A., Kang, J., Milojev, P., \& Sibley, C. G. (2019). Why do we hold mixed emotions about racial outgroups? A case for affect matching. Psychological Science, 30, 917-929.

Funding: Australian Research Council Future Fellowship (FT150100147, Barlow); Templeton Religion Trust (TRT0196, Sibley).

*Basabas, M., Greaves, L. M., Barlow, F. K., \& Sibley, C. G. (2019). Sexual orientation moderates the effect of gender on body satisfaction: results from a national probability sample. Journal of Sex Research, $56,1091-1100$.

Funding: Templeton Religion Trust (TRT0196, Sibley, Bulbulia).

Brandt, M. J., Sibley, C. G., \& Osborne, D. O. (2019). What is central to political belief system networks? Personality and Social Psychology Bulletin, 45, 1352-1364.

Funding: Templeton Religion Trust (TRT0196, Sibley); European Research Council (ERC) horizon 2020 research and innovation programme (759320; Brandt).

*Cowie, L., Greaves, L. M., \& Sibley, C. G. (2019). Sexuality and sexism: differences in ambivalent sexism across gender and sexual identity. Personality and Individual Differences, 148, 85-89.

Funding: Motu Thesis Scholarship (Cowie); Templeton Religion Trust (TRT0196, Sibley).

Greaves, L. M., *Fraser, G., Barlow, F. K., \& Sibley, C. G. (2019). Comparing pansexual and bisexual identified participants on demographics, psychological well-being, and political ideology in a New Zealand national sample. The Journal of Sex Research, 56, 1083-1090.

Funding: Templeton Religion Trust (TRT0196, Sibley).

Greaves, L. M., *Satherley, N., Barlow, F. K., \& Sibley, C. G. (2019). Investigating inappropriate and missing sexual orientation question responses in a New Zealand national survey. Psychology of Sexual Orientation and Gender Diversity, 6, 284-295. 
Funding: Templeton Religion Trust (TRT0196, Sibley).

Hawi, D., Osborne, D., Bulbulia, J., \& Sibley, C. G. (2019). Terrorism anxiety and attitudes toward Muslims. New Zealand Journal of Psychology, 47, 84-94.

Funding: Templeton Religion Trust (TRT0196, Sibley, Bulbulia).

Highland, B. R., Troughton, G., Shaver, J., Barrett, J., Sibley, C. G., \& Bulbulia, J. (2019). Attitudes to religion predict warmth for Muslims in New Zealand. New Zealand Journal of Psychology, 47.

Funding: Templeton Religion Trust (TRT0196, Sibley, Bulbulia, Troughton).

*Huang, Y., Osborne, D., \& Sibley, C. G. (2019). Sociodemographic factors associated with attitudes toward abortion in New Zealand. New Zealand Medical Journal, 132.

Funding: University of Auckland Doctoral Scholarship (Huang), Templeton Religion Trust (TRT0196, Sibley).

*Huang, Y., Osborne, D., \& Sibley, C. G. (2019). The gradual move towards gender equality: A sevenyear latent growth model of ambivalent sexism. Social Psychology and Personality Science, 10, 335-344.

Funding: University of Auckland Doctoral Scholarship (Huang), Templeton Religion Trust (TRT0196, Sibley).

*Lee, C., Sibley, C. G. (2019). Demographic, health and personality correlates of healthy lifestyle factors in New Zealand. New Zealand Journal of Psychology, 48, 14-26.

Funding: University of Auckland Doctoral Scholarship (Lee); Templeton Religion Trust (TRT0196, Sibley).

*Lee, C., Sibley, C. G. (2019). Sleep duration and psychological wellbeing among New Zealanders. Sleep Health: Journal of the National Sleep Foundation, 5, 606-614.

Funding: Templeton Religion Trust (TRT0196, Sibley).

*Matika, C. M., Houkamau, C. A., \& Sibley, C. G. (2019). Support for teaching Te Reo Maori. MAI Journal of Indigenous Scholarship, 8, 172-187.

Funding: Templeton Religion Trust (TRT0196, Sibley).

Osborne, D., Jost, J. T., Becker, J. C., Badaan, V., \& Sibley, C. G. (2019). Protesting to challenge or defend the system? A system justification perspective on collective action. European Journal of Social Psychology, 49, 244-269.

Funding: University of Auckland FRDF (\#3709123, Osborne); School of Psychology PBRF (Osborne, Sibley); Templeton Religion Trust (TRT0196, Sibley).

Osborne, D., Satheley, N., Yogeeswaran, K., Hawi, D., Sibley, C. G. (2019). White nationalism and multiculturalism support: investigating the interactive effects of white identity and national attachment on support for multiculturalism. New Zealand Journal of Psychology, 47, 65-74.

Funding: Templeton Religion Trust (TRT0196, Sibley). 
Robertson, A., \& Sibley, C. G. (2019). Research sampling: a pragmatic approach (pp 15-36). In P. Brough (Ed.), Advanced research methods for applied psychologists: design, analysis and reporting. New York: Routledge.

*Satherley, N., Osborne, D., \& Sibley, C. G. (2019). Who is for (or against) the national flag? Ideological and identity-based motivators of attitudes. Analyses of Social Issues and Public Policy, 19, 407-428.

Funding: University of Auckland Doctoral Scholarship (Satherley), Templeton Religion Trust (TRT0196, Sibley).

*Satherley, N., Yogeeswaran, K., Osborne, D., \& Sibley, C. G. (2019). Differentiating between pure patriots and nationalistic patriots: a model of national attachment profiles and their socio-political attitudes. International Journal of Intercultural Relations, 72, 13-24.

Funding: University of Auckland Doctoral Scholarship (Satherley), Templeton Religion Trust (TRT0196, Sibley).

Sengupta, N. K., \& Sibley, C. G. (2019). The political attitudes and subjective wellbeing of the top one percent. Journal of Happiness Studies, 20, 2125-2140.

Funding: Marie Skłodowska-Curie Fellowship (Sengupta); Templeton Religion Trust (TRT0196, Sibley).

Sengupta, N. K., Osborne, D., \& Sibley, C. G. (2019). On the psychological function of nationalistic 'whitelash'. Political Psychology, 40, 759-775.

Funding: Marie Skłodowska-Curie Fellowship (Sengupta); Templeton Religion Trust (TRT0196, Sibley).

Shaver, J., Sibley, C. G., Sosis, R., Galbraith, D., \& Bulbulia, J. A. (2019). Alloparenting and religious fertility: a test of the religious alloparenting hypothesis. Evolution and Human Behaviour, 40, 315-324.

Funding: John Templeton Foundation (60927, Shaver); Barnett Endowment (Sosis); Templeton World Charity Foundation Grant (ID: 0077, Sibley, Bulbulia); Royal Society of New Zealand Marsden Fund (VUW1321, Bulbulia); Templeton Religion Trust (TRT0196, Sibley, Bulbulia).

Sibley, C. G., Bergh, R., *Satherley, N., Osborne, D., Milojev, P., Greaves, L. M., *Huang, Y., *Townrow, C. S., *Faapoi, A., Yogeeswaran, K., Hawi, D., \& Duckitt, J. (2019). Profiling authoritarian leaders and followers. Testing, Psychometrics, Methodology in Applied Psychology, 26, 1-17.

Funding: Templeton Religion Trust (TRT0196, Sibley); Swedish Foundation for International Cooperation in Research and Higher Education, STINT (\#FS2011-6057; Bergh)

*Stanley, S., Milfont, T. L., Wilson, M. S., \& Sibley, C. G. (2019). The influence of social dominance orientation and right-wing authoritarianism on environmentalism: A five-year cross-lagged analysis. PLoS One, 14, e0219067.

Funding: Templeton Religion Trust (TRT0196, Sibley).

Stronge, S., Cichocka, A., \& Sibley, C. G. (2019). The heterogeneity of self-regard: a latent transition analysis of self-esteem and entitlement. Journal of Research in Personality, 82.

Funding: Templeton Religion Trust (TRT0196, Sibley). 
Stronge, S., *Mok, T., Ejova, A., *Lee, C., *Zubielevitch, E., Yogeeswaran, K., Hawi, D., Osborne, D., Bulbulia, J., \& Sibley, C. G. (2019). Social media use is (very weakly) related to psychological distress. Cyberpsychology, Behavior, and Social Networking, 22, 604-609.

Funding: Templeton Religion Trust (TRT0196, Sibley).

Stronge, S., Overall, N. O., \& Sibley, C. G. (2019). Gender differences in the associations between relationship status, social support, and wellbeing. Journal of Family Psychology, 33, 819-829.

Funding: Templeton Religion Trust (TRT0196, Sibley).

Stronge, S., Shaver, J., Bulbulia, J., \& Sibley, C. G. (2019). Only children in the 21st century: personality differences between adults with and without siblings are very, very small. Journal of Research in Personality, 83.

Funding: Templeton Religion Trust (TRT0196, Sibley).

*Waddell, N., Sibley, C. G., \& Osborne, D. (2019). Better off alone? ambivalent sexism moderates the association between relationship status and life satisfaction. Sex Roles, 80, 647-361.

Funding: University of Auckland FRDF (\#3709123, Osborne); School of Psychology PBRF (Osborne, Sibley)

*Wang, M., Yogeeswaran, K., *Andrews, N., Hawi, D., \& Sibley, C. G. (2019). Is cyberbullying a youth problem? exploring the prevalence of cyberbullying among male and female adults in a national sample. Cyberpsychology, Behavior, and Social Networking, 22(11), 736-741.

http://doi.org/10.1089/cyber.2019.0146

Funding: Templeton Religion Trust (TRT0196, Sibley).

Yogeeswaran, K., Afzali, M. U., Andrews, N. P., Chivers, E. A., Wang, M-J., Devos, T., Sibley, C. G. (2019). Exploring New Zealand national identity and its importance for attitudes toward Muslims and diversity. New Zealand Journal of Psychology, 47, 29-36.

Funding: Templeton Religion Trust (TRT0196, Sibley).

\section{8}

*Badaan, V., Jost J. T., Osborne, D., Sibley, C. G., Ungaretti, J., Etchezahar, E., \& Hennes, E. (2018). Social protest and its discontents: a system justification perspective. Contention: The Multidisciplinary Journal of Social Protest, 6, 1-22.

*Greaves, L. M., Sengupta, N. K., *Townrow, C., Osborne, D., Houkamau, C. A., \& Sibley, C. G. (2018). Māori, a politicized identity: indigenous identity, voter turnout, protest, and political party support in Aotearoa New Zealand. International Perspectives in Psychology: Research, Practice, Consultation, 7, $155-173$.

Funding: University of Auckland Doctoral Scholarship (Greaves); Templeton Religion Trust (TRT0196, Sibley); Te Whare Kura New Knowledge Acquisition Grant (\#03903/1550, Houkamau, Sibley) 
Hammond, M., Milojev, P., Sibley, C. G., \& *Huang, Y. (2018). Benevolent sexism and hostile sexism across the ages. Social Psychology and Personality Science, 9, 863-874.

*Hawkins-Elder, H., Milfont, T. L., Hammond, M., \& Sibley, C. G. (2018). Who are the lonely? A typology of loneliness in New Zealand. Australian and New Zealand Journal of Psychiatry, 52, 357-364.

Funding: Templeton World Charity Foundation (\#0077, Sibley).

*Huang, Y., Osborne, D., \& Sibley, C. G. (2018). Public support and sociodemographic predictors of

Funding: University of Auckland Doctoral Scholarship (Huang), Templeton Religion Trust (TRT0196, Sibley).

*Lee, C. H. J., Duck, I. M., \& Sibley, C. G. (2018). Confidence in the safety of standard childhood vaccinations among health professionals in New Zealand. New Zealand Medical Journal, 131, 60-68.

Funding: University of Auckland Doctoral Scholarship (Lee); Templeton Religion Trust (TRT0196, Sibley)

*Lee, C. H. J., Norris, P., Duck, I. M., \& Sibley, C. G. (2018). Demographic and psychological factors associated with feelings of antibiotic entitlement in New Zealand. Antibiotics, 7, 1-14.

Funding: University of Auckland Doctoral Scholarship (Lee), Templeton Religion Trust (TRT0196, Sibley).

*Muriwai, E., Houkamau, C. A., \& Sibley, C. G. (2018). Looking like a smoker, a smokescreen to racism? Māori perceived appearance linked to smoking status. Ethnicity and Health, 23, 353-366.

Funding: Reducing Tobacco-related Harm Research Partnership co-funded by the Health Research Council of New Zealand and the Ministry of Health of New Zealand (HRC Grant 11/818, Muriwai), Te Whare Kura New Knowledge Acquisition Grant (\#03903/1550, Houkamau, Sibley), Templeton World Charity Foundation (\#0077, Sibley).

*Newton, H., Osborne, D., \& Sibley, C. G. (2018). The predictive power of post-colonial ideologies: historical negation and symbolic exclusion undermine support for resource-based bicultural policies. International Journal of Intercultural Relations. 62. 23-33.

Funding: Templeton World Charity Foundation (\#0077, Sibley)

Norris, P., Wilson, S. E., Green, J. A., Gu, J., Goddard, S., Deadman, L., Dai, J., Fastier, K., Kothapally, C., Shi, W., Whyte, A., Aslam, H., Desai, R., Wood, N. \& Sibley, C. G. (2018). Knowledge and attitudes to prescription charges in New Zealand and England. Research in Social and Administrative Pharmacy. 14, 180-186.

Funding: Distinguished Visitor Programme, and University Research Internship Scheme, University of Central Lancashire (Norris)

Perry, R., Priest, N., Paradies, Y., Barlow, F. K., \& Sibley, C. G. (2018). Barriers to multiculturalism: ingroup favoritism and outgroup hostility are independently associated with policy opposition. Social Psychology and Personality Science, 9, 89-98.

Funding: Templeton World Charity Foundation (\#0077, Sibley) 
Radke, H., Hornsey, M., Sibley, C. G., \& Barlow, F. K. (2018). Negotiating the hierarchy: Socially dominant women are motivated to adopt benevolently sexist worldviews. Australian Journal of Psychology, 70, 158-166.

Saeri, A. K., Cruwys, T., Barlow, F. K., Stronge, S. \& Sibley, C. G. (2018). Social Connectedness Improves Public Mental Health: Investigating Bidirectional Relationships in the New Zealand Attitudes and Values Survey. Australian and New Zealand Journal of Psychiatry, 52, 365-374.

*Satherley, N., \& Sibley, C. G. (2018). A dual process model of post-colonial ideology. International Journal of Intercultural Relations, 64, 1-11.

Funding: Templeton Religion Trust (TRT0196, Sibley)

*Satherley, N., Yogeeswaran, K., Osborne, D., \& Sibley, C. G. (2018). If they say 'yes', we say 'no': partisan cues increase polarisation over national symbols. Psychological Science, 29, 1996-2009.

Funding: University of Auckland Doctoral Scholarship (Satherley); University of Auckland FRDF (\#3709123, Osborne); Templeton Religion Trust (TRT0196, Sibley).

*Satherley, N., \& Sibley, C. G. (2018). The Modern Racism toward Māori Scale. New Zealand Journal of Psychology, 46, 4-12.

Funding: Templeton Religion Trust (TRT0196, Sibley).

*Stronge, S., Milojev, P., \& Sibley, C. G. (2018). Change in psychological entitlement across the adult life span: a 6-year cohort-sequential latent growth model. Personality and Social Psychology Bulletin. 44, 200-218.

Funding: Templeton World Charity Foundation (\#0077, Sibley)

Shaver, J., Sibley, C. G., \& Bulbulia, J. A. (2018). Are contemporary Christian New Zealanders committed to peace? (pp. 201-212). In G. Troughton \& P. Fountain (Eds.), Pursuing Peace: Stories from Godzone. Wellington: Victoria University Press.

Yogeeswaran, K., Verkuyten, M., Osborne, D., \& Sibley, C. G. (2018). Dreams of a colorblind nation? examining the relation between colorblindness, system justification, and support for policies that redress racial inequalities. Journal of Social Issues, 74, 282-298.

\section{7}

*Greaves, L. M., Robertson, A., *Cowie, L. J., Osborne, D., Houkamau, C. A., \& Sibley, C. G. (2017). Predicting party vote sentiment: identifying the demographic and psychological correlates of party preference in two large datasets. New Zealand Journal of Psychology, 46, 164-175.

Funding: University of Auckland Doctoral Scholarship (Greaves); Templeton World Charity Foundation Grant (ID: 0077, Sibley)

*Greaves, L. M., Barlow, F. K., *Huang, Y., *Stronge, S., *Fraser, G., \& Sibley, C. G. (2017). Asexual identity in a national sample: demographics, wellbeing, and health. Archives of Sexual Behavior. 46, 2417-2427.

Funding: Templeton World Charity Foundation Grant (ID: 0077, Sibley) 
*Greaves, L. M., Barlow, F. K., *Lee, C. H. J., *Matike, C. M., *Wang, Q., *Lindsay, C-J., *Case, C. J. B., *Sengupta, N. K., *Huang, Y., *Cowie, L. J., *Stronge, S., *Storey, M., *De Souza, L., *Manuela, S., *Hammond, M. D., *Milojev, P., *Townrow, C. S., *Muriwai, E., *Satherley, N., *Fraser, G., WestNewman, T., Houkamau, C., Bulbulia, J., Osborne, D., Wilson, M. S., \& Sibley, C. G. (2017). The diversity and prevalence of sexual orientation self-labels in a New Zealand national sample. Archives of Sexual Behavior, 46, 1325-1336.

Funding: Templeton World Charity Foundation (\#0077, Sibley, Bulbulia)

*Greaves, L. M., Barlow, F. K., *Huang, Y., *Stronge, S., \& Sibley, C. G. (2017). Personality across sexual identity and gender in a national probability sample in New Zealand. Sex Roles, 77, 653-662.

Funding: University of Auckland Doctoral Scholarship (Greaves); Templeton World Charity Foundation (\#0077, Sibley)

*Greaves, L. M., Houkamau, C. A., Sibley, C. G. (2017). Random intercept exploratory factor analysis of the multidimensional model of Maori identity and cultural engagement. Personality and Individual Differences, 105, 14-18.

Funding: University of Auckland Doctoral Scholarship (Greaves); Te Whare Kura New Knowledge Acquisition Grant (\#03903/1550, Houkamau, Sibley); Templeton World Charity Foundation Grant (ID: 0077, Sibley)

*Greaves, L. M., Manuela, S., *Muriwai, E., *Cowie, L. J., *Lindsay, C-J., *Matika, C. M., Houkamau, C. A., Sibley, C. G. (2017). The multidimensional model of Māori identity and cultural engagement: measurement equivalence across diverse Māori groups. New Zealand Journal of Psychology, 46, 24-35.

Funding: University of Auckland Doctoral Scholarship (Greaves); Te Whare Kura New Knowledge Acquisition Grant (\#03903/1550, Houkamau, Sibley); Templeton World Charity Foundation Grant (ID: 0077, Sibley)

*Greaves, L. M., Osborne, D., Houkamau, C. A., \& Sibley, C. G. (2017). Identity and demographics predict voter enrolment on the Māori electoral roll: findings from a national sample. Mai Journal, 6, 3-16.

Funding: University of Auckland Doctoral Scholarship (Greaves); Te Whare Kura New Knowledge Acquisition Grant (\#03903/1550, Houkamau, Sibley); Templeton World Charity Foundation Grant (ID: 0077, Sibley)

Houkamau, C. A., \& Sibley, C. G. (2017). Cultural connection predicts perceptions of financial security for Māori. Social Indicators Research, 133, 395-412.

Funding: Templeton World Charity Foundation (\#0077, Sibley); Te Whare Kura New Knowledge Acquisition Grant (03903/1550, Houkamau, Sibley)

Houkamau, C. A., *Stronge, S., \& Sibley, C. G. (2017). The prevalence and impact of racism towards indigenous Māori in New Zealand. International Perspectives in Psychology, 6, 61-80.

Funding: Templeton World Charity Foundation (\#0077, Sibley)

*Isler, L., Fletcher, G. J. O., Liu, J. H., Sibley, C. G. (2017). Validation of the four-profile configuration of personality types within the Five-Factor Model. Personality and Individual Differences, 106, 257-262. 
*Lee, C. H. J., Duck, I. M., \& Sibley, C. G. (2017). Demographic and psychological correlates of New Zealander's support for Euthanasia. New Zealand Medical Journal, 130(1448), 9-17.

Funding: Templeton World Charity Foundation (\#0077, Sibley)

*Lee, C. H. J., Duck, I. M., \& Sibley, C. G. (2017). Demographic and personality correlates of vaccination attitudes in New Zealand. Vaccine, 35, 6089-6095.

Funding: Templeton World Charity Foundation (\#0077, Sibley)

*Lee, C. H. J., Duck, I. M., \& Sibley, C. G. (2017). Ethnic inequality in diagnosis with depression and anxiety disorders. New Zealand Medical Journal, 130(1454), 10-20.

Funding: Templeton World Charity Foundation (\#0077, Sibley)

*Lee, C. H. J., \& Sibley, C. G. (2017). Demographic and psychological correlates of satisfaction with healthcare access in New Zealand. New Zealand Medical Journal.

Funding: Templeton World Charity Foundation (\#0077, Sibley)

*Matika, C. M., Manuela, S., *Muriwai, E., Houkamau, C. A., \& Sibley, C. G. (in press). Cultural efficacy predicts increased self-esteem for Maori: the mediating effect of rumination. New Zealand Journal of Psychology, 46, 178-187.

Funding: Te Whare Kura New Knowledge Acquisition Grant (\#03903/1550, Houkamau, Sibley); Templeton Religion Trust (ID: TRT0196, Sibley)

*Meeusen, C., Barlow, F. K., \& Sibley, C. G. (2017). Generalized and specific components of prejudice: The decomposition of intergroup context effects. European Journal of Social Psychology, 47, 443-456.

Funding: PhD Fellowship, Research Foundation - Flanders (Meeusen); Templeton World Charity Foundation (\#0077, Sibley)

Milfont, T. L., Wilson, M. S., \& Sibley, C. G. (2017). The public's belief in climate change and its human cause are increasing over time. PLoS ONE, 12, e0174246.

Funding: Marsden Fast-Start grant (E1908, Milfont); Templeton World Charity Foundation (\#0077, Sibley)

*Milojev, P., \& Sibley, C. G. (2017). Normative personality trait development in adulthood: a six-year cohort-sequential growth model. Journal of Personality and Social Psychology, 112, 510-526.

Funding: Templeton World Charity Foundation (\#0077, Sibley)

Osborne, D., Milojev, P., \& Sibley, C. G. (2017). A dual process model of national identity: examining the longitudinal effects of SDO and RWA on nationalism and patriotism. Personality and Social Psychology Bulletin, 43, 1086-1099.

Funding: University of Auckland ECREA (\# 3709010, Osborne); University of Auckland FRDF (\#3709123, Osborne); School of Psychology PBRF (Osborne, Sibley); Templeton World Charity Foundation (\#0077, Sibley)

Osborne, D., \& Sibley, C. G. (2018). Identifying 'types' of ideologies and intergroup biases: advancing a person-centred approach to social psychology. European Review of Social Psychology, 28, 288-332. 
Funding: University of Auckland ECREA (\# 3709010, Osborne); University of Auckland FRDF (\#3709123, Osborne); Templeton World Charity Foundation (\#0077, Sibley)

Osborne, D., Yogeeswaran, K., \& Sibley, C. G. (2017). Culture-specific ideologies undermine collective action support: Examining the legitimizing effects of post-colonial belief systems. Group Processes \& Intergroup Relations, 20, 333-349.

Funding: University of Auckland ECREA (\# 3709010, Osborne); University of Auckland FRDF (\#3709123, Osborne); School of Psychology PBRF (Osborne, Sibley); Templeton World Charity Foundation (\#0077, Sibley)

Pehrson, S., Carvacho, H., \& Sibley, C. G. (2017). Group differences in the legitimization of inequality: questioning the role of social dominance orientation. British Journal of Social Psychology, 56, 28-46.

Radke, H., Hornsey, M., Sibley, C. G., Thai, M., \& Barlow, F. K. (2017). Minority group members surrounded by a high proportion of minority group members report higher Social Dominance Orientation. PLOS One, 12, e0186612.

Funding: Australian Research Council Future Fellowship (FT150100147, Barlow); Templeton World Charity Foundation (\#0077, Sibley).

*Sengupta, N. K., Greaves, L, M., Osborne, D., \& Sibley, C. G. (2017). The sigh of the oppressed: The palliative effects of ideology are stronger for people living in highly unequal neighbourhoods. British Journal of Social Psychology, 56, 437-454.

Funding: Templeton World Charity Foundation (\#0077, Sibley)

Shaver, J., Sibley, C. G., Osborne, D.., Bulbulia, J. (2017). News exposure predicts anti-Muslim prejudice. PLoS ONE, 12, e0174606.

Funding: Templeton World Charity Foundation (\#0077, Sibley, Bulbulia); Royal Society of New Zealand Marsden Grant (VUW1321, Bulbulia)

Sibley, C. G., Robertson A., Osborne, D., *Huang, Y., *Milojev, P., *Greaves, L. M., Houkamau, C. A., Bulbulia, J., \& Barlow, F. K. (2017). Bias and tracking accuracy in voting projections using the New Zealand Attitudes and Values Study. Political Science, 61, 16-34.

Funding: Templeton World Charity Foundation (\#0077, Sibley)

*Stanley, S. K., Wilson, M. S., Sibley, C. G., Milfont, T. L. (2017). Dimensions of social dominance and their associations with environmentalism. Personality and Individual Differences, 107, 228-236.

Yogeeswaran, K., *Davies, T., \& Sibley, C. G. (2017). Janus-faced nature of colorblindness: social dominance orientation moderates impact of colorblind beliefs on outgroup attitudes. European Journal of Social Psychology, 47, 509-516.

Funding: Templeton World Charity Foundation (\#0077, Sibley)

\section{6}

Bergh, R., Akrami, N., Sidanius, J., \& Sibley, C. G. (2016). Is group membership necessary for understanding generalized prejudice? a re-evaluation of why prejudices are interrelated. Journal of Personality and Social Psychology, 111, 367-395. 
Funding: Templeton World Charity Foundation (\#0077, Sibley); Swedish Research Council (2011-1891, 437-2014-231, Bergh, Akrami); Swedish Foundation for International Cooperation in Research and Higher Education (FS2001-6057, Bergh, Akrami); Ryochi Sasakawa Young Leaders Fellowship Fund (SYLFF, Bergh, Akrami).

*Brune, A. Asbrock, F. \& Sibley, C. G. (2016). Meet your neighbours: authoritarians engage in intergroup contact when they have the opportunity. Journal of Community and Applied Social Psychology, 26, 576-580.

Funding: Templeton World Charity Foundation (\#0077, Sibley)

Bulbulia, J. Troughton, G., *Greaves, L. M., Milfont, T. L., \& Sibley, C. G. (2016). To burn or to save? The opposing functions of reading scripture on environmental intentions. Religion, Brain and Behaviour, 6, 278-289.

Funding: Templeton World Charity Foundation (\#0077, Bulbulia, Sibley, Troughton); Royal Society of New Zealand Marsden Grant (VUW1321, Bulbulia); Templeton Foundation Grant (\#28745, Bulbulia)

*Cowie, L. J., *Greaves, L. M., Milfont, T. L., Houkamau, C. A., \& Sibley, C. G. (2016). Indigenous identity and environmental values: Do spirituality and political consciousness predict environmental regard among Maori? International Perspectives in Psychology, 5, 228-244.

Funding: Motu Thesis Scholarship (Cowie); Te Whare Kura New Knowledge Acquisition Grant (\#03903/1550, Houkamau, Sibley); Templeton World Charity Foundation Grant (ID: 0077, Sibley)

Duckitt, J., \& Sibley, C. G. (2016). Personality, ideological attitudes, and group identity as predictors of political orientation and behavior in majority and minority ethnic groups. Political Psychology, 37, 109124.

*Girme, Y., Overall, N. C., *Faingataa, S., \& Sibley, C. G. (2016). Happily single: the link between relationship status and wellbeing depends on avoidance and approach social goals. Social Psychology and Personality Science, 7, 122-130.

Funding: Templeton World Charity Foundation (\#0077, Sibley)

*Huang, Y., Davies, P. G., Sibley, C. G., \& Osborne, D. (2016). Benevolent sexism, attitudes toward motherhood, and reproductive rights: A multi-study longitudinal examination of abortion attitudes. Personality and Social Psychology Bulletin, 42, 970-984.

Funding: University of Auckland ECREA (Osborne); School of Psychology PBRF (Osborne, Sibley)

*Isler, L., Liu, J. H., Sibley, C. G., \& Fletcher, G. (2016). Self-regulation and personality profiles: Empirical development, longitudinal stability, and predictive ability. European Journal of Personality, 30, 274-287.

Funding: Templeton World Charity Foundation (\#0077, Sibley)

Malka, A., Osborne, D., Soto, C. J., *Greaves, L., \& Sibley, C. G. (2016). How encompassing is the effect of disgust sensitivity on political conservatism? Personality and Social Psychology Bulletin, 42, $1243-1257$. 
Funding: Templeton World Charity Foundation (\#0077, Sibley)

Milfont, T. L., Milojev, P., \& Sibley, C. G. (2016). Values stability and change in adulthood: A three-year longitudinal study of mean-level differences and rank-order stability. Personality and Social Psychology Bulletin, 42, 572-588.

Funding: Templeton World Charity Foundation (\#0077, Sibley)

Milfont, T. L., \& Sibley, C. G. (2016). Empathic and social dominance orientations help explain gender differences in environmentalism: A one-year Bayesian mediation analysis. Personality and Individual Differences, 90, 58-88.

Funding: Royal Society of New Zealand Marsden Grant (Milfont); Templeton World Charity Foundation Grant (ID:0077, Sibley)

Osborne, D., *Milojev, P., \& Sibley, C. G. (2016). Examining the indirect effects of religious orientations on well-being through personal locus of control. European Journal of Social Psychology, 46, 492-505.

Funding: Templeton World Charity Foundation (\#0077, Sibley); University of Auckland FRDF (\#3624435, Sibley \& \#3700683, Osborne); University of Auckland ECREA (\#3626075, Sibleyt \& \#3709010, Osborne); School of Psychology PBRF (Osborne, Sibley)

*Satherley, N., \& Sibley, C. G. (2016). A dual process model of attitudes toward immigration: predicting intergroup and international relations with China. International Journal of Intercultural Relations, 53, 7282.

Funding: Templeton World Charity Foundation (\#0077, Sibley)

Shaver, J., Troughton, G., Sibley, C. G., Bulbulia, J. (2016). Religion and the unmaking of prejudice towards Muslims: evidence from a large national sample. PLoS ONE, 11, e0150209.

Funding: Templeton World Charity Foundation (\#0077, Bulbulia, Sibley, Troughton); Royal Society of New Zealand Marsden Grant (VUW1321, Bulbulia, Sibley)

Sibley, C. G., \& Osborne, D. O. (2016). Ideology and post-colonial society. Advances in Political Psychology, 37, 115-161.

Funding: School of Psychology PBRF (Osborne, Sibley)

*Stronge, S., Cichocka, A., \& Sibley, C. G. (2016). Narcissistic self-esteem or optimal self-esteem? A latent profile analysis of self-esteem and psychological entitlement. Journal of Research in Personality, $63,102-110$.

Funding: Templeton World Charity Foundation (\#0077, Sibley)

*Stronge, S., *Sengupta, N. K., Barlow, F. K., Osborne, D., Houkamau, C. A., \& Sibley, C. G. (2016). Perceived discrimination predicts increased support for political rights and life satisfaction mediated by ethnic identity: a longitudinal analysis. Cultural Diversity and Ethnic Minority Psychology, 22, 359-368.

Funding: Templeton World Charity Foundation (\#0077, Sibley) 
Bergh, R., Sidanius, J., \& Sibley, C. G. (2015). Dimensions of social dominance: their personality and socio-political correlates within a New Zealand probability sample. New Zealand Journal of Psychology, 44, 25-34.

Funding: Templeton World Charity Foundation (\#0077, Sibley)

Bulbulia, J. A., Shaver, J., *Greaves, L., Sosis, R., \& Sibley, C. G. (2015). Religion and parental cooperation: an empirical test of Slone's sexual signaling model. In D. Slone \& J. Van Slyke (Eds.), The Attraction of Religion: A Sexual Selectionist Account (pp. 29-62). Bloomsbury Press.

Funding: Templeton World Charity Foundation (\#0077, Bulbulia, Sibley)

*Cowie, L. J., *Greaves, L. M., \& Sibley, C. G. (2015). Identifying distinct subgroups of Green voters: a latent profile analysis of crux values relating to Green Party support. New Zealand Journal of Psychology, 44, 45-60.

Funding: Templeton World Charity Foundation (\#0077, Sibley)

*Dawtry, R., Sutton, R., \& Sibley, C. G. (2015). Why wealthier people think people are wealthier, and why it matters: from social sampling to redistributive attitudes. Psychological Science, 26, 1389-1400.

*Fraser, G., Osborne, D., \& Sibley, C. G. (2015). "We want you in the workplace, but only in a skirt!" Social Dominance Orientation, gender-based affirmative action and the moderating role of Benevolent Sexism. Sex Roles, 73, 231-244.

Funding: Templeton World Charity Foundation (\#0077, Sibley)

*Greaves, L. M., *Cowie, L., *Fraser, G., *Muriwai, E., *Huang, Y., *Milojev, P., Osborne, D., Sibley, C. G., *Zdrenka, M., Bulbulia, J., Wilson, M. S., Liu, J. H., \& Clouston, A. (2015). Regional differences and similarities in the personality of New Zealanders. New Zealand Journal of Psychology, 44, 4-16.

Funding: Templeton World Charity Foundation (\#0077, Sibley, Bulbulia)

*Greaves, L. M., Houkamau, C., \& Sibley, C. G. (2015). Māori identity signatures: a latent profile analysis of the types of Māori identity. Cultural Diversity and Ethnic Minority Psychology, 21, 541-549.

Funding: Motu Thesis Scholarship (Greaves); Te Whare Kura New Knowledge Acquisition Grant (03903/1550, Houkamau, Sibley); Templeton World Charity Foundation (ID: 0077, Sibley)

*Greaves, L. M., *Milojev, P., *Huang, Y., *Stronge, S., Osborne, D., Bulbulia, J., Grimshaw, M., \& Sibley, C. G. (2015). Regional differences in the psychological recovery of Christchurch residents following the 2010/2011 earthquakes: a longitudinal study. PLoS ONE, 10, e0124278.

Funding: Templeton World Charity Foundation (\#0077, Sibley, Bulbulia)

*Greaves, L. M., Osborne, D., \& Sibley, C. G. (2015). Profiling the fence-sitters in New Zealand elections: a latent profile model of political voting blocs. New Zealand Journal of Psychology, 44, -43-56.

Funding: Te Whare Kura Scholarship (Greaves); Templeton World Charity Foundation (\#0077, Sibley)

Houkamau, C. A., \& Sibley, C. G. (2015). Looking Māori predicts decreased rates of home ownership: institutional racism in housing based on perceived appearance. PLoS ONE, 10, e0118540. 
Funding: Te Whare Kura New Knowledge Acquisition Grant (\#03903/1550, Houkamau, Sibley); Templeton World Charity Foundation Grant (ID: 0077, Sibley)

Houkamau, C. A., \& Sibley, C. G. (2015). The Revised Multidimensional Model of Māori Identity and Cultural Engagement (MMM-ICE2). Social Indicators Research, 122, 279-296.

Funding: Te Whare Kura New Knowledge Acquisition Grant (\#03903/1550, Houkamau, Sibley).

Milfont, T. L., *Milojev, P., *Greaves, L. M., \& Sibley, C. G. (2015). Socio-structural and psychological foundations of climate change beliefs. New Zealand Journal of Psychology, 44, 17-30.

Funding: Royal Society of New Zealand Marsden Grant (Milfont); Templeton World Charity Foundation Grant (ID:0077, Sibley)

*Milojev, P., *Greaves, L., Osborne, D., \& Sibley, C. G. (2015). Stability and change in political conservatism following the global financial crisis. Personality and Social Psychology Bulletin, 41, 127139.

Funding: Templeton World Charity Foundation (\#0077, Sibley)

*Muriwai, E., Houkamau, C., \& Sibley, C. G. (2015). Culture as cure? The protective function of Māori cultural efficacy on psychological distress New Zealand Journal of Psychology, 44, 14-24.

Funding: Te Whare Kura New Knowledge Acquisition Grant (\#03903/1550, Houkamau, Sibley); Templeton World Charity Foundation Grant (ID: 0077, Sibley)

Osborne, D., \& Sibley, C. G. (2015). Opposing paths to ideology: group-based relative deprivation predicts conservatism through discrete feelings towards ingroup and outgroup members. Social Justice Research, 28, 27-51.

Funding: Templeton World Charity Foundation (\#0077, Sibley); University of Auckland FRDF (\#3624435, Sibley \& \#3700683, Osborne); University of Auckland ECREA (\#3626075, Sibley)

Osborne, D., \& Sibley, C. G. (2015). Within the limits of civic training: education moderates the relationship between openness and political attitudes. Political Psychology, 36, 295-313.

Funding: University of Auckland FRDF (\#3624435, Sibley); University of Auckland ECREA (\#3626075, Sibley)

Osborne, D., \& Sibley, C. G., \& *Sengupta, N. K. (2015). Income and neighbourhood-level inequality predict self-esteem and ethnic identity centrality through individual- and group-based relative deprivation: A multilevel path analysis. European Journal of Social Psychology, 45, 368-377.

Osborne, D., \& Sibley, C. G., Smith, H. J., \& Huo, Y. J. (2015). Doubling-down on deprivation: Using Latent Profile Analysis to evaluate an enduring assumption in relative deprivation theory. European Journal of Social Psychology, 45, 482-495.

Osborne, D., Yogeeswaran, K., \& Sibley, C. G. (2015). The hidden consequences of political efficacy: testing an efficacy-apathy model of political mobilization. Cultural Diversity and Ethnic Minority Psychology, 21, 533-540.

Funding: Templeton World Charity Foundation (\#0077, Sibley); University of Auckland FRDF (\#3700683, Sibley); 
*Satherley, N., *Milojev, P., *Greaves, L. M., *Huang, Y., Osborne, D., Bulbulia, J., \& Sibley, C. G. (2015). Demographic and psychological predictors of panel attrition: evidence from the New Zealand Attitudes and Values Study. PLoS ONE, 10, e 0121950.

Funding: Templeton World Charity Foundation (\#0077, Sibley, Bulbulia)

*Sengupta, N. K., *Milojev, P., Barlow, F. K., \& Sibley, C. G. (2015). Ingroup friendship and political mobilization among the disadvantaged. Cultural Diversity and Ethnic Minority Psychology, 21, 358-368.

*Sengupta, N. K., \& Osborne, D., \& Sibley, C. G. (2015). The status-legitimacy hypothesis revisited: ethnic group differences in general and dimension-specific legitimacy. British Journal of Social Psychology, 54, 324-340.

Funding: University of Auckland FRDF (\#3624435, Sibley); University of Auckland ECREA (\#3626075, Sibley)

Sibley, C. G., \& Bulbulia, J. (2015). Charity explains differences in life satisfaction between religious and secular New Zealanders. Religion, Brain and Behaviour, 5, 91-100.

Funding: Templeton World Charity Foundation (\#0077, Sibley, Bulbulia); University of Auckland FRDF (\#3624435, Sibley); University of Auckland ECREA (\#3626075, Sibley)

*Stronge, S., *Greaves, L. M., *Milojev, P., West-Newman, T., Barlow, F. K., \& \& Sibley, C. G. (2015). Facebook is linked to body dissatisfaction: comparing users and non-users. Sex Roles, 73, 200-213.

Funding: Templeton World Charity Foundation (\#0077, Sibley)

*Stronge, S., Osborne, D., West-Newman, T., Wilson, M. S., *Milojev, P., *Greaves, L. M., \& Sibley, C. G. (2015). The Facebook Feedback Hypothesis of personality and social belonging. New Zealand Journal of Psychology, 44, 4-13.

Funding: Templeton World Charity Foundation (\#0077, Sibley)

*Zdrenka, M., Yogeeswaran, K., *Stronge, S., \& Sibley, C. G. (2015). Ethnic and national attachment as predictors of wellbeing among New Zealand European, Māori, Asian, and Pacific Nations peoples. International Journal of Intercultural Relations, 49, 114-120.

Funding: Templeton World Charity Foundation (\#0077, Sibley)

\section{4}

*Davies, C. L., Sibley, C. G., \& Liu, J. H. (2014). Confirmatory Factor Analysis of the Moral Foundations Questionnaire: Independent scale validation in a New Zealand sample. Social Psychology, 45, 431-436.

Funding: University of Auckland FRDF (\#3624435, Sibley); University of Auckland ECREA (\#3626075, Sibley); Chiang Ching-Kuo International Foundation for Scholarly Exchange (RG016-P-10, Liu)

*Greaves, L. M., Osborne, D., *Sengupta, N. K., Milojev, P., \& Sibley, C. G. (2014). Politics and postcolonial ideology: historical negation and symbolic exclusion predict political party preference. New Zealand Journal of Psychology, 43, 39-54.

Funding: Templeton World Charity Foundation (\#0077, Sibley) 
*Hammond, M., Sibley, C. G., \& Overall, N. O. (2014). The allure of sexism: psychological entitlement fosters women's endorsement of benevolent sexism over time. Social Psychology and Personality Science, 5, 421-428.

Funding: University of Auckland Doctoral Scholarship (Hammond); University of Auckland FRDF (\#3624435, Sibley); University of Auckland ECREA (\#3626075, Sibley)

Houkamau, C. A., \& Sibley, C. G. (2014). Social identity and differences in psychological and economic outcomes for mixed and sole-identified Māori. International Journal of Intercultural Relations, 40, 113125 .

Funding: Te Whare Kura New Knowledge Acquisition Grant (\#03903/1550, Houkamau, Sibley); University of Auckland FRDF (\#3624435, Sibley); University of Auckland ECREA (\#3626075, Sibley)

*Huang, Y., Osborne, D., Sibley, C. G., \& Davies, P. G. (2014). The precious vessel: ambivalent sexism and opposition to elective and traumatic abortion. Sex Roles, 71, 436-449.

Funding: University of Auckland FRDF (\#3700683, Osborne); School of Psychology PBRF (Osborne, Sibley)

*Manuela, S., \& Sibley, C. G. (2014). Why do Pacific people with multiple ethnic affiliations have poorer subjective wellbeing? Negative ingroup affect mediates the identity tension effect. Social Indicators Research, 115, 319-336.

Funding: University of Auckland FRDF (\#3624435, Sibley); University of Auckland ECREA (\#3626075, Sibley)

Milfont, T. L., Evans, L., Sibley, C. G., Ries, J., Cunningham, A. (2014). Proximity to coast is linked to climate change belief. PLoS ONE, 9, e103180.

Funding: Royal Society of New Zealand Marsden Grant (Milfont); University of Auckland FRDF (\#3624435, Sibley); University of Auckland ECREA (\#3626075, Sibley)

*Milojev, P., Osborne, D., \& Sibley, C. G. (2014). Personality resilience following a natural disaster. Social Psychology and Personality Science, 5, 760-768.

Funding: Templeton World Charity Foundation (\#0077, Sibley)

*Milojev, P., Osborne, D., *Greaves, L. M., Bulbulia, J., Wilson, M. S., *Davies, C. L., Liu, J. H., \& Sibley, C. G. (2014). Right-Wing Authoritarianism and Social Dominance Orientation predict different moral signatures. Social Justice Research, 27, 149-174.

Funding: Templeton World Charity Foundation (\#0077, Sibley, Bulbulia)

*Milojev, P., *Sengupta, N. K., \& Sibley, C. G. (2014). Majority group opposition to minority political entitlements: the social dominance paradox. International Journal of Intercultural Relations, 39, 82-92.

Funding: University of Auckland FRDF (\#3624435, Sibley); University of Auckland ECREA (\#3626075, Sibley)

*Milojev, P., \& Sibley, C. G. (2014). The stability of adult personality varies across age: evidence from a two-year longitudinal sample of adult New Zealanders. Journal of Research in Personality, 51, 29-37. 
Funding: University of Auckland FRDF (\#3624435, Sibley); University of Auckland ECREA (\#3626075, Sibley)

Osborne, D., \& Sibley, C. G. (2014). Endorsement of system-justifying beliefs strengthens the relationship between church attendance and Right-Wing Authoritarianism. Group Processes and Intergroup Relations, 17, 542-551.

Funding: University of Auckland FRDF (\#3624435, Sibley; \#3700683, Osborne); University of Auckland ECREA (\#3626075, Sibley)

*Rowney, C., Farvid, P. \& Sibley, C. (2014). I laugh and say 'I have Earthquake Brain!"': Resident responses to the September 2010 Christchurch Earthquake. New Zealand Journal of Psychology, 43, 4-13.

Sibley, C. G., \& Bulbulia, J. (2014). How do religious identities and basic value orientations affect each other over time? International Journal for the Psychology of Religion, 24, 64-76.

Funding: University of Auckland FRDF (\#3624435, Sibley); University of Auckland ECREA (\#3626075, Sibley); Canadian Social Sciences and Humanities Research Council Grant (Bulbulia); Templeton Foundation Grant (\#28745, Bulbulia); Victoria University URF Grant (83046-108855, Bulbulia)

Troughton, G., Bulbulia, J., \& Sibley, C. G. (2014). Strength of religion and the future of the churches. Stimulus, 21, 26-34.

Funding: Templeton World Charity Foundation (\#0077, Sibley, Bulbulia, Troughton)

\section{3}

Barlow, F. K., Hornsey, M. J., *Thai, M., *Sengupta, N. K., \& Sibley, C. G. (2013). The wallpaper effect: The contact hypothesis fails for minority group members who live in areas with a high proportion of majority group members. PLoS ONE, 12, e82228.

Funding: Australian Research Council Discovery ECRA (\#DE120102068, Barlow); Australian Research Council Grant (\#DP1093654, Hornsey); University of Auckland FRDF (\#3624435, Sibley); University of Auckland ECREA (\#3626075, Sibley)

Bulbulia, J., Osborne, D., \& Sibley, C. G. (2013). Moral foundations predict religious orientations in New Zealand. PLoS ONE, 8, e80224.

Funding: Canadian Social Sciences and Humanities Research Council Grant (Bulbulia); Templeton Foundation Grant (\#28745, Bulbulia); Victoria University URF Grant (8-3046108855, Bulbulia); University of Auckland FRDF (\#3624435, Sibley); University of Auckland ECREA (\#3626075, Sibley)

Dittman, C., Sibley, C. G., \& Farruggia, S. (2013). Attitudes toward smacking in a New Zealand probability sample: psychological and demographic correlates. New Zealand Journal of Psychology, 42, 41-50.

Funding: University of Auckland FRDF (\#3624435, Sibley); University of Auckland ECREA (\#3626075, Sibley)

Hoverd, W. J., Bulbulia, J., \& Sibley, C. G. (2013). Does poverty predict religion? Religion, Brain and Behaviour, 3, 185-200. 
Funding: University of Auckland FRDF (\#3624435, Sibley); University of Auckland ECREA (\#3626075, Sibley), Canadian DFAIT Postdoctoral Research Fellowship (Hoverd); Victoria University URF Grant (\#8-3046-108855, Bulbulia)

Hoverd, W. J., \& Sibley, C. G. (2013). Religion, deprivation and subjective wellbeing: testing a religious buffering hypothesis. International Journal of Wellbeing, 3, 182-196.

Funding: University of Auckland FRDF (\#3624435, Sibley); University of Auckland ECREA (\#3626075, Sibley); Canadian DFAIT Postdoctoral Research Fellowship (Hoverd)

*Krynen, A., Osborne, D., Duck, I. M., Houkamau, C., \& Sibley, C. G. (2013). Measuring psychological distress in New Zealand: Item response properties and demographic differences in the Kessler-6 screening measure. New Zealand Journal of Psychology, 42, 69-83.

Funding: Te Whare Kura New Knowledge Acquisition Grant (\#03903/1550, Houkamau, Sibley)

Liu, J. H., \& Sibley, C. G. (2013). From ordinal representations to representational profiles: A primer for describing and modelling social representations of history. Papers on Social Representations, 22, 5.15.30 .

Milfont, T. L., Richter, I., Sibley, C. G., Wilson, M. S., \& Fischer, R. (2013). Environmental consequences of the desire to dominate and be superior. Personality and Social Psychology Bulletin, 39, 1139-1151.

Funding: Royal Society of New Zealand Marsden Grant (Milfont); University of Auckland FRDF (\#3624435, Sibley); University of Auckland ECREA (\#3626075, Sibley)

*Milojev, P., Osborne, D., Greaves, L. M., Barlow, F. K., \& Sibley, C. G. (2013). The Mini-IPIP6: Tiny yet highly stable markers of Big Six personality. Journal of Research in Personality, 47, 936-944.

Funding: University of Auckland FRDF (\#3624435, Sibley); University of Auckland ECREA (\#3626075, Sibley)

Osborne, D., \& Sibley, C. G. (2013). After the disaster: using the Big-Five to predict changes in mental health among survivors of the 2011 Christchurch Earthquake. Disaster Prevention and Management, 22, 456-466.

Funding: University of Auckland FRDF (\#3624435, Sibley); University of Auckland ECREA (\#3626075, Sibley)

Osborne, D., \& Sibley, C. G. (2013). Through rose-coloured glasses: system-justifying beliefs dampen the effects of relative deprivation on well-being and political mobilization. Personality and Social Psychology Bulletin, 39, 991-1004.

Funding: University of Auckland FRDF (\#3700683, Osborne, \#3624435, Sibley); University of Auckland ECREA (\#3626075, Sibley); School of Psychology PBRF (Osborne, Sibley)

Osborne, D., *Wootton, L. W., \& Sibley, C. G. (2013). Are liberals agreeable or not? politeness and compassion differentially predict political conservatism via distinct ideologies. Social Psychology, 44, 354-360.

Funding: University of Auckland FRDF (\#3624435, Sibley); University of Auckland ECREA (\#3626075, Sibley) 
*Perry, R., \& Sibley, C. G. (2013). A dual-process motivational model of social and economic policy attitudes. Analyses of Social Issues and Public Policy, 13, 262-285.

Funding: University of Auckland FRDF (\#3624435, Sibley); University of Auckland ECREA (\#3626075, Sibley)

*Sengupta, N. K., \& Sibley, C. G. (2013). Perpetuating one's own disadvantage: intergroup contact enables the ideological legitimation of inequality. Personality and Social Psychology Bulletin, 39, 13911403.

Funding: University of Auckland FRDF (\#3624435, Sibley); University of Auckland ECREA (\#3626075, Sibley)

Sibley, C. G. \& Kurz, T. (2013). A model of climate change belief profiles: How much does it matter if people question human causation? Analyses of Social Issues and Public Policy, 13, 245-261.

Funding: University of Auckland FRDF (\#3624435, Sibley); University of Auckland ECREA (\#3626075, Sibley)

Sibley, C. G., \& Liu, J. H. (2013). Relocating attitudes as components of representational profiles: mapping the epidemiology of intergroup policy attitudes using Latent Class Analysis. European Journal of Social Psychology, 43, 160-174.

Funding: University of Auckland FRDF (\#3624435, Sibley); University of Auckland ECREA (\#3626075, Sibley)

Sibley, C. G., \& Pirie, D. J. (2013). Personality in New Zealand: Scale norms and demographic differences in the Mini-IPIP6. New Zealand Journal of Psychology, 42, 13-30.

Funding: University of Auckland FRDF (\#3624435, Sibley); University of Auckland ECREA (\#3626075, Sibley)

Sibley, C. G., \& Ward, C. (2013). Measuring the preconditions for a successful multicultural society: a barometer test of New Zealand. International Journal of Intercultural Relations, 37, 700-713.

Funding: University of Auckland FRDF (\#3624435, Sibley); University of Auckland ECREA (\#3626075, Sibley);

Sidanius, J., Kteily, N., Sheehy-Skeffington, J., Ho, A., Sibley, C. G., \& Duriez, B. (2013). You're inferior and not worth our concern: the interface between empathy and Social Dominance Orientation. Journal of Personality, 81, 313-323.

Funding: University of Auckland FRDF (\#3624435, Sibley); University of Auckland ECREA (\#3626075, Sibley)

\section{2}

Barlow, F. K., Sibley, C. G., \& Hornsey, M. J. (2012). Rejection as a call to arms: Inter-racial hostility and support for political action as outcomes of race-based rejection in majority and minority groups. British Journal of Social Psychology, 51, 167-177. 
Funding: University of Auckland FRDF (\#3624435, Sibley); University of Auckland ECREA (\#3626075, Sibley); Australian Research Council Grant (\#DP1093654, Hornsey)

Hoverd, W. J., Atkinson, Q., Sibley, C. G. (2012). Group size and the trajectory of religious identification. Journal for the Scientific Study of Religion, 51, 286-303.

Funding: University of Auckland FRDF (\#3624435, Sibley); University of Auckland ECREA (\#3626075, Sibley); Canadian DFAIT Postdoctoral Research Fellowship (Hoverd)

Milfont, T. L., \& Sibley, C. G. (2012). The big five personality traits and environmental engagement: associations at the individual and societal level. Journal of Environmental Psychology, 32, 187-195.

Funding: School of Psychology Start-up Grant (Milfont); Victoria University of Wellington New Researcher's Fund (Milfont); University of Auckland FRDF (\#3624435, Sibley); University of Auckland ECREA (\#3626075, Sibley)

Osborne, D., \& Sibley, C. G. (2012). Does personality matter? Openness correlates with vote choice, but particularly for educated voters. Journal of Research in Personality, 46, 743-751.

*Sengupta, N. K., Barlow, F. K., \& Sibley, C. G. (2012). Intergroup contact and post-colonial ideology: outgroup contact ameliorates symbolic exclusion but not historical negation. International Journal of Intercultural Relations, 36, 506-517.

Funding: University of Auckland FRDF (\#3624435, Sibley); University of Auckland ECREA (\#3626075, Sibley)

Sibley, C. G. (2012). The Mini-IPIP6: Item Response Theory analysis of a short measure of the big-six factors of personality in New Zealand. New Zealand Journal of Psychology, 41, 21-31.

Funding: University of Auckland FRDF (\#3624435, Sibley); University of Auckland ECREA (\#3626075, Sibley)

Sibley, C. G., \& Becker, J. C. (2012). On the nature of sexist ambivalence: profiling ambivalent and univalent sexists. European Journal of Social Psychology, 42, 589-601.

Funding: University of Auckland FRDF (\#3624435, Sibley); University of Auckland ECREA (\#3626075, Sibley)

Sibley, C. G., \& Bulbulia, J. (2012). Faith after an earthquake: a longitudinal study of religion and

Funding: University of Auckland FRDF (\#3624435, Sibley); University of Auckland ECREA (\#3626075, Sibley); Victoria University URF Grant (8-3046-108855, Bulbulia); Interacting Minds Project and Religion Cognition and Culture Unit at Aarhus University (Bulbulia).

\section{1 and earlier}

*Hammond, M. D., \& Sibley, C. G. (2011). Why are benevolent sexists happier? Sex Roles, 65, 332-343. Funding: University of Auckland FRDF (\#3624435, Sibley); University of Auckland ECREA (\#3626075, Sibley)

Houkamau, C. A., \& Sibley, C. G. (2010). The Multi-Dimensional Model of Māori Identity and Cultural Engagement. New Zealand Journal of Psychology, 39, 8-28. 
Hoverd, W. J., \& Sibley, C. G. (2010). Religious and denominational diversity in New Zealand 2009. New Zealand Sociology, 25, 59-87.

Funding: University of Auckland FRDF (\#3624435, Sibley); University of Auckland ECREA (\#3626075, Sibley)

Sibley, C. G., Harré, N., Hoverd, W. J., \& Houkamau, C. (2011). The gap in the subjective wellbeing of Māori and New Zealand Europeans widened between 2005 and 2009. Social Indicators Research, 104, 103-115.

Funding: University of Auckland FRDF (\#3624435, Sibley); University of Auckland ECREA (\#3626075, Sibley)

Sibley, C. G., Houkamau, C. A., \& Hoverd, W. J. (2011). Ethnic group labels and intergroup attitudes in New Zealand: Naming preferences predict distinct ingroup and outgroup biases. Analyses of Social Issues and Public Policy, 11, 201-220.

Funding: University of Auckland FRDF (\#3624435, Sibley); University of Auckland ECREA (\#3626075, Sibley)

Sibley, C. G., *Luyten, N., *Purnomo, M., *Moberly, A., *Wootton, L. W., *Hammond, M. D., *Sengupta, N., *Perry, R., West-Newman, T., Wilson, M. S., McLellan, L., Hoverd, W. J., \& Robertson, A. (2011). The Mini-IPIP6: Validation and extension of a short measure of the Big-Six factors of personality in New Zealand. New Zealand Journal of Psychology, 40, 142-159.

Funding: University of Auckland FRDF (\#3624435, Sibley); University of Auckland ECREA (\#3626075, Sibley) 


\section{References}

Atkinson J, Salmond C, Crampton P. 2014. NZDep2013 Index of Deprivation. Wellington: Department of Public Health, University of Otago, Wellington.

Chen, D. L., Schonger, M., \& Wickens, C. (2016). oTree-An open-source platform for laboratory, online, and field experiments. Journal of Behavioral and Experimental Finance, 9, 88-97.

Crampton, P., Salmond, C., Woodward, A., \& Reid, P. (2000). Socioeconomic deprivation and ethnicity are both important for anti-tobacco health promotion. Health Education and Behavior, 27, 317-27.

Fahy, K. M., Lee, A., \& Milne, B. J. (2017). New Zealand socio-economic index 2013. Wellington: Statistics New Zealand.

Ganzeboom, H. B., De Graaf, P. M., \& Treiman, D. J. (1992). A standard international socio-economic index of occupational status. Social science research, 21(1), 1-56.

Groves, R. M., Fowler, F. J., Couper, M. P., Lepkowski, J. M., Singer, E., \& Tourangeau, R. (2004). Survey methodology. New Jersey: Wiley.

Huang, Y., Greaves, L. M., \& Sibley, C. G., (2014). Archive of additional (non-questionnaire) materials posted to participants. NZAVS Technical Documents, e07. Available at: www.nzavs.auckland.ac.nz

HURA Research Alliance, McLeod, D., Cormack, D., Love, T., Salmond, C., Robson, B., et al. (2006). Ethnicity, socioeconomic deprivation and consultation rates in New Zealand general practice. Journal of Health Service Research Policy, 11, 141-49.

Kimbrough, E. O., \& Vostroknutov, A. (2018). A portable method of eliciting respect for social norms. Economics Letters, 168, 147-150.

Milne, B. J., Byun, U., \& Lee, A. (2013). New Zealand socio-economic index 2006. Wellington: Statistics New Zealand.

Mitchell, E., Stewart, A., Crampton, P., \& Salmond, C. (2000). Deprivation and sudden infant death syndrome. Social Science and Medicine, 51, 147-50.

Molleman, L., Kurvers, R. H., \& van den Bos, W. (2019). Unleashing the BEAST: a brief measure of human social information use. Evolution and Human Behavior, 40(5), 492-499.

Muthen, L. K., \& Muthen, B. (2002). How to use a Monte Carlo study to decide on sample size and determine power. Structural Equation Modeling, 4, 599-620.

Peysakhovich, A., Nowak, M. A., \& Rand, D. G. (2014). Humans display a 'cooperative phenotype' that is domain general and temporally stable. Nature communications, 5(1), 1-8.

Salmond, C., \& Crampton, P. (2000). Deprivation and health. In P. Howden-Chapman \& M. Tobias (Eds.), Social Inequalities in Health: New Zealand 1999 (pp. 9-63). Wellington: Ministry of Health.

Salmond, C., \& Crampton, P, (2012). Development of New Zealand's deprivation index (NZDep) and its uptake as a national policy tool. Canadian Journal of Public Health, 103, 7-11.

Salmond, C., Crampton, P., \& Atkinson, J. (2007). NZDep2006 Index of Deprivation User's Manual. University of Otago.

Satherley, N., Milojev, P., Greaves, L. M., Huang, Y., Osborne, D., Bulbulia, J., \& Sibley, C. G. (2015). Demographic and psychological predictors of panel attrition: evidence from the New Zealand Attitudes and Values Study. PLoS ONE, 10, e0121950.

Statistics New Zealand (2013). Geographic Definitions. Wellington, NZ: Statistics New Zealand. http://www.stats.govt.nz/Census/2013-census/info-about-2013-census-data/2013-censusdefinitions-forms/definitions/geographic.aspx

Statistics New Zealand (2013). Glossary of Terms. Statistics New Zealand.

Statistics New Zealand (2014). Quickstats about great Christchurch. Statistics New Zealand.

White, P., Gunston, J., Salmond, C., Atkinson, J., \& Crampton, P. (2008). Atlas of Socioeconomic Deprivation in New Zealand: NZDep2006. Wellington Ministry of Health. 


\section{Appendix: Postal Questionnaires}

Please note that this document is not the NZAVS data dictionary. If you are looking for the data dictionary, it is available at: www.nzavs.auckland.ac.nz. The data dictionary is the companion to this document, and contains a list of all items included in each wave of the NZAVS, variable names and so forth for the various NZAVS datasets, etc. It is much easier to search the data dictionary for items, and see what has been included in each wave than it is to search through the following appendix of postal questionnaires. 


\section{Consent Form and Contact Details}

Auckland, New Zealand

Telephone 6493737599

Facsimile 6493737450

www.psych.auckland.ac.nz

The University of Auckland

Private Bag 92019

This form will be kept for a period of twenty years.

Title of Project:

\section{The New Zealand Attitudes and Values Study}

Researcher:

Dr. Chris Sibley, Psychology Department, The University of Auckland. Phone: 09-373-7599, extn 88353. E-mail: c.sibley@auckland.ac.nz

This form is to gather your consent to participate in this study. Only Dr. Sibley and his research associates will have access to your responses. Your personal information will be kept separate from your responses at all times. Your questionnaire will be identified by an anonymous code. An encrypted electronic copy of all responses will be stored indefinitely for research purposes in a secure room in the Department of Psychology.

I have read and understood a description of this research project. On this basis, I agree to take part. I understand that my data will remain confidential at all times. I understand that only Dr. Sibley will have access to my contact details. I consent to publication of the results of the project with the understanding that my anonymity will be preserved. I understand that I am free to withdraw from the research at any time up until the point at which I complete and return this questionnaire.

I understand that my contact details will never be shared with anyone. I understand that Dr. Sibley will use these details to contact and invite me to complete follow-up questionnaires, possibly for the next twenty years. Finally, I understand that my contact details will be used to contact me if I win the $\$ \mathbf{5 0 0}$ grocery voucher prize draw for participating in this study.

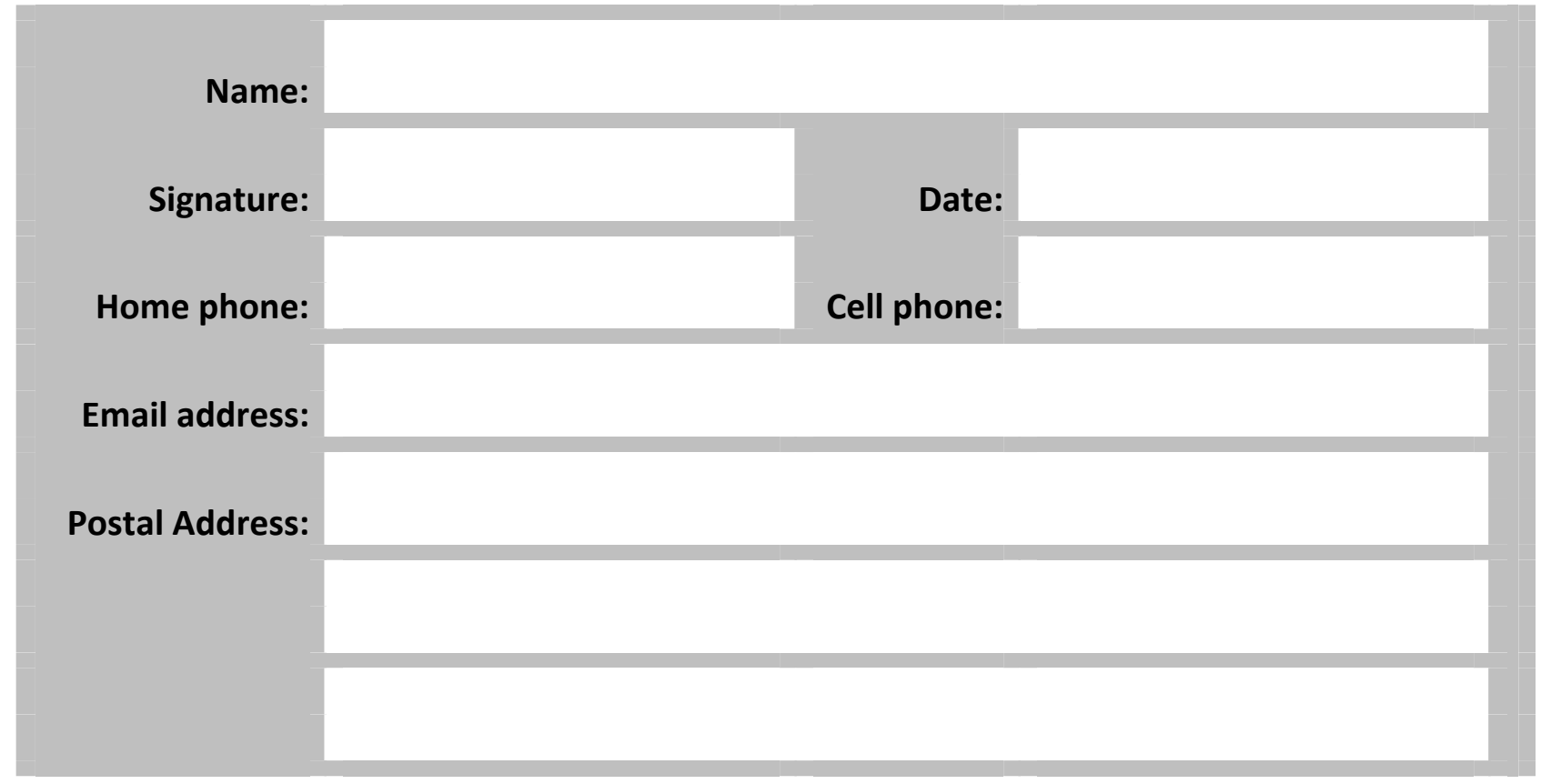


Very

Inaccurate

$\sqrt{3}$

I...

1

2. Sympathize with others' feelings.

$\begin{array}{lllllll}1 & 2 & 3 & 4 & 5 & 6 & 7\end{array}$

3. Get chores done right away.

4. Have frequent mood swings.

$\begin{array}{lllllll}1 & 2 & 3 & 4 & 5 & 6 & 7\end{array}$

5. Have a vivid imagination.

6. Don't talk a lot.

7. Am not interested in other people's problems.

8. Have difficulty understanding abstract ideas.

9. Like order.

10. Make a mess of things.

11. Do not have a good imagination.

12. Feel others' emotions.

13. Am relaxed most of the time.

14. Get upset easily.

15. Seldom feel blue.

16. Keep in the background.

17. Am not really interested in others.

18. Am not interested in abstract ideas.

19. Often forget to put things back in their proper place.

20. Talk to a lot of different people at parties.

$\begin{array}{lllllll}1 & 2 & 3 & 4 & 5 & 6 & 7 \\ 1 & 2 & 3 & 4 & 5 & 6 & 7\end{array}$

$\begin{array}{lllllll}1 & 2 & 3 & 4 & 5 & 6 & 7\end{array}$

$\begin{array}{lllllll}1 & 2 & 3 & 4 & 5 & 6 & 7\end{array}$

$\begin{array}{llllllll}1 & 2 & 3 & 4 & 5 & 6 & 7\end{array}$

$\begin{array}{lllllll}1 & 2 & 3 & 4 & 5 & 6 & 7\end{array}$

$\begin{array}{llllllll}1 & 2 & 3 & 4 & 5 & 6 & 7\end{array}$

$\begin{array}{lllllll}1 & 2 & 3 & 4 & 5 & 6 & 7\end{array}$

$\begin{array}{lllllll}1 & 2 & 3 & 4 & 5 & 6 & 7 \\ 1 & 2 & 3 & 4 & 5 & 6 & 7\end{array}$

$\begin{array}{lllllll}1 & 2 & 3 & 4 & 5 & 6 & 7\end{array}$

$\begin{array}{llllllll}1 & 2 & 3 & 4 & 5 & 6 & 7 \\ 1 & 2 & 3 & 4 & 5 & 6 & 7\end{array}$

$\begin{array}{lllllll}1 & 2 & 3 & 4 & 5 & 6 & 7\end{array}$

$\begin{array}{lllllll}1 & 2 & 3 & 4 & 5 & 6 & 7 \\ 1 & 2 & 3 & 4 & 5 & 6 & 7\end{array}$

$\begin{array}{lllllll}1 & 2 & 3 & 4 & 5 & 6 & 7\end{array}$

$\begin{array}{lllllll}1 & 2 & 3 & 4 & 5 & 6 & 7 \\ 1 & 2 & 3 & 4 & 5 & 6 & 7\end{array}$

$\begin{array}{lllllll}1 & 2 & 3 & 4 & 5 & 6 & 7\end{array}$

$\begin{array}{lllllll}1 & 2 & 3 & 4 & 5 & 6 & 7 \\ 1 & 2 & 3 & 4 & 5 & 6 & 7\end{array}$

\begin{tabular}{lrrrrrr}
1 & 2 & 3 & 4 & 5 & 6 & 7 \\
\hline $\begin{array}{l}\text { Very } \\
\text { Inaccurate }\end{array}$ & & & $\begin{array}{r}\text { Very } \\
\text { Accurate }\end{array}$ \\
\hline
\end{tabular}

21. Insult people.

22. Believe in the importance of art.

$\begin{array}{lllllll}1 & 2 & 3 & 4 & 5 & 6 & 7 \\ 1 & 2 & 3 & 4 & 5 & 6 & 7\end{array}$

23. Want people to know that I am an important person of high status. $\quad \begin{array}{llllllll}1 & 2 & 3 & 4 & 5 & 6 & 7\end{array}$

24. Feel entitled to more of everything.

25. On the whole am satisfied with myself.

26. Know that people in my life accept and value me.

\begin{tabular}{lllllll}
1 & 2 & 3 & 4 & 5 & 6 & 7 \\
\hline
\end{tabular}

27. Don't care to know what other people really think of me.

28. Love a good fight.

29. Get deeply immersed in music.

30. Would like to be seen driving around in a very expensive car.

$\begin{array}{lllllll}1 & 2 & 3 & 4 & 5 & 6 & 7 \\ 1 & 2 & 3 & 4 & 5 & 6 & 7\end{array}$

31. Deserve more things in life.

32. Take a positive attitude toward myself.

33. Feel like an outsider.

34. Don't gossip about other people's business.

$\begin{array}{lllllll}1 & 2 & 3 & 4 & 5 & 6 & 7\end{array}$

35. Hate to seem pushy.

36. Seldom daydream.

$\begin{array}{lllllll}1 & 2 & 3 & 4 & 5 & 6 & 7\end{array}$

$\begin{array}{lllllll}1 & 2 & 3 & 4 & 5 & 6 & 7\end{array}$

37. Would get a lot of pleasure from owning expensive luxury goods.

38. Would never accept a bribe, even if it were very large.

$\begin{array}{lllllll}1 & 2 & 3 & 4 & 5 & 6 & 7\end{array}$

$\begin{array}{lllllll}1 & 2 & 3 & 4 & 5 & 6 & 7\end{array}$

39. Demand the best because I'm worth it.

40. Am inclined to feel that I am a failure.

$\begin{array}{lllllll}1 & 2 & 3 & 4 & 5 & 6 & 7\end{array}$

$\begin{array}{lllllll}1 & 2 & 3 & 4 & 5 & 6 & 7 \\ 1 & 2 & 3 & 4 & 5 & 6 & 7\end{array}$

$\begin{array}{lllllll}1 & 2 & 3 & 4 & 5 & 6 & 7\end{array}$

$\begin{array}{lllllll}1 & 2 & 3 & 4 & 5 & 6 & 7\end{array}$

41. Know that people around me share my attitudes and beliefs.

\begin{tabular}{lllllll}
1 & 2 & 3 & 4 & 5 & 6 & 7 \\
\hline 1 & 2 & 3 & 4 & 5 & 6 & 7 \\
1 & 2 & 3 & 4 & 5 & 6 & 7 \\
1 & 2 & 3 & 4 & 5 & 6 & 7 \\
1 & 2 & 3 & 4 & 5 & 6 & 7 \\
\hline
\end{tabular}


Instructions: Please circle the number that best represents how important each of the following values is for you as a guiding principle in your life. Use the scale below to rate these items.

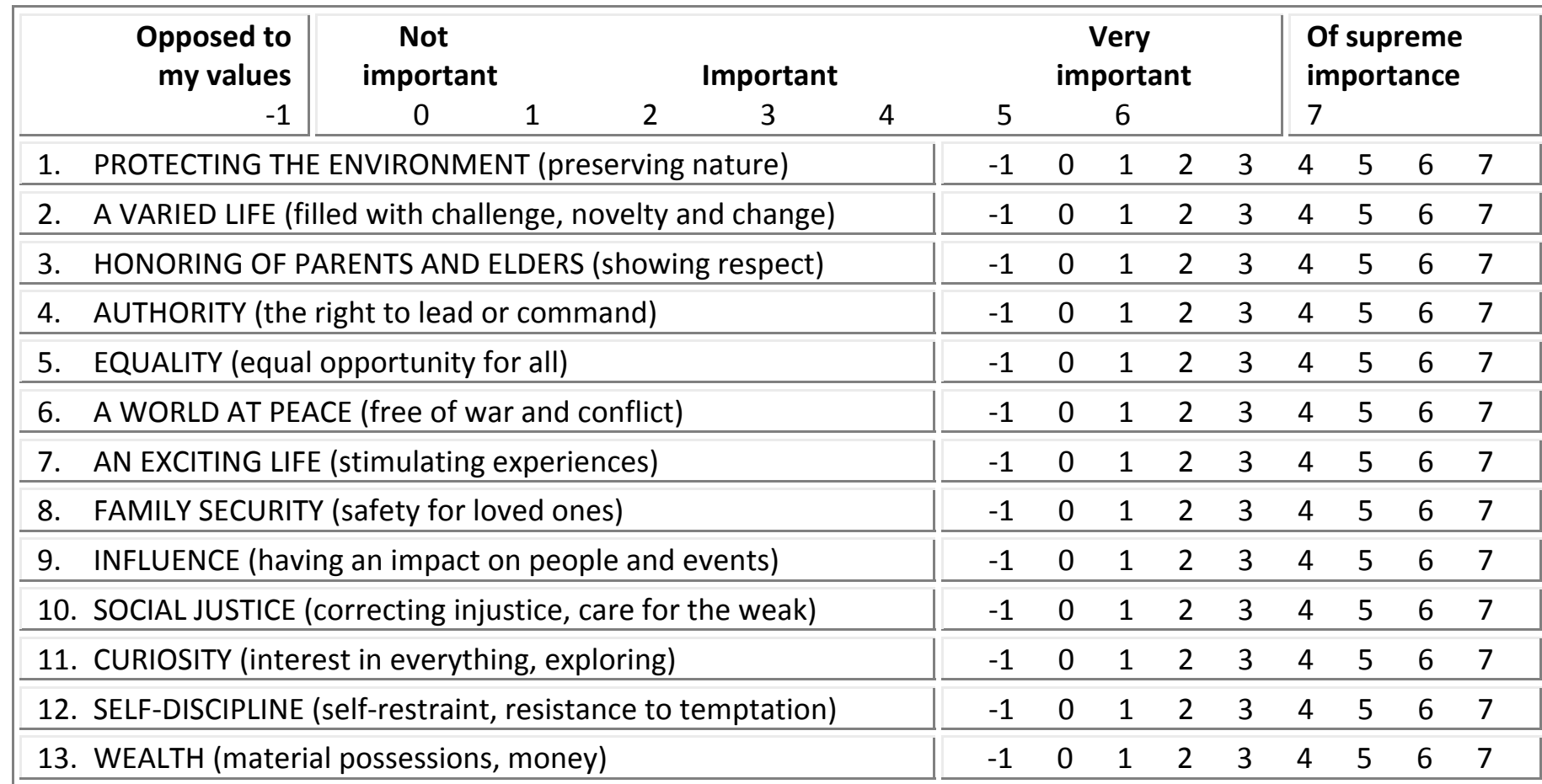

Instructions: The statements below reflect different opinions and points of view. Please indicate how strongly you disagree or agree with each statement. Remember, the best answer is your own opinion.

$\begin{array}{lr}\text { Strongly } & \text { Strongly } \\ \text { Disagree } & \text { Agree } \\ \sqrt{3} & \Omega ु\end{array}$

1. It is OK if some groups have more of a chance in life than others.

$\begin{array}{lllllll}1 & 2 & 3 & 4 & 5 & 6 & 7\end{array}$

2. It is always better to trust the judgment of the proper authorities in government and religion than to listen to the noisy rabble-rousers in our society who are trying to create doubt in people's minds.

3. I wish people in this society would stop obsessing so much about race.

$\begin{array}{lllllll}1 & 2 & 3 & 4 & 5 & 6 & 7\end{array}$

4. Inferior groups should stay in their place.

5. It would be best for everyone if the proper authorities censored magazines so that people could not get their hands on trashy and disgusting material.

6. Everyone in New Zealand has a fair shot at wealth and happiness, regardless of their ethnicity or race.

7. To get ahead in life, it is sometimes okay to step on other groups.

$\begin{array}{lllllll}1 & 2 & 3 & 4 & 5 & 6 & 7\end{array}$

$\begin{array}{lllllll}1 & 2 & 3 & 4 & 5 & 6 & 7\end{array}$

8. Our country will be destroyed some day if we do not smash the perversions eating away at our moral fibre and traditional beliefs.

9. To a large extent, a person's race biologically determines his or her abilities.

10. We should have increased social equality.

$\begin{array}{lllllll}1 & 2 & 3 & 4 & 5 & 6 & 7\end{array}$

$\begin{array}{lllllll}1 & 2 & 3 & 4 & 5 & 6 & 7\end{array}$

$\begin{array}{lllllll}1 & 2 & 3 & 4 & 5 & 6 & 7\end{array}$

$\begin{array}{lllllll}1 & 2 & 3 & 4 & 5 & 6 & 7\end{array}$

$\begin{array}{lllllll}1 & 2 & 3 & 4 & 5 & 6 & 7\end{array}$

11. People should pay less attention to The Bible and other old traditional forms of religious guidance, and instead develop their own personal standards of what is moral and immoral.

12. It would be good if groups could be equal.

$\begin{array}{lllllll}1 & 2 & 3 & 4 & 5 & 6 & 7\end{array}$

13. Atheists and others who have rebelled against established religions are no doubt every bit as good and virtuous as those who attend church regularly.

14. We should do what we can to equalise conditions for different groups.

$\begin{array}{lllllll}1 & 2 & 3 & 4 & 5 & 6 & 7 \\ 1 & 2 & 3 & 4 & 5 & 6 & 7 \\ 1 & 2 & 3 & 4 & 5 & 6 & 7 \\ 1 & 2 & 3 & 4 & 5 & 6 & 7\end{array}$

15. I often think about the fact that I am a member of my ethnic group.

16. Some of the best people in our country are those who are challenging our government, criticizing religion, and ignoring the "normal way" things are supposed to be done. 
Instructions: The following items assess your current satisfaction with different aspects of your life and aspects of New Zealand more generally. Please rate how satisfied you are with each aspect of your life and/or New Zealand society using the scale below.

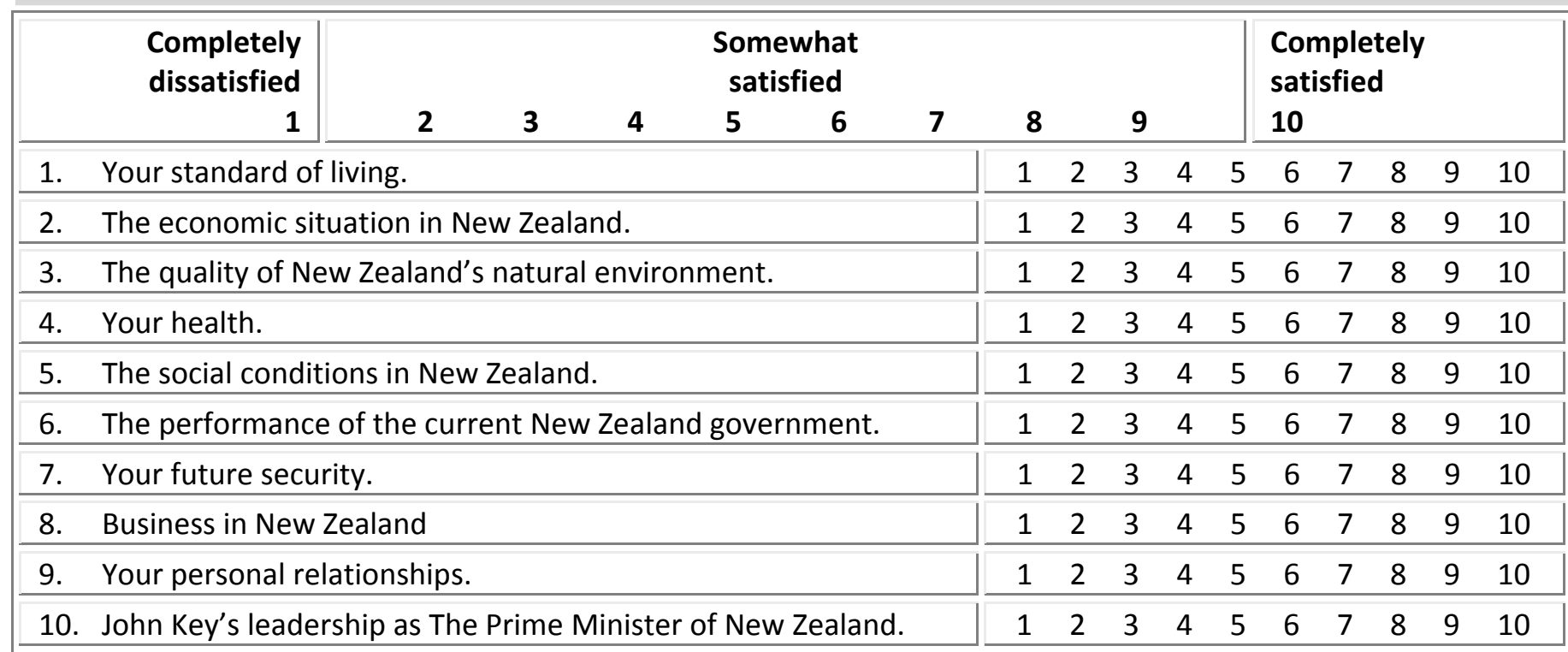

Instructions: The statements below reflect different opinions and points of view. Please indicate how strongly you disagree or agree with each statement. Remember, the best answer is your own opinion.

\begin{tabular}{lr} 
Strongly & Strongly \\
Disagree & Agree \\
$\Downarrow$ & $\Downarrow$ \\
\hline
\end{tabular}

1. We are all New Zealanders and the law should not make provision for minority groups because of their ethnicity.

$\begin{array}{lllllll}1 & 2 & 3 & 4 & 5 & 6 & 7\end{array}$

2. I think that Māori culture helps to define New Zealand in positive ways.

3. There are people I can depend on to help me if I really need it.

$\begin{array}{lllllll}1 & 2 & 3 & 4 & 5 & 6 & 7\end{array}$

4. Māori and Pacific Islanders tend to be more overweight than other NZers.

$\begin{array}{lllllll}1 & 2 & 3 & 4 & 5 & 6 & 7\end{array}$

5. We are all one nation and we should all be treated the same. No one should be entitled to anything more than the rest of us simply because they belong to one particular ethnic group.

6. New Zealand would be a better place to live if we forgot about trying to promote Māori culture to everyone.

7. In my opinion, more good jobs for Asians means fewer good jobs for members of other groups in New Zealand.

$\begin{array}{lllllll}1 & 2 & 3 & 4 & 5 & 6 & 7\end{array}$

$\begin{array}{lllllll}1 & 2 & 3 & 4 & 5 & 6 & 7\end{array}$

$\begin{array}{lllllll}1 & 2 & 3 & 4 & 5 & 6 & 7\end{array}$

$\begin{array}{lllllll}1 & 2 & 3 & 4 & 5 & 6 & 7\end{array}$

8. True equality can be achieved only once we recognize that some ethnic groups are currently more disadvantaged than others and require additional $\quad \begin{array}{llllllll}1 & 2 & 3 & 4 & 5 & 6 & 7\end{array}$ assistance from the government.

9. Māori have very different values and morals compared to most other NZers. $\quad \begin{array}{lllllllll}1 & 2 & 3 & 4 & 5 & 6 & 7\end{array}$

10. Men and women both have a fair shot at wealth and happiness in NZ.

11. The fact that I am a member of my ethnic group is an important part of my identity.

12. By taking personal action I believe I can make a positive difference to environmental problems.

$\begin{array}{lllllll}1 & 2 & 3 & 4 & 5 & 6 & 7\end{array}$

$\begin{array}{lllllll}1 & 2 & 3 & 4 & 5 & 6 & 7\end{array}$

13. There is no one I can turn to for guidance in times of stress.

14. I feel I can make a difference to the state of the environment.

$\begin{array}{lllllll}1 & 2 & 3 & 4 & 5 & 6 & 7\end{array}$

15. People from other races would be likely to reject me on the basis of my race.

16. Pacific Islanders have very different values and morals compared to most other NZers.

$\begin{array}{lllllll}1 & 2 & 3 & 4 & 5 & 6 & 7\end{array}$

$\begin{array}{lllllll}1 & 2 & 3 & 4 & 5 & 6 & 7\end{array}$

$\begin{array}{lllllll}1 & 2 & 3 & 4 & 5 & 6 & 7\end{array}$

$\begin{array}{lllllll}1 & 2 & 3 & 4 & 5 & 6 & 7\end{array}$

17. I know there are people I can turn to when I need help.

18. I reckon Māori culture should stay where it belongs-with Māori. It doesn't concern other NZers.

$\begin{array}{lllllll}1 & 2 & 3 & 4 & 5 & 6 & 7 \\ 1 & 2 & 3 & 4 & 5 & 6 & 7\end{array}$


1. People who become preoccupied by race are forgetting that we're all just human.

$\begin{array}{lllllll}1 & 2 & 3 & 4 & 5 & 6 & 7\end{array}$

2. Women, compared to men, tend to have greater moral sensibility.

$\begin{array}{lllllll}1 & 2 & 3 & 4 & 5 & 6 & 7\end{array}$

3. The New Zealand government should be involved in regulating carbon emissions.

4. I feel a great pride in the land that is our New Zealand.

$\begin{array}{lllllll}1 & 2 & 3 & 4 & 5 & 6 & 7\end{array}$

5. I am satisfied with my life.

6. Women are too easily offended.

$\begin{array}{lllllll}1 & 2 & 3 & 4 & 5 & 6 & 7\end{array}$

7. In my opinion, more good jobs for Māori means fewer good jobs for members of other groups in New Zealand.

8. Climate change is real.

9. We should all move on as one nation and forget about past differences and conflicts between ethnic groups.

$\begin{array}{lllllll}1 & 2 & 3 & 4 & 5 & 6 & 7\end{array}$

$\begin{array}{lllllll}1 & 2 & 3 & 4 & 5 & 6 & 7\end{array}$

10. Asians have different values and morals compared to most other NZers.

11. Putting racial labels on people obscures the fact that everyone is a unique individual.

$\begin{array}{lllllll}1 & 2 & 3 & 4 & 5 & 6 & 7\end{array}$

$\begin{array}{lllllll}1 & 2 & 3 & 4 & 5 & 6 & 7\end{array}$

$\begin{array}{lllllll}1 & 2 & 3 & 4 & 5 & 6 & 7\end{array}$

$\begin{array}{lllllll}1 & 2 & 3 & 4 & 5 & 6 & 7\end{array}$

12. Women exaggerate problems they have at work.

13. In general, I find New Zealand society to be fair.

$\begin{array}{lllllll}1 & 2 & 3 & 4 & 5 & 6 & 7\end{array}$

14. NZ Europeans have different values and morals compared to most other NZers.

15. Climate change is caused by humans.

16. It is OK for parents to use smacking as a way to discipline their children.

$\begin{array}{lllllll}1 & 2 & 3 & 4 & 5 & 6 & 7\end{array}$

$\begin{array}{lllllll}1 & 2 & 3 & 4 & 5 & 6 & 7\end{array}$

17. In general, relations between different ethnic groups in New Zealand are fair.

$\begin{array}{lllllll}1 & 2 & 3 & 4 & 5 & 6 & 7\end{array}$

$\begin{array}{lllllll}1 & 2 & 3 & 4 & 5 & 6 & 7\end{array}$

18. Many women have a quality of purity that few men possess.

$\begin{array}{lllllll}1 & 2 & 3 & 4 & 5 & 6 & 7\end{array}$

19. We should not have to pay for the mistakes of our ancestors.

$\begin{array}{lllllll}1 & 2 & 3 & 4 & 5 & 6 & 7\end{array}$

20. Women seek to gain power by getting control over men.

$\begin{array}{lllllll}1 & 2 & 3 & 4 & 5 & 6 & 7\end{array}$

$\begin{array}{lllllll}1 & 2 & 3 & 4 & 5 & 6 & 7\end{array}$

21. In my opinion, more good jobs for NZ Europeans means fewer good jobs for members of other groups in New Zealand.

22. In general, the New Zealand political system operates as it should.

23. Once a woman gets a man to commit to her she usually tries to put him on a tight leash.

24. Women, as compared to men, tend to have a more refined sense of culture and good taste.

25. I feel anxious about interacting with people from other races.

26. People who weren't around in previous centuries should not feel accountable for the actions of their ancestors.

27. In my opinion, more good jobs for Pacific Islanders means fewer good jobs for members of other groups in New Zealand.

$\begin{array}{lllllll}1 & 2 & 3 & 4 & 5 & 6 & 7\end{array}$

$\begin{array}{lllllll}1 & 2 & 3 & 4 & 5 & 6 & 7\end{array}$

$\begin{array}{lllllll}1 & 2 & 3 & 4 & 5 & 6 & 7\end{array}$

$\begin{array}{lllllll}1 & 2 & 3 & 4 & 5 & 6 & 7\end{array}$

$\begin{array}{lllllll}1 & 2 & 3 & 4 & 5 & 6 & 7\end{array}$

$\begin{array}{lllllll}1 & 2 & 3 & 4 & 5 & 6 & 7\end{array}$

$\begin{array}{lllllll}1 & 2 & 3 & 4 & 5 & 6 & 7\end{array}$

$\begin{array}{lllllll}1 & 2 & 3 & 4 & 5 & 6 & 7\end{array}$

28. In general, relations between men and women in New Zealand are fair.

29. In most ways my life is close to ideal.

30. Women should be cherished and protected by men.

31. Generally, the more influence NZ has on other nations, the better off they are.

32. When women lose to men in a fair competition, they typically complain about being discriminated against.

33. Although at times I may not agree with the government, my commitment to New Zealand always remains strong.

34. Every man ought to have a woman whom he adores.

$\begin{array}{lllllll}1 & 2 & 3 & 4 & 5 & 6 & 7\end{array}$

$\begin{array}{lllllll}1 & 2 & 3 & 4 & 5 & 6 & 7\end{array}$

$\begin{array}{lllllll}1 & 2 & 3 & 4 & 5 & 6 & 7\end{array}$

$\begin{array}{lllllll}1 & 2 & 3 & 4 & 5 & 6 & 7\end{array}$

$\begin{array}{lllllll}1 & 2 & 3 & 4 & 5 & 6 & 7\end{array}$

35. Being a member of my ethnic group is an important part of how I see myself.

36. Foreign nations have done some very fine things but they are still not as good as New Zealand.

$\begin{array}{lllllll}1 & 2 & 3 & 4 & 5 & 6 & 7\end{array}$

$\begin{array}{lllllll}1 & 2 & 3 & 4 & 5 & 6 & 7\end{array}$

$\begin{array}{lllllll}1 & 2 & 3 & 4 & 5 & 6 & 7\end{array}$

$\begin{array}{lllllll}1 & 2 & 3 & 4 & 5 & 6 & 7\end{array}$ 
Instructions: Please rate how strongly you oppose or support each of the following political parties.

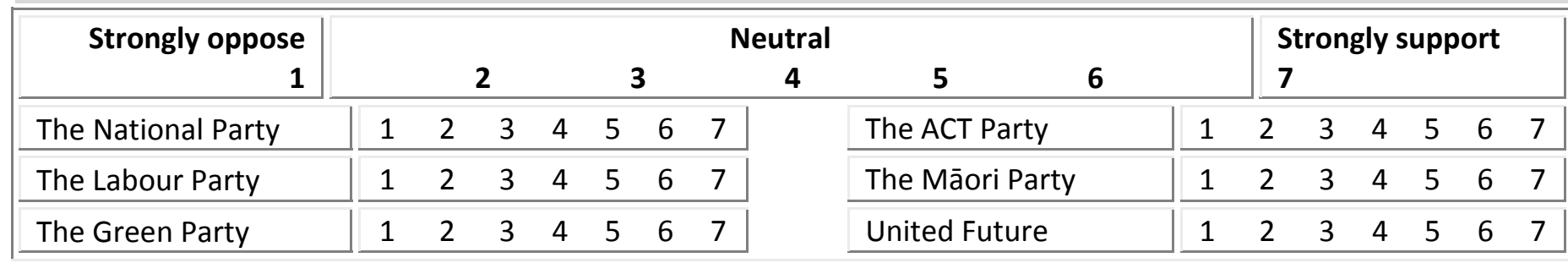

Instructions: Please answer each of the following questions by circling a number on the scale below.

Definitely NO

1
2

3

\section{Unsure}

4

5

6

Definitely YES 7

1. Of course, we all hope that there will not be another war, but if it were to come to that, would you be willing to fight for your country?

2. Should a smack as part of good parental correction be a criminal offence in NZ?

3. Are you willing to make sacrifices to your standard of living (e.g., accept higher prices, drive less, conserve energy) in order to protect the environment?

4. Have you made sacrifices to your standard of living (e.g., accepted higher prices, driven less, conserved energy) in order to protect the environment?

5. Do you think most New Zealanders are willing to make sacrifices to their standard of living in order to protect the environment?

6. Do you think people from your ethnic group are more at risk of weight-based illnesses (e.g., heart illnesses, diabetes) than other New Zealanders, on average?

7. Are you willing to change your daily routine in order to protect the environment?

8. Have you made changes to your daily routine in order to protect the environment?

9. Do you think you personally are more at risk of a weight-based illness (e.g., heart illnesses, diabetes) than other New Zealanders, on average?

Instructions: The following scale lists a variety of actual or proposed policy changes and initiatives. Please rate how strongly you oppose or support each of the following policies.

\begin{tabular}{|lllllll|}
\hline 1 & 2 & 3 & 4 & 5 & 6 & 7 \\
\hline 1 & 2 & 3 & 4 & 5 & 6 & 7 \\
\hline 1 & 2 & 3 & 4 & 5 & 6 & 7 \\
\hline 1 & 2 & 3 & 4 & 5 & 6 & 7 \\
\hline 1 & 2 & 3 & 4 & 5 & 6 & 7 \\
\hline 1 & 2 & 3 & 4 & 5 & 6 & 7 \\
\hline 1 & 2 & 3 & 4 & 5 & 6 & 7 \\
\hline 1 & 2 & 3 & 4 & 5 & 6 & 7 \\
\hline 1 & 2 & 3 & 4 & 5 & 6 & 7 \\
\hline
\end{tabular}

$\begin{array}{lllllll}1 & 2 & 3 & 4 & 5 & 6 & 7\end{array}$

|

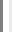


Very

Very

Inaccurate

Accurate

\

1. I try to enhance the bonding and intimacy in my close relationships.

$\begin{array}{lllllll}1 & 2 & 3 & 4 & 5 & 6 & 7\end{array}$

2. I try to avoid disagreement and conflict in my close relationships.

$\begin{array}{lllllll}1 & 2 & 3 & 4 & 5 & 6 & 7\end{array}$

3. I try to move toward growth and development in my close relationships.

4. I try to stay away from situations that would harm my close relationships.

$\begin{array}{lllllll}1 & 2 & 3 & 4 & 5 & 6 & 7\end{array}$

5. I try to share many fun and meaningful experiences with people I am close to.

$\begin{array}{lllllll}1 & 2 & 3 & 4 & 5 & 6 & 7\end{array}$

6. I try to make sure that nothing bad happens to my close relationships.

$\begin{array}{lllllll}1 & 2 & 3 & 4 & 5 & 6 & 7\end{array}$

$\begin{array}{lllllll}1 & 2 & 3 & 4 & 5 & 6 & 7\end{array}$

In your day-to-day life, how often do people in New Zealand act toward you in the following ways?

\section{Have never \\ experienced this}

\section{1}

\section{Sometimes}

experience this

1. Do things to threaten you.

2. Insist that they know what is best for you.

3. Are friendly and willing to help you.

4. Happily interact with you in formal situations but not social ones.

5. Make threatening gestures toward you.

6. Offer advice and opinions even when you don't want it.

7. Are happy to hear your opinions about things.

8. Only socialize or interact with you when it suits their purposes.

9. Attack you, or make you fear that they might.

10. Try to help you with things you'd rather do for yourself.

11. Make you feel welcome when they meet you.

12. Treat you with respect, but avoid socializing with you.

\section{Often}

experience this

7

Instructions: Please rate the warmth of your feelings toward the following groups using the "feeling thermometer scale" for each group. A rating of "1" indicates your feeling toward that group to be least warm (least favourable) while a rating of "7" indicates your feeling is most warm (most favourable).

\begin{tabular}{|c|c|c|c|c|c|c|c|c|c|c|c|c|c|c|c|}
\hline $\begin{array}{r}\text { Feel least warm } \\
\text { towards this group } \\
1\end{array}$ & \multicolumn{9}{|c|}{ Neutral } & \multicolumn{6}{|c|}{$\begin{array}{l}\text { Feel most warm } \\
\text { toward this group } \\
7\end{array}$} \\
\hline Americans & 1 & 2 & 3 & 4 & 5 & 6 & 7 & Overweight people & 1 & 2 & 3 & 4 & 5 & 6 & 7 \\
\hline Māori & 1 & 2 & 3 & 4 & 5 & 6 & 7 & Immigrants in general & 1 & 2 & 3 & 4 & 5 & 6 & 7 \\
\hline NZ Europeans & 1 & 2 & 3 & 4 & 5 & 6 & 7 & Chinese & 1 & 2 & 3 & 4 & 5 & 6 & 7 \\
\hline Pacific Islanders & 1 & 2 & 3 & 4 & 5 & 6 & 7 & Asians in general & 1 & 2 & 3 & 4 & 5 & 6 & 7 \\
\hline
\end{tabular}

Roughly how many hours (if any) have you spent with friends from each of the following groups in the last week?
(a) Americans
(b) Māori
(c) NZ Europeans
(d) Asians
(e) Pacific Islanders

Which term do you prefer to describe New Zealanders of European descent?

$\square$ New Zealander

$\square$ New Zealand European

$\square$ Pakeha

$\square$ Kiwi

$\square$ Other
Which country were you born in?

If you were born overseas, for how many years have you lived in NZ?

How much money (if any) have you donated to charity in the last year? 
1. Which ethnic group $\square$ New Zealand European do you belong to? Māori

\section{$\square$ Samoan}

Mark the space or spaces which apply to you.

2. Are you male or female?

3. What is your age?

4a. What is your relationship status?

If you are in a relationship $\sqrt{ }$

$\square$ Cook Island Māori
$\square$ Tongan
$\square$ Niuean
$\square$ Chinese
$\square$ Indian
$\square$ Other such as DUTCH,
JAPANESE, TOKELAUAN.
Please state:

Please state:

4b. How long have you been with your partner?

Male

Female (please tick $\square$ one) (years)

ingle

$\square$ Dating

$\square$ Living together/De facto Married

Other

$$
\text { (if other please specify) }
$$

(years)

(months)

4c. What is your partner's

ethnicity? (please be specific)

4d. How satisfied are you with your relationship with your partner? (please circle a number on the scale below) $\begin{array}{llllllllll}\text { Not satisfied } & 1 & 2 & 3 & 4 & 5 & 6 & 7 & \text { Very satisfied }\end{array}$

5a. What is your current $\square$ Employed full-time employment $\quad \square$ Employed part-time situation?

$\square$ Self-employed

$\square$ Own your own business Studying full-time

\section{$\square$ Unemployed, but want work}

If you are currently $\quad \square$ Unemployed, don't want work employed $\sqrt{ }$

$\square$ other

$5 b$. How long have you worked in your current job for?

$5 c$. How satisfied are you with your current job? $\begin{array}{llllllllll}\text { Not satisfied } & 1 & 2 & 3 & 4 & 5 & 6 & 7 & \text { Very satisfied }\end{array}$

$5 d$. How secure do you feel in your current job? $\begin{array}{llllllllll}\text { Not secure } & 1 & 2 & 3 & 4 & 5 & 6 & 7 & \text { Very secure }\end{array}$

6. What is your highest level of qualification?

7. What did you eat for dinner last night?

8. Do you identify as Māori and/or $\square$ Yes have any ancestors who are Māori? $\square$ No

9. Which term best describes where you grew up? (e.g., rural, suburban, city) 10a. How many children have you given birth to, fathered, or adopted? (if none, go to 11)

10b. How many of your children live with you most of the time?

11. Have you or the principal earner in your household been out-of-work at any time in the last year?

12. Have you personally been the victim of a crime in the last year?

Which political party did you vote for in the last election?

14. Please estimate your total household income (before tax) for the year 2009.

\section{$\$$}

15. Please estimate your own personal earnings (before tax) for the year 2009.

16. If an election were held today, who would you vote for to be Prime Minister?

17a. Do you identify with a religion Yes and/or spiritual group?

\section{$\$$}

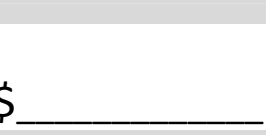

7b. If yes to $17 a$, then what religion/spiritual group?

17c. If yes to 17 a, how important is your religion to how you see yourself?

$\begin{array}{lllllllll}\text { Not important } & 1 & 2 & 3 & 4 & 5 & 6 & 7 & \text { Very important }\end{array}$

18. If an election were held today, which political party would you vote for?

19. Please estimate how many hours you spent doing each of the following things last week.
(a) Working in paid employment
(b) Housework/cooking
(c) Looking after children
(d) Playing computer games
(e) Exercising
(f) Watching TV/Films/Videos
(g) Travelling/commuting
(h) Volunteer/charity work

20a. How many hours did you spend with your romantic partner (if any) last week?

(a) In person/face-to-face

(b) Talking on phone (incl. Skype)

(c) Email, texting or on-line chat

20b. How many hours did you spend with your close friends and family (excluding your partner) in the following ways last week?
(a) In person/face-to-face
(b) Talking on phone (incl. Skype)
(c) Email, texting or on-line chat 


\section{The New Zealand Attitudes and Values Study}

\section{Follow-up Questionnaire at Time 2}

This form will be kept for a period of twenty years.

Researcher: Dr. Chris Sibley, Department of Psychology, University of Auckland. Phone: 09-373-7599, extn 88353. E-mail: c.sibley@auckland.ac.nz

\section{Consent form and contact details}

This form is to gather your consent to participate in this study. Only Dr. Sibley and his research associates will have access to your responses. Your personal information will be kept separate from your responses at all times. Your questionnaire will be identified by an anonymous code. An encrypted electronic copy of all responses will be stored indefinitely for research purposes in a secure room in the Department of Psychology.

I have read and understood a description of this research project. On this basis, I agree to take part. I understand that my data will remain confidential at all times. I understand that only Dr. Sibley will have access to my contact details. I consent to publication of the results of the project with the understanding that my anonymity will be preserved. I understand that I am free to withdraw from the research at any time up until the point at which I complete and return this questionnaire. I understand that my contact details will never be shared with anyone. I understand that Dr. Sibley will use these details to contact and invite me to complete follow-up questionnaires, possibly for the next eighteen years. Finally, I understand that my contact details will be used to contact me if I win one of the grocery voucher prize draws for $\mathbf{\$ 5 0 0 ,} \mathbf{\$ 3 0 0}$ or $\mathbf{\$ 2 0 0}$ for participating in this study.

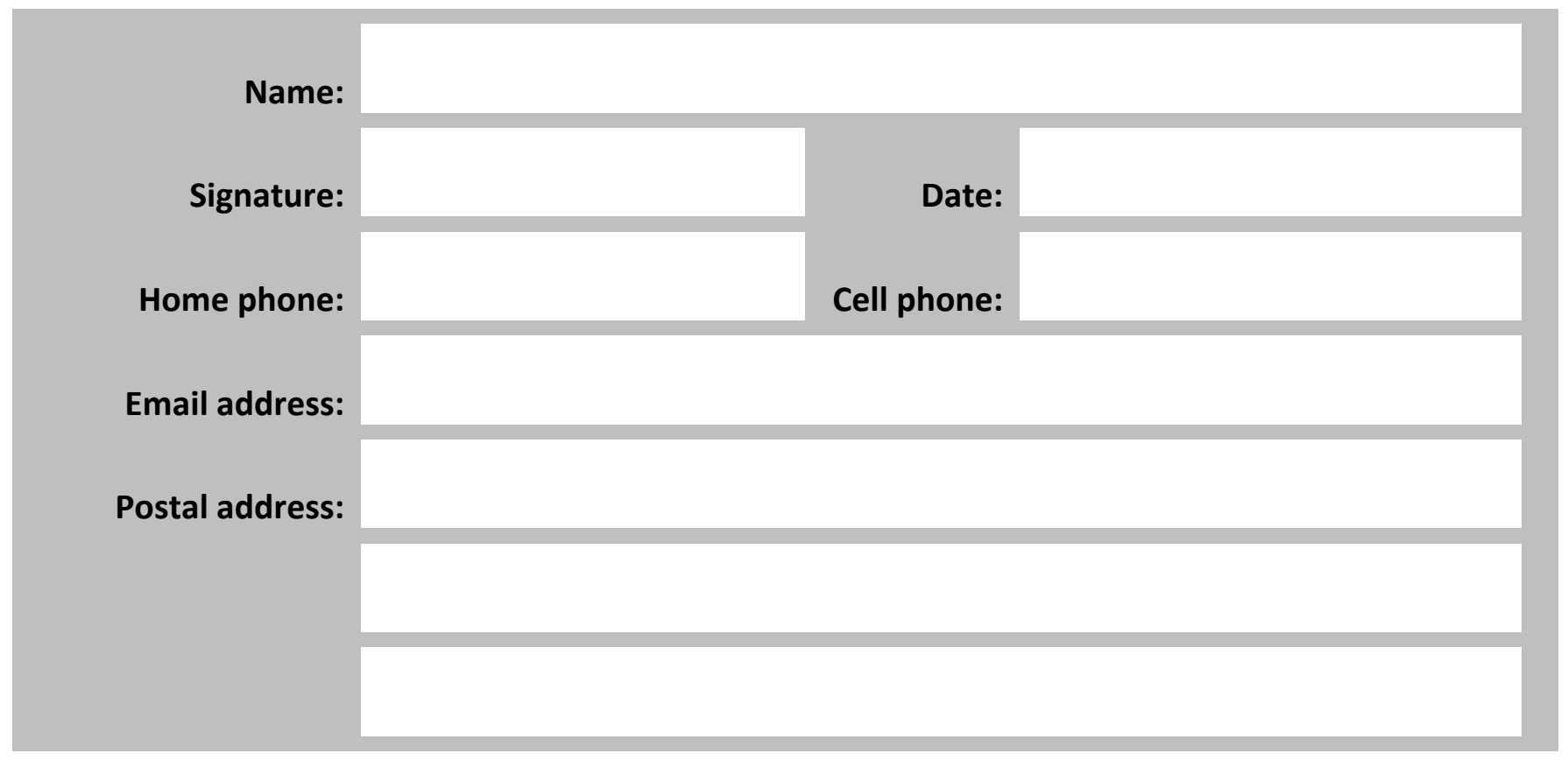

Would you like to receive a summary of key findings from the study? If yes, would you like to be sent this summary by email or in the post? Are you willing to complete a short follow-up survey about your health?

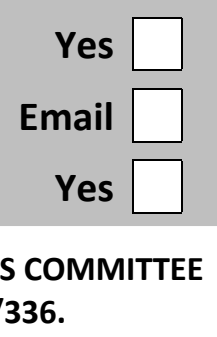
ON 09-SEPTEMBER-2009 FOR 3 YEARS. REFERENCE NUMBER: 2009/336. 


\begin{tabular}{|c|c|c|c|c|c|c|c|}
\hline \multirow{2}{*}{$\begin{array}{l}\text { I ... } \\
\text { 1. Am the life of the party. }\end{array}$} & \multicolumn{3}{|c|}{$\begin{array}{l}\text { Very } \\
\text { Inaccurate } \\
\downarrow\end{array}$} & \multicolumn{4}{|c|}{$\begin{array}{r}\text { Very } \\
\text { Accurate } \\
\downarrow\end{array}$} \\
\hline & 1 & 2 & 3 & 4 & 5 & 6 & 7 \\
\hline 2. Sympathise with others' feelings. & 1 & 2 & 3 & 4 & 5 & 6 & 7 \\
\hline 3. Get chores done right away. & 1 & 2 & 3 & 4 & 5 & 6 & 7 \\
\hline 4. Have frequent mood swings. & 1 & 2 & 3 & 4 & 5 & 6 & 7 \\
\hline 5. Have a vivid imagination. & 1 & 2 & 3 & 4 & 5 & 6 & 7 \\
\hline 6. Don't talk a lot. & 1 & 2 & 3 & 4 & 5 & 6 & 7 \\
\hline 7. Am not interested in other people's problems. & 1 & 2 & 3 & 4 & 5 & 6 & 7 \\
\hline 8. Have difficulty understanding abstract ideas. & 1 & 2 & 3 & 4 & 5 & 6 & 7 \\
\hline 9. Like order. & 1 & 2 & 3 & 4 & 5 & 6 & 7 \\
\hline 10. Make a mess of things. & 1 & 2 & 3 & 4 & 5 & 6 & 7 \\
\hline 11. Do not have a good imagination. & 1 & 2 & 3 & 4 & 5 & 6 & 7 \\
\hline 12. Feel others' emotions. & 1 & 2 & 3 & 4 & 5 & 6 & 7 \\
\hline 13. Am relaxed most of the time. & 1 & 2 & 3 & 4 & 5 & 6 & 7 \\
\hline 14. Get upset easily. & 1 & 2 & 3 & 4 & 5 & 6 & 7 \\
\hline 15. Seldom feel blue. & 1 & 2 & 3 & 4 & 5 & 6 & 7 \\
\hline 16. Keep in the background. & 1 & 2 & 3 & 4 & 5 & 6 & 7 \\
\hline 17. Am not really interested in others. & 1 & 2 & 3 & 4 & 5 & 6 & 7 \\
\hline 18. Am not interested in abstract ideas. & 1 & 2 & 3 & 4 & 5 & 6 & 7 \\
\hline 19. Often forget to put things back in their proper place. & 1 & 2 & 3 & 4 & 5 & 6 & 7 \\
\hline 20. Talk to a lot of different people at parties. & 1 & 2 & 3 & 4 & 5 & 6 & 7 \\
\hline 21. Feel entitled to more of everything. & 1 & 2 & 3 & 4 & 5 & 6 & 7 \\
\hline 22. On the whole am satisfied with myself. & 1 & 2 & 3 & 4 & 5 & 6 & 7 \\
\hline 23. Know that people in my life accept and value me. & 1 & 2 & 3 & 4 & 5 & 6 & 7 \\
\hline 24. Would like to be seen driving around in a very expensive car. & 1 & 2 & 3 & 4 & 5 & 6 & 7 \\
\hline 25. Deserve more things in life. & 1 & 2 & 3 & 4 & 5 & 6 & 7 \\
\hline 26. Take a positive attitude toward myself. & 1 & 2 & 3 & 4 & 5 & 6 & 7 \\
\hline 27. Feel like an outsider. & 1 & 2 & 3 & 4 & 5 & 6 & 7 \\
\hline 28. Would get a lot of pleasure from owning expensive luxury goods. & 1 & 2 & 3 & 4 & 5 & 6 & 7 \\
\hline 29. Am satisfied with the appearance, size and shape of my body. & 1 & 2 & 3 & 4 & 5 & 6 & 7 \\
\hline 30. Am inclined to feel that I am a failure. & 1 & 2 & 3 & 4 & 5 & 6 & 7 \\
\hline 31. Feel that I am often discriminated against because of my ethnicity. & 1 & 2 & 3 & 4 & 5 & 6 & 7 \\
\hline 32. Know that people around me share my attitudes and beliefs. & 1 & 2 & 3 & 4 & 5 & 6 & 7 \\
\hline
\end{tabular}

During the last 30 days, how often did....

(Please use the scale below to circle a number for each question)

\begin{tabular}{|c|c|c|c|c|c|c|c|}
\hline $\begin{array}{r}\text { None Of } \\
\text { The Time } \\
0 \\
\end{array}$ & $\begin{array}{c}\text { A Little Of } \\
\text { The Time } \\
1\end{array}$ & $\begin{array}{c}\text { Some of } \\
\text { The Time } \\
2\end{array}$ & $\begin{array}{c}\text { Most Of } \\
\text { The Time } \\
3\end{array}$ & & & & \\
\hline \multicolumn{3}{|c|}{ 1. ... you feel hopeless? } & 0 & 1 & 2 & 3 & 4 \\
\hline \multicolumn{3}{|c|}{ 2. ... you feel so depressed that nothing could cheer you up? } & 0 & 1 & 2 & 3 & 4 \\
\hline \multicolumn{3}{|c|}{ 3. ... you feel restless or fidgety? } & 0 & 1 & 2 & 3 & 4 \\
\hline \multicolumn{3}{|c|}{ 4. ... you feel that everything was an effort? } & 0 & 1 & 2 & 3 & 4 \\
\hline \multicolumn{3}{|c|}{ 5. ... you feel worthless? } & 0 & 1 & 2 & 3 & 4 \\
\hline \multicolumn{3}{|c|}{ 6. ... you feel nervous? } & 0 & 1 & 2 & 3 & 4 \\
\hline \multicolumn{3}{|c|}{ 7. ... you have negative thoughts that repeated over and over? } & 0 & 1 & 2 & 3 & 4 \\
\hline
\end{tabular}


Instructions: Please circle the number that best represents how important each of the following values is for you as a guiding principle in your life. Use the scale below to rate these items.

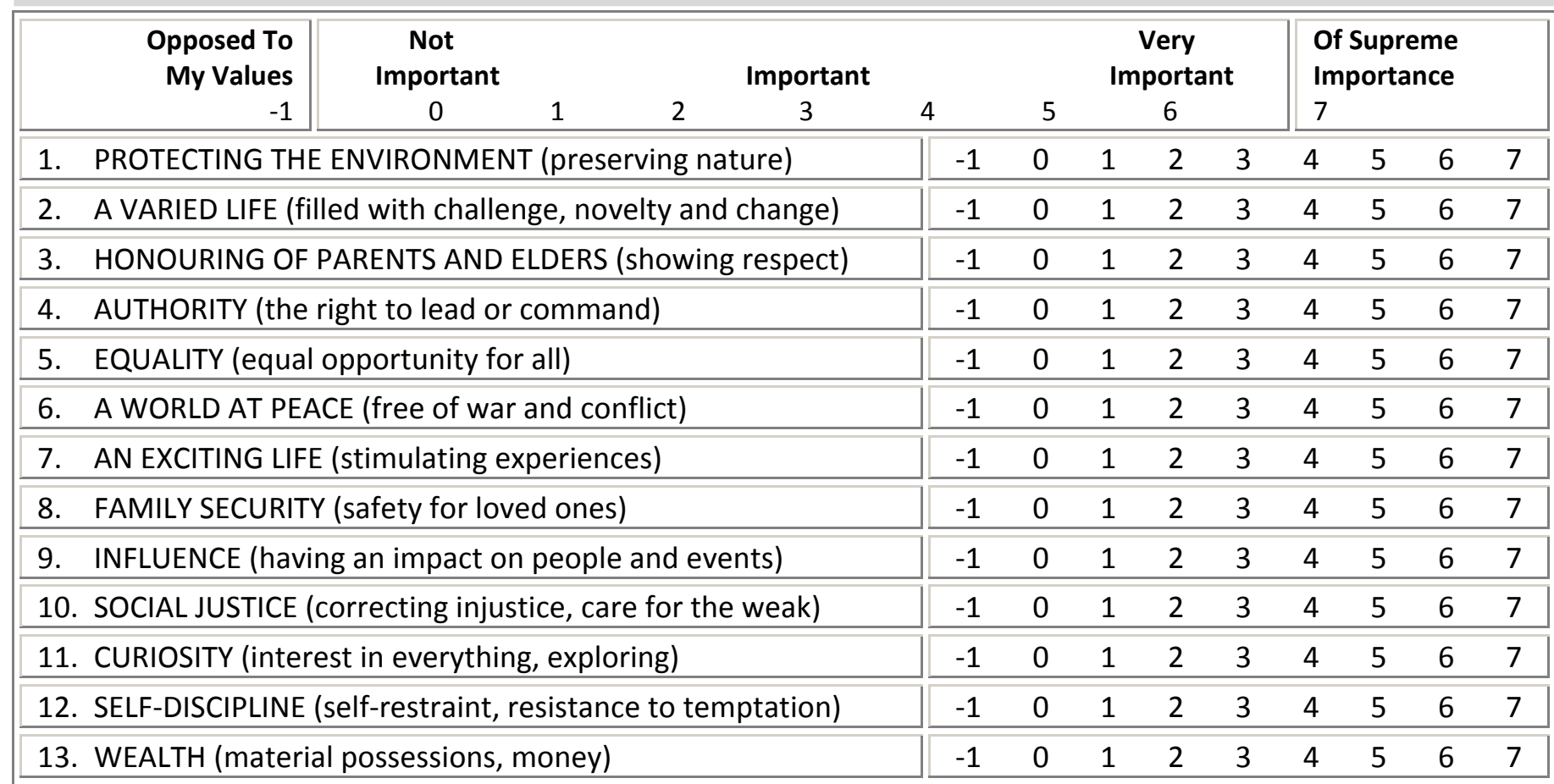

Instructions: The statements below reflect different opinions and points of view. Please indicate how strongly you disagree or agree with each statement. Remember, the best answer is your own opinion.

\begin{tabular}{|c|c|c|c|c|c|c|c|}
\hline \multirow[b]{2}{*}{ It is OK if some groups have more of a chance in life than others. } & \multicolumn{3}{|c|}{$\begin{array}{l}\text { Strongly } \\
\text { Disagree } \\
\downarrow\end{array}$} & \multirow[b]{2}{*}{4} & \multicolumn{3}{|c|}{$\begin{array}{r}\text { Strongly } \\
\text { Agree }\end{array}$} \\
\hline & 1 & 2 & 3 & & 5 & 6 & 7 \\
\hline $\begin{array}{l}\text { 2. It is always better to trust the judgment of the proper authorities in } \\
\text { government and religion than to listen to the noisy rabble-rousers in our } \\
\text { society who are trying to create doubt in people's minds. }\end{array}$ & 1 & 2 & 3 & 4 & 5 & 6 & 7 \\
\hline 3. I wish people in this society would stop obsessing so much about race. & 1 & 2 & 3 & 4 & 5 & 6 & 7 \\
\hline 4. Inferior groups should stay in their place. & 1 & 2 & 3 & 4 & 5 & 6 & 7 \\
\hline $\begin{array}{l}\text { 5. It would be best for everyone if the proper authorities censored magazines so } \\
\text { that people could not get their hands on trashy and disgusting material. }\end{array}$ & 1 & 2 & 3 & 4 & 5 & 6 & 7 \\
\hline $\begin{array}{l}\text { 6. Everyone in New Zealand has a fair shot at wealth and happiness, regardless } \\
\text { of ethnicity or race. }\end{array}$ & 1 & 2 & 3 & 4 & 5 & 6 & 7 \\
\hline 7. To get ahead in life, it is sometimes okay to step on other groups. & 1 & 2 & 3 & 4 & 5 & 6 & 7 \\
\hline $\begin{array}{l}\text { 8. Our country will be destroyed some day if we do not smash the perversions } \\
\text { eating away at our moral fibre and traditional beliefs. }\end{array}$ & 1 & 2 & 3 & 4 & 5 & 6 & 7 \\
\hline 9. To a large extent, a person's race biologically determines his or her abilities. & 1 & 2 & 3 & 4 & 5 & 6 & 7 \\
\hline 10. We should have increased social equality. & 1 & 2 & 3 & 4 & 5 & 6 & 7 \\
\hline $\begin{array}{l}\text { 11. People should pay less attention to The Bible and other old traditional forms } \\
\text { of religious guidance, and instead develop their own personal standards of } \\
\text { what is moral and immoral. }\end{array}$ & 1 & 2 & 3 & 4 & 5 & 6 & 7 \\
\hline 12. It would be good if groups could be equal. & 1 & 2 & 3 & 4 & 5 & 6 & 7 \\
\hline $\begin{array}{l}\text { 13. Atheists and others who have rebelled against established religions are no } \\
\text { doubt every bit as good and virtuous as those who attend church regularly. }\end{array}$ & 1 & 2 & 3 & 4 & 5 & 6 & 7 \\
\hline 14. We should do what we can to equalise conditions for different groups. & 1 & 2 & 3 & 4 & 5 & 6 & 7 \\
\hline 15. I often think about the fact that I am a member of my ethnic group. & 1 & 2 & 3 & 4 & 5 & 6 & 7 \\
\hline $\begin{array}{l}\text { 16. We need to invest specifically in educating young girls and women about } \\
\text { healthy lifestyles for the sake of future generations. }\end{array}$ & 1 & 2 & 3 & 4 & 5 & 6 & 7 \\
\hline 17. People close to me support and encourage me to lead a healthy lifestyle. & 1 & 2 & 3 & 4 & 5 & 6 & 7 \\
\hline 18. It is easy to lead a healthy lifestyle if you make lots of money. & 1 & 2 & 3 & 4 & 5 & 6 & 7 \\
\hline
\end{tabular}


Instructions: The following items assess your current satisfaction with different aspects of your life and aspects of New Zealand more generally.

\begin{tabular}{|c|c|c|c|c|c|c|c|c|c|c|c|c|c|c|c|c|c|}
\hline $\begin{array}{r}\text { Completely } \\
\text { Dissatisfied } \\
0\end{array}$ & \multicolumn{11}{|c|}{$\begin{array}{l}\text { Somewhat } \\
\text { Satisfied }\end{array}$} & \multicolumn{6}{|c|}{$\begin{array}{l}\text { Completely } \\
\text { Satisfied } \\
10\end{array}$} \\
\hline \multicolumn{7}{|c|}{ 1. Your standard of living. } & 0 & 1 & 2 & 3 & 4 & 5 & 6 & 7 & 8 & 9 & 10 \\
\hline \multicolumn{7}{|c|}{ 2. The economic situation in New Zealand. } & 0 & 1 & 2 & 3 & 4 & 5 & 6 & 7 & 8 & 9 & 10 \\
\hline \multicolumn{7}{|c|}{ 3. The quality of New Zealand's natural environment. } & 0 & 1 & 2 & 3 & 4 & 5 & 6 & 7 & 8 & 9 & 10 \\
\hline \multicolumn{7}{|l|}{ 4. Your health. } & 0 & 1 & 2 & 3 & 4 & 5 & 6 & 7 & 8 & 9 & 10 \\
\hline \multicolumn{7}{|c|}{ 5. The social conditions in New Zealand. } & 0 & 1 & 2 & 3 & 4 & 5 & 6 & 7 & 8 & 9 & 10 \\
\hline \multicolumn{7}{|c|}{ 6. The performance of the current New Zealand government. } & 0 & 1 & 2 & 3 & 4 & 5 & 6 & 7 & 8 & 9 & 10 \\
\hline \multicolumn{7}{|c|}{ 7. Your future security. } & 0 & 1 & 2 & 3 & 4 & 5 & 6 & 7 & 8 & 9 & 10 \\
\hline \multicolumn{7}{|c|}{ 8. Business in New Zealand. } & 0 & 1 & 2 & 3 & 4 & 5 & 6 & 7 & 8 & 9 & 10 \\
\hline \multicolumn{7}{|c|}{ 9. Your personal relationships. } & 0 & 1 & 2 & 3 & 4 & 5 & 6 & 7 & 8 & 9 & 10 \\
\hline \multicolumn{7}{|c|}{ 10. John Key's leadership as The Prime Minister of New Zealand. } & 0 & 1 & 2 & 3 & 4 & 5 & 6 & 7 & 8 & 9 & 10 \\
\hline
\end{tabular}

Instructions: The statements below reflect different opinions and points of view. Please indicate how strongly you disagree or agree with each statement. Remember, the best answer is your own opinion.

\begin{tabular}{|c|c|c|c|c|c|c|c|}
\hline \multirow[b]{2}{*}{ There are people I can depend on to help me if I really need it. } & \multicolumn{3}{|c|}{$\begin{array}{l}\text { Strongly } \\
\text { Disagree } \\
\downarrow\end{array}$} & & \multicolumn{3}{|c|}{$\begin{array}{c}\text { Strongly } \\
\text { Agree }\end{array}$} \\
\hline & 1 & 2 & 3 & 4 & 5 & 6 & 7 \\
\hline 2. I think that Māori culture helps to define New Zealand in positive ways. & 1 & 2 & 3 & 4 & 5 & 6 & 7 \\
\hline 3. Everyone has a fair shot at wealth and happiness in New Zealand. & 1 & 2 & 3 & 4 & 5 & 6 & 7 \\
\hline 4. Asian people would be likely to reject me on the basis of my race. & 1 & 2 & 3 & 4 & 5 & 6 & 7 \\
\hline $\begin{array}{l}\text { 5. In my opinion, more good jobs for Asians mean fewer good jobs for members } \\
\text { of other groups in New Zealand. }\end{array}$ & 1 & 2 & 3 & 4 & 5 & 6 & 7 \\
\hline 6. I feel anxious about interacting with NZ European people. & 1 & 2 & 3 & 4 & 5 & 6 & 7 \\
\hline $\begin{array}{l}\text { 7. New Zealand would be a better place to live if we forgot about trying to } \\
\text { promote Māori culture to everyone. }\end{array}$ & 1 & 2 & 3 & 4 & 5 & 6 & 7 \\
\hline 8. Women exaggerate problems they have at work. & 1 & 2 & 3 & 4 & 5 & 6 & 7 \\
\hline 9. In general, I find New Zealand society to be fair. & 1 & 2 & 3 & 4 & 5 & 6 & 7 \\
\hline 10. Pacific Island people would be likely to reject me on the basis of my race. & 1 & 2 & 3 & 4 & 5 & 6 & 7 \\
\hline 11. Māori have very different values and morals compared to most other NZers. & 1 & 2 & 3 & 4 & 5 & 6 & 7 \\
\hline 12. Bad smells, messes, dead animals and rotten food absolutely disgust me. & 1 & 2 & 3 & 4 & 5 & 6 & 7 \\
\hline 13. Women, compared to men, tend to have greater moral sensibility. & 1 & 2 & 3 & 4 & 5 & 6 & 7 \\
\hline $\begin{array}{l}\text { 14. The fact that I am a member of my ethnic group is an important part of my } \\
\text { identity. }\end{array}$ & 1 & 2 & 3 & 4 & 5 & 6 & 7 \\
\hline $\begin{array}{l}\text { 15. By taking personal action I believe I can make a positive difference to } \\
\text { environmental problems. }\end{array}$ & 1 & 2 & 3 & 4 & 5 & 6 & 7 \\
\hline 16. In general, the New Zealand political system operates as it should. & 1 & 2 & 3 & 4 & 5 & 6 & 7 \\
\hline 17. There is no one I can turn to for guidance in times of stress. & 1 & 2 & 3 & 4 & 5 & 6 & 7 \\
\hline 18. I feel I can make a difference to the state of the environment. & 1 & 2 & 3 & 4 & 5 & 6 & 7 \\
\hline 19. NZ European people would be likely to reject me on the basis of my race. & 1 & 2 & 3 & 4 & 5 & 6 & 7 \\
\hline 20. Protecting New Zealand's native species should be a national priority. & 1 & 2 & 3 & 4 & 5 & 6 & 7 \\
\hline 21. I feel anxious about interacting with Māori people. & 1 & 2 & 3 & 4 & 5 & 6 & 7 \\
\hline $\begin{array}{l}\text { 22. Pacific Islanders have very different values and morals compared to most } \\
\text { other NZers. }\end{array}$ & 1 & 2 & 3 & 4 & 5 & 6 & 7 \\
\hline 23. Men and women both have a fair shot at wealth and happiness in NZ. & 1 & 2 & 3 & 4 & 5 & 6 & 7 \\
\hline 24. I know there are people I can turn to when I need help. & 1 & 2 & 3 & 4 & 5 & 6 & 7 \\
\hline $\begin{array}{l}\text { 25. I reckon Māori culture should stay where it belongs-with Māori. It doesn't } \\
\text { concern other NZers. }\end{array}$ & 1 & 2 & 3 & 4 & 5 & 6 & 7 \\
\hline
\end{tabular}


1. People who become preoccupied by race are forgetting that we're all just human.

$\begin{array}{lllllll}1 & 2 & 3 & 4 & 5 & 6 & 7\end{array}$

2. I feel anxious about interacting with Pacific Island people.

$\begin{array}{lllllll}1 & 2 & 3 & 4 & 5 & 6 & 7\end{array}$

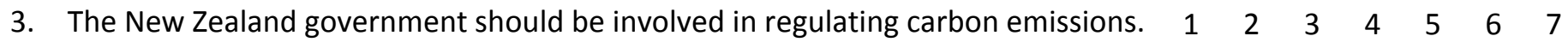

4. I feel a great pride in the land that is our New Zealand.

5. I am satisfied with my life.

6. Women are too easily offended.

7. In my opinion, more good jobs for Māori mean fewer good jobs for members of other groups in New Zealand.

8. Mãori people would be likely to reject me on the basis of my race.

9. We should all move on as one nation and forget about past differences and conflicts between ethnic groups.

10. Asians have different values and morals compared to most other NZers.

11. Putting racial labels on people obscures the fact that everyone is a unique individual.

12. I feel anxious about interacting with Asian people.

13. NZ Europeans have different values and morals compared to most other NZers.

14. Climate change is real.

15. Climate change is caused by humans.

16. It is OK for parents to use smacking as a way to discipline their children.

$\begin{array}{lllllll}1 & 2 & 3 & 4 & 5 & 6 & 7\end{array}$

$\begin{array}{lllllll}1 & 2 & 3 & 4 & 5 & 6 & 7\end{array}$

$\begin{array}{lllllll}1 & 2 & 3 & 4 & 5 & 6 & 7\end{array}$

17. In general, relations between different ethnic groups in New Zealand are fair.

18. Many women have a quality of purity that few men possess.

19. We should not have to pay for the mistakes of our ancestors.

20. Women seek to gain power by getting control over men.

21. In my opinion, more good jobs for NZ Europeans mean fewer good jobs for members of other groups in New Zealand.

22. People from other races would be likely to reject me on the basis of my race.

23. Once a woman gets a man to commit to her she usually tries to put him on a tight leash.

24. Women, as compared to men, tend to have a more refined sense of culture and good taste.

25. I feel anxious about interacting with people from other races.

26. Most of New Zealand's policies serve the greater good.

27. People who weren't around in previous centuries should not feel accountable for the actions of their ancestors.

$\begin{array}{lllllll}1 & 2 & 3 & 4 & 5 & 6 & 7\end{array}$

$\begin{array}{lllllll}1 & 2 & 3 & 4 & 5 & 6 & 7\end{array}$

$\begin{array}{lllllll}1 & 2 & 3 & 4 & 5 & 6 & 7\end{array}$

$\begin{array}{lllllll}1 & 2 & 3 & 4 & 5 & 6 & 7\end{array}$

$\begin{array}{lllllll}1 & 2 & 3 & 4 & 5 & 6 & 7\end{array}$

$\begin{array}{lllllll}1 & 2 & 3 & 4 & 5 & 6 & 7\end{array}$

$\begin{array}{lllllll}1 & 2 & 3 & 4 & 5 & 6 & 7\end{array}$

$\begin{array}{lllllll}1 & 2 & 3 & 4 & 5 & 6 & 7\end{array}$

$\begin{array}{lllllll}1 & 2 & 3 & 4 & 5 & 6 & 7\end{array}$

$\begin{array}{lllllll}1 & 2 & 3 & 4 & 5 & 6 & 7\end{array}$

$\begin{array}{lllllll}1 & 2 & 3 & 4 & 5 & 6 & 7\end{array}$

$\begin{array}{lllllll}1 & 2 & 3 & 4 & 5 & 6 & 7\end{array}$

$\begin{array}{lllllll}1 & 2 & 3 & 4 & 5 & 6 & 7\end{array}$

$\begin{array}{lllllll}1 & 2 & 3 & 4 & 5 & 6 & 7\end{array}$

$\begin{array}{lllllll}1 & 2 & 3 & 4 & 5 & 6 & 7\end{array}$

$\begin{array}{lllllll}1 & 2 & 3 & 4 & 5 & 6 & 7\end{array}$

$\begin{array}{lllllll}1 & 2 & 3 & 4 & 5 & 6 & 7\end{array}$

$\begin{array}{lllllll}1 & 2 & 3 & 4 & 5 & 6 & 7\end{array}$

$\begin{array}{lllllll}1 & 2 & 3 & 4 & 5 & 6 & 7\end{array}$

$\begin{array}{lllllll}1 & 2 & 3 & 4 & 5 & 6 & 7\end{array}$

$\begin{array}{lllllll}1 & 2 & 3 & 4 & 5 & 6 & 7\end{array}$

28. In my opinion, more good jobs for Pacific Islanders mean fewer good jobs for members of other groups in New Zealand.

29. In general, relations between men and women in New Zealand are fair.

30. In most ways my life is close to ideal.

31. Women should be cherished and protected by men.

32. Generally, the more influence NZ has on other nations, the better off they are.

33. When women lose to men in a fair competition, they typically complain about being discriminated against.

34. Although at times I may not agree with the government, my commitment to New Zealand always remains strong.

$\begin{array}{lllllll}1 & 2 & 3 & 4 & 5 & 6 & 7\end{array}$

$\begin{array}{lllllll}1 & 2 & 3 & 4 & 5 & 6 & 7\end{array}$

$\begin{array}{lllllll}1 & 2 & 3 & 4 & 5 & 6 & 7\end{array}$

$\begin{array}{lllllll}1 & 2 & 3 & 4 & 5 & 6 & 7\end{array}$

$\begin{array}{lllllll}1 & 2 & 3 & 4 & 5 & 6 & 7\end{array}$

$\begin{array}{lllllll}1 & 2 & 3 & 4 & 5 & 6 & 7\end{array}$

$\begin{array}{lllllll}1 & 2 & 3 & 4 & 5 & 6 & 7\end{array}$

$\begin{array}{lllllll}1 & 2 & 3 & 4 & 5 & 6 & 7\end{array}$

$\begin{array}{lllllll}1 & 2 & 3 & 4 & 5 & 6 & 7\end{array}$

36. Being a member of my ethnic group is an important part of how I see myself.

37. It is important for people to know the facts about healthy eating/nutrition.

$\begin{array}{lllllll}1 & 2 & 3 & 4 & 5 & 6 & 7\end{array}$

38. Foreign nations have done some very fine things but they are still not as good as New Zealand.

$\begin{array}{lllllll}1 & 2 & 3 & 4 & 5 & 6 & 7\end{array}$


Instructions: Please rate how strongly you oppose or support each of the following political parties.

\begin{tabular}{|c|c|c|c|c|c|c|c|c|c|c|c|c|c|c|c|c|}
\hline $\begin{array}{r}\text { Strongly Oppose } \\
1\end{array}$ & \multicolumn{10}{|c|}{ Neutral } & \multicolumn{6}{|c|}{$\begin{array}{l}\text { Strongly Support } \\
7\end{array}$} \\
\hline The National Party & 1 & 2 & 3 & 4 & 5 & 6 & 7 & The ACT Party & & 1 & 2 & 3 & 4 & 5 & 6 & 7 \\
\hline The Labour Party & 1 & 2 & 3 & 4 & 5 & 6 & 7 & The Māori Part & & 1 & 2 & 3 & 4 & 5 & 6 & 7 \\
\hline The Green Party & 1 & 2 & 3 & 4 & 5 & 6 & 7 & United Future & & 1 & 2 & 3 & 4 & 5 & 6 & 7 \\
\hline
\end{tabular}

Instructions: Please answer each of the following questions by circling a number on the scale below.

Definitely NO

1
2

$\underset{4}{\text { Unsure }}$

3
5
Definitely YES 7

1. Of course, we all hope that there will not be another war, but if it were to come to that, would you be willing to fight for your country?

2. Are you willing to change your daily routine in order to protect the environment?

3. Have you made changes to your daily routine in order to protect the environment?

4. Are you willing to make sacrifices to your standard of living (e.g., accept higher prices, drive less, conserve energy) in order to protect the environment?

5. Have you made sacrifices to your standard of living (e.g., accepted higher prices, driven less, conserved energy) in order to protect the environment?

6. Do you think most New Zealanders are willing to make sacrifices to their standard of living in order to protect the environment?

7. Do you support the use of $\mathbf{1 0 8 0}$ poison for possum control in New Zealand?

8. Do you lead a healthy lifestyle? (e.g., eat healthy food, exercise regularly).

9. Do you have the resources/ things you need in order to lead a healthy lifestyle?

10.Do you think you personally are more at risk of a weight-based illness (e.g., heart illnesses, diabetes) than other New Zealanders, on average?

11.Do you think people from your ethnic group are more at risk of weight-based illnesses (e.g., heart illnesses, diabetes) than other New Zealanders, on average?

$\begin{array}{lllllll}1 & 2 & 3 & 4 & 5 & 6 & 7\end{array}$

$\begin{array}{lllllll}1 & 2 & 3 & 4 & 5 & 6 & 7\end{array}$

$\begin{array}{lllllll}1 & 2 & 3 & 4 & 5 & 6 & 7\end{array}$

$\begin{array}{lllllll}1 & 2 & 3 & 4 & 5 & 6 & 7\end{array}$

$\begin{array}{lllllll}1 & 2 & 3 & 4 & 5 & 6 & 7\end{array}$

$\begin{array}{lllllll}1 & 2 & 3 & 4 & 5 & 6 & 7\end{array}$

$\begin{array}{lllllll}1 & 2 & 3 & 4 & 5 & 6 & 7\end{array}$

$\begin{array}{lllllll}1 & 2 & 3 & 4 & 5 & 6 & 7\end{array}$

$\begin{array}{lllllll}1 & 2 & 3 & 4 & 5 & 6 & 7\end{array}$

$\begin{array}{lllllll}1 & 2 & 3 & 4 & 5 & 6 & 7\end{array}$

$\begin{array}{lllllll}1 & 2 & 3 & 4 & 5 & 6 & 7\end{array}$

Instructions. Please rate how strongly you oppose or support each of the following possible policies or issues.

Strongly Strongly

Oppose

Support

1. Government initiatives to inform and promote healthy lifestyle choices.

$\downarrow$

2. Policies promoting closer trade ties between India and New Zealand.

3. Māori ownership of the seabed and foreshore.

4. Performance of the Haka at international sports events.

5. Incentives to increase women's participation in the paid workforce (paid for by government).

6. Policies promoting closer trade ties between China and New Zealand.

7. A "flat" tax rate (everyone pays the same percentage of tax on their income).

8. Reserving places for Māori students to study medicine.

9. Waitangi Day as a national celebration of biculturalism.

10. The Civil Union Act.

$\begin{array}{lllllll}1 & 2 & 3 & 4 & 5 & 6 & 7\end{array}$

11. Including religious instruction in Christianity as part of the school curriculum.

12. Rates exemptions on Māori land.

13. Teaching Māori language in New Zealand primary schools.

14. Policies promoting more immigration from India to New Zealand.

15. Introducing a programme to enhance sustainable business growth among businesses owned and operated by women.

$\begin{array}{lllllll}1 & 2 & 3 & 4 & 5 & 6 & 7 \\ 1 & 2 & 3 & 4 & 5 & 6 & 7\end{array}$

$\begin{array}{lllllll}1 & 2 & 3 & 4 & 5 & 6 & 7\end{array}$

16. Singing the national anthem in Māori and English.

17. Policies promoting more immigration from China to New Zealand.

$\begin{array}{lllllll}1 & 2 & 3 & 4 & 5 & 6 & 7\end{array}$

18. Crown (government) ownership of the seabed and foreshore.

\begin{tabular}{lllllll}
1 & 2 & 3 & 4 & 5 & 6 & 7 \\
1 & 2 & 3 & 4 & 5 & 6 & 7 \\
1 & 2 & 3 & 4 & 5 & 6 & 7 \\
1 & 2 & 3 & 4 & 5 & 6 & 7 \\
1 & 2 & 3 & 4 & 5 & 6 & 7 \\
1 & 2 & 3 & 4 & 5 & 6 & 7 \\
1 & 2 & 3 & 4 & 5 & 6 & 7 \\
1 & 2 & 3 & 4 & 5 & 6 & 7 \\
1 & 2 & 3 & 4 & 5 & 6 & 7 \\
1 & 2 & 3 & 4 & 5 & 6 & 7 \\
1 & 2 & 3 & 4 & 5 & 6 & 7 \\
1 & 2 & 3 & 4 & 5 & 6 & 7 \\
1 & 2 & 3 & 4 & 5 & 6 & 7 \\
\hline
\end{tabular}


In your day-to-day life, how often do PEOPLE IN NEW ZEALAND act toward you in the following ways?

\begin{tabular}{|c|c|c|c|}
\hline $\begin{array}{l}\text { Have Never } \\
\text { Experienced This }\end{array}$ & & & $\begin{array}{c}\text { Sometimes } \\
\text { Experience This }\end{array}$ \\
\hline 1 & 2 & 3 & 4 \\
\hline
\end{tabular}

\begin{tabular}{|c|c|c|c|c|c|c|c|}
\hline \multirow[t]{2}{*}{5} & \multicolumn{2}{|c|}{6} & & \multicolumn{4}{|c|}{$\begin{array}{l}\text { Often } \\
\text { Experience This } \\
7\end{array}$} \\
\hline & 1 & 2 & 3 & 4 & 5 & 6 & 7 \\
\hline & 1 & 2 & 3 & 4 & 5 & 6 & 7 \\
\hline & 1 & 2 & 3 & 4 & 5 & 6 & 7 \\
\hline & 1 & 2 & 3 & 4 & 5 & 6 & 7 \\
\hline & 1 & 2 & 3 & 4 & 5 & 6 & 7 \\
\hline & 1 & 2 & 3 & 4 & 5 & 6 & 7 \\
\hline
\end{tabular}

1. Do things to threaten you.

2. Insist that they know what is best for you.

3. Make threatening gestures toward you.

4. Offer advice and opinions even when you don't want it.

5. Attack you, or make you fear that they might.

6. Try to help you with things you'd rather do for yourself.

In your day-to-day life, how often do PEOPLE FROM OTHER ETHNIC GROUPS act toward you in the following ways?

1. Do things to threaten you.

2. Insist that they know what is best for you.

3. Happily interact with you in formal situations but not social ones.

4. Make threatening gestures toward you.

5. Offer advice and opinions even when you don't want it.

6. Only socialise or interact with you when it suits their purposes.

7. Attack you, or make you fear that they might.

8. Try to help you with things you'd rather do for yourself.

9. Treat you with respect, but avoid socialising with you.

\begin{tabular}{|lllllll|}
\hline 1 & 2 & 3 & 4 & 5 & 6 & 7 \\
\hline 1 & 2 & 3 & 4 & 5 & 6 & 7 \\
\hline 1 & 2 & 3 & 4 & 5 & 6 & 7 \\
\hline 1 & 2 & 3 & 4 & 5 & 6 & 7 \\
\hline 1 & 2 & 3 & 4 & 5 & 6 & 7 \\
\hline 1 & 2 & 3 & 4 & 5 & 6 & 7 \\
\hline 1 & 2 & 3 & 4 & 5 & 6 & 7 \\
\hline 1 & 2 & 3 & 4 & 5 & 6 & 7 \\
\hline 1 & 2 & 3 & 4 & 5 & 6 & 7 \\
\hline
\end{tabular}

Please rate your feelings toward the following groups using the "feeling thermometer scale" for each group. This scale measures your feelings of WARMTH toward different groups.

Feel LEAST WARM

Toward This Group 1 Neutral 4

\begin{tabular}{|l||ccccccc|}
\hline NZ Europeans & 1 & 2 & 3 & 4 & 5 & 6 & 7 \\
\hline Māori & 1 & 2 & 3 & 4 & 5 & 6 & 7 \\
\hline Asians in general & 1 & 2 & 3 & 4 & 5 & 6 & 7 \\
\hline \hline Pacific Islanders & 1 & 2 & 3 & 4 & 5 & 6 & 7 \\
\hline
\end{tabular}

\section{Feel MOST WARM} Toward This Group 7

\begin{tabular}{|l|ccccccc|}
\hline Overweight people & 1 & 2 & 3 & 4 & 5 & 6 & 7 \\
\hline Immigrants in general & 1 & 2 & 3 & 4 & 5 & 6 & 7 \\
\hline Chinese & 1 & 2 & 3 & 4 & 5 & 6 & 7 \\
\hline Indians & 1 & 2 & 3 & 4 & 5 & 6 & 7 \\
\hline
\end{tabular}

Now please rate your feelings of ANGER toward these same groups on the scale below.

\begin{tabular}{|c|c|c|c|c|c|c|c|c|c|c|c|c|c|c|c|}
\hline $\begin{array}{r}\text { Feel } \frac{\text { NO ANGER }}{\text { Toward This Group }} \\
1\end{array}$ & \multicolumn{9}{|c|}{ Neutral } & \multicolumn{6}{|c|}{$\begin{array}{l}\text { Feel ANGER } \\
\text { Toward This Group } \\
7\end{array}$} \\
\hline NZ Europeans & 1 & 2 & 3 & 4 & 5 & 6 & 7 & Overweight people & 1 & 2 & 3 & 4 & 5 & 6 & 7 \\
\hline Māori & 1 & 2 & 3 & 4 & 5 & 6 & 7 & Immigrants in general & 1 & 2 & 3 & T & J & 6 & 7 \\
\hline Asians in general & 1 & 2 & 3 & 4 & 5 & 6 & 7 & Chinese & 1 & 2 & 3 & 4 & 5 & 6 & 7 \\
\hline Pacific Islanders & 1 & 2 & 3 & 4 & 5 & 6 & 7 & Indians & 1 & 2 & 3 & 4 & 5 & 0 & 7 \\
\hline
\end{tabular}

How IMPORTANT do you think the following behaviours are for a healthy lifestyle, and how REGULARLY do you do them?

\begin{tabular}{|c|c|c|c|c|c|c|c|c|}
\hline \multirow[b]{3}{*}{ Limit intake of salt. } & \multicolumn{4}{|c|}{$\begin{array}{l}\text { How IMPORTANT do you think this } \\
\text { is for leading a healthy lifestyle? }\end{array}$} & \multicolumn{4}{|c|}{$\begin{array}{l}\text { How REGULARLY do you do you } \\
\text { do this on a daily basis? }\end{array}$} \\
\hline & \multicolumn{2}{|c|}{ Unimportant } & \multicolumn{2}{|c|}{ Important } & \multirow{2}{*}{$\begin{array}{l}\mathbf{N} \\
\downarrow \\
\\
\end{array}$} & \multirow{2}{*}{$\begin{array}{r}\text { Rarel } \\
1 \\
\end{array}$} & \multirow{2}{*}{$\begin{array}{r}\text { Often } \\
2 \\
\end{array}$} & \multirow{2}{*}{ Always } \\
\hline & 0 & 1 & 2 & 3 & & & & \\
\hline Limit intake of saturated fats. & 0 & 1 & 2 & 3 & 0 & 1 & 2 & 3 \\
\hline Limit intake of foods/drinks high in sugar. & 0 & 1 & 2 & 3 & 0 & 1 & 2 & 3 \\
\hline Eat lots of fibre and whole grains. & 0 & 1 & 2 & 3 & 0 & 1 & 2 & 3 \\
\hline Eat lots of fruit and vegetables. & 0 & 1 & 2 & 3 & 0 & 1 & 2 & 3 \\
\hline Engage in regular physical activity. & 0 & 1 & 2 & 3 & 0 & 1 & 2 & 3 \\
\hline
\end{tabular}


1. Which ethnic group $\square$ New Zealand European do you belong to?

$\square$ Māori

$\square$ Samoan

Please tick $\square$ the box

$\square$ Cook Island Māori

or boxes which apply

$\square$ Tongan

to you.

$\square$ Niuean

$\square$ Chinese

$\square$ Indian

$\square$ Other such as DUTCH, JAPANESE, TOKELAUAN.

Please state:

2. Are you male or female?

3. What is your date of birth?

4. How long have you lived at your current address?

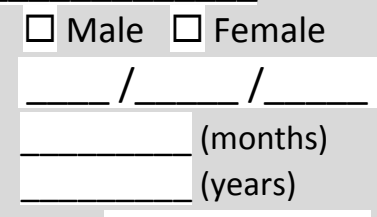

5. Which country were you born in?

6a. What is your $\square$ Single

relationship status?

$\square$ Dating

$\square$ Living together/De facto

If you are in a

relationship $\sqrt{ }$

6b. How long have you

been with your

partner?

$\square$ Married

$\square$ other

(if other please specify)

(years)

(months)

6c. How satisfied are you with your relationship with

your partner? (please circle a number on the scale below)

$\begin{array}{lllllllll}\text { Not satisfied } & 1 & 2 & 3 & 4 & 5 & 6 & 7 & \text { Very satisfied }\end{array}$

7. Please rate how politically liberal versus conservative you see yourself as being:

Extremely liberal $1 \begin{array}{llllllll}1 & 2 & 3 & 4 & 5 & 6 & 7 & \text { Extremely conservative }\end{array}$

8a. What is your current $\square$ Employed full-time

employment

situation?

$\square$ Employed part-time

$\square$ Self-employed

$\square$ Own your own business

$\square$ Studying full-time

$\square$ Unemployed, but want work

If you are currently $\quad \square$ Unemployed, don't want work employed $\Omega$

$\square$ Other

8 b. How long have you worked in your current job for?

(years) (months)

$8 \mathrm{c}$. How satisfied are you with your current job? $\begin{array}{lllllllll}\text { Not satisfied } & 1 & 2 & 3 & 4 & 5 & 6 & 7 & \text { Very satisfied }\end{array}$

$8 d$. How secure do you feel in your current job? $\begin{array}{lllllllll}\text { Not secure } & 1 & 2 & 3 & 4 & 5 & 6 & 7 & \text { Very secure }\end{array}$

9. How much money have you donated to charity in the last year?

10. How many other adults live in your household with you regularly?

11. Do you believe in a God? Yes $\square$ No

12. Do you believe in some form of spirit or life force?

Yes $\square$ No

13. What is your height? (m)

14. What is your weight? (kg)

15. Were you the $1^{\text {st }}$ born, $2^{\text {nd }}$ born, or $3^{\text {rd }}$ born, etc, child of your mother? 16a. How many children have you given

birth to, fathered, or adopted?

(if none, please enter ' 0 ' and go to q. 17)

16b. How many of your children live with you most of the time?

17. Have you or the principal earner in your household been out-of-work at any time in the last year?

Yes $\square$ No

18. Please estimate your total household income (before tax) for the year 2010

19a. Are you pregnant?

Yes $\square$ No

19b. If yes, what trimester are you in?

20. Were you born premature?

\section{$\$$}

$\square$ Yes $\square$ No

\section{(i.e., born pre-term?) \\ (i.e., born pre-term?)}

21. Were you breastfed as a baby?

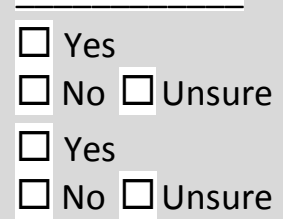

If you voted in 2008 , to which party did you give your...

22a. party vote?

22b. electorate vote? (please list the party not the candidate)

23a. Do you identify with a religion and/or spiritual group?

23b. If yes to 23a, then what religion/spiritual group?

23c. If yes to 23 a, then how many times did you attend a church or place of worship in the last month?

23d. If yes to 23a, how important is your religion to how you see yourself?

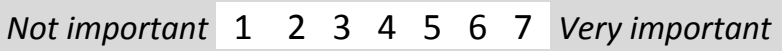

24. Roughly how many hours have you spent with FRIENDS/FAMILY and OTHERS (e.g., workmates, strangers) from each group in the last week?
(a) Māori
(b) NZ Europeans
(c) Asians
(d) Pacific Islanders

25. Have you been Friends/family

Others

diagnosed by a

doctor with any

of the following

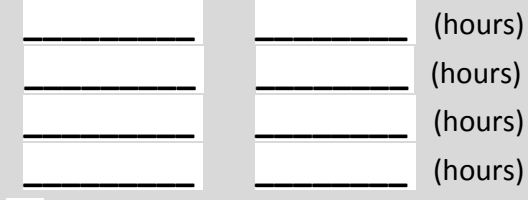

health conditions?

High cholesterol

$\square$ High blood pressure

Vitamin/mineral deficiency

Heart disease

$\square$ Diabetes $\square$ other

26a. Do you plan to vote in the next $\square$ Yes

New Zealand election in 2011? $\square$ No $\square$ Unsure

If yes, to which party do you plan to give your ...

26b. party vote?

26c. electorate vote?

27. In the last year, have you personally...
(a) been forced to buy cheaper food so that you could pay for other things you needed?
(b) put up with feeling cold to save on heating costs?
(c) been the victim of a crime? 


\section{The New Zealand Attitudes and Values Study}

\section{Follow-up Questionnaire at Time 3}

This form will be kept for a period of twenty years.

Researcher: Dr. Chris Sibley, Department of Psychology, University of Auckland. Phone: 09-373-7599, extn 88353. E-mail: c.sibley@auckland.ac.nz

\section{Consent form and contact details}

This form is to gather your consent to participate in this phase of the New Zealand Attitudes and Values Study. Only Dr. Sibley and his research associates will have access to your responses. Your personal information will be kept separate from your responses at all times. Your questionnaire will be identified by an anonymous code. An encrypted electronic copy of all responses will be stored indefinitely for research purposes in a secure room in the Department of Psychology.

I have read and understood a description of this research project. On this basis, I agree to take part. I understand that my data will remain confidential at all times. I understand that only Dr. Sibley will have access to my contact details. I consent to publication of the results of the project with the understanding that my anonymity will be preserved. I understand that I am free to withdraw from the research at any time up until the point at which I complete and return this questionnaire. I understand that my contact details will never be shared with anyone. I understand that Dr. Sibley will use these details to contact and invite me to complete follow-up questionnaires, possibly for the next seventeen years. Finally, I understand that my contact details will be used to contact me if I win one of the grocery voucher prize draws for $\mathbf{\$ 5 0 0 ,} \mathbf{\$ 3 0 0}$ or $\mathbf{\$ 2 0 0}$ for participating in this study.

\begin{tabular}{r|r|r|}
\hline Name: & \\
\hline Signature: & \\
\hline Home phone: & Date: \\
\hline Email address: & \\
\hline Postal address: & \\
\hline & \\
\hline & \\
\hline
\end{tabular}

Would you like to receive a summary of key findings from the study?

Would you be willing to complete a short follow-up email survey about your ethnic identity and your feelings about your ethnicity? 


\begin{tabular}{|c|c|c|c|c|c|c|c|}
\hline \multirow{2}{*}{$\begin{array}{l}\text { I ... } \\
\text { 1. Am the life of the party. }\end{array}$} & \multicolumn{3}{|c|}{$\begin{array}{l}\text { Very } \\
\text { Inaccurate } \\
\downarrow\end{array}$} & \multicolumn{4}{|c|}{$\begin{array}{r}\text { Ver } \\
\text { Accurat }\end{array}$} \\
\hline & 1 & 2 & 3 & 4 & 5 & 6 & \\
\hline 2. Sympathise with others' feelings. & 1 & 2 & 3 & 4 & 5 & 6 & \\
\hline 3. Get chores done right away. & 1 & 2 & 3 & 4 & 5 & 6 & trat \\
\hline 4. Have frequent mood swings. & 1 & 2 & 3 & 4 & 5 & 6 & \\
\hline 5. Have a vivid imagination. & 1 & 2 & 3 & 4 & 5 & 6 & \\
\hline 6. Don't talk a lot. & 1 & 2 & 3 & 4 & 5 & 6 & 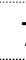 \\
\hline 7. Am not interested in other people's problems. & 1 & 2 & 3 & 4 & 5 & 6 & \\
\hline 8. Have difficulty understanding abstract ideas. & 1 & 2 & 3 & 4 & 5 & 6 & \\
\hline 9. Like order. & 1 & 2 & 3 & 4 & 5 & 6 & \\
\hline 10. Make a mess of things. & 1 & 2 & 3 & 4 & 5 & 6 & \\
\hline 11. Do not have a good imagination. & 1 & 2 & 3 & 4 & 5 & 6 & \\
\hline 12. Feel others' emotions. & 1 & 2 & 3 & 4 & 5 & 6 & trata \\
\hline 13. Am relaxed most of the time. & 1 & 2 & 3 & 4 & 5 & 6 & trata \\
\hline 14. Get upset easily. & 1 & 2 & 3 & 4 & 5 & 6 & trata \\
\hline 15. Seldom feel blue. & 1 & 2 & 3 & 4 & 5 & 6 & trata \\
\hline 16. Keep in the background. & 1 & 2 & 3 & 4 & 5 & 6 & \\
\hline 17. Am not really interested in others. & 1 & 2 & 3 & 4 & 5 & 6 & \\
\hline 18. Am not interested in abstract ideas. & 1 & 2 & 3 & 4 & 5 & 6 & \\
\hline 19. Often forget to put things back in their proper place. & 1 & 2 & 3 & 4 & 5 & 6 & \\
\hline 20. Talk to a lot of different people at parties. & 1 & 2 & 3 & 4 & 5 & 6 & \\
\hline 21. Feel entitled to more of everything. & 1 & 2 & 3 & 4 & 5 & 6 & \\
\hline 22. On the whole am satisfied with myself. & 1 & 2 & 3 & 4 & 5 & 6 & \\
\hline 23. Know that people in my life accept and value me. & 1 & 2 & 3 & 4 & 5 & 6 & trata \\
\hline 24. Would like to be seen driving around in a very expensive car. & 1 & 2 & 3 & 4 & 5 & 6 & \\
\hline 25. Deserve more things in life. & 1 & 2 & 3 & 4 & 5 & 6 & trata \\
\hline 26. Take a positive attitude toward myself. & 1 & 2 & 3 & 4 & 5 & 6 & tin \\
\hline 27. Feel like an outsider. & 1 & 2 & 3 & 4 & 5 & 6 & 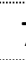 \\
\hline 28. Would get a lot of pleasure from owning expensive luxury goods. & 1 & 2 & 3 & 4 & 5 & 6 & \\
\hline 29. Am satisfied with the appearance, size and shape of my body. & 1 & 2 & 3 & 4 & 5 & 6 & \\
\hline 30. Am inclined to feel that I am a failure. & 1 & 2 & 3 & 4 & 5 & 6 & \\
\hline 31. Feel that I am often discriminated against because of my ethnicity. & 1 & 2 & 3 & 4 & 5 & 6 & \\
\hline 32. Know that people around me share my attitudes and beliefs. & 1 & 2 & 3 & 4 & 5 & 6 & \\
\hline 33. Being a woman/man is an important part of how I see myself. & 1 & 2 & 3 & 4 & 5 & 6 & \\
\hline
\end{tabular}

During the last 30 davs. how often did....

(Please use the scale below to circle a number for each question)

\begin{tabular}{|c|c|c|c|c|c|c|c|}
\hline $\begin{array}{r}\text { None Of } \\
\text { The Time } \\
0\end{array}$ & $\begin{array}{c}\text { A Little Of } \\
\text { The Time } \\
1\end{array}$ & $\begin{array}{c}\text { Some of } \\
\text { The Time } \\
2\end{array}$ & $\begin{array}{l}\text { ost } 0 \\
\text { Tim } \\
3\end{array}$ & & & & \\
\hline \multicolumn{3}{|c|}{ 1. ... you feel hopeless? } & 0 & 1 & 2 & 3 & 4 \\
\hline \multicolumn{3}{|c|}{ 2. ... you feel so depressed that nothing could cheer you up? } & 0 & 1 & 2 & 3 & 4 \\
\hline \multicolumn{3}{|c|}{ 3. ... you feel restless or fidgety? } & 0 & 1 & 2 & 3 & 4 \\
\hline \multicolumn{3}{|c|}{ 4. ... you feel that everything was an effort? } & 0 & 1 & 2 & 3 & 4 \\
\hline \multicolumn{3}{|c|}{ 5. ... you feel worthless? } & 0 & 1 & 2 & 3 & 4 \\
\hline \multicolumn{3}{|c|}{ 6. ... you feel nervous? } & 0 & 1 & 2 & 3 & 4 \\
\hline \multicolumn{3}{|c|}{ 7. ... you have negative thoughts that repeated over and over? } & 0 & 1 & 2 & 3 & 4 \\
\hline
\end{tabular}


Instructions: Please circle the number that best represents how important each of the following values is for you as a guiding principle in your life. Use the scale below to rate these items.

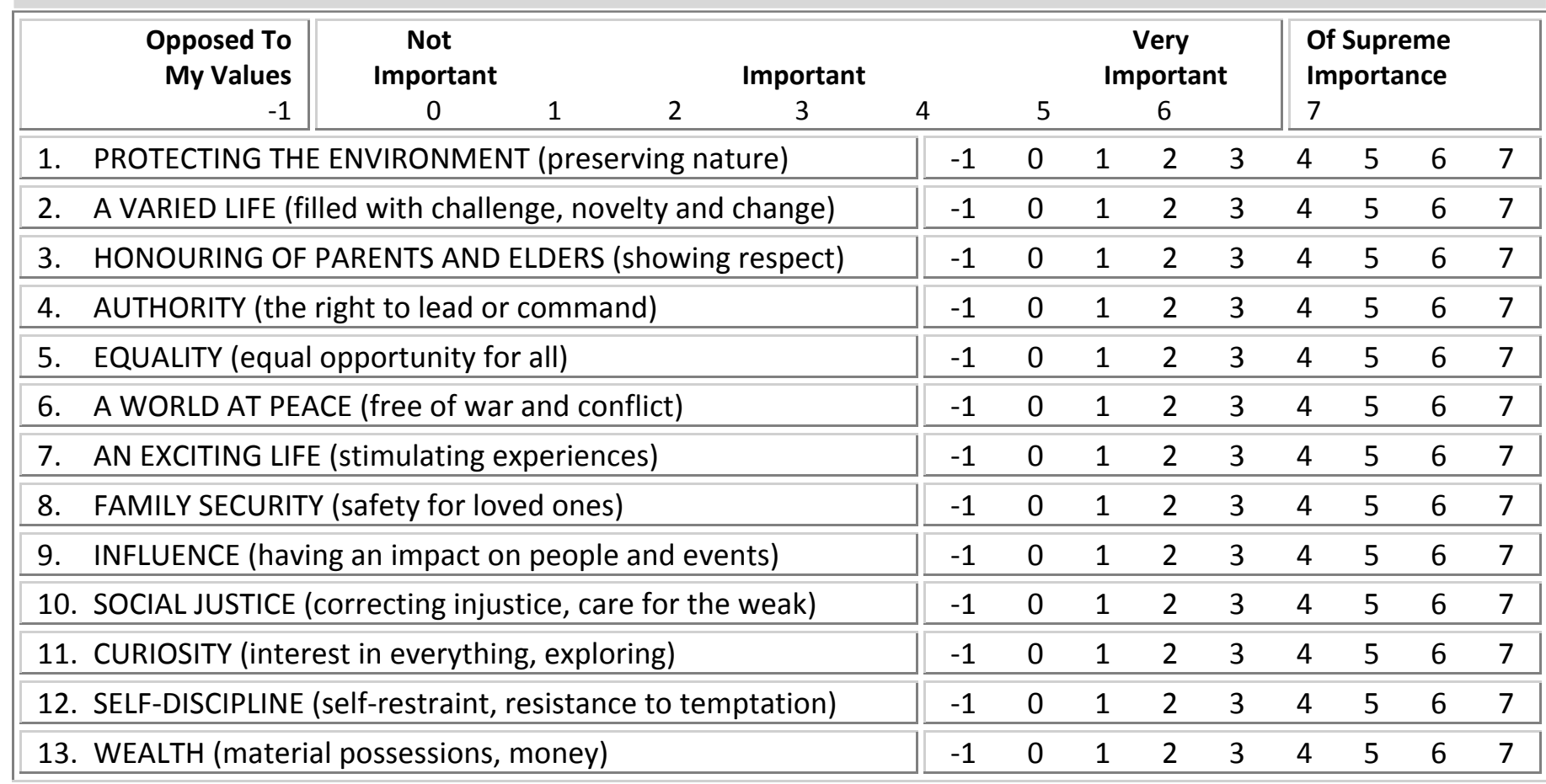

Instructions: The statements below reflect different opinions and points of view. Please indicate how strongly you disagree or agree with each statement. Remember, the best answer is your own opinion.

\begin{tabular}{|c|c|c|c|c|c|c|c|}
\hline \multirow[b]{2}{*}{ It is OK if some groups have more of a chance in life than others. } & \multicolumn{3}{|c|}{$\begin{array}{l}\text { Strongly } \\
\text { Disagree } \\
\downarrow\end{array}$} & \multirow[b]{2}{*}{4} & \multicolumn{3}{|c|}{$\begin{array}{r}\text { Strongly } \\
\text { Agree } \\
\end{array}$} \\
\hline & 1 & 2 & 3 & & 5 & 6 & 7 \\
\hline $\begin{array}{l}\text { 2. It is always better to trust the judgment of the proper authorities in } \\
\text { government and religion than to listen to the noisy rabble-rousers in our } \\
\text { society who are trying to create doubt in people's minds. }\end{array}$ & 1 & 2 & 3 & 4 & 5 & 6 & 7 \\
\hline 3. I wish people in this society would stop obsessing so much about race. & 1 & 2 & 3 & 4 & 5 & 6 & 7 \\
\hline 4. Inferior groups should stay in their place. & 1 & 2 & 3 & 4 & 5 & 6 & 7 \\
\hline $\begin{array}{l}\text { 5. It would be best for everyone if the proper authorities censored magazines so } \\
\text { that people could not get their hands on trashy and disgusting material. }\end{array}$ & 1 & 2 & 3 & 4 & 5 & 6 & 7 \\
\hline $\begin{array}{l}\text { 6. Everyone in New Zealand has a fair shot at wealth and happiness, regardless } \\
\text { of ethnicity or race. }\end{array}$ & 1 & 2 & 3 & 4 & 5 & 6 & 7 \\
\hline 7. To get ahead in life, it is sometimes okay to step on other groups. & 1 & 2 & 3 & 4 & 5 & 6 & 7 \\
\hline $\begin{array}{l}\text { 8. Our country will be destroyed some day if we do not smash the perversions } \\
\text { eating away at our moral fibre and traditional beliefs. }\end{array}$ & 1 & 2 & 3 & 4 & 5 & 6 & 7 \\
\hline 9. To a large extent, a person's race biologically determines his or her abilities. & 1 & 2 & 3 & 4 & 5 & 6 & 7 \\
\hline 10. We should have increased social equality. & 1 & 2 & 3 & 4 & 5 & 6 & 7 \\
\hline $\begin{array}{l}\text { 11. People should pay less attention to The Bible and other old traditional forms } \\
\text { of religious guidance, and instead develop their own personal standards of } \\
\text { what is moral and immoral. }\end{array}$ & 1 & 2 & 3 & 4 & 5 & 6 & 7 \\
\hline 12. It would be good if groups could be equal. & 1 & 2 & 3 & 4 & 5 & 6 & 7 \\
\hline $\begin{array}{l}\text { 13. Atheists and others who have rebelled against established religions are no } \\
\text { doubt every bit as good and virtuous as those who attend church regularly. }\end{array}$ & 1 & 2 & 3 & 4 & 5 & 6 & 7 \\
\hline 14. We should do what we can to equalise conditions for different groups. & 1 & 2 & 3 & 4 & 5 & 6 & 7 \\
\hline 15. I often think about the fact that I am a member of my ethnic group. & 1 & 2 & 3 & 4 & 5 & 6 & 7 \\
\hline $\begin{array}{l}\text { 16. Some of the best people in our country are those who are challenging our } \\
\text { government, criticizing religion, and ignoring the "normal way" things are } \\
\text { supposed to be done. }\end{array}$ & 1 & 2 & 3 & 4 & 5 & 6 & 7 \\
\hline 17. People from my ethnic group generally earn less than other groups in NZ. & 1 & 2 & 3 & 4 & 5 & 6 & 7 \\
\hline
\end{tabular}


Instructions: Please rate your level of satisfaction with the following aspects of your life and New Zealand.

Completely Dissatisfied

Somewhat Satisfied

Completely Satisfied

0

1. Your standard of living.

$\begin{array}{lllllllll}1 & 2 & 3 & 4 & 5 & 6 & 7 & 8 & 9\end{array}$

10

2. The economic situation in New Zealand.

3. The quality of New Zealand's natural environment.

4. Your health.

5. The social conditions in New Zealand.

6. The performance of the current New Zealand government.

7. Your future security.

8. Business in New Zealand.

9. Your personal relationships.

\begin{tabular}{|lllllllllll|}
\hline 0 & 1 & 2 & 3 & 4 & 5 & 6 & 7 & 8 & 9 & 10 \\
\hline 0 & 1 & 2 & 3 & 4 & 5 & 6 & 7 & 8 & 9 & 10 \\
\hline 0 & 1 & 2 & 3 & 4 & 5 & 6 & 7 & 8 & 9 & 10 \\
\hline 0 & 1 & 2 & 3 & 4 & 5 & 6 & 7 & 8 & 9 & 10 \\
\hline 0 & 1 & 2 & 3 & 4 & 5 & 6 & 7 & 8 & 9 & 10 \\
\hline 0 & 1 & 2 & 3 & 4 & 5 & 6 & 7 & 8 & 9 & 10 \\
\hline 0 & 1 & 2 & 3 & 4 & 5 & 6 & 7 & 8 & 9 & 10 \\
\hline 0 & 1 & 2 & 3 & 4 & 5 & 6 & 7 & 8 & 9 & 10 \\
\hline 0 & 1 & 2 & 3 & 4 & 5 & 6 & 7 & 8 & 9 & 10 \\
\hline
\end{tabular}

Instructions: Please indicate how strongly you disagree or agree with each statement.

\begin{tabular}{|c|c|c|c|c|c|c|c|}
\hline \multirow[b]{2}{*}{ There are people I can depend on to help me if I really need it. } & \multicolumn{3}{|c|}{$\begin{array}{l}\text { Strongly } \\
\text { Disagree } \\
\downarrow\end{array}$} & & \multicolumn{3}{|c|}{$\begin{array}{r}\text { Strongly } \\
\text { Agree }\end{array}$} \\
\hline & 1 & 2 & 3 & 4 & 5 & 6 & 7 \\
\hline 2. I think that Māori culture helps to define New Zealand in positive ways. & 1 & 2 & 3 & 4 & 5 & 6 & 7 \\
\hline 3. I think liking rugby is an important part of being a 'true' New Zealander. & 1 & 2 & 3 & 4 & 5 & 6 & 7 \\
\hline 4. Everyone has a fair shot at wealth and happiness in New Zealand. & 1 & 2 & 3 & 4 & 5 & 6 & 7 \\
\hline $\begin{array}{l}\text { 5. Despite what one hears about 'crime in the street,' there probably isn't any } \\
\text { more now than there ever has been. }\end{array}$ & 1 & 2 & 3 & 4 & 5 & 6 & 7 \\
\hline
\end{tabular}

6. In my opinion, more good jobs for Asians mean fewer good jobs for members of other groups in New Zealand.

7. I feel anxious about interacting with NZ European people.

8. New Zealand would be a better place to live if we forgot about trying to promote Māori culture to everyone.

9. Women exaggerate problems they have at work.

10. In general, I find New Zealand society to be fair.

11. It's a dog-eat-dog world where you have to be ruthless at times.

$\begin{array}{lllllll}1 & 2 & 3 & 4 & 5 & 6 & 7 \\ 1 & 2 & 3 & 4 & 5 & 6 & 7\end{array}$

12. Māori people would be likely to reject me on the basis of my race.

$\begin{array}{lllllll}1 & 2 & 3 & 4 & 5 & 6 & 7\end{array}$

13. Bad smells, messes, dead animals and rotten food absolutely disgust me.

14. Women, compared to men, tend to have greater moral sensibility.

$\begin{array}{lllllll}1 & 2 & 3 & 4 & 5 & 6 & 7\end{array}$

$\begin{array}{lllllll}1 & 2 & 3 & 4 & 5 & 6 & 7\end{array}$

$\begin{array}{lllllll}1 & 2 & 3 & 4 & 5 & 6 & 7\end{array}$

15. The fact that I am a member of my ethnic group is an important part of my identity.

16. By taking personal action I believe I can make a positive difference to environmental problems.

$\begin{array}{lllllll}1 & 2 & 3 & 4 & 5 & 6 & 7\end{array}$

$\begin{array}{lllllll}1 & 2 & 3 & 4 & 5 & 6 & 7\end{array}$

$\begin{array}{lllllll}1 & 2 & 3 & 4 & 5 & 6 & 7\end{array}$

17. In general, the New Zealand political system operates as it should.

18. There is no one I can turn to for guidance in times of stress.

19. I feel I can make a difference to the state of the environment.

20. Life is not governed by the 'survival of the fittest.' We should let compassion and moral laws be our guide.

21. If they knew me, most NZers would respect what I have accomplished in life.

22. I feel anxious about interacting with Mãori people.

$\begin{array}{lllllll}1 & 2 & 3 & 4 & 5 & 6 & 7\end{array}$

23. Māori have too much political power and influence in decisions affecting NZ.

24. Pacific Island people would be likely to reject me on the basis of my race.

25. Men and women both have a fair shot at wealth and happiness in NZ.

26. I know there are people I can turn to when I need help.

27. I reckon Māori culture should stay where it belongs-with Māori. It doesn't concern other NZers.

28. I'm frustrated by what I earn relative to other people in NZ.

$\begin{array}{lllllll}1 & 2 & 3 & 4 & 5 & 6 & 7 \\ 1 & 2 & 3 & 4 & 5 & 6 & 7 \\ 1 & 2 & 3 & 4 & 5 & 6 & 7 \\ 1 & 2 & 3 & 4 & 5 & 6 & 7 \\ 1 & 2 & 3 & 4 & 5 & 6 & 7 \\ 1 & 2 & 3 & 4 & 5 & 6 & 7 \\ 1 & 2 & 3 & 4 & 5 & 6 & 7 \\ 1 & 2 & 3 & 4 & 5 & 6 & 7 \\ 1 & 2 & 3 & 4 & 5 & 6 & 7 \\ 1 & 2 & 3 & 4 & 5 & 6 & 7 \\ 1 & 2 & 3 & 4 & 5 & 6 & 7 \\ 1 & 2 & 3 & 4 & 5 & 6 & 7 \\ 1 & 2 & 3 & 4 & 5 & 6 & 7\end{array}$

$\begin{array}{lllllll}1 & 2 & 3 & 4 & 5 & 6 & 7\end{array}$ 
1. People who become preoccupied by race are forgetting that we're all just human.

2. I feel anxious about interacting with Pacific Island people.

3. The New Zealand government should be involved in regulating carbon emissions.

4. I feel a great pride in the land that is our New Zealand.

5. I am satisfied with my life.

6. Women are too easily offended.

7. In my opinion, more good jobs for Māori mean fewer good jobs for members of other groups in New Zealand.

1250.45

$\begin{array}{lllllll}1 & 2 & 3 & 4 & 5 & 6 & 7\end{array}$

$\begin{array}{lllllll}1 & 2 & 3 & 4 & 5 & 6 & 7\end{array}$

8. There are many dangerous people in our society who will attack someone out of pure meanness, for no reason at all.

$\begin{array}{lllllll}1 & 2 & 3 & 4 & 5 & 6 & 7\end{array}$

$\begin{array}{lllllll}1 & 2 & 3 & 4 & 5 & 6 & 7\end{array}$

$\begin{array}{lllllll}1 & 2 & 3 & 4 & 5 & 6 & 7\end{array}$

$\begin{array}{lllllll}1 & 2 & 3 & 4 & 5 & 6 & 7\end{array}$

9. We should all move on as one nation and forget about past differences and conflicts between ethnic groups.

10. Asian people would be likely to reject me on the basis of my race.

11. Putting racial labels on people obscures the fact that everyone is a unique individual.

12. I feel anxious about interacting with Asian people.

13. NZ European people would be likely to reject me on the basis of my race.

14. Climate change is real.

15. Climate change is caused by humans.

$\begin{array}{lllllll}1 & 2 & 3 & 4 & 5 & 6 & 7\end{array}$

16. I generally earn less than other people in NZ.

17. In general, relations between different ethnic groups in New Zealand are fair.

18. Many women have a quality of purity that few men possess.

19. We should not have to pay for the mistakes of our ancestors.

$\begin{array}{lllllll}1 & 2 & 3 & 4 & 5 & 6 & 7\end{array}$

20. Women seek to gain power by getting control over men.

21. In my opinion, more good jobs for NZ Europeans mean fewer good jobs for members of other groups in New Zealand.

$\begin{array}{lllllll}1 & 2 & 3 & 4 & 5 & 6 & 7\end{array}$

22. People from other races would be likely to reject me on the basis of my race.

23. Once a woman gets a man to commit to her she usually tries to put him on a tight leash.

$\begin{array}{lllllll}1 & 2 & 3 & 4 & 5 & 6 & 7\end{array}$

$\begin{array}{lllllll}1 & 2 & 3 & 4 & 5 & 6 & 7\end{array}$

$\begin{array}{lllllll}1 & 2 & 3 & 4 & 5 & 6 & 7\end{array}$

$\begin{array}{lllllll}1 & 2 & 3 & 4 & 5 & 6 & 7\end{array}$

$\begin{array}{lllllll}1 & 2 & 3 & 4 & 5 & 6 & 7\end{array}$

$\begin{array}{lllllll}1 & 2 & 3 & 4 & 5 & 6 & 7\end{array}$

$\begin{array}{lllllll}1 & 2 & 3 & 4 & 5 & 6 & 7\end{array}$

$\begin{array}{lllllll}1 & 2 & 3 & 4 & 5 & 6 & 7\end{array}$

$\begin{array}{lllllll}1 & 2 & 3 & 4 & 5 & 6 & 7\end{array}$

$\begin{array}{lllllll}1 & 2 & 3 & 4 & 5 & 6 & 7\end{array}$

\begin{tabular}{lllllll}
1 & 2 & 3 & 4 & 5 & 6 & 7 \\
\hline
\end{tabular}

$\begin{array}{lllllll}1 & 2 & 3 & 4 & 5 & 6 & 7\end{array}$

24. Women, as compared to men, tend to have a more refined sense of culture and good taste.

25. I feel anxious about interacting with people from other races.

26. Most of New Zealand's policies serve the greater good.

27. People who weren't around in previous centuries should not feel accountable for the actions of their ancestors.

28. In my opinion, more good jobs for Pacific Islanders mean fewer good jobs for members of other groups in New Zealand.

29. In general, relations between men and women in New Zealand are fair.

$\begin{array}{lllllll}1 & 2 & 3 & 4 & 5 & 6 & 7\end{array}$

30. In most ways my life is close to ideal.

31. Women should be cherished and protected by men.

$\begin{array}{lllllll}1 & 2 & 3 & 4 & 5 & 6 & 7 \\ 1 & 2 & 3 & 4 & 5 & 6 & 7 \\ 1 & 2 & 3 & 4 & 5 & 6 & 7 \\ 1 & 2 & 3 & 4 & 5 & 6 & 7\end{array}$

$\begin{array}{lllllll}1 & 2 & 3 & 4 & 5 & 6 & 7\end{array}$

$\begin{array}{llllllll}1 & 2 & 3 & 4 & 5 & 6 & 7\end{array}$

$\begin{array}{lllllll}1 & 2 & 3 & 4 & 5 & 6 & 7\end{array}$

$\begin{array}{lllllll}1 & 2 & 3 & 4 & 5 & 6 & 7\end{array}$

32. Generally, the more influence NZ has on other nations, the better off they are. $\quad \begin{array}{llllllllll}1 & 2 & 3 & 4 & 5 & 6 & 7\end{array}$

33. When women lose to men in a fair competition, they typically complain about being discriminated against.

34. Although at times I may not agree with the government, my commitment to New Zealand always remains strong.

$\begin{array}{lllllll}1 & 2 & 3 & 4 & 5 & 6 & 7\end{array}$

35. Every man ought to have a woman whom he adores.

36. Being a member of my ethnic group is an important part of how I see myself.

37. I'm frustrated by what my ethnic group earns relative to other groups in NZ.

38. Foreign nations have done some very fine things but they are still not as good as New Zealand.

$\begin{array}{lllllll}1 & 2 & 3 & 4 & 5 & 6 & 7\end{array}$

$\begin{array}{lllllll}1 & 2 & 3 & 4 & 5 & 6 & 7\end{array}$

$\begin{array}{lllllll}1 & 2 & 3 & 4 & 5 & 6 & 7\end{array}$

$\begin{array}{lllllll}1 & 2 & 3 & 4 & 5 & 6 & 7\end{array}$

$\begin{array}{lllllll}1 & 2 & 3 & 4 & 5 & 6 & 7\end{array}$ 
Instructions: Please rate how strongly you oppose or support each of the following political parties.

Strongly Oppose

1
Neutral

4

5

6 Strongly Support 7

\begin{tabular}{|l||lllllll|}
\hline The National Party & 1 & 2 & 3 & 4 & 5 & 6 & 7 \\
\hline \hline The Labour Party & 1 & 2 & 3 & 4 & 5 & 6 & 7 \\
\hline
\end{tabular}

\begin{tabular}{|l|lllllll|}
\hline The Green Party & 1 & 2 & 3 & 4 & 5 & 6 & 7 \\
\hline The Mãori Party & 1 & 2 & 3 & 4 & 5 & 6 & 7 \\
\hline
\end{tabular}

Instructions: Please answer each of the following questions by circling a number on the scale below.

\section{Definitely NO}

1
2

$\underset{4}{\text { Unsure }}$

6

5

Definitely YES 7

1. Do you think people from your ethnic group are discriminated against in NZ?

2. Are you willing to change your daily routine in order to protect the environment?

3. Have you made changes to your daily routine in order to protect the environment?

4. Are you willing to make sacrifices to your standard of living (e.g., accept higher prices, drive less, conserve energy) in order to protect the environment?

5. Have you made sacrifices to your standard of living (e.g., accepted higher prices, driven less, conserved energy) in order to protect the environment?

6. Do you think most New Zealanders are willing to make sacrifices to their standard of living in order to protect the environment?

7. Of course, we all hope that there will not be another war, but if it were to come to that, would you be willing to fight for your country?

8. Do you think most New Zealanders respect the achievements of your ethnic group?

9. Do you think you personally are more at risk of a weight-based illness (e.g., heart illnesses, diabetes) than other New Zealanders, on average?

10.Do you think people from your ethnic group are more at risk of weight-based illnesses (e.g., heart illnesses, diabetes) than other New Zealanders, on average?

$\begin{array}{lllllll}1 & 2 & 3 & 4 & 5 & 6 & 7\end{array}$ $\begin{array}{lllllll}1 & 2 & 3 & 4 & 5 & 6 & 7\end{array}$

$\begin{array}{lllllll}1 & 2 & 3 & 4 & 5 & 6 & 7\end{array}$

$\begin{array}{lllllll}1 & 2 & 3 & 4 & 5 & 6 & 7\end{array}$

$\begin{array}{lllllll}1 & 2 & 3 & 4 & 5 & 6 & 7\end{array}$

$\begin{array}{lllllll}1 & 2 & 3 & 4 & 5 & 6 & 7\end{array}$

$\begin{array}{lllllll}1 & 2 & 3 & 4 & 5 & 6 & 7\end{array}$

$\begin{array}{lllllll}1 & 2 & 3 & 4 & 5 & 6 & 7\end{array}$

$\begin{array}{lllllll}1 & 2 & 3 & 4 & 5 & 6 & 7\end{array}$

Instructions. Please rate how strongly you oppose or support each of the following possible policies or issues.

Strongly

Oppose

Strongly

Support

1. Legalized abortion for women, regardless of the reason.

2. Policies promoting closer trade ties between India and New Zealand.

$\begin{array}{lllllll}1 & 2 & 3 & 4 & 5 & 6 & 7\end{array}$

3. Māori ownership of the seabed and foreshore.

4. Performance of the Haka at international sports events.

$\begin{array}{lllllll}1 & 2 & 3 & 4 & 5 & 6 & 7\end{array}$

5. Protest marches and public demonstrations supporting the rights of Māori.

$\begin{array}{lllllll}1 & 2 & 3 & 4 & 5 & 6 & 7\end{array}$

6. Incentives to increase women's participation in the paid workforce (paid for by government).

7. Policies promoting closer trade ties between China and New Zealand.

$\begin{array}{lllllll}1 & 2 & 3 & 4 & 5 & 6 & 7\end{array}$

8. A "flat" tax rate (everyone pays the same percentage of tax on their income).

9. Legalized abortion when the woman's life is endangered.

10. Reserving places for Māori students to study medicine.

$\begin{array}{lllllll}1 & 2 & 3 & 4 & 5 & 6 & 7\end{array}$

11. Waitangi Day as a national celebration of biculturalism.

12. The Civil Union Act.

$\begin{array}{lllllll}1 & 2 & 3 & 4 & 5 & 6 & 7\end{array}$

13. Including religious instruction in Christianity as part of the school curriculum.

14. Rates exemptions on Māori land.

15. Teaching Māori language in New Zealand primary schools.

16. Policies promoting more immigration from India to New Zealand.

$\begin{array}{lllllll}1 & 2 & 3 & 4 & 5 & 6 & 7\end{array}$

17. Introducing a programme to enhance sustainable business growth among businesses owned and operated by women.

18. Singing the national anthem in Māori and English.

$\begin{array}{lllllll}1 & 2 & 3 & 4 & 5 & 6 & 7\end{array}$

19. Policies promoting more immigration from China to New Zealand.

$\begin{array}{lllllll}1 & 2 & 3 & 4 & 5 & 6 & 7\end{array}$

$\begin{array}{lllllll}1 & 2 & 3 & 4 & 5 & 6 & 7\end{array}$

$\begin{array}{lllllll}1 & 2 & 3 & 4 & 5 & 6 & 7\end{array}$

$\begin{array}{lllllll}1 & 2 & 3 & 4 & 5 & 6 & 7\end{array}$

$\begin{array}{lllllll}1 & 2 & 3 & 4 & 5 & 6 & 7\end{array}$

$\begin{array}{lllllll}1 & 2 & 3 & 4 & 5 & 6 & 7\end{array}$

$\begin{array}{lllllll}1 & 2 & 3 & 4 & 5 & 6 & 7\end{array}$

$\begin{array}{lllllll}1 & 2 & 3 & 4 & 5 & 6 & 7\end{array}$

20. Crown (government) ownership of the seabed and foreshore.

$\begin{array}{lllllll}1 & 2 & 3 & 4 & 5 & 6 & 7\end{array}$

$\begin{array}{lllllll}1 & 2 & 3 & 4 & 5 & 6 & 7\end{array}$

$\begin{array}{lllllll}1 & 2 & 3 & 4 & 5 & 6 & 7\end{array}$

$\begin{array}{lllllll}1 & 2 & 3 & 4 & 5 & 6 & 7\end{array}$


In your day-to-day life, how often do PEOPLE IN NEW ZEALAND act toward you in the following ways?

\section{Have Never \\ Experienced This}

Sometimes

Experience This
1
2

1. Do things to threaten you.

2. Insist that they know what is best for you.

3. Make threatening gestures toward you.

4. Offer advice and opinions even when you don't want it.

5. Attack you, or make you fear that they might.

6. Try to help you with things you'd rather do for yourself.
45
Often

Experience This

7

In your day-to-day life, how often do PEOPLE FROM OTHER ETHNIC GROUPS act toward you in the following ways?

1. Do things to threaten you.

2. Insist that they know what is best for you.

3. Happily interact with you in formal situations but not social ones.

4. Make threatening gestures toward you.

5. Offer advice and opinions even when you don't want it.

6. Only socialise or interact with you when it suits their purposes.

7. Attack you, or make you fear that they might.

8. Try to help you with things you'd rather do for yourself.

9. Treat you with respect, but avoid socialising with you.

\begin{tabular}{|lllllll|}
\hline 1 & 2 & 3 & 4 & 5 & 6 & 7 \\
\hline 1 & 2 & 3 & 4 & 5 & 6 & 7 \\
\hline 1 & 2 & 3 & 4 & 5 & 6 & 7 \\
\hline 1 & 2 & 3 & 4 & 5 & 6 & 7 \\
\hline 1 & 2 & 3 & 4 & 5 & 6 & 7 \\
\hline 1 & 2 & 3 & 4 & 5 & 6 & 7 \\
\hline 1 & 2 & 3 & 4 & 5 & 6 & 7 \\
\hline 1 & 2 & 3 & 4 & 5 & 6 & 7 \\
\hline 1 & 2 & 3 & 4 & 5 & 6 & 7 \\
\hline
\end{tabular}

Please rate your feelings toward the following groups using the "feeling thermometer scale" for each group. This scale measures your feelings of WARMTH toward different groups.

Feel LEAST WARM

Toward This Group

1
Neutral
Feel MOST WARM Toward This Group 7

\begin{tabular}{|c|c|c|c|c|c|c|c|c|c|c|c|c|c|c|c|}
\hline NZ Europeans & 1 & 2 & 3 & 4 & 5 & 6 & 7 & Overweight people & 1 & 2 & 3 & 4 & 5 & 6 & 7 \\
\hline Māori & 1 & 2 & 3 & 4 & 5 & 6 & 7 & Immigrants in general & 1 & 2 & 3 & 4 & 5 & 6 & 7 \\
\hline Asians in general & 1 & 2 & 3 & 4 & 5 & 6 & 7 & Chinese & 1 & 2 & 3 & 4 & 5 & 6 & 7 \\
\hline Pacific Islanders & 1 & 2 & 3 & 4 & 5 & 6 & 7 & Indians & 1 & 2 & 3 & 4 & 5 & 6 & 7 \\
\hline
\end{tabular}

Now please rate your feelings of ANGER toward these same groups on the scale below.

Feel NO ANGER

Toward This Group 1
Neutral 4
Feel ANGER Toward This Group 7

\begin{tabular}{|c|c|c|c|c|c|c|c|c|c|c|c|c|c|c|c|}
\hline NZ Europeans & 1 & 2 & 3 & 4 & 5 & 6 & 7 & Overweight people & 1 & 2 & 3 & 4 & 5 & 6 & 7 \\
\hline Māori & 1 & 2 & 3 & 4 & 5 & 6 & 7 & Immigrants in general & 1 & 2 & 3 & 4 & 5 & 6 & 7 \\
\hline Asians in general & 1 & 2 & 3 & 4 & 5 & 6 & 7 & Chinese & 1 & 2 & 3 & 4 & 5 & 6 & 7 \\
\hline Pacific Islanders & 1 & 2 & 3 & 4 & 5 & $\epsilon$ & 7 & Indians & 1 & 2 & 3 & 4 & 5 & 6 & 7 \\
\hline
\end{tabular}

1. How frequently do you have POSITIVE/GOOD contact with NZ Europeans?

$\begin{array}{lllllll}1 & 2 & 3 & 4 & 5 & 6 & 7\end{array}$

2. How frequently do you have NEGATIVE/BAD contact with NZ Europeans?

$\begin{array}{lllllll}1 & 2 & 3 & 4 & 5 & 6 & 7\end{array}$

3. How frequently do you have POSITIVE/GOOD contact with Māori ?

$\begin{array}{lllllll}1 & 2 & 3 & 4 & 5 & 6 & 7\end{array}$

4. How frequently do you have NEGATIVE/BAD contact with Māori ?

$\begin{array}{lllllll}1 & 2 & 3 & 4 & 5 & 6 & 7\end{array}$

5. How frequently do you have POSITIVE/GOOD contact with Pacific Islanders?

6. How frequently do you have NEGATIVE/BAD contact with Pacific Islanders?

$\begin{array}{lllllll}1 & 2 & 3 & 4 & 5 & 6 & 7\end{array}$

7. How frequently do you have POSITIVE/GOOD contact with Asians?

$\begin{array}{lllllll}1 & 2 & 3 & 4 & 5 & 6 & 7\end{array}$


1. Which ethnic group(s) do you belong to?

2. Are you male or female?

3. What is your date of birth?

4. Were you personally affected by the Christchurch earthquakes?

5. How long have you lived at your current address?

6a. Do you have an emergency survival kit in your home?
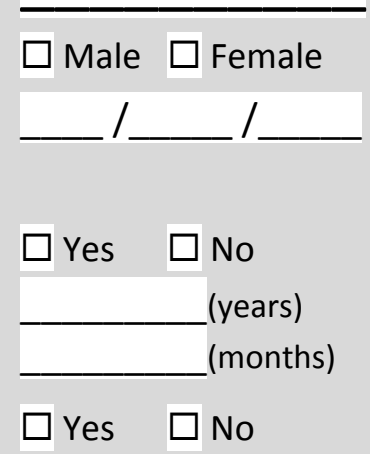

6b. If yes to $6 a$, which of the following items does it contain? $\square$ First aid kit $\square$ Transistor radio with batteries

(tick those that apply) $\square$ Wind \& waterproof clothes

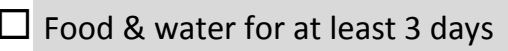

$\square$ Torch with spare batteries

7a. What is your $\square$ single relationship $\square$ Dating status? $\square$ Living together/De facto If you are in a relationship $\Omega$

7b. How long have you been with your partner?

$\square$ Married $\square$ other (if other please specify) (years) (months)

7c. How satisfied are you with your relationship with your partner? (please circle a number on the scale below) $\begin{array}{llllllllll}\text { Not satisfied } & 1 & 2 & 3 & 4 & 5 & 6 & 7 & \text { Very satisfied }\end{array}$

8. Please rate how politically liberal versus conservative you see yourself as being:

Extremely liberal $1 \begin{array}{llllllll}1 & 2 & 3 & 4 & 5 & 6 & 7 & \text { Extremely conservative }\end{array}$

9a. What is your current employment situation?

$\square$ Employed full-time

$\square$ Employed part-time

$\square$ Self-employed

$\square$ Own your own business

$\square$ Studying full-time

$\square$ Unemployed, but want work

If you are currently $\quad \square$ Unemployed, don't want work employed $\sqrt{ }$

$\square$ Other

9b. How long have you worked in your current job for? (months)

9c. How satisfied are you with your current job? $\begin{array}{lllllllll}\text { Not satisfied } & 1 & 2 & 3 & 4 & 5 & 6 & 7 & \text { Very satisfied }\end{array}$

9d. How secure do you feel in your current job? $\begin{array}{llllllllll}\text { Not secure } & 1 & 2 & 3 & 4 & 5 & 6 & 7 & \text { Very secure }\end{array}$

10. How much money have you donated to charity in the last year?

11. How many other adults live in your household with you regularly?

12. Do you believe in a God? $\overline{\square \text { Yes } \square \text { No }}$

13. Do you believe in some form of spirit or life force? $\square$ Yes $\square$ No

14. Please rate how politically left-wing versus right-wing you see yourself as being:

Extremely left-wing $1122 \quad 3 \quad 4 \quad 5 \quad 6 \quad 7$ Extremely right-wing 15. Do you regularly watch the news? $\square$ Yes $\square$ No 16a. How many children have you given birth to, fathered, or adopted? (if none, please enter ' 0 ' and go to q. 17)

16b. How many of your children live with you most of the time?

17. Have you or the principal earner in your household been out-of-work at any time in the last year?

18. Please estimate your total household income (before tax) for the year 2011

19a. Are you pregnant?

19b. If yes, what trimester are you in?

20a. What is your height?

$20 \mathrm{~b}$. What is your weight?

21a. Do you have a Facebook profile?

21b. If yes, how many hours in the last week have you spent using Facebook?

21c. How important a part of your daily routine is using Facebook?

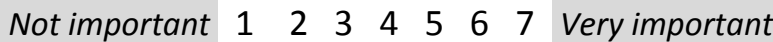

22a. Do you identify with a religion and/or spiritual group?

Yes $\square$ No

$22 b$. If yes to $22 a$, then what religion/spiritual group?

22c. If yes to $22 \mathrm{a}$, then how many times did you attend a church or place of worship in the last month?

22d. If yes to $22 \mathrm{a}$, how important is your religion to how you see yourself?

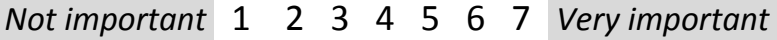

23. Roughly how many hours have you spent with FRIENDS/FAMILY and OTHERS (e.g., workmates, strangers) from each group in the last week?

(a) Māori

(b) NZ Europeans

(c) Asians

(d) Pacific Islanders

24. Have you been Friends/family Others diagnosed by a doctor with any of the following

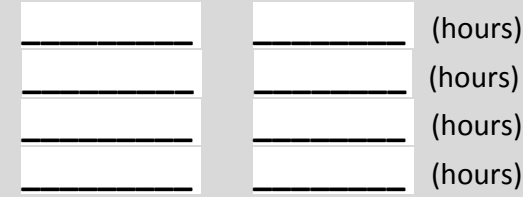
health conditions? $\square$ Diabetes $\square$ Other

25a. Do you plan to vote in the next $\square$ Yes New Zealand election in 2011? $\square$ No $\square$ Unsure If yes, to which party do you plan to give your ...

25b. party vote?

25c. electorate vote?

26. In the last year, have you personally...

(a) been forced to buy cheaper food so that you could pay for other things you needed? $\quad \square$ Yes $\square$ No

(b) put up with feeling cold to save on heating costs? Yes $\square$ No

(c) been the victim of a crime? 


\section{The New Zealand Attitudes and Values Study}

\section{Follow-up Questionnaire for 2012/2013}

This form will be kept for a period of fifteen years.

Researcher:

Dr. Chris Sibley, Department of Psychology, University of Auckland.

Phone: 09-373-7599, extn 88353. E-mail: c.sibley@auckland.ac.nz

\section{Consent form and contact details}

This form is to gather your consent to participate in this phase of the New Zealand Attitudes and Values Study. Only Dr. Sibley and his research associates will have access to your responses. Your personal information will be kept separate from your responses at all times. Your questionnaire will be identified by an anonymous code. An encrypted electronic copy of all responses will be stored indefinitely for research purposes in a secure room in the Department of Psychology.

I have read and understood a description of this research project. On this basis, I agree to take part. I understand that my data will remain confidential at all times. I understand that only Dr. Sibley will have access to my contact details. I consent to publication of the results of the project with the understanding that my anonymity will be preserved. I understand that I am free to withdraw from the research at any time up until the point at which I complete and return this questionnaire. I understand that my contact details will never be shared with anyone. I understand that Dr. Sibley will use these details to contact and invite me to complete follow-up questionnaires, possibly for the next sixteen years. Finally, I understand that my contact details will be used to contact me if I win one of the grocery voucher prize draws for $\mathbf{\$ 5 0 0 ,} \mathbf{\$ 3 0 0}$ or $\mathbf{\$ 2 0 0}$ for participating in this study. Prizes will be drawn in December 2013.

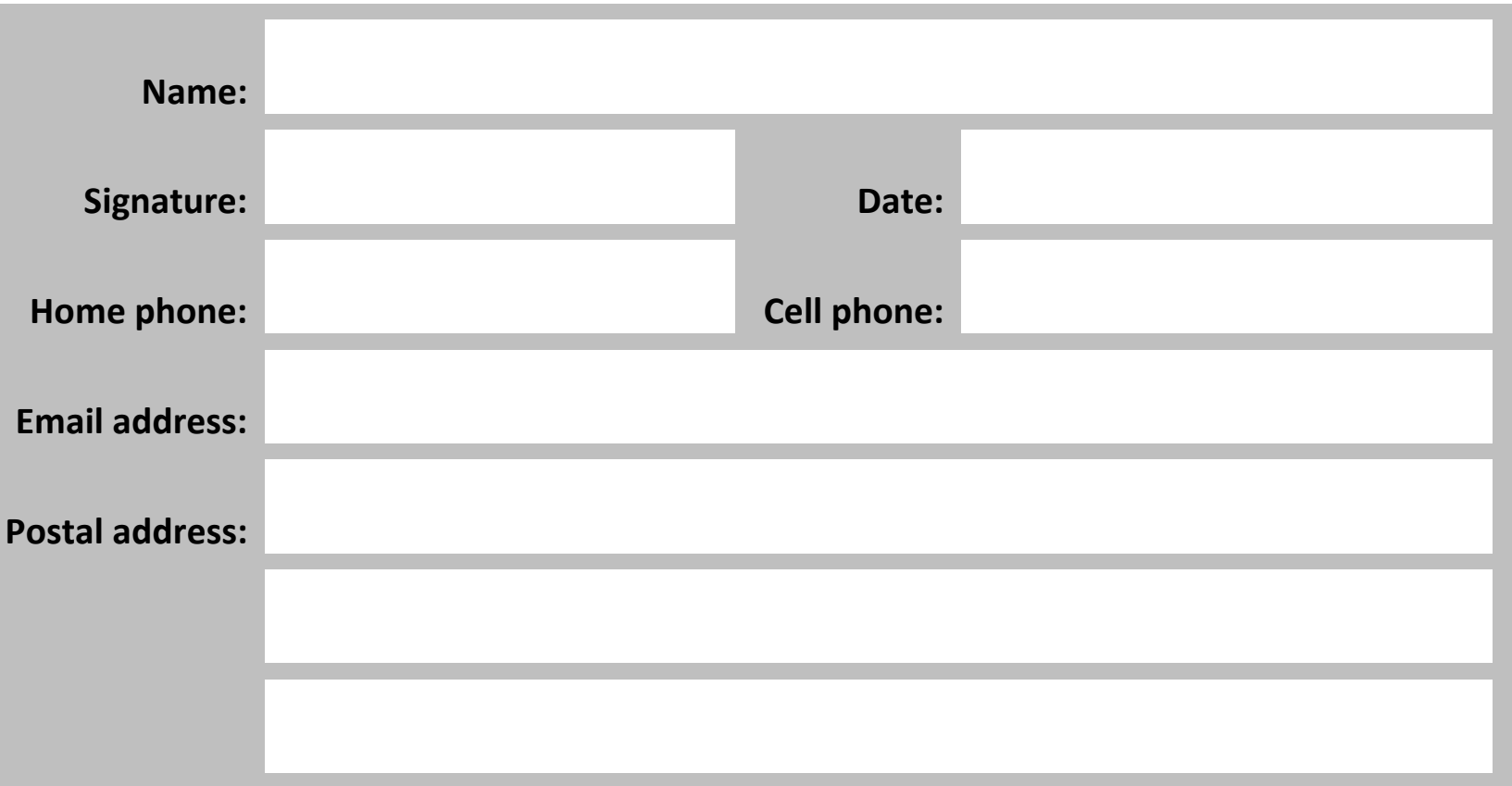

Would you like to receive a summary of key findings from the study?

Would you be willing to complete a short follow-up email survey about religion and your religious attitudes and beliefs? 
This page left intentionally blank 
1. Am the life of the party.

2. Sympathise with others' feelings.

$\begin{array}{lllllll}1 & 2 & 3 & 4 & 5 & 6 & 7\end{array}$

3. Get chores done right away.

$\begin{array}{lllllll}1 & 2 & 3 & 4 & 5 & 6 & 7\end{array}$

4. Have frequent mood swings.

$\begin{array}{lllllll}1 & 2 & 3 & 4 & 5 & 6 & 7\end{array}$

5. Have a vivid imagination.

$\begin{array}{lllllll}1 & 2 & 3 & 4 & 5 & 6 & 7\end{array}$

6. Don't talk a lot.

7. Am not interested in other people's problems.

$\begin{array}{lllllll}1 & 2 & 3 & 4 & 5 & 6 & 7\end{array}$

8. Have difficulty understanding abstract ideas.

$\begin{array}{lllllll}1 & 2 & 3 & 4 & 5 & 6 & 7\end{array}$

9. Like order.

10. Make a mess of things.

$\begin{array}{lllllll}1 & 2 & 3 & 4 & 5 & 6 & 7\end{array}$

11. Do not have a good imagination.

12. Feel others' emotions.

$\begin{array}{lllllll}1 & 2 & 3 & 4 & 5 & 6 & 7\end{array}$

13. Am relaxed most of the time.

14. Get upset easily.

15. Seldom feel blue.

$\begin{array}{lllllll}1 & 2 & 3 & 4 & 5 & 6 & 7\end{array}$

16. Keep in the background.

$\begin{array}{lllllll}1 & 2 & 3 & 4 & 5 & 6 & 7\end{array}$

17. Am not really interested in others.

$\begin{array}{lllllll}1 & 2 & 3 & 4 & 5 & 6 & 7\end{array}$

18. Am not interested in abstract ideas.

19. Often forget to put things back in their proper place.

$\begin{array}{lllllll}1 & 2 & 3 & 4 & 5 & 6 & 7\end{array}$

20. Talk to a lot of different people at parties.

21. Feel entitled to more of everything.

$\begin{array}{lllllll}1 & 2 & 3 & 4 & 5 & 6 & 7\end{array}$

22. On the whole am satisfied with myself.

$\begin{array}{lllllll}1 & 2 & 3 & 4 & 5 & 6 & 7\end{array}$

23. Know that people in my life accept and value me.

$\begin{array}{lllllll}1 & 2 & 3 & 4 & 5 & 6 & 7\end{array}$

24. Would like to be seen driving around in a very expensive car.

$\begin{array}{lllllll}1 & 2 & 3 & 4 & 5 & 6 & 7\end{array}$

25. Deserve more things in life.

26. Take a positive attitude toward myself.

$\begin{array}{lllllll}1 & 2 & 3 & 4 & 5 & 6 & 7\end{array}$

27. Feel like an outsider.

$\begin{array}{lllllll}1 & 2 & 3 & 4 & 5 & 6 & 7\end{array}$

28. Would get a lot of pleasure from owning expensive luxury goods.

29. Am satisfied with the appearance, size and shape of my body.

30. Am inclined to feel that I am a failure.

31. Feel that I am often discriminated against because of my ethnicity.

32. Know that people around me share my attitudes and beliefs.

33. Being a woman/man is an important part of how I see myself.

$\begin{array}{lllllll}1 & 2 & 3 & 4 & 5 & 6 & 7 \\ 1 & 2 & 3 & 4 & 5 & 6 & 7 \\ 1 & 2 & 3 & 4 & 5 & 6 & 7 \\ 1 & 2 & 3 & 4 & 5 & 6 & 7 \\ 1 & 2 & 3 & 4 & 5 & 6 & 7 \\ 1 & 2 & 3 & 4 & 5 & 6 & 7 \\ 1 & 2 & 3 & 4 & 5 & 6 & 7 \\ 1 & 2 & 3 & 4 & 5 & 6 & 7 \\ 1 & 2 & 3 & 4 & 5 & 6 & 7 \\ 1 & 2 & 3 & 4 & 5 & 6 & 7 \\ 1 & 2 & 3 & 4 & 5 & 6 & 7 \\ 1 & 2 & 3 & 4 & 5 & 6 & 7 \\ 1 & 2 & 3 & 4 & 5 & 6 & 7 \\ 1 & 2 & 3 & 4 & 5 & 6 & 7 \\ 1 & 2 & 3 & 4 & 5 & 6 & 7\end{array}$

During the last 30 days, how often did....

(Please use the scale below to circle a number for each question)

\begin{tabular}{r|c}
$\begin{array}{r}\text { None of } \\
\text { The Time }\end{array}$ & $\begin{array}{c}\text { A Little of } \\
\text { The Time } \\
0\end{array}$ \\
1
\end{tabular}

Some Of
The Time
2

Most Of
The Time
3

1. ... you feel hopeless?

2. ... you feel so depressed that nothing could cheer you up?

3. ... you feel restless or fidgety?

4. ... you feel that everything was an effort?

5. ... you feel worthless?

6. ... you feel nervous?

7. ... you have negative thoughts that repeated over and over?

8. ... you worry that a big earthquake might hit your region?

\begin{tabular}{|lllll|}
\hline 0 & 1 & 2 & 3 & 4 \\
\hline 0 & 1 & 2 & 3 & 4 \\
\hline 0 & 1 & 2 & 3 & 4 \\
\hline 0 & 1 & 2 & 3 & 4 \\
\hline 0 & 1 & 2 & 3 & 4 \\
\hline 0 & 1 & 2 & 3 & 4 \\
\hline 0 & 1 & 2 & 3 & 4 \\
\hline 0 & 1 & 2 & 3 & 4 \\
\hline
\end{tabular}


Instructions: Please circle the number that best represents how important each of the following values is for you as a guiding principle in your life. Use the scale below to rate these items.

Opposed To
My Values $-1$
Not Important

0
Very

Important 3
Important

6
Of Supreme

Importance

7

1. PROTECTING THE ENVIRONMENT (preserving nature)

2. A VARIED LIFE (filled with challenge, novelty and change)

3. HONOURING OF PARENTS AND ELDERS (showing respect)

4. AUTHORITY (the right to lead or command)

5. EQUALITY (equal opportunity for all)

6. A WORLD AT PEACE (free of war and conflict)

7. AN EXCITING LIFE (stimulating experiences)

8. FAMILY SECURITY (safety for loved ones)

9. INFLUENCE (having an impact on people and events)

10. SOCIAL JUSTICE (correcting injustice, care for the weak)

11. CURIOSITY (interest in everything, exploring)

12. SELF-DISCIPLINE (self-restraint, resistance to temptation)

13. WEALTH (material possessions, money)

$4 \quad 5 \quad 6 \quad 0$

\begin{tabular}{|rrrrrrrrr|}
\hline-1 & 0 & 1 & 2 & 3 & 4 & 5 & 6 & 7 \\
\hline-1 & 0 & 1 & 2 & 3 & 4 & 5 & 6 & 7 \\
\hline-1 & 0 & 1 & 2 & 3 & 4 & 5 & 6 & 7 \\
\hline-1 & 0 & 1 & 2 & 3 & 4 & 5 & 6 & 7 \\
\hline-1 & 0 & 1 & 2 & 3 & 4 & 5 & 6 & 7 \\
\hline-1 & 0 & 1 & 2 & 3 & 4 & 5 & 6 & 7 \\
\hline-1 & 0 & 1 & 2 & 3 & 4 & 5 & 6 & 7 \\
\hline-1 & 0 & 1 & 2 & 3 & 4 & 5 & 6 & 7 \\
\hline-1 & 0 & 1 & 2 & 3 & 4 & 5 & 6 & 7 \\
\hline-1 & 0 & 1 & 2 & 3 & 4 & 5 & 6 & 7 \\
\hline-1 & 0 & 1 & 2 & 3 & 4 & 5 & 6 & 7 \\
\hline-1 & 0 & 1 & 2 & 3 & 4 & 5 & 6 & 7 \\
\hline-1 & 0 & 1 & 2 & 3 & 4 & 5 & 6 & 7 \\
\hline
\end{tabular}

Instructions: The statements below reflect different opinions and points of view. Please indicate how strongly you disagree or agree with each statement. Remember, the best answer is your own opinion.

\title{
Strongly
}

Disagree

Strongly

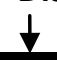

1. It is OK if some groups have more of a chance in life than others.

$\begin{array}{lllllll}1 & 2 & 3 & 4 & 5 & 6 & 7\end{array}$

2. It is always better to trust the judgment of the proper authorities in government and religion than to listen to the noisy rabble-rousers in our society who are trying to create doubt in people's minds.

3. I wish people in this society would stop obsessing so much about race.

4. Inferior groups should stay in their place.

$\begin{array}{lllllll}1 & 2 & 3 & 4 & 5 & 6 & 7\end{array}$

5. It would be best for everyone if the proper authorities censored magazines so that people could not get their hands on trashy and disgusting material.

6. Everyone in New Zealand has a fair shot at wealth and happiness, regardless of ethnicity or race.

7. To get ahead in life, it is sometimes okay to step on other groups.

8. Our country will be destroyed some day if we do not smash the perversions eating away at our moral fibre and traditional beliefs.

9. To a large extent, a person's race biologically determines his or her abilities.

10. We should have increased social equality.

11. People should pay less attention to The Bible and other old traditional forms of religious guidance, and instead develop their own personal standards of what is moral and immoral.

12. It would be good if groups could be equal.

13. Atheists and others who have rebelled against established religions are no doubt every bit as good and virtuous as those who attend church regularly.

14. We should do what we can to equalise conditions for different groups.

15. I often think about the fact that I am a member of my ethnic group.

16. Some of the best people in our country are those who are challenging our government, criticizing religion, and ignoring the "normal way" things are supposed to be done.

17. People from my ethnic group generally earn less than other groups in NZ.

18. I feel anxious about interacting with NZ European people.

$\begin{array}{lllllll}1 & 2 & 3 & 4 & 5 & 6 & 7 \\ 1 & 2 & 3 & 4 & 5 & 6 & 7 \\ 1 & 2 & 3 & 4 & 5 & 6 & 7\end{array}$

$\begin{array}{lllllll}1 & 2 & 3 & 4 & 5 & 6 & 7\end{array}$

\begin{tabular}{lllllll}
1 & 2 & 3 & 4 & 5 & 6 & 7 \\
\hline
\end{tabular}

$\begin{array}{lllllll}1 & 2 & 3 & 4 & 5 & 6 & 7\end{array}$

$\begin{array}{lllllll}1 & 2 & 3 & 4 & 5 & 6 & 7 \\ 1 & 2 & 3 & 4 & 5 & 6 & 7\end{array}$

$\begin{array}{lllllll}1 & 2 & 3 & 4 & 5 & 6 & 7\end{array}$

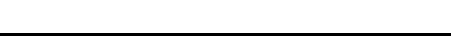

\begin{tabular}{lllllll}
1 & 2 & 3 & 4 & 5 & 6 & 7 \\
1 & 2 & 3 & 4 & 5 & 6 & 7 \\
1 & 2 & 3 & 4 & 5 & 6 & 7 \\
1 & 2 & 3 & 4 & 5 & 6 & 7 \\
\hline
\end{tabular}

$\begin{array}{lllllll}1 & 2 & 3 & 4 & 5 & 6 & 7\end{array}$

\begin{tabular}{lllllll}
1 & 2 & 3 & 4 & 5 & 6 & 7 \\
1 & 2 & 3 & 4 & 5 & 6 & 7 \\
\hline
\end{tabular}


Instructions: Please rate your level of satisfaction with the following aspects of your life and New Zealand.

Completely Dissatisfied

Somewhat Satisfied

Completely Satisfied

0

1. Your standard of living.

2. The economic situation in New Zealand.

3. The quality of New Zealand's natural environment.

4. Your health.

5. The social conditions in New Zealand.

6. The performance of the current New Zealand government.

7. Your future security.

8. Business in New Zealand.

9. Your personal relationships.

10. John Key's leadership as The Prime Minister of New Zealand.

$\begin{array}{lll}7 & 8 & 9\end{array}$
10

nstructions: Please indicate how strongly you disagree or agree with each statement.

\begin{tabular}{|c|c|c|c|c|c|c|c|}
\hline \multirow[b]{2}{*}{ 1. } & \multicolumn{3}{|c|}{$\begin{array}{l}\text { Strongly } \\
\text { Disagree } \\
\downarrow\end{array}$} & \multicolumn{4}{|c|}{$\begin{array}{r}\text { Strongly } \\
\text { Agree } \\
\downarrow\end{array}$} \\
\hline & 1 & 2 & 3 & 4 & 5 & 6 & 7 \\
\hline 2. I think that Māori culture helps to define New Zealand in positive ways. & 1 & 2 & 3 & 4 & 5 & 6 & 7 \\
\hline 3. I think liking rugby is an important part of being a 'true' New Zealander. & 1 & 2 & 3 & 4 & 5 & 6 & 7 \\
\hline 4. Everyone has a fair shot at wealth and happiness in New Zealand. & 1 & 2 & 3 & 4 & 5 & 6 & 7 \\
\hline $\begin{array}{l}\text { 5. Despite what one hears about 'crime in the street,' there probably isn't any } \\
\text { more now than there ever has been. }\end{array}$ & 1 & 2 & 3 & 4 & 5 & 6 & 7 \\
\hline $\begin{array}{l}\text { 6. In my opinion, more good jobs for Asians mean fewer good jobs for members } \\
\text { of other groups in New Zealand. }\end{array}$ & 1 & 2 & 3 & 4 & 5 & 6 & 7 \\
\hline $\begin{array}{l}\text { 7. New Zealand would be a better place to live if we forgot about trying to } \\
\text { promote Māori culture to everyone. }\end{array}$ & 1 & 2 & 3 & 4 & 5 & 6 & 7 \\
\hline 8. Women exaggerate problems they have at work. & 1 & 2 & 3 & 4 & 5 & 6 & 7 \\
\hline 9. In general, I find New Zealand society to be fair. & 1 & 2 & 3 & 4 & 5 & 6 & 7 \\
\hline 10. It's a dog-eat-dog world where you have to be ruthless at times. & 1 & 2 & 3 & 4 & 5 & 6 & 7 \\
\hline 11. Māori people would be likely to reject me on the basis of my race. & 1 & 2 & 3 & 4 & 5 & 6 & 7 \\
\hline 12. Bad smells, messes, dead animals and rotten food absolutely disgust me. & 1 & 2 & 3 & 4 & 5 & 6 & 7 \\
\hline 13. Women, compared to men, tend to have greater moral sensibility. & 1 & 2 & 3 & 4 & 5 & 6 & 7 \\
\hline $\begin{array}{l}\text { 14. The fact that I am a member of my ethnic group is an important part of my } \\
\text { identity. }\end{array}$ & 1 & 2 & 3 & 4 & 5 & 6 & 7 \\
\hline $\begin{array}{l}\text { 15. By taking personal action I believe I can make a positive difference to } \\
\text { environmental problems. }\end{array}$ & 1 & 2 & 3 & 4 & 5 & 6 & 7 \\
\hline 16. In general, the New Zealand political system operates as it should. & 1 & 2 & 3 & 4 & 5 & 6 & 7 \\
\hline 17. There is no one I can turn to for guidance in times of stress. & 1 & 2 & 3 & 4 & 5 & 6 & 7 \\
\hline 18. I feel I can make a difference to the state of the environment. & 1 & 2 & 3 & 4 & 5 & 6 & 7 \\
\hline $\begin{array}{l}\text { 19. Life is not governed by the 'survival of the fittest.' We should let compassion } \\
\text { and moral laws be our guide. }\end{array}$ & 1 & 2 & 3 & 4 & 5 & 6 & 7 \\
\hline 20. If they knew me, most NZers would respect what I have accomplished in life. & 1 & 2 & 3 & 4 & 5 & 6 & 7 \\
\hline 21. I feel anxious about interacting with Māori people. & 1 & 2 & 3 & 4 & 5 & 6 & 7 \\
\hline 22. Māori have too much political power and influence in decisions affecting NZ. & 1 & 2 & 3 & 4 & 5 & 6 & 7 \\
\hline 23. Pacific Island people would be likely to reject me on the basis of my race. & 1 & 2 & 3 & 4 & 5 & 6 & 7 \\
\hline 24. Men and women both have a fair shot at wealth and happiness in NZ. & 1 & 2 & 3 & 4 & 5 & 6 & 7 \\
\hline 25. I know there are people I can turn to when I need help. & 1 & 2 & 3 & 4 & 5 & 6 & 7 \\
\hline $\begin{array}{l}\text { 26. I reckon Māori culture should stay where it belongs-with Māori. It doesn't } \\
\text { concern other NZers. }\end{array}$ & 1 & 2 & 3 & 4 & 5 & 6 & 7 \\
\hline 27. I'm frustrated by what I earn relative to other people in NZ. & 1 & 2 & 3 & 4 & 5 & 6 & 7 \\
\hline
\end{tabular}


1. People who become preoccupied by race are forgetting that we're all just human.

2. I feel anxious about interacting with Pacific Island people.

3. The New Zealand government should be involved in regulating carbon emissions.

4. I feel a great pride in the land that is our New Zealand.

5. I am satisfied with my life.

6. Women are too easily offended.

7. In my opinion, more good jobs for Māori mean fewer good jobs for members of other groups in New Zealand.

$\begin{array}{lllllll}1 & 2 & 3 & 4 & 5 & 6 & 7\end{array}$

8. There are many dangerous people in our society who will attack someone out of pure meanness, for no reason at all.

9. We should all move on as one nation and forget about past differences and conflicts between ethnic groups.

10. Asian people would be likely to reject me on the basis of my race.

11. Putting racial labels on people obscures the fact that everyone is a unique individual.

$\begin{array}{lllllll}1 & 2 & 3 & 4 & 5 & 6 & 7\end{array}$

2. I feel anxious about interacting with Asian people.

\begin{tabular}{lllllll}
1 & 2 & 3 & 4 & 5 & 6 & 7 \\
\hline
\end{tabular}

$\begin{array}{lllllll}1 & 2 & 3 & 4 & 5 & 6 & 7\end{array}$

\begin{tabular}{lllllll}
1 & 2 & 3 & 4 & 5 & 6 & 7 \\
\hline
\end{tabular}

$\begin{array}{lllllll}1 & 2 & 3 & 4 & 5 & 6 & 7\end{array}$

13. NZ European people would be likely to reject me on the basis of my race.

14. Climate change is real.

15. Climate change is caused by humans.

$\begin{array}{lllllll}1 & 2 & 3 & 4 & 5 & 6 & 7\end{array}$

16. I generally earn less than other people in NZ.

17. In general, relations between different ethnic groups in New Zealand are fair.

18. Many women have a quality of purity that few men possess.

19. We should not have to pay for the mistakes of our ancestors.

20. Women seek to gain power by getting control over men.

21. In my opinion, more good jobs for NZ Europeans mean fewer good jobs for members of other groups in New Zealand.

$\begin{array}{lllllll}1 & 2 & 3 & 4 & 5 & 6 & 7\end{array}$

\begin{tabular}{lllllll}
1 & 2 & 3 & 4 & 5 & 6 & 7 \\
\hline
\end{tabular}

$\begin{array}{lllllll}1 & 2 & 3 & 4 & 5 & 6 & 7\end{array}$

$\begin{array}{lllllll}1 & 2 & 3 & 4 & 5 & 6 & 7\end{array}$

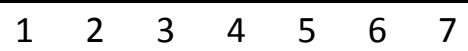

$\begin{array}{lllllll}1 & 2 & 3 & 4 & 5 & 6 & 7\end{array}$

\begin{tabular}{lllllll}
1 & 2 & 3 & 4 & 5 & 6 & 7 \\
\hline
\end{tabular}

$\begin{array}{lllllll}1 & 2 & 3 & 4 & 5 & 6 & 7\end{array}$

$\begin{array}{lllllll}1 & 2 & 3 & 4 & 5 & 6 & 7\end{array}$

$\begin{array}{lllllll}1 & 2 & 3 & 4 & 5 & 6 & 7\end{array}$

\begin{tabular}{lllllll}
1 & 2 & 3 & 4 & 5 & 6 & 7 \\
\hline
\end{tabular}

\begin{tabular}{lllllll}
1 & 2 & 3 & 4 & 5 & 6 & 7 \\
\hline
\end{tabular}

$\begin{array}{lllllll}1 & 2 & 3 & 4 & 5 & 6 & 7\end{array}$

22. People from other races would be likely to reject me on the basis of my race.

23. Once a woman gets a man to commit to her she usually tries to put him on a tight leash.

\begin{tabular}{lllllll}
1 & 2 & 3 & 4 & 5 & 6 & 7 \\
\hline
\end{tabular}

$\begin{array}{lllllll}1 & 2 & 3 & 4 & 5 & 6 & 7\end{array}$

24. Women, as compared to men, tend to have a more refined sense of culture and good taste.

25. I feel anxious about interacting with people from other races.

26. Most of New Zealand's policies serve the greater good.

27. People who weren't around in previous centuries should not feel accountable for the actions of their ancestors.

28. In my opinion, more good jobs for Pacific Islanders mean fewer good jobs for members of other groups in New Zealand.

$\begin{array}{lllllll}1 & 2 & 3 & 4 & 5 & 6 & 7\end{array}$

29. In general, relations between men and women in New Zealand are fair.

$\begin{array}{lllllll}1 & 2 & 3 & 4 & 5 & 6 & 7\end{array}$

$\begin{array}{lllllll}1 & 2 & 3 & 4 & 5 & 6 & 7\end{array}$

$\begin{array}{lllllll}1 & 2 & 3 & 4 & 5 & 6 & 7\end{array}$

$\begin{array}{lllllll}1 & 2 & 3 & 4 & 5 & 6 & 7\end{array}$

30. In most ways my life is close to ideal.

31. Women should be cherished and protected by men.

32. Generally, the more influence NZ has on other nations, the better off they are.

33. When women lose to men in a fair competition, they typically complain about being discriminated against.

$\begin{array}{lllllll}1 & 2 & 3 & 4 & 5 & 6 & 7\end{array}$

\begin{tabular}{lllllll}
1 & 2 & 3 & 4 & 5 & 6 & 7 \\
\hline
\end{tabular}

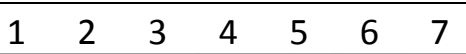

$\begin{array}{lllllll}1 & 2 & 3 & 4 & 5 & 6 & 7\end{array}$

$\begin{array}{lllllll}1 & 2 & 3 & 4 & 5 & 6 & 7\end{array}$

$\begin{array}{lllllll}1 & 2 & 3 & 4 & 5 & 6 & 7\end{array}$

34. Although at times I may not agree with the government, my commitment to New Zealand always remains strong.

35. Every man ought to have a woman whom he adores.

36. Being a member of my ethnic group is an important part of how I see myself.

37. I'm frustrated by what my ethnic group earns relative to other groups in NZ.

38. Foreign nations have done some very fine things but they are still not as good as New Zealand.

$\begin{array}{lllllll}1 & 2 & 3 & 4 & 5 & 6 & 7\end{array}$

$\begin{array}{lllllll}1 & 2 & 3 & 4 & 5 & 6 & 7\end{array}$

$\begin{array}{lllllll}1 & 2 & 3 & 4 & 5 & 6 & 7\end{array}$ 
Instructions: Please answer each of the following questions by circling a number on the scale below.

Definitely NO

1
2
Unsure

4
5
Definitely YES 7

1. Do you think people from your ethnic group are discriminated against in NZ?

2. Are you willing to change your daily routine in order to protect the environment?

3. Have you made changes to your daily routine in order to protect the environment?

4. Are you willing to make sacrifices to your standard of living (e.g., accept higher prices, drive less, conserve energy) in order to protect the environment?

$\begin{array}{lllllll}1 & 2 & 3 & 4 & 5 & 6 & 7\end{array}$

$\begin{array}{lllllll}1 & 2 & 3 & 4 & 5 & 6 & 7\end{array}$

$\begin{array}{lllllll}1 & 2 & 3 & 4 & 5 & 6 & 7\end{array}$

$\begin{array}{lllllll}1 & 2 & 3 & 4 & 5 & 6 & 7\end{array}$

5. Have you made sacrifices to your standard of living (e.g., accepted higher prices, driven less, conserved energy) in order to protect the environment?

6. Do you think most New Zealanders are willing to make sacrifices to their standard of living in order to protect the environment?

7. Of course, we all hope that there will not be another war, but if it were to come to that, would you be willing to fight for your country?

8. Do you think most New Zealanders respect the achievements of your ethnic group?

9. Should a smack as part of good parental correction be a criminal offence in NZ?

10. Do you think people from your ethnic group are more at risk of weight-based illnesses (e.g., heart illnesses, diabetes) than other New Zealanders, on average?

11. Do you think you personally are more at risk of a weight-based illness (e.g., heart illnesses, diabetes) than other New Zealanders, on average?

$\begin{array}{lllllll}1 & 2 & 3 & 4 & 5 & 6 & 7\end{array}$

$\begin{array}{lllllll}1 & 2 & 3 & 4 & 5 & 6 & 7\end{array}$

$\begin{array}{lllllll}1 & 2 & 3 & 4 & 5 & 6 & 7\end{array}$

$\begin{array}{lllllll}1 & 2 & 3 & 4 & 5 & 6 & 7\end{array}$

$\begin{array}{lllllll}1 & 2 & 3 & 4 & 5 & 6 & 7\end{array}$

$\begin{array}{lllllll}1 & 2 & 3 & 4 & 5 & 6 & 7\end{array}$

$\begin{array}{lllllll}1 & 2 & 3 & 4 & 5 & 6 & 7\end{array}$

Instructions. Please rate how strongly you oppose or support each of the following possible policies or issues. Oppose

1. Legalized abortion for women, regardless of the reason.

$\begin{array}{lllllll}1 & 2 & 3 & 4 & 5 & 6 & 7\end{array}$

2. Policies promoting closer trade ties between India and New Zealand.

3. Māori ownership of the seabed and foreshore.

$\begin{array}{lllllll}1 & 2 & 3 & 4 & 5 & 6 & 7\end{array}$

4. Performance of the Haka at international sports events.

5. Protest marches and public demonstrations supporting the rights of Māori.

$\begin{array}{lllllll}1 & 2 & 3 & 4 & 5 & 6 & 7\end{array}$

6. Incentives to increase women's participation in the paid workforce (paid for by government).

7. Policies promoting closer trade ties between China and New Zealand.

8. Government subsidy of public transport.

$\begin{array}{lllllll}1 & 2 & 3 & 4 & 5 & 6 & 7\end{array}$

9. The current anti-smacking bill. (i.e., it being illegal to smack children).

10. Increased government spending on new motorways.

$\begin{array}{lllllll}1 & 2 & 3 & 4 & 5 & 6 & 7\end{array}$

11. Government initiatives to inform and promote healthy lifestyle choices.

$\begin{array}{lllllll}1 & 2 & 3 & 4 & 5 & 6 & 7\end{array}$

12. A "flat" tax rate (everyone pays the same percentage of tax on their income).

13. Legalized abortion when the woman's life is endangered.

14. Reserving places for Māori students to study medicine.

15. Waitangi Day as a national celebration of biculturalism.

16. The Civil Union Act.

17. Including religious instruction in Christianity as part of the school curriculum.

18. Rates exemptions on Māori land.

19. Teaching Māori language in New Zealand primary schools.

20. Policies promoting more immigration from India to New Zealand.

21. Introducing a programme to enhance sustainable business growth among

businesses owned and operated by women.

$\begin{array}{lllllll}1 & 2 & 3 & 4 & 5 & 6 & 7 \\ 1 & 2 & 3 & 4 & 5 & 6 & 7\end{array}$

$\begin{array}{lllllll}1 & 2 & 3 & 4 & 5 & 6 & 7 \\ 1 & 2 & 3 & 4 & 5 & 6 & 7\end{array}$

$\begin{array}{lllllll}1 & 2 & 3 & 4 & 5 & 6 & 7\end{array}$

$\begin{array}{lllllll}1 & 2 & 3 & 4 & 5 & 6 & 7\end{array}$

$\begin{array}{lllllll}1 & 2 & 3 & 4 & 5 & 6 & 7\end{array}$

$\begin{array}{lllllll}1 & 2 & 3 & 4 & 5 & 6 & 7\end{array}$

$\begin{array}{lllllll}1 & 2 & 3 & 4 & 5 & 6 & 7\end{array}$

$\begin{array}{lllllll}1 & 2 & 3 & 4 & 5 & 6 & 7\end{array}$

$\begin{array}{lllllll}1 & 2 & 3 & 4 & 5 & 6 & 7\end{array}$

$\begin{array}{lllllll}1 & 2 & 3 & 4 & 5 & 6 & 7\end{array}$

$\begin{array}{lllllll}1 & 2 & 3 & 4 & 5 & 6 & 7 \\ 1 & 2 & 3 & 4 & 5 & 6 & 7\end{array}$

$\begin{array}{lllllll}1 & 2 & 3 & 4 & 5 & 6 & 7 \\ 1 & 2 & 3 & 4 & 5 & 6 & 7\end{array}$

22. Singing the national anthem in Māori and English.

23. Policies promoting more immigration from China to New Zealand.

24. Crown (government) ownership of the seabed and foreshore.

$\begin{array}{lllllll}1 & 2 & 3 & 4 & 5 & 6 & 7\end{array}$

25. A free-to-air Māori television channel.

$\begin{array}{lllllll}1 & 2 & 3 & 4 & 5 & 6 & 7 \\ 1 & 2 & 3 & 4 & 5 & 6 & 7 \\ 1 & 2 & 3 & 4 & 5 & 6 & 7 \\ 1 & 2 & 3 & 4 & 5 & 6 & 7\end{array}$


Instructions: Please rate how strongly you oppose or support each of the following political parties.

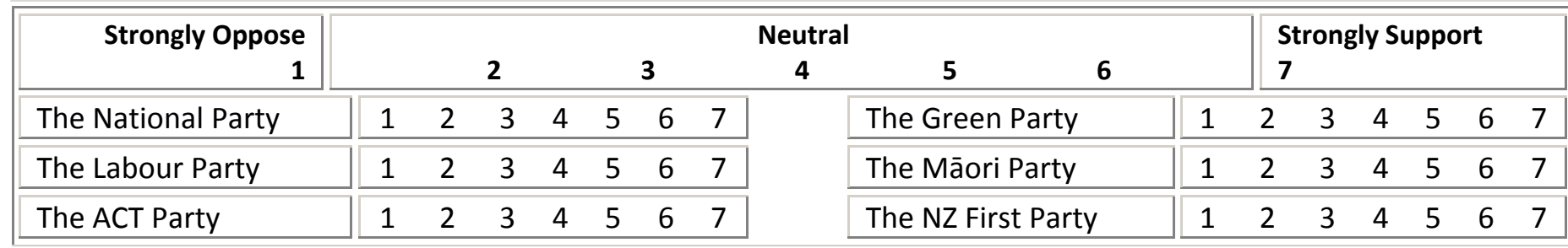

Please rate your feelings toward the following groups using the "feeling thermometer scale" for each group.

This scale measures your feelings of WARMTH toward different groups.

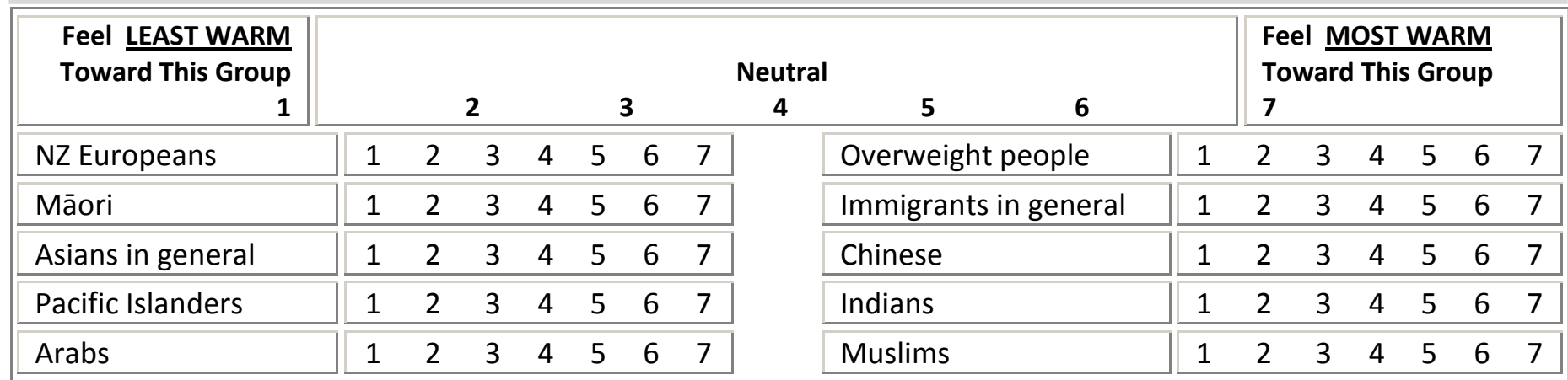

Now please rate your feelings of ANGER toward these same groups on the scale below.

\begin{tabular}{|c|c|c|c|c|c|c|c|c|c|c|c|c|c|c|c|}
\hline $\begin{array}{r}\text { Feel } \frac{\text { NO ANGER }}{\text { Toward This Group }} \\
1\end{array}$ & \multicolumn{9}{|c|}{ Neutral } & \multicolumn{6}{|c|}{$\begin{array}{l}\text { Feel ANGER } \\
\text { Toward This Group } \\
7\end{array}$} \\
\hline NZ Europeans & 1 & 2 & 3 & 4 & 5 & 6 & 7 & Overweight people & 1 & 2 & 3 & 4 & 5 & 6 & 7 \\
\hline Māori & 1 & 2 & 3 & 4 & 5 & 6 & 7 & Immigrants in general & 1 & 2 & 3 & 4 & 5 & 6 & 7 \\
\hline Asians in general & 1 & 2 & 3 & 4 & 5 & 6 & 7 & Chinese & 1 & 2 & 3 & 4 & 5 & 6 & 7 \\
\hline Pacific Islanders & 1 & 2 & 3 & 4 & 5 & 6 & 7 & Indians & 1 & 2 & 3 & 4 & 5 & 6 & 7 \\
\hline Arabs & 1 & 2 & 3 & 4 & 5 & 6 & 7 & Muslims & 1 & 2 & 3 & 4 & 5 & 6 & 7 \\
\hline
\end{tabular}

\begin{tabular}{|c|c|c|c|c|c|c|c|}
\hline 1. How frequently do you have POSITIVE/GOOD contact with NZ Europeans? & 1 & 2 & 3 & 4 & 5 & 6 & 7 \\
\hline 2. How frequently do you have NEGATIVE/BAD contact with NZ Europeans? & 1 & 2 & 3 & 4 & 5 & 6 & 7 \\
\hline 3. How frequently do you have POSITIVE/GOOD contact with Māori? & 1 & 2 & 3 & 4 & 5 & 6 & 7 \\
\hline 4. How frequently do you have NEGATIVE/BAD contact with Māori? & 1 & 2 & 3 & 4 & 5 & 6 & 7 \\
\hline 5. How frequently do you have POSITIVE/GOOD contact with Pacific Islanders? & 1 & 2 & 3 & 4 & 5 & 6 & $\gamma$ \\
\hline 6. How frequently do you have NEGATIVE/BAD contact with Pacific Islanders? & 1 & 2 & 3 & 4 & 5 & 6 & 7 \\
\hline 7. How frequently do you have POSITIVE/GOOD contact with Asians? & 1 & 2 & 3 & 4 & 5 & 6 & 7 \\
\hline 8. How frequently do you have NEGATIVE/BAD contact with Asians? & 1 & 2 & 3 & 4 & 5 & 6 & 7 \\
\hline
\end{tabular}

01. Please estimate how many hours you spent doing each of the following things last week (please enter ' 0 hours' if you did not do that activity last week)
(a) Working in paid employment
(b) Housework/cooking
(c) Looking after children
(d) Playing computer games
(e) Exercising/physical activity
(f) Watching TV/Films
(g) Travelling/commuting
(h) Volunteer/charity work
(i) Using the internet

02. Should the design of the New Zealand flag be changed?

Yes No Don't know

03. Do you think foreign investors should be able to buy NZ farms?

Yes No Don't know
04. Have you been diagnosed by a doctor with any of the following health conditions?

05a. Do you smoke?

05b. If you smoke, how many cigarettes do you smoke in a normal day?

06. What is your height?

07. What is your weight?

08. Do you believe in a God?

09. Do you believe in some form of spirit or life force?
High cholesterol High blood pressure Vitamin/mineral deficiency Heart disease Diabetes Other (please state):

Yes No (metres) (kg)

Yes No

\begin{tabular}{ll}
\hline Yes & No \\
& $($ metres $)$ \\
& $(\mathrm{kg})$ \\
Yes & No \\
Yes & No
\end{tabular}


01. Which ethnic group(s) do you belong to?

(Mark the space or spaces that apply to you).

02. Which term do you prefer to describe New Zealanders of European descent?

New Zealander
New Zealand European
Pākehā
Kiwi
Other:

03. Are you male or female?

04. How long have you lived at your current address?

$\begin{array}{ll}\text { Male Female } & \text { Fears) } \\ & \text { (months) }\end{array}$

05a. Do you have an emergency survival kit in your home?

05b. If yes to $05 a$, which of the following items does it contain? (tick those that apply)

06a. What is your relationship status? If you are in a relationship...

06b. How long have you been together?

Yes No

Other such as DUTCH, JAPANESE, TOKELAUAN

Please state:

\section{6c. What is your} partner's ethnicity?

06d. How satisfied are you with your relationship? $\begin{array}{lllllllll}\text { Not satisfied } & 1 & 2 & 3 & 4 & 5 & 6 & 7 & \text { Very satisfied }\end{array}$

06e. Do you live with your partner? Yes No

06f. To what extent do you experience conflict or disagreement with your partner?

$\begin{array}{llllllllll}\text { No conflict at all } & 1 & 2 & 3 & 4 & 5 & 6 & 7 & \text { A great deal of conflict }\end{array}$

07. What is your mother's ethnicity?

08. What is your father's ethnicity?

09a. Are you currently employed?

09b. If employed, how long have you been in your current job?

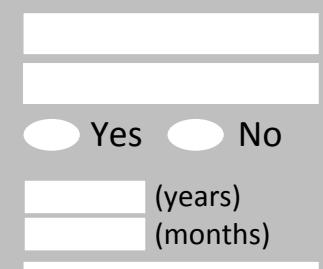

09c. What is your current occupation?

09d. How satisfied are you with your current job? $\begin{array}{llllllllll}\text { Not satisfied } & 1 & 2 & 3 & 4 & 5 & 6 & 7 & \text { Very satisfied }\end{array}$

09e. How secure do you feel in your current job?

$$
\begin{array}{lllllllll}
\text { Not secure } & 1 & 2 & 3 & 4 & 5 & 6 & 7 & \text { Very secure }
\end{array}
$$

10. How much money have you donated to charity in the last year? \$

11. Please rate how politically left-wing versus right-wing you see yourself as being:

Extremely left-wing $1 \begin{array}{llllllll}1 & 2 & 3 & 4 & 5 & 6 & 7 & \text { Extremely right-wing }\end{array}$
12. What is your date of birth?

l $\quad I$

13. What is your highest level of qualification?

14. In which country ... was your mother born? ... was your father born? ... were you born?

15. Please estimate your total household income (before tax) for the year 2012

16. Please estimate your own personal earnings (before tax) for the year 2012

\section{$\$$}

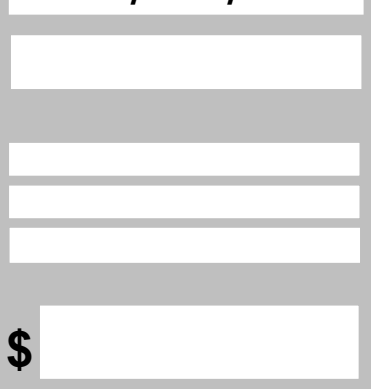

$\$$

17. Please rate how politically liberal versus conservative you see yourself as being:

Extremely liberal $1 \begin{array}{llllllll}1 & 2 & 3 & 4 & 5 & 6 & 7 & \text { Extremely conservative }\end{array}$

18a. How many children have you given birth to, fathered, or adopted?

18b. How many of your children live with you most of the time?

19a. Do you have a Facebook profile?

19b How many hours in the last week have you spent using Facebook?

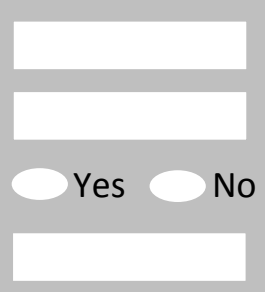

19c. How important a part of your daily routine is using Facebook?

Not important $1 \begin{array}{llllllll}1 & 2 & 3 & 4 & 5 & 6 & 7 & \text { Very important }\end{array}$

20. Do you identify with a religion and/or spiritual group? If yes...

(a) what religion or spiritual group?

(b) how many times did you attend a church or place of worship in the last month?

(c) how important is your religion to how you see yourself?

$\begin{array}{llllllllll}\text { Not important } & 1 & 2 & 3 & 4 & 5 & 6 & 7 & \text { Very important }\end{array}$

21. Roughly how many hours have you spent with both FRIENDS/FAMILY and OTHERS (e.g., workmates, strangers) from each ethnic group in the last week?
(a) Māori
(b) NZ Europeans
(c) Pacific Islanders
(d) Asians

FRIENDS/FAMILY

OTHERS

22a. Did you vote in the last (2011) New Zealand general election?

22b. If yes, to which party did you give... your party vote?
your electorate vote?

23. In the last year have you personally...
(a) been forced to buy cheaper food so you could pay for other things you needed?

(b) put up with feeling cold to save on heating costs?

(c) been the victim of a crime?

(d) or the principal earner in your household been out-of-work?

24. Do you identify as Māori and/or have any ancestors who are Mãori?

25. Do you have an internet connection in your home?
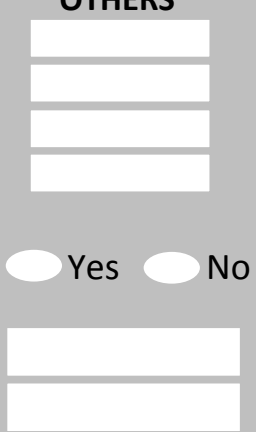
Thank you for taking part in the New Zealand Attitudes and Values Study!

Please post back your completed questionnaire using the included freepost return envelope. The freepost envelope will work from anywhere in the world, so you can post it back even if you are overseas.

If you would like to know more about the New Zealand Attitudes and Values Study then please feel free to phone us (contact details on the front) or you can visit the study website:

http://www.psych.auckland.ac.nz/uoa/NZAVS 


\section{The New Zealand Attitudes and Values Study}

\section{Follow-up Questionnaire for 2013/2014}

A scanned copy of this form will be kept for a period of up to fifteen years

Lead researcher:

Dr. Chris Sibley, School of Psychology, The University of Auckland.

Phone: 09-373-7599, extn 87498. E-mail: nzavs@auckland.ac.nz

\section{Consent form and contact details}

This form is to gather your consent to participate in this phase of the New Zealand Attitudes and Values Study. Only Dr. Sibley and his research associates will have access to your responses. Your personal information will be kept separate from your responses at all times. Your questionnaire will be identified by an anonymous code. An encrypted electronic copy of all responses will be stored indefinitely for research purposes in a secure room in the School of Psychology.

I have read and understood a description of this research project. On this basis, I agree to take part. I understand that my data will remain confidential at all times. I understand that only Dr. Sibley and trusted research assistants working on the study in secure conditions will have access to my contact details. I consent to publication of the results of the project with the understanding that my anonymity will be preserved. I understand that I am free to withdraw from the research at any time up until the point at which I complete and return this questionnaire. I understand that my contact details will never be shared with anyone. I understand that Dr. Sibley will use these details to contact and invite me to complete follow-up questionnaires, possibly for the next fifteen years. Finally, I understand that my contact details will be used to contact me if I win one of the grocery voucher prize draws for $\mathbf{\$ 5 0 0 ,} \mathbf{\$ 3 0 0}$ or $\mathbf{\$ 2 0 0}$ for participating in this study. Prizes will be drawn in June 2014.

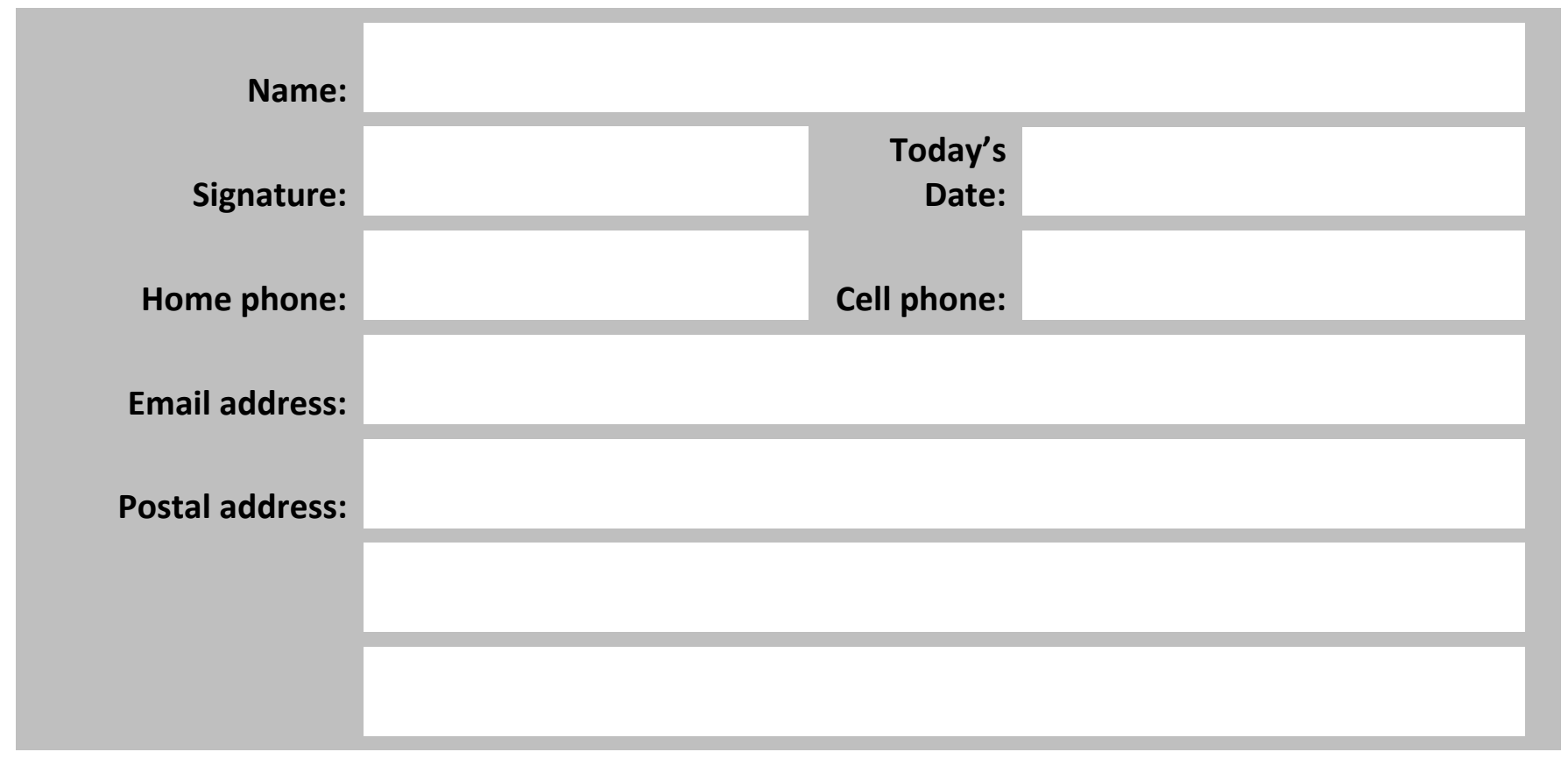

Would you like to receive a summary of key findings from the study?

Would you be willing to complete a short follow-up email survey about your religious beliefs later in about six months time? 
This page left intentionally blank 
Instructions: This part of the questionnaire measures your feelings about yourself. Please circle the number that best represents how accurately each statement describes you.

\begin{tabular}{|c|c|c|c|c|c|c|c|}
\hline \multirow{2}{*}{$\begin{array}{l}\text { I ... } \\
\text { 1. Am the life of the party. }\end{array}$} & \multicolumn{3}{|c|}{$\begin{array}{l}\text { Very } \\
\text { Inaccurate } \\
\perp\end{array}$} & \multicolumn{4}{|c|}{$\begin{array}{r}\text { Very } \\
\text { Accurate } \\
\downarrow\end{array}$} \\
\hline & 1 & 2 & 3 & 4 & 5 & 6 & 7 \\
\hline 2. Sympathise with others' feelings. & 1 & 2 & 3 & 4 & 5 & 6 & 7 \\
\hline 3. Get chores done right away. & 1 & 2 & 3 & 4 & 5 & 6 & 7 \\
\hline 4. Have frequent mood swings. & 1 & 2 & 3 & 4 & 5 & 6 & 7 \\
\hline 5. Have a vivid imagination. & 1 & 2 & 3 & 4 & 5 & 6 & 7 \\
\hline 6. Don't talk a lot. & 1 & 2 & 3 & 4 & 5 & 6 & 7 \\
\hline 7. Am not interested in other people's problems. & 1 & 2 & 3 & 4 & 5 & 6 & 7 \\
\hline 8. Have difficulty understanding abstract ideas. & 1 & 2 & 3 & 4 & 5 & 6 & 7 \\
\hline 9. Like order. & 1 & 2 & 3 & 4 & 5 & 6 & 7 \\
\hline 10. Make a mess of things. & 1 & 2 & 3 & 4 & 5 & 6 & 7 \\
\hline 11. Do not have a good imagination. & 1 & 2 & 3 & 4 & 5 & 6 & 7 \\
\hline 12. Feel others' emotions. & 1 & 2 & 3 & 4 & 5 & 6 & 7 \\
\hline 13. Am relaxed most of the time. & 1 & 2 & 3 & 4 & 5 & 6 & 7 \\
\hline 14. Get upset easily. & 1 & 2 & 3 & 4 & 5 & 6 & 7 \\
\hline 15. Seldom feel blue. & 1 & 2 & 3 & 4 & 5 & 6 & 7 \\
\hline 16. Keep in the background. & 1 & 2 & 3 & 4 & 5 & 6 & 7 \\
\hline 17. Am not really interested in others. & 1 & 2 & 3 & 4 & 5 & 6 & 7 \\
\hline 18. Am not interested in abstract ideas. & 1 & 2 & 3 & 4 & 5 & 6 & 7 \\
\hline 19. Often forget to put things back in their proper place. & 1 & 2 & 3 & 4 & 5 & 6 & 7 \\
\hline 20. Talk to a lot of different people at parties. & 1 & 2 & 3 & 4 & 5 & 6 & 7 \\
\hline 21. Feel entitled to more of everything. & 1 & 2 & 3 & 4 & 5 & 6 & 7 \\
\hline 22. On the whole am satisfied with myself. & 1 & 2 & 3 & 4 & 5 & 6 & 7 \\
\hline 23. Know that people in my life accept and value me. & 1 & 2 & 3 & 4 & 5 & 6 & 7 \\
\hline 24. Would like to be seen driving around in a very expensive car. & 1 & 2 & 3 & 4 & 5 & 6 & 7 \\
\hline 25. Deserve more things in life. & 1 & 2 & 3 & 4 & 5 & 6 & 7 \\
\hline 26. Take a positive attitude toward myself. & 1 & 2 & 3 & 4 & 5 & 6 & 7 \\
\hline 27. Feel like an outsider. & 1 & 2 & 3 & 4 & 5 & 6 & 7 \\
\hline 28. Would get a lot of pleasure from owning expensive luxury goods. & 1 & 2 & 3 & 4 & 5 & 6 & 7 \\
\hline 29. Am satisfied with the appearance, size and shape of my body. & 1 & 2 & 3 & 4 & 5 & 6 & 7 \\
\hline 30. Am inclined to feel that I am a failure. & 1 & 2 & 3 & 4 & 5 & 6 & 7 \\
\hline 31. Feel that I am often discriminated against because of my ethnicity. & 1 & 2 & 3 & 4 & 5 & 6 & 7 \\
\hline 32. Know that people around me share my attitudes and beliefs. & 1 & 2 & 3 & 4 & 5 & 6 & 7 \\
\hline 33. Being a woman/man is an important part of how I see myself. & 1 & 2 & 3 & 4 & 5 & 6 & 7 \\
\hline
\end{tabular}

During the last 30 days, how often did

(Please use the scale below to circle a number for each question)

\begin{tabular}{|c|c|c|c|c|c|c|c|}
\hline $\begin{array}{r}\text { None Of } \\
\text { The Time } \\
0\end{array}$ & $\begin{array}{c}\text { A Little of } \\
\text { The Time } \\
1\end{array}$ & $\begin{array}{l}\text { Some of } \\
\text { The Time } \\
2\end{array}$ & $\begin{array}{c}\text { Most of } \\
\text { The Time } \\
3\end{array}$ & & & & \\
\hline \multicolumn{3}{|c|}{ 1. ... you feel hopeless? } & 0 & 1 & 2 & 3 & 4 \\
\hline \multicolumn{3}{|c|}{ 2. ... you feel so depressed that nothing could cheer you up? } & 0 & 1 & 2 & 3 & 4 \\
\hline \multicolumn{3}{|c|}{ 3. ... you feel restless or fidgety? } & 0 & 1 & 2 & 3 & 4 \\
\hline \multicolumn{3}{|c|}{ 4. ... you feel that everything was an effort? } & 0 & 1 & 2 & 3 & 4 \\
\hline \multicolumn{3}{|c|}{ 5. ... you feel worthless? } & 0 & 1 & 2 & 3 & 4 \\
\hline \multicolumn{3}{|c|}{ 6. ... you feel nervous? } & 0 & 1 & 2 & 3 & 4 \\
\hline \multicolumn{3}{|c|}{ 7. ... you have negative thoughts that repeated over and over? } & 0 & 1 & 2 & 3 & 4 \\
\hline \multicolumn{3}{|c|}{ 8. ... you worry that a big earthquake might hit your region? } & 0 & 1 & 2 & 3 & 4 \\
\hline \multicolumn{3}{|c|}{ 9. ... you feel exhausted? } & 0 & 1 & 2 & 3 & 4 \\
\hline
\end{tabular}




\begin{tabular}{|c|c|c|c|c|c|c|c|c|}
\hline 1. & Protecting New Zealand's native species should be a national priority. & \multicolumn{3}{|c|}{$\begin{array}{l}\text { Strongly } \\
\text { Disagree } \\
\downarrow\end{array}$} & & \multicolumn{3}{|c|}{$\begin{array}{r}\text { Strongly } \\
\text { Agree } \\
\downarrow\end{array}$} \\
\hline 2. & I wish people in this society would stop obsessing so much about race. & 1 & 2 & 3 & 4 & 5 & 6 & 7 \\
\hline 3. & It would be good if groups could be equal. & 1 & 2 & 3 & 4 & 5 & 6 & 7 \\
\hline 5. & $\begin{array}{l}\text { It would be best for everyone if the proper authorities censored magazines so } \\
\text { that people could not get their hands on trashy and disgusting material. }\end{array}$ & 1 & 2 & 3 & 4 & 5 & 6 & 7 \\
\hline 6. & We should have increased social equality. & 1 & 2 & 3 & 4 & 5 & 6 & 7 \\
\hline 7. & I expect my health to get worse. & 1 & 2 & 3 & 4 & 5 & 6 & 7 \\
\hline 8. & $\begin{array}{l}\text { Our country will be destroyed some day if we do not smash the perversions } \\
\text { eating away at our moral fibre and traditional beliefs. }\end{array}$ & 1 & 2 & 3 & 4 & 5 & 6 & 7 \\
\hline 11. & $\begin{array}{l}\text { People should pay less attention to The Bible and other old traditional forms } \\
\text { of religious guidance, and instead develop their own personal standards of } \\
\text { what is moral and immoral. }\end{array}$ & 1 & 2 & 3 & 4 & 5 & 6 & 7 \\
\hline
\end{tabular}

12. We are all one nation and we should all be treated the same. No one should be entitled to anything more than the rest of us simply because they belong to one $\quad \begin{array}{llllllll}1 & 2 & 3 & 4 & 5 & 6 & 7\end{array}$ particular ethnic group.

13. Atheists and others who have rebelled against established religions are no doubt every bit as good and virtuous as those who attend church regularly.

14. To get ahead in life, it is sometimes okay to step on other groups.

$\begin{array}{lllllll}1 & 2 & 3 & 4 & 5 & 6 & 7\end{array}$

15. The unity of New Zealand is weakened by too many immigrants.

$\begin{array}{lllllll}1 & 2 & 3 & 4 & 5 & 6 & 7\end{array}$

16. Some of the best people in our country are those who are challenging our government, criticizing religion, and ignoring the "normal way" things are supposed to be done.

17. People from my ethnic group generally earn less than other groups in NZ.

$\begin{array}{lllllll}1 & 2 & 3 & 4 & 5 & 6 & 7\end{array}$

18. I feel anxious about interacting with NZ European people.

$\begin{array}{lllllll}1 & 2 & 3 & 4 & 5 & 6 & 7\end{array}$

19. True equality can be achieved only once we recognize that some ethnic groups are currently more disadvantaged than others and require additional assistance $\quad \begin{array}{llllllll}1 & 2 & 3 & 4 & 5 & 6 & 7\end{array}$ from the government.

20. I have considered voting in terms of what is good for my particular ethnic group. $\begin{array}{llllllll}1 & 2 & 3 & 4 & 5 & 6 & 7\end{array}$

21. I feel at ease when I am in a city district in New Zealand with many immigrants.

22. We are all New Zealanders and the law should not make provision for minority groups because of their ethnicity.

$\begin{array}{lllllll}1 & 2 & 3 & 4 & 5 & 6 & 7\end{array}$

$\begin{array}{lllllll}1 & 2 & 3 & 4 & 5 & 6 & 7\end{array}$

23. It is always better to trust the judgment of the proper authorities in government and religion than to listen to the noisy rabble-rousers in our society who are trying to create doubt in people's minds.

24. I have considered participating in demonstrations on behalf of my ethnic group. $\begin{array}{lllllllll}1 & 2 & 3 & 4 & 5 & 6 & 7\end{array}$

25. Everyone in New Zealand has a fair shot at wealth and happiness, regardless of

26. It is OK if some groups have more of a chance in life than others.

$\begin{array}{lllllll}1 & 2 & 3 & 4 & 5 & 6 & 7 \\ 1 & 2 & 3 & 4 & 5 & 6 & 7\end{array}$

$10-3-4,5-6-7$

$\begin{array}{lllllll}1 & 2 & 3 & 4 & 5 & 6 & 7\end{array}$

$\begin{array}{lllllll}1 & 2 & 3 & 4 & 5 & 6 & 7\end{array}$

27. There are too many immigrants living in New Zealand.

$\begin{array}{lllllll}1 & 2 & 3 & 4 & 5 & 6 & 7\end{array}$

28. I generally earn less than other people in NZ.

29. I have considered signing petitions on behalf of my ethnic group.

$\begin{array}{lllllll}1 & 2 & 3 & 4 & 5 & 6 & 7\end{array}$

30. Inferior groups should stay in their place.

$\begin{array}{lllllll}1 & 2 & 3 & 4 & 5 & 6 & 7\end{array}$

31. It is safe to vaccinate children following the standard NZ immunization schedule.

32. Economic positions are legitimate reflections of people's achievements.

33. To a large extent, a person's race biologically determines his or her abilities.

$\begin{array}{lllllll}1 & 2 & 3 & 4 & 5 & 6 & 7\end{array}$

$\begin{array}{lllllll}1 & 2 & 3 & 4 & 5 & 6 & 7\end{array}$

$\begin{array}{llllllll}1 & 2 & 3 & 4 & 5 & 6 & 7\end{array}$

$\begin{array}{lllllll}1 & 2 & 3 & 4 & 5 & 6 & 7 \\ 1 & 2 & 3 & 4 & 5 & 6 & 7\end{array}$


Instructions: Please rate your level of satisfaction with the following aspects of your life and New Zealand.

1. Your standard of living.

2. The economic situation in New Zealand.

3. The quality of New Zealand's natural environment.

4. Your health.

5. The social conditions in New Zealand.

6. The performance of the current New Zealand government.

7. Your future security.

8. Business in New Zealand.

9. Your personal relationships.

10. Your access to health care when you need it (e.g., doctor, GP).

$\begin{array}{lll}7 & 8 & 9\end{array}$

1. There are people I can depend on to help me if I really need it.

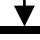

2. I think that Māori culture helps to define New Zealand in positive ways.

$\begin{array}{lllllll}1 & 2 & 3 & 4 & 5 & 6 & 7\end{array}$

3. I think liking rugby is an important part of being a 'true' New Zealander.

$\begin{array}{lllllll}1 & 2 & 3 & 4 & 5 & 6 & 7\end{array}$

4. Everyone has a fair shot at wealth and happiness in New Zealand.

5. Despite what one hears about 'crime in the street,' there probably isn't any more now than there ever has been.

6. I wish I had more self-discipline.

7. By taking personal action I believe I can make a positive difference to environmental problems.

$\begin{array}{lllllll}1 & 2 & 3 & 4 & 5 & 6 & 7 \\ 1 & 2 & 3 & 4 & 5 & 6 & 7\end{array}$

8. New Zealand would be a better place to live if we forgot about trying to promote Māori culture to everyone.

9. Women exaggerate problems they have at work.

$\begin{array}{lllllll}1 & 2 & 3 & 4 & 5 & 6 & 7\end{array}$

10. In general, I find New Zealand society to be fair.

$\begin{array}{lllllll}1 & 2 & 3 & 4 & 5 & 6 & 7\end{array}$

11. It's a dog-eat-dog world where you have to be ruthless at times.

$\begin{array}{lllllll}1 & 2 & 3 & 4 & 5 & 6 & 7\end{array}$

12. Māori people would be likely to reject me on the basis of my race.

13. Bad smells, messes, dead animals and rotten food absolutely disgust me.

14. Women, compared to men, tend to have greater moral sensibility.

15. The fact that I am a member of my ethnic group is an important part of my identity.

16. In general, I have a lot of self-control.

$\begin{array}{lllllll}1 & 2 & 3 & 4 & 5 & 6 & 7\end{array}$

17. In general, the New Zealand political system operates as it should.

$\begin{array}{lllllll}1 & 2 & 3 & 4 & 5 & 6 & 7\end{array}$

$\begin{array}{lllllll}1 & 2 & 3 & 4 & 5 & 6 & 7\end{array}$

18. There is no one I can turn to for guidance in times of stress.

19. I feel I can make a difference to the state of the environment.

$\begin{array}{lllllll}1 & 2 & 3 & 4 & 5 & 6 & 7\end{array}$

20. Life is not governed by the 'survival of the fittest.' We should let compassion and moral laws be our guide.

$\begin{array}{lllllll}1 & 2 & 3 & 4 & 5 & 6 & 7\end{array}$

$\begin{array}{lllllll}1 & 2 & 3 & 4 & 5 & 6 & 7\end{array}$

21. If they knew me, most NZers would respect what I have accomplished in life.

22. I feel anxious about interacting with Māori people.

23. Māori have too much political power and influence in decisions affecting NZ. $\begin{array}{llllllll}1 & 2 & 3 & 4 & 5 & 6 & 7\end{array}$

24. Pacific Island people would be likely to reject me on the basis of my race.

$\begin{array}{lllllll}1 & 2 & 3 & 4 & 5 & 6 & 7\end{array}$

$\begin{array}{lllllll}1 & 2 & 3 & 4 & 5 & 6 & 7\end{array}$

$\begin{array}{lllllll}1 & 2 & 3 & 4 & 5 & 6 & 7\end{array}$

25. Men and women both have a fair shot at wealth and happiness in NZ.

26. I know there are people I can turn to when I need help.

27. I reckon Māori culture should stay where it belongs-with Mãori. It doesn't concern other NZers.

28. I'm frustrated by what I earn relative to other people in NZ.

$\begin{array}{lllllll}1 & 2 & 3 & 4 & 5 & 6 & 7\end{array}$

$\begin{array}{lllllll}1 & 2 & 3 & 4 & 5 & 6 & 7\end{array}$

$\begin{array}{lllllll}1 & 2 & 3 & 4 & 5 & 6 & 7\end{array}$

$\begin{array}{lllllll}1 & 2 & 3 & 4 & 5 & 6 & 7 \\ 1 & 2 & 3 & 4 & 5 & 6 & 7\end{array}$

$\begin{array}{lllllll}1 & 2 & 3 & 4 & 5 & 6 & 7\end{array}$

$\begin{array}{lllllll}1 & 2 & 3 & 4 & 5 & 6 & 7\end{array}$


1. I make an effort to appear consistent to others.

$\begin{array}{lllllll}1 & 2 & 3 & 4 & 5 & 6 & 7\end{array}$

2. People who become preoccupied by race are forgetting that we're all just human. $\begin{array}{llllllll}1 & 2 & 3 & 4 & 5 & 6 & 7\end{array}$

3. The New Zealand government should be involved in regulating carbon emissions.

4. I feel a great pride in the land that is our New Zealand.

5. I am satisfied with my life.

6. Women are too easily offended.

7. Discrimination against Māori is no longer a problem in New Zealand.

$\begin{array}{llllllll}1 & 2 & 3 & 4 & 5 & 6 & 7\end{array}$

8. Everyone has the right to just and reasonable pay for the work they perform.

9. There are many dangerous people in our society who will attack someone out of pure meanness, for no reason at all.

10. We should all move on as one nation and forget about past differences and conflicts between ethnic groups.

$\begin{array}{lllllll}1 & 2 & 3 & 4 & 5 & 6 & 7\end{array}$

$\begin{array}{lllllll}1 & 2 & 3 & 4 & 5 & 6 & 7\end{array}$

$\begin{array}{lllllll}1 & 2 & 3 & 4 & 5 & 6 & 7\end{array}$

$\begin{array}{lllllll}1 & 2 & 3 & 4 & 5 & 6 & 7\end{array}$

$\begin{array}{lllllll}1 & 2 & 3 & 4 & 5 & 6 & 7\end{array}$

$\begin{array}{lllllll}1 & 2 & 3 & 4 & 5 & 6 & 7\end{array}$

1. Asian people would be likely to reject me on the basis of my race.

12. Putting racial labels on people obscures the fact that everyone is a unique individual.

13. I feel anxious about interacting with Asian people.

14. NZ European people would be likely to reject me on the basis of my race.

15. Climate change is real.

16. Climate change is caused by humans.

$\begin{array}{lllllll}1 & 2 & 3 & 4 & 5 & 6 & 7\end{array}$

17. I am deeply concerned about climate change.

18. I feel anxious about interacting with Pacific Island people.

19. In general, relations between different ethnic groups in New Zealand are fair.

20. Many women have a quality of purity that few men possess.

$\begin{array}{llllllll}1 & 2 & 3 & 4 & 5 & 6 & 7\end{array}$

21. We should not have to pay for the mistakes of our ancestors.

22. Women seek to gain power by getting control over men.

$\begin{array}{lllllll}1 & 2 & 3 & 4 & 5 & 6 & 7\end{array}$

23. Everyone has the right to food, clothing, housing and medicine, no matter what.

24. Some people are simply not responsible enough to own property.

25. People from other races would be likely to reject me on the basis of my race.

26. Once a woman gets a man to commit to her she usually tries to put him on a tight leash.

27. Women, as compared to men, tend to have a more refined sense of culture and good taste.

28. I feel anxious about interacting with people from other races.

29. Most of New Zealand's policies serve the greater good.

30. People who weren't around in previous centuries should not feel accountable for the actions of their ancestors.

31. Some people are simply not responsible enough to vote or take part in the

government of their country.

$\begin{array}{lllllll}1 & 2 & 3 & 4 & 5 & 6 & 7\end{array}$

$\begin{array}{lllllll}1 & 2 & 3 & 4 & 5 & 6 & 7\end{array}$

$\begin{array}{lllllll}1 & 2 & 3 & 4 & 5 & 6 & 7\end{array}$

$\begin{array}{lllllll}1 & 2 & 3 & 4 & 5 & 6 & 7\end{array}$

$\begin{array}{lllllll}1 & 2 & 3 & 4 & 5 & 6 & 7\end{array}$

$\begin{array}{lllllll}1 & 2 & 3 & 4 & 5 & 6 & 7\end{array}$

$\begin{array}{lllllll}1 & 2 & 3 & 4 & 5 & 6 & 7\end{array}$

$\begin{array}{lllllll}1 & 2 & 3 & 4 & 5 & 6 & 7\end{array}$

$\begin{array}{lllllll}1 & 2 & 3 & 4 & 5 & 6 & 7\end{array}$

$\begin{array}{lllllll}1 & 2 & 3 & 4 & 5 & 6 & 7\end{array}$

$\begin{array}{lllllll}1 & 2 & 3 & 4 & 5 & 6 & 7\end{array}$

$\begin{array}{lllllll}1 & 2 & 3 & 4 & 5 & 6 & 7\end{array}$

$\begin{array}{lllllll}1 & 2 & 3 & 4 & 5 & 6 & 7\end{array}$

$\begin{array}{lllllll}1 & 2 & 3 & 4 & 5 & 6 & 7\end{array}$

$\begin{array}{lllllll}1 & 2 & 3 & 4 & 5 & 6 & 7\end{array}$

$\begin{array}{lllllll}1 & 2 & 3 & 4 & 5 & 6 & 7\end{array}$

$\begin{array}{lllllll}1 & 2 & 3 & 4 & 5 & 6 & 7\end{array}$

$\begin{array}{lllllll}1 & 2 & 3 & 4 & 5 & 6 & 7\end{array}$

32. The average citizen can have an influence on government decisions.

33. In general, relations between men and women in New Zealand are fair.

34. In most ways my life is close to ideal.

35. Women should be cherished and protected by men.

$\begin{array}{lllllll}1 & 2 & 3 & 4 & 5 & 6 & 7\end{array}$

36. Generally, the more influence NZ has on other nations, the better off they are.

37. When women lose to men in a fair competition, they typically complain about being discriminated against.

38. Although at times I may not agree with the government, my commitment to New Zealand always remains strong.

$\begin{array}{lllllll}1 & 2 & 3 & 4 & 5 & 6 & 7\end{array}$

$\begin{array}{lllllll}1 & 2 & 3 & 4 & 5 & 6 & 7\end{array}$

$\begin{array}{lllllll}1 & 2 & 3 & 4 & 5 & 6 & 7\end{array}$

$\begin{array}{lllllll}1 & 2 & 3 & 4 & 5 & 6 & 7\end{array}$

$\begin{array}{lllllll}1 & 2 & 3 & 4 & 5 & 6 & 7\end{array}$

$\begin{array}{lllllll}1 & 2 & 3 & 4 & 5 & 6 & 7\end{array}$

$\begin{array}{lllllll}1 & 2 & 3 & 4 & 5 & 6 & 7\end{array}$

39. Every man ought to have a woman whom he adores.

40. Being a member of my ethnic group is an important part of how I see myself.

41. I'm frustrated by what my ethnic group earns relative to other groups in NZ.

42. Foreign nations have done some very fine things but they are still not as good as New Zealand.

$\begin{array}{lllllll}1 & 2 & 3 & 4 & 5 & 6 & 7\end{array}$

$\begin{array}{lllllll}1 & 2 & 3 & 4 & 5 & 6 & 7\end{array}$

$\begin{array}{lllllll}1 & 2 & 3 & 4 & 5 & 6 & 7\end{array}$


Instructions: Please answer each of the following questions by circling a number on the scale below.

Definitely NO

1
2

3

\section{Unsure}

4
Definitely YES

7

1. Do you think people from your ethnic group are discriminated against in NZ?

2. Are you willing to change your daily routine in order to protect the environment?

3. Have you made changes to your daily routine in order to protect the environment?

4. Are you willing to make sacrifices to your standard of living (e.g., accept higher prices, drive less, conserve energy) in order to protect the environment?

5. Have you made sacrifices to your standard of living (e.g., accepted higher prices, driven less, conserved energy) in order to protect the environment?

6. Do you think most New Zealanders are willing to make sacrifices to their standard of living in order to protect the environment?

7. Of course, we all hope that there will not be another war, but if it were to come to that, would you be willing to fight for your country?

8. Do you think most New Zealanders respect the achievements of your ethnic group?

9. Do you support the use of $\mathbf{1 0 8 0}$ poison for possum control in New Zealand?

10. Do you lead a healthy lifestyle? (e.g., eat healthy food, exercise regularly).

11. Do you think you personally are more at risk of a weight-based illness (e.g., heart illnesses, diabetes) than other New Zealanders, on average?

$\begin{array}{lllllll}1 & 2 & 3 & 4 & 5 & 6 & 7 \\ 1 & 2 & 3 & 4 & 5 & 6 & 7 \\ 1 & 2 & 3 & 4 & 5 & 6 & 7\end{array}$

$\begin{array}{lllllll}1 & 2 & 3 & 4 & 5 & 6 & 7\end{array}$

$\begin{array}{lllllll}1 & 2 & 3 & 4 & 5 & 6 & 7\end{array}$

$\begin{array}{lllllll}1 & 2 & 3 & 4 & 5 & 6 & 7\end{array}$

$\begin{array}{lllllll}1 & 2 & 3 & 4 & 5 & 6 & 7\end{array}$

$\begin{array}{lllllll}1 & 2 & 3 & 4 & 5 & 6 & 7\end{array}$

$\begin{array}{lllllll}1 & 2 & 3 & 4 & 5 & 6 & 7\end{array}$

$\begin{array}{lllllll}1 & 2 & 3 & 4 & 5 & 6 & 7\end{array}$

$\begin{array}{lllllll}1 & 2 & 3 & 4 & 5 & 6 & 7\end{array}$

Instructions: Please rate how strongly you oppose or support each of the following possible policies or issues.

\begin{tabular}{|c|c|c|c|c|c|c|c|}
\hline \multirow[b]{2}{*}{ Legalized abortion for women, regardless of the reason. } & \multicolumn{2}{|c|}{$\begin{array}{l}\text { Strongly } \\
\text { Oppose }\end{array}$} & \multirow[b]{2}{*}{3} & \multirow[b]{2}{*}{4} & \multirow[b]{2}{*}{5} & \multicolumn{2}{|c|}{$\begin{array}{c}\text { Strongly } \\
\text { Support }\end{array}$} \\
\hline & 1 & 2 & & & & 6 & 7 \\
\hline 2. Policies promoting closer trade ties between India and New Zealand. & 1 & 2 & 3 & 4 & 5 & 6 & 7 \\
\hline 3. Māori ownership of the seabed and foreshore. & 1 & 2 & 3 & 4 & 5 & 6 & 7 \\
\hline 4. Performance of the Haka at international sports events. & 1 & 2 & 3 & 4 & 5 & 6 & 7 \\
\hline 5. Protest marches and public demonstrations supporting the rights of Māori. & 1 & 2 & 3 & 4 & 5 & 6 & 7 \\
\hline $\begin{array}{l}\text { 6. Incentives to increase women's participation in the paid workforce (paid for } \\
\text { by government). }\end{array}$ & 1 & 2 & 3 & 4 & 5 & 6 & 7 \\
\hline 7. Policies promoting closer trade ties between China and New Zealand. & 1 & 2 & 3 & 4 & 5 & 6 & 7 \\
\hline 8. Government subsidy of public transport. & 1 & 2 & 3 & 4 & 5 & 6 & 7 \\
\hline 9. The current anti-smacking bill. (i.e., it being illegal to smack children). & 1 & 2 & 3 & 4 & 5 & 6 & 7 \\
\hline 10. Increased government spending on new motorways. & 1 & 2 & 3 & 4 & 5 & 6 & 7 \\
\hline 11. Government initiatives to inform and promote healthy lifestyle choices. & 1 & 2 & 3 & 4 & 5 & 6 & 7 \\
\hline 12. A "flat" tax rate (everyone pays the same percentage of tax on their income). & 1 & 2 & 3 & 4 & 5 & 6 & 7 \\
\hline 13. Legalized abortion when the woman's life is endangered. & 1 & 2 & 3 & 4 & 5 & 6 & 7 \\
\hline 14. Reserving places for Māori students to study medicine. & 1 & 2 & 3 & 4 & 5 & 6 & 7 \\
\hline 15. Waitangi Day as a national celebration of biculturalism. & 1 & 2 & 3 & 4 & 5 & 6 & 7 \\
\hline 16. The Civil Union Act. & 1 & 2 & 3 & 4 & 5 & 6 & 7 \\
\hline 17. Same-sex marriage in NZ (The Marriage Amendment Act 2013). & 1 & 2 & 3 & 4 & 5 & 6 & 7 \\
\hline 18. Including religious instruction in Christianity as part of the school curriculum. & 1 & 2 & 3 & 4 & 5 & 6 & 7 \\
\hline 19. Rates exemptions on Māori land. & 1 & 2 & 3 & 4 & 5 & 6 & 7 \\
\hline 20. Teaching Māori language in New Zealand primary schools. & 1 & 2 & 3 & 4 & 5 & 6 & 7 \\
\hline 21. Policies promoting more immigration from India to New Zealand. & 1 & 2 & 3 & 4 & 5 & 6 & 7 \\
\hline $\begin{array}{l}\text { 22. Introducing a programme to enhance sustainable business growth among } \\
\text { businesses owned and operated by women. }\end{array}$ & 1 & 2 & 3 & 4 & 5 & 6 & 7 \\
\hline 23. Singing the national anthem in Māori and English. & 1 & 2 & 3 & 4 & 5 & 6 & 7 \\
\hline 24. Policies promoting more immigration from China to New Zealand. & 1 & 2 & 3 & 4 & 5 & 6 & 7 \\
\hline 25. Crown (government) ownership of the seabed and foreshore. & 1 & 2 & 3 & 4 & 5 & 6 & 7 \\
\hline 26. A free-to-air Māori television channel. & 1 & 2 & 3 & 4 & 5 & 6 & 7 \\
\hline
\end{tabular}


Instructions: Please rate how strongly you oppose or support each of the following political parties.

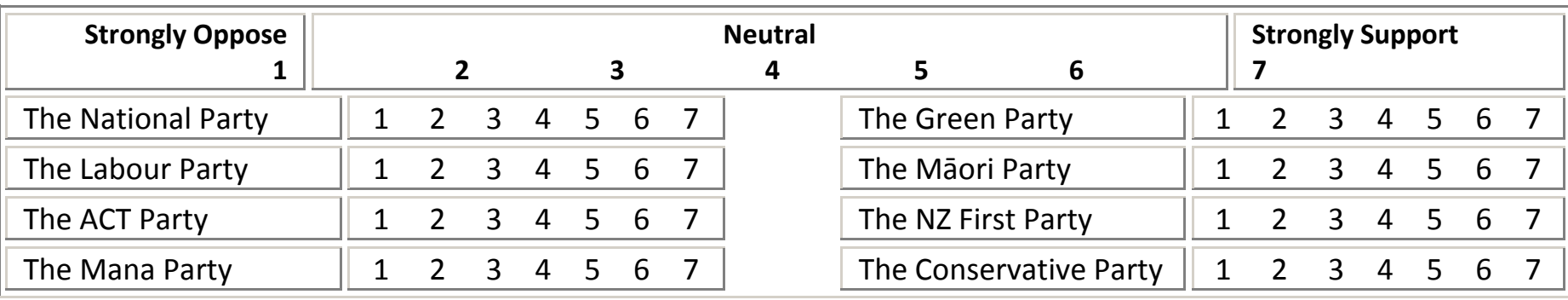

Please rate your feelings of WARMTH toward the following groups using the "feeling thermometer scale" for each group.

\begin{tabular}{|c|c|c|c|c|c|c|c|c|c|c|c|c|c|c|c|c|}
\hline $\begin{array}{r}\text { Feel LEAST WARM } \\
\text { Toward This Group } \\
1\end{array}$ & \multicolumn{9}{|c|}{ Neutral } & & \multicolumn{6}{|c|}{$\begin{array}{l}\text { Feel MOST WARM } \\
\text { Toward This Group } \\
7\end{array}$} \\
\hline NZ Europeans & 1 & 2 & 3 & 4 & 5 & 6 & 7 & & Overweight people & 1 & 2 & 3 & 4 & 5 & 6 & 7 \\
\hline Māori & 1 & 2 & 3 & 4 & 5 & 6 & 7 & & Immigrants in general & 1 & 2 & 3 & 4 & 5 & 6 & 7 \\
\hline Asians in general & 1 & 2 & 3 & 4 & 5 & 6 & 7 & & Chinese & 1 & 2 & 3 & 4 & 5 & 6 & 7 \\
\hline Pacific Islanders & 1 & 2 & 3 & 4 & 5 & 6 & 7 & & Indians & 1 & 2 & 3 & 4 & 5 & 6 & 7 \\
\hline Arabs & 1 & 2 & 3 & 4 & 5 & 6 & 7 & & Muslims & 1 & 2 & 3 & 4 & 5 & 6 & 7 \\
\hline
\end{tabular}

Now please rate your feelings of ANGER toward these same groups on the scale below.

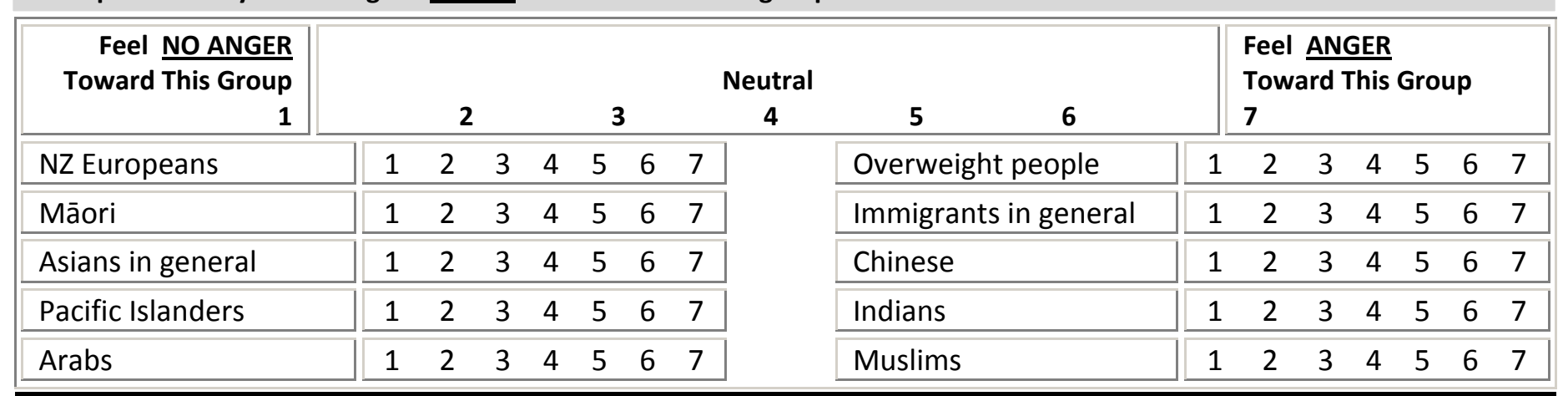

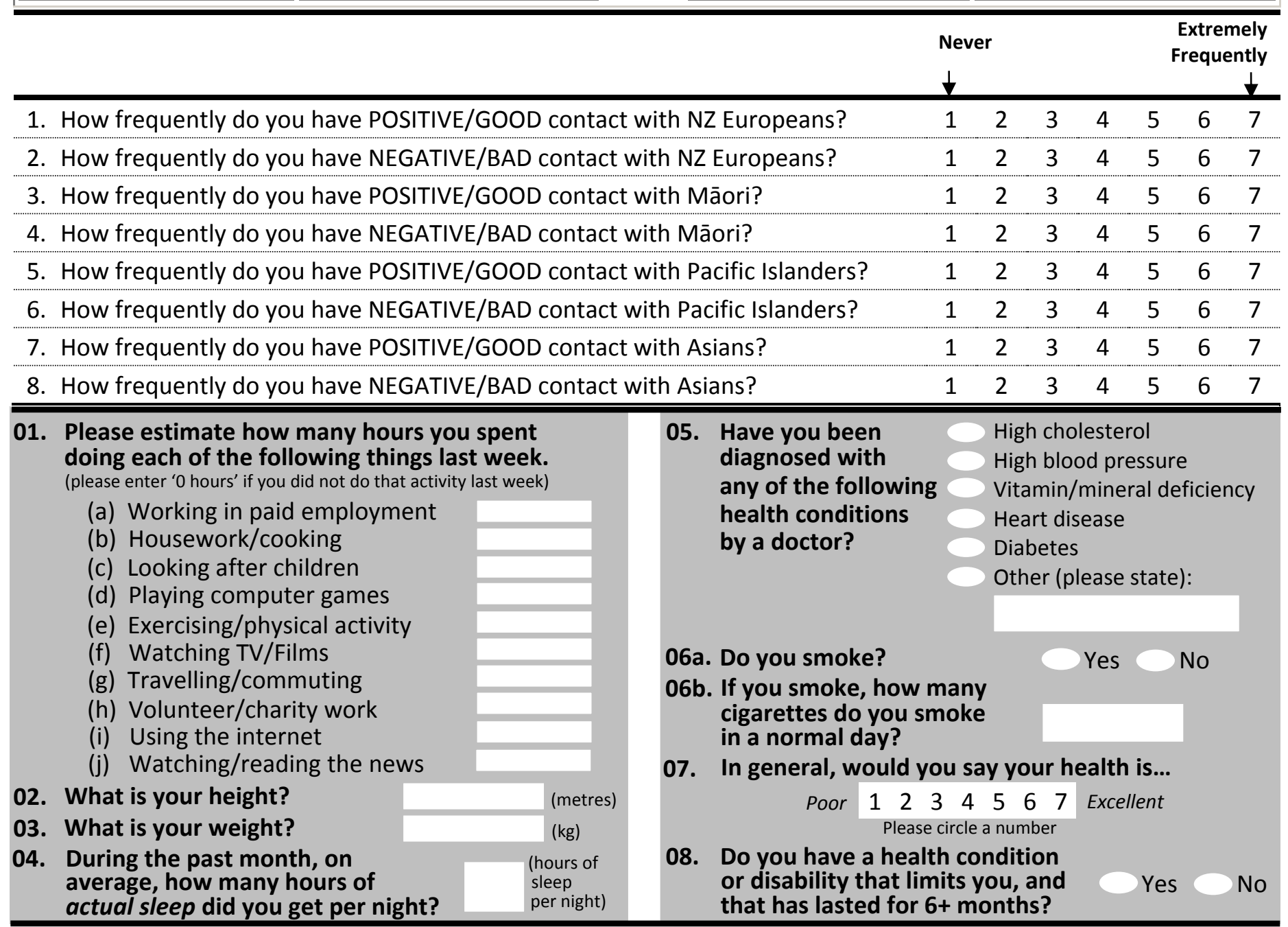


01. Which ethnic group(s) do you belong to?

(Mark the space or spaces that apply to you).

02. Which term do you prefer to describe New Zealanders of European descent?

New Zealander
New Zealand European
Pākehā
Kiwi
Other:

03. Are you male or female?

$\begin{array}{cl}\text { Male } & \text { Female } \\ & \text { (years) } \\ & \text { (months) }\end{array}$

04. What is your date of birth?

05. How long have you lived at your current address?

06a. Do you have an emergency survival kit in your home?

06b. If yes to $06 a$, which of the following items does it contain? (tick those that apply)

07a. What is your relationship status? If you are in a relationship...

07b. How long have you been together?

07c. What is your partner's ethnicity?

07d. How satisfied are you with your relationship? $\begin{array}{llllllllll}\text { Not satisfied } & 1 & 2 & 3 & 4 & 5 & 6 & 7 & \text { Very satisfied }\end{array}$

07e. Do you live with your partner? together, dating, widowed)

together, dating, widow) (months)

07f. To what extent do you experience conflict or disagreement with your partner?

$\begin{array}{llllllllll}\text { No conflict at all } & 1 & 2 & 3 & 4 & 5 & 6 & 7 & \text { A great deal of conflict }\end{array}$

08. What is your mother's ethnicity?

09. What is your father's ethnicity?

10a. Are you currently employed? Yes No
(years)
(months)

10b. If yes, how long have you worked at your current organization?

10c. What is your current occupation?

10d. How satisfied are you with your current job? $\begin{array}{llllllllll}\text { Not satisfied } & 1 & 2 & 3 & 4 & 5 & 6 & 7 & \text { Very satisfied }\end{array}$

10e. How secure do you feel in your current job? $\begin{array}{lllllllll}\text { Not secure } & 1 & 2 & 3 & 4 & 5 & 6 & 7 & \text { Very secure }\end{array}$

11. How much money have you donated to charity in the last year? \$

12. Please rate how politically left-wing versus right-wing you see yourself as being:

Extremely left-wing $1 \begin{array}{llllllll}1 & 2 & 3 & 4 & 5 & 6 & 7 & \text { Extremely right-wing }\end{array}$

13. Do you believe in a God?

14. Do you believe in a some form of spirit or life force?
15. What is your highest

level of qualification?

16. In which country

... was your mother born?

... was your father born?

... were you born?

17. Please estimate your total household income (before tax) for the year 2013

18. Please estimate your own personal earnings (before tax) for the year 2013

\section{$\$$}

$\$$

19. Please rate how politically liberal versus conservative you see yourself as being:

Extremely liberal $1 \begin{array}{llllllll}1 & 2 & 3 & 4 & 5 & 6 & 7 & \text { Extremely conservative }\end{array}$

20a. How many children have you given birth to, fathered, or adopted?

20b. If you are a parent, what is the birth date of your eldest child?

20c. And, if you have more than one child, the birth date of your youngest child?

20d. How many of your children live with you most of the time?

21a. Do you have a Facebook profile?

21b. How many hours in the last week have you spent using Facebook?

21c. How important a part of your daily routine is using Facebook?

Not important $1 \begin{array}{llllllll}1 & 2 & 3 & 4 & 5 & 6 & 7 & \text { Very important }\end{array}$

22. Do you identify with a religion and/or spiritual group? If yes...

(a) what religion or spiritual group?

(b) how many times did you attend a church or place of worship in the last month?

(c) how important is your religion to how you see yourself?

Not important $1 \begin{array}{llllllll}1 & 2 & 3 & 4 & 5 & 6 & 7 & \text { Very important }\end{array}$

23. Roughly how many hours have you spent with both FRIENDS/FAMILY and OTHERS (e.g., workmates, strangers) from each ethnic group in the last week?
(a) Mãori
(b) NZ Europeans
(c) Pacific Islanders
(d) Asians
FRIENDS/FAMILY

OTHERS

24a. Do you plan to vote in the next New Zealand election in 2014?

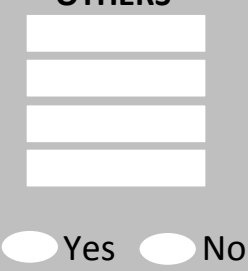

24b. If yes, to which party do you plan to give...

your party vote?

your electorate vote?

25. How important are your political beliefs to how you see yourself?

$\begin{array}{llllllllll}\text { Not important } & 1 & 2 & 3 & 4 & 5 & 6 & 7 & \text { Very important }\end{array}$

26. In the last year have you personally...

(a) been forced to buy cheaper food so you could pay for other things you needed?

(b) put up with feeling cold to save on heating costs?

(c) or the principal earner in your household been out-of-work?

(d) been the victim of a crime?

27. How would you describe your sexual orientation? 
Thank you for taking part in the New Zealand Attitudes and Values Study!

Please post back your completed questionnaire using the included freepost return envelope. The freepost envelope will work from anywhere in the world, so you can post it back even if you are overseas. If you lose the envelope, you can post this questionnaire back for free to:

FREEPOST AUTHORITY: 124589

Dr Chris Sibley, New Zealand Attitudes and Values Study

School of Psychology (Cost 9450/71708)

The University of Auckland

Private Bag 92019

Auckland 1142, New Zealand

If you would like to know more about the New Zealand Attitudes and Values Study then please feel free to phone us (contact details on the front) or you can visit the study website. We will also post out a brochure to everyone in the study summarising the most exciting findings from the study later in the year.

\section{http://www.psych.auckland.ac.nz/uoa/NZAVS}

\section{Optional Feedback Box}

We are always looking for feedback to help improve the New Zealand Attitudes and Values Study. Have we missed anything important that would affect the interpretation of your responses? Or do you have any other general comments or suggestions about how we can improve the study for next year? 


\section{The New Zealand Attitudes and Values Study}

\section{Follow-up Questionnaire for 2014/2015}

A scanned copy of this form will be kept for a period of up to fifteen years

Lead researcher:

Dr. Chris Sibley, School of Psychology, The University of Auckland.

Phone: 09-373-7599, extn 87498. E-mail: nzavs@auckland.ac.nz

\section{Consent form and contact details}

This form is to gather your consent to participate in this phase of the New Zealand Attitudes and Values Study (NZAVS). Only Dr. Sibley and his research associates will have access to your responses. Your personal information will be kept separate from your responses at all times. Your questionnaire will be identified by an anonymous code. An encrypted electronic copy of all responses will be stored indefinitely for research purposes in a secure room in the School of Psychology.

I have read and understood a description of this research project. On this basis, I agree to take part. I understand that my data will remain confidential at all times. I understand that only Dr. Sibley and trusted research assistants working on the study in secure conditions will have access to my contact details. I consent to publication of the results of the project with the understanding that my anonymity will be preserved. I understand that I am free to withdraw from the research at any time up until the point at which I complete and return this questionnaire. I understand that my contact details will never be shared with anyone outside of the immediate research team. I understand that Dr. Sibley and the research team will use these details to contact and invite me to complete follow-up questionnaires, possibly for the next fourteen years. I understand that my contact details will be used to contact me if I win one of the grocery voucher prize draws for $\mathbf{\$ 5 0 0 ,} \mathbf{\$ 3 0 0}$ or $\mathbf{\$ 2 0 0}$ for participating in this study.

\begin{tabular}{r|r} 
Name: & Today's \\
\hline Signature: & Date: \\
\hline Home phone: & Cell phone: \\
\hline Email address: & \\
\hline & \\
\hline & \\
\hline
\end{tabular}

Would you like to receive a summary of key findings from the study?

Would you be willing to complete a short follow-up questionnaire on your social relationships and identity in about six months' time?

Yes

No 
This page left intentionally blank 
Instructions: This part of the questionnaire measures your feelings about yourself. Please circle the number that best represents how accurately each statement describes you.

\begin{tabular}{|c|c|c|c|c|c|c|c|}
\hline I $\ldots$ & \multicolumn{3}{|c|}{$\begin{array}{l}\text { Very } \\
\text { Inaccurate } \\
\downarrow\end{array}$} & \multicolumn{4}{|c|}{$\begin{array}{r}\text { Very } \\
\text { Accurate } \\
\downarrow\end{array}$} \\
\hline 1. Am the life of the party. & 1 & 2 & 3 & 4 & 5 & 6 & 7 \\
\hline 2. Sympathise with others' feelings. & 1 & 2 & 3 & 4 & 5 & 6 & 7 \\
\hline 3. Get chores done right away. & 1 & 2 & 3 & 4 & 5 & 6 & 7 \\
\hline 4. Have frequent mood swings. & 1 & 2 & 3 & 4 & 5 & 6 & 7 \\
\hline 5. Have a vivid imagination. & 1 & 2 & 3 & 4 & 5 & 6 & 7 \\
\hline 6. Don't talk a lot. & 1 & 2 & 3 & 4 & 5 & 6 & 7 \\
\hline 7. Am not interested in other people's problems. & 1 & 2 & 3 & 4 & 5 & 6 & 7 \\
\hline 8. Have difficulty understanding abstract ideas. & 1 & 2 & 3 & 4 & 5 & 6 & 7 \\
\hline 9. Like order. & 1 & 2 & 3 & 4 & 5 & 6 & 7 \\
\hline 10. Make a mess of things. & 1 & 2 & 3 & 4 & 5 & 6 & 7 \\
\hline 11. Do not have a good imagination. & 1 & 2 & 3 & 4 & 5 & 6 & 7 \\
\hline 12. Feel others' emotions. & 1 & 2 & 3 & 4 & 5 & 6 & 7 \\
\hline 13. Am relaxed most of the time. & 1 & 2 & 3 & 4 & 5 & 6 & 7 \\
\hline 14. Get upset easily. & 1 & 2 & 3 & 4 & 5 & 6 & 7 \\
\hline 15. Seldom feel blue. & 1 & 2 & 3 & 4 & 5 & 6 & 7 \\
\hline 16. Keep in the background. & 1 & 2 & 3 & 4 & 5 & 6 & 7 \\
\hline 17. Am not really interested in others. & 1 & 2 & 3 & 4 & 5 & 6 & 7 \\
\hline 18. Am not interested in abstract ideas. & 1 & 2 & 3 & 4 & 5 & 6 & 7 \\
\hline 19. Often forget to put things back in their proper place. & 1 & 2 & 3 & 4 & 5 & 6 & 7 \\
\hline 20. Talk to a lot of different people at parties. & 1 & 2 & 3 & 4 & 5 & 6 & 7 \\
\hline 21. Feel entitled to more of everything. & 1 & 2 & 3 & 4 & 5 & 6 & 7 \\
\hline 22. On the whole am satisfied with myself. & 1 & 2 & 3 & 4 & 5 & 6 & 7 \\
\hline 23. Know that people in my life accept and value me. & 1 & 2 & 3 & 4 & 5 & 6 & 7 \\
\hline 24. Would like to be seen driving around in a very expensive car. & 1 & 2 & 3 & 4 & 5 & 6 & 7 \\
\hline 25. Deserve more things in life. & 1 & 2 & 3 & 4 & 5 & 6 & 7 \\
\hline 26. Take a positive attitude toward myself. & 1 & 2 & 3 & 4 & 5 & 6 & 7 \\
\hline 27. Feel like an outsider. & 1 & 2 & 3 & 4 & 5 & 6 & 7 \\
\hline 28. Would get a lot of pleasure from owning expensive luxury goods. & 1 & 2 & 3 & 4 & 5 & 6 & 7 \\
\hline 29. Am satisfied with the appearance, size and shape of my body. & 1 & 2 & 3 & 4 & 5 & 6 & 7 \\
\hline 30. Am inclined to feel that I am a failure. & 1 & 2 & 3 & 4 & 5 & 6 & 7 \\
\hline 31. Feel that I am often discriminated against because of my ethnicity. & 1 & 2 & 3 & 4 & 5 & 6 & 7 \\
\hline 32. Feel that I am often discriminated against because of my gender. & 1 & 2 & 3 & 4 & 5 & 6 & 7 \\
\hline 33. Know that people around me share my attitudes and beliefs. & 1 & 2 & 3 & 4 & 5 & 6 & 7 \\
\hline
\end{tabular}

During the last 30 days, how often did

(Please use the scale below to circle a number for each question)

\begin{tabular}{r|c}
$\begin{array}{r}\text { None Of } \\
\text { The Time }\end{array}$ & $\begin{array}{c}\text { A Little of } \\
\text { The Time }\end{array}$ \\
0 & 1
\end{tabular}

Some of
The Time
2

2

1. ... you feel hopeless?

2. ... you feel so depressed that nothing could cheer you up?

3. ... you feel restless or fidgety?

4. ... you feel that everything was an effort?

5. ... you feel worthless?

6. ... you feel nervous?

7. ... you have negative thoughts that repeated over and over?

8. ... you worry that a big earthquake might hit your region?

9. ... you feel exhausted?

\section{Most Of}

The Time

3

\section{All Of \\ The Time \\ 4}

\begin{tabular}{lllll}
0 & 1 & 2 & 3 & 4 \\
\hline 0 & 1 & 2 & 3 & 4 \\
\hline 0 & 1 & 2 & 3 & 4 \\
\hline 0 & 1 & 2 & 3 & 4 \\
\hline 0 & 1 & 2 & 3 & 4 \\
\hline 0 & 1 & 2 & 3 & 4 \\
\hline 0 & 1 & 2 & 3 & 4 \\
\hline 0 & 1 & 2 & 3 & 4 \\
\hline 0 & 1 & 2 & 3 & 4 \\
\hline
\end{tabular}




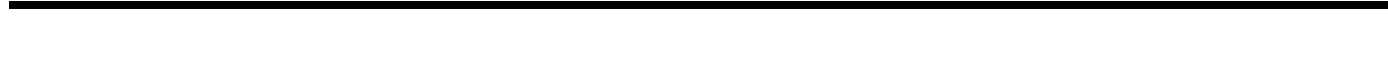

Strongly Strongly

Disagree

$\downarrow$

1. I wish people in this society would stop obsessing so much about race.

$\begin{array}{lllllll}1 & 2 & 3 & 4 & 5 & 6 & 7\end{array}$

2. It would be good if groups could be equal.

$\begin{array}{lllllll}1 & 2 & 3 & 4 & 5 & 6 & 7\end{array}$

3. I often think about the fact that I am a member of my ethnic group.

$\begin{array}{lllllll}1 & 2 & 3 & 4 & 5 & 6 & 7\end{array}$

4. I expect my health to get worse.

5. It would be best for everyone if the proper authorities censored magazines so that people could not get their hands on trashy and disgusting material.

$\begin{array}{lllllll}1 & 2 & 3 & 4 & 5 & 6 & 7\end{array}$

6. We should have increased social equality.

$\begin{array}{lllllll}1 & 2 & 3 & 4 & 5 & 6 & 7\end{array}$

7. I know there are people I can turn to when I need help.

$\begin{array}{lllllll}1 & 2 & 3 & 4 & 5 & 6 & 7\end{array}$

8. I wish I had more self-discipline.

9. We should do what we can to equalise conditions for different groups.

$\begin{array}{lllllll}1 & 2 & 3 & 4 & 5 & 6 & 7\end{array}$

$\begin{array}{lllllll}1 & 2 & 3 & 4 & 5 & 6 & 7\end{array}$

10. I seem to get sick a little easier than other people.

11. If incomes were more equal, people would be less motivated to work hard.

$\begin{array}{lllllll}1 & 2 & 3 & 4 & 5 & 6 & 7\end{array}$

12. Atheists and others who have rebelled against established religions are no doubt every bit as good and virtuous as those who attend church regularly.

13. To get ahead in life, it is sometimes okay to step on other groups.

14. The unity of New Zealand is weakened by too many immigrants.

15. Some of the best people in our country are those who are challenging our government, criticizing religion, and ignoring the "normal way" things are supposed to be done.

16. People from my ethnic group generally earn less than other groups in NZ.

17. People should pay less attention to The Bible and other old traditional forms of religious guidance, and instead develop their own personal standards of what is moral and immoral.

18. I have considered voting in terms of what is good for my particular ethnic group. $\begin{array}{llllllll}1 & 2 & 3 & 4 & 5 & 6 & 7\end{array}$

19. I feel at ease when I am in a city district in New Zealand with many immigrants. $\quad \begin{array}{lllllll}1 & 2 & 3 & 4 & 5 & 6 & 7\end{array}$

20. Our country will be destroyed some day if we do not smash the perversions eating away at our moral fibre and traditional beliefs.

21. I have considered participating in demonstrations on behalf of my ethnic group.

22. It is always better to trust the judgment of the proper authorities in government and religion than to listen to the noisy rabble-rousers in our society who are trying to create doubt in people's minds.

23. Everyone in New Zealand has a fair shot at wealth and happiness, regardless of ethnicity or race.

$\begin{array}{lllllll}1 & 2 & 3 & 4 & 5 & 6 & 7 \\ 1 & 2 & 3 & 4 & 5 & 6 & 7\end{array}$

$\begin{array}{lllllll}1 & 2 & 3 & 4 & 5 & 6 & 7\end{array}$

$\begin{array}{lllllll}1 & 2 & 3 & 4 & 5 & 6 & 7\end{array}$

$\begin{array}{lllllll}1 & 2 & 3 & 4 & 5 & 6 & 7\end{array}$

$\begin{array}{lllllll}1 & 2 & 3 & 4 & 5 & 6 & 7\end{array}$

$\begin{array}{lllllll}1 & 2 & 3 & 4 & 5 & 6 & 7\end{array}$

$\begin{array}{lllllll}1 & 2 & 3 & 4 & 5 & 6 & 7\end{array}$ 
1. By taking personal action I believe I can make a positive difference to environmental problems.

$\begin{array}{lllllll}1 & 2 & 3 & 4 & 5 & 6 & 7\end{array}$

2. Everyone has a fair shot at wealth and happiness in New Zealand.

$\begin{array}{lllllll}1 & 2 & 3 & 4 & 5 & 6 & 7\end{array}$

3. Despite what one hears about 'crime in the street,' there probably isn't any more now than there ever has been.

4. There are people I can depend on to help me if I really need it.

$\begin{array}{lllllll}1 & 2 & 3 & 4 & 5 & 6 & 7\end{array}$

5. I feel I can make a difference to the state of the environment.

$\begin{array}{lllllll}1 & 2 & 3 & 4 & 5 & 6 & 7\end{array}$

6. I think that Māori culture helps to define New Zealand in positive ways.

7. Women exaggerate problems they have at work.

8. In general, I find New Zealand society to be fair.

9. It's a dog-eat-dog world where you have to be ruthless at times.

$\begin{array}{lllllll}1 & 2 & 3 & 4 & 5 & 6 & 7\end{array}$

10. Bad smells, messes, dead animals and rotten food absolutely disgust me.

11. Women, compared to men, tend to have greater moral sensibility.

12. The fact that I am a member of my ethnic group is an important part of my identity.

13. In general, I have a lot of self-control.

14. I feel a sense of community with others in my local neighbourhood.

15. It is OK if some groups have more of a chance in life than others.

$\begin{array}{lllllll}1 & 2 & 3 & 4 & 5 & 6 & 7\end{array}$

16. There are too many immigrants living in New Zealand.

17. I generally earn less than other people in NZ.

18. I have considered signing petitions on behalf of my ethnic group.

19. Inferior groups should stay in their place.

20. Economic positions are legitimate reflections of people's achievements.

21. With enough support and professional help, people who have committed violent offences can be rehabilitated to become safe members of our society.

22. With enough support and professional help, people who have committed sexual offences can be rehabilitated to become safe members of our society.

23. It is OK for parents to use smacking as a way to discipline their children.

24. In general, the New Zealand political system operates as it should.

$\begin{array}{lllllll}1 & 2 & 3 & 4 & 5 & 6 & 7\end{array}$

$\begin{array}{lllllll}1 & 2 & 3 & 4 & 5 & 6 & 7\end{array}$

$\begin{array}{lllllll}1 & 2 & 3 & 4 & 5 & 6 & 7\end{array}$

$\begin{array}{lllllll}1 & 2 & 3 & 4 & 5 & 6 & 7\end{array}$

$\begin{array}{lllllll}1 & 2 & 3 & 4 & 5 & 6 & 7\end{array}$

25. There is no one I can turn to for guidance in times of stress.

$\begin{array}{lllllll}1 & 2 & 3 & 4 & 5 & 6 & 7\end{array}$

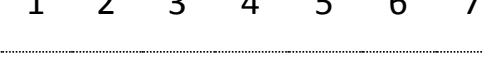

26. New Zealand would be a better place to live if we forgot about trying to promote Māori culture to everyone.

$\begin{array}{lllllll}1 & 2 & 3 & 4 & 5 & 6 & 7 \\ 1 & 2 & 3 & 4 & 5 & 6 & 7 \\ 1 & 2 & 3 & 4 & 5 & 6 & 7 \\ 1 & 2 & 3 & 4 & 5 & 6 & 7 \\ 1 & 2 & 3 & 4 & 5 & 6 & 7 \\ 1 & 2 & 3 & 4 & 5 & 6 & 7 \\ 1 & 2 & 3 & 4 & 5 & 6 & 7 \\ 1 & 2 & 3 & 4 & 5 & 6 & 7 \\ 1 & 2 & 3 & 4 & 5 & 6 & 7\end{array}$

$\begin{array}{lllllll}1 & 2 & 3 & 4 & 5 & 6 & 7 \\ 1 & 2 & 3 & 4 & 5 & 6 & 7 \\ 1 & 2 & 3 & 4 & 5 & 6 & 7 \\ 1 & 2 & 3 & 4 & 5 & 6 & 7 \\ 1 & 2 & 3 & 4 & 5 & 6 & 7\end{array}$

27. Life is not governed by the 'survival of the fittest.' We should let compassion and moral laws be our guide.

28. If they knew me, most NZers would respect what I have accomplished in life.

29. Māori have too much political power and influence in decisions affecting NZ.

30. Men and women both have a fair shot at wealth and happiness in NZ.

31. I think that homosexuality should be accepted by society.

$\begin{array}{lllllll}1 & 2 & 3 & 4 & 5 & 6 & 7\end{array}$

Please rate your feelings of WARMTH toward the following groups using the "feeling thermometer scale" for each group.

\section{Feel LEAST WARM \\ Toward This Group}

\section{1}

NZ Europeans

Māori

Asians in general

Pacific Islanders

Arabs

1

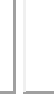

\begin{tabular}{|lllllll|}
\multicolumn{1}{c}{} & \multicolumn{1}{c}{} & & & & \\
\hline 1 & 2 & 3 & 4 & 5 & 6 & 7 \\
\hline 1 & 2 & 3 & 4 & 5 & 6 & 7 \\
\hline 1 & 2 & 3 & 4 & 5 & 6 & 7 \\
\hline 1 & 2 & 3 & 4 & 5 & 6 & 7 \\
\hline 1 & 2 & 3 & 4 & 5 & 6 & 7 \\
\hline
\end{tabular}

\section{Feel MOST WARM}

Toward This Group 7 
Now please rate your feelings of ANGER toward these same groups on the scale below.

Feel NO ANGER

Toward This Group
Feel ANGER

Toward This Group 7

\begin{tabular}{|l|lllllll|}
\hline Overweight people & 1 & 2 & 3 & 4 & 5 & 6 & 7 \\
\hline Immigrants in general & 1 & 2 & 3 & 4 & 5 & 6 & 7 \\
\hline Chinese & 1 & 2 & 3 & 4 & 5 & 6 & 7 \\
\hline Indians & 1 & 2 & 3 & 4 & 5 & 6 & 7 \\
\hline Muslims & 1 & 2 & 3 & 4 & 5 & 6 & 7 \\
\hline
\end{tabular}

Instructions: Please answer each of the following questions by circling a number on the scale below.

Definitely NO

1
2

\section{Unsure}

4
5

\section{Definitely YES}

7

1. Do you think people from your ethnic group are discriminated against in NZ?

$\begin{array}{lllllll}1 & 2 & 3 & 4 & 5 & 6 & 7\end{array}$

2. Are you willing to make sacrifices to your standard of living (e.g., accept higher prices, drive less, conserve energy) in order to protect the environment?

$\begin{array}{lllllll}1 & 2 & 3 & 4 & 5 & 6 & 7\end{array}$

3. Have you made sacrifices to your standard of living (e.g., accepted higher prices, driven less, conserved energy) in order to protect the environment?

$\begin{array}{lllllll}1 & 2 & 3 & 4 & 5 & 6 & 7\end{array}$

4. Do you think most New Zealanders are willing to make sacrifices to their standard of living in order to protect the environment?

5. Do you think most New Zealanders respect the achievements of your ethnic group?

6. Suppose a person has a painful incurable disease. Do you think that doctors should be allowed by law to end the patient's life if the patient requests it?

$\begin{array}{lllllll}1 & 2 & 3 & 4 & 5 & 6 & 7\end{array}$

$\begin{array}{lllllll}1 & 2 & 3 & 4 & 5 & 6 & 7\end{array}$

$\begin{array}{lllllll}1 & 2 & 3 & 4 & 5 & 6 & 7\end{array}$

Instructions: Please rate how strongly you oppose or support each of the following political parties.

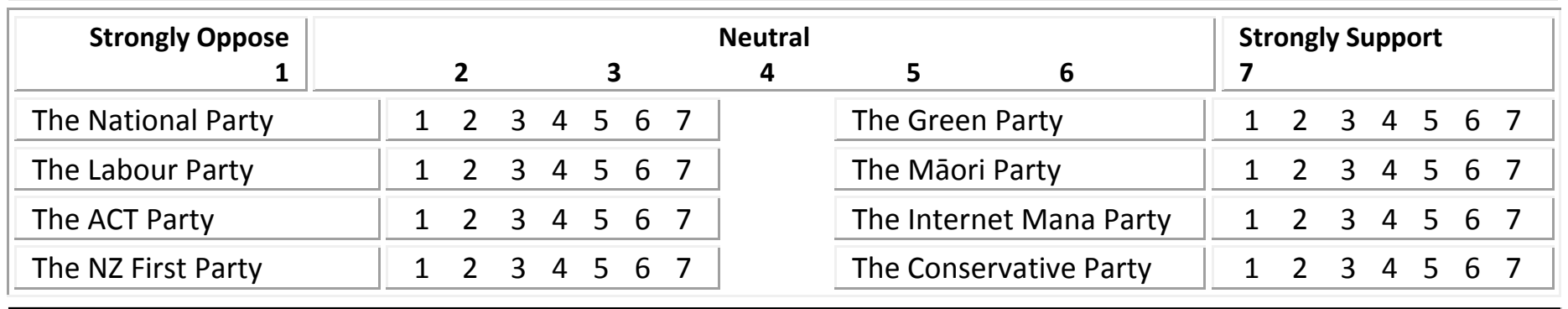

01. Please estimate how many hours you spent doing each of the following things last week. (please enter ' 0 hours' if you did not do that activity last week)

(a) Working in paid employment

(b) Housework/cooking

(c) Looking after children

(d) Playing computer games

(e) Exercising/physical activity

(f) Watching TV/Films

(g) Travelling/commuting

(h) Volunteer/charity work

(i) Using the internet

(j) Watching/reading the news

02. During the past month, on average, how many hours of actual sleep did you get per night?

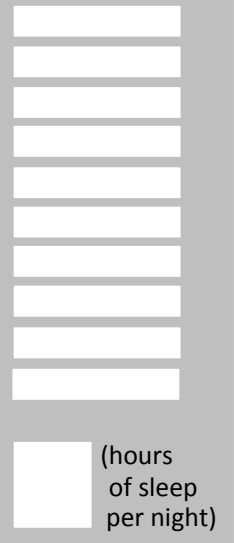

03a. How often do you have a drink containing alcohol?

And, if you drink alcohol..

03b. How many drinks containing alcohol do you have on a typical day when drinking?
04. Have you been diagnosed with, or treated for, any of the following health conditions by a doctor in the last five years?
High cholesterol
High blood pressure
Asthma
Heart disease
Diabetes (Type II)
Depression
Anxiety disorder
Other (please state):

05a. Do you smoke?

05b. If you smoke, how many cigarettes do you smoke in a normal day?

\section{Yes No \\ (cigarettes per day)}

06. Do you have a health condition or disability that limits you, and Yes No that has lasted for $\mathbf{6 + \text { months? }}$
(a) if yes, please state:

07. What is your height?

08. What is your weight? (metres) (kg)

09. In general, would you say your health is... Poor $\begin{array}{llllllll}1 & 2 & 3 & 4 & 5 & 6 & 7 & \text { Excellent }\end{array}$ 


\begin{tabular}{|c|c|c|c|c|c|c|c|}
\hline \multirow[b]{2}{*}{ Policies promoting closer trade ties between India and New Zealand. } & \multicolumn{2}{|c|}{$\begin{array}{l}\text { Strongly } \\
\text { Oppose } \\
\downarrow\end{array}$} & \multirow[b]{2}{*}{3} & \multirow[b]{2}{*}{4} & \multicolumn{3}{|c|}{$\begin{array}{c}\text { Strongly } \\
\text { Support } \\
\downarrow\end{array}$} \\
\hline & 1 & 2 & & & 5 & 6 & 7 \\
\hline 2. Performance of the Haka at international sports events. & 1 & 2 & 3 & 4 & 5 & 6 & 7 \\
\hline 3. Māori ownership of the seabed and foreshore. & 1 & 2 & 3 & 4 & 5 & 6 & 7 \\
\hline 4. Legalized abortion for women, regardless of the reason. & 1 & 2 & 3 & 4 & 5 & 6 & 7 \\
\hline $\begin{array}{l}\text { 5. Ensuring that all food and food ingredients sold in New Zealand are free from } \\
\text { Genetically Modified Organisms. }\end{array}$ & 1 & 2 & 3 & 4 & 5 & 6 & 7 \\
\hline $\begin{array}{l}\text { 6. Incentives to increase women's participation in the paid workforce (paid for } \\
\text { by government). }\end{array}$ & 1 & 2 & 3 & 4 & 5 & 6 & 7 \\
\hline 7. Policies promoting closer trade ties between China and New Zealand. & 1 & 2 & 3 & 4 & 5 & 6 & 7 \\
\hline 8. Protest marches and public demonstrations supporting the rights of Māori. & 1 & 2 & 3 & 4 & 5 & 6 & 7 \\
\hline 9. Restricting foreign ownership of New Zealand farms. & 1 & 2 & 3 & 4 & 5 & 6 & 7 \\
\hline 10. Restricting foreign ownership of New Zealand residential property. & 1 & 2 & 3 & 4 & 5 & 6 & 7 \\
\hline 11. The current anti-smacking law (i.e., it being illegal to smack children). & 1 & 2 & 3 & 4 & 5 & 6 & 7 \\
\hline $\begin{array}{l}\text { 12. The current ' } 3 \text { Strikes' law for violent/sexual offences, where the maximum } \\
\text { possible sentence must be imposed without parole upon the third conviction. }\end{array}$ & 1 & 2 & 3 & 4 & 5 & 6 & 7 \\
\hline 13. A publicly available online database of all convicted sex offenders in NZ. & 1 & 2 & 3 & 4 & 5 & 6 & 7 \\
\hline 14. Teaching Māori language in New Zealand primary schools. & 1 & 2 & 3 & 4 & 5 & 6 & 7 \\
\hline 15. Legalized abortion when the woman's life is endangered. & 1 & 2 & 3 & 4 & 5 & 6 & 7 \\
\hline 16. Reserving places for Māori students to study medicine. & 1 & 2 & 3 & 4 & 5 & 6 & 7 \\
\hline $\begin{array}{l}\text { 17. Increase payments for those receiving Jobseeker Support (formerly the } \\
\text { Unemployment Benefit). }\end{array}$ & 1 & 2 & 3 & 4 & 5 & 6 & 7 \\
\hline $\begin{array}{l}\text { 18. Increase payments for those receiving Sole Parent Support (formerly the } \\
\text { Domestic Purposes Benefit). }\end{array}$ & 1 & 2 & 3 & 4 & 5 & 6 & 7 \\
\hline 19. Waitangi Day as a national celebration of biculturalism. & 1 & 2 & 3 & 4 & 5 & 6 & 7 \\
\hline 20. The Civil Union Act. & 1 & 2 & 3 & 4 & 5 & 6 & 7 \\
\hline 21. Same-sex marriage in NZ (The Marriage Amendment Act 2013). & 1 & 2 & 3 & 4 & 5 & 6 & 7 \\
\hline 22. Including religious instruction in Christianity as part of the school & 1 & 2 & 3 & 4 & 5 & 6 & 7 \\
\hline 23. Rates exemptions on Māori land. & 1 & 2 & 3 & 4 & 5 & 6 & 7 \\
\hline $\begin{array}{l}\text { 24. Redistributing money and wealth more evenly among a larger percentage of } \\
\text { the people in New Zealand through heavy taxes on the rich. }\end{array}$ & 1 & 2 & 3 & 4 & 5 & 6 & 7 \\
\hline 25. Policies promoting more immigration from India to New Zealand. & 1 & 2 & 3 & 4 & 5 & 6 & 7 \\
\hline $\begin{array}{l}\text { 26. Introducing a programme to enhance sustainable business growth among } \\
\text { businesses owned and operated by women. }\end{array}$ & 1 & 2 & 3 & 4 & 5 & 6 & 7 \\
\hline 27. Singing the national anthem in Māori and English. & 1 & 2 & 3 & 4 & 5 & 6 & 7 \\
\hline 28. Policies promoting more immigration from China to New Zeala & 1 & 2 & 3 & 4 & 5 & 6 & 7 \\
\hline 29. Crown (government) ownership of the seabed and foreshore. & 1 & 2 & 3 & 4 & 5 & 6 & 7 \\
\hline \multirow[t]{2}{*}{ 30. A free-to-air Māori television channel. } & 1 & 2 & 3 & 4 & 5 & 6 & 7 \\
\hline & \multicolumn{3}{|c|}{ Never } & \multicolumn{4}{|c|}{$\begin{array}{l}\text { Extremely } \\
\text { Frequently }\end{array}$} \\
\hline 1. How frequently do you have POSITIVE/GOOD contact with NZ Europeans? & 1 & 2 & 3 & 4 & 5 & 6 & 7 \\
\hline 2. How frequently do you have NEGATIVE/BAD contact with NZ Europeans? & 1 & 2 & 3 & 4 & 5 & 6 & 7 \\
\hline 3. How frequently do you have POSITIVE/GOOD contact with Māori? & 1 & 2 & 3 & 4 & 5 & 6 & 7 \\
\hline 4. How frequently do you have NEGATIVE/BAD contact with Māori? & 1 & 2 & 3 & 4 & 5 & 6 & 7 \\
\hline 5. How frequently do you have POSITIVE/GOOD contact with Pacific Islanders? & 1 & 2 & 3 & 4 & 5 & 6 & 7 \\
\hline 6. How frequently do you have NEGATIVE/BAD contact with Pacific Islanders? & 1 & 2 & 3 & 4 & 5 & 6 & 7 \\
\hline 7. How frequently do you have POSITIVE/GOOD contact with Asians? & 1 & 2 & 3 & 4 & 5 & 6 & 7 \\
\hline 8. How frequently do you have NEGATIVE/BAD contact with Asians? & 1 & 2 & 3 & 4 & 5 & 6 & 7 \\
\hline
\end{tabular}


1. I make an effort to appear consistent to others.

$\begin{array}{lllllll}1 & 2 & 3 & 4 & 5 & 6 & 7\end{array}$

2. People who become preoccupied by race are forgetting that we're all just human. $\quad \begin{array}{llllll}1 & 2 & 3 & 4 & 5 & 7\end{array}$

3. The New Zealand government should be involved in regulating carbon emissions. $\quad \begin{array}{llllllllll}1 & 2 & 3 & 4 & 5 & 6\end{array}$

4. I feel a great pride in the land that is our New Zealand.

5. I am satisfied with my life.

6. Women are too easily offended.

7. Discrimination against Māori is no longer a problem in New Zealand.

$\begin{array}{lllllll}1 & 2 & 3 & 4 & 5 & 6 & 7\end{array}$

$\begin{array}{lllllll}1 & 2 & 3 & 4 & 5 & 6 & 7\end{array}$

$\begin{array}{lllllll}1 & 2 & 3 & 4 & 5 & 6 & 7\end{array}$

8. Everyone has the right to just and reasonable pay for the work they perform.

9. There are many dangerous people in our society who will attack someone out of pure meanness, for no reason at all.

10. We should all move on as one nation and forget about past differences and

conflicts between ethnic groups.

$\begin{array}{lllllll}1 & 2 & 3 & 4 & 5 & 6 & 7\end{array}$

$\begin{array}{lllllll}1 & 2 & 3 & 4 & 5 & 6 & 7\end{array}$

$\begin{array}{lllllll}1 & 2 & 3 & 4 & 5 & 6 & 7\end{array}$

$\begin{array}{lllllll}1 & 2 & 3 & 4 & 5 & 6 & 7\end{array}$

11. Putting racial labels on people obscures the fact that everyone is a unique individual.

12. Climate change is real.

13. Climate change is caused by humans.

14. I am deeply concerned about climate change.

15. In general, relations between different ethnic groups in New Zealand are fair.

16. Many women have a quality of purity that few men possess.

17. We should not have to pay for the mistakes of our ancestors.

18. Women seek to gain power by getting control over men.

19. Everyone has the right to food, clothing, housing and medicine, no matter what.

20. Some people are simply not responsible enough to own property.

21. People from other races would be likely to reject me on the basis of my race.

$\begin{array}{lllllll}1 & 2 & 3 & 4 & 5 & 6 & 7\end{array}$

$\begin{array}{lllllll}1 & 2 & 3 & 4 & 5 & 6 & 7\end{array}$

$\begin{array}{lllllll}1 & 2 & 3 & 4 & 5 & 6 & 7\end{array}$

22. Once a woman gets a man to commit to her she usually tries to put him on a tight leash.

23. Women, as compared to men, tend to have a more refined sense of culture and good taste.

24. I feel anxious about interacting with people from other races.

25. Most of New Zealand's policies serve the greater good.

26. People who weren't around in previous centuries should not feel accountable for

the actions of their ancestors.
27. Some people are simply not responsible enough to vote or take part in the

$\begin{array}{lllllll}1 & 2 & 3 & 4 & 5 & 6 & 7\end{array}$

$\begin{array}{lllllll}1 & 2 & 3 & 4 & 5 & 6 & 7\end{array}$

$\begin{array}{lllllll}1 & 2 & 3 & 4 & 5 & 6 & 7\end{array}$

$\begin{array}{lllllll}1 & 2 & 3 & 4 & 5 & 6 & 7\end{array}$

$\begin{array}{lllllll}1 & 2 & 3 & 4 & 5 & 6 & 7\end{array}$

$\begin{array}{lllllll}1 & 2 & 3 & 4 & 5 & 6 & 7\end{array}$

$\begin{array}{lllllll}1 & 2 & 3 & 4 & 5 & 6 & 7\end{array}$

$\begin{array}{lllllll}1 & 2 & 3 & 4 & 5 & 6 & 7\end{array}$

$\begin{array}{lllllll}1 & 2 & 3 & 4 & 5 & 6 & 7\end{array}$

$\begin{array}{lllllll}1 & 2 & 3 & 4 & 5 & 6 & 7\end{array}$

$\begin{array}{lllllll}1 & 2 & 3 & 4 & 5 & 6 & 7\end{array}$

28. The average citizen can have an influence on government decisions.
government of their country.

$\begin{array}{lllllll}1 & 2 & 3 & 4 & 5 & 6 & 7\end{array}$

$\begin{array}{lllllll}1 & 2 & 3 & 4 & 5 & 6 & 7\end{array}$

29. In general, relations between men and women in New Zealand are fair.

$\begin{array}{lllllll}1 & 2 & 3 & 4 & 5 & 6 & 7\end{array}$

30. In most ways my life is close to ideal.

31. Women should be cherished and protected by men.

$\begin{array}{lllllll}1 & 2 & 3 & 4 & 5 & 6 & 7\end{array}$

$\begin{array}{lllllll}1 & 2 & 3 & 4 & 5 & 6 & 7\end{array}$

32. Generally, the more influence NZ has on other nations, the better off they are.

33. When women lose to men in a fair competition, they typically complain about being discriminated against.

$\begin{array}{lllllll}1 & 2 & 3 & 4 & 5 & 6 & 7\end{array}$

$\begin{array}{lllllll}1 & 2 & 3 & 4 & 5 & 6 & 7\end{array}$

34. Although at times I may not agree with the government, my commitment to New Zealand always remains strong.

5. Every man ought to have a woman whom he adores.

$\begin{array}{lllllll}1 & 2 & 3 & 4 & 5 & 6 & 7\end{array}$

36. Being a member of my ethnic group is an important part of how I see myself.

$\begin{array}{lllllll}1 & 2 & 3 & 4 & 5 & 6 & 7\end{array}$

37. I'm frustrated by what my ethnic group earns relative to other groups in NZ.

38. I reckon Māori culture should stay where it belongs-with Māori. It doesn't concern other NZers.

39. I'm frustrated by what I earn relative to other people in NZ.

40. Foreign nations have done some very fine things but they are still not as good as New Zealand.

$\begin{array}{lllllll}1 & 2 & 3 & 4 & 5 & 6 & 7 \\ 1 & 2 & 3 & 4 & 5 & 6 & 7\end{array}$

$\begin{array}{lllllll}1 & 2 & 3 & 4 & 5 & 6 & 7\end{array}$

$\begin{array}{lllllll}1 & 2 & 3 & 4 & 5 & 6 & 7\end{array}$

$\begin{array}{lllllll}1 & 2 & 3 & 4 & 5 & 6 & 7\end{array}$ 
01. Which ethnic group(s) do you belong to?

(Mark the space or spaces that apply to you).
New Zealand European

Māori

Samoan

Cook Island Māori

Tongan

Niuean

Chinese

Indian

Other such as DUTCH, JAPANESE, TOKELAUAN. Please state:

\section{What is your gender?}

03. What is your date of birth?

04. Were you personally affected by the Christchurch earthquakes?

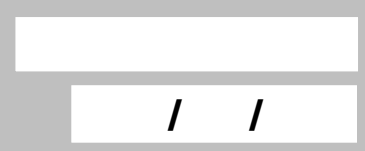

05. How long have you lived at your current address?

06a. What is your relationship status?

If you are in a relationship..

(e.g., single, married, de-facto, civil union, widowed, living together, etc.)

06b. How long have you been with your partner?

(years) (months)

06c. If you are currently married or in a civil union, what was the date of your marriage or union?

06d. How satisfied are you with your relationship?

$$
\begin{array}{llllllllll}
\text { Not satisfied } & 1 & 2 & 3 & 4 & 5 & 6 & 7 & \text { Very satisfied } \\
& \multicolumn{7}{c}{\text { Please circle a number }}
\end{array}
$$

06e. To what extent do you experience conflict or disagreement with your partner?

$\begin{array}{llllllllll}\text { No conflict at all } & 1 & 2 & 3 & 4 & 5 & 6 & 7 & \text { A great deal of conflict }\end{array}$

06f. Do you live with your partner? Yes No

06g. How satisfied do you think your PARTNER is with your relationship?

$$
\begin{array}{lllllllll}
\text { Not satisfied } & 1 & 2 & 3 & 4 & 5 & 6 & 7 & \text { Very satisfied } \\
& \multicolumn{7}{c}{\text { Please circle a number }}
\end{array}
$$

07a. Are you currently employed? (This includes self-employed or casual work)

07b. If yes, how long have you worked at your current organization?

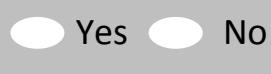

d (years) (months)

07c. What is your current occupation?

07d. How satisfied are you with your current job? $\begin{array}{llllllllll}\text { Not satisfied } & 1 & 2 & 3 & 4 & 5 & 6 & 7 & \text { Very satisfied }\end{array}$

07e. How secure do you feel in your current job?

$$
\begin{array}{llllllllll}
\text { Not secure } & 1 & 2 & 3 & 4 & 5 & 6 & 7 & \text { Very secure }
\end{array}
$$

08a. Has someone ever used the internet, a mobile phone, or digital camera to hurt, intimidate or embarrass you?

Yes No

09b. ...has this occurred in the last month? Yes No

10. How much money have you donated to charity in the last year?

\section{$\$$}

11. Please rate how politically left-wing versus right-wing you see yourself as being:

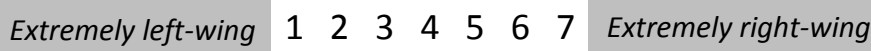

12. Have you ever been divorced?

Yes No

13. Where were you born?

(please be specific, e.g., which town/city?)
14. What is your highest

level of qualification?

15. Please estimate your total household income (before tax) for the year 2014

16. Please estimate your own personal earnings (before tax) for the year 2014

17. Please rate how politically liberal versus conservative you see yourself as being:

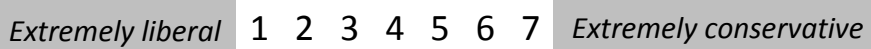

18a. How many children have you given birth to, fathered, or adopted?

18b. If you are a parent, what is the birth date of your eldest child?

18c. And, if you have more than one child, the birth date of your youngest child?

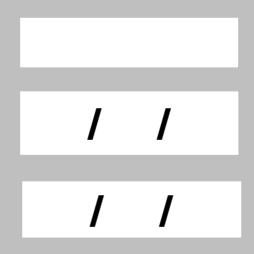

18d. How many children live with you most of the time?

19a. Do you have a Facebook profile?

19b. How many hours in the last week have you spent using Facebook?

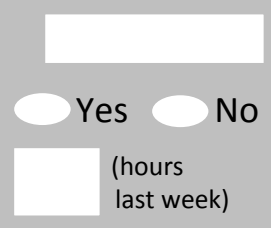

19c. How important a part of your daily routine is using Facebook?

$\begin{array}{lllllllll}\text { Not important } & 1 & 2 & 3 & 4 & 5 & 6 & 7 & \text { Very important }\end{array}$

20. Do you identify with a religion and/or spiritual group? If yes...

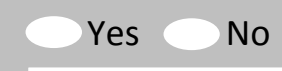

(a) what religion or spiritual group?

(b) how many times did you attend a church or place of worship in the last month?

(c) how many times did you pray in the last week?

(d) how many times did you read religious scripture in the last week?

(e) how important is your religion to how you see yourself?

$\begin{array}{llllllllll}\text { Not important } & 1 & 2 & 3 & 4 & 5 & 6 & 7 & \text { Very important }\end{array}$

21. Roughly how many hours have you spent with both FRIENDS/FAMILY and OTHERS (e.g., workmates, strangers) from each ethnic group in the last week?
(a) Māori
(b) NZ Europeans
(c) Pacific Islanders
(d) Asians

22a. Did you vote in the

New Zealand election in 2014?

FRIENDS/FAMILY OTHERS

22b. If yes, to which party did you give...
your party vote?
your electorate vote?

23. How important are your political beliefs to how you see yourself?

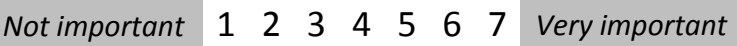

24. In the last year have you personally...
(a) been forced to buy cheaper food so you could pay for other things you needed?
(b) put up with feeling cold to save on heating costs?
(c) or the principal earner in your household been out-of-work?

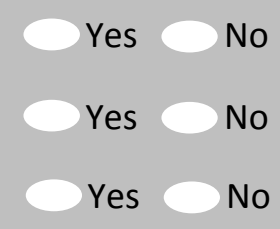

25. How would you describe your sexual orientation? 
Thank you for taking part in the New Zealand Attitudes and Values Study!

Please post back your completed questionnaire using the included freepost return envelope. The freepost envelope will work from anywhere in the world, so you can post it back even if you are overseas. If you lose the envelope, you can post this questionnaire back for free to:

FREEPOST AUTHORITY: 124589

Dr Chris Sibley, New Zealand Attitudes and Values Study

School of Psychology (Cost 9450/71708)

The University of Auckland

Private Bag 92019

Auckland 1142, New Zealand

If you would like to know more about the New Zealand Attitudes and Values Study then please feel free to phone us (contact details on the front) or you can visit the study website. We will also send a pamphlet to everyone in the study summarising the most exciting findings from the study this year.

http://www.psych.auckland.ac.nz/uoa/NZAVS

\section{Optional Feedback Box}

We are always looking for feedback to help improve the New Zealand Attitudes and Values Study. Have we missed anything important that would affect the interpretation of your responses? Or do you have any other general comments or suggestions about how we can improve the study for next year? 


\section{Follow-up Questionnaire for 2015/2016}

A scanned copy of this form will be kept for a period of up to fifteen years

www.psych.auckland.ac.nz

The University of Auckland

Private Bag 92019

Auckland, New Zealand

\section{Lead researcher:}

Dr. Chris Sibley, School of Psychology, The University of Auckland.

Phone: 09-373-7599, extn 87498. e-mail: nzavs@auckland.ac.nz

\section{Consent form and contact details}

This form is to gather your consent to participate in this phase of the New Zealand Attitudes and Values Study (NZAVS). Only Dr. Sibley and his research associates will have access to your responses. Your personal information will be kept separate from your responses at all times. Your questionnaire will be identified by an anonymous code. An encrypted electronic copy of all responses will be stored indefinitely for research purposes in a secure room in the School of Psychology.

I have read and understood a description of this research project. On this basis, I agree to take part. I understand that my data will remain confidential at all times. I understand that only Dr. Sibley and trusted research assistants working on the study in secure conditions will have access to my contact details. I consent to publication of the results of the project with the understanding that my anonymity will be preserved. I understand that I am free to withdraw from the research at any time up until the point at which I complete and return this questionnaire. I understand that my contact details will never be shared with anyone outside of the immediate research team. I understand that Dr. Sibley and the research team will use these details to contact and invite me to complete follow-up questionnaires, possibly for the next fourteen years. I understand that my contact details will be used to contact me if I win one of the grocery voucher prize draws for $\mathbf{\$ 5 0 0 ,} \mathbf{\$ 3 0 0}$ or $\mathbf{\$ 2 0 0}$ for participating in this study.

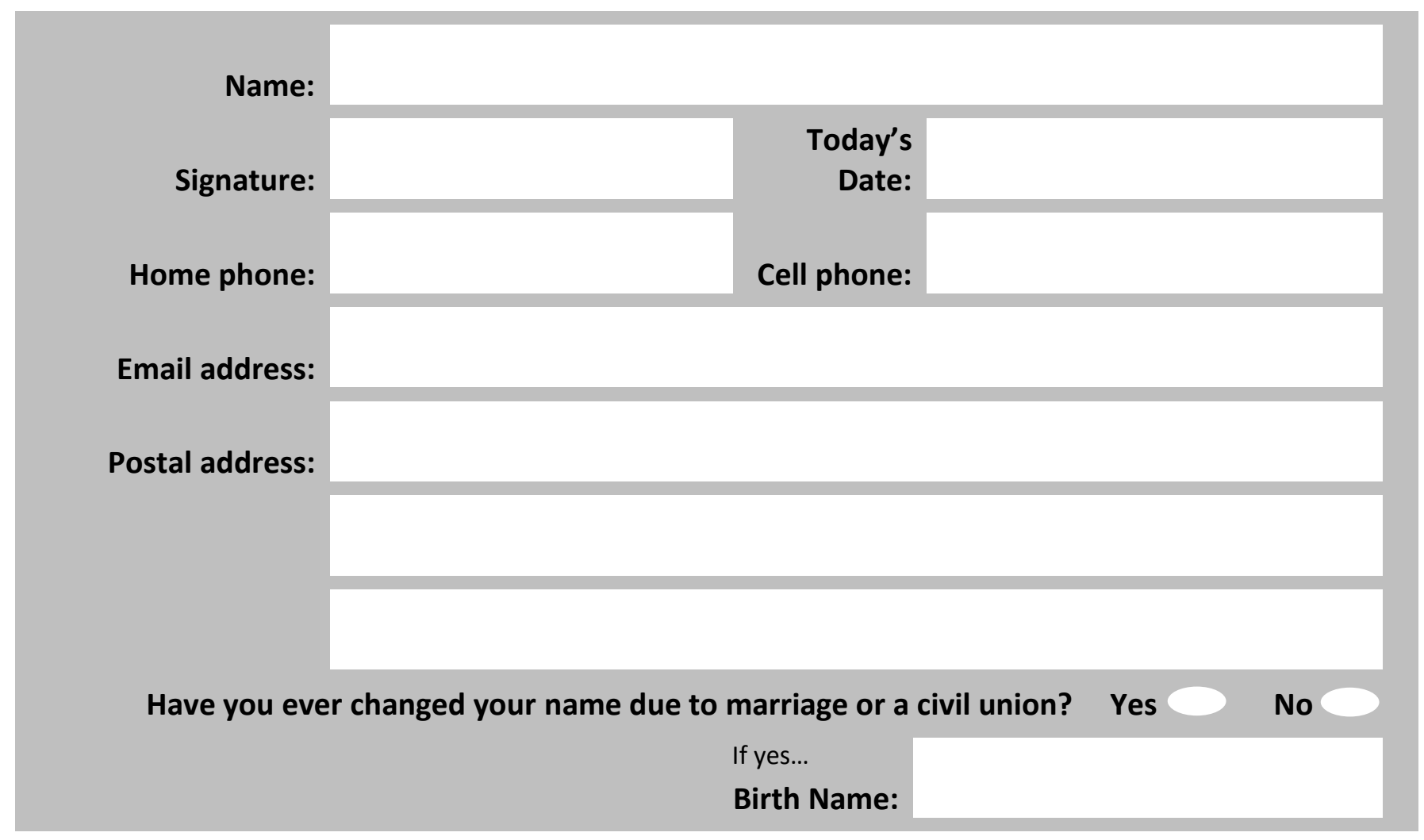


Page left intentionally blank 


\begin{tabular}{|c|c|c|c|c|c|c|c|}
\hline I $\ldots$ & \multicolumn{3}{|c|}{$\begin{array}{l}\text { Very } \\
\text { Inaccurate } \\
\downarrow\end{array}$} & \multicolumn{4}{|c|}{$\begin{array}{r}\text { Very } \\
\text { Accurate } \\
\downarrow\end{array}$} \\
\hline 1. Am the life of the party. & 1 & 2 & 3 & 4 & 5 & 6 & 7 \\
\hline 2. Sympathise with others' feelings. & 1 & 2 & 3 & 4 & 5 & 6 & 7 \\
\hline 3. Get chores done right away. & 1 & 2 & 3 & 4 & 5 & 6 & 7 \\
\hline 4. Have frequent mood swings. & 1 & 2 & 3 & 4 & 5 & 6 & 7 \\
\hline 5. Have a vivid imagination. & 1 & 2 & 3 & 4 & 5 & 6 & 7 \\
\hline 6. Don't talk a lot. & 1 & 2 & 3 & 4 & 5 & 6 & 7 \\
\hline 7. Am not interested in other people's problems. & 1 & 2 & 3 & 4 & 5 & 6 & 7 \\
\hline 8. Have difficulty understanding abstract ideas. & 1 & 2 & 3 & 4 & 5 & 6 & 7 \\
\hline 9. Like order. & 1 & 2 & 3 & 4 & 5 & 6 & 7 \\
\hline 10. Make a mess of things. & 1 & 2 & 3 & 4 & 5 & 6 & 7 \\
\hline 11. Do not have a good imagination. & 1 & 2 & 3 & 4 & 5 & 6 & 7 \\
\hline 12. Feel others' emotions. & 1 & 2 & 3 & 4 & 5 & 6 & 7 \\
\hline 13. Am relaxed most of the time. & 1 & 2 & 3 & 4 & 5 & 6 & 7 \\
\hline 14. Get upset easily. & 1 & 2 & 3 & 4 & 5 & 6 & 7 \\
\hline 15. Seldom feel blue. & 1 & 2 & 3 & 4 & 5 & 6 & 7 \\
\hline 16. Keep in the background. & 1 & 2 & 3 & 4 & 5 & 6 & 7 \\
\hline 17. Am not really interested in others. & 1 & 2 & 3 & 4 & 5 & 6 & 7 \\
\hline 18. Am not interested in abstract ideas. & 1 & 2 & 3 & 4 & 5 & 6 & 7 \\
\hline 19. Often forget to put things back in their proper place. & 1 & 2 & 3 & 4 & 5 & 6 & 7 \\
\hline 20. Talk to a lot of different people at parties. & 1 & 2 & 3 & 4 & 5 & 6 & 7 \\
\hline 21. Feel entitled to more of everything. & 1 & 2 & 3 & 4 & 5 & 6 & 7 \\
\hline 22. On the whole am satisfied with myself. & 1 & 2 & 3 & 4 & 5 & 6 & 7 \\
\hline 23. Know that people in my life accept and value me. & 1 & 2 & 3 & 4 & 5 & 6 & 7 \\
\hline 24. Would like to be seen driving around in a very expensive car. & 1 & 2 & 3 & 4 & 5 & 6 & 7 \\
\hline 25. Deserve more things in life. & 1 & 2 & 3 & 4 & 5 & 6 & 7 \\
\hline 26. Take a positive attitude toward myself. & 1 & 2 & 3 & 4 & 5 & 6 & 7 \\
\hline 27. Feel like an outsider. & 1 & 2 & 3 & 4 & 5 & 6 & 7 \\
\hline 28. Would get a lot of pleasure from owning expensive luxury goods. & 1 & 2 & 3 & 4 & 5 & 6 & 7 \\
\hline 29. Am satisfied with the appearance, size and shape of my body. & 1 & 2 & 3 & 4 & 5 & 6 & 7 \\
\hline 30. Am inclined to feel that I am a failure. & 1 & 2 & 3 & 4 & 5 & 6 & 7 \\
\hline 31. Feel that I am often discriminated against because of my ethnicity. & 1 & 2 & 3 & 4 & 5 & 6 & 7 \\
\hline 32. Feel that I am often discriminated against because of my gender. & 1 & 2 & 3 & 4 & 5 & 6 & 7 \\
\hline 33. Know that people around me share my attitudes and beliefs. & 1 & 2 & 3 & 4 & 5 & 6 & 7 \\
\hline
\end{tabular}

During the last 30 days, how often did

None Of
The Time

0

\section{A Little Of} The Time

1

(Please use the scale below to circle a number for each question)

1. ... you feel hopeless?

2. ... you feel so depressed that nothing could cheer you up?

Some of Most of

The Time The Time

2 3

3

3. ... you feel restless or fidgety?

4. ... you feel that everything was an effort?

5. ... you feel worthless?

6. ... you feel nervous?

7. ... you have negative thoughts that repeated over and over?

8. ... you worry that a big earthquake might hit your region?

9. ... you feel exhausted?

\begin{tabular}{lllll}
0 & 1 & 2 & 3 & 4 \\
\hline 0 & 1 & 2 & 3 & 4 \\
\hline 0 & 1 & 2 & 3 & 4 \\
\hline 0 & 1 & 2 & 3 & 4 \\
\hline 0 & 1 & 2 & 3 & 4 \\
\hline 0 & 1 & 2 & 3 & 4 \\
\hline 0 & 1 & 2 & 3 & 4 \\
\hline 0 & 1 & 2 & 3 & 4 \\
\hline 0 & 1 & 2 & 3 & 4 \\
\hline
\end{tabular}




\begin{tabular}{llllllll|}
$\begin{array}{c}\text { Strongly } \\
\text { Disagree } \\
\downarrow\end{array}$ & & & $\begin{array}{r}\text { Strongly } \\
\text { Agree } \\
\downarrow\end{array}$ \\
\hline 1 & 2 & 3 & 4 & 5 & 6 & 7 \\
\hline 1 & 2 & 3 & 4 & 5 & 6 & 7 \\
\hline 1 & 2 & 3 & 4 & 5 & 6 & 7 \\
\hline 1 & 2 & 3 & 4 & 5 & 6 & 7 \\
\hline 1 & 2 & 3 & 4 & 5 & 6 & 7 \\
\hline 1 & 2 & 3 & 4 & 5 & 6 & 7 \\
\hline 1 & 2 & 3 & 4 & 5 & 6 & 7 \\
\hline 1 & 2 & 3 & 4 & 5 & 6 & 7 \\
\hline 1 & 2 & 3 & 4 & 5 & 6 & 7 \\
\hline 1 & 2 & 3 & 4 & 5 & 6 & 7 \\
\hline 1 & 2 & 3 & 4 & 5 & 6 & 7 \\
\hline 1 & 2 & 3 & 4 & 5 & 6 & 7 \\
\hline 1 & 2 & 3 & 4 & 5 & 6 & 7 \\
\hline 1 & 2 & 3 & 4 & 5 & 6 & 7 \\
\hline 1 & 2 & 3 & 4 & 5 & 6 & 7 \\
\hline 1 & 2 & 3 & 4 & 5 & 6 & 7 \\
\hline 1 & 2 & 3 & 4 & 5 & 6 & 7 \\
\hline 1 & & & & & & \\
\hline
\end{tabular}

1. I am in control of my health.

2. It would be good if groups could be equal.

3. I often think about the fact that I am a member of my ethnic group.

4. I expect my health to get worse.

5. It would be best for everyone if the proper authorities censored magazines so that people could not get their hands on trashy and disgusting material.

6. We should have increased social equality.

7. I know there are people I can turn to when I need help.

8. I wish I had more self-discipline.

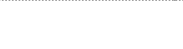

9. We should do what we can to equalise conditions for different groups.

10. I seem to get sick a little easier than other people.

11. If incomes were more equal, people would be less motivated to work hard.

12. Atheists and others who have rebelled against established religions are no doubt every bit as good and virtuous as those who attend church regularly.

13. To get ahead in life, it is sometimes okay to step on other groups.

14. The unity of New Zealand is weakened by too many immigrants.

$\begin{array}{lllllll}1 & 2 & 3 & 4 & 5 & 6 & 7\end{array}$

18. I have considered voting in terms of what is good for my particular ethnic group.

19. I feel at ease when I am in a city district in New Zealand with many immigrants.

20. Our country will be destroyed some day if we do not smash the perversions

eating away at our moral fibre and traditional beliefs.

$\begin{array}{lllllll}1 & 2 & 3 & 4 & 5 & 6 & 7\end{array}$

16. People from my ethnic group generally earn less than other groups in NZ.

17. People should pay less attention to The Bible and other old traditional forms of religious guidance, and instead develop their own personal standards of what is moral and immoral.

$\begin{array}{lllllll}1 & 2 & 3 & 4 & 5 & 6 & 7\end{array}$

21. I have considered participating in demonstrations on behalf of my ethnic group.

22. I identify with New Zealand.

23. It is always better to trust the judgment of the proper authorities in government and religion than to listen to the noisy rabble-rousers in our society who are trying to create doubt in people's minds.

24. Everyone in New Zealand has a fair shot at wealth and happiness, regardless of ethnicity or race.

$\begin{array}{lllllll}1 & 2 & 3 & 4 & 5 & 6 & 7 \\ 1 & 2 & 3 & 4 & 5 & 6 & 7\end{array}$

$\begin{array}{lllllll}1 & 2 & 3 & 4 & 5 & 6 & 7\end{array}$

$\begin{array}{lllllll}1 & 2 & 3 & 4 & 5 & 6 & 7\end{array}$

\section{Instructions: Please rate your level of satisfaction with the following aspects of your life and New Zealand.}

Completely Dissatisfied Somewhat Satisfied

\begin{tabular}{l|lllllllllll}
0 & 1 & 2 & 3 & 4 & 5 & 6 & 7 & 8 & 9 & 10 \\
\hline
\end{tabular}

1. Your standard of living.

2. The economic situation in New Zealand.

3. The quality of New Zealand's natural environment.

4. Your health.

5. The social conditions in New Zealand.

6. The performance of the current New Zealand government.

7. Your future security.

8. Business in New Zealand.

9. Your personal relationships.

10. Your access to health care when you need it (e.g., doctor, GP).

\begin{tabular}{lllllllllll}
0 & 1 & 2 & 3 & 4 & 5 & 6 & 7 & 8 & 9 & 10 \\
0 & 1 & 2 & 3 & 4 & 5 & 6 & 7 & 8 & 9 & 10 \\
0 & 1 & 2 & 3 & 4 & 5 & 6 & 7 & 8 & 9 & 10 \\
\hline 0 & 1 & 2 & 3 & 4 & 5 & 6 & 7 & 8 & 9 & 10 \\
0 & 1 & 2 & 3 & 4 & 5 & 6 & 7 & 8 & 9 & 10 \\
0 & 1 & 2 & 3 & 4 & 5 & 6 & 7 & 8 & 9 & 10 \\
0 & 1 & 2 & 3 & 4 & 5 & 6 & 7 & 8 & 9 & 10 \\
0 & 1 & 2 & 3 & 4 & 5 & 6 & 7 & 8 & 9 & 10 \\
0 & 1 & 2 & 3 & 4 & 5 & 6 & 7 & 8 & 9 & 10 \\
0 & 1 & 2 & 3 & 4 & 5 & 6 & 7 & 8 & 9 & 10
\end{tabular}


1. Everyone has a fair shot at wealth and happiness in New Zealand.

$\begin{array}{lllllll}1 & 2 & 3 & 4 & 5 & 6 & 7 \\ 1 & 2 & 3 & 4 & 5 & 6 & 7 \\ 1 & 2 & 3 & 4 & 5 & 6 & 7 \\ 1 & 2 & 3 & 4 & 5 & 6 & 7 \\ 1 & 2 & 3 & 4 & 5 & 6 & 7 \\ 1 & 2 & 3 & 4 & 5 & 6 & 7 \\ 1 & 2 & 3 & 4 & 5 & 6 & 7 \\ 1 & 2 & 3 & 4 & 5 & 6 & 7 \\ 1 & 2 & 3 & 4 & 5 & 6 & 7\end{array}$

2. If I take care of myself, I can avoid illness.

3. I feel a great pride in the land that is our New Zealand.

4. There are people I can depend on to help me if I really need it.

5. Most of New Zealand's policies serve the greater good.

6. People who weren't around in previous centuries should not feel accountable for the actions of their ancestors.

7. I think that Māori culture helps to define New Zealand in positive ways.

8. Women exaggerate problems they have at work.

9. In general, I find New Zealand society to be fair.

10. True equality can be achieved only once we recognize that some ethnic groups are currently more disadvantaged than others and require additional assistance from the government.

11. Women, compared to men, tend to have greater moral sensibility.

$\begin{array}{lllllll}1 & 2 & 3 & 4 & 5 & 6 & 7\end{array}$

12. The fact that I am a member of my ethnic group is an important part of my identity.

13. In general, I have a lot of self-control.

14. I feel a sense of community with others in my local neighbourhood.

$\begin{array}{lllllll}1 & 2 & 3 & 4 & 5 & 6 & 7\end{array}$

15. It is OK if some groups have more of a chance in life than others.

16. People's basic rights are well protected by the New Zealand Police.

17. There are too many immigrants living in New Zealand.

18. I generally earn less than other people in NZ.

19. I have considered signing petitions on behalf of my ethnic group.

$\begin{array}{lllllll}1 & 2 & 3 & 4 & 5 & 6 & 7\end{array}$

20. Māori have too much political power and influence in decisions affecting NZ.

21. Inferior groups should stay in their place.

$\begin{array}{lllllll}1 & 2 & 3 & 4 & 5 & 6 & 7\end{array}$

22. We are all one nation and we should all be treated the same. No one should be entitled to anything more than the rest of us simply because they belong to one particular ethnic group.

23. Economic positions are legitimate reflections of people's achievements.

24. By taking an active part in political and social affairs we, the people, can control world events.

25. In general, the New Zealand political system operates as it should.

26. There is no one I can turn to for guidance in times of stress.

27. New Zealand would be a better place to live if we forgot about trying to promote Māori culture to everyone.

$\begin{array}{lllllll}1 & 2 & 3 & 4 & 5 & 6 & 7\end{array}$

$\begin{array}{lllllll}1 & 2 & 3 & 4 & 5 & 6 & 7\end{array}$

$\begin{array}{lllllll}1 & 2 & 3 & 4 & 5 & 6 & 7\end{array}$

$\begin{array}{lllllll}1 & 2 & 3 & 4 & 5 & 6 & 7\end{array}$

$\begin{array}{lllllll}1 & 2 & 3 & 4 & 5 & 6 & 7\end{array}$

$\begin{array}{lllllll}1 & 2 & 3 & 4 & 5 & 6 & 7\end{array}$

$\begin{array}{lllllll}1 & 2 & 3 & 4 & 5 & 6 & 7\end{array}$

$\begin{array}{lllllll}1 & 2 & 3 & 4 & 5 & 6 & 7\end{array}$

28. if they knew me, most Nzers would resp

28. If they knew me, most NZers would respect what I have accomplished in life.

29. Foreign nations have done some very fine things but they are still not as good as New Zealand.

30. I think that homosexuality should be accepted by society.

31. We are all New Zealanders and the law should not make provision for minority groups because of their ethnicity.

32. There are many things about the New Zealand Police and its policies that need to be changed.

33. With enough effort we can wipe out political corruption.

34. It is safe to vaccinate children following the standard New Zealand

immunization schedule.

$\begin{array}{lllllll}1 & 2 & 3 & 4 & 5 & 6 & 7\end{array}$

$\begin{array}{lllllll}1 & 2 & 3 & 4 & 5 & 6 & 7\end{array}$

35. Men and women both have a fair shot at wealth and happiness in NZ.

36. Every man ought to have a woman whom he adores.

$\begin{array}{lllllll}1 & 2 & 3 & 4 & 5 & 6 & 7\end{array}$

37. The New Zealand Police care about the well-being of everyone they deal with.

\begin{tabular}{lllllll}
1 & 2 & 3 & 4 & 5 & 6 & 7 \\
1 & 2 & 3 & 4 & 5 & 6 & 7 \\
1 & 2 & 3 & 4 & 5 & 6 & 7 \\
1 & 2 & 3 & 4 & 5 & 6 & 7 \\
1 & 2 & 3 & 4 & 5 & 6 & 7 \\
1 & 2 & 3 & 4 & 5 & 6 & 7 \\
1 & 2 & 3 & 4 & 5 & 6 & 7 \\
1 & 2 & 3 & 4 & 5 & 6 & 7 \\
1 & 2 & 3 & 4 & 5 & 6 & 7 \\
1 & 2 & 3 & 4 & 5 & 6 & 7 \\
1 & 2 & 3 & 4 & 5 & 6 & 7 \\
1 & 2 & 3 & 4 & 5 & 6 & 7 \\
1 & 2 & 3 & 4 & 5 & 6 & 7 \\
\hline
\end{tabular}


Please rate your feelings of WARMTH toward the following groups using the "feeling thermometer scale" for each group.

\begin{tabular}{|c|c|c|c|c|c|c|c|c|c|c|c|c|c|c|c|}
\hline $\begin{array}{r}\text { Feel LEAST WARM } \\
\text { Toward This Group } \\
1\end{array}$ & \multicolumn{8}{|c|}{ Neutral } & \multicolumn{7}{|c|}{$\begin{array}{l}\text { Feel MOST WARM } \\
\text { Toward This Group } \\
7\end{array}$} \\
\hline NZ Europeans & 1 & 2 & 3 & 4 & 5 & 6 & 7 & Overweight people & 1 & 2 & 3 & 4 & 5 & 6 & 7 \\
\hline Māori & 1 & 2 & 3 & 4 & 5 & 6 & 7 & Immigrants in general & 1 & 2 & 3 & 4 & 5 & 6 & 7 \\
\hline Asians in general & 1 & 2 & 3 & 4 & 5 & 6 & 7 & Chinese & 1 & 2 & 3 & 4 & 5 & 6 & 7 \\
\hline Pacific Islanders & 1 & 2 & 3 & 4 & 5 & 6 & 7 & Indians & 1 & 2 & 3 & 4 & 5 & 6 & 7 \\
\hline Arabs & 1 & 2 & 3 & 4 & 5 & 6 & 7 & Muslims & 1 & 2 & 3 & 4 & 5 & 6 & 7 \\
\hline
\end{tabular}

Instructions: Please circle the number that best represents how important each of the following values is for you as a guiding principle in your life. Use the scale below to rate these items.

\begin{tabular}{|c|c|c|c|c|c|c|c|c|c|c|c|}
\hline $\begin{array}{r}\text { Opposed To } \\
\text { My Values } \\
-1 \\
\end{array}$ & $\begin{array}{c}\text { Not } \\
\text { Important } \\
0\end{array}$ & \multicolumn{2}{|c|}{ Important } & 5 & \multicolumn{3}{|c|}{$\begin{array}{c}\text { Very } \\
\text { Important }\end{array}$} & \multicolumn{4}{|c|}{$\begin{array}{l}\text { Of Supreme } \\
\text { Importance } \\
7\end{array}$} \\
\hline \multicolumn{3}{|c|}{ 1. PROTECTING THE ENVIRONMENT (preserving nature) } & -1 & 0 & 1 & 2 & 3 & 4 & 5 & 6 & 7 \\
\hline \multicolumn{3}{|c|}{ 2. A VARIED LIFE (filled with challenge, novelty and change) } & -1 & 0 & 1 & 2 & 3 & 4 & 5 & 6 & 7 \\
\hline \multicolumn{3}{|c|}{ 3. HONOURING OF PARENTS AND ELDERS (showing respect) } & -1 & 0 & 1 & 2 & 3 & 4 & 5 & 6 & 7 \\
\hline \multicolumn{3}{|c|}{ 4. AUTHORITY (the right to lead or command) } & -1 & 0 & 1 & 2 & 3 & 4 & 5 & 6 & 7 \\
\hline \multicolumn{3}{|c|}{ 5. EQUALITY (equal opportunity for all) } & -1 & 0 & 1 & 2 & 3 & 4 & 5 & 6 & 7 \\
\hline \multicolumn{3}{|c|}{ 6. UNITY WITH NATURE (fitting into nature) } & -1 & 0 & 1 & 2 & 3 & 4 & 5 & 6 & 7 \\
\hline \multicolumn{3}{|c|}{ 7. A WORLD AT PEACE (free of war and conflict) } & -1 & 0 & 1 & 2 & 3 & 4 & 5 & 6 & 7 \\
\hline \multicolumn{3}{|c|}{ 8. AN EXCITING LIFE (stimulating experiences) } & -1 & 0 & 1 & 2 & 3 & 4 & 5 & 6 & 7 \\
\hline \multicolumn{3}{|c|}{ 9. FAMILY SECURITY (safety for loved ones) } & -1 & 0 & 1 & 2 & 3 & 4 & 5 & 6 & 7 \\
\hline \multicolumn{3}{|c|}{ 10. INFLUENCE (having an impact on people and events) } & -1 & 0 & 1 & 2 & 3 & 4 & 5 & 6 & 7 \\
\hline \multicolumn{3}{|c|}{ 11. SOCIAL JUSTICE (correcting injustice, care for the weak) } & -1 & 0 & 1 & 2 & 3 & 4 & 5 & 6 & 7 \\
\hline \multicolumn{3}{|c|}{ 12. CURIOSITY (interest in everything, exploring) } & -1 & 0 & 1 & 2 & 3 & 4 & 5 & 6 & 7 \\
\hline \multicolumn{3}{|c|}{ 13. SELF-DISCIPLINE (self-restraint, resistance to temptation) } & -1 & 0 & 1 & 2 & 3 & 4 & 5 & 6 & 7 \\
\hline \multicolumn{3}{|c|}{ 14. WEALTH (material possessions, money) } & -1 & 0 & 1 & 2 & 3 & 4 & 5 & 6 & 7 \\
\hline
\end{tabular}

01. Please estimate how many hours you spent doing each of the following things last week. (please enter 'O hours' if you did not do that activity last week)

(a) Working in paid employment

(b) Housework/cooking

(c) Looking after children

(d) Volunteer/charity work

(e) Exercising/physical activity

(f) Watching TV/Films

(g) Travelling/commuting

(h) Watching/reading the news

(i) Using the internet (in total)

(j) Using social media (e.g., Facebook)

(k) Playing computer games

(I) Interacting with pets

(m) Putting on makeup/cosmetics

04. During the past month, on average, how many hours of actual sleep did you get per night?
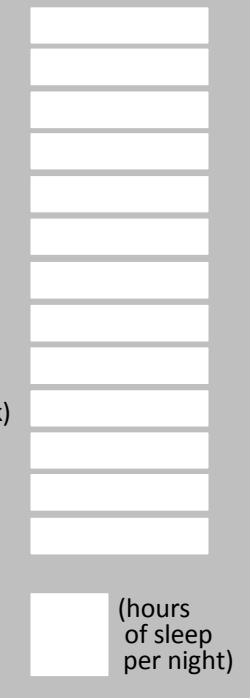

05a. How often do you have a drink containing alcohol?

And, if you drink alcohol..

05b. How many drinks containing alcohol do you have on a typical day when drinking?
06. Have you been diagnosed with, or treated for, any of the following health conditions by a doctor in the last five years?

High cholesterol
High blood pressure
Asthma
Heart disease
Diabetes (Type II)
Depression
Anxiety disorder
Other (please state):

07a. Have you ever smoked?

07b. If yes, at what age did you start smoking tobacco?

07c. Do you currently smoke?

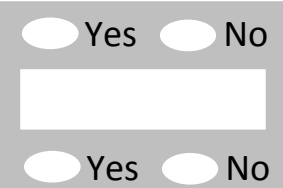

07d. If you currently smoke, how many cigarettes do you smoke in a normal day?

(cigarettes per day)

08. Do you have a health condition or disability that limits you, and that has lasted for $6+$ months?

Yes No

(a) if yes, please state:

09. In general, would you say your health is...

$$
\text { Poor } \begin{array}{llllllll}
1 & 2 & 3 & 4 & 5 & 6 & 7 & \text { Excellent }
\end{array}
$$$$
\text { Please circle a number }
$$

10. Should the design of the New Zealand flag be changed? 


\begin{tabular}{|c|c|c|c|c|c|c|c|}
\hline \multirow[b]{2}{*}{ Policies promoting closer trade ties between India and New Zealand. } & \multicolumn{2}{|c|}{$\begin{array}{l}\text { Strongly } \\
\text { Oppose }\end{array}$} & \multirow[b]{2}{*}{3} & \multirow[b]{2}{*}{4} & \multirow[b]{2}{*}{5} & \multicolumn{2}{|c|}{$\begin{array}{l}\text { Strongly } \\
\text { Support }\end{array}$} \\
\hline & 1 & 2 & & & & 6 & 7 \\
\hline 2. Performance of the Haka at international sports events. & 1 & 2 & 3 & 4 & 5 & 6 & 7 \\
\hline 3. Māori ownership of the seabed and foreshore. & 1 & 2 & 3 & 4 & 5 & 6 & 7 \\
\hline 4. Legalized abortion for women, regardless of the reason. & 1 & 2 & 3 & 4 & 5 & 6 & 7 \\
\hline $\begin{array}{l}\text { 5. Ensuring that all food and food ingredients sold in New Zealand are free from } \\
\text { Genetically Modified Organisms. }\end{array}$ & 1 & 2 & 3 & 4 & 5 & 6 & 7 \\
\hline $\begin{array}{l}\text { 6. Incentives to increase women's participation in the paid workforce (paid for } \\
\text { by government). }\end{array}$ & 1 & 2 & 3 & 4 & 5 & 6 & 7 \\
\hline 7. Policies promoting closer trade ties between China and New Zealand. & 1 & 2 & 3 & 4 & 5 & 6 & 7 \\
\hline 8. Protest marches and public demonstrations supporting the rights of Māori. & 1 & 2 & 3 & 4 & 5 & 6 & 7 \\
\hline 9. Restricting foreign ownership of New Zealand farms. & 1 & 2 & 3 & 4 & 5 & 6 & 7 \\
\hline 10. Restricting foreign ownership of New Zealand residential property. & 1 & 2 & 3 & 4 & 5 & 6 & 7 \\
\hline 11. Teaching Māori language in New Zealand primary schools. & 1 & 2 & 3 & 4 & 5 & 6 & 7 \\
\hline 12. Legalized abortion when the woman's life is endangered. & 1 & 2 & 3 & 4 & 5 & 6 & 7 \\
\hline 13. Reserving places for Māori students to study medicine. & 1 & 2 & 3 & 4 & 5 & 6 & 7 \\
\hline 14. Waitangi Day as a national celebration of biculturalism. & 1 & 2 & 3 & 4 & 5 & 6 & 7 \\
\hline 15. Same-sex marriage in NZ (The Marriage Amendment Act 2013). & 1 & 2 & 3 & 4 & 5 & 6 & 7 \\
\hline 16. Including religious instruction in Christianity as part of the school curriculum. & 1 & 2 & 3 & 4 & 5 & 6 & 7 \\
\hline 17. Rates exemptions on Māori land. & 1 & 2 & 3 & 4 & 5 & 6 & 7 \\
\hline $\begin{array}{l}\text { 18. Redistributing money and wealth more evenly among a larger percentage of } \\
\text { the people in New Zealand through heavy taxes on the rich. }\end{array}$ & 1 & 2 & 3 & 4 & 5 & 6 & 7 \\
\hline 19. Policies promoting more immigration from India to New Zealand. & 1 & 2 & 3 & 4 & 5 & 6 & 7 \\
\hline $\begin{array}{l}\text { 20. Introducing a programme to enhance sustainable business growth among } \\
\text { businesses owned and operated by women. }\end{array}$ & 1 & 2 & 3 & 4 & 5 & 6 & 7 \\
\hline 21. Singing the national anthem in Mãori and English. & 1 & 2 & 3 & 4 & 5 & 6 & 7 \\
\hline 22. Policies promoting more immigration from China to New Zealand. & 1 & 2 & 3 & 4 & 5 & 6 & 7 \\
\hline 23. Crown (government) ownership of the seabed and foreshore. & 1 & 2 & 3 & 4 & 5 & 6 & 7 \\
\hline 24. A free-to-air Māori television channel. & 1 & 2 & 3 & 4 & 5 & 6 & 7 \\
\hline 25. The current anti-smacking law (i.e., it being illegal to smack chi & 1 & 2 & 3 & 4 & 5 & 6 & 7 \\
\hline
\end{tabular}

Instructions: Please rate how strongly you oppose or support each of the following political parties.

\section{Strongly Oppose}

1

2

3

Neutral

4
5

\section{Strongly Support} 7

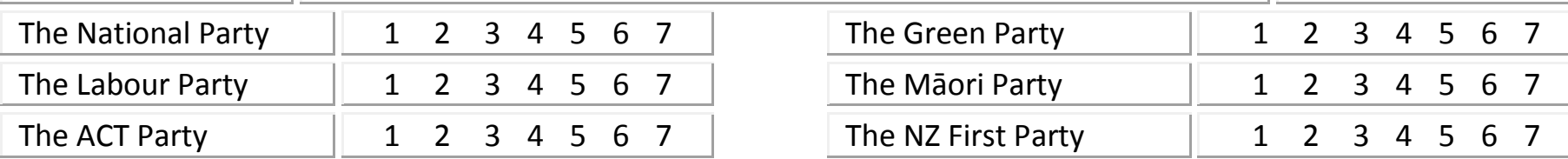

Instructions: Some people say that there are certain qualities that make someone a 'true' New Zealander. Others say there are not. How important do you personally think the following qualities are for being a 'true' New Zealander?

\section{Not Important}

1

2

Somewhat Important

3

4

1. To have New Zealand citizenship.

2. To be able to speak English.

3. To respect New Zealand's political institutions and laws.

4. To have Māori or European ancestry.

5. To like rugby.

6. To have a knowledge of Māori culture.

7. To be egalitarian - believe in equality.

8. To have a 'clean and green' attitude.

Very Important 7

6

\begin{tabular}{lllllll}
1 & 2 & 3 & 4 & 5 & 6 & 7 \\
\hline 1 & 2 & 3 & 4 & 5 & 6 & 7 \\
1 & 2 & 3 & 4 & 5 & 6 & 7 \\
1 & 2 & 3 & 4 & 5 & 6 & 7 \\
1 & 2 & 3 & 4 & 5 & 6 & 7 \\
1 & 2 & 3 & 4 & 5 & 6 & 7 \\
1 & 2 & 3 & 4 & 5 & 6 & 7 \\
1 & 2 & 3 & 4 & 5 & 6 & 7
\end{tabular}


1. If I get sick, it is my own behavior which determines how soon I get well again.

2. I am satisfied with my life.

3. Women are too easily offended.

$\begin{array}{lllllll}1 & 2 & 3 & 4 & 5 & 6 & 7\end{array}$

4. In general, relations between men and women in New Zealand are fair.

$\begin{array}{lllllll}1 & 2 & 3 & 4 & 5 & 6 & 7\end{array}$

5. We should all move on as one nation and forget about past differences and conflicts between ethnic groups.

6. Climate change is real.

7. Climate change is caused by humans.

$\begin{array}{lllllll}1 & 2 & 3 & 4 & 5 & 6 & 7\end{array}$

8. I am deeply concerned about climate change.

9. In general, relations between different ethnic groups in New Zealand are fair.

10. Many women have a quality of purity that few men possess.

$\begin{array}{lllllll}1 & 2 & 3 & 4 & 5 & 6 & 7\end{array}$

11. We should not have to pay for the mistakes of our ancestors.

$\begin{array}{lllllll}1 & 2 & 3 & 4 & 5 & 6 & 7\end{array}$

12. Women seek to gain power by getting control over men.

13. People from other races would be likely to reject me on the basis of my race.

14. Once a woman gets a man to commit to her she usually tries to put him on a tight leash.

15. Women, as compared to men, tend to have a more refined sense of culture and good taste.

16. I feel anxious about interacting with people from other races.

17. I would always provide information to the police to help them find someone suspected of committing a crime.

18. The average citizen can have an influence on government decisions.

$\begin{array}{lllllll}1 & 2 & 3 & 4 & 5 & 6 & 7\end{array}$

$\begin{array}{lllllll}1 & 2 & 3 & 4 & 5 & 6 & 7\end{array}$

$\begin{array}{lllllll}1 & 2 & 3 & 4 & 5 & 6 & 7\end{array}$

$\begin{array}{lllllll}1 & 2 & 3 & 4 & 5 & 6 & 7\end{array}$

$\begin{array}{lllllll}1 & 2 & 3 & 4 & 5 & 6 & 7\end{array}$

$\begin{array}{lllllll}1 & 2 & 3 & 4 & 5 & 6 & 7\end{array}$

$\begin{array}{lllllll}1 & 2 & 3 & 4 & 5 & 6 & 7\end{array}$

$\begin{array}{lllllll}1 & 2 & 3 & 4 & 5 & 6 & 7 \\ 1 & 2 & 3 & 4 & 5 & 6 & 7\end{array}$

$\begin{array}{lllllll}1 & 2 & 3 & 4 & 5 & 6 & 7\end{array}$

19. Discrimination against Māori is no longer a problem in New Zealand.

20. If I go to my doctor/GP with a minor illness (e.g., sore throat, cough, runny nose, etc.), I think that I should be prescribed antibiotics by default.

21. Women should be cherished and protected by men.

22. Generally, the more influence NZ has on other nations, the better off they are.

23. When women lose to men in a fair competition, they typically complain about being discriminated against.

24. Although at times I may not agree with the government, my commitment to New

Zealand always remains strong.

$\begin{array}{lllllll}1 & 2 & 3 & 4 & 5 & 6 & 7 \\ 1 & 2 & 3 & 4 & 5 & 6 & 7 \\ 1 & 2 & 3 & 4 & 5 & 6 & 7 \\ 1 & 2 & 3 & 4 & 5 & 6 & 7 \\ 1 & 2 & 3 & 4 & 5 & 6 & 7 \\ 1 & 2 & 3 & 4 & 5 & 6 & 7 \\ 1 & 2 & 3 & 4 & 5 & 6 & 7 \\ 1 & 2 & 3 & 4 & 5 & 6 & 7 \\ 1 & 2 & 3 & 4 & 5 & 6 & 7\end{array}$

25. I feel that I am often discriminated against because of my religious/spiritual beliefs.

26. In most ways my life is close to ideal.

27. Being a member of my ethnic group is an important part of how I see myself.

28. I'm frustrated by what my ethnic group earns relative to other groups in NZ.

$\begin{array}{lllllll}1 & 2 & 3 & 4 & 5 & 6 & 7\end{array}$

29. I reckon Māori culture should stay where it belongs-with Māori. It doesn't concern other NZers.

30. I'm frustrated by what I earn relative to other people in NZ.

31. I would always report dangerous or suspicious activities occurring in my neighbourhood to the police.

$\begin{array}{lllllll}1 & 2 & 3 & 4 & 5 & 6 & 7\end{array}$

$\begin{array}{lllllll}1 & 2 & 3 & 4 & 5 & 6 & 7\end{array}$

$\begin{array}{lllllll}1 & 2 & 3 & 4 & 5 & 6 & 7\end{array}$

$\begin{array}{lllllll}1 & 2 & 3 & 4 & 5 & 6 & 7\end{array}$

$\begin{array}{lllllll}1 & 2 & 3 & 4 & 5 & 6 & 7\end{array}$

$\begin{array}{lllllll}1 & 2 & 3 & 4 & 5 & 6 & 7\end{array}$

$\begin{array}{lllllll}1 & 2 & 3 & 4 & 5 & 6 & 7\end{array}$

\section{nemighourhood to the police.}

Never

Extremely Frequently

1. How frequently do you have POSITIVE/GOOD contact with NZ Europeans?

2. How frequently do you have NEGATIVE/BAD contact with NZ Europeans?

3. How frequently do you have POSITIVE/GOOD contact with Māori?

4. How frequently do you have NEGATIVE/BAD contact with Māori?

$\downarrow$

5. How frequently do you have POSITIVE/GOOD contact with Pacific Islanders?

6. How frequently do you have NEGATIVE/BAD contact with Pacific Islanders?

\begin{tabular}{lllllll}
1 & 2 & 3 & 4 & 5 & 6 & 7 \\
1 & 2 & 3 & 4 & 5 & 6 & 7 \\
1 & 2 & 3 & 4 & 5 & 6 & 7 \\
1 & 2 & 3 & 4 & 5 & 6 & 7 \\
1 & 2 & 3 & 4 & 5 & 6 & 7 \\
1 & 2 & 3 & 4 & 5 & 6 & 7 \\
1 & 2 & 3 & 4 & 5 & 6 & 7 \\
1 & 2 & 3 & 4 & 5 & 6 & 7 \\
\hline
\end{tabular}

8. How frequently do you have NEGATIVE/BAD contact with Asians?

(2)


01. Which ethnic group(s) do you belong to?

(Mark the space or spaces that apply to you).

02. What is your gender?

03a. What is your height?

$03 \mathrm{~b}$. What is your weight?

New Zealand European

Māori

Samoan

Cook Island Māori

Tongan

Niuean

Chinese

Indian

Other such as DUTCH, JAPANESE, TOKELAUAN. Please state:

04. What is your date of birth?

05a. What is your relationship status?

If you are in a relationship...

(e.g., single, married, de-facto, civil union, widowed, living together, etc.)

05b. How long have you been with your partner?
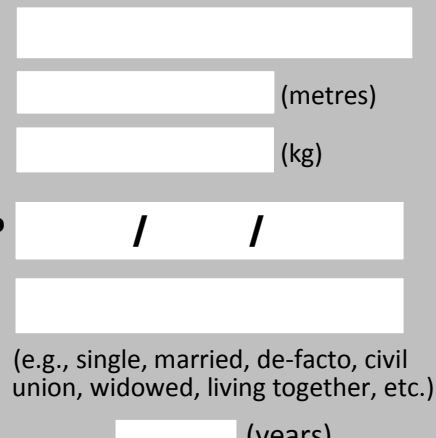
(years)
(months)

05c. If you are currently married or in a civil union, what was the date of your marriage or union?

05d. How satisfied are you with your relationship?

$$
\begin{array}{lllllllll}
\text { Not satisfied } & 1 & 2 & 3 & 4 & 5 & 6 & 7 & \text { Very satisfied } \\
& \multicolumn{7}{c}{\text { Please circle a number }}
\end{array}
$$

05e. To what extent do you experience conflict or disagreement with your partner?

$\begin{array}{lllllllll}\text { No conflict at all } & 1 & 2 & 3 & 4 & 5 & 6 & 7 & \text { A great deal of conflict }\end{array}$

05f. Do you live with your partner? Yes No

05g. What is your partner's gender?

05h. How satisfied do you think your PARTNER is with your relationship?

$$
\begin{array}{lllllllll}
\text { Not satisfied } & 1 & 2 & 3 & 4 & 5 & 6 & 7 & \text { Very satisfied } \\
& \multicolumn{7}{c}{\text { Please circle a number }} &
\end{array}
$$

06a. Are you currently employed?

(This includes self-employed or casual work)

06b. What is your current occupation?

06c. How satisfied are you with your current job?

$$
\begin{array}{llllllllll}
\text { Not satisfied } & 1 & 2 & 3 & 4 & 5 & 6 & 7 & \text { Very satisfied }
\end{array}
$$

06d. How secure do you feel in your current job?

$$
\begin{array}{llllllllll}
\text { Not secure } & 1 & 2 & 3 & 4 & 5 & 6 & 7 & \text { Very secure }
\end{array}
$$

07a. Has someone ever used the internet, a mobile phone, or digital camera to hurt, intimidate or embarrass you?

07b. ...has this occurred in the last month? Yes No

08. How much money have you donated to charity in the last year?

09. Please rate how politically left-wing versus right-wing you see yourself as being:

Extremely left-wing $1 \begin{array}{llllllll}1 & 2 & 3 & 4 & 5 & 6 & 7 & \text { Extremely right-wing }\end{array}$

10. Have you ever been divorced? Yes No

11. Do you own your own home? (either partly or fully owned)
12. What is your highest

level of qualification?

13. Please estimate your total household income (before tax) for the year 2015

14. Please estimate your own personal earnings (before tax) for the year 2015

15. Please rate how politically liberal versus conservative you see yourself as being:

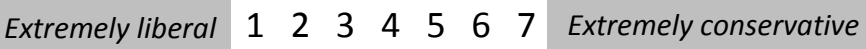

16a. How many children have you given birth to, fathered, or adopted?

16b. If you are a parent, what is the birth date of your eldest child?

16c. And, if you have more than one child, the birth date of your youngest child?

$16 \mathrm{~d}$. If you have children under 5 , do they go to a paid daycare program?

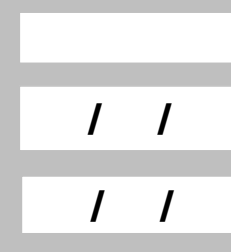

16e. If you have children under 18 , are their vaccinations up-to-date, as per the recommendations of your doctor/GP?

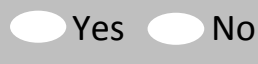

17. Do you identify with a religion and/or spiritual group? If yes...

(a) what religion or spiritual group?

(b) how many times did you attend a church or place of worship in the last month?

(c) how many times did you pray in the last week?

(d) how many times did you read religious scripture in the last week?

(e) approximately how many people belong to the church or place of worship that you attend most often?

(f) how important is your religion to how you see yourself?

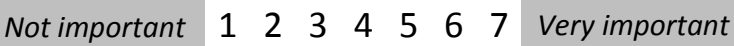

18. Roughly how many hours have you spent with both FRIENDS/FAMILY and OTHERS (e.g., workmates, strangers) from each ethnic group in the last week? FRIENDS/FAMILY OTHERS
(a) Māori
(b) NZ Europeans
(c) Pacific Islanders
(d) Asians
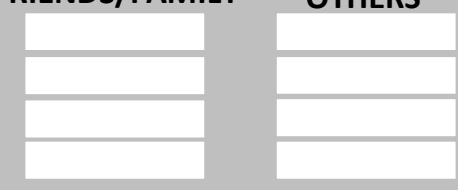

19a. Do you plan to vote in the next New Zealand election in 2017?

19b. If yes, to which party do you plan to give...

your party vote?

your electorate vote?

20. How important are your political beliefs to how you see yourself?

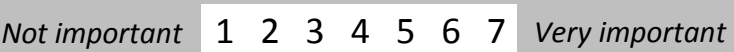

21. Do you believe in a God?

22. Do you believe in some form of spirit or life force?

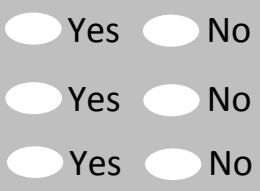

23. Do you have any pets?
(a) if yes, please specify: (e.g., 1 dog, 2 cats, etc.)

24. How would you describe your sexual orientation? 
Thank you for taking part in the New Zealand Attitudes and Values Study!

Please post back your completed questionnaire using the included freepost return envelope. The freepost envelope will work from anywhere in the world, so you can post it back even if you are overseas. If you lose the envelope, you can post this questionnaire back for free to:

FREEPOST AUTHORITY: 124589

Dr Chris Sibley, New Zealand Attitudes and Values Study

School of Psychology (Cost 9450/71708)

The University of Auckland

Private Bag 92019

Auckland 1142, New Zealand

If you would like to know more about the New Zealand Attitudes and Values Study, then please feel free to phone us (contact details on the front) or you can visit the study website. We will also send a pamphlet to everyone in the study summarising the most exciting findings from the study this year.

http://www.psych.auckland.ac.nz/uoa/NZAVS

\section{Optional Feedback Box}

We are always looking for feedback to help improve the New Zealand Attitudes and Values Study. Have we missed anything important that would affect the interpretation of your responses? Or do you have any other general comments or suggestions about how we can improve the study for next year? 


\section{The New Zealand Attitudes and Values Study}

\section{Follow-up Questionnaire for 2016/2017}

A scanned copy of this form will be kept for a period of up to fifteen years
Te Whare Wãnanga o Tãmaki Makaurau

Human Sciences Building

Level 6, 10 Symonds Street Auckland, New Zealand

Telephone 6493737599 ext. 87498

Facsimile 6493737450

www.psych.auckland.ac.nz

The University of Auckland

Private Bag 92019

Auckland, New Zealand

\section{Lead researcher: $\quad$ Dr. Chris Sibley, School of Psychology, The University of Auckland.}

Phone: 09-373-7599, extn 87498. e-mail: nzavs@auckland.ac.nz

\section{Consent form and contact details}

This form is to gather your consent to participate in this phase of the New Zealand Attitudes and Values Study (NZAVS). Only Dr. Sibley and his research associates will have access to your responses. Your personal information will be kept separate from your responses at all times. Your questionnaire will be identified by an anonymous code. An encrypted electronic copy of all responses will be stored indefinitely for research purposes in a secure room in the School of Psychology.

I have read and understood a description of this research project. On this basis, I agree to take part. I understand that my data will remain confidential at all times. I understand that only Dr. Sibley and trusted research assistants working on the study in secure conditions will have access to my contact details. I consent to publication of the results of the project with the understanding that my anonymity will be preserved. I understand that I am free to withdraw from the research at any time up until the point at which I complete and return this questionnaire. I understand that my contact details will never be shared with anyone outside of the immediate research team. I understand that Dr. Sibley and the research team will use these details to contact and invite me to complete follow-up questionnaires, possibly for the next twelve years. I understand that my contact details will be used to contact me if I win one of the grocery voucher prize draws for $\mathbf{\$ 5 0 0 ,} \mathbf{\$ 3 0 0}$ or $\mathbf{\$ 2 0 0}$ for participating in this study.

\begin{tabular}{r|r}
\hline Name: & $\begin{array}{r}\text { Today's } \\
\text { Date: }\end{array}$ \\
\hline Signature: & Cell phone: \\
\hline Home phone: & \\
\hline Postal address: & \\
\hline Have you ever changed your name due to marriage or a civil union? & Yes \\
\hline & If yes... \\
\hline & Birth Name: \\
\hline
\end{tabular}


Page left intentionally blank 


\begin{tabular}{|c|c|c|c|c|c|c|c|}
\hline I ... & \multicolumn{3}{|c|}{$\begin{array}{l}\text { Very } \\
\text { Inaccurate } \\
\downarrow\end{array}$} & \multicolumn{4}{|c|}{$\begin{array}{r}\text { Very } \\
\text { Accurate } \\
\downarrow\end{array}$} \\
\hline 1. Am the life of the party. & 1 & 2 & 3 & 4 & 5 & 6 & 7 \\
\hline 2. Sympathise with others' feelings. & 1 & 2 & 3 & 4 & 5 & 6 & 7 \\
\hline 3. Get chores done right away. & 1 & 2 & 3 & 4 & 5 & 6 & 7 \\
\hline 4. Have frequent mood swings. & 1 & 2 & 3 & 4 & 5 & 6 & 7 \\
\hline 5. Have a vivid imagination. & 1 & 2 & 3 & 4 & 5 & 6 & 7 \\
\hline 6. Don't talk a lot. & 1 & 2 & 3 & 4 & 5 & 6 & 7 \\
\hline 7. Am not interested in other people's problems. & 1 & 2 & 3 & 4 & 5 & 6 & 7 \\
\hline 8. Have difficulty understanding abstract ideas. & 1 & 2 & 3 & 4 & 5 & 6 & 7 \\
\hline 9. Like order. & 1 & 2 & 3 & 4 & 5 & 6 & 7 \\
\hline 10. Make a mess of things. & 1 & 2 & 3 & 4 & 5 & 6 & 7 \\
\hline 11. Do not have a good imagination. & 1 & 2 & 3 & 4 & 5 & 6 & 7 \\
\hline 12. Feel others' emotions. & 1 & 2 & 3 & 4 & 5 & 6 & 7 \\
\hline 13. Am relaxed most of the time. & 1 & 2 & 3 & 4 & 5 & 6 & 7 \\
\hline 14. Get upset easily. & 1 & 2 & 3 & 4 & 5 & 6 & 7 \\
\hline 15. Seldom feel blue. & 1 & 2 & 3 & 4 & 5 & 6 & 7 \\
\hline 16. Keep in the background. & 1 & 2 & 3 & 4 & 5 & 6 & 7 \\
\hline 17. Am not really interested in others. & 1 & 2 & 3 & 4 & 5 & 6 & 7 \\
\hline 18. Am not interested in abstract ideas. & 1 & 2 & 3 & 4 & 5 & 6 & 7 \\
\hline 19. Often forget to put things back in their proper place. & 1 & 2 & 3 & 4 & 5 & 6 & 7 \\
\hline 20. Talk to a lot of different people at parties. & 1 & 2 & 3 & 4 & 5 & 6 & 7 \\
\hline 21. Feel entitled to more of everything. & 1 & 2 & 3 & 4 & 5 & 6 & 7 \\
\hline 22. On the whole am satisfied with myself. & 1 & 2 & 3 & 4 & 5 & 6 & 7 \\
\hline 23. Know that people in my life accept and value me. & 1 & 2 & 3 & 4 & 5 & 6 & 7 \\
\hline 24. Would like to be seen driving around in a very expensive car. & 1 & 2 & 3 & 4 & 5 & 6 & 7 \\
\hline 25. Deserve more things in life. & 1 & 2 & 3 & 4 & 5 & 6 & 7 \\
\hline 26. Take a positive attitude toward myself. & 1 & 2 & 3 & 4 & 5 & 6 & 7 \\
\hline 27. Feel like an outsider. & 1 & 2 & 3 & 4 & 5 & 6 & 7 \\
\hline 28. Would get a lot of pleasure from owning expensive luxury goods. & 1 & 2 & 3 & 4 & 5 & 6 & 7 \\
\hline 29. Am satisfied with the appearance, size and shape of my body. & 1 & 2 & 3 & 4 & 5 & 6 & 7 \\
\hline 30. Am inclined to feel that I am a failure. & 1 & 2 & 3 & 4 & 5 & 6 & 7 \\
\hline 31. Feel that I am often discriminated against because of my ethnicity. & 1 & 2 & 3 & 4 & 5 & 6 & 7 \\
\hline 32. Feel that I am often discriminated against because of my gender. & 1 & 2 & 3 & 4 & 5 & 6 & 7 \\
\hline 33. Know that people around me share my attitudes and beliefs. & 1 & 2 & 3 & 4 & 5 & 6 & 7 \\
\hline
\end{tabular}

During the last 30 days, how often did

None of
The Time

0

\section{A Little Of The Time}

1
(Please use the scale below to circle a number for each question)

$\begin{array}{ll}\text { Some of } & \text { Most Of } \\ \text { The Time } & \text { The Time }\end{array}$

2

3

1. ... you feel hopeless?

2. ... you feel so depressed that nothing could cheer you up?

3. ... you feel restless or fidgety?

4. ... you feel that everything was an effort?

5. ... you feel worthless?

6. ... you feel nervous?

7. ... you have negative thoughts that repeated over and over?

8. ... you worry that a big earthquake might hit your region?

9. ... you feel exhausted?

\begin{tabular}{lllll}
0 & 1 & 2 & 3 & 4 \\
\hline 0 & 1 & 2 & 3 & 4 \\
0 & 1 & 2 & 3 & 4 \\
0 & 1 & 2 & 3 & 4 \\
0 & 1 & 2 & 3 & 4 \\
\hline 0 & 1 & 2 & 3 & 4 \\
0 & 1 & 2 & 3 & 4 \\
\hline 0 & 1 & 2 & 3 & 4 \\
0 & 1 & 2 & 3 & 4 \\
\hline
\end{tabular}




\begin{tabular}{lllllll|l}
$\begin{array}{c}\text { Strongly } \\
\text { Disagree } \\
\downarrow\end{array}$ & & & $\begin{array}{r}\text { Strongly } \\
\text { Agree } \\
\downarrow\end{array}$ \\
\hline 1 & 2 & 3 & 4 & 5 & 6 & 7 \\
\hline 1 & 2 & 3 & 4 & 5 & 6 & 7 \\
\hline 1 & 2 & 3 & 4 & 5 & 6 & 7 \\
\hline 1 & 2 & 3 & 4 & 5 & 6 & 7 \\
\hline 1 & 2 & 3 & 4 & 5 & 6 & 7 \\
\hline 1 & 2 & 3 & 4 & 5 & 6 & 7 \\
\hline 1 & 2 & 3 & 4 & 5 & 6 & 7 \\
\hline 1 & 2 & 3 & 4 & 5 & 6 & 7 \\
\hline 1 & 2 & 3 & 4 & 5 & 6 & 7 \\
\hline 1 & 2 & 3 & 4 & 5 & 6 & 7 \\
\hline 1 & 2 & 3 & 4 & 5 & 6 & 7 \\
\hline 1 & 2 & 3 & 4 & 5 & 6 & 7 \\
\hline 1 & 2 & 3 & 4 & 5 & 6 & 7 \\
\hline 1 & 2 & 3 & 4 & 5 & 6 & 7 \\
\hline 1 & 2 & 3 & 4 & 5 & 6 & 7 \\
\hline 1 & 2 & 3 & 4 & 5 & 6 & 7 \\
\hline 1 & 2 & 3 & 4 & 5 & 6 & 7 \\
\hline 1 & 2 & 3 & 4 & 6 & 7 \\
\hline
\end{tabular}

1. I am in control of my health.

2. It would be good if groups could be equal.

3. I often think about the fact that I am a member of my ethnic group.

4. I expect my health to get worse.

5. It would be best for everyone if the proper authorities censored magazines so that people could not get their hands on trashy and disgusting material.

6. We should have increased social equality.

7. I know there are people I can turn to when I need help.

8. I wish I had more self-discipline.

9. We should do what we can to equalise conditions for different groups.

10. I seem to get sick a little easier than other people.

11. If incomes were more equal, people would be less motivated to work hard.

12. Atheists and others who have rebelled against established religions are no doubt every bit as good and virtuous as those who attend church regularly.

13. To get ahead in life, it is sometimes okay to step on other groups.

14. The unity of New Zealand is weakened by too many immigrants.

(n)

5. Some of the best people in our country are those who are challenging our government, criticizing religion, and ignoring the "normal way" things are supposed to be done.

16. People from my ethnic group generally earn less than other groups in NZ.

17. People should pay less attention to The Bible and other old traditional forms of religious guidance, and instead develop their own personal standards of what is moral and immoral.

18. I have considered voting in terms of what is good for my particular ethnic group. $\quad \begin{array}{llllllll}1 & 2 & 3 & 4 & 5 & 6 & 7\end{array}$

19. I feel at ease when I am in a city district in New Zealand with many immigrants. $\quad \begin{array}{llllllll}1 & 2 & 3 & 4 & 5 & 6 & 7\end{array}$

20. Our country will be destroyed some day if we do not smash the perversions eating away at our moral fibre and traditional beliefs.

$\begin{array}{lllllll}1 & 2 & 3 & 4 & 5 & 6 & 7\end{array}$

21. I have considered participating in demonstrations on behalf of my ethnic group.

22. I identify with New Zealand.

23. It is always better to trust the judgment of the proper authorities in government and religion than to listen to the noisy rabble-rousers in our society who are trying to create doubt in people's minds.

24. Everyone in New Zealand has a fair shot at wealth and happiness, regardless of ethnicity or race.

$\begin{array}{lllllll}1 & 2 & 3 & 4 & 5 & 6 & 7 \\ 1 & 2 & 3 & 4 & 5 & 6 & 7\end{array}$

$\begin{array}{lllllll}1 & 2 & 3 & 4 & 5 & 6 & 7\end{array}$

$\begin{array}{lllllll}1 & 2 & 3 & 4 & 5 & 6 & 7\end{array}$

\section{Instructions: Please rate your level of satisfaction with the following aspects of your life and New Zealand.}

Completely Dissatisfied

0

Somewhat Satisfied

$\begin{array}{llllll}4 & 5 & 6 & 7 & 8 & 9\end{array}$

\section{Completely Satisfied} 10

1. Your standard of living.

2. The economic situation in New Zealand.

3. The quality of New Zealand's natural environment.

4. Your health.

5. The social conditions in New Zealand.

6. The performance of the current New Zealand government.

7. Your future security.

8. Business in New Zealand.

9. Your personal relationships.

10. Your access to health care when you need it (e.g., doctor, GP).

$\begin{array}{lllllllllll}0 & 1 & 2 & 3 & 4 & 5 & 6 & 7 & 8 & 9 & 10\end{array}$

$\begin{array}{lllllllllll}0 & 1 & 2 & 3 & 4 & 5 & 6 & 7 & 8 & 9 & 10\end{array}$

$\begin{array}{lllllllllll}0 & 1 & 2 & 3 & 4 & 5 & 6 & 7 & 8 & 9 & 10\end{array}$

$\begin{array}{lllllllllll}0 & 1 & 2 & 3 & 4 & 5 & 6 & 7 & 8 & 9 & 10\end{array}$

$\begin{array}{lllllllllll}0 & 1 & 2 & 3 & 4 & 5 & 6 & 7 & 8 & 9 & 10\end{array}$

$\begin{array}{lllllllllll}0 & 1 & 2 & 3 & 4 & 5 & 6 & 7 & 8 & 9 & 10\end{array}$

$\begin{array}{lllllllllll}0 & 1 & 2 & 3 & 4 & 5 & 6 & 7 & 8 & 9 & 10\end{array}$

$\begin{array}{lllllllllll}0 & 1 & 2 & 3 & 4 & 5 & 6 & 7 & 8 & 9 & 10\end{array}$

$\begin{array}{lllllllllll}0 & 1 & 2 & 3 & 4 & 5 & 6 & 7 & 8 & 9 & 10\end{array}$

$\begin{array}{lllllllllll}0 & 1 & 2 & 3 & 4 & 5 & 6 & 7 & 8 & 9 & 10\end{array}$




\begin{tabular}{|c|c|c|c|c|c|c|}
\hline \multirow[b]{2}{*}{ Everyone has a fair shot at wealth and happiness in New Zealand. } & \multicolumn{2}{|c|}{$\begin{array}{l}\text { Strongly } \\
\text { Disagree } \\
\downarrow\end{array}$} & & \multicolumn{3}{|c|}{$\begin{array}{r}\text { Strongly } \\
\text { Agree } \\
\downarrow\end{array}$} \\
\hline & 1 & 3 & 4 & 5 & 6 & 7 \\
\hline 2. If I take care of myself, I can avoid illness. & 1 & 3 & 4 & 5 & 6 & 7 \\
\hline 3. I feel a great pride in the land that is our New Zealand. & 1 & 3 & 4 & 5 & 6 & 7 \\
\hline 4. There are people I can depend on to help me if I really need it. & 1 & 3 & 4 & 5 & 6 & 7 \\
\hline 5. Most of New Zealand's policies serve the greater good. & 1 & 3 & 4 & 5 & 6 & 7 \\
\hline $\begin{array}{l}\text { 6. People who weren't around in previous centuries should not feel accountable } \\
\text { for the actions of their ancestors. }\end{array}$ & 1 & 3 & 4 & 5 & 6 & 7 \\
\hline 7. I think that Māori culture helps to define New Zealand in positive ways. & 1 & 3 & 4 & 5 & 6 & 7 \\
\hline 8. Women exaggerate problems they have at work. & 1 & 3 & 4 & 5 & 6 & 7 \\
\hline 9. In general, I find New Zealand society to be fair. & 1 & 3 & 4 & 5 & 6 & 7 \\
\hline 10. Women, compared to men, tend to have greater moral sensibility. & 1 & 3 & 4 & 5 & 6 & 7 \\
\hline $\begin{array}{l}\text { 11. The fact that I am a member of my ethnic group is an important part of my } \\
\text { identity. }\end{array}$ & 1 & 3 & 4 & 5 & 6 & 7 \\
\hline 12. In general, I have a lot of self-control. & 1 & 3 & 4 & 5 & 6 & 7 \\
\hline 13. I feel a sense of community with others in my local neighbourhood. & 1 & 3 & 4 & 5 & 6 & 7 \\
\hline 14. It is OK if some groups have more of a chance in life than others. & 1 & 3 & 4 & 5 & 6 & 7 \\
\hline 15. Protecting New Zealand's native species should be a national priority. & 1 & 3 & 4 & 5 & 6 & 7 \\
\hline 16. There are too many immigrants living in New Zealand. & 1 & 3 & 4 & 5 & 6 & 7 \\
\hline 17. I generally earn less than other people in NZ. & 1 & 3 & 4 & 5 & 6 & 7 \\
\hline 18. I have considered signing petitions on behalf of my ethnic group. & 1 & 3 & 4 & 5 & 6 & 7 \\
\hline 19. Māori have too much political power and influence in decisions affecting NZ. & 1 & 3 & 4 & 5 & 6 & 7 \\
\hline 20. Inferior groups should stay in their place. & 1 & 3 & 4 & 5 & 6 & 7 \\
\hline 21. Economic positions are legitimate reflections of people's achievements. & 1 & 3 & 4 & 5 & 6 & 7 \\
\hline $\begin{array}{l}\text { 22. By taking an active part in political and social affairs we, the people, can } \\
\text { control world events. }\end{array}$ & 1 & 3 & 4 & 5 & 6 & 7 \\
\hline 23. In general, the New Zealand political system operates as it should. & 1 & 3 & 4 & 5 & 6 & 7 \\
\hline 24. The teachings of traditional religions are still helpful today. & 1 & 3 & 4 & 5 & 6 & 7 \\
\hline $\begin{array}{l}\text { 25. New Zealand would be a better place to live if we forgot about trying to } \\
\text { promote Māori culture to everyone. }\end{array}$ & 1 & 3 & 4 & 5 & 6 & 7 \\
\hline 26. If they knew me, most NZers would respect what I have accomplished in life. & 1 & 3 & 4 & 5 & 6 & 7 \\
\hline 27. Every man ought to have a woman whom he adores. & 1 & 3 & 4 & 5 & 6 & 7 \\
\hline 28. I think that homosexuality should be accepted by society. & 1 & 3 & 4 & 5 & 6 & 7 \\
\hline 29. Women should avoid breastfeeding in public. & 1 & 3 & 4 & 5 & 6 & 7 \\
\hline 30. With enough effort we can wipe out political corruption. & 1 & 3 & 4 & 5 & 6 & 7 \\
\hline 31. There is no one I can turn to for guidance in times of stress. & 1 & 3 & 4 & 5 & 6 & 7 \\
\hline 32. Men and women both have a fair shot at wealth and happiness in NZ. & 1 & 3 & 4 & 5 & 6 & 7 \\
\hline $\begin{array}{l}\text { 33. Foreign nations have done some very fine things but they are still not as good } \\
\text { as New Zealand. }\end{array}$ & 1 & 3 & 4 & 5 & 6 & 7 \\
\hline $\begin{array}{l}\text { 34. We should invest more in educating men to not be physically/sexually violent } \\
\text { toward women. }\end{array}$ & 1 & 3 & 4 & 5 & 6 & 7 \\
\hline $\begin{array}{l}\text { 35. We should invest more in educating women how to avoid physical/sexual } \\
\text { violence from men. }\end{array}$ & 1 & 3 & 4 & 5 & 6 & 7 \\
\hline
\end{tabular}

01. Do you have siblings? Yes No If yes, how many...

(a) older sisters do you have?

(b) younger sisters do you have?

(c) older brothers do you have?

(d) younger brothers do you have?
02. Were you born preterm?

(i.e., born before 37 weeks)

Yes No

Don't know

03. Were you breastfed as a baby?

04. Are you pregnant?

If yes, what trimester are you in?
Yes No

Don't know

Yes No 
Please rate your feelings of WARMTH toward the following groups using the "feeling thermometer scale" for each group.

\begin{tabular}{|c|c|c|c|c|c|c|c|c|c|c|c|c|c|c|c|}
\hline $\begin{array}{r}\text { Feel LEAST WARM } \\
\text { Toward This Group } \\
1\end{array}$ & \multicolumn{8}{|c|}{ Neutral } & \multicolumn{7}{|c|}{$\begin{array}{l}\text { Feel MOST WARM } \\
\text { Toward This Group } \\
7\end{array}$} \\
\hline NZ Europeans & 1 & 2 & 3 & 4 & 5 & 6 & 7 & Overweight people & 1 & 2 & 3 & 4 & 5 & 6 & 7 \\
\hline Māori & 1 & 2 & 3 & 4 & 5 & 6 & 7 & Immigrants in general & 1 & 2 & 3 & 4 & 5 & 6 & 7 \\
\hline Asians in general & 1 & 2 & 3 & 4 & 5 & 6 & 7 & Chinese & 1 & 2 & 3 & 4 & 5 & 6 & 7 \\
\hline Pacific Islanders & 1 & 2 & 3 & 4 & 5 & 6 & 7 & Indians & 1 & 2 & 3 & 4 & 5 & 6 & 7 \\
\hline Arabs & 1 & 2 & 3 & 4 & 5 & 6 & 7 & Muslims & 1 & 2 & 3 & 4 & 5 & 6 & 7 \\
\hline
\end{tabular}

Instructions: Please circle the number that best represents how important each of the following values is for you as a guiding principle in your life. Use the scale below to rate these items.

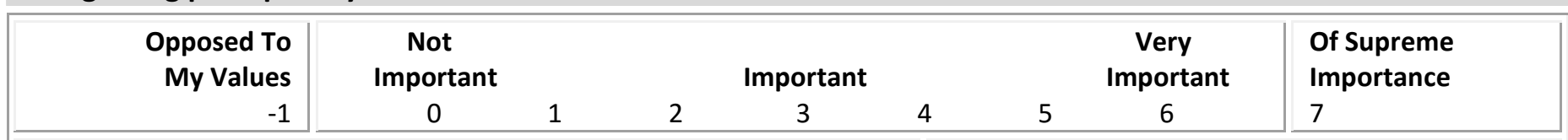

1. PROTECTING THE ENVIRONMENT (preserving nature)

2. A VARIED LIFE (filled with challenge, novelty and change)

3. HONOURING OF PARENTS AND ELDERS (showing respect)

4. AUTHORITY (the right to lead or command)

5. EQUALITY (equal opportunity for all)

6. A WORLD AT PEACE (free of war and conflict)

7. AN EXCITING LIFE (stimulating experiences)

8. FAMILY SECURITY (safety for loved ones)

9. INFLUENCE (having an impact on people and events)

10. SOCIAL JUSTICE (correcting injustice, care for the weak)

11. CURIOSITY (interest in everything, exploring)

12. SELF-DISCIPLINE (self-restraint, resistance to temptation)

13. WEALTH (material possessions, money)

01. Please estimate how many hours you spent doing each of the following things last week. (please enter ' 0 hours' if you did not do that activity last week)
(a) Working in paid employment
(b) Housework/cooking
(c) Looking after children
(d) Volunteer/charity work
(e) Exercising/physical activity
(f) Watching TV/Films
(g) Travelling/commuting
(h) Watching/reading the news
(i) Using the internet (in total)
(j) Using social media (e.g., Facebook)
(k) Playing computer games
(I) Listening to music
(m) Putting on makeup/cosmetics

02. During the past month, on average, how many hours of actual sleep did you get per night?

03a. How often do you have a drink containing alcohol? And, if you drink alcohol...

03b. How many drinks containing alcohol do you have on a typical day when drinking?

04. What is your date of birth?
05. Have you been diagnosed with, or treated for, any of the following health conditions by a doctor in the last five years?
High cholesterol High blood pressure Asthma Heart disease Diabetes (Type II) Depression Anxiety disorder Other (please state):

06a. Have you ever smoked?

06b. Do you currently smoke?

Yes No
Yes No
$\begin{aligned} & \text { (cigarettes } \\ & \text { per day) }\end{aligned}$

how many cigarettes do you smoke in a normal day?

07. Do you have a health condition or disability that limits you, and that has lasted for $6+$ months? Yes No (a) if yes, please state:

08. In general, would you say your health is...

$$
\text { Poor } \begin{array}{llllllll}
1 & 2 & 3 & 4 & 5 & 6 & 7 & \text { Excellent }
\end{array}
$$

09. In the last year, how many weeks (if any) have you spent on holiday where you travelled...
(a) overseas?
(b) within New Zealand?
(c) where did you travel to for your holiday(s)?




\section{Strongly}

Oppose

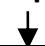

1. Policies promoting closer trade ties between India and New Zealand.

2. Performance of the Haka at international sports events.

3. Māori ownership of the seabed and foreshore.

4. Legalized abortion for women, regardless of the reason.

$\begin{array}{lllllll}1 & 2 & 3 & 4 & 5 & 6 & 7\end{array}$

5. Ensuring that all food and food ingredients sold in New Zealand are free from Genetically Modified Organisms.

6. The Civil Union Act.

$\begin{array}{lllllll}1 & 2 & 3 & 4 & 5 & 6 & 7\end{array}$

7. Government initiatives to inform and promote healthy lifestyle choices.

8. Policies promoting closer trade ties between China and New Zealand.

$\begin{array}{lllllll}1 & 2 & 3 & 4 & 5 & 6 & 7\end{array}$

9. Protest marches and public demonstrations supporting the rights of Māori.

$\begin{array}{lllllll}1 & 2 & 3 & 4 & 5 & 6 & 7\end{array}$

10. Restricting foreign ownership of New Zealand farms.

11. Restricting foreign ownership of New Zealand residential property.

$\begin{array}{lllllll}1 & 2 & 3 & 4 & 5 & 6 & 7\end{array}$

12. Teaching Māori language in New Zealand primary schools.

13. Legalized abortion when the woman's life is endangered.

$\begin{array}{lllllll}1 & 2 & 3 & 4 & 5 & 6 & 7\end{array}$

14. Reserving places for Māori students to study medicine.

15. Waitangi Day as a national celebration of biculturalism.

$\begin{array}{lllllll}1 & 2 & 3 & 4 & 5 & 6 & 7\end{array}$

16. Same-sex marriage in NZ (The Marriage Amendment Act 2013).

$\begin{array}{llllllll}1 & 2 & 3 & 4 & 5 & 6 & 7\end{array}$

17. Including religious instruction in Christianity as part of the school curriculum.

18. Greater investment in reducing domestic violence.

$\begin{array}{lllllll}1 & 2 & 3 & 4 & 5 & 6 & 7\end{array}$

19. Collection of telephone and internet data by the New Zealand Government as part of anti-terrorism efforts.

20. Rates exemptions on Māori land.

21. Redistributing money and wealth more evenly among a larger percentage of the people in New Zealand through heavy taxes on the rich.

22. Policies promoting more immigration from India to New Zealand.

23. Singing the national anthem in Māori and English.

$\begin{array}{lllllll}1 & 2 & 3 & 4 & 5 & 6 & 7\end{array}$

$\begin{array}{lllllll}1 & 2 & 3 & 4 & 5 & 6 & 7\end{array}$

$\begin{array}{lllllll}1 & 2 & 3 & 4 & 5 & 6 & 7\end{array}$

$\begin{array}{lllllll}1 & 2 & 3 & 4 & 5 & 6 & 7\end{array}$

$\begin{array}{lllllll}1 & 2 & 3 & 4 & 5 & 6 & 7\end{array}$

$\begin{array}{lllllll}1 & 2 & 3 & 4 & 5 & 6 & 7\end{array}$

$\begin{array}{lllllll}1 & 2 & 3 & 4 & 5 & 6 & 7\end{array}$

$\begin{array}{lllllll}1 & 2 & 3 & 4 & 5 & 6 & 7\end{array}$

$\begin{array}{lllllll}1 & 2 & 3 & 4 & 5 & 6 & 7\end{array}$

24. Policies promoting more immigration from China to New Zealand.

25. Crown (government) ownership of the seabed and foreshore.

26. A free-to-air Māori television channel.

27. The current anti-smacking law (i.e., it being illegal to smack children)

\begin{tabular}{lllllll}
1 & 2 & 3 & 4 & 5 & 6 & 7 \\
1 & 2 & 3 & 4 & 5 & 6 & 7 \\
1 & 2 & 3 & 4 & 5 & 6 & 7 \\
1 & 2 & 3 & 4 & 5 & 6 & 7 \\
1 & 2 & 3 & 4 & 5 & 6 & 7 \\
1 & 2 & 3 & 4 & 5 & 6 & 7 \\
1 & 2 & 3 & 4 & 5 & 6 & 7 \\
1 & 2 & 3 & 4 & 5 & 6 & 7 \\
1 & 2 & 3 & 4 & 5 & 6 & 7 \\
\hline
\end{tabular}

Instructions: Please rate how strongly you oppose or support each of the following political parties.

\section{Strongly Oppose}

\section{1}

2

3

Neutral

4

5

6

Strongly Support 7

The National Party

$\begin{array}{lllllll}1 & 2 & 3 & 4 & 5 & 6 & 7\end{array}$

The Labour Party

$\begin{array}{lllllll}1 & 2 & 3 & 4 & 5 & 6 & 7\end{array}$

The ACT Party

$\begin{array}{lllllll}1 & 2 & 3 & 4 & 5 & 6 & 7\end{array}$

The Green Party

The Māori Party

$\begin{array}{lllllll}1 & 2 & 3 & 4 & 5 & 6 & 7\end{array}$

The NZ First Party

$\begin{array}{lllllll}1 & 2 & 3 & 4 & 5 & 6 & 7\end{array}$

Instructions: Please answer each of the following questions by circling a number on the scale below. Definitely NO 1 2

3

Unsure

4
5
Definitely YES

7

1. Do you think people from your ethnic group are discriminated against in NZ?

2. Do you support the use of 1080 poison for possum control in New Zealand?

3. Of course, we all hope that there will not be another war, but if it were to come to that, would you be willing to fight for your country?

4. Do you think most New Zealanders respect the achievements of your ethnic group?

5. Suppose a person has a painful incurable disease. Do you think that doctors should be allowed by law to end the patient's life if the patient requests it?

\begin{tabular}{|lllllll|}
1 & 2 & 3 & 4 & 5 & 6 & 7 \\
\hline 1 & 2 & 3 & 4 & 5 & 6 & 7 \\
\hline 1 & 2 & 3 & 4 & 5 & 6 & 7 \\
1 & 2 & 3 & 4 & 5 & 6 & 7 \\
1 & 2 & 3 & 4 & 5 & 6 & 7 \\
\hline
\end{tabular}




\begin{tabular}{|c|c|c|c|c|c|c|c|}
\hline \multirow[b]{2}{*}{ 1. If I get sick, it is my own behaviour which determines how soon I get well again. } & \multicolumn{3}{|c|}{$\begin{array}{l}\text { Strongly } \\
\text { Disagree } \\
\downarrow\end{array}$} & & \multicolumn{3}{|c|}{$\begin{array}{r}\text { Strongly } \\
\text { Agree } \\
\square\end{array}$} \\
\hline & 1 & 2 & 3 & 4 & 5 & 6 & 7 \\
\hline 2. I am satisfied with my life. & 1 & 2 & 3 & 4 & 5 & 6 & 7 \\
\hline 3. Women are too easily offended. & 1 & 2 & 3 & 4 & 5 & 6 & 7 \\
\hline 4. It is OK for parents to use smacking as a way to discipline their children. & 1 & 2 & 3 & 4 & 5 & 6 & 7 \\
\hline 5. In general, relations between men and women in New Zealand are fair. & 1 & 2 & 3 & 4 & 5 & 6 & 7 \\
\hline $\begin{array}{l}\text { 6. We should all move on as one nation and forget about past differences and } \\
\text { conflicts between ethnic groups. }\end{array}$ & 1 & 2 & 3 & 4 & 5 & 6 & 7 \\
\hline 7. Climate change is real. & 1 & 2 & 3 & 4 & 5 & 6 & 7 \\
\hline 8. Climate change is caused by humans. & 1 & 2 & 3 & 4 & 5 & 6 & 7 \\
\hline 9. I am deeply concerned about climate change. & 1 & 2 & 3 & 4 & 5 & 6 & 7 \\
\hline 10. In general, relations between different ethnic groups in New Zealand are fair. & 1 & 2 & 3 & 4 & 5 & 6 & 7 \\
\hline 11. Many women have a quality of purity that few men possess. & 1 & 2 & 3 & 4 & 5 & 6 & 7 \\
\hline 12. I try to enhance the bonding and intimacy in my close relationships. & 1 & 2 & 3 & 4 & 5 & 6 & 7 \\
\hline 13. We should not have to pay for the mistakes of our ancestors. & 1 & 2 & 3 & 4 & 5 & 6 & 7 \\
\hline $\begin{array}{l}\text { 14. It is safe to vaccinate children following the standard New Zealand immunization } \\
\text { schedule. }\end{array}$ & 1 & 2 & 3 & 4 & 5 & 6 & 7 \\
\hline 15. Women seek to gain power by getting control over men. & 1 & 2 & 3 & 4 & 5 & 6 & 7 \\
\hline 16. People from other races would be likely to reject me on th & 1 & 2 & 3 & 4 & 5 & 6 & 7 \\
\hline 17. I try to move toward growth and development in my close relationships. & 1 & 2 & 3 & 4 & 5 & 6 & 7 \\
\hline $\begin{array}{l}\text { 18. Once a woman gets a man to commit to her she usually tries to put him on a tight } \\
\text { leash. }\end{array}$ & 1 & 2 & 3 & 4 & 5 & 6 & 7 \\
\hline $\begin{array}{l}\text { 19. Women, as compared to men, tend to have a more refined sense of culture and } \\
\text { good taste. }\end{array}$ & 1 & 2 & 3 & 4 & 5 & 6 & 7 \\
\hline 20. I try to share many fun and meaningful experiences with people I am close to. & 1 & 2 & 3 & 4 & 5 & 6 & 7 \\
\hline 21. I feel anxious about interacting with people from other races. & 1 & 2 & 3 & 4 & 5 & 6 & 7 \\
\hline 22. I oppose religion in any form. & 1 & 2 & 3 & 4 & 5 & 6 & 7 \\
\hline 23. The average citizen can have an influence on government decisions. & 1 & 2 & 3 & 4 & 5 & 6 & 7 \\
\hline 24. Discrimination against Māori is no longer a problem in New Zealand. & 1 & 2 & 3 & 4 & 5 & 6 & 7 \\
\hline $\begin{array}{l}\text { 25. By taking personal action I believe I can make a positive difference to } \\
\text { environmental problems. }\end{array}$ & 1 & 2 & 3 & 4 & 5 & 6 & 7 \\
\hline $\begin{array}{l}\text { 26. If I go to my doctor/GP with a minor illness (e.g., sore throat, cough, runny nose, } \\
\text { etc.), I think that I should be prescribed antibiotics by default. }\end{array}$ & 1 & 2 & 3 & 4 & 5 & 6 & 7 \\
\hline 27. I try to avoid disagreement and conflict in my close relationships. & 1 & 2 & 3 & 4 & 5 & 6 & 7 \\
\hline 28. Women should be cherished and protected by men. & 1 & 2 & 3 & 4 & 5 & 6 & 7 \\
\hline 29. Generally, the more influence NZ has on other nations, the better off they are. & 1 & 2 & 3 & 4 & 5 & 6 & 7 \\
\hline $\begin{array}{l}\text { 30. When women lose to men in a fair competition, they typically complain about } \\
\text { being discriminated against. }\end{array}$ & 1 & 2 & 3 & 4 & 5 & 6 & 7 \\
\hline 31. I try to stay away from situations that would harm my close relationships. & 1 & 2 & 3 & 4 & 5 & 6 & 7 \\
\hline $\begin{array}{l}\text { 32. Although at times I may not agree with the government, my commitment t } \\
\text { Zealand always remains strong. }\end{array}$ & 1 & 2 & 3 & 4 & 5 & 6 & 7 \\
\hline 33. I feel that I am often discriminated against because of my religious/spiritual beliefs. & 1 & 2 & 3 & 4 & 5 & 6 & 7 \\
\hline 34. In most ways my life is close to ideal. & 1 & 2 & 3 & 4 & 5 & 6 & 7 \\
\hline 35. I feel I can make a difference to the state of the environment. & 1 & 2 & 3 & 4 & 5 & 6 & 7 \\
\hline 36. Being a member of my ethnic group is an important part of how I see & 1 & 2 & 3 & 4 & 5 & 6 & 7 \\
\hline 37. I identify as a spiritual person. & 1 & 2 & 3 & 4 & 5 & 6 & 7 \\
\hline 38. I'm frustrated by what my ethnic group earns relative to other groups in NZ. & 1 & 2 & 3 & 4 & 5 & 6 & 7 \\
\hline 39. I often worry about terrorist attacks happening in New Zealand. & 1 & 2 & 3 & 4 & 5 & 6 & 7 \\
\hline $\begin{array}{l}\text { 40. I reckon Māori culture should stay where it belongs-with Māori. It doesn't } \\
\text { concern other NZers. }\end{array}$ & 1 & 2 & 3 & 4 & 5 & 6 & 7 \\
\hline 41. I'm frustrated by what I earn relative to other people in NZ. & 1 & 2 & 3 & 4 & 5 & 6 & 7 \\
\hline 42. All things considered, religion is a cause for good in the world. & 1 & 2 & 3 & 4 & 5 & 6 & 7 \\
\hline
\end{tabular}


01. Which ethnic group(s) do you belong to?

(Mark the space or spaces which apply to you).

02. What is your gender?

03a. What is your height?

$03 \mathrm{~b}$. What is your weight?

04. What is your highest level of qualification?

05a. What is your relationship status? If you are in a relationship..

05b. How long have you been with your partner?

New Zealand European

Māori

Samoan

Cook Island Māori

Tongan

Niuean

Chinese

Indian

Other such as DUTCH, JAPANESE, TOKELAUAN. Please state:

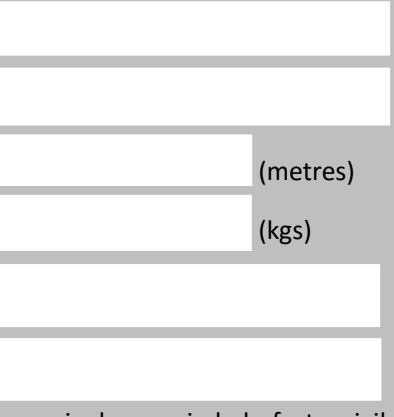

(e.g., single, married, de-facto, civil union, widowed, living together, etc.)

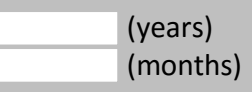

05c. If you are currently married or in a civil union, what was the date of your marriage or union?

05d. How satisfied are you with your relationship?

$$
\begin{array}{lllllllll}
\text { Not satisfied } & 1 & 2 & 3 & 4 & 5 & 6 & 7 & \text { Very satisfied } \\
& \multicolumn{7}{c}{\text { Please circle a number }} &
\end{array}
$$

05e. To what extent do you experience conflict or disagreement with your partner?

$\begin{array}{lllllllll}\text { No conflict at all } & 1 & 2 & 3 & 4 & 5 & 6 & 7 & \text { A great deal of conflict }\end{array}$

05f. How satisfied do you think your

PARTNER is with your relationship?

$$
\begin{array}{llllllllll}
\text { Not satisfied } & 1 & 2 & 3 & 4 & 5 & 6 & 7 & \text { Very satisfied }
\end{array}
$$

06a. Are you currently employed? (This includes self-employed or casual work)

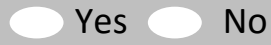

06b. What is your current occupation?

07. Please rate your ability to speak Māori (Te Reo)

$$
\begin{array}{llllllllll}
\text { Verypoor } & 1 & 2 & 3 & 4 & 5 & 6 & 7 & \text { Excellent }
\end{array}
$$

08. How would you describe your dietary behaviour?

(e.g., meat \& veges, vegetarian, vegan, halal, pescatarian, etc.)

09. How much money have you donated to charity in the last year?

\section{$\$$}

10. Please rate how politically liberal versus conservative you see yourself as being:

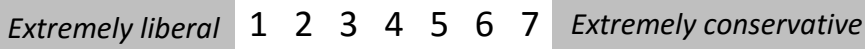

11a. Has someone ever used the internet, a mobile phone, or digital camera to hurt, intimidate or embarrass you?

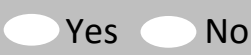

11b. ...has this occurred in the last month? Yes No

12. Please rate how politically left-wing versus right-wing you see yourself as being:

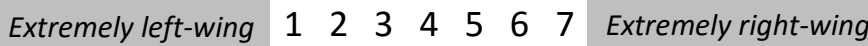

13. Have you ever been divorced?

Yes No

14. How would you describe your sexual orientation?
15. Please estimate your total household income (before tax) for the year 2016:

16a. Now, think about all the other households in NZ. Give your best estimate of the average income of those households:

16b. Now, think about all the other households in your immediate neighbourhood. Give your best estimate of the average income of those households:

17a. How many children have you given birth to, fathered, or adopted?

17b. If you are a parent, what is the birth date of your eldest child?

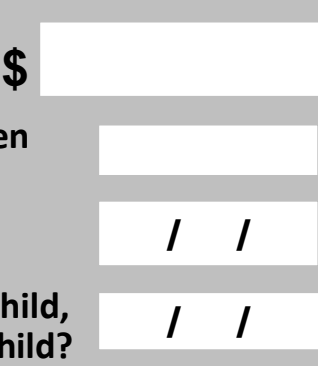

17c. And, if you have more than one child, the birth date of your youngest child?

17d. If you have children under 5 , do they go to a paid daycare program?

17e. If you have children under 18 , are their vaccinations up-to-date, as per the recommendations of your doctor/GP?

18. Do you identify with a religion and/or spiritual group? If yes...

(a) what religion or spiritual group?

(b) how many times did you attend a church or place of worship in the last month?

(c) how many times did you pray in the last week?

(d) how many times did you read religious scripture in the last week?

(e) approximately how many people belong to the church or place of worship that you attend most often?

(f) how important is your religion to how you see yourself?

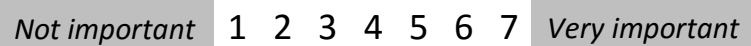

19. Roughly how many hours have you spent with both FRIENDS/FAMILY and OTHERS (e.g., workmates, strangers) from each ethnic group in the last week? FRIENDS/FAMILY

OTHERS
(a) Māori
(b) NZ Europeans
(c) Pacific Islanders
(d) Asians

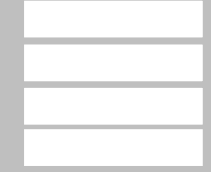

20a. Do you plan to vote in the next New Zealand election in 2017?

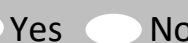

$20 \mathrm{~b}$. If yes, to which party do you plan to give...

your party vote?

your electorate vote?

21. How important are your political beliefs to how you see yourself?

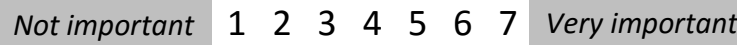

22. Do you believe in a God?

23. Do you believe in some form of spirit or life force?

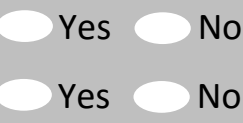

24. Where were you born?

(please be specific, e.g., which town/city?)

25. If you were born overseas, for how many years have you lived in NZ? 


\section{Thank you for taking part in the New Zealand Attitudes and Values Study!}

Please post back your completed questionnaire using the included freepost return envelope. The freepost envelope will work from anywhere in New Zealand. If you lose the envelope, you can post this questionnaire back for free to:

FREEPOST AUTHORITY: 124589

Dr Chris Sibley, New Zealand Attitudes and Values Study

School of Psychology (Cost 9450/71708)

The University of Auckland

Private Bag 92019

Auckland 1142, New Zealand

If you would like to know more about the New Zealand Attitudes and Values Study, then please feel free to phone us (contact details on the front) or you can visit the study website. We will also send a newsletter to everyone in the study summarising the most exciting findings from the study this year.

http://www.psych.auckland.ac.nz/uoa/NZAVS

\section{Optional Feedback Box}

We are always looking for feedback to help improve the New Zealand Attitudes and Values Study. Have we missed anything important? Or do you have any other general comments or suggestions about how we can improve the study for next year?

Finally, have you experienced any significant life events in the past year?

This is a final optional question. Your responses could help us to understand important changes in people's lives that are missed by the specific questions in the survey. 


\section{The New Zealand Attitudes and Values Study}

SCHOOL OF PSYCHOLOGY

Science Centre, Building 302

23 Symonds Street, Auckland,

New Zealand

T 09-923-7498

Enzavs@auckland.ac.nz

\section{Follow-up Questionnaire for 2017/2018}

$\mathbf{w}$ www.nzavs.auckland.ac.nz

A scanned copy of this form will be kept for a period of up to fifteen years

Lead researcher:

Dr. Chris Sibley, School of Psychology, The University of Auckland.

Phone: 09-923-7498. e-mail: nzavs@auckland.ac.nz

\section{Consent form and contact details}

This form is to gather your consent to participate in this phase of the New Zealand Attitudes and Values Study (NZAVS). Only Dr. Sibley and his research associates will have access to your responses. Your personal information will be kept separate from your responses at all times. Your questionnaire will be identified by an anonymous code. An encrypted electronic copy of all responses will be stored indefinitely for research purposes in a secure room in the School of Psychology.

I have read and understood a description of this research project. On this basis, I agree to take part. I understand that my data will remain confidential at all times. I understand that only Dr. Sibley and trusted research assistants working on the study in secure conditions will have access to my contact details. I consent to publication of the results of the project with the understanding that my anonymity will be preserved. I understand that I am free to withdraw from the research at any time up until the point at which I complete and return this questionnaire. I understand that my contact details will never be shared with anyone outside of the immediate research team. I understand that Dr. Sibley and the research team will use these details to contact and invite me to complete follow-up questionnaires, possibly for the next eleven years. I understand that my contact details will also be used to contact me if I win one of the five prize draws for $\$ \mathbf{1 0 0 0}$ grocery vouchers (total prize pool $\$ 5000$ ) for participating in this study.

\begin{tabular}{r|r}
\hline Name: & $\begin{array}{r}\text { Today's } \\
\text { Date: }\end{array}$ \\
\hline Signature: & Cell phone: \\
\hline Home phone: & \\
\hline Postal address: & \\
\hline Have you ever changed your name due to marriage or a civil union? & Yes \\
\hline & If yes... \\
\hline & Birth Name: \\
\hline
\end{tabular}

Are you open to being contacted and invited to participate in an additional online research project studying how people interact and make economic decisions in groups? 
You can complete an online version of this questionnaire instead at: $\underline{w w w . p s y c h . a u c k l a n d . a c . n z / N Z A V S-s u r v e y}$

The QR code on the right also links to the online version of the study.

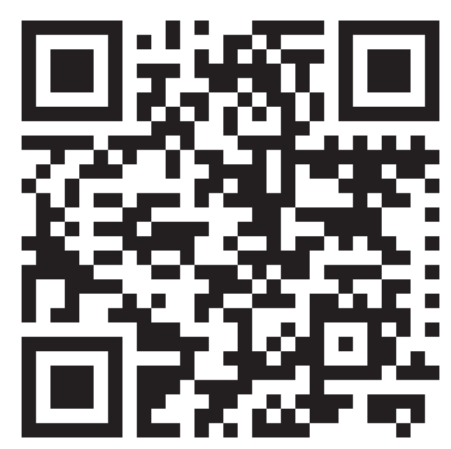


Instructions: This part of the questionnaire measures your feelings about yourself.

Please circle the number that best represents how accurately each statement describes you.

\section{I ...}

Very

Inaccurate

1. Am the life of the party.

2. Sympathise with others' feelings.

$\begin{array}{lllllll}1 & 2 & 3 & 4 & 5 & 6 & 7\end{array}$

3. Get chores done right away.

4. Have frequent mood swings.

$\begin{array}{lllllll}1 & 2 & 3 & 4 & 5 & 6 & 7\end{array}$

5. Have a vivid imagination.

6. Don't talk a lot.

$\begin{array}{lllllll}1 & 2 & 3 & 4 & 5 & 6 & 7\end{array}$

7. Am not interested in other people's problems.

$\begin{array}{lllllll}1 & 2 & 3 & 4 & 5 & 6 & 7\end{array}$

8. Have difficulty understanding abstract ideas.

9. Like order.

10. Make a mess of things.

11. Do not have a good imagination.

$\begin{array}{lllllll}1 & 2 & 3 & 4 & 5 & 6 & 7\end{array}$

12. Feel others' emotions.

$\begin{array}{lllllll}1 & 2 & 3 & 4 & 5 & 6 & 7\end{array}$

13. Am relaxed most of the time.

$\begin{array}{lllllll}1 & 2 & 3 & 4 & 5 & 6 & 7\end{array}$

14. Get upset easily.

15. Seldom feel blue.

$\begin{array}{lllllll}1 & 2 & 3 & 4 & 5 & 6 & 7 \\ 1 & 2 & 3 & 4 & 5 & 6 & 7\end{array}$

16. Keep in the background.

17. Am not really interested in others.

$\begin{array}{lllllll}1 & 2 & 3 & 4 & 5 & 6 & 7 \\ 1 & 2 & 3 & 4 & 5 & 6 & 7\end{array}$

18. Am not interested in abstract ideas.

$\begin{array}{lllllll}1 & 2 & 3 & 4 & 5 & 6 & 7\end{array}$

19. Often forget to put things back in their proper place.

$\begin{array}{lllllll}1 & 2 & 3 & 4 & 5 & 6 & 7\end{array}$

20. Talk to a lot of different people at parties.

$\begin{array}{llllllll}1 & 2 & 3 & 4 & 5 & 6 & 7\end{array}$

21. Feel entitled to more of everything.

22. On the whole am satisfied with myself.

23. Know that people in my life accept and value me.

$\begin{array}{ccccccc}1 & 2 & 3 & 4 & 5 & 6 & 7 \\ 1 & 2 & 3 & 4 & 5 & 6 & 7\end{array}$

24. Would like to be seen driving around in a very expensive car.

$\begin{array}{lllllll}1 & 2 & 3 & 4 & 5 & 6 & 7 \\ 1 & 2 & 3 & 4 & 5 & 6 & 7\end{array}$

25. Deserve more things in life.

26. Take a positive attitude toward myself.

27. Feel like an outsider.

28. Would get a lot of pleasure from owning expensive luxury goods.

$\begin{array}{lllllll}1 & 2 & 3 & 4 & 5 & 6 & 7\end{array}$

29. Am satisfied with the appearance, size and shape of my body.

30. Am inclined to feel that I am a failure.

$\begin{array}{lllllll}1 & 2 & 3 & 4 & 5 & 6 & 7 \\ 1 & 2 & 3 & 4 & 5 & 6 & 7\end{array}$

31. Feel that I am often discriminated against because of my ethnicity.

32. Feel that I am often discriminated against because of my gender.

33. Know that people around me share my attitudes and beliefs.

$\begin{array}{lllllll}1 & 2 & 3 & 4 & 5 & 6 & 7 \\ 1 & 2 & 3 & 4 & 5 & 6 & 7\end{array}$

$\begin{array}{lllllll}1 & 2 & 3 & 4 & 5 & 6 & 7\end{array}$

During the last $\mathbf{3 0}$ days, how often did (Please use the scale below to circle a number for each question)

\begin{tabular}{r|c}
$\begin{array}{r}\text { None Of } \\
\text { The Time }\end{array}$ & $\begin{array}{c}\text { A Little Of } \\
\text { The Time }\end{array}$ \\
0 & 1 \\
\hline
\end{tabular}

\section{Some of}

The Time

2

1. ... you feel hopeless?

2. ... you feel so depressed that nothing could cheer you up?

3. ... you feel restless or fidgety?

4. ... you feel that everything was an effort?

5. ... you feel worthless?

6. ... you feel nervous?

7. ... you have negative thoughts that repeated over and over?

8. ... you worry that a big earthquake might hit your region?

9. ... you feel exhausted?

$\begin{array}{lllllll}1 & 2 & 3 & 4 & 5 & 6 & 7\end{array}$

$\begin{array}{lllllll}1 & 2 & 3 & 4 & 5 & 6 & 7\end{array}$

$\begin{array}{lllllll}1 & 2 & 3 & 4 & 5 & 6 & 7\end{array}$

$\begin{array}{lllllll}1 & 2 & 3 & 4 & 5 & 6 & 7\end{array}$

$\begin{array}{lllllll}1 & 2 & 3 & 4 & 5 & 6 & 7\end{array}$

$\begin{array}{lllllll}1 & 2 & 3 & 4 & 5 & 6 & 7\end{array}$

$\begin{array}{lllllll}1 & 2 & 3 & 4 & 5 & 6 & 7\end{array}$

$\begin{array}{lllllll}1 & 2 & 3 & 4 & 5 & 6 & 7\end{array}$

$\begin{array}{lllllll}1 & 2 & 3 & 4 & 5 & 6 & 7\end{array}$

\begin{tabular}{lllllll}
1 & 2 & 3 & 4 & 5 & 6 & 7 \\
1 & 2 & 3 & 4 & 5 & 6 & 7 \\
\hline
\end{tabular}




\begin{tabular}{llllllll}
$\begin{array}{l}\text { Strongly } \\
\text { Disagree } \\
\downarrow\end{array}$ & & & \multicolumn{2}{r}{$\begin{array}{r}\text { Strongly } \\
\text { Agree } \\
1\end{array}$} \\
\hline 1 & 2 & 3 & 4 & 5 & 6 & 7 \\
\hline 1 & 2 & 3 & 4 & 5 & 6 & 7 \\
\hline 1 & 2 & 3 & 4 & 5 & 6 & 7 \\
\hline 1 & 2 & 3 & 4 & 5 & 6 & 7 \\
\hline 1 & 2 & 3 & 4 & 5 & 6 & 7 \\
\hline 1 & 2 & 3 & 4 & 5 & 6 & 7 \\
\hline 1 & 2 & 3 & 4 & 5 & 6 & 7 \\
\hline 1 & 2 & 3 & 4 & 5 & 6 & 7 \\
\hline 1 & 2 & 3 & 4 & 5 & 6 & 7 \\
\hline 1 & 2 & 3 & 4 & 5 & 6 & 7 \\
\hline 1 & 2 & 3 & 4 & 5 & 6 & 7 \\
\hline 1 & 2 & 3 & 4 & 5 & 6 & 7 \\
\hline 1 & 2 & 3 & 4 & 5 & 6 & 7 \\
\hline 1 & 2 & 3 & 4 & 5 & 6 & 7 \\
\hline 1 & 2 & 3 & 4 & 5 & 6 & 7 \\
\hline 1 & 2 & 3 & 4 & 5 & 6 & 7 \\
\hline 1 & 2 & 3 & 4 & 5 & 6 & 7 \\
\hline
\end{tabular}

1. I am in control of my health.

2. It would be good if groups could be equal.

3. I often think about the fact that I am a member of my ethnic group.

4. I expect my health to get worse.

5. It would be best for everyone if the proper authorities censored magazines so that people could not get their hands on trashy and disgusting material.

6. We should have increased social equality.

7. I know there are people I can turn to when I need help.

8. I wish I had more self-discipline.

9. We should do what we can to equalise conditions for different groups.

10. I seem to get sick a little easier than other people.

11. If incomes were more equal, people would be less motivated to work hard.

12. Atheists and others who have rebelled against established religions are no doubt every bit as good and virtuous as those who attend church regularly.

13. To get ahead in life, it is sometimes okay to step on other groups.

14. Some of the best people in our country are those who are challenging our government, criticizing religion, and ignoring the "normal way" things are supposed to be done.

15. People from my ethnic group generally earn less than other groups in NZ.

16. People should pay less attention to The Bible and other old traditional forms of religious guidance, and instead develop their own personal standards of what is moral and immoral.

17. I have considered voting in terms of what is good for my particular ethnic group. $\quad \begin{array}{llllllll}1 & 2 & 3 & 4 & 5 & 6 & 7\end{array}$

18. I feel at ease when I am in a city district in New Zealand with many immigrants. $\quad \begin{array}{llllllll}1 & 2 & 3 & 4 & 5 & 6 & 7\end{array}$

19. Our country will be destroyed some day if we do not smash the perversions eating away at our moral fibre and traditional beliefs.

$\begin{array}{lllllll}1 & 2 & 3 & 4 & 5 & 6 & 7\end{array}$

20. I have considered participating in demonstrations on behalf of my ethnic group.

21. I think that the Mãori language helps to define New Zealand in positive ways.

$\begin{array}{llllllll}1 & 2 & 3 & 4 & 5 & 6 & 7\end{array}$

22. It is always better to trust the judgment of the proper authorities in government and religion than to listen to the noisy rabble-rousers in our society who are trying to create doubt in people's minds.

23. Everyone in New Zealand has a fair shot at wealth and happiness, regardless of ethnicity or race.

$\begin{array}{lllllll}1 & 2 & 3 & 4 & 5 & 6 & 7\end{array}$

$\begin{array}{lllllll}1 & 2 & 3 & 4 & 5 & 6 & 7\end{array}$

Instructions: Please rate your level of satisfaction with the following aspects of your life and New Zealand.

Completely Dissatisfied

\section{Somewhat Satisfied}

$\begin{array}{llll}7 & 8 & 9\end{array}$

10

1. Your standard of living.

2. The economic situation in New Zealand.

3. The quality of New Zealand's natural environment.

4. Your health.

5. The social conditions in New Zealand.

6. The performance of the current New Zealand government.

7. Your future security.

8. Business in New Zealand.

9. Your personal relationships.

10. Your access to health care when you need it (e.g., doctor, GP).

11. The quality and health of the waterways in your local region.

$\begin{array}{lllllllllll}0 & 1 & 2 & 3 & 4 & 5 & 6 & 7 & 8 & 9 & 10 \\ 0 & 1 & 2 & 3 & 4 & 5 & 6 & 7 & 8 & 9 & 10\end{array}$

$\begin{array}{lllllllllll}0 & 1 & 2 & 3 & 4 & 5 & 6 & 7 & 8 & 9 & 10\end{array}$

$\begin{array}{lllllllllll}0 & 1 & 2 & 3 & 4 & 5 & 6 & 7 & 8 & 9 & 10\end{array}$

$\begin{array}{lllllllllll}0 & 1 & 2 & 3 & 4 & 5 & 6 & 7 & 8 & 9 & 10\end{array}$

$\begin{array}{lllllllllll}0 & 1 & 2 & 3 & 4 & 5 & 6 & 7 & 8 & 9 & 10\end{array}$

$\begin{array}{lllllllllll}0 & 1 & 2 & 3 & 4 & 5 & 6 & 7 & 8 & 9 & 10\end{array}$

$\begin{array}{lllllllllll}0 & 1 & 2 & 3 & 4 & 5 & 6 & 7 & 8 & 9 & 10\end{array}$

$\begin{array}{lllllllllll}0 & 1 & 2 & 3 & 4 & 5 & 6 & 7 & 8 & 9 & 10\end{array}$

$\begin{array}{lllllllllll}0 & 1 & 2 & 3 & 4 & 5 & 6 & 7 & 8 & 9 & 10\end{array}$

$\begin{array}{lllllllllll}0 & 1 & 2 & 3 & 4 & 5 & 6 & 7 & 8 & 9 & 10\end{array}$




\begin{tabular}{|c|c|c|c|c|c|c|}
\hline \multirow[b]{2}{*}{ Everyone has a fair shot at wealth and happiness in New Zealand. } & \multicolumn{2}{|c|}{$\begin{array}{l}\text { Strongly } \\
\text { Disagree }\end{array}$} & & \multicolumn{3}{|c|}{$\begin{array}{r}\text { Strongly } \\
\text { Agree } \\
\downarrow\end{array}$} \\
\hline & 1 & 3 & 4 & 5 & 6 & 7 \\
\hline 2. If I take care of myself, I can avoid illness. & 1 & 3 & 4 & 5 & 6 & 7 \\
\hline 3. I feel a great pride in the land that is our New Zealand. & 1 & 3 & 4 & 5 & 6 & 7 \\
\hline 4. There are people I can depend on to help me if I really need it. & 1 & 3 & 4 & 5 & 6 & 7 \\
\hline 5. Most of New Zealand's policies serve the greater good. & 1 & 3 & 4 & 5 & 6 & 7 \\
\hline $\begin{array}{l}\text { 6. People who weren't around in previous centuries should not feel accountable } \\
\text { for the actions of their ancestors. }\end{array}$ & 1 & 3 & 4 & 5 & 6 & 7 \\
\hline 7. I think that Māori culture helps to define New Zealand in positive ways. & 1 & 3 & 4 & 5 & 6 & 7 \\
\hline 8. Women exaggerate problems they have at work. & 1 & 3 & 4 & 5 & 6 & 7 \\
\hline 9. In general, I find New Zealand society to be fair. & 1 & 3 & 4 & 5 & 6 & 7 \\
\hline 10. Women, compared to men, tend to have greater moral sensibility. & 1 & 3 & 4 & 5 & 6 & 7 \\
\hline $\begin{array}{l}\text { 11. The fact that I am a member of my ethnic group is an important part of my } \\
\text { identity. }\end{array}$ & 1 & 3 & 4 & 5 & 6 & 7 \\
\hline 12. In general, I have a lot of self-control. & 1 & 3 & 4 & 5 & 6 & 7 \\
\hline 13. I feel a sense of community with others in my local neighbourhood. & 1 & 3 & 4 & 5 & 6 & 7 \\
\hline 14. It is OK if some groups have more of a chance in life than others. & 1 & 3 & 4 & 5 & 6 & 7 \\
\hline 15. Protecting New Zealand's native species should be a national priority. & 1 & 3 & 4 & 5 & 6 & 7 \\
\hline $\begin{array}{l}\text { 16. The current income gap between New Zealand Europeans and other ethnic } \\
\text { groups would be very hard to change. }\end{array}$ & 1 & 3 & 4 & 5 & 6 & 7 \\
\hline 17. There are too many immigrants living in New Zealand. & 1 & 3 & 4 & 5 & 6 & 7 \\
\hline 18. I generally earn less than other people in NZ. & 1 & 3 & 4 & 5 & 6 & 7 \\
\hline 19. I have considered signing petitions on behalf of my ethnic group. & 1 & 3 & 4 & 5 & 6 & 7 \\
\hline 20. Māori have too much political power and influence in decisions affecting NZ. & 1 & 3 & 4 & 5 & 6 & 7 \\
\hline 21. Inferior groups should stay in their place. & 1 & 3 & 4 & 5 & 6 & 7 \\
\hline 22. Economic positions are legitimate reflections of people's achievements. & 1 & 3 & 4 & 5 & 6 & 7 \\
\hline 23. I believe I am capable, as an individual, of improving my status in society. & 1 & 3 & 4 & 5 & 6 & 7 \\
\hline $\begin{array}{l}\text { 24. By taking an active part in political and social affairs we, the people, can } \\
\text { control world events. }\end{array}$ & 1 & 3 & 4 & 5 & 6 & 7 \\
\hline 25. In general, the New Zealand political system operates as it should. & 1 & 3 & 4 & 5 & 6 & 7 \\
\hline 26. People's basic rights are well protected by the New Zealand Police. & 1 & 3 & 4 & 5 & 6 & 7 \\
\hline $\begin{array}{l}\text { 27. New Zealand would be a better place to live if we forgot about trying to } \\
\text { promote Mãori culture to everyone. }\end{array}$ & 1 & 3 & 4 & 5 & 6 & 7 \\
\hline 28. If they knew me, most NZers would respect what I have accomplished in life. & 1 & 3 & 4 & 5 & 6 & 7 \\
\hline 29. Politicians in New Zealand can generally be trusted. & 1 & 3 & 4 & 5 & 6 & 7 \\
\hline 30. Every man ought to have a woman whom he adores. & 1 & 3 & 4 & 5 & 6 & 7 \\
\hline $\begin{array}{l}\text { 31. Foreign nations have done some very fine things but they are still not as good } \\
\text { as New Zealand. }\end{array}$ & 1 & 3 & 4 & 5 & 6 & 7 \\
\hline 32. Women should avoid breastfeeding in public. & 1 & 3 & 4 & 5 & 6 & 7 \\
\hline $\begin{array}{l}\text { 33. There are many things about the New Zealand Police and its policies that need } \\
\text { to be changed. }\end{array}$ & 1 & 3 & 4 & 5 & 6 & 7 \\
\hline 34. With enough effort we can wipe out political corruption. & 1 & 3 & 4 & 5 & 6 & 7 \\
\hline 35. The unity of New Zealand is weakened by too many immigrants. & 1 & 3 & 4 & 5 & 6 & 7 \\
\hline 36. There is no one I can turn to for guidance in times of stress. & 1 & 3 & 4 & 5 & 6 & 7 \\
\hline 37. Men and women both have a fair shot at wealth and happiness in NZ. & 1 & 3 & 4 & 5 & 6 & 7 \\
\hline 38. I think that homosexuality should be accepted by society. & 1 & 3 & 4 & 5 & 6 & 7 \\
\hline $\begin{array}{l}\text { 39. We should invest more in educating men to not be physically/sexually violent } \\
\text { toward women. }\end{array}$ & 1 & 3 & 4 & 5 & 6 & 7 \\
\hline $\begin{array}{l}\text { 40. We should invest more in educating women how to avoid physical/sexual } \\
\text { violence from men. }\end{array}$ & 1 & 3 & 4 & 5 & 6 & 7 \\
\hline
\end{tabular}


Please rate your feelings of WARMTH toward the following groups using the "feeling thermometer scale" for each group.

\begin{tabular}{|c|c|c|c|c|c|c|c|c|c|c|c|c|c|c|c|}
\hline $\begin{array}{r}\text { Feel LEAST WARM } \\
\text { Toward This Group } \\
1\end{array}$ & \multicolumn{8}{|c|}{ Neutral } & \multicolumn{7}{|c|}{$\begin{array}{l}\text { Feel MOST WARM } \\
\text { Toward This Group } \\
7\end{array}$} \\
\hline NZ Europeans & 1 & 2 & 3 & 4 & 5 & 6 & 7 & Overweight people & 1 & 2 & 3 & 4 & 5 & 6 & 7 \\
\hline Māori & 1 & 2 & 3 & 4 & 5 & 6 & 7 & Immigrants in general & 1 & 2 & 3 & 4 & 5 & 6 & 7 \\
\hline Asians in general & 1 & 2 & 3 & 4 & 5 & 6 & 7 & Chinese & 1 & 2 & 3 & 4 & 5 & 6 & 7 \\
\hline Pacific Islanders & 1 & 2 & 3 & 4 & 5 & 6 & 7 & Indians & 1 & 2 & 3 & 4 & 5 & 6 & 7 \\
\hline Elderly people & 1 & 2 & 3 & 4 & 5 & 6 & 7 & Muslims & 1 & 2 & 3 & 4 & 5 & 6 & 7 \\
\hline Refugees & 1 & 2 & 3 & 4 & 5 & 6 & 7 & People with mental illness & 1 & 2 & 3 & 4 & 5 & 6 & 7 \\
\hline
\end{tabular}

Instructions: Please rate how strongly you oppose or support each of the following political parties.

\begin{tabular}{|c|c|c|c|c|c|c|c|c|c|c|c|c|c|c|c|c|}
\hline \multirow{2}{*}{$\begin{array}{r}\text { Strongly Oppose } \\
1 \\
\end{array}$} & \multicolumn{9}{|c|}{ Neutral } & & \multicolumn{6}{|c|}{$\begin{array}{l}\text { Strongly Support } \\
7\end{array}$} \\
\hline & 1 & 2 & 3 & 4 & 5 & 6 & 7 & & The Green Party & 1 & 2 & 3 & 4 & 5 & 6 & 7 \\
\hline The Labour Party & 1 & 2 & 3 & 4 & 5 & 6 & 7 & & The Māori Party & 1 & 2 & 3 & 4 & 5 & 6 & 7 \\
\hline The ACT Party & 1 & 2 & 3 & 4 & 5 & 6 & 7 & & The NZ First Party & 1 & 2 & 3 & 4 & 5 & 6 & 7 \\
\hline
\end{tabular}

01. Please estimate how many hours you spent doing each of the following things last week. (please enter ' 0 hours' if you did not do that activity last week)
(a) Working in paid employment
(b) Housework/cooking
(c) Looking after children
(d) Volunteer/charity work
(e) Exercising/physical activity
(f) Watching TV/Netflix/movies
(g) Travelling/commuting
(h) Watching/reading the news
(i) Using the internet (in total)
(j) Using social media (e.g., Facebook)
(k) Playing video/computer games
(I) Putting on makeup/cosmetics

02. During the past month, on average, how many hours of actual sleep did you get per night?

03a. How often do you have a drink containing alcohol?

And, if you drink alcohol...

03b. How many drinks containing alcohol do you have on a typical day when drinking?

04. What is your date of birth?

05. Which ethnic group(s) do you belong to?

(Mark the space or spaces which apply to you).
07. Have you been diagnosed with, or treated for, any of the following health conditions by a doctor in the last five years?
High cholesterol High blood pressure Asthma

Heart disease

Diabetes (Type II)

Depression

Anxiety disorder

Other (please state):

08a. Have you ever smoked?

$08 \mathrm{~b}$. Do you currently smoke?

Yes No
Yes No

08c. If you currently smoke, how many cigarettes do you smoke in a normal day?

(cigarettes per day)

09. Do you have a health condition or disability that limits you, and that has lasted for $6+$ months? Yes No

(a) if yes, please state:

10. In general, would you say your health is...

$$
\text { Poor } \begin{array}{llllllll}
1 & 2 & 3 & 4 & 5 & 6 & 7 & \text { Excellent }
\end{array}
$$

11a. Do you have a regular family doctor/GP?

And, if you have a regular doctor/GP, to what extent...

11b. How satisfied are you with the service and care you receive from your family doctor/GP?

$$
\begin{array}{llllllllll}
\text { Not satisfied } & 1 & 2 & 3 & 4 & 5 & 6 & 7 & \text { Very satisfied }
\end{array}
$$

11c. Do you think your doctor/GP shares a similar cultural background to you?

$$
\text { Definitely NO } 1 \begin{array}{llllllll} 
& 2 & 3 & 4 & 5 & 6 & 7 & \text { Definitely YES }
\end{array}
$$

11d. Does your doctor/GP respect your cultural background when you are discussing health issues with them?

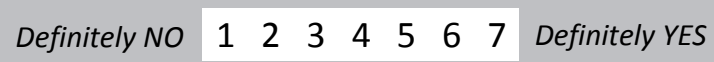

Please state: 


\begin{tabular}{|c|c|c|c|c|c|c|c|}
\hline \multirow[b]{2}{*}{ Policies promoting closer trade ties between India and New Zealand. } & \multicolumn{2}{|c|}{$\begin{array}{l}\text { Strongly } \\
\text { Oppose } \\
\downarrow\end{array}$} & \multirow[b]{2}{*}{3} & \multirow[b]{2}{*}{4} & \multirow[b]{2}{*}{5} & \multirow{2}{*}{\multicolumn{2}{|c|}{\begin{tabular}{rr} 
Strongly \\
Support \\
& \multicolumn{1}{|}{} \\
6 & 7
\end{tabular}}} \\
\hline & 1 & 2 & & & & & \\
\hline Performance of the Haka at international sports events. & 1 & 2 & 3 & 4 & 5 & 6 & 7 \\
\hline Māori ownership of the seabed and foreshore. & 1 & 2 & 3 & 4 & 5 & 6 & 7 \\
\hline 4. Legalized abortion for women, regardless of the reason. & 1 & 2 & 3 & 4 & 5 & 6 & 7 \\
\hline $\begin{array}{l}\text { 5. Ensuring that all food and food ingredients sold in New Zealand are free from } \\
\text { Genetically Modified Organisms. }\end{array}$ & 1 & 2 & 3 & 4 & 5 & 6 & 7 \\
\hline 6. Government initiatives to inform and promote healthy lifestyle choices. & 1 & 2 & 3 & 4 & 5 & 6 & 7 \\
\hline 7. Policies promoting closer trade ties between China and New Zealand. & 1 & 2 & 3 & 4 & 5 & 6 & 7 \\
\hline 8. Protest marches and public demonstrations supporting the rights of Māori. & 1 & 2 & 3 & 4 & 5 & 6 & 7 \\
\hline 9. Restricting foreign ownership of New Zealand farms. & 1 & 2 & 3 & 4 & 5 & 6 & 7 \\
\hline 10. Restricting foreign ownership of New Zealand residential property. & 1 & 2 & 3 & 4 & 5 & 6 & 7 \\
\hline 11. Teaching Māori language in New Zealand primary schools. & 1 & 2 & 3 & 4 & 5 & 6 & 7 \\
\hline 12. Legalized abortion when the woman's life is endangered. & 1 & 2 & 3 & 4 & 5 & 6 & 7 \\
\hline 13. Reserving places for Māori students to study medicine. & 1 & 2 & 3 & 4 & 5 & 6 & 7 \\
\hline 14. Waitangi Day as a national celebration of biculturalism. & 1 & 2 & 3 & 4 & 5 & 6 & 7 \\
\hline 15. Same-sex marriage in NZ (The Marriage Amendment Act 2013). & 1 & 2 & 3 & 4 & 5 & 6 & 7 \\
\hline 16. Including religious instruction in Christianity as part of the school curriculum. & 1 & 2 & 3 & 4 & 5 & 6 & 7 \\
\hline 17. Greater investment in reducing domestic violence. & 1 & 2 & 3 & 4 & 5 & 6 & 7 \\
\hline $\begin{array}{l}\text { 18. Collection of telephone and internet data by the New Zealand Government as } \\
\text { part of anti-terrorism efforts. }\end{array}$ & 1 & 2 & 3 & 4 & 5 & 6 & 7 \\
\hline 19. Rates exemptions on Māori land. & 1 & 2 & 3 & 4 & 5 & 6 & 7 \\
\hline $\begin{array}{l}\text { 20. Redistributing money and wealth more evenly among a larger percentage of } \\
\text { the people in New Zealand through heavy taxes on the rich. }\end{array}$ & 1 & 2 & 3 & 4 & 5 & 6 & 7 \\
\hline 21. Displaying signage in public places in both Māori and English. & 1 & 2 & 3 & 4 & 5 & 6 & 7 \\
\hline 22. Policies promoting more immigration from India to New Zealand. & 1 & 2 & 3 & 4 & 5 & 6 & 7 \\
\hline 23. Singing the national anthem in Māori and English. & 1 & 2 & 3 & 4 & 5 & 6 & 7 \\
\hline 24. Policies promoting more immigration from China to New Zealand. & 1 & 2 & 3 & 4 & 5 & 6 & 7 \\
\hline 25. Crown (government) ownership of the seabed and foreshore. & 1 & 2 & 3 & 4 & 5 & 6 & 7 \\
\hline 26. A free-to-air Māori television channel. & 1 & 2 & 3 & 4 & 5 & 6 & 7 \\
\hline $\begin{array}{l}\text { 27. Protest marches and public demonstrations supporting the rights of New } \\
\text { Zealand Europeans. }\end{array}$ & 1 & & 3 & 4 & 5 & 6 & 7 \\
\hline
\end{tabular}

\section{Instructions: Please answer each of the following questions by circling a number on the scale below.}

\section{Definitely NO}

1

\section{Unsure}

4
5
Definitely YES 7

1. Do you think people from your ethnic group are discriminated against in NZ?

2. Do you support the use of 1080 poison for possum control in New Zealand?

3. Do you think most New Zealanders respect the achievements of your ethnic group?

4. Of course, we all hope that there will not be another war, but if it were to come to that, would you be willing to fight for your country?

5. Suppose a person has a painful incurable disease. Do you think that doctors should be allowed by law to end the patient's life if the patient requests it?

6. Are you willing to make sacrifices to your standard of living (e.g., accept higher prices, drive less, conserve energy) in order to protect the environment?

7. Have you made sacrifices to your standard of living (e.g., accepted higher prices, driven less, conserved energy) in order to protect the environment?

8. Do you think most New Zealanders are willing to make sacrifices to their standard of living in order to protect the environment?

$\begin{array}{lllllll}1 & 2 & 3 & 4 & 5 & 6 & 7\end{array}$

$\begin{array}{lllllll}1 & 2 & 3 & 4 & 5 & 6 & 7\end{array}$

$\begin{array}{lllllll}1 & 2 & 3 & 4 & 5 & 6 & 7\end{array}$

$\begin{array}{lllllll}1 & 2 & 3 & 4 & 5 & 6 & 7\end{array}$

$\begin{array}{lllllll}1 & 2 & 3 & 4 & 5 & 6 & 7\end{array}$

$\begin{array}{lllllll}1 & 2 & 3 & 4 & 5 & 6 & 7\end{array}$

$\begin{array}{lllllll}1 & 2 & 3 & 4 & 5 & 6 & 7\end{array}$ 
1. If I get sick, it is my own behaviour which determines how soon I get well again.

2. I am satisfied with my life.

$\begin{array}{lllllll}1 & 2 & 3 & 4 & 5 & 6 & 7\end{array}$

3. Women are too easily offended.

$\begin{array}{lllllll}1 & 2 & 3 & 4 & 5 & 6 & 7\end{array}$

4. The New Zealand Police care about the well-being of everyone they deal with.

$\begin{array}{lllllll}1 & 2 & 3 & 4 & 5 & 6 & 7\end{array}$

5. In general, relations between men and women in New Zealand are fair.

$\begin{array}{lllllll}1 & 2 & 3 & 4 & 5 & 6 & 7\end{array}$

6. We should all move on as one nation and forget about past differences and conflicts between ethnic groups.

$\begin{array}{lllllll}1 & 2 & 3 & 4 & 5 & 6 & 7\end{array}$

7. Climate change is real.

8. Climate change is caused by humans.

$\begin{array}{lllllll}1 & 2 & 3 & 4 & 5 & 6 & 7\end{array}$

9. I am deeply concerned about climate change.

10. In general, relations between different ethnic groups in New Zealand are fair.

11. Many women have a quality of purity that few men possess.

12. It would be good if all people living in New Zealand could speak Māori and English.

13. We should not have to pay for the mistakes of our ancestors.

14. It is safe to vaccinate children following the standard New Zealand immunization schedule.

15. I would always report dangerous or suspicious activities occurring in my neighbourhood to the police.

$\begin{array}{lllllll}1 & 2 & 3 & 4 & 5 & 6 & 7\end{array}$

$\begin{array}{lllllll}1 & 2 & 3 & 4 & 5 & 6 & 7\end{array}$

$\begin{array}{lllllll}1 & 2 & 3 & 4 & 5 & 6 & 7\end{array}$

$\begin{array}{lllllll}1 & 2 & 3 & 4 & 5 & 6 & 7\end{array}$

$\begin{array}{lllllll}1 & 2 & 3 & 4 & 5 & 6 & 7\end{array}$

$\begin{array}{lllllll}1 & 2 & 3 & 4 & 5 & 6 & 7\end{array}$

$\begin{array}{lllllll}1 & 2 & 3 & 4 & 5 & 6 & 7\end{array}$

16. Women seek to gain power by getting control over men.

$\begin{array}{lllllll}1 & 2 & 3 & 4 & 5 & 6 & 7\end{array}$

17. People from other races would be likely to reject me on the basis of my race.

18. Once a woman gets a man to commit to her she usually tries to put him on a tight leash.

19. Women, as compared to men, tend to have a more refined sense of culture and good taste.

20. I would always provide information to the police to help them find someone suspected of committing a crime.

21. I feel anxious about interacting with people from other races.

22. I insist upon my ethnic group getting the respect that is due to it.

23. The average citizen can have an influence on government decisions.

$\begin{array}{lllllll}1 & 2 & 3 & 4 & 5 & 6 & 7\end{array}$

24. Discrimination against Māori is no longer a problem in New Zealand.

25. By taking personal action I believe I can make a positive difference to environmental problems.

26. If I go to my doctor/GP with a minor illness (e.g., sore throat, cough, runny nose, etc.), I think that I should be prescribed antibiotics by default.

$\begin{array}{lllllll}1 & 2 & 3 & 4 & 5 & 6 & 7\end{array}$

$\begin{array}{lllllll}1 & 2 & 3 & 4 & 5 & 6 & 7\end{array}$

$\begin{array}{lllllll}1 & 2 & 3 & 4 & 5 & 6 & 7\end{array}$

$\begin{array}{lllllll}1 & 2 & 3 & 4 & 5 & 6 & 7\end{array}$

$\begin{array}{lllllll}1 & 2 & 3 & 4 & 5 & 6 & 7\end{array}$

$\begin{array}{lllllll}1 & 2 & 3 & 4 & 5 & 6 & 7\end{array}$

$\begin{array}{lllllll}1 & 2 & 3 & 4 & 5 & 6 & 7\end{array}$

$\begin{array}{lllllll}1 & 2 & 3 & 4 & 5 & 6 & 7\end{array}$

$\begin{array}{lllllll}1 & 2 & 3 & 4 & 5 & 6 & 7\end{array}$

$\begin{array}{lllllll}1 & 2 & 3 & 4 & 5 & 6 & 7\end{array}$

$\begin{array}{lllllll}1 & 2 & 3 & 4 & 5 & 6 & 7\end{array}$

27. If my ethnic group had a major say in the world, the world would be a much better place.

28. Women should be cherished and protected by men.

29. Generally, the more influence NZ has on other nations, the better off they are.

$\begin{array}{lllllll}1 & 2 & 3 & 4 & 5 & 6 & 7\end{array}$

$\begin{array}{lllllll}1 & 2 & 3 & 4 & 5 & 6 & 7\end{array}$

30. When women lose to men in a fair competition, they typically complain about being discriminated against.

$\begin{array}{lllllll}1 & 2 & 3 & 4 & 5 & 6 & 7\end{array}$

11. Although at times I may not agree with the government, my commitment to New Zealand always remains strong.

32. I feel that I am often discriminated against because of my religious/spiritual beliefs.

33. In most ways my life is close to ideal.

34. I feel I can make a difference to the state of the environment.

35. Being a member of my ethnic group is an important part of how I see myself.

36. I'm frustrated by what my ethnic group earns relative to other groups in NZ.

37. I often worry about terrorist attacks happening in New Zealand.

38. I reckon Māori culture should stay where it belongs-with Mãori. It doesn't concern other New Zealanders.

$\begin{array}{lllllll}1 & 2 & 3 & 4 & 5 & 6 & 7\end{array}$

$\begin{array}{lllllll}1 & 2 & 3 & 4 & 5 & 6 & 7\end{array}$

$\begin{array}{llllllll}1 & 2 & 3 & 4 & 5 & 6 & 7\end{array}$

$\begin{array}{lllllll}1 & 2 & 3 & 4 & 5 & 6 & 7\end{array}$

$\begin{array}{lllllll}1 & 2 & 3 & 4 & 5 & 6 & 7\end{array}$


01. What is your highest

level of qualification?

02a. Are you currently employed? (This includes self-employed or casual work)
Yes No

(years)

(months) 02c. What is your current occupation?

02d. How satisfied are you with your current job?

$$
\begin{array}{llllllllll}
\text { Not satisfied } & 1 & 2 & 3 & 4 & 5 & 6 & 7 & \text { Very satisfied }
\end{array}
$$

02e. How secure do you feel in your current job?

$$
\begin{array}{llllllllll}
\text { Not secure } & 1 & 2 & 3 & 4 & 5 & 6 & 7 & \text { Very secure }
\end{array}
$$

03a. What is your relationship status?

If you are in a relationship..

(e.g., single, married, de-facto, civil union, widowed, living together, etc.)

03b. How long have you been with your partner?

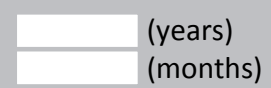

03c. If you are currently married or in a civil union, what was the date of your marriage or union?

\section{l 1}

03d. How satisfied are you with your relationship?

$$
\begin{array}{lllllllll}
\text { Not satisfied } & 1 & 2 & 3 & 4 & 5 & 6 & 7 & \text { Very satisfied } \\
& \multicolumn{7}{c}{\text { Please circle a number }}
\end{array}
$$

03e. To what extent do you experience conflict or disagreement with your partner?

$\begin{array}{llllllllll}\text { No conflict at all } & 1 & 2 & 3 & 4 & 5 & 6 & 7 & \text { A great deal of conflict }\end{array}$

03f. How satisfied do you think your PARTNER is with your relationship?

$$
\begin{array}{llllllllll}
\text { Not satisfied } & 1 & 2 & 3 & 4 & 5 & 6 & 7 & \text { Very satisfied }
\end{array}
$$

03g. What is your partner's ethnicity?

04. How long have you lived at your current address?

05. How many other people live in the same household as you?

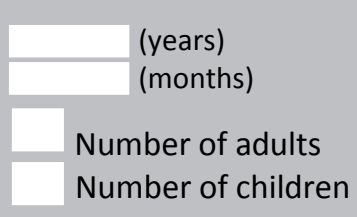

06. Please rate your ability to speak Māori (Te Reo)

$$
\begin{array}{llllllllll}
\text { Verypoor } & 1 & 2 & 3 & 4 & 5 & 6 & 7 & \text { Excellent }
\end{array}
$$

07. How would you describe your dietary behaviour?

(e.g., meat \& vegetables, vegetarian, vegan, halal, pescatarian, etc.)

08. How much money have you donated to charity in the last year?

\section{$\$$}

09. Please rate how politically liberal versus conservative you see yourself as being:

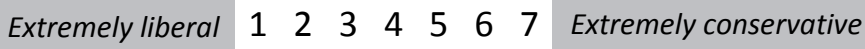

10a. Has someone ever used the internet, a mobile phone, or digital camera to hurt, intimidate or embarrass you?

10b. ...has this occurred in the last month? Yes No

11. Please rate how politically left-wing versus right-wing you see yourself as being:

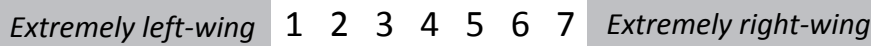

12. Have you ever been divorced? Yes No

13. How would you describe your sexual orientation? (e.g., heterosexual, homosexual, straight, gay, lesbian, bisexual, etc.)
14. Please estimate your total household income (before tax) for the year 2017:

15a. Now, think about all the other households in NZ. Give your best estimate of the average income of those households:

\section{$\$$}

15b. Now, think about all the other households in your immediate neighbourhood. Give your best estimate of the average income of those households:

16a. How many children have you given birth to, fathered, or adopted?

16b. If you are a parent, what is the birth date of your eldest child?

16c. And, if you have more than one child, the birth date of your youngest child?

$16 \mathrm{~d}$. If you have children under 5 , do they go to a paid daycare program?

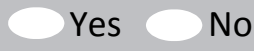

16e. If you have children under 18 , are their vaccinations up-to-date, as per the recommendations of your doctor/GP?

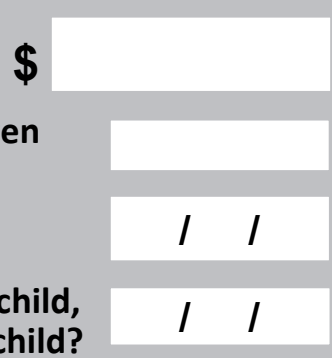

17. Do you identify with a religion and/or spiritual group? If yes...
(a) what religion or spiritual group?
(b) how many times did you attend a church or place of worship in the last month?
(c) how many times did you pray in the last week?
(d) how many times did you read religious scripture in the last week?
(e) approximately how many people belong to the church or place of worship that you attend most often?
(f) how important is your religion to how you see yourself?
$\begin{array}{llllllllll}\text { Not important } & 1 & 2 & 3 & 4 & 5 & 6 & 7 & \text { Very important }\end{array}$

Yes - fully No - partially

No - none

Don't know

18. Roughly how many hours have you spent with both FRIENDS/FAMILY and OTHERS (e.g., workmates, strangers) from each ethnic group in the last week? FRIENDS/FAMILY OTHERS
(a) Māori
(b) NZ Europeans
(c) Pacific Islanders
(d) Asians

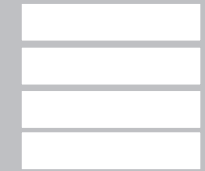

19a. Did you vote in the

New Zealand election in 2017?

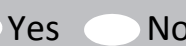

19b. If yes, to which party did you give...

$$
\begin{aligned}
& \text { your party vote? } \\
& \text { your electorate vote? }
\end{aligned}
$$

20. How important are your political beliefs to how you see yourself?

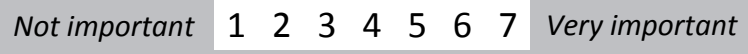

21. Do you believe in a God?

22. Do you believe in some form of spirit or life force?

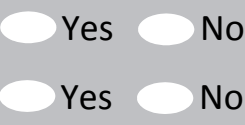

23. Where were you born?

(please be specific, e.g., which town/city?)

24. If you were born overseas, for how many years have you lived in NZ? 


\section{Thank you for taking part in the New Zealand Attitudes and Values Study!}

Please post back your completed questionnaire using the included freepost return envelope. The freepost envelope will work from anywhere in New Zealand. If you lose the envelope, you can post this questionnaire back for free to:

FREEPOST AUTHORITY: 124589

New Zealand Attitudes and Values Study

School of Psychology (Cost 9450/71708)

The University of Auckland

Private Bag 92019

Auckland 1142, New Zealand

If you would like to know more about the New Zealand Attitudes and Values Study, then please feel free to phone us (contact details on the front) or you can visit the study website. We will also send a newsletter to everyone in the study summarising the most exciting findings from the study this year.

\section{Optional Feedback Box}

We are always looking for feedback to help improve the New Zealand Attitudes and Values Study. Have we missed anything important? Or do you have any other general comments or suggestions about how we can improve the study for next year?

Finally, have you experienced any significant life events in the past year?

This is a final optional question. Your responses could help us to understand important changes in people's lives that are missed by the specific questions in the survey. 


\section{The New Zealand Attitudes and Values Study}

SCHOOL OF PSYCHOLOGY

Science Centre, Building 302

23 Symonds Street, Auckland,

New Zealand

T $09-923-7498$

Enzavs@auckland.ac.nz

$\mathbf{w}$ www.nzavs.auckland.ac.nz

\section{Follow-up Questionnaire for 2018/2019}

A scanned copy of this form will be kept for a period of up to fifteen years.

Lead researcher:

Professor Chris Sibley, School of Psychology, The University of Auckland.

Phone: 09-923-7498. e-mail: nzavs@auckland.ac.nz

\section{Consent form and contact details}

This form is to gather your consent to participate in this phase of the New Zealand Attitudes and Values Study (NZAVS). Only Professor Sibley and his research associates will have access to your responses. Your personal information will be kept separate from your responses at all times. Your questionnaire will be identified by an anonymous code. An encrypted electronic copy of all responses will be stored indefinitely for research purposes in a secure room in the School of Psychology.

I have read and understood a description of this research project. On this basis, I agree to take part. I understand that my data will remain confidential at all times. I understand that only Professor Sibley and trusted research assistants working on the study in secure conditions will have access to my contact details. I consent to publication of the results of the project with the understanding that my anonymity will be preserved. I understand that I am free to withdraw from the research at any time up until the point at which I complete and return this questionnaire. I understand that my contact details will never be shared with anyone outside of the immediate research team. I understand that Professor Sibley and the research team will use these details to contact and invite me to complete follow-up questionnaires, possibly for the next ten years. I understand that my contact details will also be used to contact me if I win one of the five prize draws for $\$ 1000$ grocery vouchers (total prize pool $\$ 5000$ ) for participating in this study.

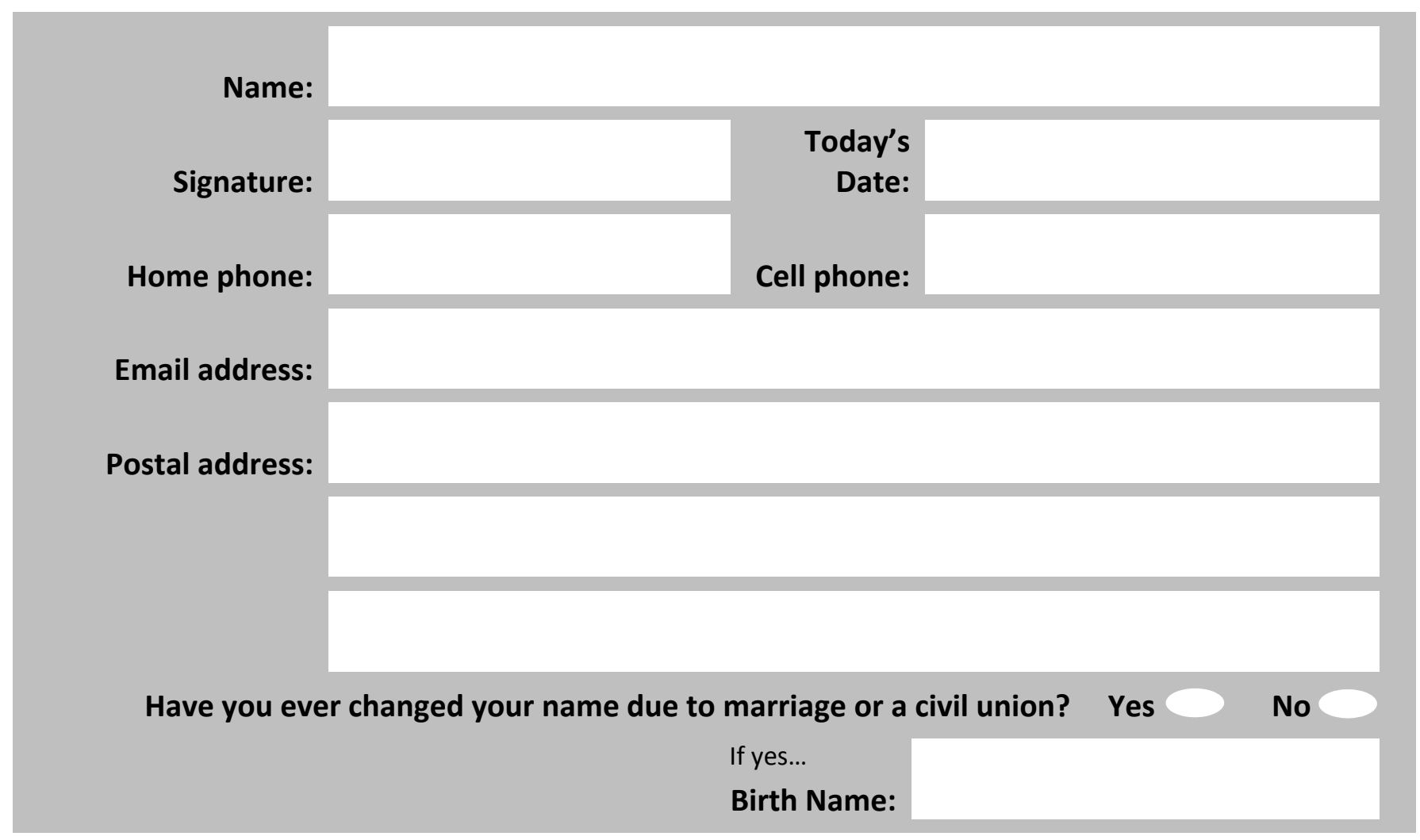

Are you open to being contacted and invited to participate in an additional online research project studying how people interact and make economic decisions in groups? 
You can complete an online version of this questionnaire instead at: www.nzavs.auckland.ac.nz/survey

The QR code on the right also links to the online version of the study.

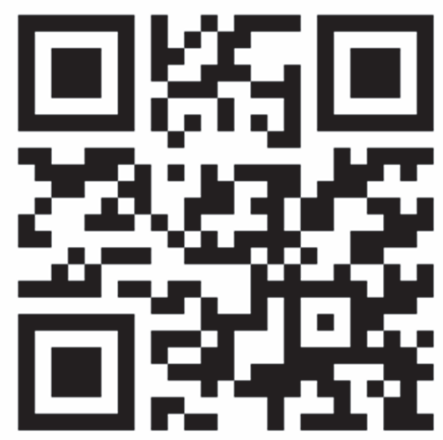


Instructions: This part of the questionnaire measures your feelings about yourself.

Please circle the number that best represents how accurately each statement describes you.

\section{I ...}

Very

Inaccurate

1. Am the life of the party.

2. Sympathise with others' feelings.

$\begin{array}{lllllll}1 & 2 & 3 & 4 & 5 & 6 & 7\end{array}$

3. Get chores done right away.

4. Have frequent mood swings.

$\begin{array}{lllllll}1 & 2 & 3 & 4 & 5 & 6 & 7\end{array}$

5. Have a vivid imagination.

6. Don't talk a lot.

$\begin{array}{lllllll}1 & 2 & 3 & 4 & 5 & 6 & 7\end{array}$

7. Am not interested in other people's problems.

$\begin{array}{lllllll}1 & 2 & 3 & 4 & 5 & 6 & 7\end{array}$

8. Have difficulty understanding abstract ideas.

9. Like order.

10. Make a mess of things.

11. Do not have a good imagination.

$\begin{array}{lllllll}1 & 2 & 3 & 4 & 5 & 6 & 7\end{array}$

12. Feel others' emotions.

$\begin{array}{lllllll}1 & 2 & 3 & 4 & 5 & 6 & 7\end{array}$

13. Am relaxed most of the time.

$\begin{array}{lllllll}1 & 2 & 3 & 4 & 5 & 6 & 7\end{array}$

14. Get upset easily.

15. Seldom feel blue.

$\begin{array}{lllllll}1 & 2 & 3 & 4 & 5 & 6 & 7 \\ 1 & 2 & 3 & 4 & 5 & 6 & 7\end{array}$

16. Keep in the background.

17. Am not really interested in others.

$\begin{array}{lllllll}1 & 2 & 3 & 4 & 5 & 6 & 7\end{array}$

18. Am not interested in abstract ideas.

$\begin{array}{lllllll}1 & 2 & 3 & 4 & 5 & 6 & 7\end{array}$

19. Often forget to put things back in their proper place.

$\begin{array}{lllllll}1 & 2 & 3 & 4 & 5 & 6 & 7\end{array}$

20. Talk to a lot of different people at parties.

$\begin{array}{llllllll}1 & 2 & 3 & 4 & 5 & 6 & 7\end{array}$

21. Feel entitled to more of everything.

22. On the whole am satisfied with myself.

23. Know that people in my life accept and value me.

$\begin{array}{lllllll}1 & 2 & 3 & 4 & 5 & 6 & 7 \\ 1 & 2 & 3 & 4 & 5 & 6 & 7\end{array}$

24. Would like to be seen driving around in a very expensive car.

$\begin{array}{lllllll}1 & 2 & 3 & 4 & 5 & 6 & 7 \\ 1 & 2 & 3 & 4 & 5 & 6 & 7\end{array}$

25. Deserve more things in life.

$\begin{array}{lllllll}1 & 2 & 3 & 4 & 5 & 6 & 7\end{array}$

26. Feel that I am often discriminated against because of my ethnicity.

27. Feel like an outsider.

28. Would get a lot of pleasure from owning expensive luxury goods.

$\begin{array}{lllllll}1 & 2 & 3 & 4 & 5 & 6 & 7\end{array}$

29. Am satisfied with the appearance, size and shape of my body.

30. Am inclined to feel that I am a failure.

31. Take a positive attitude toward myself.

$\begin{array}{lllllll}1 & 2 & 3 & 4 & 5 & 6 & 7\end{array}$

32. Feel that I am often discriminated against because of my gender.

33. Know that people around me share my attitudes and beliefs.

$\begin{array}{lllllll}1 & 2 & 3 & 4 & 5 & 6 & 7 \\ 1 & 2 & 3 & 4 & 5 & 6 & 7 \\ 1 & 2 & 3 & 4 & 5 & 6 & 7 \\ 1 & 2 & 3 & 4 & 5 & 6 & 7 \\ 1 & 2 & 3 & 4 & 5 & 6 & 7 \\ 1 & 2 & 3 & 4 & 5 & 6 & 7 \\ 1 & 2 & 3 & 4 & 5 & 6 & 7 \\ 1 & 2 & 3 & 4 & 5 & 6 & 7 \\ 1 & 2 & 3 & 4 & 5 & 6 & 7 \\ 1 & 2 & 3 & 4 & 5 & 6 & 7 \\ 1 & 2 & 3 & 4 & 5 & 6 & 7 \\ 1 & 2 & 3 & 4 & 5 & 6 & 7 \\ 1 & 2 & 3 & 4 & 5 & 6 & 7\end{array}$

During the last $\mathbf{3 0}$ days, how often did. (Please use the scale below to circle a number for each question)

\begin{tabular}{r|c} 
None Of & A Little of \\
The Time & The Time \\
0 & 1
\end{tabular}

Some of
The Time
2

Most Of
The Time
3

1. ... you feel hopeless?

2. ... you feel so depressed that nothing could cheer you up?

3. ... you feel restless or fidgety?

4. ... you feel that everything was an effort?

5. ... you feel worthless?

6. ... you feel nervous?

7. ... you have negative thoughts that repeated over and over?

8. ... you worry that a big earthquake might hit your region?

9. ... you feel exhausted?

\begin{tabular}{lllll}
0 & 1 & 2 & 3 & 4 \\
\hline 0 & 1 & 2 & 3 & 4 \\
\hline 0 & 1 & 2 & 3 & 4 \\
\hline 0 & 1 & 2 & 3 & 4 \\
\hline 0 & 1 & 2 & 3 & 4 \\
\hline 0 & 1 & 2 & 3 & 4 \\
\hline 0 & 1 & 2 & 3 & 4 \\
\hline 0 & 1 & 2 & 3 & 4 \\
\hline 0 & 1 & 2 & 3 & 4 \\
\hline
\end{tabular}




\begin{tabular}{llllllll}
$\begin{array}{l}\text { Strongly } \\
\text { Disagree } \\
\downarrow\end{array}$ & & $\begin{array}{r}\text { Strongly } \\
\text { Agree } \\
\downarrow\end{array}$ \\
\hline 1 & 2 & 3 & 4 & 5 & 6 & 7 \\
\hline 1 & 2 & 3 & 4 & 5 & 6 & 7 \\
\hline 1 & 2 & 3 & 4 & 5 & 6 & 7 \\
\hline 1 & 2 & 3 & 4 & 5 & 6 & 7 \\
\hline 1 & 2 & 3 & 4 & 5 & 6 & 7 \\
\hline 1 & 2 & 3 & 4 & 5 & 6 & 7 \\
\hline 1 & 2 & 3 & 4 & 5 & 6 & 7 \\
\hline 1 & 2 & 3 & 4 & 5 & 6 & 7 \\
\hline
\end{tabular}

1. I have much in my life to be thankful for.

$\begin{array}{lllllll}1 & 2 & 3 & 4 & 5 & 6 & 7\end{array}$

2. It would be good if groups could be equal.

3. I often think about the fact that I am a member of my ethnic group.

4. I expect my health to get worse.

5. I feel a sense of community with others in my local neighbourhood.

6. We should have increased social equality.

7. I know there are people I can turn to when I need help.

8. There are many things about the New Zealand Police and its policies that need to be changed.

9. If I go to my doctor/GP with a minor illness (e.g., sore throat, cough, runny nose, etc.), I think that I should be prescribed antibiotics by default.

10. I wish I had more self-discipline.

11. We should do what we can to equalise conditions for different groups.

$\begin{array}{lllllll}1 & 2 & 3 & 4 & 5 & 6 & 7\end{array}$

12. By taking an active part in political and social affairs we, the people, can control world events.

13. I seem to get sick a little easier than other people.

$\begin{array}{lllllll}1 & 2 & 3 & 4 & 5 & 6 & 7\end{array}$

14. If incomes were more equal, people would be less motivated to work hard.

$\begin{array}{lllllll}1 & 2 & 3 & 4 & 5 & 6 & 7\end{array}$

$\begin{array}{lllllll}1 & 2 & 3 & 4 & 5 & 6 & 7\end{array}$

15. I have a good sense of what makes my life meaningful.

$\begin{array}{lllllll}1 & 2 & 3 & 4 & 5 & 6 & 7\end{array}$

16. To get ahead in life, it is sometimes okay to step on other groups.

$\begin{array}{lllllll}1 & 2 & 3 & 4 & 5 & 6 & 7\end{array}$

17. I am hardly ever satisfied with my performance.

18. People from my ethnic group generally earn less than other groups in NZ.

$\begin{array}{lllllll}1 & 2 & 3 & 4 & 5 & 6 & 7\end{array}$

19. When I feel negative emotions, I suppress or hide my emotions.

20. I have considered voting in terms of what is good for my particular ethnic group.

21. I am grateful to a wide variety of people.

$\begin{array}{lllllll}1 & 2 & 3 & 4 & 5 & 6 & 7\end{array}$

$\begin{array}{llllllll}1 & 2 & 3 & 4 & 5 & 6 & 7\end{array}$

$\begin{array}{lllllll}1 & 2 & 3 & 4 & 5 & 6 & 7\end{array}$

$\begin{array}{lllllll}1 & 2 & 3 & 4 & 5 & 6 & 7\end{array}$

22. I feel at ease when I am in a city district in New Zealand with many immigrants.

23. I find myself regularly thinking about past times that I have been wronged.

$\begin{array}{lllllll}1 & 2 & 3 & 4 & 5 & 6 & 7\end{array}$

24. With enough support and professional help, people who have committed violent offences can be rehabilitated to become safe members of our society.

25. The fact that I am a member of my ethnic group is an important part of my identity.

$\begin{array}{lllllll}1 & 2 & 3 & 4 & 5 & 6 & 7\end{array}$

$\begin{array}{lllllll}1 & 2 & 3 & 4 & 5 & 6 & 7\end{array}$

$\begin{array}{lllllll}1 & 2 & 3 & 4 & 5 & 6 & 7\end{array}$

$\begin{array}{lllllll}1 & 2 & 3 & 4 & 5 & 6 & 7\end{array}$

26. People who are 'tall poppies' should be cut down to size.

27. Everyone in New Zealand has a fair shot at wealth and happiness, regardless of ethnicity or race.

Instructions: Please rate your level of satisfaction with the following aspects of your life and New Zealand.

Completely Dissatisfied

0

\section{Somewhat Satisfied}

3

1. Your standard of living.

2. The economic situation in New Zealand.

3. The quality of New Zealand's natural environment.

4. Your health.

5. The social conditions in New Zealand.

6. The performance of the current New Zealand government.

7. Your future security.

8. Business in New Zealand.

9. Your personal relationships.

10. Your access to health care when you need it (e.g., doctor, GP).

11. The quality and health of the waterways in your local region. $\begin{array}{lll}7 & 8 & 9\end{array}$

Completely Satisfied 10

$\begin{array}{lllllllllll}0 & 1 & 2 & 3 & 4 & 5 & 6 & 7 & 8 & 9 & 10 \\ 0 & 1 & 2 & 3 & 4 & 5 & 6 & 7 & 8 & 9 & 10 \\ 0 & 1 & 2 & 3 & 4 & 5 & 6 & 7 & 8 & 9 & 10 \\ 0 & 1 & 2 & 3 & 4 & 5 & 6 & 7 & 8 & 9 & 10 \\ 0 & 1 & 2 & 3 & 4 & 5 & 6 & 7 & 8 & 9 & 10 \\ 0 & 1 & 2 & 3 & 4 & 5 & 6 & 7 & 8 & 9 & 10 \\ 0 & 1 & 2 & 3 & 4 & 5 & 6 & 7 & 8 & 9 & 10 \\ 0 & 1 & 2 & 3 & 4 & 5 & 6 & 7 & 8 & 9 & 10 \\ 0 & 1 & 2 & 3 & 4 & 5 & 6 & 7 & 8 & 9 & 10 \\ 0 & 1 & 2 & 3 & 4 & 5 & 6 & 7 & 8 & 9 & 10 \\ 0 & 1 & 2 & 3 & 4 & 5 & 6 & 7 & 8 & 9 & 10\end{array}$




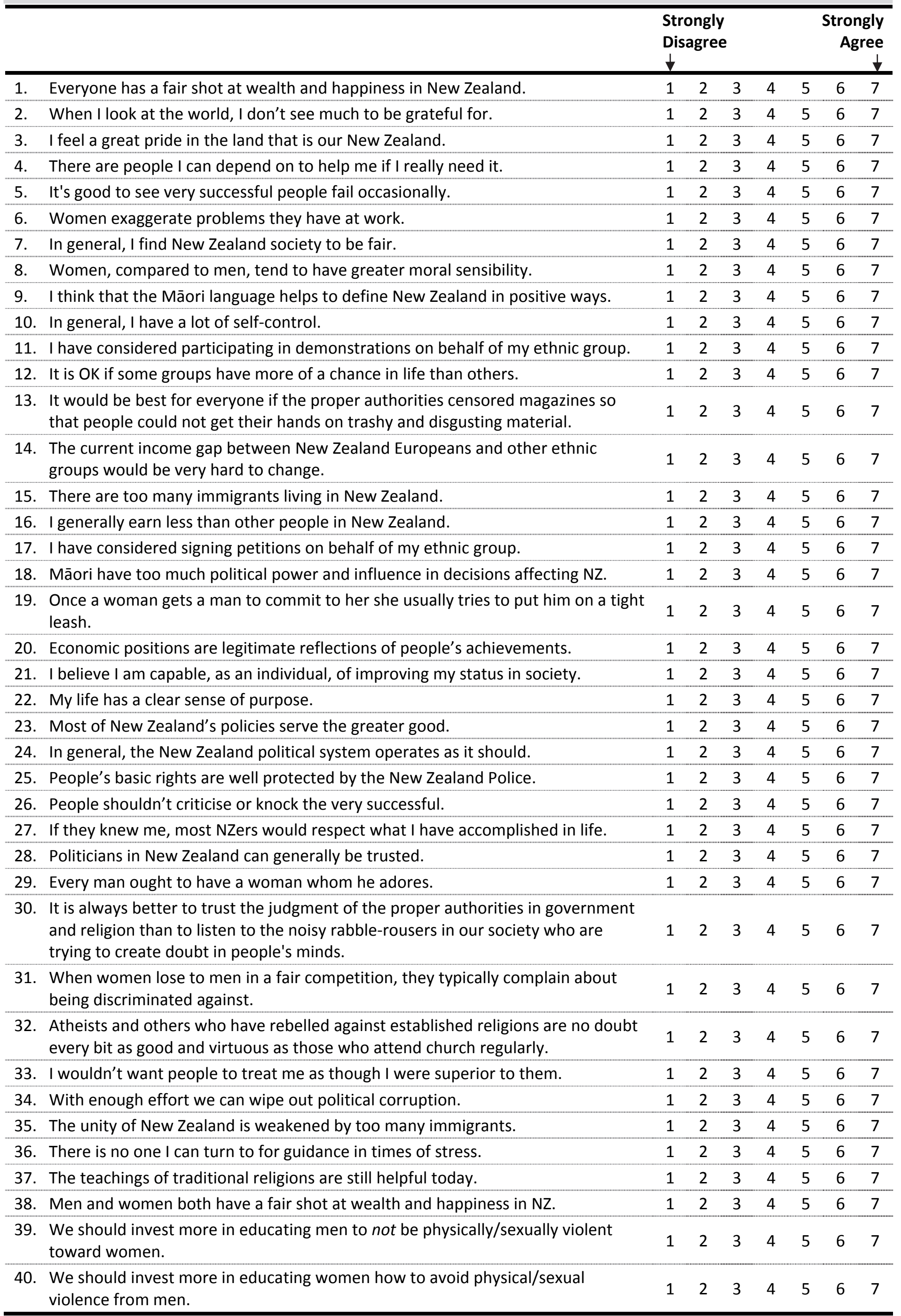


Please rate your feelings of WARMTH toward the following groups using the "feeling thermometer scale" for each group.

\begin{tabular}{|c|c|c|c|c|c|c|c|c|c|c|c|c|c|c|c|}
\hline $\begin{array}{r}\text { Feel LEAST WARM } \\
\text { Toward This Group } \\
1\end{array}$ & \multicolumn{8}{|c|}{ Neutral } & \multicolumn{7}{|c|}{$\begin{array}{l}\text { Feel MOST WARM } \\
\text { Toward This Group } \\
7\end{array}$} \\
\hline NZ Europeans & 1 & 2 & 3 & 4 & 5 & 6 & 7 & Overweight people & 1 & 2 & 3 & 4 & 5 & 6 & 7 \\
\hline Māori & 1 & 2 & 3 & 4 & 5 & 6 & 7 & Immigrants in general & 1 & 2 & 3 & 4 & 5 & 6 & 7 \\
\hline Asians in general & 1 & 2 & 3 & 4 & 5 & 6 & 7 & Chinese & 1 & 2 & 3 & 4 & 5 & 6 & 7 \\
\hline Pacific Islanders & 1 & 2 & 3 & 4 & 5 & 6 & 7 & Indians & 1 & 2 & 3 & 4 & 5 & 6 & 7 \\
\hline Elderly people & 1 & 2 & 3 & 4 & 5 & 6 & 7 & Muslims & 1 & 2 & 3 & 4 & 5 & 6 & 7 \\
\hline Refugees & 1 & 2 & 3 & 4 & 5 & 6 & 7 & People with mental illness & 1 & 2 & 3 & 4 & 5 & 6 & 7 \\
\hline
\end{tabular}

Instructions: Please rate how strongly you oppose or support each of the following political parties.

\begin{tabular}{|c|c|c|c|c|c|c|c|c|c|c|c|c|c|c|c|c|}
\hline $\begin{array}{r}\text { Strongly Oppose } \\
1\end{array}$ & \multicolumn{9}{|c|}{ Neutral } & & \multicolumn{6}{|c|}{$\begin{array}{l}\text { Strongly Support } \\
7\end{array}$} \\
\hline The National Party & 1 & 2 & 3 & 4 & 5 & 6 & & & The Green Party & 1 & 2 & 3 & 4 & 5 & 6 & 7 \\
\hline The Labour Party & 1 & 2 & 3 & 4 & 5 & 6 & & & The Māori Party & 1 & 2 & 3 & 4 & 5 & 6 & 7 \\
\hline The ACT Party & 1 & 2 & 3 & 4 & 5 & 6 & 7 & & The NZ First Party & 1 & 2 & 3 & 4 & 5 & 6 & 7 \\
\hline
\end{tabular}

01. What is your date of birth?

02. Which ethnic group(s) do you belong to?

(Mark the space or spaces which apply to you).

03. What is your gender?

04. What is your height?

05 . What is your weight? (metres) (kgs)

06a. How often do you have a drink containing alcohol? And, if you drink alcohol...

06b. How many drinks containing alcohol do you have on a typical day when drinking?

07. During the past month, on average, how many hours of actual sleep did you get per night?

New Zealand European

Māori

Samoan

Cook Island Māori

Tongan

Niuean

Chinese

Indian

Other such as DUTCH, JAPANESE, TOKELAUAN. Please state:

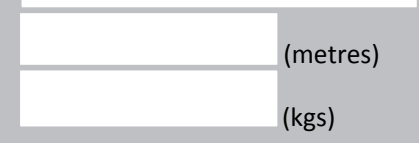

Never - I don't drink Monthly or less Up to 4 times a month Up to 3 times a week 4 or more times a week Don't know

(number of drinks on a typical day)

08. Please rate your ability to speak Māori (Te Reo)

$$
\begin{array}{lllllllll}
\text { Very poor } & 1 & 2 & 3 & 4 & 5 & 6 & 7 & \text { Excellent }
\end{array}
$$

09. Do you have siblings?

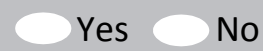

If yes, how many.
(a) older sisters do you have?
(b) younger sisters do you have?
(c) older brothers do you have?
(d) younger brothers do you have?

10. In which language(s) could you have a conversation about a lot of everyday things? (Remember to include English if you could have a conversation in English)

11. Have you been diagnosed with, or treated for, any of the following health conditions by a doctor in the last five years?

High cholesterol High blood pressure Asthma Heart disease Diabetes (Type II) Depression Anxiety disorder Other (please state):

12. Have you ever regularly...
(a) smoked tobacco cigarettes?
Yes No
(b) vaped or used e-cigarettes?
Yes No

13. Do you currently...

(a) smoke tobacco cigarettes?
(b) vape or use e-cigarettes?

Yes No

Yes No

14. Do you have a health condition or disability that limits you, and that has lasted for $6+$ months?

Yes No

(a) if yes, please state:

15. In general, would you say your health is...

$$
\text { Poor } \begin{array}{llllllll}
1 & 2 & 3 & 4 & 5 & 6 & 7 & \text { Excellent } \\
& \multicolumn{7}{c}{\text { Please circle a number }}
\end{array}
$$

16. Please estimate how many hours you spent doing each of the following things last week. (please enter ' 0 hours' if you did not do that activity last week)
(a) Working in paid employment
(b) Housework/cooking
(c) Looking after children
(d) Volunteer/charitable work
(e) Exercising/physical activity
(f) Watching TV/Netflix/movies
(g) Travelling/commuting
(h) Watching/reading the news
(i) Using the internet (in total)
(j) Using social media (e.g., Facebook)
(k) Playing video/computer games
(I) Socialising with friends
(m) Socialising with family
(n) Socialising with community groups
(o) Socialising with religious groups 


\begin{tabular}{|c|c|c|c|c|c|c|c|}
\hline \multirow[b]{2}{*}{$\begin{array}{l}\text { Collection of telephone and internet data by the New Zealand Government as } \\
\text { part of anti-terrorism efforts. }\end{array}$} & \multicolumn{3}{|c|}{$\begin{array}{l}\text { Strongly } \\
\text { Oppose } \\
\end{array}$} & \multirow[b]{2}{*}{4} & \multirow[b]{2}{*}{5} & \multicolumn{2}{|c|}{$\begin{array}{r}\text { Strongly } \\
\text { Support } \\
\downarrow\end{array}$} \\
\hline & 1 & 2 & 3 & & & 6 & 7 \\
\hline $\begin{array}{l}\text { 2. Redistributing money and wealth more evenly among a larger percentage of } \\
\text { the people in New Zealand through heavy taxes on the rich. }\end{array}$ & 1 & 2 & 3 & 4 & 5 & 6 & 7 \\
\hline 3. Strict regulation limiting the use of genetic engineering in humans. & 1 & 2 & 3 & 4 & 5 & 6 & 7 \\
\hline 4. Protest marches and public demonstrations supporting the rights of Māori. & 1 & 2 & 3 & 4 & 5 & 6 & 7 \\
\hline 5. Singing the national anthem in Māori and English. & 1 & 2 & 3 & 4 & 5 & 6 & 7 \\
\hline $\begin{array}{l}\text { 6. Increase payments for those receiving Jobseeker Support (formerly the } \\
\text { Unemployment Benefit). }\end{array}$ & 1 & 2 & 3 & 4 & 5 & 6 & 7 \\
\hline 7. Legalized abortion for women, regardless of the reason. & 1 & 2 & 3 & 4 & 5 & 6 & 7 \\
\hline 8. Teaching Māori language in New Zealand primary schools. & 1 & 2 & 3 & 4 & 5 & 6 & 7 \\
\hline 9. Greater investment in reducing domestic violence. & 1 & 2 & 3 & 4 & 5 & 6 & 7 \\
\hline 10. Restricting foreign ownership of New Zealand residential property. & 1 & 2 & 3 & 4 & 5 & 6 & 7 \\
\hline $\begin{array}{l}\text { 11. Increase payments for those receiving Sole Parent Support (formerly the } \\
\text { Domestic Purposes Benefit). }\end{array}$ & 1 & 2 & 3 & 4 & 5 & 6 & 7 \\
\hline 12. Including religious instruction in Christianity as part of the school curriculum. & 1 & 2 & 3 & 4 & 5 & 6 & 7 \\
\hline 13. Displaying signage in public places in both Māori and English. & 1 & 2 & 3 & 4 & 5 & 6 & 7 \\
\hline $\begin{array}{l}\text { 14. Ensuring that all food and food ingredients sold in New Zealand are free from } \\
\text { Genetically Modified Organisms. }\end{array}$ & 1 & 2 & 3 & 4 & 5 & 6 & 7 \\
\hline 15. Strict regulation limiting the development and use of Artificial Intelligence. & 1 & 2 & 3 & 4 & 5 & 6 & 7 \\
\hline 16. Government subsidy of public transport. & 1 & 2 & 3 & 4 & 5 & 6 & 7 \\
\hline 17. A publicly available online database of all convicted sex offenders in NZ. & 1 & 2 & 3 & 4 & 5 & 6 & 7 \\
\hline 18. Waitangi Day as a national celebration of biculturalism. & 1 & 2 & 3 & 4 & 5 & 6 & 7 \\
\hline $\begin{array}{l}\text { 19. The current ' } 3 \text { Strikes' law for violent/sexual offences, where the maximum } \\
\text { possible sentence must be imposed without parole upon the third conviction. }\end{array}$ & 1 & 2 & 3 & 4 & 5 & 6 & 7 \\
\hline $\begin{array}{l}\text { 20. Protest marches and public demonstrations supporting the rights of New } \\
\text { Zealand Europeans. }\end{array}$ & 1 & 2 & 3 & 4 & 5 & 6 & 7 \\
\hline 21. Legalized abortion when the woman's life is endangered. & 1 & 2 & 3 & 4 & 5 & 6 & 7 \\
\hline 22. Restricting foreign ownership of New Zealand farms. & 1 & 2 & 3 & 4 & 5 & 6 & 7 \\
\hline 23. Increased government spending on new motorways. & 1 & 2 & 3 & 4 & 5 & 6 & 7 \\
\hline
\end{tabular}

Instructions: Please indicate how strongly you disagree or agree with each statement.

\begin{tabular}{|c|c|c|c|c|c|c|c|}
\hline \multirow[b]{2}{*}{ I identify with New Zealand. } & \multicolumn{3}{|c|}{$\begin{array}{l}\text { Strongly } \\
\text { Disagree } \\
\end{array}$} & \multirow[b]{2}{*}{4} & \multirow[b]{2}{*}{5} & \multicolumn{2}{|c|}{$\begin{array}{r}\text { Strongly } \\
\text { Agree } \\
\downarrow\end{array}$} \\
\hline & 1 & 2 & 3 & & & 6 & 7 \\
\hline 2. Being a woman/man is an important part of how I see myself. & 1 & 2 & 3 & 4 & 5 & 6 & 7 \\
\hline 3. I am satisfied with my life. & 1 & 2 & 3 & 4 & 5 & 6 & 7 \\
\hline $\begin{array}{l}\text { 4. Our country will be destroyed some day if we do not smash the perversions } \\
\text { eating away at our moral fibre and traditional beliefs. }\end{array}$ & 1 & 2 & 3 & 4 & 5 & 6 & 7 \\
\hline 5. I do not have enough power or control over important parts of my life. & 1 & 2 & 3 & 4 & 5 & 6 & 7 \\
\hline 6. Women are too easily offended. & 1 & 2 & 3 & 4 & 5 & 6 & 7 \\
\hline 7. When I feel negative emotions, my emotions feel out of control. & 1 & 2 & 3 & 4 & 5 & 6 & 7 \\
\hline 8. Doing my best never seems to be enough. & 1 & 2 & 3 & 4 & 5 & 6 & 7 \\
\hline 9. Many women have a quality of purity that few men possess. & 1 & 2 & 3 & 4 & 5 & 6 & 7 \\
\hline $\begin{array}{l}\text { 10. It is safe to vaccinate children following the standard New Zealand } \\
\text { immunization schedule. }\end{array}$ & 1 & 2 & 3 & 4 & 5 & 6 & 7 \\
\hline $\begin{array}{l}\text { 11. With enough support and professional help, people who have committed } \\
\text { sexual offences can be rehabilitated to become safe members of our society. }\end{array}$ & 1 & 2 & 3 & 4 & 5 & 6 & 7 \\
\hline 12. The New Zealand Police care about the well-being of everyone they deal with. & 1 & 2 & 3 & 4 & 5 & 6 & 7 \\
\hline 13. I feel anxious about interacting with people from other races. & 1 & 2 & 3 & 4 & 5 & 6 & 7 \\
\hline
\end{tabular}


1. Sometimes I can't sleep because of thinking about past wrongs I have suffered.

$\begin{array}{lllllll}1 & 2 & 3 & 4 & 5 & 6 & 7\end{array}$

2. I want people to know that I am an important person of high status.

$\begin{array}{lllllll}1 & 2 & 3 & 4 & 5 & 6 & 7\end{array}$

3. When I meet new people in New Zealand, they often assume that I am a foreigner.

4. In general, relations between men and women in New Zealand are fair.

$\begin{array}{lllllll}1 & 2 & 3 & 4 & 5 & 6 & 7\end{array}$

5. People should pay less attention to The Bible and other old traditional forms of religious guidance, and instead develop their own personal standards of what is moral and immoral.

6. I think that homosexuality should be accepted by society.

7. Climate change is real.

8. Climate change is caused by humans.

$\begin{array}{lllllll}1 & 2 & 3 & 4 & 5 & 6 & 7\end{array}$

9. I am deeply concerned about climate change.

10. I would always report dangerous or suspicious activities occurring in my neighbourhood to the police.

11. In general, relations between different ethnic groups in New Zealand are fair.

12. All things considered, religion is a cause for good in the world.

13. Most New Zealanders respect the achievements of my ethnic group.

$\begin{array}{lllllll}1 & 2 & 3 & 4 & 5 & 6 & 7\end{array}$

14. It would be good if all people living in New Zealand could speak Māori and English.

15. I identify as a spiritual person.

16. Inferior groups should stay in their place.

17. The average citizen can have an influence on government decisions.

18. Women seek to gain power by getting control over men.

19. People from other races would be likely to reject me on the basis of my race.

20. I think that I am entitled to more respect than the average person is.

21. Bad smells, messes, dead animals and rotten food absolutely disgust me.

22. When I feel negative emotions, I change the way I think to help me stay calm.

23. I would always provide information to the police to help them find someone suspected of committing a crime.

24. Other people have too much power or control over important parts of my life.

25. I oppose religion in any form.

26. Discrimination against Māori is no longer a problem in New Zealand.

27. I can usually forgive and forget when someone does me wrong.

28. My performance rarely measures up to my standards.

29. Foreign nations have done some very fine things but they are still not as good as New Zealand.

30. Women should be cherished and protected by men.

31. Generally, the more influence NZ has on other nations, the better off they are.

32. Although at times I may not agree with the government, my commitment to New Zealand always remains strong.

$\begin{array}{lllllll}1 & 2 & 3 & 4 & 5 & 6 & 7\end{array}$

$\begin{array}{lllllll}1 & 2 & 3 & 4 & 5 & 6 & 7\end{array}$

$\begin{array}{lllllll}1 & 2 & 3 & 4 & 5 & 6 & 7\end{array}$

$\begin{array}{lllllll}1 & 2 & 3 & 4 & 5 & 6 & 7\end{array}$

$\begin{array}{lllllll}1 & 2 & 3 & 4 & 5 & 6 & 7\end{array}$

$\begin{array}{lllllll}1 & 2 & 3 & 4 & 5 & 6 & 7\end{array}$

$\begin{array}{lllllll}1 & 2 & 3 & 4 & 5 & 6 & 7\end{array}$

$\begin{array}{lllllll}1 & 2 & 3 & 4 & 5 & 6 & 7\end{array}$

$\begin{array}{lllllll}1 & 2 & 3 & 4 & 5 & 6 & 7\end{array}$

$\begin{array}{lllllll}1 & 2 & 3 & 4 & 5 & 6 & 7\end{array}$

$\begin{array}{lllllll}1 & 2 & 3 & 4 & 5 & 6 & 7\end{array}$

$\begin{array}{lllllll}1 & 2 & 3 & 4 & 5 & 6 & 7\end{array}$

$\begin{array}{lllllll}1 & 2 & 3 & 4 & 5 & 6 & 7\end{array}$

$\begin{array}{lllllll}1 & 2 & 3 & 4 & 5 & 6 & 7\end{array}$

$\begin{array}{lllllll}1 & 2 & 3 & 4 & 5 & 6 & 7\end{array}$

$\begin{array}{lllllll}1 & 2 & 3 & 4 & 5 & 6 & 7\end{array}$

$\begin{array}{lllllll}1 & 2 & 3 & 4 & 5 & 6 & 7\end{array}$

$\begin{array}{lllllll}1 & 2 & 3 & 4 & 5 & 6 & 7\end{array}$

$\begin{array}{lllllll}1 & 2 & 3 & 4 & 5 & 6 & 7\end{array}$

$\begin{array}{lllllll}1 & 2 & 3 & 4 & 5 & 6 & 7\end{array}$

$\begin{array}{lllllll}1 & 2 & 3 & 4 & 5 & 6 & 7\end{array}$

$\begin{array}{lllllll}1 & 2 & 3 & 4 & 5 & 6 & 7\end{array}$

$\begin{array}{llllllll}1 & 2 & 3 & 4 & 5 & 6 & 7\end{array}$

$\begin{array}{lllllll}1 & 2 & 3 & 4 & 5 & 6 & 7\end{array}$

$\begin{array}{llllllll}1 & 2 & 3 & 4 & 5 & 6 & 7\end{array}$

$\begin{array}{lllllll}1 & 2 & 3 & 4 & 5 & 6 & 7\end{array}$

33. I feel that I am often discriminated against because of my religious/spiritual beliefs.

34. In most ways my life is close to ideal.

35. To a large extent, a person's race biologically determines his or her abilities.

36. Being a member of my ethnic group is an important part of how I see myself.

37. I'm frustrated by what my ethnic group earns relative to other groups in NZ.

38. I am an ordinary person who is no better than others.

39. I often worry about terrorist attacks happening in New Zealand.

40. Some of the best people in our country are those who are challenging our government, criticizing religion, and ignoring the "normal way" things are supposed to be done.

41. Women, as compared to men, tend to have a more refined sense of culture and good taste.

$\begin{array}{lllllll}1 & 2 & 3 & 4 & 5 & 6 & 7\end{array}$


01. What is your highest level of qualification?

02a. Are you currently employed? (This includes self-employed or casual work)

Yes (years) (months) 02b. If yes, how long have you worked at your current organisation?

02c. What is your current occupation?

02d. How satisfied are you with your current job? $\begin{array}{llllllllll}\text { Not satisfied } & \mathbf{1} & \mathbf{2} & \mathbf{3} & \mathbf{4} & \mathbf{5} & \mathbf{6} & \mathbf{7} & \text { Very satisfied }\end{array}$

02e. How secure do you feel in your current job? $\begin{array}{lllllllll}\text { Not secure } & \mathbf{1} & \mathbf{2} & \mathbf{3} & \mathbf{4} & \mathbf{5} & \mathbf{6} & \mathbf{7} & \text { Very secure }\end{array}$

02f. How valued do you feel by your current organisation?

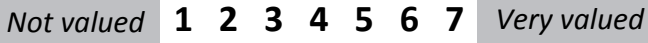

03a. What is your relationship status?

If you are in a relationship..

(e.g., single, married, de-facto, civil union, widowed, living together, etc.)

03b. How long have you been with your partner?

03c. If you are currently married or in a civil union, what was the date of your marriage or union?

\begin{tabular}{|l}
\hline $\begin{array}{l}\text { (years) } \\
\text { (months) }\end{array}$ \\
\hline I
\end{tabular}

03d. How satisfied are you with your relationship?

$\begin{array}{llllllllll}\text { Not satisfied } & \mathbf{1} & \mathbf{2} & \mathbf{3} & \mathbf{4} & \mathbf{5} & \mathbf{6} & \mathbf{7} & \text { Very satisfied }\end{array}$

03e. To what extent do you experience conflict or disagreement with your partner?

$\begin{array}{llllllllll}\text { No conflict at all } & 1 & 2 & 3 & 4 & 5 & 6 & 7 & \text { A great deal of conflict }\end{array}$

03f. Is your partner currently employed? Yes No If your partner is employed...

03g. What is your partner's occupation?

03h. On average, how many hours per week does your partner work?

(hours per week)

04. Please list the adult(s) who lived with you while you were growing up. Please describe their relationship to you and their occupation.

RELATIONSHIP TO YOU: THEIR OCCUPATION: (e.g., mother, father, aunt) (e.g., builder, homemaker)

Person 1:

Person 2:

Person 3:

Person 4:

05. How would you describe your dietary behaviour?

(e.g., meat \& vegetables, vegetarian, vegan, halal, pescatarian, etc.)

06. How much money have you donated to charity in the last year?

\section{$\$$}

07. Please rate how politically liberal versus conservative you see yourself as being:

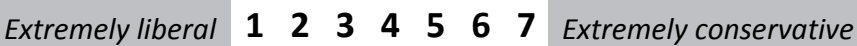

08a. Has someone ever used the internet, a mobile phone, or digital camera to hurt, intimidate or embarrass you?

Yes No

08b. ...has this occurred in the last month? Yes No

09. Please rate how politically left-wing versus right-wing you see yourself as being:

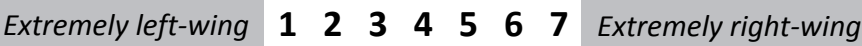

10. Please estimate your total household income (before tax) for the year 2018:

11. Please estimate how much help you have received from the following sources in the last week?

(a) family:

(b) friends:

(c) members of my community:

12a. How many children have you given birth to, fathered, or adopted?

12b. If you are a parent, in which year...

(a) was your eldest child born?

(b) was your youngest born?

13. What was the name of the high school/secondary school that you attended? (Please be specific, and if more than one, list them all)

14. Do you identify with a religion and/or spiritual group? If yes...

TIME MONEY

(hours) (dollars)
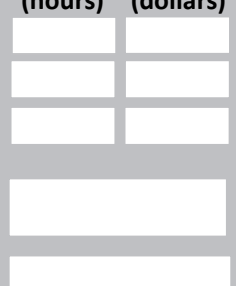

(a) what religion or spiritual group?

(b) how many times did you attend a church or place of worship in the last month?

(c) how many times did you pray in the last week?

(d) how many times did you read religious scripture in the last week?

(f) how important is your religion to how you see yourself?

Not important $\begin{array}{lllllllll}1 & \mathbf{2} & \mathbf{3} & \mathbf{4} & \mathbf{5} & \mathbf{6} & \mathbf{7} & \text { Very important }\end{array}$

15. Roughly how many hours have you spent with both FRIENDS/FAMILY and OTHERS (e.g., workmates, strangers) from each ethnic group in the last week? FRIENDS/FAMILY OTHERS
(a) Māori
(b) NZ Europeans
(c) Pacific Islanders
(d) Asians

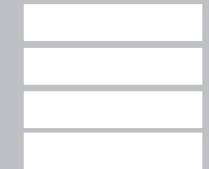

16a. Did you vote in the

New Zealand election in 2017?

Yes

No

16b. If yes, to which party did you give...

$$
\begin{aligned}
& \text { your party vote? } \\
& \text { your electorate vote? }
\end{aligned}
$$

17. How important are your political beliefs to how you see yourself?

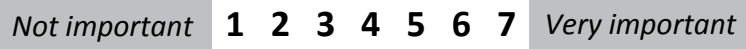

18. Do you believe in a God?

19. Do you believe in some form of spirit or life force?

20. Where were you born?

(please be specific, e.g., which town/city?)

21. If you were born overseas, for how many years have you lived in NZ?

22. Are you a New Zealand citizen?

23. Do you own your own home?

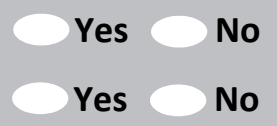

(either partly or fully owned)

24. How would you describe your sexual orientation?

(e.g., heterosexual, homosexual, straight, gay, lesbian, bisexual, etc.)

25. How satisfied are you with your sex life?

$$
\begin{array}{llllllllll}
\text { Not satisfied } & \mathbf{1} & \mathbf{2} & \mathbf{3} & \mathbf{4} & \mathbf{5} & \mathbf{6} & \mathbf{7} & \text { Very satisfied }
\end{array}
$$


Finally, have you experienced any significant life events in the past year?

A lot of things can happen in a year. This is a final optional question that can help us to understand if you have experienced significant life events that might have shaped your responses to the questionnaire for this year. Here are some examples of the significant life events that people might experience (please tick any that you have experienced in the last year):

Began a new serious romantic relationship

Got married/entered a civil union

Separated from your romantic partner/spouse

Got divorced

The birth of a child

Someone stole something that was yours or burgled your home

Someone assaulted you, abused you, or attacked you

Someone sexually harassed you

Lost your job or had the principal earner in your household lose their job

Retired

Suffered a serious and ongoing illness or disease

A family member suffered a serious and ongoing illness or disease

Suffered an accident leading to serious injury

A family member suffered an accident leading to serious injury

The death of a family member or loved one

Have we missed anything important or would you like to provide more detail about your experiences? If so, please let us know in the box below:

Thank you for taking part in the New Zealand Attitudes and Values Study!

Please post back your completed questionnaire using the included freepost return envelope. The freepost envelope will work from anywhere in New Zealand. If you lose the envelope, you can post this questionnaire back for free to:

FREEPOST AUTHORITY: 124589

New Zealand Attitudes and Values Study

School of Psychology (Cost 9450/71708)

The University of Auckland

Private Bag 92019

Auckland 1142, New Zealand

If you would like to know more about the New Zealand Attitudes and Values Study, then please feel free to phone us (contact details on the front) or you can visit the study website. We will also send out a regular e-newsletter to everyone in the study summarising the most interesting findings from the study. 


\section{The New Zealand Attitudes and Values Study}

SCHOOL OF PSYCHOLOGY

Science Centre, Building 302

23 Symonds Street, Auckland,

New Zealand

T $09-923-7498$

Enzavs@auckland.ac.nz

$\mathbf{w}$ www.nzavs.auckland.ac.nz

\section{Follow-up Questionnaire for 2019/2020}

A scanned copy of this form will be kept for a period of up to fifteen years.

Lead researcher:

Professor Chris Sibley, School of Psychology, The University of Auckland.

Phone: 09-923-7498. e-mail: nzavs@auckland.ac.nz

\section{Consent form and contact details}

This form is to gather your consent to participate in this phase of the New Zealand Attitudes and Values Study (NZAVS). Only Professor Sibley and his research associates will have access to your responses. Your personal information will be kept separate from your responses at all times. Your questionnaire will be identified by an anonymous code. An encrypted electronic copy of all responses will be stored indefinitely for research purposes in a secure room in the School of Psychology.

I have read and understood a description of this research project. On this basis, I agree to take part. I understand that my data will remain confidential at all times. I understand that only Professor Sibley and trusted research assistants working on the study in secure conditions will have access to my contact details. I consent to publication of the results of the project with the understanding that my anonymity will be preserved. I understand that I am free to withdraw from the research at any time up until the point at which I complete and return this questionnaire. I understand that my contact details will never be shared with anyone outside of the immediate research team. I understand that Professor Sibley and the research team will use these details to contact and invite me to complete follow-up questionnaires, possibly for the next nine years. I understand that my contact details will also be used to contact me if I win one of the five prize draws for $\$ \mathbf{1 0 0 0}$ grocery vouchers (total prize pool $\$ 5000$ ) for participating in this study.

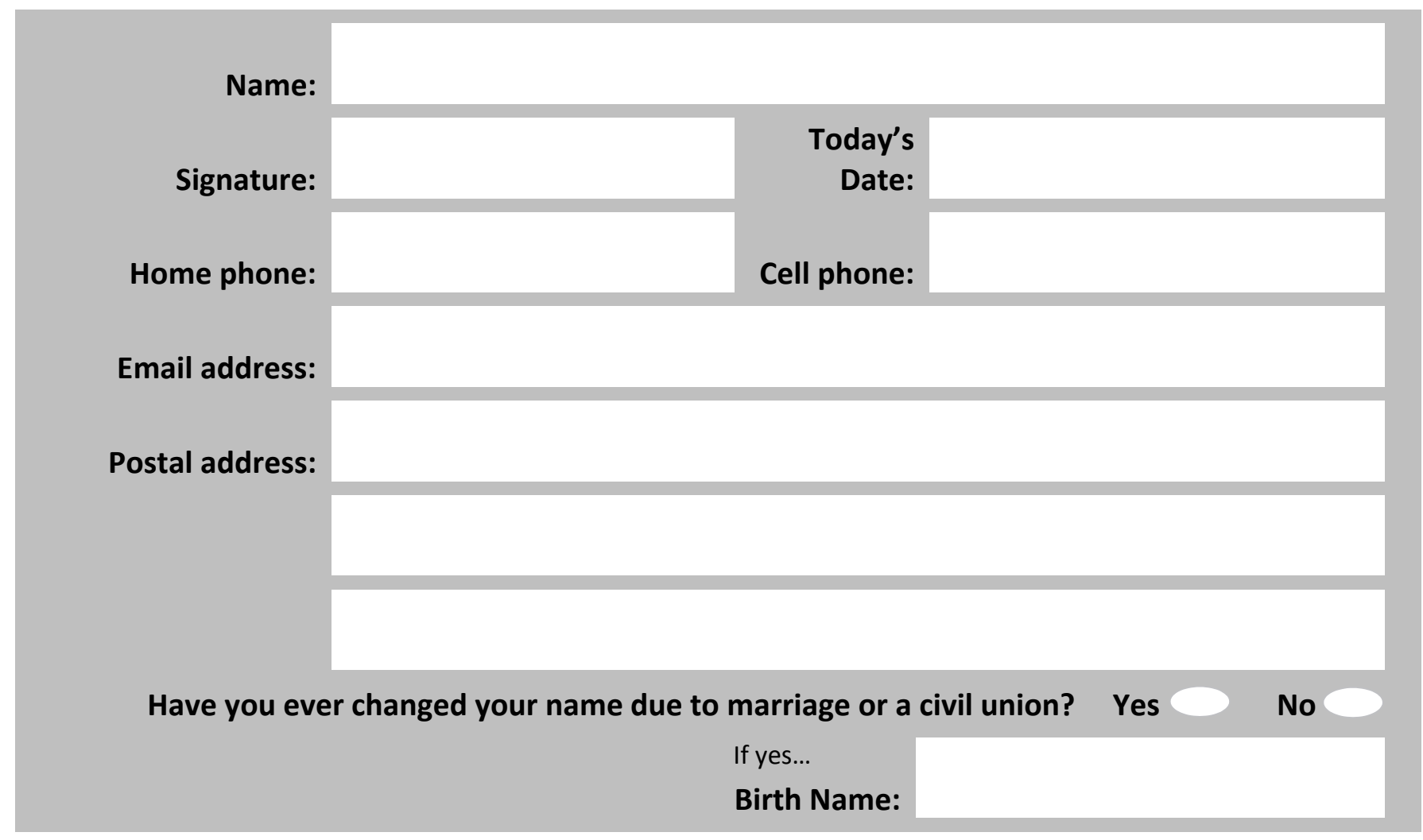




\section{Do you have a partner who would also like to join the NZAVS?}

Over the years, a number of participants have got in touch to let us know that their partner is also interested in joining the NZAVS, and to ask if their partner could also be sent a copy of the questionnaire.

If you have a partner who would like to join the NZAVS and complete their own copy of the questionnaire, then they are most welcome to do so. The easiest way for your partner to join the study is to simply complete the questionnaire online.

The online version is available at: www.nzavs.auckland.ac.nz/survey

Alternatively, please ask your partner to email us at nzavs@auckland.ac.nz and let us know they are interested in joining the study. We would then be happy to post them a paper copy of the questionnaire. 
Instructions: This part of the questionnaire measures your feelings about yourself.

Please circle the number that best represents how accurately each statement describes you.

\section{I ...}

Very

Inaccurate

1. Am the life of the party.

2. Sympathise with others' feelings.

$\begin{array}{lllllll}1 & 2 & 3 & 4 & 5 & 6 & 7\end{array}$

3. Get chores done right away.

4. Have frequent mood swings.

$\begin{array}{lllllll}1 & 2 & 3 & 4 & 5 & 6 & 7\end{array}$

5. Have a vivid imagination.

6. Don't talk a lot.

$\begin{array}{lllllll}1 & 2 & 3 & 4 & 5 & 6 & 7\end{array}$

7. Am not interested in other people's problems.

$\begin{array}{lllllll}1 & 2 & 3 & 4 & 5 & 6 & 7\end{array}$

8. Have difficulty understanding abstract ideas.

9. Like order.

10. Make a mess of things.

11. Do not have a good imagination.

$\begin{array}{lllllll}1 & 2 & 3 & 4 & 5 & 6 & 7\end{array}$

12. Feel others' emotions.

$\begin{array}{lllllll}1 & 2 & 3 & 4 & 5 & 6 & 7\end{array}$

13. Am relaxed most of the time.

$\begin{array}{lllllll}1 & 2 & 3 & 4 & 5 & 6 & 7\end{array}$

14. Get upset easily.

15. Seldom feel blue.

$\begin{array}{lllllll}1 & 2 & 3 & 4 & 5 & 6 & 7 \\ 1 & 2 & 3 & 4 & 5 & 6 & 7\end{array}$

16. Keep in the background.

17. Am not really interested in others.

$\begin{array}{lllllll}1 & 2 & 3 & 4 & 5 & 6 & 7\end{array}$

18. Am not interested in abstract ideas.

$\begin{array}{lllllll}1 & 2 & 3 & 4 & 5 & 6 & 7\end{array}$

19. Often forget to put things back in their proper place.

$\begin{array}{lllllll}1 & 2 & 3 & 4 & 5 & 6 & 7\end{array}$

20. Talk to a lot of different people at parties.

$\begin{array}{llllllll}1 & 2 & 3 & 4 & 5 & 6 & 7\end{array}$

21. Feel entitled to more of everything.

22. On the whole am satisfied with myself.

23. Know that people in my life accept and value me.

$\begin{array}{lllllll}1 & 2 & 3 & 4 & 5 & 6 & 7 \\ 1 & 2 & 3 & 4 & 5 & 6 & 7\end{array}$

24. Would like to be seen driving around in a very expensive car.

$\begin{array}{lllllll}1 & 2 & 3 & 4 & 5 & 6 & 7 \\ 1 & 2 & 3 & 4 & 5 & 6 & 7\end{array}$

25. Deserve more things in life.

$\begin{array}{lllllll}1 & 2 & 3 & 4 & 5 & 6 & 7\end{array}$

26. Feel that I am often discriminated against because of my ethnicity.

27. Feel like an outsider.

28. Would get a lot of pleasure from owning expensive luxury goods.

$\begin{array}{lllllll}1 & 2 & 3 & 4 & 5 & 6 & 7\end{array}$

29. Am satisfied with the appearance, size and shape of my body.

30. Am inclined to feel that I am a failure.

31. Take a positive attitude toward myself.

$\begin{array}{lllllll}1 & 2 & 3 & 4 & 5 & 6 & 7\end{array}$

32. Feel that I am often discriminated against because of my gender.

33. Know that people around me share my attitudes and beliefs.

$\begin{array}{lllllll}1 & 2 & 3 & 4 & 5 & 6 & 7 \\ 1 & 2 & 3 & 4 & 5 & 6 & 7 \\ 1 & 2 & 3 & 4 & 5 & 6 & 7 \\ 1 & 2 & 3 & 4 & 5 & 6 & 7 \\ 1 & 2 & 3 & 4 & 5 & 6 & 7 \\ 1 & 2 & 3 & 4 & 5 & 6 & 7 \\ 1 & 2 & 3 & 4 & 5 & 6 & 7 \\ 1 & 2 & 3 & 4 & 5 & 6 & 7 \\ 1 & 2 & 3 & 4 & 5 & 6 & 7 \\ 1 & 2 & 3 & 4 & 5 & 6 & 7 \\ 1 & 2 & 3 & 4 & 5 & 6 & 7 \\ 1 & 2 & 3 & 4 & 5 & 6 & 7 \\ 1 & 2 & 3 & 4 & 5 & 6 & 7\end{array}$

During the last $\mathbf{3 0}$ days, how often did (Please use the scale below to circle a number for each question)

\begin{tabular}{r|c} 
None of & A Little of \\
The Time & The Time \\
0 & 1
\end{tabular}

$\begin{array}{cc}\text { Some of } & \text { Most Of } \\ \text { The Time } & \text { The Time }\end{array}$

2 3

1. ... you feel hopeless?

2. ... you feel so depressed that nothing could cheer you up?

3. ... you feel restless or fidgety?

4. ... you feel that everything was an effort?

5. ... you feel worthless?

6. ... you feel nervous?

7. ... you have negative thoughts that repeated over and over?

\begin{tabular}{|lllll|}
\hline 0 & 1 & 2 & 3 & 4 \\
\hline 0 & 1 & 2 & 3 & 4 \\
\hline 0 & 1 & 2 & 3 & 4 \\
\hline 0 & 1 & 2 & 3 & 4 \\
\hline 0 & 1 & 2 & 3 & 4 \\
\hline 0 & 1 & 2 & 3 & 4 \\
\hline 0 & 1 & 2 & 3 & 4 \\
\hline 0 & 1 & 2 & 3 & 4 \\
\hline 0 & 1 & 2 & 3 & 4 \\
\hline
\end{tabular}

8. ... you worry that a big earthquake might hit your region?

9. ... you feel exhausted? 


\begin{tabular}{lllllll}
$\begin{array}{l}\text { Strongly } \\
\text { Disagree } \\
\downarrow\end{array}$ & & $\begin{array}{r}\text { Strongly } \\
\text { Agree } \\
\downarrow\end{array}$ \\
\hline 1 & 2 & 3 & 4 & 5 & 6 & 7 \\
\hline 1 & 2 & 3 & 4 & 5 & 6 & 7 \\
\hline 1 & 2 & 3 & 4 & 5 & 6 & 7 \\
\hline 1 & 2 & 3 & 4 & 5 & 6 & 7 \\
\hline 1 & 2 & 3 & 4 & 5 & 6 & 7 \\
\hline 1 & 2 & 3 & 4 & 5 & 6 & 7 \\
\hline 1 & 2 & 3 & 4 & 5 & 6 & 7 \\
\hline 1 & 2 & 3 & 4 & 5 & 6 & 7 \\
\hline
\end{tabular}

1. I have much in my life to be thankful for.

$\begin{array}{lllllll}1 & 2 & 3 & 4 & 5 & 6 & 7\end{array}$

2. It would be good if groups could be equal.

3. I often think about the fact that I am a member of my ethnic group.

4. I expect my health to get worse.

5. I feel a sense of community with others in my local neighbourhood.

6. We should have increased social equality.

7. I know there are people I can turn to when I need help.

8. There are many things about the New Zealand Police and its policies that need to be changed.

9. If I go to my doctor/GP with a minor illness (e.g., sore throat, cough, runny nose, etc.), I think that I should be prescribed antibiotics by default.

10. I wish I had more self-discipline.

11. We should do what we can to equalise conditions for different groups.

$\begin{array}{lllllll}1 & 2 & 3 & 4 & 5 & 6 & 7\end{array}$

12. By taking an active part in political and social affairs we, the people, can control world events.

13. I seem to get sick a little easier than other people.

$\begin{array}{lllllll}1 & 2 & 3 & 4 & 5 & 6 & 7\end{array}$

14. If incomes were more equal, people would be less motivated to work hard.

$\begin{array}{lllllll}1 & 2 & 3 & 4 & 5 & 6 & 7\end{array}$

$\begin{array}{lllllll}1 & 2 & 3 & 4 & 5 & 6 & 7\end{array}$

15. I have a good sense of what makes my life meaningful.

$\begin{array}{lllllll}1 & 2 & 3 & 4 & 5 & 6 & 7\end{array}$

16. To get ahead in life, it is sometimes okay to step on other groups.

$\begin{array}{lllllll}1 & 2 & 3 & 4 & 5 & 6 & 7\end{array}$

17. I am hardly ever satisfied with my performance.

18. People from my ethnic group generally earn less than other groups in NZ.

$\begin{array}{lllllll}1 & 2 & 3 & 4 & 5 & 6 & 7\end{array}$

19. When I feel negative emotions, I suppress or hide my emotions.

20. I have considered voting in terms of what is good for my particular ethnic group.

21. I am grateful to a wide variety of people.

$\begin{array}{lllllll}1 & 2 & 3 & 4 & 5 & 6 & 7\end{array}$

$\begin{array}{llllllll}1 & 2 & 3 & 4 & 5 & 6 & 7\end{array}$

$\begin{array}{lllllll}1 & 2 & 3 & 4 & 5 & 6 & 7\end{array}$

$\begin{array}{lllllll}1 & 2 & 3 & 4 & 5 & 6 & 7\end{array}$

22. I feel at ease when I am in a city district in New Zealand with many immigrants.

23. I find myself regularly thinking about past times that I have been wronged.

24. I would always report dangerous or suspicious activities occurring in my neighbourhood to the police.

$\begin{array}{lllllll}1 & 2 & 3 & 4 & 5 & 6 & 7\end{array}$

$\begin{array}{lllllll}1 & 2 & 3 & 4 & 5 & 6 & 7\end{array}$

$\begin{array}{lllllll}1 & 2 & 3 & 4 & 5 & 6 & 7\end{array}$

$\begin{array}{lllllll}1 & 2 & 3 & 4 & 5 & 6 & 7\end{array}$

$\begin{array}{lllllll}1 & 2 & 3 & 4 & 5 & 6 & 7\end{array}$

25. The fact that I am a member of my ethnic group is an important part of my identity.

26. People who are 'tall poppies' should be cut down to size.

27. Everyone in New Zealand has a fair shot at wealth and happiness, regardless of ethnicity or race.

Instructions: Please rate your level of satisfaction with the following aspects of your life and New Zealand.

0

Completely Dissatisfied

\section{Somewhat Satisfied}

3

1. Your standard of living.

2. The economic situation in New Zealand.

3. The quality of New Zealand's natural environment.

4. Your health.

5. The social conditions in New Zealand.

6. The performance of the current New Zealand government.

7. Your future security.

8. Business in New Zealand.

9. Your personal relationships.

10. Your access to health care when you need it (e.g., doctor, GP).

11. The quality and health of the waterways in your local region.

\section{Completely Satisfied} 10

\begin{tabular}{lllllllllll}
0 & 1 & 2 & 3 & 4 & 5 & 6 & 7 & 8 & 9 & 10 \\
\hline 0 & 1 & 2 & 3 & 4 & 5 & 6 & 7 & 8 & 9 & 10 \\
\hline 0 & 1 & 2 & 3 & 4 & 5 & 6 & 7 & 8 & 9 & 10 \\
\hline 0 & 1 & 2 & 3 & 4 & 5 & 6 & 7 & 8 & 9 & 10 \\
\hline 0 & 1 & 2 & 3 & 4 & 5 & 6 & 7 & 8 & 9 & 10 \\
\hline 0 & 1 & 2 & 3 & 4 & 5 & 6 & 7 & 8 & 9 & 10 \\
\hline 0 & 1 & 2 & 3 & 4 & 5 & 6 & 7 & 8 & 9 & 10 \\
\hline 0 & 1 & 2 & 3 & 4 & 5 & 6 & 7 & 8 & 9 & 10 \\
\hline 0 & 1 & 2 & 3 & 4 & 5 & 6 & 7 & 8 & 9 & 10 \\
\hline 0 & 1 & 2 & 3 & 4 & 5 & 6 & 7 & 8 & 9 & 10 \\
\hline 0 & 1 & 2 & 3 & 4 & 5 & 6 & 7 & 8 & 9 & 10 \\
\hline
\end{tabular}




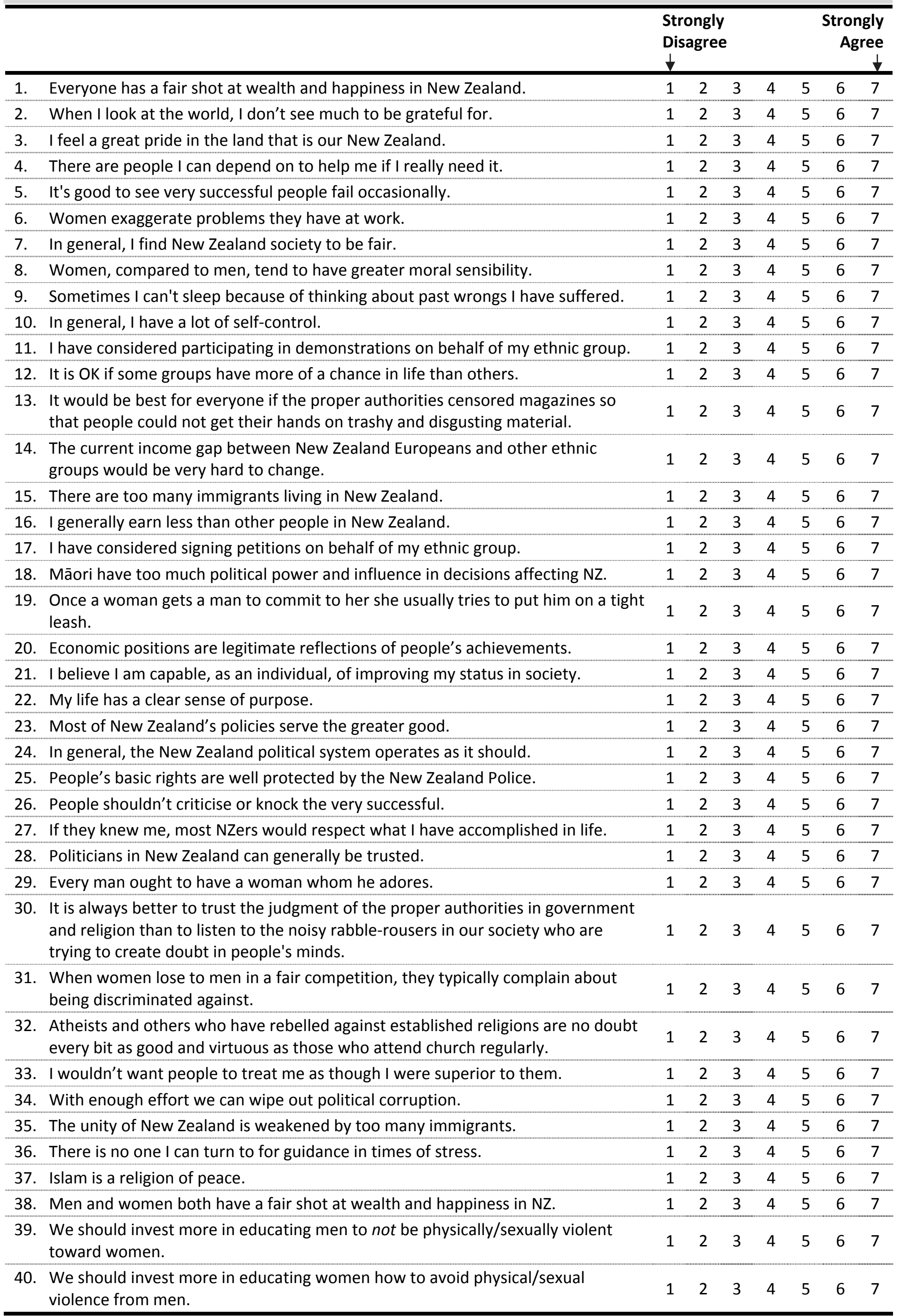


Please rate your feelings of WARMTH toward the following groups using the "feeling thermometer scale" for each group.

\begin{tabular}{|c|c|c|c|c|c|c|c|c|c|c|c|c|c|c|c|}
\hline $\begin{array}{r}\text { Feel LEAST WARM } \\
\text { Toward This Group } \\
1\end{array}$ & \multicolumn{8}{|c|}{ Neutral } & \multicolumn{7}{|c|}{$\begin{array}{l}\text { Feel MOST WARM } \\
\text { Toward This Group } \\
7\end{array}$} \\
\hline NZ Europeans & 1 & 2 & 3 & 4 & 5 & 6 & 7 & Overweight people & 1 & 2 & 3 & 4 & 5 & 6 & 7 \\
\hline Māori & 1 & 2 & 3 & 4 & 5 & 6 & 7 & Immigrants in general & 1 & 2 & 3 & 4 & 5 & 6 & 7 \\
\hline Asians in general & 1 & 2 & 3 & 4 & 5 & 6 & 7 & Chinese & 1 & 2 & 3 & 4 & 5 & 6 & 7 \\
\hline Pacific Islanders & 1 & 2 & 3 & 4 & 5 & 6 & 7 & Indians & 1 & 2 & 3 & 4 & 5 & 6 & 7 \\
\hline Elderly people & 1 & 2 & 3 & 4 & 5 & 6 & 7 & Muslims & 1 & 2 & 3 & 4 & 5 & 6 & 7 \\
\hline Refugees & 1 & 2 & 3 & 4 & 5 & 6 & 7 & People with mental illness & 1 & 2 & 3 & 4 & 5 & 6 & 7 \\
\hline
\end{tabular}

Instructions: Please rate how strongly you oppose or support each of the following political parties.

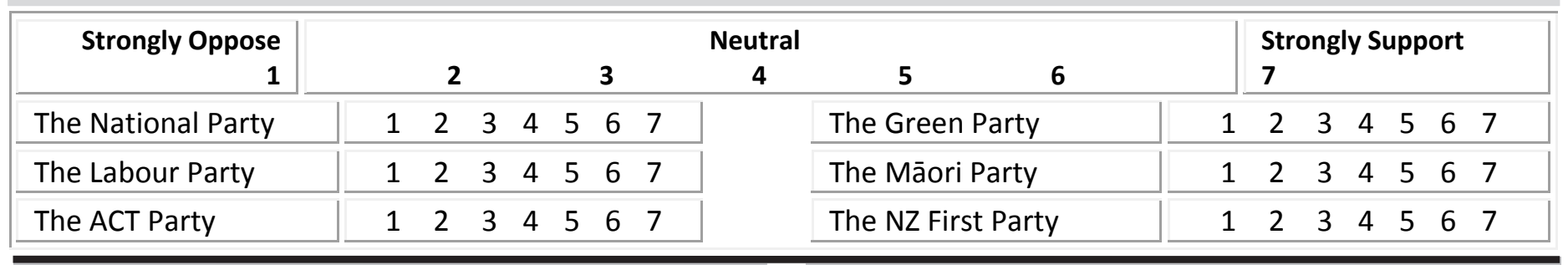

01. What is your date of birth?

02. Which ethnic group(s) do you belong to?

(Mark the space or spaces which apply to you).

03. What is your gender?

04. What is your height?

05. What is your weight?

06a. How often do you have a drink containing alcohol? And, if you drink alcohol...

06b. How many drinks containing alcohol do you have on a typical day when drinking?

$$
\text { l I }
$$

New Zealand European

Māori

Samoan

Cook Island Māori

Tongan

Niuean

Chinese

Indian

Other such as DUTCH, JAPANESE, TOKELAUAN. Please state:
12. Have you been diagnosed with, or treated for, any of the following health conditions by a doctor in the last five years?
High cholesterol High blood pressure Asthma Heart disease Diabetes (Type II) Depression Anxiety disorder Other (please state):

13. Have you ever regularly...
(a) smoked tobacco cigarettes?
Yes No
(b) vaped or used e-cigarettes?
Yes No

14. Do you currently...
(a) smoke tobacco cigarettes?
Yes No
(b) vape or use e-cigarettes?
Yes No

15. Do you have a health condition or disability that limits you, and that has lasted for $6+$ months?

Yes No

(a) if yes, please state:

Never - I don't drink Monthly or less Up to 4 times a month Up to 3 times a week 4 or more times a week Don't know (number of
drinks on a typical day
07. During the past month, on average, how many hours of actual sleep did you get per night?

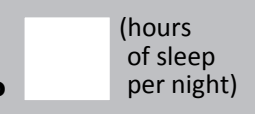

08. Do you support legalising the personal use of recreational cannabis?

09a. Where were you born? (please be specific, e.g., which town/city?)

09b. If you were born overseas, for how many years have you lived in NZ?

10. Are you a New Zealand citizen? Yes No

11. Do you have any pets? Yes No (a) if yes, please specify:
16. In general, would you say your health is...

$$
\text { Poor } \begin{array}{llllllll}
1 & 2 & 3 & 4 & 5 & 6 & 7 & \text { Excellent } \\
& \multicolumn{7}{c}{\text { Please circle a number }}
\end{array}
$$

17. Please estimate how many hours you spent doing each of the following things last week. (please enter ' 0 hours' if you did not do that activity last week)
(a) Working in paid employment
(b) Housework/cooking
(c) Looking after children
(d) Volunteer/charitable work
(e) Exercising/physical activity
(f) Watching TV/Netflix/movies
(g) Travelling/commuting
(h) Watching/reading the news
(i) Using the internet (in total)
(j) Using social media (e.g., Facebook)
(k) Playing video/computer games
(I) Socialising with friends
(m) Socialising with family
(n) Socialising with community groups
(o) Socialising with religious groups 


\begin{tabular}{|c|c|c|c|c|c|c|c|}
\hline \multirow[b]{2}{*}{$\begin{array}{l}\text { Collection of telephone and internet data by the New Zealand Government as } \\
\text { part of anti-terrorism efforts. }\end{array}$} & \multicolumn{3}{|c|}{$\begin{array}{l}\text { Strongly } \\
\text { Oppose } \\
\downarrow\end{array}$} & \multirow[b]{2}{*}{4} & \multirow[b]{2}{*}{5} & \multicolumn{2}{|c|}{$\begin{array}{c}\text { Strongly } \\
\text { Support } \\
\downarrow\end{array}$} \\
\hline & 1 & 2 & 3 & & & 6 & 7 \\
\hline $\begin{array}{l}\text { 2. Redistributing money and wealth more evenly among a larger percentage of } \\
\text { the people in New Zealand through heavy taxes on the rich. }\end{array}$ & 1 & 2 & 3 & 4 & 5 & 6 & 7 \\
\hline $\begin{array}{l}\text { 3. Introducing a programme to enhance sustainable business growth among } \\
\text { businesses owned and operated by women. }\end{array}$ & 1 & 2 & 3 & 4 & 5 & 6 & 7 \\
\hline 4. Protest marches and public demonstrations supporting the rights of Māori. & 1 & 2 & 3 & 4 & 5 & 6 & 7 \\
\hline 5. Legalized abortion for women, regardless of the reason. & 1 & 2 & 3 & 4 & 5 & 6 & 7 \\
\hline 6. Greater investment in reducing domestic violence. & 1 & 2 & 3 & 4 & 5 & 6 & 7 \\
\hline 7. Restricting foreign ownership of New Zealand residential property. & 1 & 2 & 3 & 4 & 5 & 6 & 7 \\
\hline 8. Including religious instruction in Christianity as part of the school curriculum. & 1 & 2 & 3 & 4 & 5 & 6 & 7 \\
\hline $\begin{array}{l}\text { 9. Ensuring that all food and food ingredients sold in New Zealand are free from } \\
\text { Genetically Modified Organisms. }\end{array}$ & 1 & 2 & 3 & 4 & 5 & 6 & 7 \\
\hline $\begin{array}{l}\text { 10. Incentives to increase women's participation in the paid workforce (paid for } \\
\text { by government). }\end{array}$ & 1 & 2 & 3 & 4 & 5 & 6 & 7 \\
\hline 11. Government subsidy of public transport. & 1 & 2 & 3 & 4 & 5 & 6 & 7 \\
\hline $\begin{array}{l}\text { 12. Protest marches and public demonstrations supporting the rights of New } \\
\text { Zealand Europeans. }\end{array}$ & 1 & 2 & 3 & 4 & 5 & 6 & 7 \\
\hline 13. Legalized abortion when the woman's life is endangered. & 1 & 2 & 3 & 4 & 5 & 6 & 7 \\
\hline 14. Same-sex marriage in NZ (The Marriage Amendment Act 2013). & 1 & 2 & 3 & 4 & 5 & 6 & 7 \\
\hline 15. Restricting foreign ownership of New Zealand farms. & 1 & 2 & 3 & 4 & 5 & 6 & 7 \\
\hline 16. Increased government spending on new motorways. & 1 & 2 & 3 & 4 & 5 & 6 & 7 \\
\hline
\end{tabular}

Instructions: Please indicate how strongly you disagree or agree with each statement.

\begin{tabular}{|c|c|c|c|c|c|c|c|}
\hline \multirow[b]{2}{*}{ I identify with New Zealand. } & \multicolumn{3}{|c|}{$\begin{array}{l}\text { Strongly } \\
\text { Disagree } \\
\downarrow\end{array}$} & \multirow[b]{2}{*}{4} & \multirow[b]{2}{*}{5} & \multicolumn{2}{|c|}{$\begin{array}{r}\text { Strongly } \\
\text { Agree } \\
\downarrow \\
\downarrow\end{array}$} \\
\hline & 1 & 2 & 3 & & & 6 & 7 \\
\hline $\begin{array}{l}\text { 2. Although I may disagree with the opinions that other people hold, they } \\
\text { should be allowed to express those views publicly. }\end{array}$ & 1 & 2 & 3 & 4 & 5 & 6 & 7 \\
\hline 3. I am satisfied with my life. & 1 & 2 & 3 & 4 & 5 & 6 & 7 \\
\hline 4. Protecting New Zealand's native species should be a national priority. & 1 & 2 & 3 & 4 & 5 & 6 & 7 \\
\hline $\begin{array}{l}\text { 5. Foreign nations have done some very fine things but they are still not as good } \\
\text { as New Zealand. }\end{array}$ & 1 & 2 & 3 & 4 & 5 & 6 & 7 \\
\hline 6. I do not have enough power or control over important parts of my life. & 1 & 2 & 3 & 4 & 5 & 6 & 7 \\
\hline 7. Our society places too much emphasis on science. & 1 & 2 & 3 & 4 & 5 & 6 & 7 \\
\hline 8. I think that homosexuality should be accepted by society. & 1 & 2 & 3 & 4 & 5 & 6 & 7 \\
\hline 9. Women seek to gain power by getting control over men. & 1 & 2 & 3 & 4 & 5 & 6 & 7 \\
\hline 10. When I feel negative emotions, my emotions feel out of control. & 1 & 2 & 3 & 4 & 5 & 6 & 7 \\
\hline 11. Doing my best never seems to be enough. & 1 & 2 & 3 & 4 & 5 & 6 & 7 \\
\hline 12. Many women have a quality of purity that few men possess. & 1 & 2 & 3 & 4 & 5 & 6 & 7 \\
\hline $\begin{array}{l}\text { 13. It is safe to vaccinate children following the standard New Zealand } \\
\text { immunization schedule. }\end{array}$ & 1 & 2 & 3 & 4 & 5 & 6 & 7 \\
\hline $\begin{array}{l}\text { 14. Although at times I may not agree with the government, my commitment to } \\
\text { New Zealand always remains strong. }\end{array}$ & 1 & 2 & 3 & 4 & 5 & 6 & 7 \\
\hline 15. The New Zealand Police care about the well-being of everyone they deal with. & 1 & 2 & 3 & 4 & 5 & 6 & 7 \\
\hline $\begin{array}{l}\text { 16. People should pay less attention to The Bible and other old traditional forms } \\
\text { of religious guidance, and instead develop their own personal standards of } \\
\text { what is moral and immoral. }\end{array}$ & 1 & 2 & 3 & 4 & 5 & 6 & 7 \\
\hline 17. I feel anxious about interacting with people from other races. & 1 & 2 & 3 & 4 & 5 & 6 & 7 \\
\hline 18. In general, relations between men and women in New Zealand are fair. & 1 & 2 & 3 & 4 & 5 & 6 & 7 \\
\hline
\end{tabular}


1. I want people to know that I am an important person of high status.

$\begin{array}{lllllll}1 & 2 & 3 & 4 & 5 & 6 & 7\end{array}$

2. When I meet new people in New Zealand, they often assume that I am a foreigner.

$\begin{array}{lllllll}1 & 2 & 3 & 4 & 5 & 6 & 7\end{array}$

3. Climate change is real.

4. Climate change is caused by humans.

$\begin{array}{lllllll}1 & 2 & 3 & 4 & 5 & 6 & 7\end{array}$

5. I am deeply concerned about climate change.

$\begin{array}{llllllll}1 & 2 & 3 & 4 & 5 & 6 & 7\end{array}$

6. In general, relations between different ethnic groups in New Zealand are fair.

$\begin{array}{lllllll}1 & 2 & 3 & 4 & 5 & 6 & 7\end{array}$

7. Muslims in New Zealand should have the right to found Islamic schools.

$\begin{array}{lllllll}1 & 2 & 3 & 4 & 5 & 6 & 7\end{array}$

8. Most New Zealanders respect the achievements of my ethnic group.

$\begin{array}{llllllll}1 & 2 & 3 & 4 & 5 & 6 & 7\end{array}$

9. Our country will be destroyed some day if we do not smash the perversions eating away at our moral fibre and traditional beliefs.

10. My performance rarely measures up to my standards.

11. I'm frustrated by what I earn relative to other people in NZ.

$\begin{array}{lllllll}1 & 2 & 3 & 4 & 5 & 6 & 7\end{array}$

12. Inferior groups should stay in their place.

13. The average citizen can have an influence on government decisions.

14. I think that the official version of major world events given by authorities often hides the truth.

15. Women, as compared to men, tend to have a more refined sense of culture and good taste.

16. People from other races would be likely to reject me on the basis of my race.

17. I think that I am entitled to more respect than the average person is.

18. When I feel negative emotions, I change the way I think to help me stay calm.

19. I would always provide information to the police to help them find someone suspected of committing a crime.

$\begin{array}{lllllll}1 & 2 & 3 & 4 & 5 & 6 & 7\end{array}$

0. Other people have too much power or control over important parts of my life.

21. I have a high degree of confidence in the scientific community.

22. If I could, I would live in a place where there were no Muslims.

23. Discrimination against Māori is no longer a problem in New Zealand.

$\begin{array}{lllllll}1 & 2 & 3 & 4 & 5 & 6 & 7\end{array}$

$\begin{array}{lllllll}1 & 2 & 3 & 4 & 5 & 6 & 7\end{array}$

$\begin{array}{lllllll}1 & 2 & 3 & 4 & 5 & 6 & 7\end{array}$

$\begin{array}{lllllll}1 & 2 & 3 & 4 & 5 & 6 & 7\end{array}$

24. I can usually forgive and forget when someone does me wrong.

25. Women should be cherished and protected by men.

26. Generally, the more influence NZ has on other nations, the better off they are.

$\begin{array}{lllllll}1 & 2 & 3 & 4 & 5 & 6 & 7\end{array}$

27. I feel that I am often discriminated against because of my religious/spiritual beliefs.

28. In most ways my life is close to ideal.

29. Being a member of my ethnic group is an important part of how I see myself.

30. I'm frustrated by what my ethnic group earns relative to other groups in NZ.

31. Women are too easily offended.

32. I am an ordinary person who is no better than others.

33. I often worry about terrorist attacks happening in New Zealand.

$\begin{array}{lllllll}1 & 2 & 3 & 4 & 5 & 6 & 7\end{array}$

$12-3-456-7$

$\begin{array}{lllllll}1 & 2 & 3 & 4 & 5 & 6 & 7\end{array}$

$\begin{array}{lllllll}1 & 2 & 3 & 4 & 5 & 6 & 7\end{array}$

$\begin{array}{lllllll}1 & 2 & 3 & 4 & 5 & 6 & 7\end{array}$

$\begin{array}{lllllll}1 & 2 & 3 & 4 & 5 & 6 & 7\end{array}$

34. Some of the best people in our country are those who are challenging our government, criticizing religion, and ignoring the "normal way" things are supposed to be done.

35. People who hold opinions that are harmful or offensive to minority groups should be banned from expressing those views publicly.

Instructions: Please answer each of the following questions by circling a number on the scale below.

Definitely NO

1
2

3

\section{Unsure}

4

$\begin{array}{lllllll}1 & 2 & 3 & 4 & 5 & 6 & 7\end{array}$

$\begin{array}{lllllll}1 & 2 & 3 & 4 & 5 & 6 & 7\end{array}$

$\begin{array}{lllllll}1 & 2 & 3 & 4 & 5 & 6 & 7\end{array}$

$\begin{array}{lllllll}1 & 2 & 3 & 4 & 5 & 6 & 7\end{array}$

$\begin{array}{lllllll}1 & 2 & 3 & 4 & 5 & 6 & 7\end{array}$

$\begin{array}{lllllll}1 & 2 & 3 & 4 & 5 & 6 & 7\end{array}$

$\begin{array}{lllllll}1 & 2 & 3 & 4 & 5 & 6 & 7\end{array}$

$\begin{array}{lllllll}1 & 2 & 3 & 4 & 5 & 6 & 7\end{array}$

$\begin{array}{lllllll}1 & 2 & 3 & 4 & 5 & 6 & 7\end{array}$

$\begin{array}{lllllll}1 & 2 & 3 & 4 & 5 & 6 & 7\end{array}$

$\begin{array}{lllllll}1 & 2 & 3 & 4 & 5 & 6 & 7\end{array}$

$\begin{array}{lllllll}1 & 2 & 3 & 4 & 5 & 6 & 7\end{array}$

$\begin{array}{lllllll}1 & 2 & 3 & 4 & 5 & 6 & 7\end{array}$

$\begin{array}{lllllll}1 & 2 & 3 & 4 & 5 & 6 & 7\end{array}$

$\begin{array}{lllllll}1 & 2 & 3 & 4 & 5 & 6 & 7\end{array}$

$\begin{array}{lllllll}1 & 2 & 3 & 4 & 5 & 6 & 7\end{array}$

1. Do you think people from your ethnic group are discriminated against in NZ?

2. Do you support the use of 1080 poison for possum control in New Zealand?

3. Of course, we all hope that there will not be another war, but if it were to come to that, would you be willing to fight for your country?

4. Suppose a person has a painful incurable disease. Do you think that doctors should be allowed by law to end the patient's life if the patient requests it?

\section{Definitely YES}

7

$\begin{array}{lllllll}1 & 2 & 3 & 4 & 5 & 6 & 7 \\ 1 & 2 & 3 & 4 & 5 & 6 & 7 \\ 1 & 2 & 3 & 4 & 5 & 6 & 7\end{array}$


01. What is your highest level of qualification?

02a. Are you currently employed? (This includes self-employed or casual work)

02b. If yes, how long have you worked at your current organisation?

02c. What is your current occupation?

02d. How satisfied are you with your current job? $\begin{array}{llllllllll}\text { Not satisfied } & 1 & 2 & 3 & 4 & 5 & 6 & 7 & \text { Very satisfied }\end{array}$

02e. How secure do you feel in your current job? $\begin{array}{llllllllll}\text { Not secure } & \mathbf{1} & \mathbf{2} & \mathbf{3} & \mathbf{4} & \mathbf{5} & \mathbf{6} & \mathbf{7} & \text { Very secure }\end{array}$

02f. How valued do you feel by your current organisation? $\begin{array}{llllllllll}\text { Not valued } & \mathbf{1} & \mathbf{2} & \mathbf{3} & \mathbf{4} & \mathbf{5} & \mathbf{6} & \mathbf{7} & \text { Very valued }\end{array}$

03a. What is your relationship status?

If you are in a relationship...

(e.g., single, married, de-facto, civil union, widowed, living together, etc.)

03b. How long have you been with your partner?

(years) (months)

03c. If you are currently married or in a civil union, what was the date of your marriage or union?

03d. How satisfied are you with your relationship?

$\begin{array}{llllllllll}\text { Not satisfied } & \mathbf{1} & \mathbf{2} & \mathbf{3} & \mathbf{4} & \mathbf{5} & \mathbf{6} & \mathbf{7} & \text { Very satisfied }\end{array}$

03e. To what extent do you experience conflict or disagreement with your partner?

$\begin{array}{llllllllll}\text { No conflict at all } & \mathbf{1} & \mathbf{2} & \mathbf{3} & \mathbf{4} & \mathbf{5} & \mathbf{6} & \mathbf{7} & \text { A great deal of conflict }\end{array}$

04a. Do you have a regular family doctor/GP? Yes No

And, if you have a regular doctor/GP...

04b. How satisfied are you with the service and care you receive from your family doctor/GP?

$\begin{array}{llllllllll}\text { Not satisfied } & \mathbf{1} & \mathbf{2} & \mathbf{3} & \mathbf{4} & \mathbf{5} & \mathbf{6} & \mathbf{7} & \text { Very satisfied }\end{array}$

04c. Do you think your doctor/GP shares a similar cultural background to you?

Definitely NO $\begin{array}{llllllll}\mathbf{1} & \mathbf{2} & \mathbf{3} & \mathbf{4} & \mathbf{5} & \mathbf{6} & \mathbf{7} & \text { Definitely YES }\end{array}$

04d. Does your doctor/GP respect your cultural background when you are discussing health issues with them?

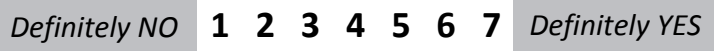

05. How would you describe your dietary behaviour? (e.g., meat \& vegetables, vegetarian, vegan, halal, pescatarian, etc.)

06. How much money have you donated to charity in the last year?

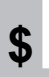

07. Please rate how politically liberal versus conservative you see yourself as being:

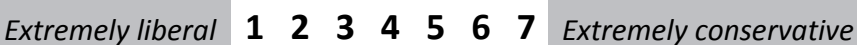

08a. Has someone ever used the internet, a mobile phone, or digital camera to hurt, intimidate or embarrass you? Yes No 08b. ...has this occurred in the last month? Yes No

09. Please rate how politically left-wing versus right-wing you see yourself as being:

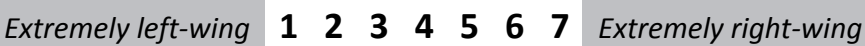

10. Please estimate your total household income (before tax) for the year 2019:

11. Please estimate how much help you have received from the following sources in the last week?

(a) family:

(b) friends:

(c) members of my community:

12a. How many children have you given birth to, fathered, or adopted?

$12 b$. If you are a parent, in which year...

(a) was your eldest child born?

(b) was your youngest born?

13. If you have children under 18 , are their vaccinations up-to-date, as per the recommendations of your doctor/GP?

TIME MONEY (hours) (dollars)
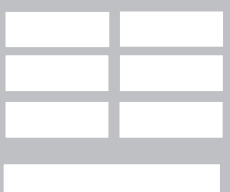

14. Do you identify with a religion and/or spiritual group? If yes...

(a) what religion or spiritual group?

(b) how many times did you attend a church or place of worship in the last month?

(c) how many times did you pray in the last week?

(d) how many times did you read religious scripture in the last week?

(f) how important is your religion to how you see yourself?

Not important $\begin{array}{lllllllll}1 & \mathbf{2} & \mathbf{3} & \mathbf{4} & \mathbf{5} & \mathbf{6} & \mathbf{7} & \text { Very important }\end{array}$

15. Roughly how many hours have you spent with both FRIENDS/FAMILY and OTHERS (e.g., workmates, strangers) from each ethnic group in the last week?
(a) Māori
(b) NZ Europeans
(c) Pacific Islanders
(d) Asians FRIENDS/FAMILY OTHERS

16a. Do you plan to vote in the next New Zealand election in 2020?

16b. If yes, to which party do you plan to give...

$$
\begin{aligned}
& \text { your party vote? } \\
& \text { your electorate vote? }
\end{aligned}
$$

17. How important are your political beliefs to how you see yourself?

Not important $\begin{array}{lllllllll}1 & 2 & 3 & 4 & 5 & 6 & 7 & \text { Very important }\end{array}$

18. Do you believe in a God?

19. Do you believe in some form of spirit or life force?

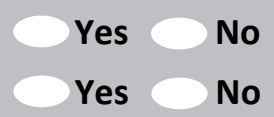

20. In which country... was your mother born? was your father born?

21. What is your... mother's ethnicity? father's ethnicity?

22. How would you describe your sexual orientation? (e.g., heterosexual, homosexual, straight, gay, lesbian, bisexual, etc.)

23. How satisfied are you with your sex life?

$$
\begin{array}{lllllllll}
\text { Not satisfied } & \mathbf{1} & \mathbf{2} & \mathbf{3} & \mathbf{4} & \mathbf{5} & \mathbf{6} & \mathbf{7} & \text { Very satisfied }
\end{array}
$$


Finally, have you experienced any significant life events in the past year?

A lot of things can happen in a year. This is a final optional question that can help us to understand if you have experienced significant life events that might have shaped your responses to the questionnaire for this year. Here are some examples of the significant life events that people might experience (please tick any that you have experienced in the last year):

Began a new serious romantic relationship

Got married/entered a civil union

Separated from your romantic partner/spouse

Got divorced

The birth of a child

Someone stole something that was yours or burgled your home

Someone assaulted you, abused you, or attacked you

Someone sexually harassed you

Lost your job or had the principal earner in your household lose their job

Retired

Suffered a serious and ongoing illness or disease

A family member suffered a serious and ongoing illness or disease

Suffered an accident leading to serious injury

A family member suffered an accident leading to serious injury

The death of a family member or loved one

Have we missed anything important or would you like to provide more detail about your experiences? If so, please let us know in the box below:

Thank you for taking part in the New Zealand Attitudes and Values Study!

Please post back your completed questionnaire using the included freepost return envelope. The freepost envelope will work from anywhere in New Zealand. If you lose the envelope, you can post this questionnaire back for free to:

FREEPOST AUTHORITY: 124589

New Zealand Attitudes and Values Study

School of Psychology (Cost 9450/71708)

The University of Auckland

Private Bag 92019

Auckland 1142, New Zealand

If you would like to know more about the New Zealand Attitudes and Values Study, then please feel free to phone us (contact details on the front) or you can visit the study website. We will also send out a regular e-newsletter to everyone in the study summarising the most interesting findings from the study. 


\section{The New Zealand Attitudes and Values Study}

SCHOOL OF PSYCHOLOGY

Science Centre, Building 302

23 Symonds Street, Auckland,

New Zealand

T $09-923-7498$

E nzavs@auckland.ac.nz

w $\underline{\text { www.nzavs.auckland.ac.nz }}$

\section{Follow-up Questionnaire for 2020/2021}

A scanned copy of this form will be kept for a period of up to fourteen years.

Lead researcher:

Professor Chris Sibley, School of Psychology, The University of Auckland. Phone: 09-923-7498. e-mail: nzavs@auckland.ac.nz

\section{Consent form and contact details}

This form is to gather your consent to participate in this phase of the New Zealand Attitudes and Values Study (NZAVS). Only Professor Sibley and his research associates will have access to your responses. Your personal information will be kept separate from your responses at all times. Your questionnaire will be identified by an anonymous code. An encrypted electronic copy of all responses will be stored indefinitely for research purposes in a secure room in the School of Psychology.

I have read and understood a description of this research project. On this basis, I agree to take part. I understand that my data will remain confidential at all times. I understand that only Professor Sibley and trusted research assistants working on the study in secure conditions will have access to my contact details. I consent to publication of the results of the project with the understanding that my anonymity will be preserved. I understand that I am free to withdraw from the research at any time up until the point at which I complete and return this questionnaire. I understand that my contact details will never be shared with anyone outside of the immediate research team. I understand that Professor Sibley and the research team will use these details to contact and invite me to complete annual follow-up questionnaires. I understand that my contact details will also be used to contact me if I win one of the five prize draws for $\$ 1000$ grocery vouchers (total prize pool $\$ 5000$ ) for participating in this study.

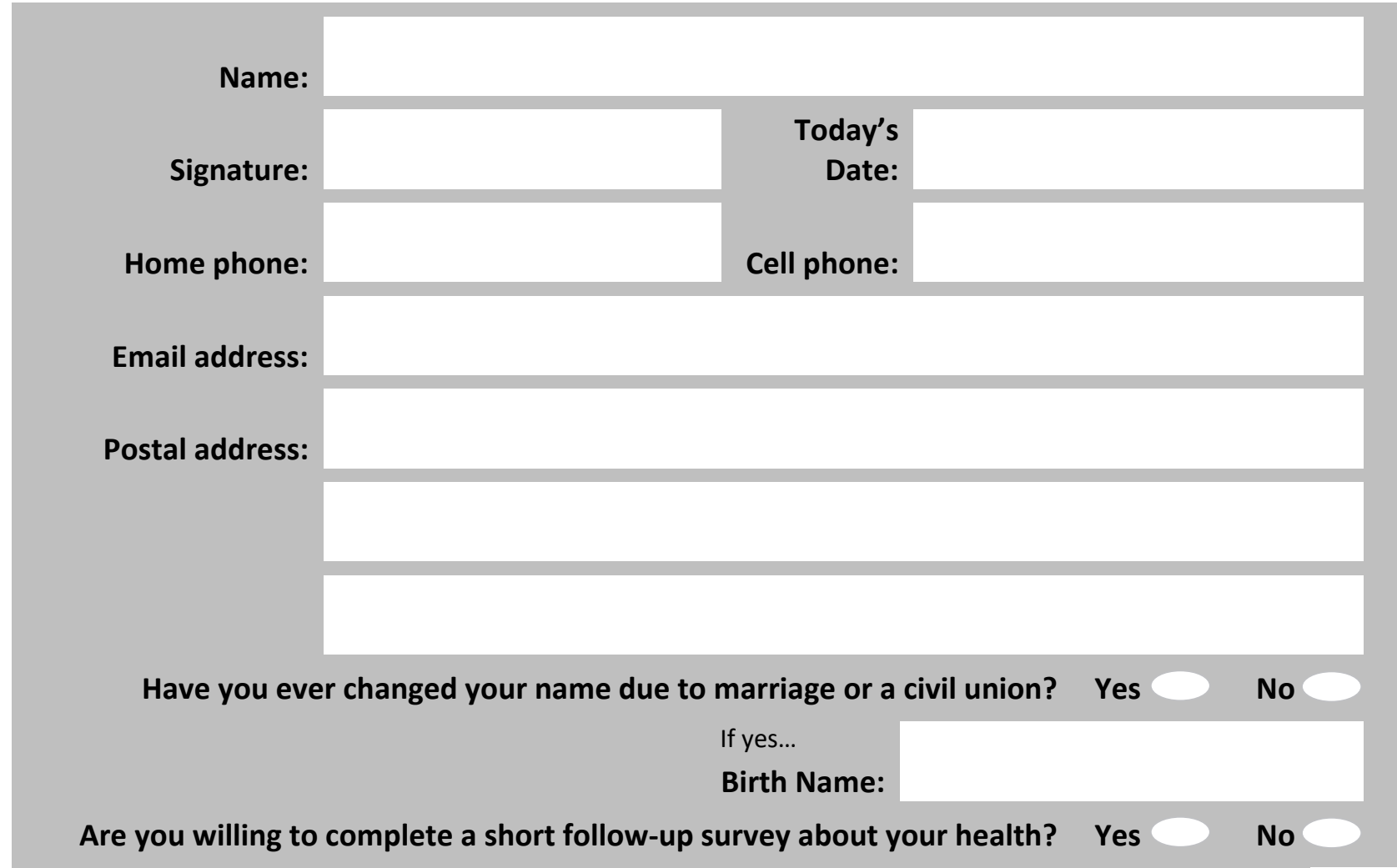




\section{Do you have a partner who would also like to join the NZAVS?}

Over the years, a number of participants have got in touch to let us know that their partner is also interested in joining the NZAVS, and to ask if their partner could also be sent a copy of the questionnaire.

If you have a partner who would like to join the NZAVS and complete their own copy of the questionnaire, then they are most welcome to do so. The easiest way for your partner to join the study is to simply complete the questionnaire online.

The online version is available at: www.nzavs.auckland.ac.nz/survey

Alternatively, please ask your partner to email us at nzavs@auckland.ac.nz and let us know they are interested in joining the study. We would then be happy to post them a paper copy of the questionnaire. 
Instructions: This part of the questionnaire measures your feelings about yourself.

Please circle the number that best represents how accurately each statement describes you.

\begin{tabular}{|c|c|c|c|c|c|c|}
\hline $\mathbf{I} \ldots$ & \multicolumn{2}{|c|}{$\begin{array}{l}\text { Very } \\
\text { Inaccurate }\end{array}$} & & \multicolumn{3}{|c|}{$\begin{array}{r}\text { Very } \\
\text { Accurate } \\
\downarrow\end{array}$} \\
\hline 1. Am the life of the party. & 2 & 3 & 4 & 5 & 6 & 7 \\
\hline 2. Sympathise with others' feelings. & 2 & 3 & 4 & 5 & 6 & 7 \\
\hline 3. Get chores done right away. & 2 & 3 & 4 & 5 & 6 & 7 \\
\hline 4. Have frequent mood swings. & 2 & 3 & 4 & 5 & 6 & 7 \\
\hline 5. Have a vivid imagination. & 2 & 3 & 4 & 5 & 6 & 7 \\
\hline 6. Don't talk a lot. & 2 & 3 & 4 & 5 & 6 & 7 \\
\hline 7. Am not interested in other people's problems. & 2 & 3 & 4 & 5 & 6 & 7 \\
\hline 8. Have difficulty understanding abstract ideas. & 2 & 3 & 4 & 5 & 6 & 7 \\
\hline 9. Like order. & 2 & 3 & 4 & 5 & 6 & 7 \\
\hline 10. Make a mess of things. & 2 & 3 & 4 & 5 & 6 & 7 \\
\hline 11. Do not have a good imagination. & 2 & 3 & 4 & 5 & 6 & 7 \\
\hline 12. Feel others' emotions. & 2 & 3 & 4 & 5 & 6 & 7 \\
\hline 13. Am relaxed most of the time. & 2 & 3 & 4 & 5 & 6 & 7 \\
\hline 14. Get upset easily. & 2 & 3 & 4 & 5 & 6 & 7 \\
\hline 15. Seldom feel blue. & 2 & 3 & 4 & 5 & 6 & 7 \\
\hline 16. Keep in the background. & 2 & 3 & 4 & 5 & 6 & 7 \\
\hline 17. Am not really interested in others. & 2 & 3 & 4 & 5 & 6 & 7 \\
\hline 18. Am not interested in abstract ideas. & 2 & 3 & 4 & 5 & 6 & 7 \\
\hline 19. Often forget to put things back in their proper place. & 1 & 3 & 4 & 5 & 6 & 7 \\
\hline 20. Talk to a lot of different people at parties. & 2 & 3 & 4 & 5 & 6 & 7 \\
\hline 21. Feel entitled to more of everything. & 2 & 3 & 4 & 5 & 6 & 7 \\
\hline 22. On the whole am satisfied with myself. & 1 & 3 & 4 & 5 & 6 & 7 \\
\hline 23. Know that people in my life accept and value me. & 2 & 3 & 4 & 5 & 6 & 7 \\
\hline 24. Would like to be seen driving around in a very expensive car. & 2 & 3 & 4 & 5 & 6 & 7 \\
\hline 25. Deserve more things in life. & 1 & 3 & 4 & 5 & 6 & 7 \\
\hline 26. Feel like an outsider. & 2 & 3 & 4 & 5 & 6 & 7 \\
\hline 27. Would get a lot of pleasure from owning expensive luxury goods. & 2 & 3 & 4 & 5 & 6 & 7 \\
\hline 28. Am satisfied with the appearance, size and shape of my body. & 2 & 3 & 4 & 5 & 6 & 7 \\
\hline 29. Am inclined to feel that I am a failure. & 2 & 3 & 4 & 5 & 6 & 7 \\
\hline 30. Take a positive attitude toward myself. & 2 & 3 & 4 & 5 & 6 & 7 \\
\hline 31. Know that people around me share my attitudes and beliefs. & 1 & 3 & 4 & 5 & 6 & 7 \\
\hline
\end{tabular}

During the last 30 days, how often did.

(Please use the scale below to circle a number for each question)

\begin{tabular}{|c|c|c|c|c|c|c|c|c|}
\hline & $\begin{array}{r}\text { None Of } \\
\text { The Time } \\
0\end{array}$ & $\begin{array}{c}\text { A Little of } \\
\text { The Time } \\
1\end{array}$ & $\begin{array}{c}\text { Some of } \\
\text { The Time } \\
2\end{array}$ & $\begin{array}{c}\text { Most Of } \\
\text { The Time } \\
3\end{array}$ & & $\begin{array}{l}\text { All of } \\
\text { The T } \\
4\end{array}$ & & \\
\hline 1. & ... you feel hope & & & 0 & 1 & 2 & 3 & 4 \\
\hline 2. & ... you feel so de & hat nothing & d cheer you up? & 0 & 1 & 2 & 3 & 4 \\
\hline 3. & ... you feel restl & ety? & & 0 & 1 & 2 & 3 & 4 \\
\hline 4. & ... you feel that & g was an eff & & 0 & 1 & 2 & 3 & 4 \\
\hline 5. & ... you feel wort & & & 0 & 1 & 2 & 3 & 4 \\
\hline 6. & ... you feel nerv & & & 0 & 1 & 2 & 3 & 4 \\
\hline 7. & ... you have neg & ights that re & d over and over? & 0 & 1 & 2 & 3 & 4 \\
\hline 8. & ... you feel exha & & & 0 & 1 & 2 & 3 & 4 \\
\hline 9. & ... you believe y & $t$ risk of catc & COVID-19? & 0 & 1 & 2 & 3 & 4 \\
\hline 1 & ... you have rep & tive thou & out COVID-19? & 0 & 1 & 2 & 3 & 4 \\
\hline 11 & ... you worry th & thquake $\mathrm{m}$ & it your region? & 0 & 1 & 2 & 3 & 4 \\
\hline
\end{tabular}




\begin{tabular}{|c|c|c|c|c|c|c|c|}
\hline & \multicolumn{3}{|c|}{$\begin{array}{l}\text { Strongly } \\
\text { Disagree } \\
\end{array}$} & & \multicolumn{3}{|c|}{$\begin{array}{r}\text { Strongly } \\
\text { Agree } \\
\downarrow\end{array}$} \\
\hline 1. I have much in my life to be thankful for. & 1 & 2 & 3 & 4 & 5 & 6 & 7 \\
\hline 2. It would be good if groups could be equal. & 1 & 2 & 3 & 4 & 5 & 6 & 7 \\
\hline 3. I often think about the fact that I am a member of my ethnic group. & 1 & 2 & 3 & 4 & 5 & 6 & 7 \\
\hline 4. I expect my health to get worse. & 1 & 2 & 3 & 4 & 5 & 6 & 7 \\
\hline 5. I feel a sense of community with others in my local neighbourhood. & 1 & 2 & 3 & 4 & 5 & 6 & 7 \\
\hline 6. We should have increased social equality. & 1 & 2 & 3 & 4 & 5 & 6 & 7 \\
\hline 7. I know there are people I can turn to when I need help. & 1 & 2 & 3 & 4 & 5 & 6 & 7 \\
\hline $\begin{array}{l}\text { 8. There are many things about the New Zealand Police and its policies that need to } \\
\text { be changed. }\end{array}$ & 1 & 2 & 3 & 4 & 5 & 6 & 7 \\
\hline $\begin{array}{l}\text { 9. If I go to my doctor/GP with a minor illness (e.g., sore throat, cough, runny nose, } \\
\text { etc.), I think that I should be prescribed antibiotics by default. }\end{array}$ & 1 & 2 & 3 & 4 & 5 & 6 & 7 \\
\hline 10. I wish I had more self-discipline. & 1 & 2 & 3 & 4 & 5 & 6 & 7 \\
\hline 11. We should do what we can to equalise conditions for different groups. & 1 & 2 & 3 & 4 & 5 & 6 & 7 \\
\hline $\begin{array}{l}\text { 12. By taking an active part in political and social affairs we, the people, can control } \\
\text { world events. }\end{array}$ & 1 & 2 & 3 & 4 & 5 & 6 & 7 \\
\hline 13. I seem to get sick a little easier than other people. & 1 & 2 & 3 & 4 & 5 & 6 & 7 \\
\hline 14. If incomes were more equal, people would be less motivated to work hard. & 1 & 2 & 3 & 4 & 5 & 6 & 7 \\
\hline 15. I have a good sense of what makes my life meaningful. & 1 & 2 & 3 & 4 & 5 & 6 & 7 \\
\hline 16. To get ahead in life, it is sometimes okay to step on other groups. & 1 & 2 & 3 & 4 & 5 & 6 & 7 \\
\hline 17. I am hardly ever satisfied with my performance. & 1 & 2 & 3 & 4 & 5 & 6 & 7 \\
\hline 18. People from my ethnic group generally earn less than other groups in NZ. & 1 & 2 & 3 & 4 & 5 & 6 & 7 \\
\hline 19. When I feel negative emotions, I suppress or hide my emotions. & 1 & 2 & 3 & 4 & 5 & 6 & 7 \\
\hline 20. I have considered voting in terms of what is good for my particular ethnic group. & 1 & 2 & 3 & 4 & 5 & 6 & 7 \\
\hline 21. I am grateful to a wide variety of people. & 1 & 2 & 3 & 4 & 5 & 6 & 7 \\
\hline 22. I feel at ease when I am in a city district in New Zealand with many immigrants. & 1 & 2 & 3 & 4 & 5 & 6 & 7 \\
\hline 23. I find myself regularly thinking about past times that I have been wronged. & 1 & 2 & 3 & 4 & 5 & 6 & 7 \\
\hline $\begin{array}{l}\text { 24. I would always report dangerous or suspicious activities occurring in my } \\
\text { neighbourhood to the police. }\end{array}$ & 1 & 2 & 3 & 4 & 5 & 6 & 7 \\
\hline $\begin{array}{l}\text { 25. The fact that I am a member of my ethnic group is an important part of my } \\
\text { identity. }\end{array}$ & 1 & 2 & 3 & 4 & 5 & 6 & 7 \\
\hline 26. In general, I have a lot of self-control. & 1 & 2 & 3 & 4 & 5 & 6 & 7 \\
\hline $\begin{array}{l}\text { 27. Everyone in New Zealand has a fair shot at wealth and happiness, regardless of } \\
\text { ethnicity or race. }\end{array}$ & 1 & 2 & 3 & 4 & 5 & 6 & 7 \\
\hline
\end{tabular}

Instructions: Please rate your level of satisfaction with the following aspects of your life and New Zealand.

Completely Dissatisfied

0

Somewhat Satisfied
Completely Satisfied

10

1. Your standard of living.

2. The economic situation in New Zealand.

3. The quality of New Zealand's natural environment.

4. Your health.

5. The social conditions in New Zealand.

6. The performance of the current New Zealand government.

7. Your future security.

8. Business in New Zealand.

9. Your personal relationships.

10. Your access to health care when you need it (e.g., doctor, GP).

11. The New Zealand government response to COVID-19.

$\begin{array}{lll}7 & 8 & 9\end{array}$

\begin{tabular}{lllllllllll}
0 & 1 & 2 & 3 & 4 & 5 & 6 & 7 & 8 & 9 & 10 \\
\hline 0 & 1 & 2 & 3 & 4 & 5 & 6 & 7 & 8 & 9 & 10 \\
0 & 1 & 2 & 3 & 4 & 5 & 6 & 7 & 8 & 9 & 10 \\
0 & 1 & 2 & 3 & 4 & 5 & 6 & 7 & 8 & 9 & 10 \\
\hline 0 & 1 & 2 & 3 & 4 & 5 & 6 & 7 & 8 & 9 & 10 \\
0 & 1 & 2 & 3 & 4 & 5 & 6 & 7 & 8 & 9 & 10 \\
0 & 1 & 2 & 3 & 4 & 5 & 6 & 7 & 8 & 9 & 10 \\
0 & 1 & 2 & 3 & 4 & 5 & 6 & 7 & 8 & 9 & 10 \\
0 & 1 & 2 & 3 & 4 & 5 & 6 & 7 & 8 & 9 & 10 \\
0 & 1 & 2 & 3 & 4 & 5 & 6 & 7 & 8 & 9 & 10 \\
0 & 1 & 2 & 3 & 4 & 5 & 6 & 7 & 8 & 9 & 10
\end{tabular}




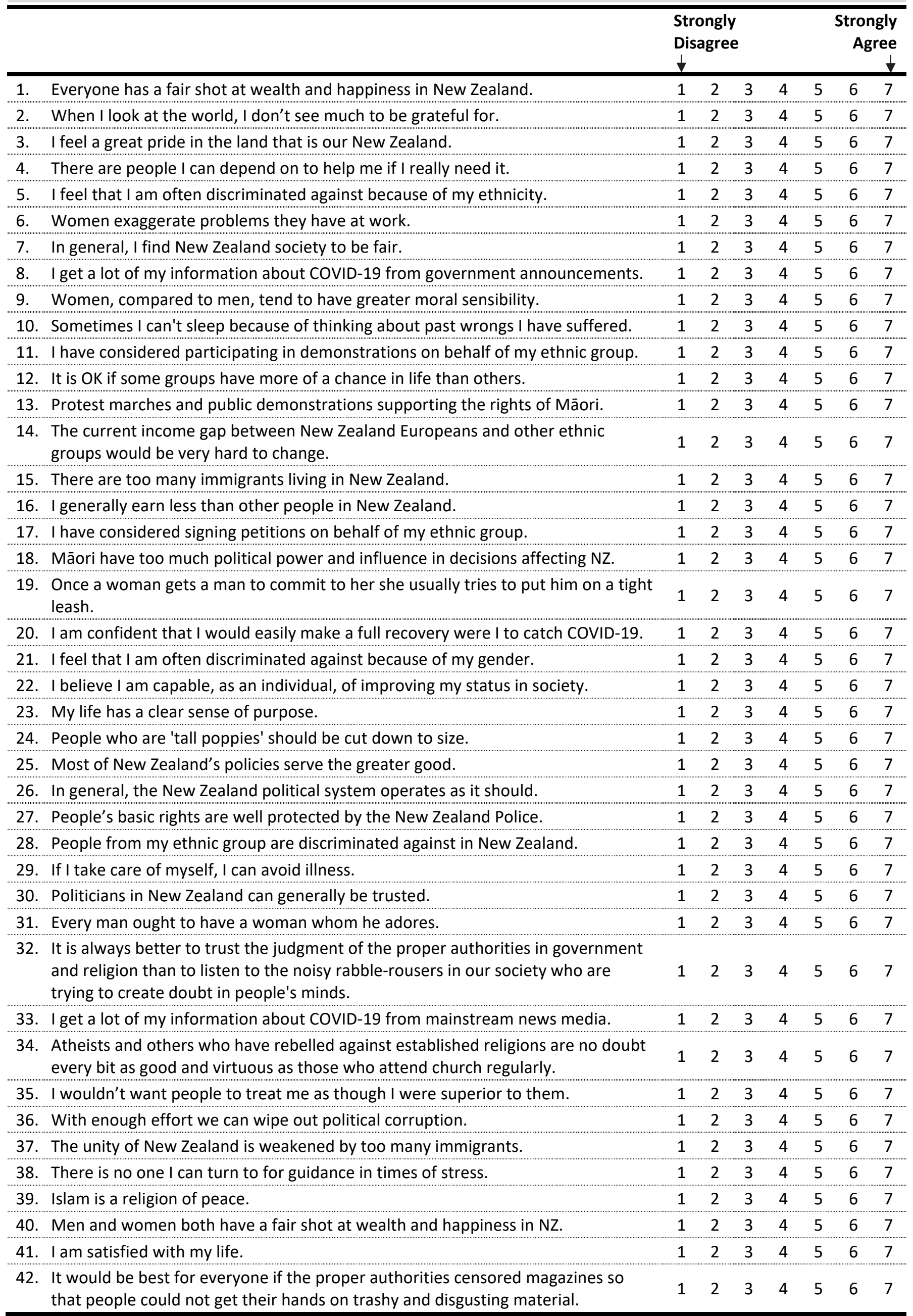


Please rate your feelings of WARMTH toward the following groups using the "feeling thermometer scale" for each group.

\begin{tabular}{|c|c|c|c|c|c|c|c|c|c|c|c|c|c|c|c|}
\hline $\begin{array}{r}\text { Feel LEAST WARM } \\
\text { Toward This Group } \\
1\end{array}$ & \multicolumn{8}{|c|}{ Neutral } & \multicolumn{7}{|c|}{$\begin{array}{l}\text { Feel MOST WARM } \\
\text { Toward This Group } \\
7\end{array}$} \\
\hline NZ Europeans & 1 & 2 & 3 & 4 & 5 & 6 & 7 & Overweight people & 1 & 2 & 3 & 4 & 5 & 6 & 7 \\
\hline Māori & 1 & 2 & 3 & 4 & 5 & 6 & 7 & Immigrants in general & 1 & 2 & 3 & 4 & 5 & 6 & 7 \\
\hline Asians in general & 1 & 2 & 3 & 4 & 5 & 6 & 7 & Chinese & 1 & 2 & 3 & 4 & 5 & 6 & 7 \\
\hline Pacific Islanders & 1 & 2 & 3 & 4 & 5 & 6 & 7 & Indians & 1 & 2 & 3 & 4 & 5 & 6 & 7 \\
\hline Elderly people & 1 & 2 & 3 & 4 & 5 & 6 & 7 & Muslims & 1 & 2 & 3 & 4 & 5 & 6 & 7 \\
\hline People with a disability & 1 & 2 & 3 & 4 & 5 & 6 & 7 & LGBTQ+ people & 1 & 2 & 3 & 4 & 5 & 6 & 7 \\
\hline Refugees & 1 & 2 & 3 & 4 & 5 & 6 & 7 & People with mental illness & 1 & 2 & 3 & 4 & 5 & 6 & 7 \\
\hline
\end{tabular}

01. What is your date of birth?

02. Which ethnic group(s) do you belong to?

(Mark the space or spaces which apply to you).

03. What is your gender?

04. What is your height?

05. What is your weight?

06a. How often do you have a drink containing alcohol? And, if you drink alcohol...

06b. How many drinks containing alcohol do you have on a typical day when drinking?

07. During the past month, on average, how many hours of actual sleep did you get per night?

\section{l $\quad 1$}

New Zealand European

Māori

Samoan

Cook Island Māori

Tongan

Niuean

Chinese

Indian

Other such as DUTCH, JAPANESE, TOKELAUAN. Please state:

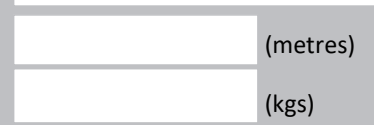

Never - I don't drink Monthly or less Up to 4 times a month Up to 3 times a week 4 or more times a week Don't know

(number of drinks on a typical day) 08a. Do you have a regular

family doctor/GP?

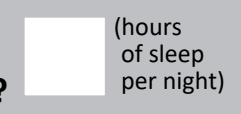

And, if you have a regular doctor/GP...

08b. How satisfied are you with the service and care you receive from your family doctor/GP?

$$
\begin{array}{llllllllll}
\text { Not satisfied } & \mathbf{1} & \mathbf{2} & \mathbf{3} & \mathbf{4} & \mathbf{5} & \mathbf{6} & \mathbf{7} & \text { Very satisfied } \\
& \multicolumn{7}{c}{\text { Please circle a number }} &
\end{array}
$$

08c. Do you think your doctor/GP shares a similar cultural background to you?

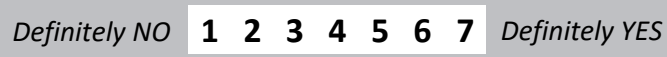

08d. Does your doctor/GP respect your cultural background when you are discussing health issues with them?

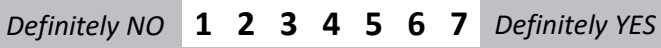

09. How would you describe your dietary behaviour?
10. Have you been diagnosed with, or treated for, any of the following health conditions by a doctor in the last five years?

High cholesterol High blood pressure Asthma Heart disease Diabetes (Type II) Depression Anxiety disorder Other (please state):

11. Have you ever regularly...
(a) smoked tobacco cigarettes?
Yes No
(b) vaped or used e-cigarettes?
Yes No

12. Do you currently...
(a) smoke tobacco cigarettes?
Yes No
(b) vape or use e-cigarettes?
Yes No

13. Do you have a health condition or disability that limits you, and that has lasted for $6+$ months?

(a) if yes, please state:

14. In general, would you say your health is...

$$
\begin{array}{ccccccccc}
\text { Poor } & 1 & 2 & 3 & 4 & 5 & 6 & 7 & \text { Excellent } \\
\text { Please circle a number } &
\end{array}
$$

15. Within the last month, have you...

(a) been tested for COVID-19? Yes No

(b) requested a COVID-19 test? Yes No

(c) if yes, where did you request the test from?

(d) asked for, but been declined, a COVID-19 test? Yes No

(e) if yes, why was your request declined?

(f) been advised to get a COVID-19 test but did not?

Yes No

(h) if yes, why did you decline to be tested?

16. Do you own your own home?

(either partly or fully owned)

17. Do you believe in a God?

18. Do you believe in some form of spirit or life force?

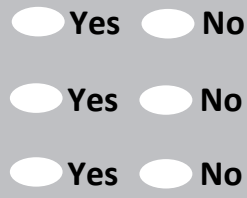

19. How much money have you donated to charity in the last year? \$

20. Where were you born?

(please be specific, e.g., which town/city?) 


\begin{tabular}{|c|c|c|c|c|c|c|c|}
\hline \multirow[b]{2}{*}{1.} & \multicolumn{3}{|c|}{$\begin{array}{l}\text { Strongly } \\
\text { Disagree } \\
\downarrow\end{array}$} & \multirow[b]{2}{*}{4} & \multirow[b]{2}{*}{5} & \multicolumn{2}{|c|}{$\begin{array}{r}\text { Strongly } \\
\text { Agree } \\
\downarrow\end{array}$} \\
\hline & 1 & 2 & 3 & & & 6 & 7 \\
\hline $\begin{array}{l}\text { 2. I am willing to get vaccinated for COVID-19 once an approved vaccine is } \\
\text { available. }\end{array}$ & 1 & 2 & 3 & 4 & 5 & 6 & 7 \\
\hline 3. I am willing to wear a face mask to help stop the spread of COVID-19. & 1 & 2 & 3 & 4 & 5 & 6 & 7 \\
\hline 4. I am willing to stay at home to help stop the spread of COVID-19. & 1 & 2 & 3 & 4 & 5 & 6 & 7 \\
\hline 5. I am willing to use a COVID-19 contact tracing app. & 1 & 2 & 3 & 4 & 5 & 6 & 7 \\
\hline $\begin{array}{l}\text { 6. I am willing to strictly follow any and all guidelines provided by the Ministry of } \\
\text { Health for managing COVID-19 in New Zealand. }\end{array}$ & 1 & 2 & 3 & 4 & 5 & 6 & 7 \\
\hline 7. I do not have enough power or control over important parts of my life. & 1 & 2 & 3 & 4 & 5 & 6 & 7 \\
\hline 8. I think that homosexuality should be accepted by society. & 1 & 2 & 3 & 4 & 5 & 6 & 7 \\
\hline 9. Women seek to gain power by getting control over men. & 1 & 2 & 3 & 4 & 5 & 6 & 7 \\
\hline 10. When I feel negative emotions, my emotions feel out of control. & 1 & 2 & 3 & 4 & 5 & 6 & 7 \\
\hline 11. Our society places too much emphasis on science. & 1 & 2 & 3 & 4 & 5 & 6 & 7 \\
\hline 12. Women are too easily offended. & 1 & 2 & 3 & 4 & 5 & 6 & 7 \\
\hline $\begin{array}{l}\text { 13. Protest marches and public demonstrations supporting the rights of New } \\
\text { Zealand Europeans. }\end{array}$ & 1 & 2 & 3 & 4 & 5 & 6 & 7 \\
\hline 14. I identify with New Zealand. & 1 & 2 & 3 & 4 & 5 & 6 & 7 \\
\hline 15. Economic positions are legitimate reflections of people's achievements. & 1 & 2 & 3 & 4 & 5 & 6 & 7 \\
\hline $\begin{array}{l}\text { 16. Although I may disagree with the opinions that other people hold, they } \\
\text { should be allowed to express those views publicly. }\end{array}$ & 1 & 2 & 3 & 4 & 5 & 6 & 7 \\
\hline 17. Being a woman/man is an important part of how I see myself. & 1 & 2 & 3 & 4 & 5 & 6 & 7 \\
\hline 18. I feel that I am often discriminated against because of my age. & 1 & 2 & 3 & 4 & 5 & 6 & 7 \\
\hline 19. In general, relations between men and women in New Zealand are fair. & 1 & 2 & 3 & 4 & 5 & 6 & 7 \\
\hline 20. I have a good balance between work and other important things in my life. & 1 & 2 & 3 & 4 & 5 & 6 & 7 \\
\hline $\begin{array}{l}\text { 21. I trust the government to make sensible decisions about how to best manage } \\
\text { COVID-19 here in New Zealand. }\end{array}$ & 1 & 2 & 3 & 4 & 5 & 6 & 7 \\
\hline $\begin{array}{l}\text { 22. By taking personal action I believe I can make a positive difference to } \\
\text { environmental problems. }\end{array}$ & 1 & 2 & 3 & 4 & 5 & 6 & 7 \\
\hline 23. I feel anxious about interacting with people from other races. & 1 & 2 & 3 & 4 & 5 & 6 & 7 \\
\hline $\begin{array}{l}\text { 24. When women lose to men in a fair competition, they typically complain about } \\
\text { being discriminated against. }\end{array}$ & 1 & 2 & 3 & 4 & 5 & 6 & 7 \\
\hline 25. Doing my best never seems to be enough. & 1 & 2 & 3 & 4 & 5 & 6 & 7 \\
\hline 26. Everyone has the right to just and reasonable pay for the work they perform. & 1 & 2 & 3 & 4 & 5 & 6 & 7 \\
\hline 27. Many women have a quality of purity that few men possess. & 1 & 2 & 3 & 4 & 5 & 6 & 7 \\
\hline 28. Bad smells, messes, dead animals and rotten food absolutely disgust me. & 1 & 2 & 3 & 4 & 5 & 6 & 7 \\
\hline $\begin{array}{l}\text { 29. I think that the official version of major world events given by authorities } \\
\text { often hides the truth. }\end{array}$ & 1 & 2 & 3 & 4 & 5 & 6 & 7 \\
\hline 30. I am in control of my health. & 1 & 2 & 3 & 4 & 5 & 6 & 7 \\
\hline $\begin{array}{l}\text { 31. It is safe to vaccinate children following the standard New Zealand } \\
\text { immunization schedule. }\end{array}$ & 1 & 2 & 3 & 4 & 5 & 6 & 7 \\
\hline $\begin{array}{l}\text { 32. Although at times I may not agree with the government, my commitment to } \\
\text { New Zealand always remains strong. }\end{array}$ & 1 & 2 & 3 & 4 & 5 & 6 & 7 \\
\hline 33. The New Zealand Police care about the well-being of everyone they deal with. & 1 & 2 & 3 & 4 & 5 & 6 & 7 \\
\hline $\begin{array}{l}\text { 34. People should pay less attention to The Bible and other old traditional forms } \\
\text { of religious guidance, and instead develop their own personal standards of } \\
\text { what is moral and immoral. }\end{array}$ & 1 & 2 & 3 & 4 & 5 & 6 & 7 \\
\hline
\end{tabular}

35. People who hold opinions that are harmful or offensive to minority groups should be banned from expressing those views publicly.

36. I get a lot of my information about COVID-19 from social media.

\begin{tabular}{lllllll}
1 & 2 & 3 & 4 & 5 & 6 & 7 \\
\hline
\end{tabular}




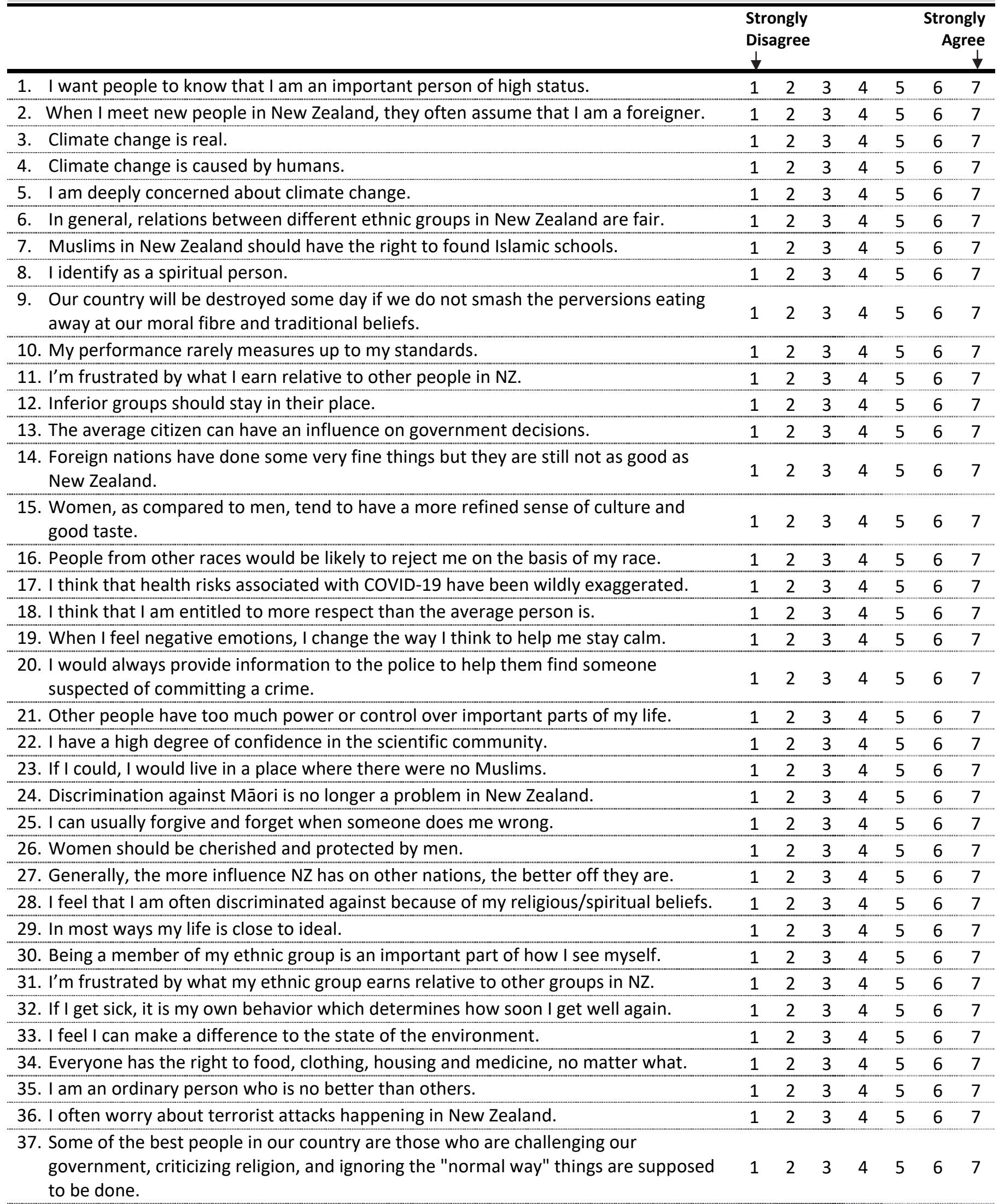

38. I think it is quite likely that COVID-19 was created in a laboratory.

$\begin{array}{lllllll}1 & 2 & 3 & 4 & 5 & 6 & 7\end{array}$

Instructions: Please rate how strongly you oppose or support each of the following political parties.

\section{Strongly Oppose}

1

The National Party

The Labour Party

The ACT Party

\section{Neutral}

4

23

\begin{tabular}{lllllll}
1 & 2 & 3 & 4 & 5 & 6 & 7 \\
1 & 2 & 3 & 4 & 5 & 6 & 7 \\
1 & 2 & 3 & 4 & 5 & 6 & 7 \\
\hline
\end{tabular}

5

5

The Green Party

The Māori Party

The NZ First Party
Strongly Support 7

$\begin{array}{lllllll}1 & 2 & 3 & 4 & 5 & 6 & 7 \\ 1 & 2 & 3 & 4 & 5 & 6 & 7 \\ 1 & 2 & 3 & 4 & 5 & 6 & 7\end{array}$


01. What is your highest

level of qualification?

02a. Are you currently employed? (This includes self-employed or casual work)

02b. In your main job, which one of these are you?

A paid employee

Self-employed and NOT employing others

An employer of persons in my own business

Working in a family business or family farm without pay

02c. In that job, what is your current occupation?

(e.g., primary school teacher, civil engineer, motel manager).

$02 \mathrm{~d}$. In that job, what is your contractual arrangement?

(e.g., permanent employee, casual, fixed-term, independent contractor).

02e. What is the main activity of the business or employer that you work for?

(e.g., primary school education, civil engineering construction, accommodation).

02f. How long have you worked at your current organisation? (years) (months)

02g. How satisfied are you with your current job?

$$
\begin{array}{llllllllll}
\text { Not satisfied } & \mathbf{1} & \mathbf{2} & \mathbf{3} & \mathbf{4} & \mathbf{5} & \mathbf{6} & \mathbf{7} & \text { Very satisfied }
\end{array}
$$

$02 \mathrm{~h}$. How secure do you feel in your current job?

$$
\begin{array}{llllllllll}
\text { Not secure } & \mathbf{1} & \mathbf{2} & \mathbf{3} & \mathbf{4} & \mathbf{5} & \mathbf{6} & \mathbf{7} & \text { Very secure }
\end{array}
$$

02i. How valued do you feel by your current organisation?

$$
\begin{array}{llllllllll}
\text { Not valued } & 1 & 2 & 3 & 4 & 5 & 6 & 7 & \text { Very valued }
\end{array}
$$

02j. How able are you to perform your job from home?

$$
\begin{array}{lllllllll}
\text { Not at all } & 1 & 2 & 3 & 4 & 5 & 6 & 7 & \text { Completely }
\end{array}
$$

02k. To what extent does your organization provide opportunities for skill development/further training?

$$
\begin{array}{llllllllll}
\text { Not at all } & 1 & 2 & 3 & 4 & 5 & 6 & 7 & \text { A great deal }
\end{array}
$$

02I. How likely is it that you will need to re-train or gain a qualification for a new job within the next 5 years?

$$
\begin{array}{lllllllll}
\text { Very unlikely } & \mathbf{1} & \mathbf{2} & \mathbf{3} & \mathbf{4} & \mathbf{5} & \mathbf{6} & \mathbf{7} & \text { Very likely }
\end{array}
$$

03a. What is your

$$
\text { relationship status? }
$$

If you are in a relationship...

(e.g., single, married, de-facto, civil union, widowed, living together, etc.)

03b. How long have you been with your partner?

(years)

(months)

03c. If you are currently married or in a civil union, what was the date of your marriage or union?

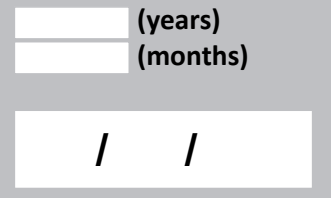

03d. How satisfied are you with your relationship?

$$
\begin{array}{llllllllll}
\text { Not satisfied } & \mathbf{1} & \mathbf{2} & \mathbf{3} & \mathbf{4} & \mathbf{5} & \mathbf{6} & \mathbf{7} & \text { Very satisfied }
\end{array}
$$

03e. To what extent do you experience conflict or disagreement with your partner?

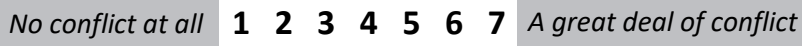

03f. Do you live with your partner? Yes No

04. Please rate how politically left-wing versus right-wing you see yourself as being:

Extremely left-wing $1 \begin{array}{llllllll}1 & 2 & 3 & 4 & 5 & \mathbf{6} & \mathbf{7} & \text { Extremely right-wing }\end{array}$
05. Please estimate your total household income (before tax) for the last year:

06. Please estimate how much help you have received from the following sources in the last week?
(a) family:
(b) friends:
(c) members of my community:

07a. How many children have you given birth to, fathered, and/or parented?

07b. If you are a parent, in which year...

(a) was your eldest child born?

(b) was your youngest born?

08. How many other people live in the same household as you?

Number of adults Number of children

09. Please rate how politically liberal versus conservative you see yourself as being:

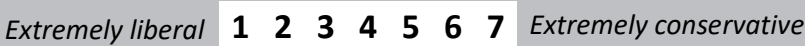

10. Do you identify with a religion and/or spiritual group? If yes...
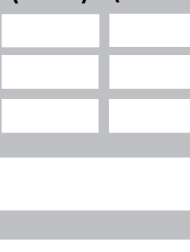

(a) what religion or spiritual group?

(b) how important is your religion

to how you see yourself?

Not important $\begin{array}{llllllll}\mathbf{1} & \mathbf{2} & \mathbf{3} & \mathbf{4} & \mathbf{5} & \mathbf{6} & \mathbf{7} & \text { Very important }\end{array}$

11. Please estimate how many hours you spent doing each of the following things last week. (please enter ' 0 hours' if you did not do that activity last week)

(a) Working in paid employment

(b) Housework/cooking

(c) Looking after children

(d) Volunteer/charitable work

(e) Exercising/physical activity

(f) Watching TV/Netflix/movies

(g) Travelling/commuting

(h) Watching/reading the news

(i) Using the internet (in total)

(j) Using social media (e.g., Facebook)

(k) Playing video/computer games

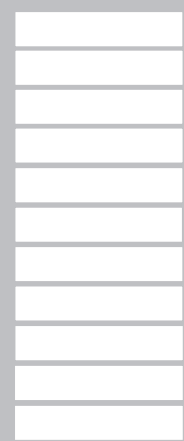

12. Roughly how many hours have you spent with both FRIENDS/FAMILY and OTHERS (e.g., workmates, strangers) from each ethnic group in the last week? FRIENDS/FAMILY OTHERS
(a) Māori
(b) NZ Europeans
(c) Pacific Islanders
(d) Asians
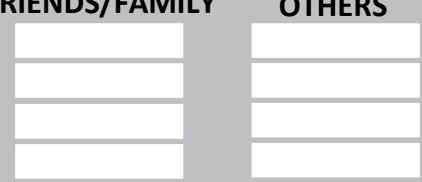

13a. Did you vote in the

New Zealand election in 2020?

13b. If yes, to which party did you give...

your party vote?

your electorate vote?

14. How important are your political beliefs to how you see yourself?

$\begin{array}{llllllllll}\text { Not important } & \mathbf{1} & \mathbf{2} & \mathbf{3} & \mathbf{4} & \mathbf{5} & \mathbf{6} & \mathbf{7} & \text { Very important }\end{array}$

15. How would you describe your sexual orientation?

(e.g., heterosexual, homosexual, straight, gay, lesbian, bisexual, etc.)

16. How satisfied are you with your sex life?

$\begin{array}{llllllllll}\text { Not satisfied } & \mathbf{1} & \mathbf{2} & \mathbf{3} & \mathbf{4} & \mathbf{5} & \mathbf{6} & \mathbf{7} & \text { Very satisfied }\end{array}$ 
Finally, have you experienced any significant life events in the past year?

A lot of things can happen in a year. This is a final optional question that can help us to understand if you have experienced significant life events that might have shaped your responses to the questionnaire for this year. Here are some examples of the significant life events that people might experience (please tick any that you have experienced in the last year):

Began a new serious romantic relationship

Got married/entered a civil union

Separated from your romantic partner/spouse

Got divorced

The birth of a child

Someone stole something that was yours or burgled your home

Someone assaulted you, abused you, or attacked you

Someone sexually harassed you

Lost your job or had the principal earner in your household lose their job

Retired

Suffered a serious and ongoing illness or disease

A family member suffered a serious and ongoing illness or disease

Suffered an accident leading to serious injury

A family member suffered an accident leading to serious injury

The death of a family member or loved one

Have we missed anything important or would you like to provide more detail about your experiences? If so, please let us know in the box below:

Thank you for taking part in the New Zealand Attitudes and Values Study!

Please post back your completed questionnaire using the included freepost return envelope. The freepost envelope will work from anywhere in New Zealand. If you lose the envelope, you can post this questionnaire back for free to:

FREEPOST AUTHORITY: 124589

New Zealand Attitudes and Values Study

School of Psychology (Cost 9450/71708)

The University of Auckland

Private Bag 92019

Auckland 1142, New Zealand

If you would like to know more about the New Zealand Attitudes and Values Study, then please feel free to phone us (contact details on the front) or you can visit the study website. We will also send out a regular e-newsletter to everyone in the study summarising the most interesting findings from the study. 


\section{The New Zealand Attitudes and Values Study}

\section{Follow-up Questionnaire for 2021/2022}

SCHOOL OF PSYCHOLOGY

Science Centre, Building 302

23 Symonds Street, Auckland,

New Zealand

T $09-923-7498$

Enzavs@auckland.ac.nz

$\mathbf{w}$ www.nzavs.auckland.ac.nz

A scanned copy of this form will be kept for a period of up to fourteen years.

Lead researcher:

Professor Chris Sibley, School of Psychology, The University of Auckland. Phone: 09-923-7498. e-mail: nzavs@auckland.ac.nz

\section{Consent form and contact details}

This form is to gather your consent to participate in this phase of the New Zealand Attitudes and Values Study (NZAVS). Only Professor Sibley and his research associates will have access to your responses. Your personal information will be kept separate from your responses at all times. Your questionnaire will be identified by an anonymous code. An encrypted electronic copy of all responses will be stored indefinitely for research purposes in a secure room in the School of Psychology.

I have read and understood a description of this research project. On this basis, I agree to take part. I understand that my data will remain confidential at all times. I understand that only Professor Sibley and trusted research assistants working on the study in secure conditions will have access to my contact details. I consent to publication of the results of the project with the understanding that my anonymity will be preserved. I understand that I am free to withdraw from the research at any time up until the point at which I complete and return this questionnaire. I understand that my contact details will never be shared with anyone outside of the immediate research team. I understand that Professor Sibley and the research team will use these details to contact and invite me to complete annual follow-up questionnaires. I understand that my contact details will also be used to contact me if I win one of the five prize draws for $\$ 1000$ grocery vouchers (total prize pool $\$ 5000$ ) for participating in this study.

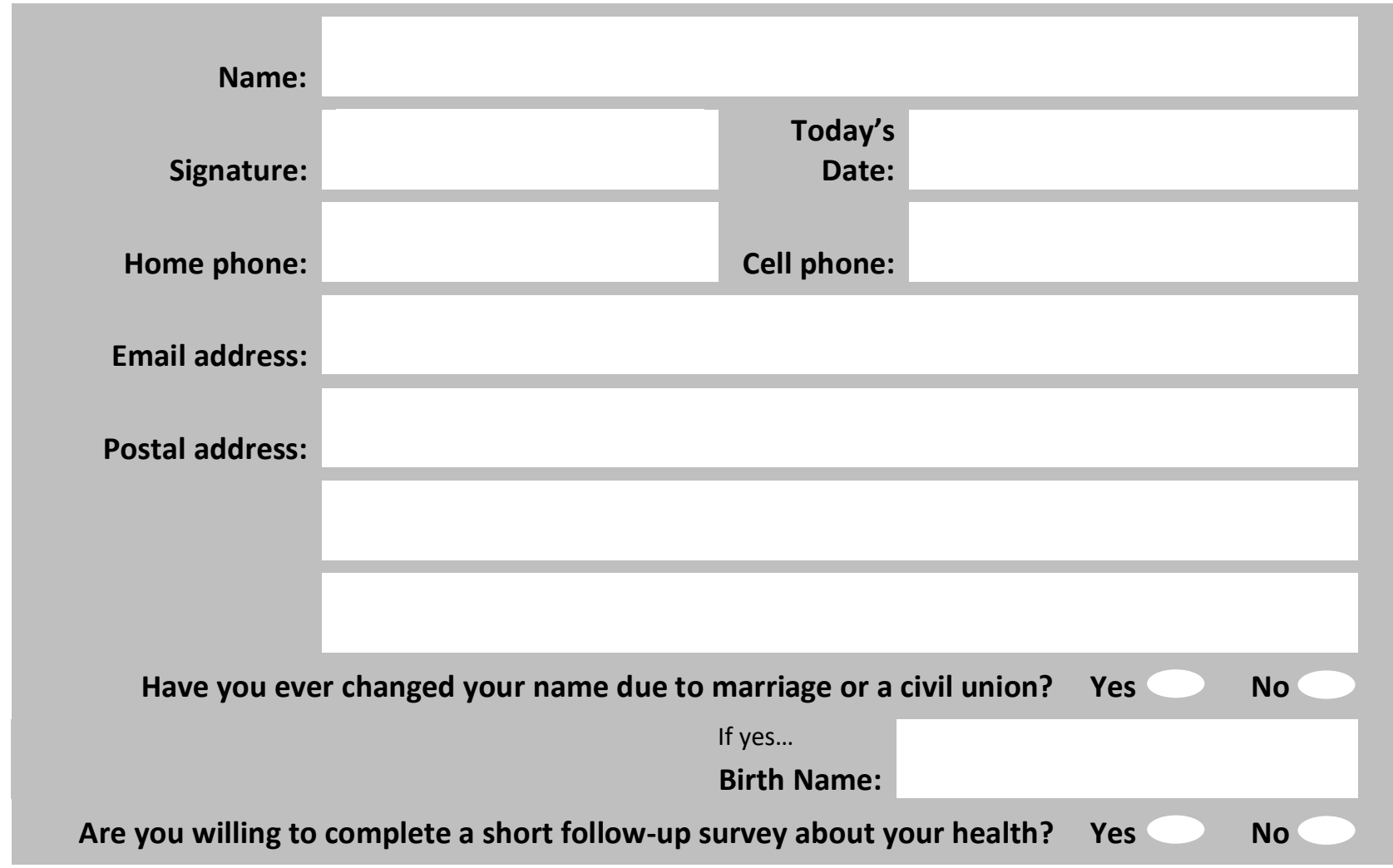




\section{Do you have a partner who would also like to join the NZAVS?}

Over the years, a number of participants have got in touch to let us know that their partner is also interested in joining the NZAVS, and to ask if their partner could also be sent a copy of the questionnaire.

If you have a partner who would like to join the NZAVS and complete their own copy of the questionnaire, then they are most welcome to do so. The easiest way for your partner to join the study is to simply complete the questionnaire online.

The online version is available at: $\underline{w w w . n z a v s . a u c k l a n d . a c . n z / s u r v e y}$

Alternatively, please ask your partner to email us at nzavs@auckland.ac.nz and let us know they are interested in joining the study. We would then be happy to post them a paper copy of the questionnaire. 
Instructions: This part of the questionnaire measures your feelings about yourself.

Please circle the number that best represents how accurately each statement describes you.

\begin{tabular}{|c|c|c|c|c|c|c|}
\hline I ... & \multicolumn{2}{|c|}{$\begin{array}{l}\text { Very } \\
\text { Inaccurate } \\
\downarrow\end{array}$} & & \multicolumn{3}{|c|}{$\begin{array}{r}\text { Very } \\
\text { Accurate } \\
\downarrow\end{array}$} \\
\hline 1. Am the life of the party. & 1 & 3 & 4 & 5 & 6 & 7 \\
\hline 2. Sympathise with others' feelings. & 1 & 3 & 4 & 5 & 6 & 7 \\
\hline 3. Get chores done right away. & 1 & 3 & 4 & 5 & 6 & 7 \\
\hline 4. Have frequent mood swings. & 1 & 3 & 4 & 5 & 6 & 7 \\
\hline 5. Have a vivid imagination. & 1 & 3 & 4 & 5 & 6 & 7 \\
\hline 6. Don't talk a lot. & 1 & 3 & 4 & 5 & 6 & 7 \\
\hline 7. Am not interested in other people's problems. & 1 & 3 & 4 & 5 & 6 & 7 \\
\hline 8. Have difficulty understanding abstract ideas. & 1 & 3 & 4 & 5 & 6 & 7 \\
\hline 9. Like order. & 1 & 3 & 4 & 5 & 6 & 7 \\
\hline 10. Make a mess of things. & 1 & 3 & 4 & 5 & 6 & 7 \\
\hline 11. Do not have a good imagination. & 1 & 3 & 4 & 5 & 6 & 7 \\
\hline 12. Feel others' emotions. & 1 & 3 & 4 & 5 & 6 & 7 \\
\hline 13. Am relaxed most of the time. & 1 & 3 & 4 & 5 & 6 & 7 \\
\hline 14. Get upset easily. & 1 & 3 & 4 & 5 & 6 & 7 \\
\hline 15. Seldom feel blue. & 1 & 3 & 4 & 5 & 6 & 7 \\
\hline 16. Keep in the background. & 1 & 3 & 4 & 5 & 6 & 7 \\
\hline 17. Am not really interested in others. & 1 & 3 & 4 & 5 & 6 & 7 \\
\hline 18. Am not interested in abstract ideas. & 1 & 3 & 4 & 5 & 6 & 7 \\
\hline 19. Often forget to put things back in their proper place. & 1 & 3 & 4 & 5 & 6 & 7 \\
\hline 20. Talk to a lot of different people at parties. & 1 & 3 & 4 & 5 & 6 & 7 \\
\hline 21. Feel entitled to more of everything. & 1 & 3 & 4 & 5 & 6 & 7 \\
\hline 22. On the whole am satisfied with myself. & 1 & 3 & 4 & 5 & 6 & 7 \\
\hline 23. Know that people in my life accept and value me. & 1 & 3 & 4 & 5 & 6 & 7 \\
\hline 24. Would like to be seen driving around in a very expensive car. & 1 & 3 & 4 & 5 & 6 & 7 \\
\hline 25. Deserve more things in life. & 1 & 3 & 4 & 5 & 6 & 7 \\
\hline 26. Feel that I am often discriminated against because of my ethnicity. & 1 & 3 & 4 & 5 & 6 & 7 \\
\hline 27. Feel like an outsider. & 1 & 3 & 4 & 5 & 6 & 7 \\
\hline 28. Would get a lot of pleasure from owning expensive luxury goods. & 1 & 3 & 4 & 5 & 6 & 7 \\
\hline 29. Am satisfied with the appearance, size and shape of my body. & 1 & 3 & 4 & 5 & 6 & 7 \\
\hline 30. Am inclined to feel that I am a failure. & 1 & 3 & 4 & 5 & 6 & 7 \\
\hline 31. Take a positive attitude toward myself. & 1 & 3 & 4 & 5 & 6 & 7 \\
\hline 32. Feel that I am often discriminated against because of my gender. & 1 & 3 & 4 & 5 & 6 & 7 \\
\hline 33. Know that people around me share my attitudes and beliefs. & 1 & 3 & 4 & 5 & 6 & 7 \\
\hline
\end{tabular}

During the last 30 days, how often did

(Please use the scale below to circle a number for each question)

\begin{tabular}{|r|rcc|l|}
$\begin{array}{r}\text { None Of } \\
\text { The Time }\end{array}$ & $\begin{array}{r}\text { A Little of } \\
\text { The Time }\end{array}$ & $\begin{array}{c}\text { Some of } \\
\text { The Time }\end{array}$ & $\begin{array}{c}\text { Most of } \\
\text { The Time }\end{array}$ & $\begin{array}{l}\text { All Of } \\
\text { The Time } \\
4\end{array}$ \\
\hline
\end{tabular}

1. ... you feel hopeless?

2. ... you feel so depressed that nothing could cheer you up?

3. ... you feel restless or fidgety?

4. ... you feel that everything was an effort?

5. ... you feel worthless?

6. ... you feel nervous?

7. ... you have negative thoughts that repeated over and over?

\begin{tabular}{|lllll}
0 & 1 & 2 & 3 & 4 \\
\hline 0 & 1 & 2 & 3 & 4 \\
\hline 0 & 1 & 2 & 3 & 4 \\
\hline 0 & 1 & 2 & 3 & 4 \\
\hline 0 & 1 & 2 & 3 & 4 \\
\hline 0 & 1 & 2 & 3 & 4 \\
\hline 0 & 1 & 2 & 3 & 4 \\
\hline 0 & 1 & 2 & 3 & 4 \\
\hline 0 & 1 & 2 & 3 & 4 \\
\hline
\end{tabular}


Instructions: The statements below reflect different opinions and points of view. Please indicate how strongly you disagree or agree with each statement. Remember, the best answer is your own opinion.

\begin{tabular}{|c|c|c|c|c|c|c|c|}
\hline & \multicolumn{3}{|c|}{$\begin{array}{l}\text { Strongly } \\
\text { Disagree } \\
\downarrow\end{array}$} & \multicolumn{4}{|c|}{$\begin{array}{r}\text { Strongly } \\
\text { Agree }\end{array}$} \\
\hline 1. I have much in my life to be thankful for. & 1 & 2 & 3 & 4 & 5 & 6 & 7 \\
\hline 2. It would be good if groups could be equal. & 1 & 2 & 3 & 4 & 5 & 6 & 7 \\
\hline 3. I often think about the fact that I am a member of my ethnic group. & 1 & 2 & 3 & 4 & 5 & 6 & 7 \\
\hline 4. I expect my health to get worse. & 1 & 2 & 3 & 4 & 5 & 6 & 7 \\
\hline 5. I feel a sense of community with others in my local neighbourhood. & 1 & 2 & 3 & 4 & 5 & 6 & 7 \\
\hline 6. We should have increased social equality. & 1 & 2 & 3 & 4 & 5 & 6 & 7 \\
\hline 7. I know there are people I can turn to when I need help. & 1 & 2 & 3 & 4 & 5 & 6 & 7 \\
\hline $\begin{array}{l}\text { 8. There are many things about the New Zealand Police and its policies that need to } \\
\text { be changed. }\end{array}$ & 1 & 2 & 3 & 4 & 5 & 6 & 7 \\
\hline $\begin{array}{l}\text { 9. If I go to my doctor/GP with a minor illness (e.g., sore throat, cough, runny nose, } \\
\text { etc.), I think that I should be prescribed antibiotics by default. }\end{array}$ & 1 & 2 & 3 & 4 & 5 & 6 & 7 \\
\hline 10. I wish I had more self-discipline. & 1 & 2 & 3 & 4 & 5 & 6 & 7 \\
\hline 11. We should do what we can to equalise conditions for different groups. & 1 & 2 & 3 & 4 & 5 & 6 & 7 \\
\hline $\begin{array}{l}\text { 12. By taking an active part in political and social affairs we, the people, can control } \\
\text { world events. }\end{array}$ & 1 & 2 & 3 & 4 & 5 & 6 & 7 \\
\hline 13. I seem to get sick a little easier than other people. & 1 & 2 & 3 & 4 & 5 & 6 & 7 \\
\hline 14. If incomes were more equal, people would be less motivated to worl & 1 & 2 & 3 & 4 & 5 & 6 & 7 \\
\hline 15. I have a good sense of what makes my life meaningful. & 1 & 2 & 3 & 4 & 5 & 6 & 7 \\
\hline 16. To get ahead in life, it is sometimes okay to step on other groups. & 1 & 2 & 3 & 4 & 5 & 6 & 7 \\
\hline 17. I am hardly ever satisfied with my performance. & 1 & 2 & 3 & 4 & 5 & 6 & 7 \\
\hline 18. People from my ethnic group generally earn less than other groups in NZ. & 1 & 2 & 3 & 4 & 5 & 6 & 7 \\
\hline 19. When I feel negative emotions, I suppress or hide my emotions. & 1 & 2 & 3 & 4 & 5 & 6 & 7 \\
\hline 20. I have considered voting in terms of what is good for my particula & 1 & 2 & 3 & 4 & 5 & 6 & 7 \\
\hline 21. I am grateful to a wide variety of people. & 1 & 2 & 3 & 4 & 5 & 6 & 7 \\
\hline 22. I feel at ease when I am in a city district in New Zealand with many immigrants. & 1 & 2 & 3 & 4 & 5 & 6 & 7 \\
\hline 23. I find myself regularly thinking about past times that I have been wronged. & 1 & 2 & 3 & 4 & 5 & 6 & 7 \\
\hline $\begin{array}{l}\text { 24. I would always report dangerous or suspicious activities occurring in my } \\
\text { neighbourhood to the police. }\end{array}$ & 1 & 2 & 3 & 4 & 5 & 6 & 7 \\
\hline $\begin{array}{l}\text { 25. The fact that I am a member of my ethnic group is an important part of my } \\
\text { identity. }\end{array}$ & 1 & 2 & 3 & 4 & 5 & 6 & 7 \\
\hline 26. In general, I have a lot of self-control. & 1 & 2 & 3 & 4 & 5 & 6 & 7 \\
\hline $\begin{array}{l}\text { 27. Everyone in New Zealand has a fair shot at we } \\
\text { ethnicity or race. }\end{array}$ & 1 & 2 & 3 & 4 & 5 & 6 & 7 \\
\hline
\end{tabular}

Instructions: Please rate your level of satisfaction with the following aspects of your life and New Zealand.

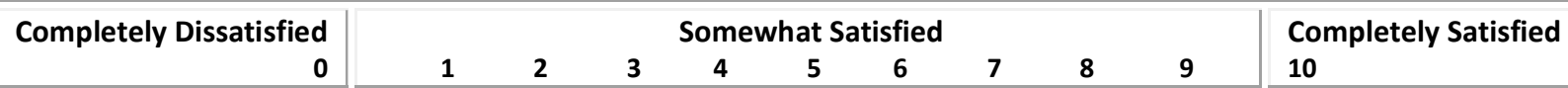

1. Your standard of living.

\begin{tabular}{lllllllllll}
\hline 0 & 1 & 2 & 3 & 4 & 5 & 6 & 7 & 8 & 9 & 10 \\
\hline 0 & 1 & 2 & 3 & 4 & 5 & 6 & 7 & 8 & 9 & 10 \\
\hline 0 & 1 & 2 & 3 & 4 & 5 & 6 & 7 & 8 & 9 & 10 \\
\hline 0 & 1 & 2 & 3 & 4 & 5 & 6 & 7 & 8 & 9 & 10 \\
\hline 0 & 1 & 2 & 3 & 4 & 5 & 6 & 7 & 8 & 9 & 10 \\
\hline 0 & 1 & 2 & 3 & 4 & 5 & 6 & 7 & 8 & 9 & 10 \\
\hline 0 & 1 & 2 & 3 & 4 & 5 & 6 & 7 & 8 & 9 & 10 \\
\hline 0 & 1 & 2 & 3 & 4 & 5 & 6 & 7 & 8 & 9 & 10 \\
\hline 0 & 1 & 2 & 3 & 4 & 5 & 6 & 7 & 8 & 9 & 10 \\
\hline 0 & 1 & 2 & 3 & 4 & 5 & 6 & 7 & 8 & 9 & 10 \\
\hline 0 & 1 & 2 & 3 & 4 & 5 & 6 & 7 & 8 & 9 & 10 \\
\hline
\end{tabular}

3. The quality of New Zealand's natural environment.

4. Your health.

5. The social conditions in New Zealand.

6. The performance of the current New Zealand government.

7. Your future security.

8. Business in New Zealand.

9. Your personal relationships.

10. Your access to health care when you need it (e.g., doctor, GP).

11. The New Zealand government response to COVID-19. 


\begin{tabular}{|c|c|c|c|c|c|c|c|}
\hline Everyone has a fair shot at wealth and happiness in New Zealand. & \multicolumn{3}{|c|}{$\begin{array}{l}\text { Strongly } \\
\text { Disagree } \\
\downarrow\end{array}$} & & \multicolumn{3}{|c|}{$\begin{array}{r}\text { Strongly } \\
\text { Agree }\end{array}$} \\
\hline 2. When I look at the world, I don't see much to be grateful for. & 1 & 2 & 3 & 4 & 5 & 6 & 7 \\
\hline 3. I feel a great pride in the land that is our New Zealand. & 1 & 2 & 3 & 4 & 5 & 6 & 7 \\
\hline 6. In general, I find New Zealand society to be fair. & 1 & 2 & 3 & 4 & 5 & 6 & 7 \\
\hline 7. All political conservatives are fools. & 1 & 2 & 3 & 4 & 5 & 6 & 7 \\
\hline 8. Women, compared to men, tend to have greater moral sensibility. & 1 & 2 & 3 & 4 & 5 & 6 & 7 \\
\hline 9. Sometimes I can't sleep because of thinking about past wrongs I have suffered. & 1 & 2 & 3 & 4 & 5 & 6 & 7 \\
\hline 12. Protest marches and public demonstrations supporting the rights of Mãori. & 1 & 2 & 3 & 4 & 5 & 6 & 7 \\
\hline $\begin{array}{l}\text { 13. The current income gap between New Zealand Europeans and other ethnic } \\
\text { groups would be very hard to change. }\end{array}$ & 1 & 2 & 3 & 4 & 5 & 6 & 7 \\
\hline 14. There are too many immigrants living in New Zealand. & 1 & 2 & 3 & 4 & 5 & 6 & 7 \\
\hline 15. I generally earn less than other people in New Zealand. & 1 & 2 & 3 & 4 & 5 & 6 & 7 \\
\hline 16. I have considered signing petitions on behalf of my ethnic group. & 1 & 2 & 3 & 4 & 5 & 6 & 7 \\
\hline 17. Māori have too much political power and influence in decisions affecting NZ. & 1 & 2 & 3 & 4 & 5 & 6 & 7 \\
\hline $\begin{array}{l}\text { 18. Once a woman gets a man to commit to her she usually tries to put him on a tight } \\
\text { leash. }\end{array}$ & 1 & 2 & 3 & 4 & 5 & 6 & 7 \\
\hline
\end{tabular}

19. We are all one nation and we should all be treated the same. No one should be entitled to anything more than the rest of us simply because they belong to one particular ethnic group.

20. I believe I am capable, as an individual, of improving my status in society.

21. My life has a clear sense of purpose.

$\begin{array}{lllllll}1 & 2 & 3 & 4 & 5 & 6 & 7\end{array}$

22. People who are 'tall poppies' should be cut down to size.

23. Most of New Zealand's policies serve the greater good.

24. In general, the New Zealand political system operates as it should.

25. People's basic rights are well protected by the New Zealand Police.

26. People from my ethnic group are discriminated against in New Zealand.

27. If I take care of myself, I can avoid illness.

28. Politicians in New Zealand can generally be trusted.

29. Every man ought to have a woman whom he adores.

30. It is always better to trust the judgment of the proper authorities in government and religion than to listen to the noisy rabble-rousers in our society who are trying to create doubt in people's minds.

31. The teachings of traditional religions are still helpful today.

$\begin{array}{lllllll}1 & 2 & 3 & 4 & 5 & 6 & 7\end{array}$

$\begin{array}{lllllll}1 & 2 & 3 & 4 & 5 & 6 & 7\end{array}$

$\begin{array}{lllllll}1 & 2 & 3 & 4 & 5 & 6 & 7\end{array}$

$\begin{array}{lllllll}1 & 2 & 3 & 4 & 5 & 6 & 7\end{array}$

$\begin{array}{lllllll}1 & 2 & 3 & 4 & 5 & 6 & 7\end{array}$

$\begin{array}{lllllll}1 & 2 & 3 & 4 & 5 & 6 & 7\end{array}$

$\begin{array}{lllllll}1 & 2 & 3 & 4 & 5 & 6 & 7\end{array}$

$\begin{array}{lllllll}1 & 2 & 3 & 4 & 5 & 6 & 7\end{array}$

$\begin{array}{lllllll}1 & 2 & 3 & 4 & 5 & 6 & 7\end{array}$

$\begin{array}{lllllll}1 & 2 & 3 & 4 & 5 & 6 & 7\end{array}$

32. Atheists and others who have rebelled against established religions are no doubt every bit as good and virtuous as those who attend church regularly.

$\begin{array}{lllllll}1 & 2 & 3 & 4 & 5 & 6 & 7\end{array}$

$\begin{array}{lllllll}1 & 2 & 3 & 4 & 5 & 6 & 7\end{array}$

33. I wouldn't want people to treat me as though I were superior to them.

$\begin{array}{lllllll}1 & 2 & 3 & 4 & 5 & 6 & 7\end{array}$

34. With enough effort we can wipe out political corruption.

35. The unity of New Zealand is weakened by too many immigrants.

$\begin{array}{lllllll}1 & 2 & 3 & 4 & 5 & 6 & 7\end{array}$

$\begin{array}{lllllll}1 & 2 & 3 & 4 & 5 & 6 & 7\end{array}$

36. There is no one I can turn to for guidance in times of stress.

$\begin{array}{lllllll}1 & 2 & 3 & 4 & 5 & 6 & 7\end{array}$

37. Islam is a religion of peace.

$\begin{array}{lllllll}1 & 2 & 3 & 4 & 5 & 6 & 7\end{array}$

38. Men and women both have a fair shot at wealth and happiness in NZ.

$\begin{array}{lllllll}1 & 2 & 3 & 4 & 5 & 6 & 7\end{array}$

38. Men and women both have a fair shot at wealth and happiness in $\mathrm{NZ}$

$\begin{array}{lllllll}1 & 2 & 3 & 4 & 5 & 6 & 7\end{array}$

39. I am satisfied with my life.

40. It would be best for everyone if the proper authorities censored magazines so that people could not get their hands on trashy and disgusting material.

$\begin{array}{lllllll}1 & 2 & 3 & 4 & 5 & 6 & 7\end{array}$

$\begin{array}{lllllll}1 & 2 & 3 & 4 & 5 & 6 & 7\end{array}$ 
Please rate your feelings of WARMTH toward the following groups using the "feeling thermometer scale" for each group.

\begin{tabular}{|c|c|c|c|c|c|c|c|c|c|c|c|c|c|c|c|}
\hline $\begin{array}{r}\text { Feel LEAST WARM } \\
\text { Toward This Group } \\
1\end{array}$ & & 2 & & & 3 & & $\mathrm{Neu}$ & 5 & & $\mathbf{w a l}$ & $\frac{O S}{T h}$ & $W$ & $\begin{array}{l}\text { ARN } \\
\text { rou }\end{array}$ & & \\
\hline NZ Europeans & 1 & 2 & 3 & 4 & 5 & 6 & 7 & Overweight people & 1 & 2 & 3 & 4 & 5 & 6 & 7 \\
\hline Māori & 1 & 2 & 3 & 4 & 5 & 6 & 7 & Immigrants in general & 1 & 2 & 3 & 4 & 5 & 6 & 7 \\
\hline Asians in general & 1 & 2 & 3 & 4 & 5 & 6 & 7 & Chinese & 1 & 2 & 3 & 4 & 5 & 6 & 7 \\
\hline Pacific Islanders & 1 & 2 & 3 & 4 & 5 & 6 & 7 & Indians & 1 & 2 & 3 & 4 & 5 & 6 & 7 \\
\hline Elderly people & 1 & 2 & 3 & 4 & 5 & 6 & 7 & Muslims & 1 & 2 & 3 & 4 & 5 & 6 & 7 \\
\hline People with a disability & 1 & 2 & 3 & 4 & 5 & 6 & 7 & LGBTQ+ people & 1 & 2 & 3 & 4 & 5 & 6 & 7 \\
\hline Refugees & 1 & 2 & 3 & 4 & 5 & 6 & 7 & People with mental illness & 1 & 2 & 3 & 4 & 5 & 6 & 7 \\
\hline
\end{tabular}

01. What is your date of birth?

02. Which ethnic group(s) do you belong to?

(Mark the space or spaces which apply to you).

03. What is your gender?

04. What is your height?

05. What is your weight?

06a. How often do you have a drink containing alcohol? And, if you drink alcohol...

06b. How many drinks containing alcohol do you have on a typical day when drinking?

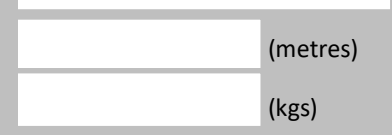

Never - I don't drink Monthly or less Up to 4 times a month Up to 3 times a week Don't know

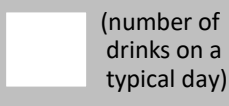
4 or more times a week

07. During the past month, on average, how many hours of actual sleep did you get per night?

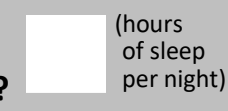

08a. Do you have a regular family doctor/GP? Yes No And, if you have a regular doctor/GP...

08b. How satisfied are you with the service and care you receive from your family doctor/GP?

$$
\begin{array}{llllllllll}
\text { Not satisfied } & 1 & \mathbf{2} & \mathbf{3} & \mathbf{4} & \mathbf{5} & \mathbf{6} & \mathbf{7} & \text { Very satisfied }
\end{array}
$$

08c. Do you think your doctor/GP shares a similar cultural background to you?

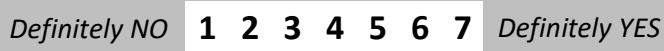

08d. Does your doctor/GP respect your cultural background when you are discussing health issues with them?

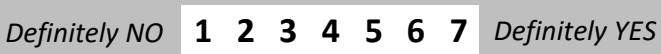

09. How would you describe your dietary behaviour? (e.g., meat \& vegetables, vegetarian, vegan, halal, pescatarian, etc.)
10. Have you been diagnosed with, or treated for, any of the following health conditions by a doctor in the last five years?
High cholesterol High blood pressure Asthma

Heart disease

Diabetes (Type II)

Depression

Anxiety disorder Other (please state):
11. Have you ever regularly...
(a) smoked tobacco cigarettes?
Yes No
(b) vaped or used e-cigarettes?
Yes No

12. Do you currently...
(a) smoke tobacco cigarettes?
Yes No
(b) vape or use e-cigarettes?
Yes No

13. Do you have a health condition or disability that limits you, and that has lasted for $6+$ months?

Yes No

(a) if yes, please state:

14. In general, would you say your health is...

$$
\text { Poor } \begin{array}{llllllll}
1 & 2 & 3 & 4 & 5 & 6 & 7 & \text { Excellent } \\
& \multicolumn{7}{c}{\text { Please circle a number }}
\end{array}
$$

15a. Have you been vaccinated for COVID-19?

15b. If not, do you intend to get vaccinated for COVID-19?

Yes No

15c. If you are not, and do not intend to get, vaccinated for COVID-19, why not?

16a. If you think about a scene such as a sunrise, or the appearance of a familiar person or place, to what extent can you visualise the scene in your mind?

$$
\begin{array}{lllllllll}
\text { Not at all } & \mathbf{1} & \mathbf{2} & \mathbf{3} & \mathbf{4} & \mathbf{5} & \mathbf{6} & \mathbf{7} & \begin{array}{l}
\text { As vividly as } \\
\text { actually seeing it. }
\end{array}
\end{array}
$$

16b. If you think about a sound, such as a dog barking, someone's voice, or a tune, to what extent can you hear the sound in your mind?

$$
\begin{array}{lllllllll}
\text { Not at all } & 1 & \mathbf{2} & \mathbf{3} & \mathbf{4} & \mathbf{5} & \mathbf{6} & \mathbf{7} & \begin{array}{l}
\text { As clearly as } \\
\text { actually hearing it. }
\end{array}
\end{array}
$$

17. Do you believe in a God?

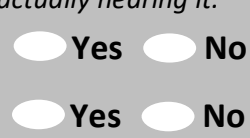

18. Do you believe in some form

of spirit or life force?

19. How much money have you donated to charity in the last year? \$

20. Where were you born?

(please be specific, e.g., which town/city?) 


\begin{tabular}{|c|c|c|c|c|c|c|c|}
\hline \multirow[b]{2}{*}{ I oppose religion in any form. } & \multicolumn{3}{|c|}{$\begin{array}{l}\text { Strongly } \\
\text { Disagree } \\
\downarrow\end{array}$} & \multirow[b]{2}{*}{4} & \multirow[b]{2}{*}{5} & \multicolumn{2}{|c|}{$\begin{array}{r}\text { Strongl } \\
\text { Agre } \\
+\end{array}$} \\
\hline & 1 & 2 & 3 & & & 6 & 7 \\
\hline 2. The rich should be stripped of their belongings and status. & 1 & 2 & 3 & 4 & 5 & 6 & 7 \\
\hline $\begin{array}{l}\text { 3. True equality can be achieved only once we recognize that some ethnic } \\
\text { groups are currently more disadvantaged than others and require additional } \\
\text { assistance from the government. }\end{array}$ & 1 & 2 & 3 & 4 & 5 & 6 & 7 \\
\hline $\begin{array}{l}\text { 4. Although I may disagree with the opinions that other people hold, they } \\
\text { should be allowed to express those views publicly. }\end{array}$ & 1 & 2 & 3 & 4 & 5 & 6 & 7 \\
\hline 5. All things considered, religion is a cause for good in the world. & 1 & 2 & 3 & 4 & 5 & 6 & 7 \\
\hline 6. I do not have enough power or control over important parts of my life. & 1 & 2 & 3 & 4 & 5 & 6 & 7 \\
\hline 7. I think that homosexuality should be accepted by society. & 1 & 2 & 3 & 4 & 5 & 6 & 7 \\
\hline 8. Women seek to gain power by getting control over men. & 1 & 2 & 3 & 4 & 5 & 6 & 7 \\
\hline 9. When I feel negative emotions, my emotions feel out of control. & 1 & 2 & 3 & 4 & 5 & 6 & 7 \\
\hline 10. Our society places too much emphasis on science. & 1 & 2 & 3 & 4 & 5 & 6 & 7 \\
\hline 11. Women are too easily offended. & 1 & 2 & 3 & 4 & 5 & 6 & 7 \\
\hline $\begin{array}{l}\text { 12. New Zealand would be much better off if all of the rich people were at the } \\
\text { bottom of the social ladder. }\end{array}$ & 1 & 2 & 3 & 4 & 5 & 6 & 7 \\
\hline 13. I identify with New Zealand. & 1 & 2 & 3 & 4 & 5 & 6 & 7 \\
\hline 14. Economic positions are legitimate reflections of people's achievements. & 1 & 2 & 3 & 4 & 5 & 6 & 7 \\
\hline $\begin{array}{l}\text { 15. We are all New Zealanders and the law should not make provision for } \\
\text { minority groups because of their ethnicity. }\end{array}$ & 1 & 2 & 3 & 4 & 5 & 6 & 7 \\
\hline 16. Being a woman/man is an important part of how I see myself. & 1 & 2 & 3 & 4 & 5 & 6 & 7 \\
\hline 17. I feel that I am often discriminated against because of my age. & 1 & 2 & 3 & 4 & 5 & 6 & 7 \\
\hline 18. In general, relations between men and women in New Zealand are fair. & 1 & 2 & 3 & 4 & 5 & 6 & 7 \\
\hline 19. I have a good balance between work and other important things in my life. & 1 & 2 & 3 & 4 & 5 & 6 & 7 \\
\hline $\begin{array}{l}\text { 20. I trust the government to make sensible decisions about how to best manage } \\
\text { COVID-19 here in New Zealand. }\end{array}$ & 1 & 2 & 3 & 4 & 5 & 6 & 7 \\
\hline $\begin{array}{l}\text { 21. By taking personal action I believe I can make a positive difference to } \\
\text { environmental problems. }\end{array}$ & 1 & 2 & 3 & 4 & 5 & 6 & 7 \\
\hline 22. I feel anxious about interacting with people from other races. & 1 & 2 & 3 & 4 & 5 & 6 & 7 \\
\hline $\begin{array}{l}\text { 23. When women lose to men in a fair competition, they typically complain about } \\
\text { being discriminated against. }\end{array}$ & 1 & 2 & 3 & 4 & 5 & 6 & 7 \\
\hline 24. Doing my best never seems to be enough. & 1 & 2 & 3 & 4 & 5 & 6 & 7 \\
\hline 25. We need to replace the established order by any means necessary. & 1 & 2 & 3 & 4 & 5 & 6 & 7 \\
\hline 26. Many women have a quality of purity that few men possess. & 1 & 2 & 3 & 4 & 5 & 6 & 7 \\
\hline 27. Bad smells, messes, dead animals and rotten food absolutely disgust me. & 1 & 2 & 3 & 4 & 5 & 6 & 7 \\
\hline $\begin{array}{l}\text { 28. I think that the official version of major world events given by authorities } \\
\text { often hides the truth. }\end{array}$ & 1 & 2 & 3 & 4 & 5 & 6 & 7 \\
\hline 29. I am in control of my health. & 1 & 2 & 3 & 4 & 5 & 6 & 7 \\
\hline $\begin{array}{l}\text { 30. It is safe to vaccinate children following the standard New Zealand } \\
\text { immunization schedule. }\end{array}$ & 1 & 2 & 3 & 4 & 5 & 6 & 7 \\
\hline $\begin{array}{l}\text { 31. Although at times I may not agree with the government, my commitment to } \\
\text { New Zealand always remains strong. }\end{array}$ & 1 & 2 & 3 & 4 & 5 & 6 & 7 \\
\hline 32. The New Zealand Police care about the well-being of everyone they deal with. & 1 & 2 & 3 & 4 & 5 & 6 & 7 \\
\hline $\begin{array}{l}\text { 33. People should pay less attention to The Bible and other old traditional forms } \\
\text { of religious guidance, and instead develop their own personal standards of } \\
\text { what is moral and immoral. }\end{array}$ & 1 & 2 & 3 & 4 & 5 & 6 & 7 \\
\hline $\begin{array}{l}\text { 34. People who hold opinions that are harmful or offensive to minority groups } \\
\text { should be banned from expressing those views publicly. }\end{array}$ & 1 & 2 & 3 & 4 & 5 & 6 & 7 \\
\hline $\begin{array}{l}\text { 35. It is safe for adults to get vaccinated for COVID-19 using the Pfizer vaccine } \\
\text { (Pfizer is the vaccine used in New Zealand's COVID-19 vaccine rollout). }\end{array}$ & 1 & 2 & 3 & 4 & 5 & 6 & 7 \\
\hline
\end{tabular}




\begin{tabular}{|c|c|c|c|c|c|c|c|}
\hline \multirow[b]{2}{*}{ 1. I want people to know that I am an important person of high status. } & \multicolumn{3}{|c|}{$\begin{array}{l}\text { Strongly } \\
\text { Disagree } \\
\downarrow\end{array}$} & \multirow[b]{2}{*}{4} & \multirow[b]{2}{*}{5} & \multirow{2}{*}{\multicolumn{2}{|c|}{ 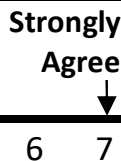 }} \\
\hline & 1 & 2 & 3 & & & & \\
\hline 2. When I meet new people in New Zealand, they often assume that I am a foreigner. & 1 & 2 & 3 & 4 & 5 & 6 & 7 \\
\hline 3. Climate change is real. & 1 & 2 & 3 & 4 & 5 & 6 & 7 \\
\hline 4. Climate change is caused by humans. & 1 & 2 & 3 & 4 & 5 & 6 & 7 \\
\hline 5. I am deeply concerned about climate change. & 1 & 2 & 3 & 4 & 5 & 6 & 7 \\
\hline 6. In general, relations between different ethnic groups in New Zealand are fair. & 1 & 2 & 3 & 4 & 5 & 6 & 7 \\
\hline 7. Muslims in New Zealand should have the right to found Islamic schools. & 1 & 2 & 3 & 4 & 5 & 6 & 7 \\
\hline 8. I identify as a spiritual person. & 1 & 2 & 3 & 4 & 5 & 6 & 7 \\
\hline $\begin{array}{l}\text { 9. Our country will be destroyed some day if we do not smash the perversions eating } \\
\text { away at our moral fibre and traditional beliefs. }\end{array}$ & 1 & 2 & 3 & 4 & 5 & 6 & 7 \\
\hline 10. My performance rarely measures up to my standards. & 1 & 2 & 3 & 4 & 5 & 6 & 7 \\
\hline 11. I'm frustrated by what I earn relative to other people in NZ. & 1 & 2 & 3 & 4 & 5 & 6 & 7 \\
\hline 12. Inferior groups should stay in their place. & 1 & 2 & 3 & 4 & 5 & 6 & 7 \\
\hline 13. The average citizen can have an influence on government decisions. & 1 & 2 & 3 & 4 & 5 & 6 & 7 \\
\hline $\begin{array}{l}\text { 14. Foreign nations have done some very fine things but they are still not as good as } \\
\text { New Zealand. }\end{array}$ & 1 & 2 & 3 & 4 & 5 & 6 & 7 \\
\hline $\begin{array}{l}\text { 15. Women, as compared to men, tend to have a more refined sense of culture and } \\
\text { good taste. }\end{array}$ & 1 & 2 & 3 & 4 & 5 & 6 & 7 \\
\hline 16. People from other races would be likely to reject me on the basis of my race. & 1 & 2 & 3 & 4 & 5 & 6 & 7 \\
\hline 17. I think that health risks associated with COVID-19 have been wildly exaggerated. & 1 & 2 & 3 & 4 & 5 & 6 & 7 \\
\hline 18. I think that I am entitled to more respect than the average person is. & 1 & 2 & 3 & 4 & 5 & 6 & 7 \\
\hline 19. When I feel negative emotions, I change the way I think to help me stay calm. & 1 & 2 & 3 & 4 & 5 & 6 & 7 \\
\hline $\begin{array}{l}\text { 20. I would always provide information to the police to help them find someone } \\
\text { suspected of committing a crime. }\end{array}$ & 1 & 2 & 3 & 4 & 5 & 6 & 7 \\
\hline 21. Other people have too much power or control over important parts of my life. & 1 & 2 & 3 & 4 & 5 & 6 & 7 \\
\hline 22. I have a high degree of confidence in the scientific community. & 1 & 2 & 3 & 4 & 5 & 6 & 7 \\
\hline 23. If I could, I would live in a place where there were no Muslims. & 1 & 2 & 3 & 4 & 5 & 6 & 7 \\
\hline 24. Discrimination against Māori is no longer a problem in New Zealand. & 1 & 2 & 3 & 4 & 5 & 6 & 7 \\
\hline 25. I can usually forgive and forget when someone does me wrong. & 1 & 2 & 3 & 4 & 5 & 6 & 7 \\
\hline 26. Women should be cherished and protected by men. & 1 & 2 & 3 & 4 & 5 & 6 & 7 \\
\hline 27. Generally, the more influence NZ has on other nations, the better off they are. & 1 & 2 & 3 & 4 & 5 & 6 & 7 \\
\hline 28. I feel that I am often discriminated against because of my religious/spiritual beliefs. & 1 & 2 & 3 & 4 & 5 & 6 & 7 \\
\hline 29. In most ways my life is close to ideal. & 1 & 2 & 3 & 4 & 5 & 6 & 7 \\
\hline 30. Being a member of my ethnic group is an important part of how I see myself. & 1 & 2 & 3 & 4 & 5 & 6 & 7 \\
\hline 31. I'm frustrated by what my ethnic group earns relative to other groups in NZ. & 1 & 2 & 3 & 4 & 5 & 6 & 7 \\
\hline 32. If I get sick, it is my own behavior which determines how soon I get well again. & 1 & 2 & 3 & 4 & 5 & 6 & 7 \\
\hline 33. I feel I can make a difference to the state of the environment. & 1 & 2 & 3 & 4 & 5 & 6 & 7 \\
\hline $\begin{array}{l}\text { 34. If I could remake society, I would put people who currently have the most privilege } \\
\text { at the very bottom. }\end{array}$ & 1 & & 3 & 4 & 5 & 6 & 7 \\
\hline 35. I am an ordinary person who is no better than others. & 1 & 2 & 3 & 4 & 5 & 6 & 7 \\
\hline 36. I often worry about terrorist attacks happening in New Zealand. & 1 & 2 & 3 & 4 & 5 & 6 & 7 \\
\hline $\begin{array}{l}\text { 37. Some of the best people in our country are those who are challenging our } \\
\text { government, criticizing religion, and ignoring the "normal way" things are supposed } \\
\text { to be done. }\end{array}$ & 1 & & 3 & 4 & 5 & 6 & 7 \\
\hline 38. I think it is quite likely that COVID-19 was created in a laboratory. & 1 & 2 & 3 & 4 & 5 & 6 & 7 \\
\hline
\end{tabular}

Instructions: Please rate how strongly you oppose or support each of the following political parties.

\section{Strongly Oppose}

1

\section{Neutral}

4

23

\begin{tabular}{|lllllll}
1 & 2 & 3 & 4 & 5 & 6 & 7 \\
\hline 1 & 2 & 3 & 4 & 5 & 6 & 7 \\
\hline 1 & 2 & 3 & 4 & 5 & 6 & 7 \\
\hline
\end{tabular}

The National Party

The Labour Party

The ACT Party

\section{Strongly Support}

7

The Green Party

The Māori Party

The NZ First Party

$\begin{array}{lllllll}1 & 2 & 3 & 4 & 5 & 6 & 7 \\ 1 & 2 & 3 & 4 & 5 & 6 & 7 \\ 1 & 2 & 3 & 4 & 5 & 6 & 7\end{array}$


01. What is your highest

level of qualification?

02a. Are you currently employed? (This includes self-employed or casual work)

02b. In your main job, which one of these are you?

A paid employee

Self-employed and NOT employing others

An employer of persons in my own business

Working in a family business or family farm without pay

02c. In that job, what is your current occupation?

$02 \mathrm{~d}$. In that job, what is your contractual arrangement?

(e.g., primary school teacher, civil engineer, motel manager).

(e.g., permanent employee, casual, fixed-term, independent contractor)

02e. What is the main activity of the business or employer that you work for?

(e.g., primary school education, civil engineering construction, accommodation).

02f. How long have you worked at your current organisation? (years) (months)

02g. How satisfied are you with your current job?

$$
\begin{array}{lllllllll}
\text { Not satisfied } & \mathbf{1} & \mathbf{2} & \mathbf{3} & \mathbf{4} & \mathbf{5} & \mathbf{6} & \mathbf{7} & \text { Very satisfied }
\end{array}
$$

$02 \mathrm{~h}$. How secure do you feel in your current job?

$$
\begin{array}{llllllllll}
\text { Not secure } & \mathbf{1} & \mathbf{2} & \mathbf{3} & \mathbf{4} & \mathbf{5} & \mathbf{6} & \mathbf{7} & \text { Very secure }
\end{array}
$$

02i. How valued do you feel by your current organisation?

$$
\begin{array}{llllllllll}
\text { Not valued } & \mathbf{1} & \mathbf{2} & \mathbf{3} & \mathbf{4} & \mathbf{5} & \mathbf{6} & \mathbf{7} & \text { Very valued }
\end{array}
$$

03a. What is your relationship status?

If you are in a relationship...

(e.g., single, married, de-facto, civil union, widowed, living together, etc.)

03b. How long have you been with your partner? (years) (months)

03c. If you are currently married or in a civil union, what was the date of your marriage or union?

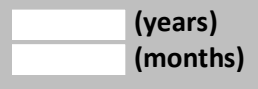

03d. How satisfied are you with your relationship?

$$
\begin{array}{llllllllll}
\text { Not satisfied } & \mathbf{1} & \mathbf{2} & \mathbf{3} & \mathbf{4} & \mathbf{5} & \mathbf{6} & \mathbf{7} & \text { Very satisfied }
\end{array}
$$

03e. To what extent do you experience conflict or disagreement with your partner?

$$
\begin{array}{lllllllll}
\text { No conflict at all } & \mathbf{1} & \mathbf{2} & \mathbf{3} & \mathbf{4} & \mathbf{5} & \mathbf{6} & \mathbf{7} & \text { A great deal of conflict }
\end{array}
$$

03f. How satisfied do you think YOUR PARTNER is with your relationship?

$$
\begin{array}{llllllllll}
\text { Not satisfied } & 1 & \mathbf{2} & \mathbf{3} & \mathbf{4} & \mathbf{5} & \mathbf{6} & \mathbf{7} & \text { Very satisfied }
\end{array}
$$

03g. Please estimate how many hours YOUR PARTNER spent doing each of the following things last week. (please enter ' 0 hours' if you they did not do that activity last week)
(a) Working in paid employment
(b) Housework/cooking
(c) Looking after children
(d) Exercising/physical activity
(e) Using social media (e.g., Facebook)
(f) Playing video/computer games

04. Please rate how politically left-wing versus right-wing you see yourself as being:

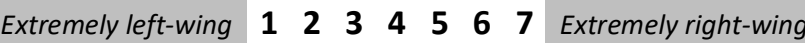

05. Please estimate your total household income (before tax) for the last year:

06. Please estimate how much help you have received from the following sources in the last week?
(a) family:
(b) friends:
(c) members of my community:

07a. How many children have you given birth to, fathered, and/or parented?

07b. If you are a parent, in which year...

(a) was your eldest child born?

(b) was your youngest born?

08. How many other people live in the same household as you?

Number of adults Number of children

09. Please rate how politically liberal versus conservative you see yourself as being:

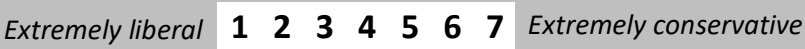

10. Do you identify with a religion and/or spiritual group? If yes...
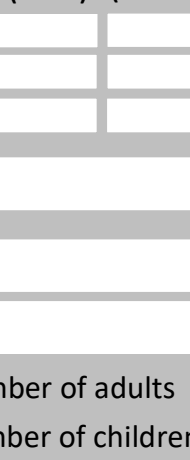

(a) what religion or spiritual group?

(b) how important is your religion

to how you see yourself?

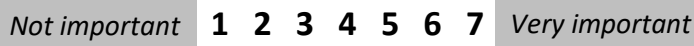

11. Please estimate how many hours you spent doing each of the following things last week. (please enter 'o hours' if you did not do that activity last week)
(a) Working in paid employment
(b) Housework/cooking
(c) Looking after children
(d) Volunteer/charitable work
(e) Exercising/physical activity
(f) Watching TV/Netflix/movies
(g) Travelling/commuting
(h) Watching/reading the news
(i) Using the internet (in total)
(j) Using social media (e.g., Facebook)
(k) Playing video/computer games

Yes No

12. Roughly how many hours have you spent with both FRIENDS/FAMILY and OTHERS (e.g., workmates, strangers) from each ethnic group in the last week? FRIENDS/FAMILY OTHERS
(a) Māori
(b) NZ Europeans
(c) Pacific Islanders
(d) Asians
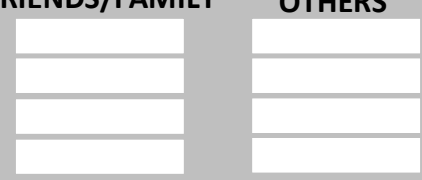

13a. Do you plan to vote in the next New Zealand election in 2023?

13b. If yes, to which party do you plan to give...

your party vote?

your electorate vote?

14. How important are your political beliefs to how you see yourself?

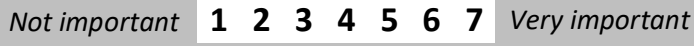

15. How would you describe your sexual orientation?

(e.g., heterosexual, homosexual, straight, gay, lesbian, bisexual, etc.)

16. How satisfied are you with your sex life?

$\begin{array}{llllllllll}\text { Not satisfied } & \mathbf{1} & \mathbf{2} & \mathbf{3} & \mathbf{4} & \mathbf{5} & \mathbf{6} & \mathbf{7} & \text { Very satisfied }\end{array}$ 
Finally, have you experienced any significant life events in the past year?

A lot of things can happen in a year. This is a final optional question that can help us to understand if you have experienced significant life events that might have shaped your responses to the questionnaire for this year. Here are some examples of the significant life events that people might experience (please tick any that you have experienced in the last year):

Began a new serious romantic relationship

Got married/entered a civil union

Separated from your romantic partner/spouse

Got divorced

The birth of a child

Someone stole something that was yours or burgled your home

Someone assaulted you, abused you, or attacked you

Someone sexually harassed you

Lost your job or had the principal earner in your household lose their job

Retired

Suffered a serious and ongoing illness or disease

A family member suffered a serious and ongoing illness or disease

Suffered an accident leading to serious injury

A family member suffered an accident leading to serious injury

The death of a family member or loved one

Have we missed anything important or would you like to provide more detail about your experiences? If so, please let us know in the box below:

Thank you for taking part in the New Zealand Attitudes and Values Study!

Please post back your completed questionnaire using the included freepost return envelope. The freepost envelope will work from anywhere in New Zealand. If you lose the envelope, you can post this questionnaire back for free to:

FREEPOST AUTHORITY: 124589

New Zealand Attitudes and Values Study

School of Psychology (Cost 9450/71708)

The University of Auckland

Private Bag 92019

Auckland 1142, New Zealand

If you would like to know more about the New Zealand Attitudes and Values Study, then please feel free to phone us (contact details on the front) or you can visit the study website. We will also send out a regular e-newsletter to everyone in the study summarising the most interesting findings from the study. 


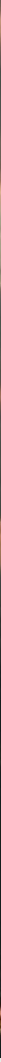

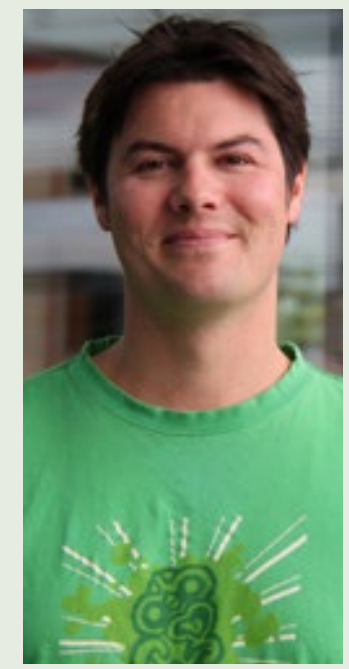

Professor Chris Sibley

Dear NZAVS Participant,

My name is Chris Sibley, and I am the Lead Investigator for the New Zealand Attitudes and Values Study (or NZAVS). On behalf of the NZAVS research team and myself, I would like to thank you for your continued participation in the study. Your responses are very important, and have already helped to answer a number of research questions about significant issues facing New Zealand. We would also like to send our congratulations to the winners of our most recent prize draw.

This newsletter summarises some of the latest findings from the NZAVS. As a participant in the study, you have directly helped in making this research possible. This newsletter provides a snapshot of some of the great work that comes out of the NZAVS each year.

Jump to our recent findings related to:

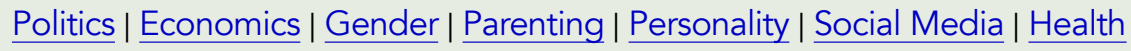

Thanks again for taking part in the study,

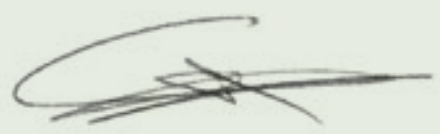

Sincerely,

Professor Chris Sibley

School of Psychology

University of Auckland

Email: nzavs@auckland.ac.nz

Phone: 09-923-7498

\section{Other Useful Links:}

Have you moved recently? Click here to update your contact details. Click here to look at our Frequently Asked Questions page Click here to see the official NZAVS website. Click here to see our full list of publications.
Find us on social media:

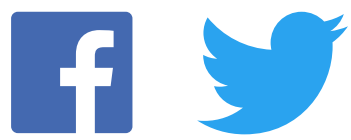

You 


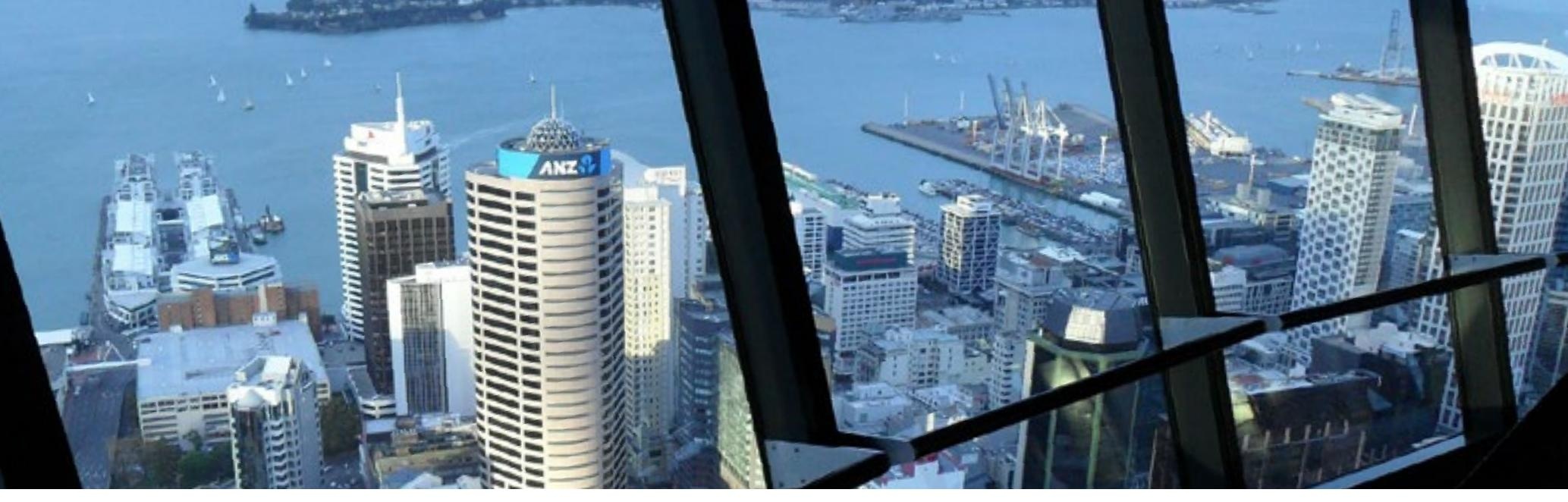

\section{Mixed feelings about the economy, but improvement over time}

Every year, we ask our participants how satisfied they feel with the economic conditions in New Zealand. In 2016, while most people were satisfied with the economy (43\%), not everybody agreed. $21 \%$ of participants were dissatisfied with the New Zealand economy and 36\% felt neutral.

However, satisfaction with the economy has improved over the last decade. When we first asked about economic conditions in 2009, New Zealand had just emerged from a recession. At that time, more people were dissatisfied with the economic conditions in New Zealand (39\%) than were satisfied (22\%).

Economic Conditions in New Zealand in $2016(N=21,936)$

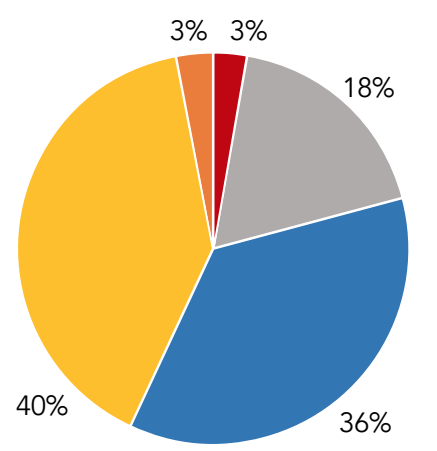

- Completely Dissatisfied

- Dissatisfied

- Neutral

- Satisfied

- Completely Satisfied

Economic Conditions in New Zealand in $2009(\mathrm{~N}=6,518)$

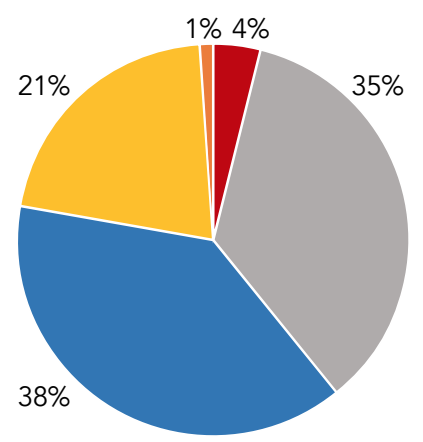

- Completely Dissatisfied

Dissatisfied

- Neutral

- Satisfied

- Completely Satisfied

On a scale of 0 to 10, 0 was coded as completely dissatisfied, 1 - 3 as dissatisfied, 4-6 as neutral, 7-9 as satisfied, and 10 as completely satisfied.

\section{Most New Zealanders are satisfied with their jobs}

In 2015, we asked almost 14000 New Zealanders how satisfied they were with their jobs. Among the 13500 people that were working, only 5 percent reported having low levels of job satisfaction (although a further 20 percent of people didn't answer the question). We also asked people about how secure they felt in their jobs, and we found that people reporting higher levels of job security also tended to report higher levels of job satisfaction.

New Zealanders' job satisfaction in $2015(N=13,490)$

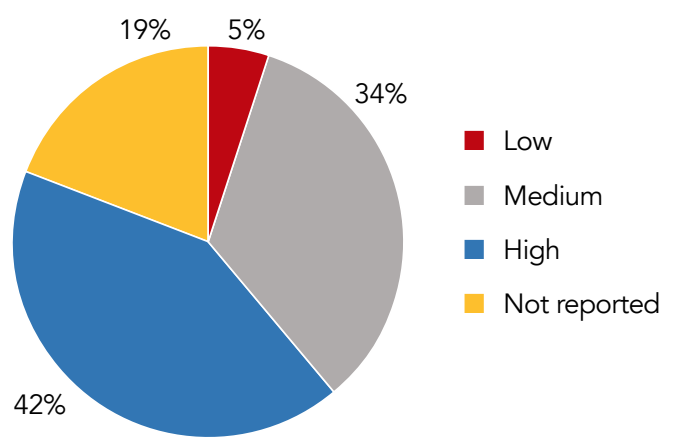

On a scale of 1 to $7,1-2$ was coded as low, $3-5$ was coded as medium, and $6-7$ was coded as high job satisfaction.

Very satisfied

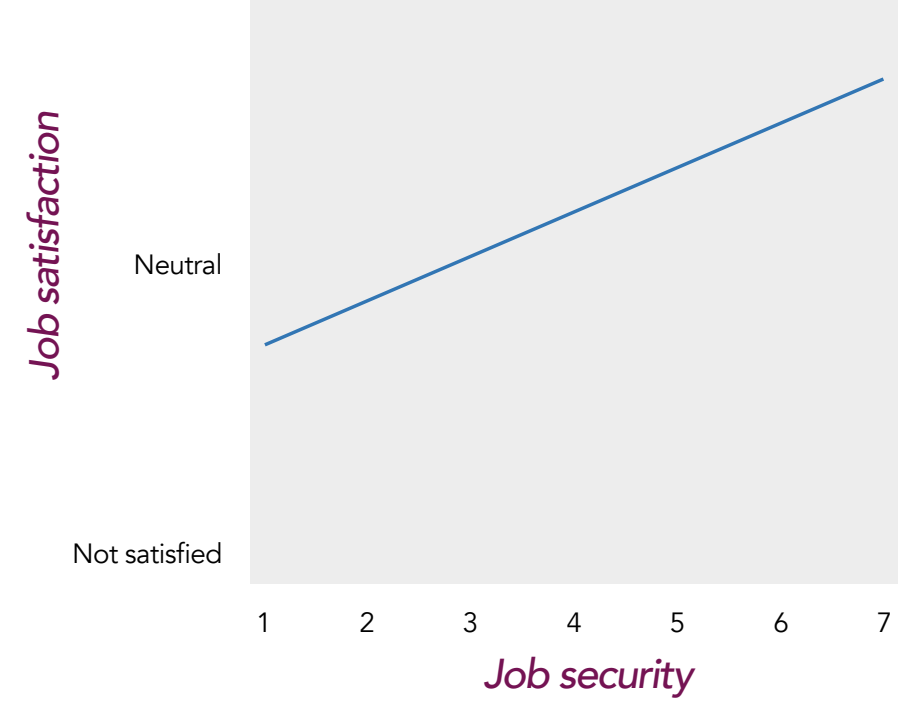




\section{New Zealanders support action on climate change across political parties}

As negotiation takes place among politicians on a new zero carbon law, what do New Zealanders think about climate change? We take a look using our most recent data.

The average level of concern about climate change increased between 2013 and 2016. Supporters of all political parties, except NZ First, reported that they were more concerned about climate change in 2016 than they were three years earlier. Overall, in 2016, 47\% of New Zealanders strongly agreed that they were deeply concerned about climate change, with a further $44 \%$ somewhat agreeing.

At the same time, there was increasing support for government regulation of carbon emissions across political parties, particularly among NZ First party supporters and non-voters. Overall, in 2014, $47 \%$ of New Zealanders strongly supported government regulation of carbon emissions, with a further $46 \%$ somewhat supporting regulation.

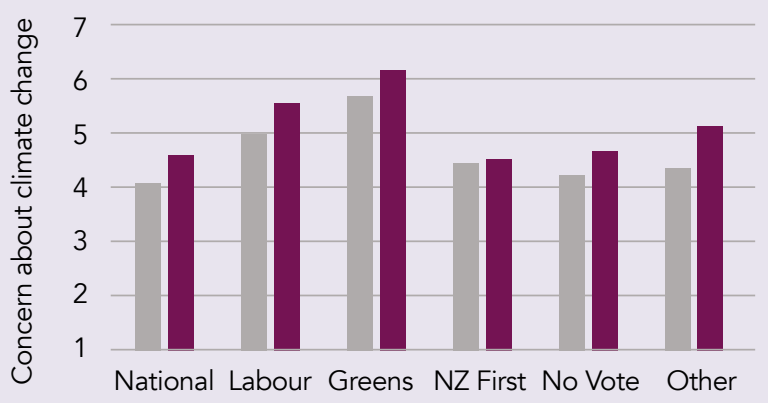

2013

2016

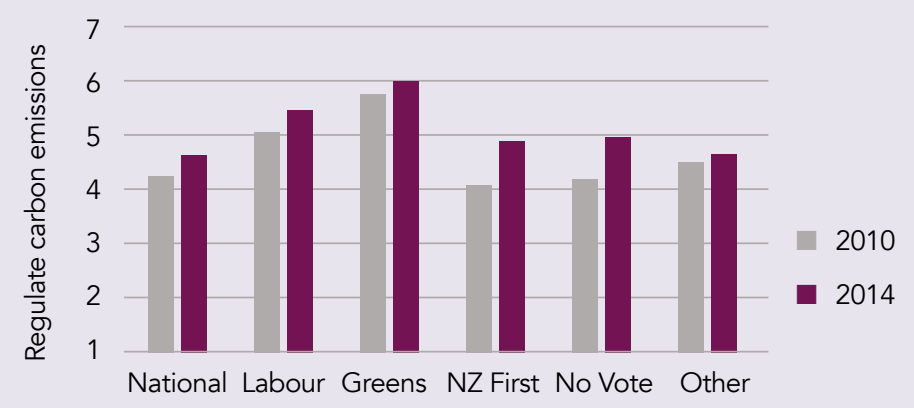

On a scale of 1 to $7,1-2$ was coded as disagreeing, $3-5$ as somewhat agreeing, and $6-7$ as strongly agreeing.

\section{Political leaders can change our opinions}

How much can our own attitudes be affected by our political leaders?

In 2015, then-leaders of National and Labour publicly expressed their personal opinions on whether the New Zealand flag should be changed, with John Key (National) arguing New Zealanders should choose a new, flag, and Andrew Little (Labour) arguing New Zealanders should keep the current flag. We measured public, support for changing the flag both before and after these opinions were published in the media.

Overall, $30.5 \%$ of National party supporters and $27.5 \%$ of Labour party supporters changed their original opinion to match their party leaders. This research provides a rare real-time example of politicians' influence on public opinion.

To learn more, read the article from the Association of Psychological Science.

(Research led by Nicole Satherley, PhD Student, University of Auckland.) 


\section{Who enrols on the Māori electoral roll?}

Every five years, if you are of Māori descent, you can choose whether to be on the Māori or the General Electoral Roll. In 2018, the percentage of Māori on the Māori electoral roll dropped from $55 \%$ to $52 \%$.

We investigated which factors influenced the decision to be on the Māori roll, and found that identity was more important than any other factor (e.g, age, education, living in urban or rural areas). Those who identified as solely Māori (versus those identifying as both Māori and Pākehā) were more likely to be on the Māori roll.

People were more likely to be on the roll if they reported seeing their Māori identity as important and positive, or believed that it is important to stand up for Māori rights.

Watch the video to find out more.

(Research led by Lara Greaves (Ngāti Kuri, Ngāpuhi), Lecturer, University of Auckland).

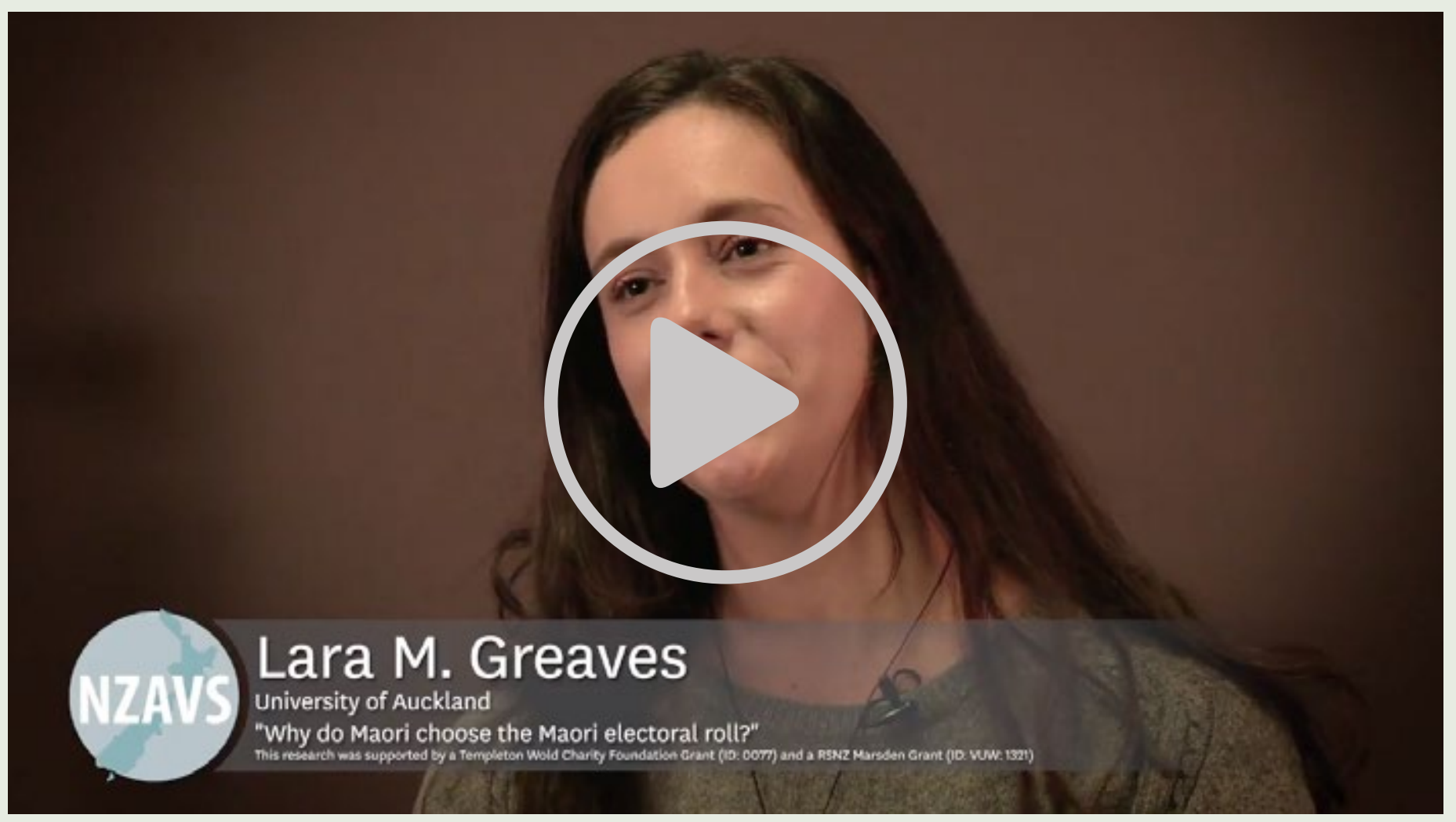

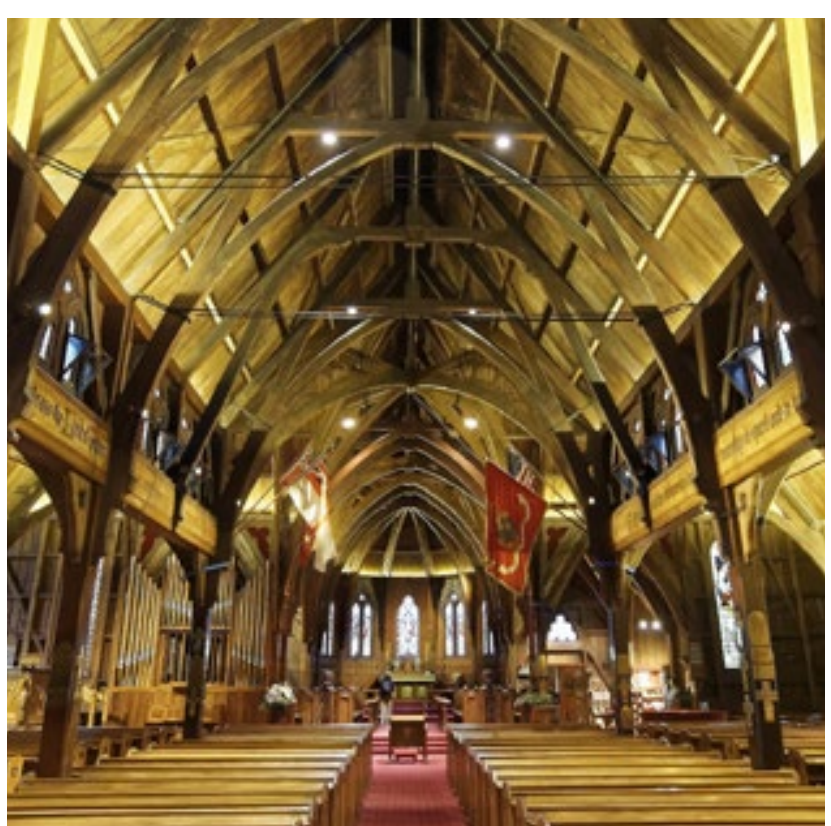

\section{Religious communities offer parenting support}

Today, in the age of nuclear families, parents receive less help from extended family and community structures than they did throughout human history. However, in this research, we found that not only do religious people have more children than secular people, religious people without children also spend more time looking after other people's children. In fact, religious people may have more children because of the extra childcare support available to religious people from their religious communities.

To find out more, read the press coverage in NewsNow and the Otago Daily Times.

(Research led by John Shaver, Senior Lecturer, University of Otago). 


\section{Women increasingly report frequent gender discrimination}

Over the past few years, women have increasingly reported that they feel they are "often discriminated against because of their gender".

Where $40 \%$ of women somewhat or strongly agreed they were discriminated against in $2014,45 \%$ of women agreed in 2016. This may reflect that discrimination itself is on the rise - but as we report in the research above, changing attitudes to gender equality may mean that women are more likely to recognise and report gender discrimination.

Men also report gender discrimination, but at lower rates, with $19 \%$ somewhat or strongly agreeing they are often discriminated against. Men's reported gender discrimination has not changed over time.

As we analyse questionnaires from 2017 and 2018 when movements such as \#MeToo were prominent, reports of gender discrimination may continue to increase.

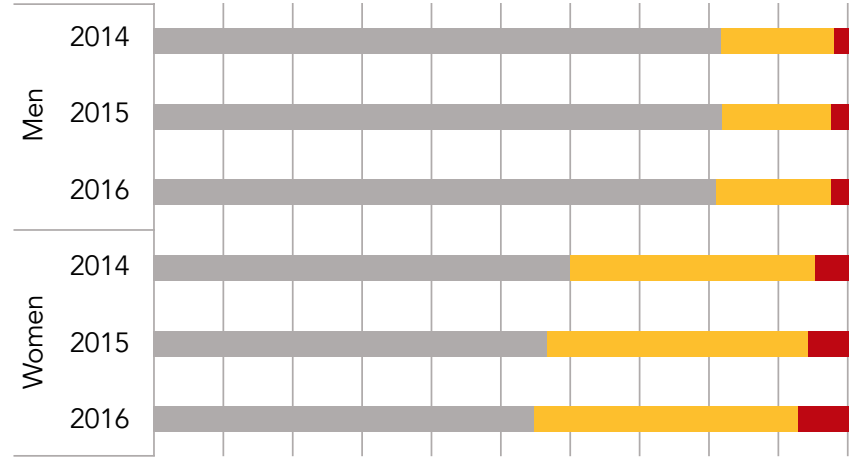

$\begin{array}{llllllllllllll}0 & 0 & 10 \% & 20 \% & 30 \% & 40 \% & 50 \% & 60 \% & 70 \% & 80 \% & 90 \% & 100 \%\end{array}$

On a scale of 1 to $7,1-2$ was coded as disagreeing, $3-5$ as somewhat agreeing, and $6-7$ as strongly agreeing.
Disagree
- Somewhat Agree
- Strongly Agree

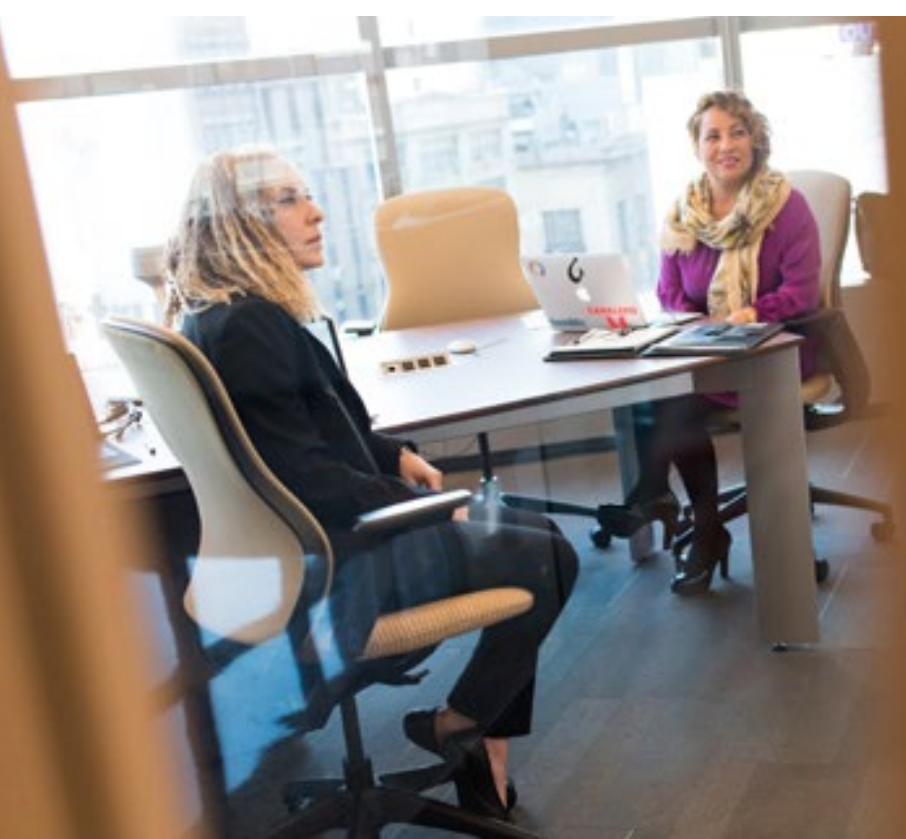

\section{Is support for gender equality increasing in New Zealand?}

In recent years, has sexism been decreasing? This research used seven years of NZAVS questionnaires to track changes in sexist attitudes over time, from 2009 to 2016.

We found that sexist attitudes were on the decline among both men and women. The decline was slow, but steady. This research indicates that sexist attitudes are capable of being changed, and have the potential to decline further over time.

(Research led by Yanshu Huang, PhD Student, University of Auckland) 


\section{How entitled are young New Zealanders?}

A common belief about younger generations such as millennials is that they are more narcissistic and entitled than older generations. In research published last year, we tracked changes in average entitlement from 2009 to 2014, and compared entitlement levels across the generations.

We found that entitlement was highest among young people, but decreased steadily as they aged. There was no evidence of entitlement increasing over time, and no evidence of generational differences in entitlement.

This research suggests that every generation follows the same process, where young people grow out of narcissism as they age, mature, and have more life experiences.

Watch the video to find out more, or read articles from the New Zealand Herald and BBC.

(Research led by Samantha Stronge, Research Fellow, University of Auckland)

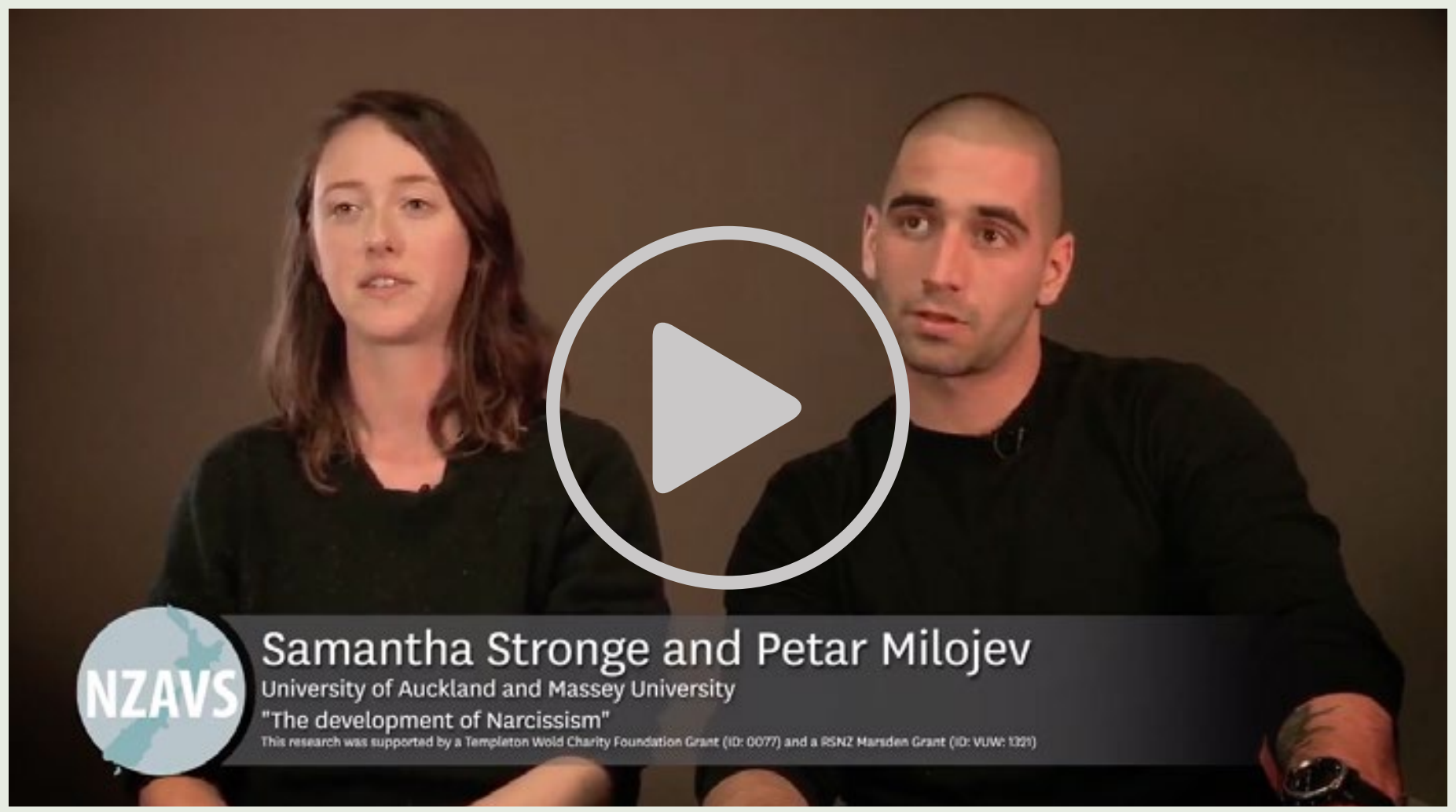

\section{Most New Zealanders have a pet}

We asked our participants about their animal companions in 2015, and found that $62 \%$ of people reported they had at least one pet, compared to $38 \%$ who had no pets.

Nearly twice as many New Zealanders are a 'cat person' than a 'dog person', with $29 \%$ reporting they had at least one cat (but no dogs), while $16 \%$ had at least one dog (but no cats). 14\% reported having both cats and dogs, while only $3 \%$ reported having a different kind of pet.
Do you have any pets?

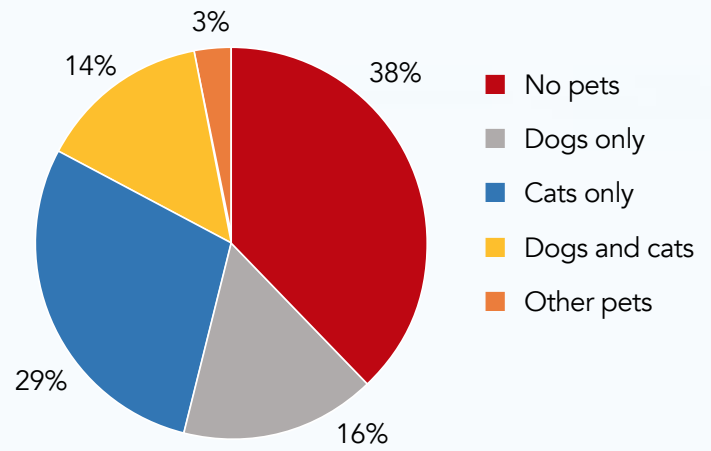




\section{A snapshot of hours spent on work, childcare and household chores by men and women in 2016: Women of all ages take on more childcare and chores}

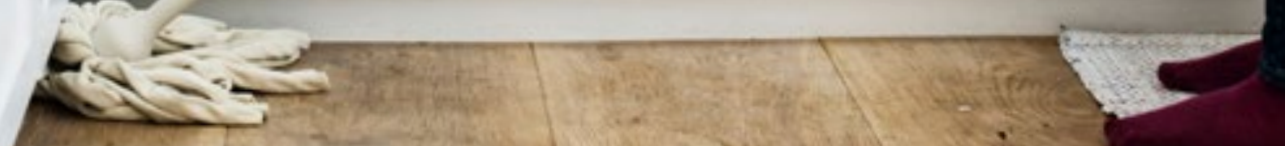

In 2016, our participants were asked about the number hours they had spent working, looking after children and doing housework during the previous week. We surveyed about 2,500 people aged $18-30$, almost 8,000 people aged 31 -50 , and over 11,000 people aged $51-64$. Men are more likely to report working at least 35 hours per week in paid employment. At the same time, among people aged $18-50$, women are more likely than men to spend at least 35 hours per week taking care of children, even if they are employed.

On average, women also spend more time than men on housework, even if they are employed.

Working in paid employment 35 or more hours per week

Women

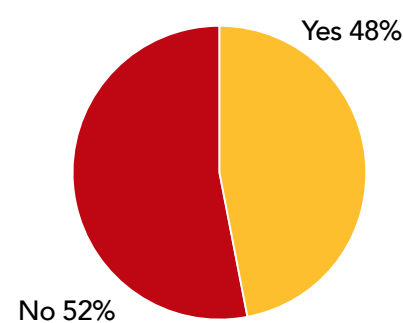

No $40 \%$

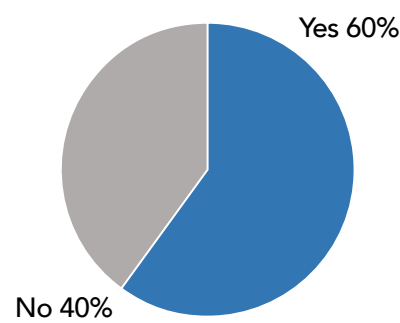

Aged $18-30, \mathrm{~N}=2,565(1,752 \mathrm{~W})$
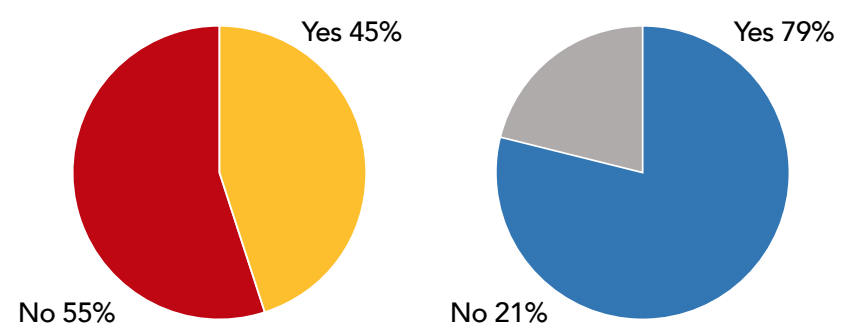

Aged $31-50, N=7,881(5,236 \mathrm{~W})$
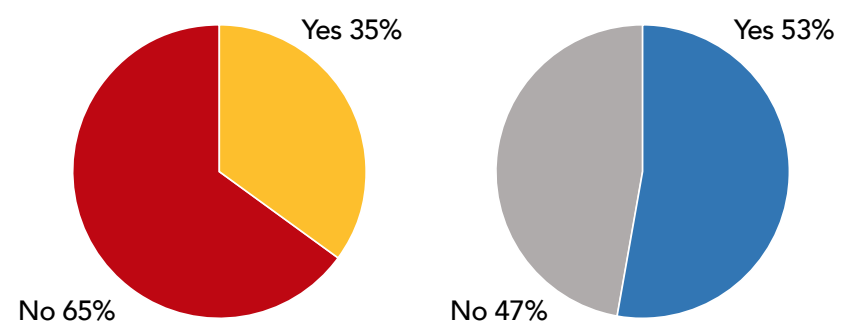

Aged $51-64, N=11,389(6,699 W)$

\section{Childcare 35 or more hours per week}

Women

Men
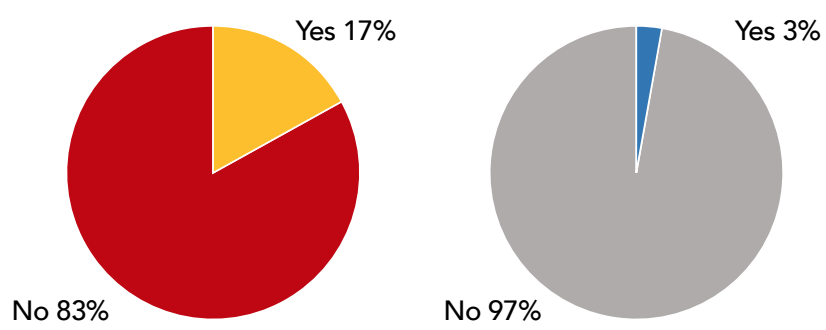

Aged $18-30, N=2,565(1,752 W)$
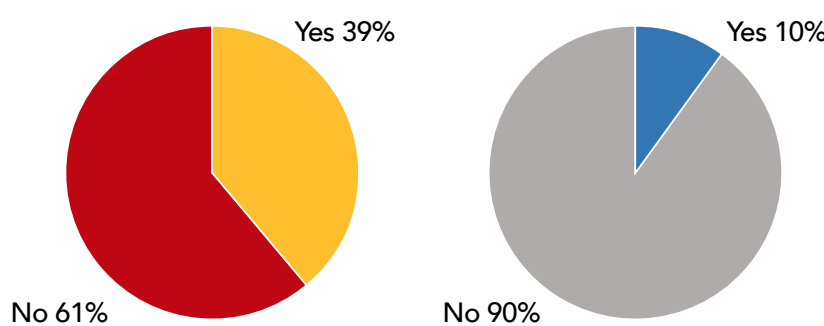

Aged $31-50, N=7,881(5,236 W)$
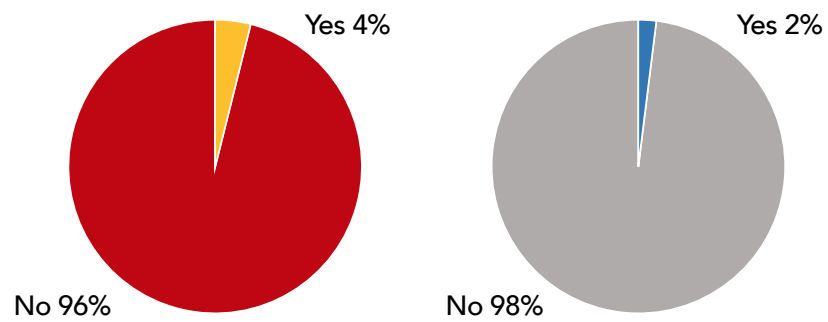

Aged $51-64, N=11,389(6,699 \mathrm{~W})$ 
Women

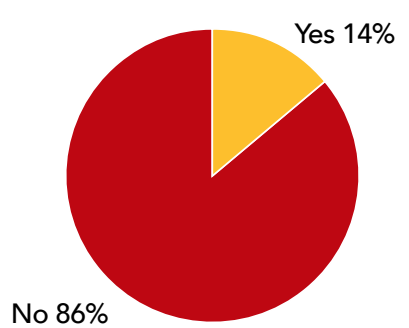

Employed. Aged $18-30, N=2,039$ (1,394 W)
Men

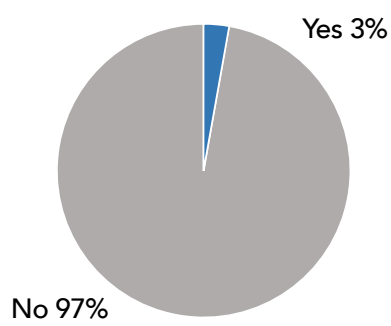

No $97 \%$
Women

Men
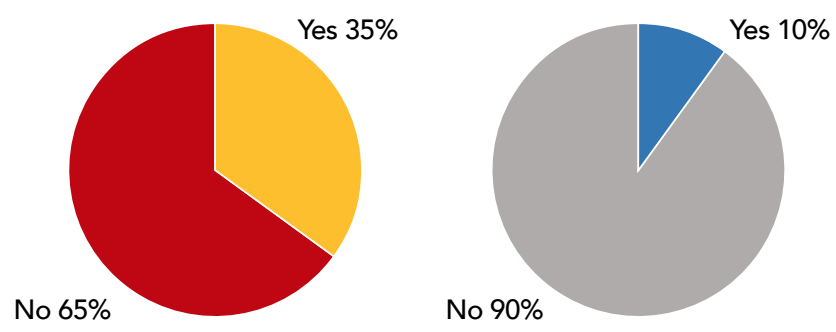

Employed. Aged 31 - 50, N = 6,868 (4,413 W)

Average number of hours per week spent on housework

Women | Men

\section{0}

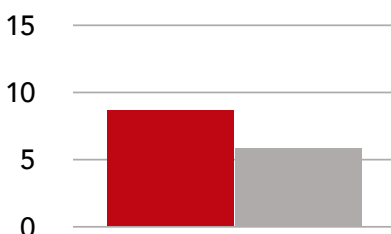

Aged $18-30$ $N=2,565(1,752 W)$

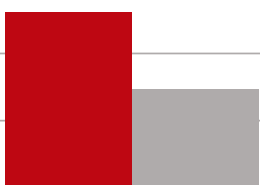

Aged $31-50$ $N=7,881(5,236 \mathrm{~W})$

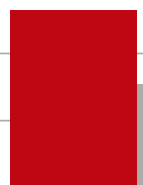

Aged $51-64$ $N=11,389(6,699 \mathrm{~W})$

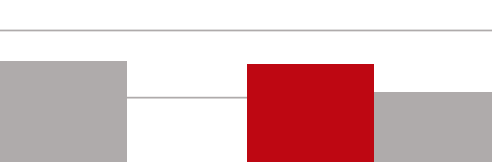

Employed. Aged 18 - 30 $\mathrm{N}=2,039(1,394 \mathrm{~W})$

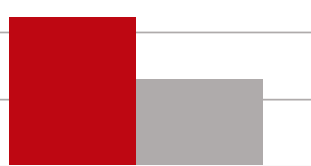

Employed. Aged 31 - 50 $\mathrm{N}=6,868(4,413 \mathrm{~W})$

\section{Health professionals are confident about the safety of childhood vaccines}

Childhood vaccination is a spectacularly successful global public health initiative that relies on high rates of vaccination. Yet, childhood vaccination is incorrectly perceived as unsafe and unnecessary by a growing number of parents around the world. Health professionals have a critical role to play in shaping parents' decisions around vaccination, and we investigated the extent to which different types of health professionals in New Zealand agree with the statement "it is safe to vaccinate children following the standard New Zealand immunisation schedule".
146 (95\%) of the 154 GPs and specialist doctors we surveyed rated their agreement as 6 or 7 out of 7 , meaning that they strongly agreed that vaccines are safe for children. This research was published in the New Zealand Medical Journal.

To find out more, read the article from the New Zealand Herald.

(Research led by Carol Lee, PhD Student, University of Auckland)

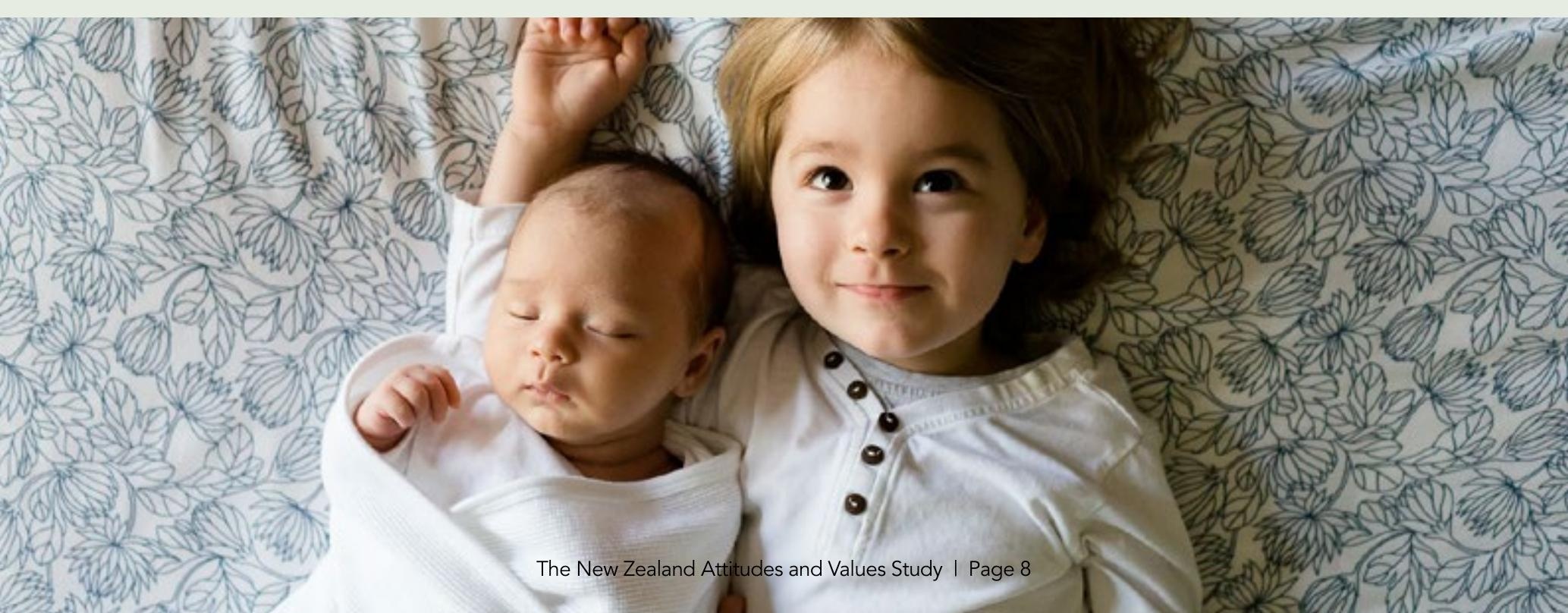




\section{New Zealanders overwhelmingly support women breastfeeding in public}

\section{Drawing on data from almost 20,000 people who completed our 2016/17 questionnaire, we found that most New Zealanders (75.3\%) support breastfeeding in public, whereas a small minority $(5.2 \%)$ are opposed and a further $19.5 \%$ are neutral on the issue.}

Women, parents, younger people, people in a relationship or married, and people with higher education were particularly likely to support public breastfeeding, but New Zealanders were generally positive towards public breastfeeding, regardless of where they sat demographically. Overall, these results suggest that New Zealanders are likely to rally behind any future health initiatives aimed at supporting women who choose to breastfeed in public.

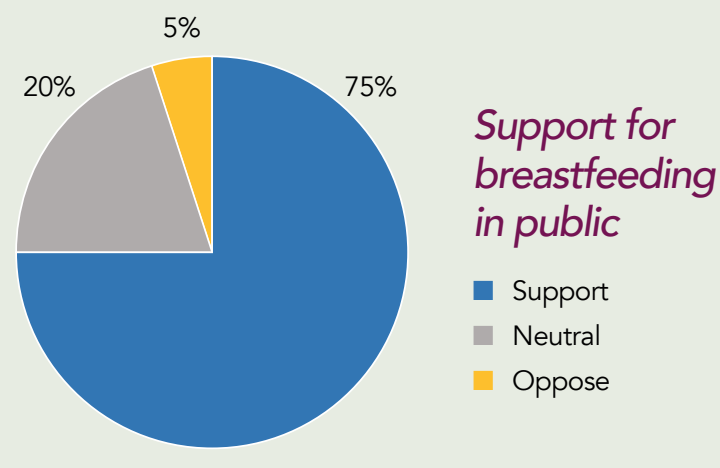

To find out more, read the article from Stuff.

(Research led by Yanshu Huang, PhD Student, University of Auckland)

\section{Cyberbullying}

We reported on rates of cyberbullying in

New Zealand in 2014, when we first asked about it in the NZAVS. Two years later, we find that the number of people who report that someone has ever "used the internet, a mobile phone, or digital camera to hurt, intimidate or embarrass" them is steadily increasing, for both men and women. Women are more likely to report they have been cyberbullied than men.

Younger people are still the most likely to have experienced cyberbullying, with $51 \%$ of $18-19$ year olds reporting they have been cyberbullied.

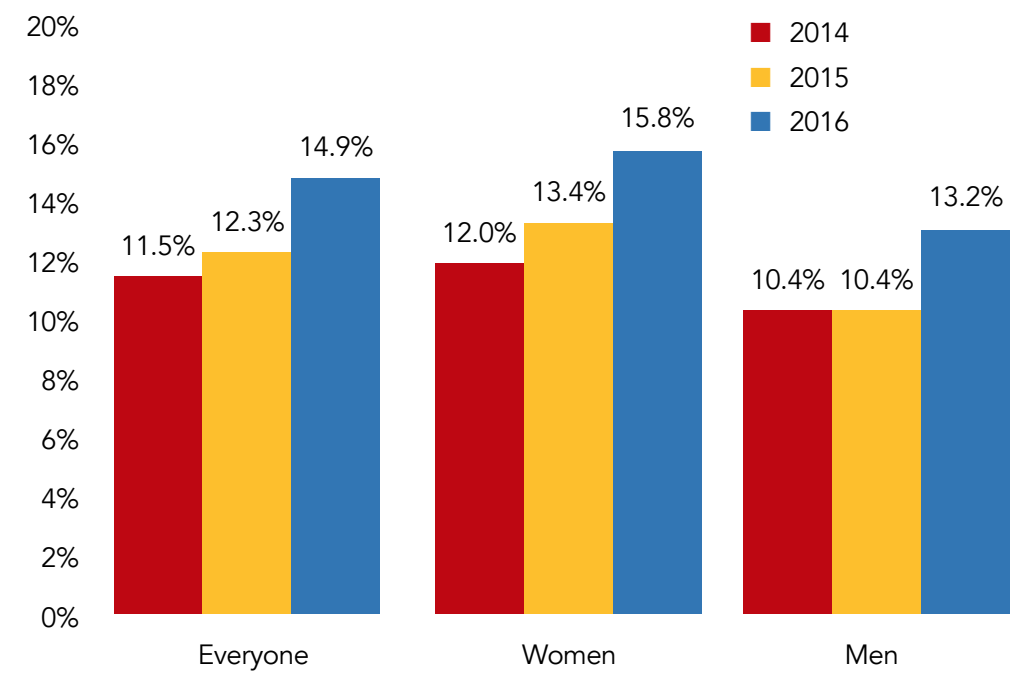

$60 \%$

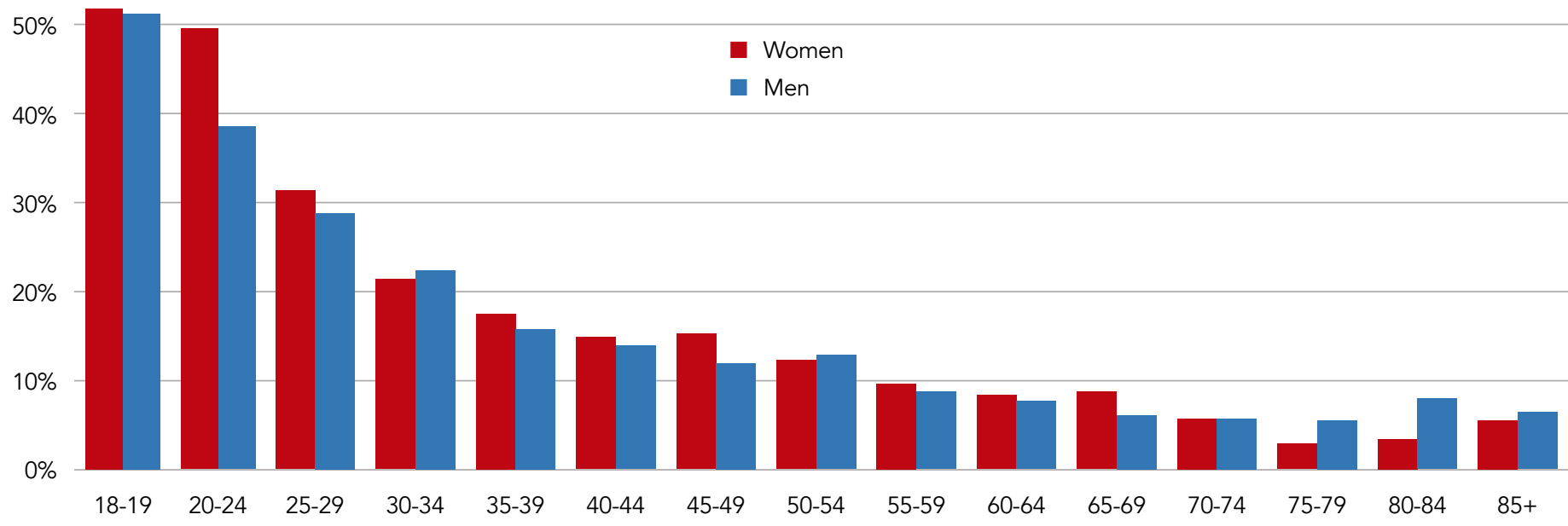




\section{A snapshot of hours spent on social media and computer gaming in 2016: Young women are more active on social media, but $80 \%$ don't play computer games}

When reporting on the number of hours in the preceding week that they had spent using social media (e.g.,

Facebook) and playing computer games, we can see that almost $50 \%$ of women aged $18-30$ and $25 \%$ of women aged 31 - 50 reported using social media for 7 hours or

Social media 7 or more hours per week

\section{Women}

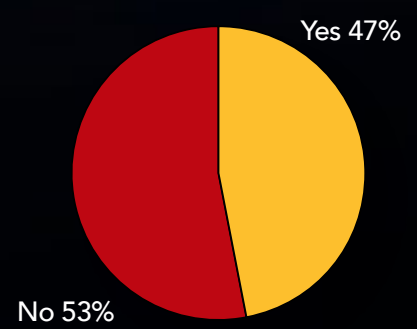

Aged $18-30, \mathrm{~N}=2,565(1,752 \mathrm{~W})$

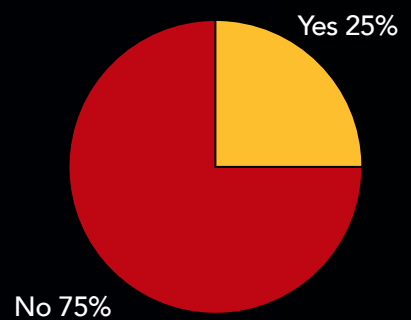

Aged $31-50, N=7,881(5,236 \mathrm{~W})$

No $84 \%$

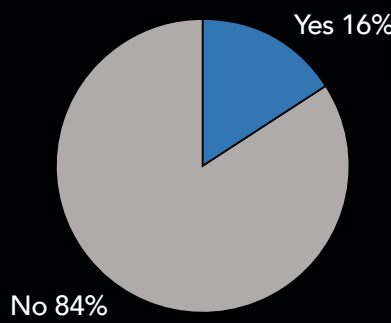

No $84 \%$

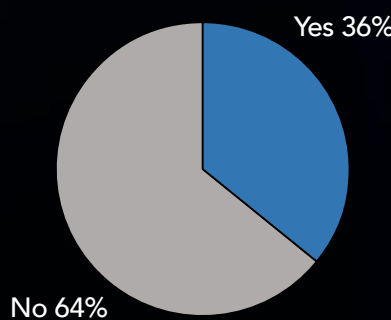

Men more per week - on average, one hour or more per day. Among men, these usage rates were reported by only a third of men aged $18-30$ and $16 \%$ of men aged 31 to 50 . When it came to computer gaming, $82 \%$ of women aged 18 - 30 did not play computer games.

Play computer games during the week

Women

Men

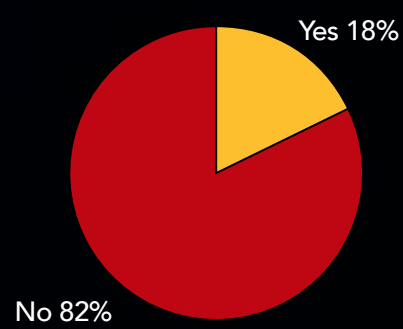

No $48 \%$

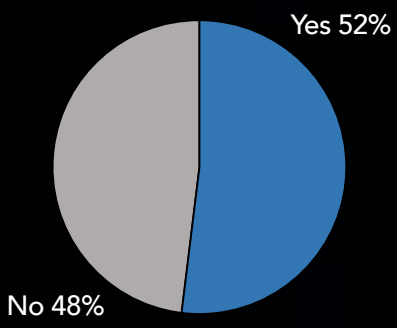

Aged $18-30, N=2,565(1,752 \mathrm{~W})$
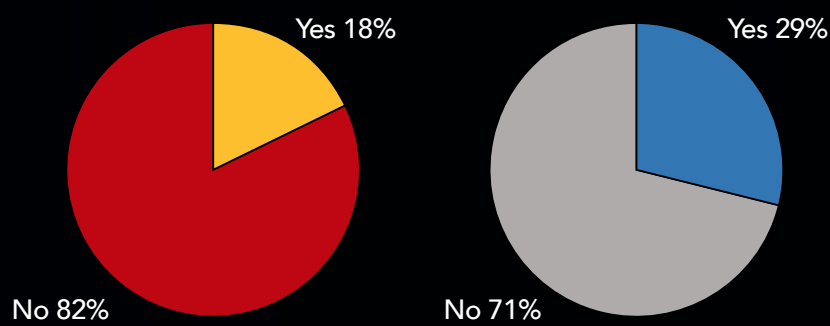

Aged $31-50, N=7,881(5,236 \mathrm{~W})$
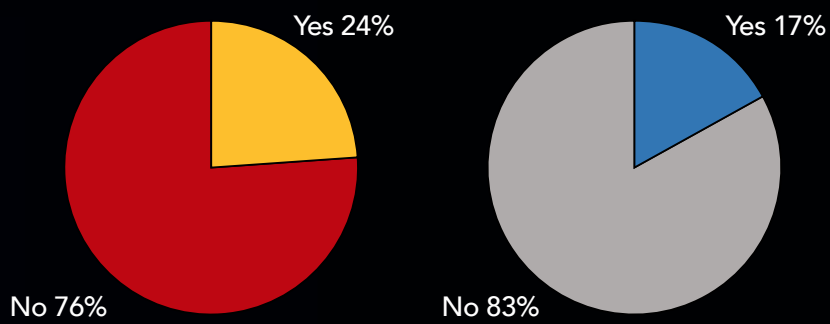

Aged $51-64, \mathrm{~N}=11,389(6,699 \mathrm{~W})$ 


\section{Ten percent of New Zealanders aren't getting enough sleep}

Sleep is necessary for our nervous system to work properly, and international guidelines recommend a minimum of 6 hours of sleep per night for adults.

Our data from 2016 shows that about 10 percent of New Zealanders sleep less than this minimum recommended amount. In the two left-hand graphs, responses to our question about sleep hours per night are broken down by age, since international guidelines for what constitutes potentially too much sleep are slightly different for young adults (aged 18-25). Rectangles are colourcoded based on international guidelines. The two right-hand graphs focus on people aged over 25 in 2016, and it shows that sleeping less than 6 hours is equally prevalent among men and women.
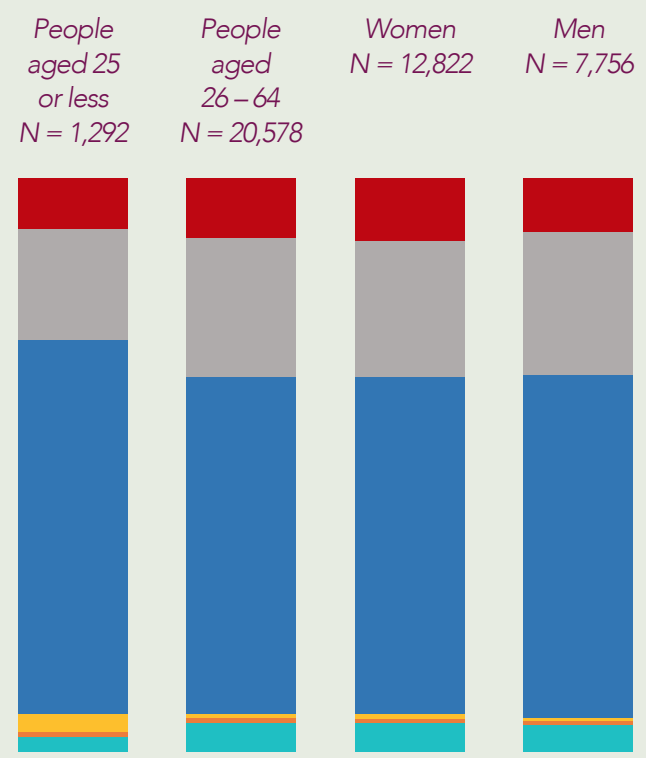

Sleep hours per night

- Too few: <6

- Few but maybe appropriate: 6 to 6.9

- As recommended: 7 to 9

- Many but maybe appropriate: 9.1 to 11 for young and to 10 for older

Too many: $>11$ for young, $>10$ for older

- Not reported

\section{Other Useful Links:}

Have you moved recently? Click here to update your contact details.

For more information about the study, please contact: Phone: 09-923-7498

Email: nzavs@auckland.ac.nz

Website: www.nzavs.auckland.ac.nz
Find us on social media:
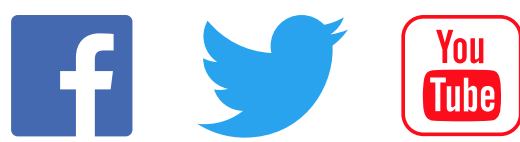



\section{THEPSYCHOLOGICAL IMPACTS OF LOCKDOWN}

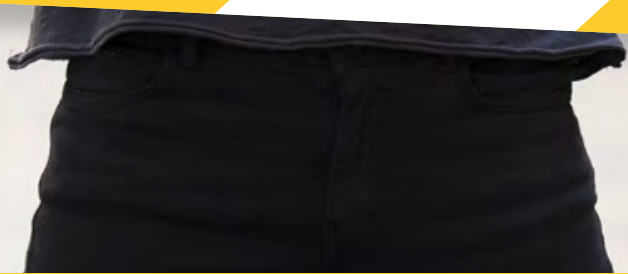

COVID-19 has brought about unprecedented change in the ways we live, work, and socialise. Early on in the Level 4 lockdown beginning in March 2020, NZAVS researchers worked to assess whether and how lockdown impacted our wellbeing and attitudes towards one another. Here is a summary of our results written and published during that first lockdown.

How can we measure the impact?

Thanks to participants filling in their questionnaires throughout lockdown, we have information on how people are doing during these unusual times. In the first 18 days of Level 4 lockdown, 1,003 participants completed their questionnaires. For comparison, we selected another 1,003 participants who completed their questionnaires before COVID-19 emerged. The participants in this 'pre-lockdown' group were carefully selected to match the 'lockdown group' by gender, age, ethnicity, health, parental status, religiosity, and so on. This means that when we compare these two groups, we can be sure that any differences we find are solely because of the effects of lockdown.

How do we feel about New Zealand?

We looked at two main areas: societal attitudes, and health and wellbeing. One concern about lockdown is that it would allow fear and misinformation to flourish. Instead, our results suggest that people are banding together. Our research found that people in lockdown felt more patriotic and were more satisfied with the government's performance than people pre-lockdown. Trust in politicians, the police, and science were also higher during lockdown. People in lockdown did not feel any less satisfied with the economy, healthcare, or social conditions. Finally, people in lockdown were more supportive of investing in reducing domestic violence. This suggests that New Zealanders are largely confident in the country's response to COVID-19 and are pulling together (rather than apart) while in lockdown.

How are Kiwis doing?

Another concern about lockdown is that mental health will be significantly impacted. However, our results suggest that not much has changed, at least in the short-term. 
No changes were detected in rumination (repeated negative thoughts), belongingness (feeling connected to others), or social support (having people you can depend on). There was no change in how satisfied people were with their life, standard of living, future security, personal relationships, or health. In fact, participants who were in lockdown actually reported they felt less fatigued than participants pre-lockdown. People also felt a greater sense of community in their neighbourhoods while in lockdown. These feelings of community, patriotism, and trust in the government may be helping to maintain wellbeing despite the great restrictions New Zealanders are facing.

While most indicators of wellbeing stayed the same or improved, there was some evidence of poorer mental health. Psychological distress measures how often people report feeling signs and symptoms of poor mental health. The amount of people who reported feeling some anxious or depressive symptoms increased from $16 \%$ pre-lockdown to $21 \%$ during lockdown.

\section{Where to from here?}

In sum, the general picture was one of resilience.

New Zealanders feel close to their communities and trust their politicians, scientists, and country. Health and wellbeing remain largely the same in the first weeks of lockdown, although mental distress has risen a little.

It remains to be seen whether this resilience will continue on through the weeks to come. Some things may change long-term rather than short-term, such as dissatisfaction with the economy. The NZAVS will continue to track the changing psychological impact of the lockdown measures, with the aim of detecting early warning signs of declining wellbeing so that appropriate measures can be taken.

This research was led by Professor Chris Sibley and was published in American Psychologist.
These graphs represent what has changed during lockdown. We measured

many other types of satisfaction with New Zealand society that did not change.
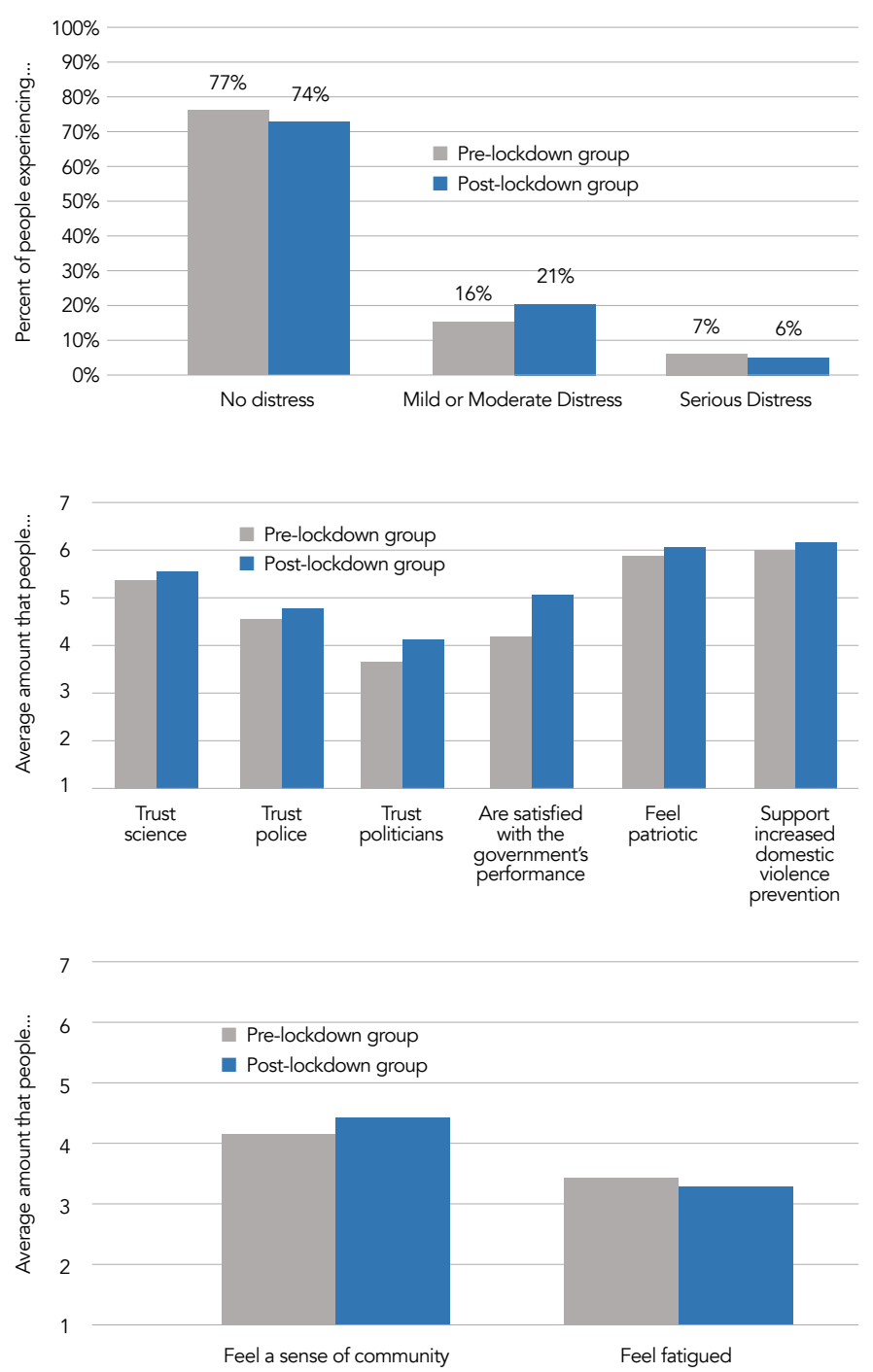

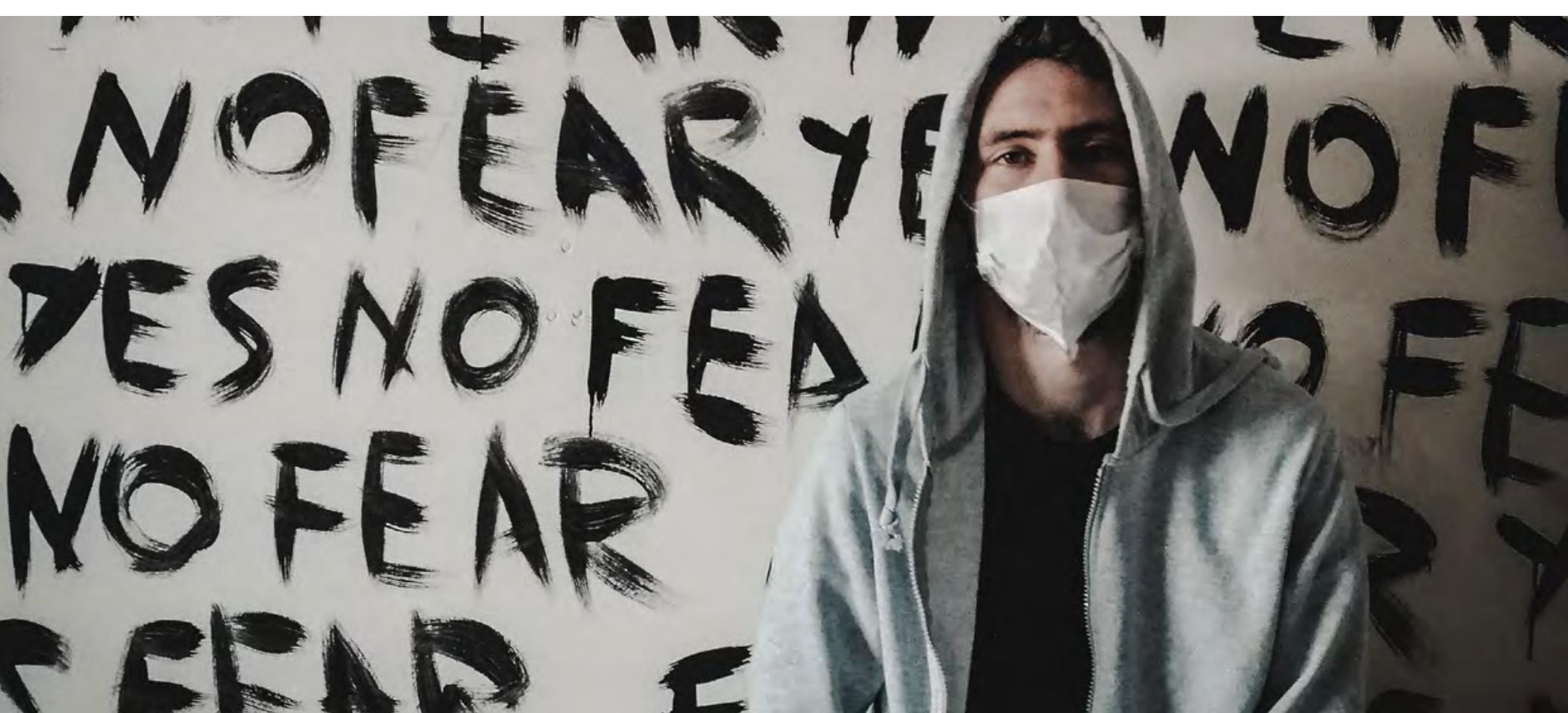




\section{Social connectedness and mental health}

While people with poor mental health generally feel less connected than others, one difficult-to-answer question about mental health is which comes first. Is it that people who feel disconnected from others then see their mental health suffer? Or does having poor mental health make it harder to maintain relationships?

Recent research used four waves of NZAVS data to track the direction of this association. Social connectedness was measured by asking whether participants felt accepted and valued by those around them. Results showed that feeling connected to others more strongly predicted better mental health than the reverse. These results show the importance of social relationships for psychological health, and support policy that facilitates engaging and connecting with others.

This research was led by Research Fellow Alexander Saeri and was published in the Australian and New Zealand Journal of Psychiatry.

Read our piece in the Conversation for more.

\section{Who is affected by cyberbullying?}

Cyberbullying is well-known to be a growing issue among children and teens. However, new NZAVS research has found that cyberbullying affects a significant portion of adults as well.

Participants were asked if they had ever been cyberbullied. Young adults and teens reported the highest rates of cyberbullying, but significant portions of older adults also reported they had been cyberbullied. Women were more likely to report cyberbullying than men, and Māori and Pasifika peoples were more likely to report cyberbullying than Asian peoples or Pākehā. Similar patterns were found when participants were asked whether they had been cyberbullied within the last month, although rates were much lower. These results highlight the spreading problem of cyberbullying across all ages in an increasingly connected society.

This research was led by PhD student Meng-Jie Wang and was published in Cyberpsychology, Behaviour, and Social Networking.

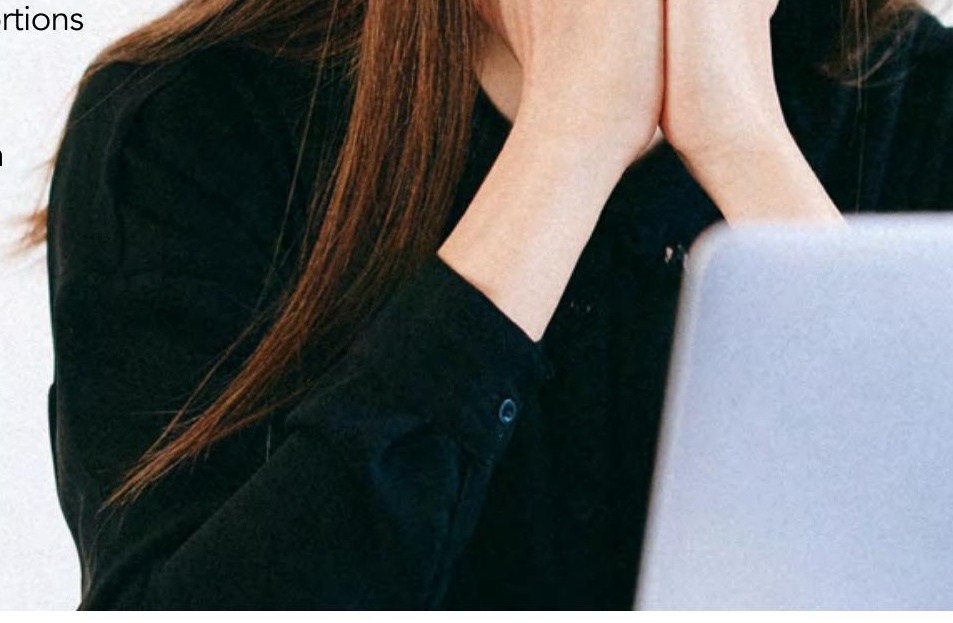

Who is affected by cyberbullying?

$100 \%$ 


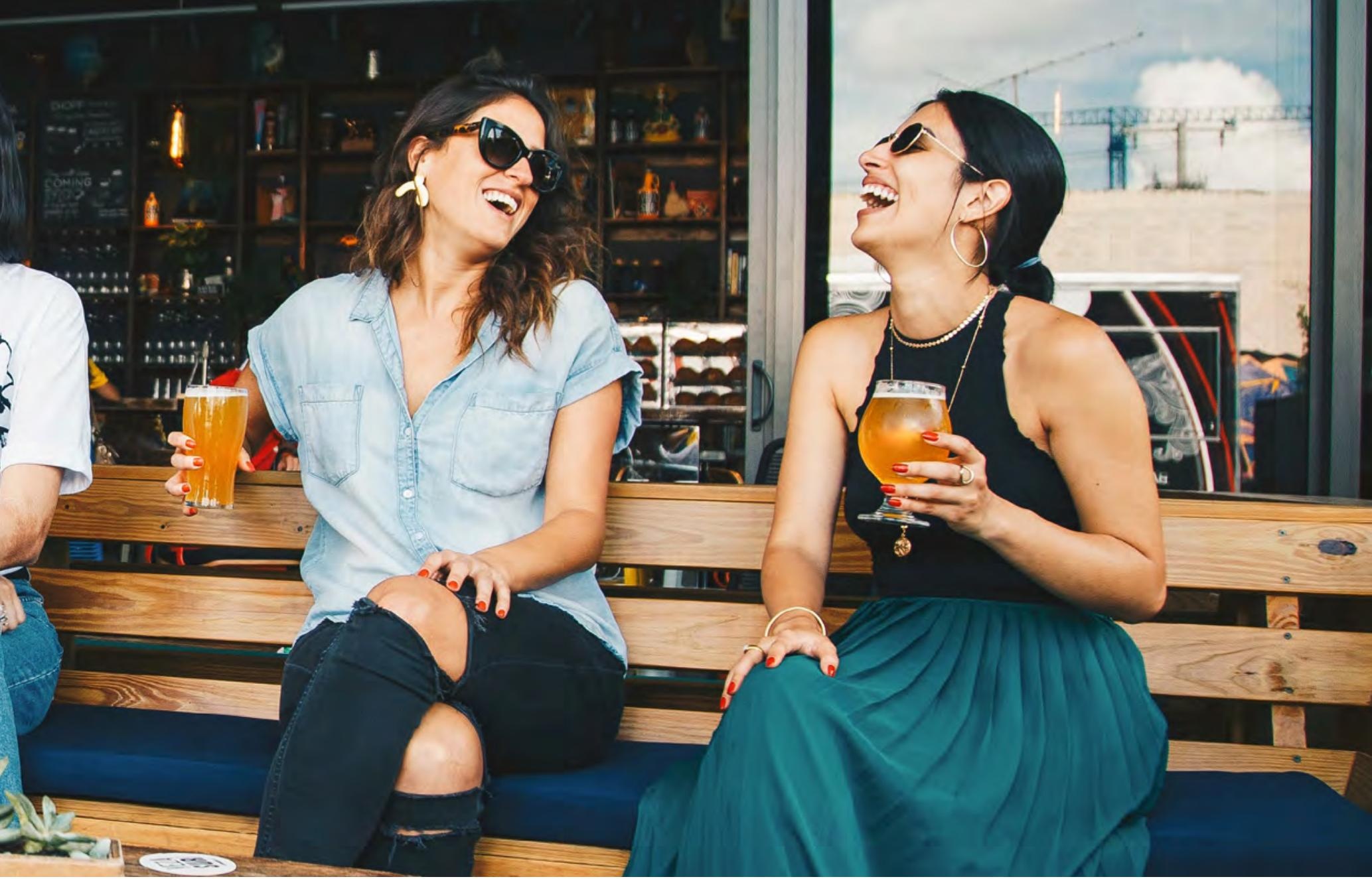

\section{Social support in relationships for men and women}

Previous research has found that men tend to be happier and healthier when they are in a relationship than when they are single. For women, whether or not they are in a relationship doesn't matter as much for their wellbeing.

One theory about why this happens is that women are more likely to get social support from their friends, whereas men may get most of their social support from a romantic partner. This theory was tested for the first time in recent NZAVS research.

Social support was measured by asking participants whether they have someone they can depend on when they need it, and who they can turn to in times of stress. For men, compared to women, social support was more strongly tied to whether or not they were in a relationship.

This difference in social support then had knock-on effects to men's self-esteem and life satisfaction. Among single people, men had lower wellbeing than women, but among people in a relationship, men had the same or higher wellbeing than women. These differences were small, indicating there may be more explanations to research in
Wellbeing in relationships

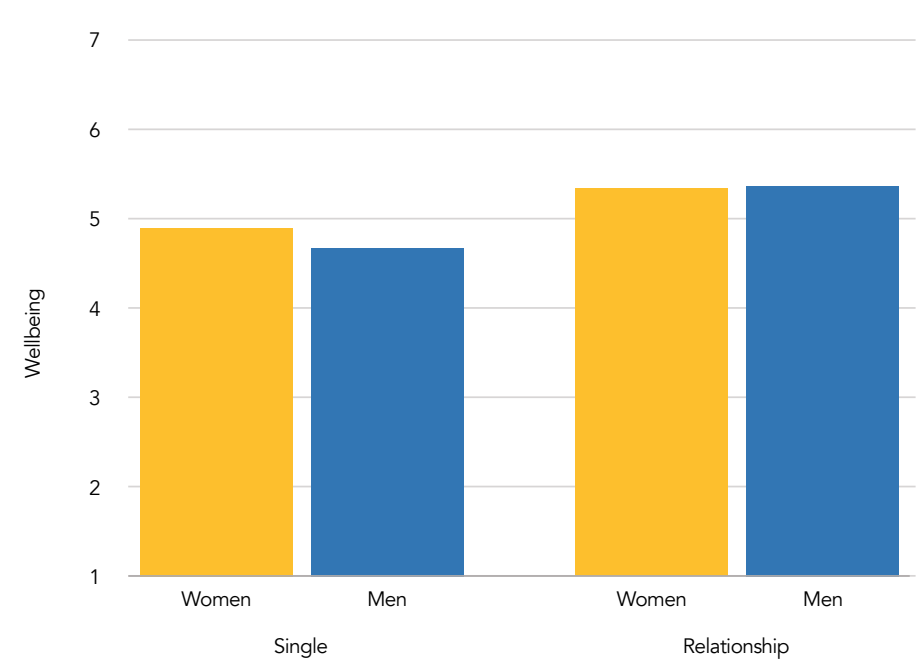

the future. However, they highlight the importance of a supportive social network outside of a romantic partner.

This research was led by Research Fellow Samantha Stronge and was published in the Journal of Family Psychology. 


\section{changisis Inclimate change}

\section{As climate change is more and more a topic of conversation, how have New Zealanders' beliefs changed?}

Recent research used six years of NZAVS data from 2009 to 2015 to measure how much more (or less) our participants agreed that 'climate change is real' and 'climate change is caused by humans'.

Results showed that across 2009 to 2012, there was little change, but in more recent years, people are more and more likely to believe in climate change and believe it is caused by humans. The two beliefs were also correlated; the more people increased their belief in climate change over time, the more their belief that climate change is caused by humans also increased over time (and vice-versa).

This research, led by Associate Professor Taciano Milfont, is the first study that tracks the same people and shows their beliefs changing. While a small percentage of people $(2 \%)$ disagree that climate change is real, with a further
$6 \%$ doubtful, most people increasingly believe in climate change. These findings show that the national (and global) conversation about climate change is having a real impact on New Zealanders' attitudes.

This research was published in PloS ONE.

\section{Changing belief in climate change}

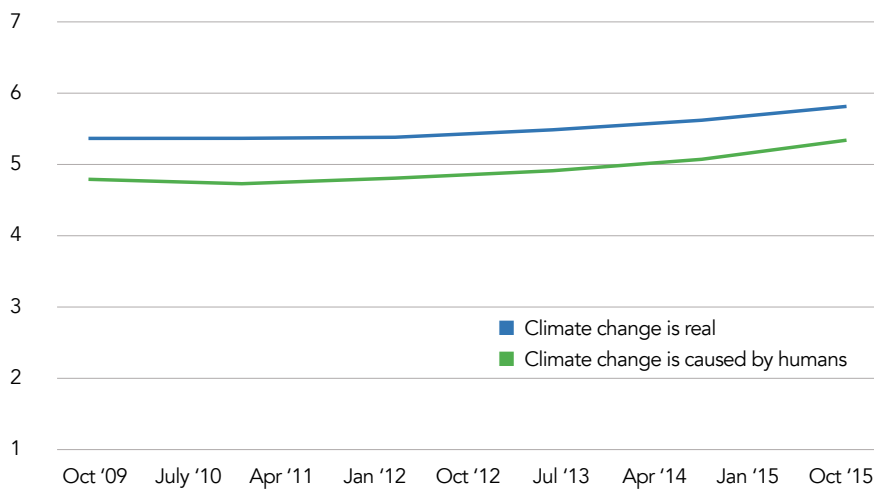

\section{OUR PETS AND US}

\section{What difference do pets make to our lives?}

New research led by PhD student Gloria Fraser found very few differences between pet owners and non-owners in terms of health and wellbeing. Pet owners had personalities that were more tolerant of mess and more open to new experiences than non-owners. Pet owners also felt a greater sense of community than non-owners.

However, pet owners were also more likely to report they had been diagnosed with anxiety and depression than people who did not have pets, with cat owners in particular more likely to report an anxiety diagnosis.

Does this mean pets are bad for us? Not necessarily! It may be that people who have anxiety and depression are more likely to get an animal companion to help them cope. To test this question thoroughly, the NZAVS is currently collecting more longitudinal data so that we can explore the mental health of pet owners and non-owners over time.

This research will be published in Anthrozoös. 


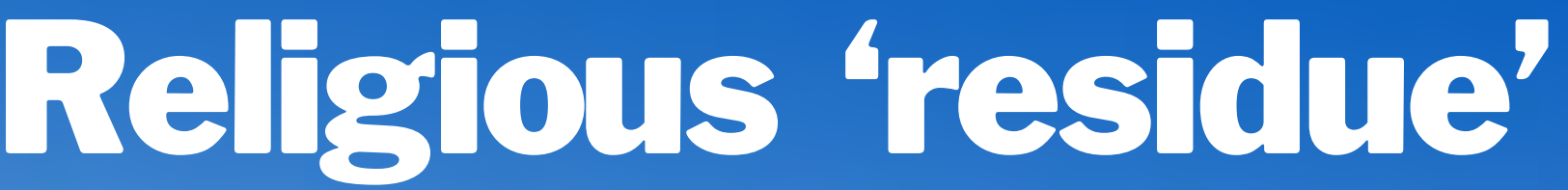

There are many different ways to be religious, but are there different ways to be non-religious? Researchers have previously distinguished between religious 'nones', who have never identified as religious, and religious 'dones', who were religious in the past but are now non-religious. One theory is that religious 'dones' may keep some of their behaviours from when they were religious.

Recent research using the NZAVS, published in the Journal of Personality and Social Psychology, has tested this theory for the first time. Among NZAVS participants, religious 'dones' were substantially more likely to do volunteer and charity work than were religious 'nones', and more likely to continue volunteering over the years than religious 'nones'.
This finding supports cross-sectional research from participants in Hong Kong and the Netherlands that relied on participants memories. This research suggests that religious affiliation and volunteering behaviours are jointly reinforcing traits.

This research was led by Associate Professor Daryl Van Tongeren.
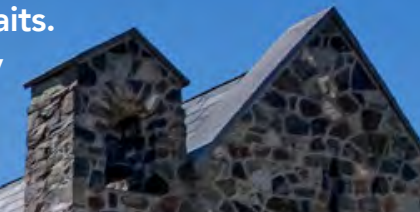

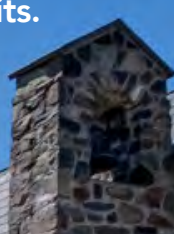


Is social media bad for our mental health?

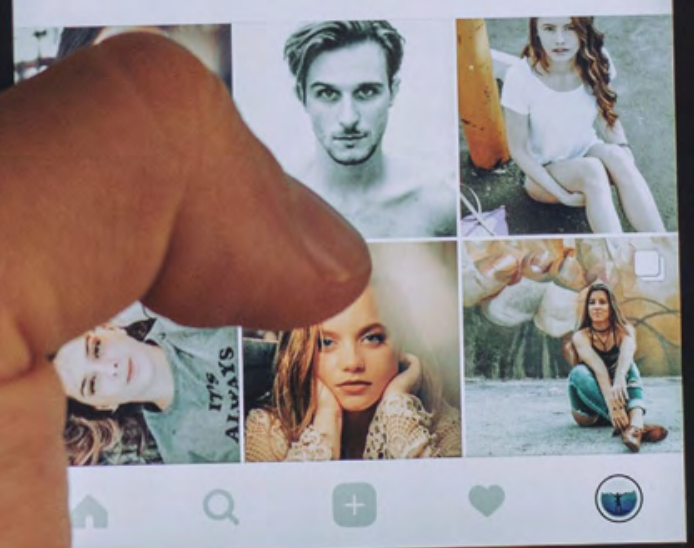

\section{An ongoing concern about social media is that it might be making mental health worse.}

Recent NZAVS research investigated whether spending more hours using social media is associated with psychological distress - signs and symptoms of poor mental health. This research also compared how much of an impact time spent on social media has on mental health compared to time spent sleeping, exercising, playing video games, doing housework, working, and so on.

The results showed that while social media use was associated with psychological distress, the effect was very small. On average, accounting for demographic factors such as gender, age, and ethnicity, someone would have to use social media literally 24/7 to see large changes in their mental health. Of course, some individuals may still find their social media use makes them unhappy.

What this research suggests is that social media is unlikely to be driving a societal wide mental health crisis. This research was led by Research Fellow Samantha Stronge and is published in Cyberpsychology, Behaviour, and Social Networking.

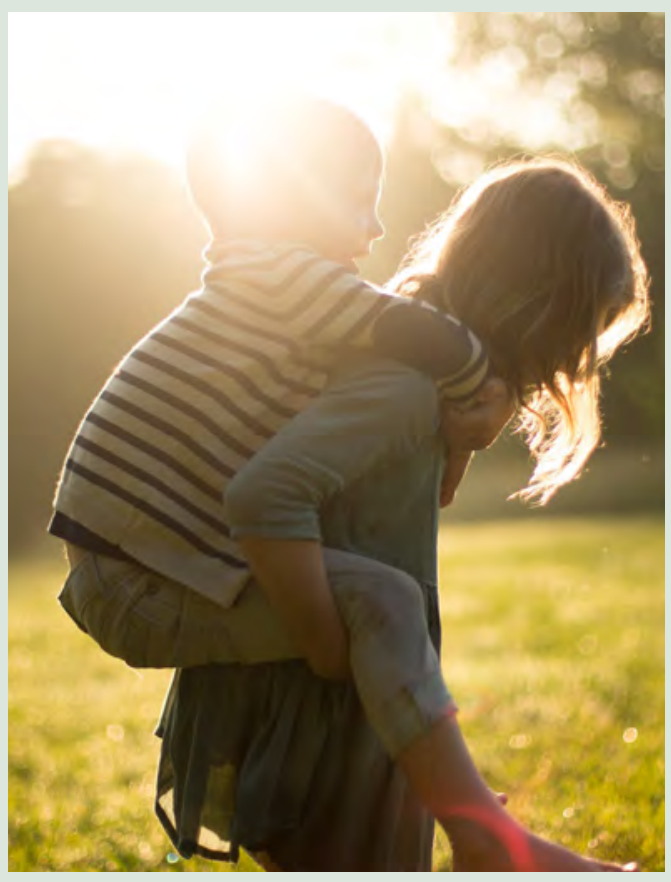

\section{What difference do siblings make?}

We've all heard of "Only Child Syndrome" - the popular idea that only-children are more selfish and narcissistic than people who grew up with siblings. But is there any truth to this?

Recent research led by Research Fellow Samantha Stronge tested for personality differences between adults who had siblings and adults who didn't. Very few differences in personality were found. Only children were found to be slightly less humble, less hardworking, and more emotional, and slightly more open to new experiences. However, the size of these personality differences was very, very small. While these differences can be detected statistically, they suggest that in real life only children behave no differently to others. As more and more people choose to have one-child families, these results suggest the "only child" persona is mostly a myth.

This research was published in the Journal of Research in Personality.
Other Useful Links:

Have you moved recently? Click here to update your contact details.

For more information about the study, please contact: Phone: 09-923-7498

Email: nzavs@auckland.ac.nz

Website: www.nzavs.auckland.ac.nz
Find us on social media:

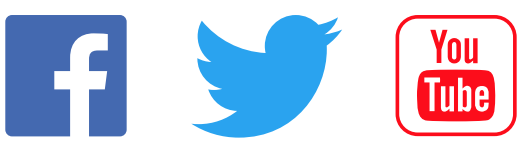




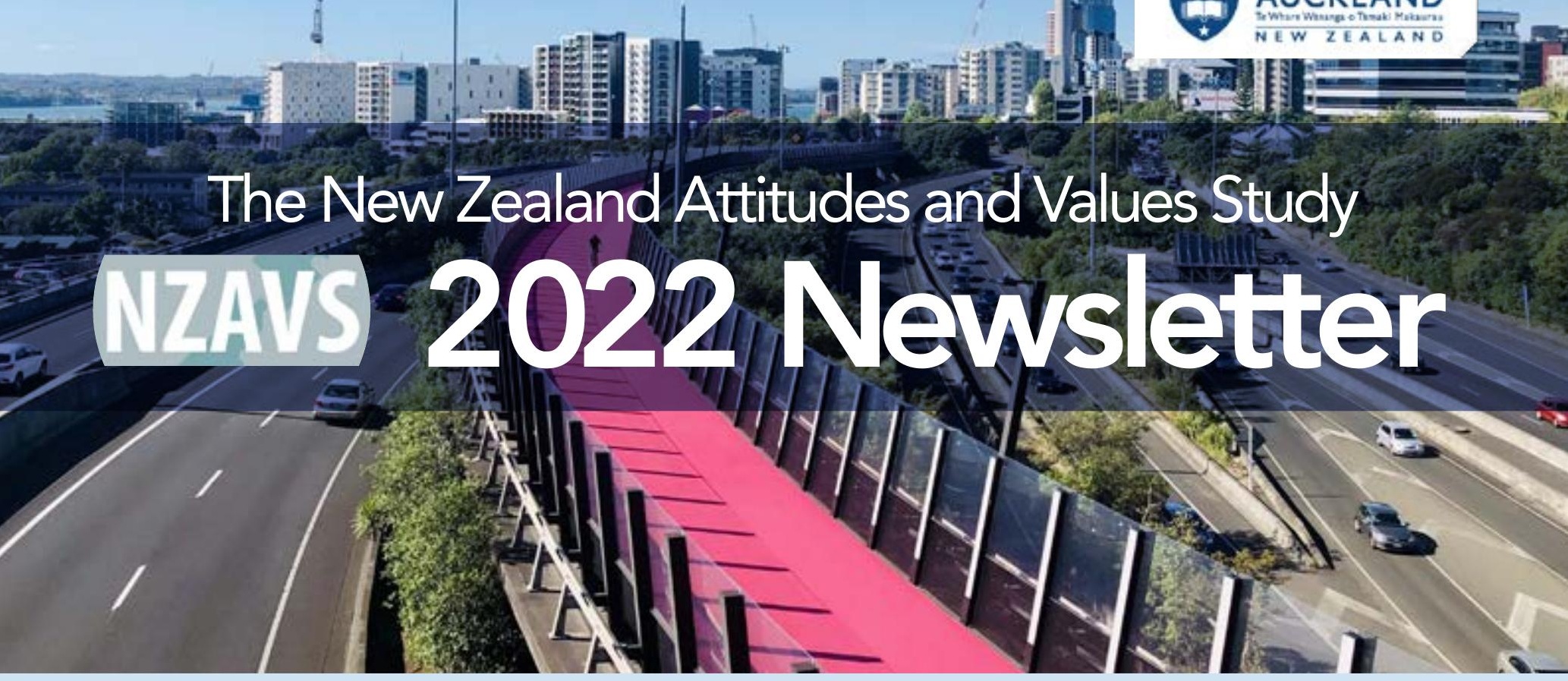

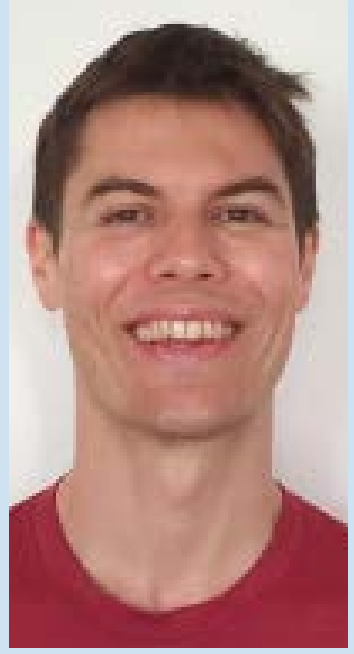

Professor Chris Sibley

Dear NZAVS Participant,

My name is Chris Sibley, and I am the Lead Investigator for the New Zealand Attitudes and Values Study (or NZAVS). On behalf of the NZAVS research team and myself, I would like to thank you for your continued participation in the study. Your responses are very important, and have already helped to answer a number of research questions about significant issues facing New Zealand. We would also like to send our congratulations to the winners of our most recent prize draw.

This newsletter summarises some of the latest findings from the NZAVS.

As a participant in the study, you have directly helped in making this research possible. This newsletter provides a snapshot of some of the great work that comes out of the NZAVS each year.

Thanks again for taking part in the study.

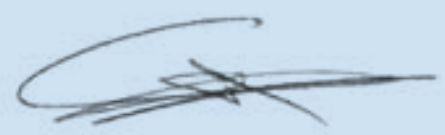

Sincerely,

Professor Chris Sibley

School of Psychology

University of Auckland

Email: nzavs@auckland.ac.nz

Phone: 09-923-7498

\section{Other Useful Links:}

Have you moved recently? Click here to update your contact details. Click here to look at our Frequently Asked Questions page.

Click here to see the official NZAVS website.

Click here to see our full list of publications.
Find us on social media:
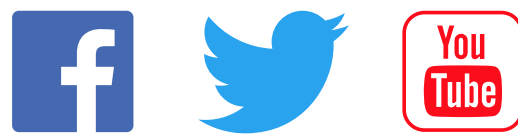


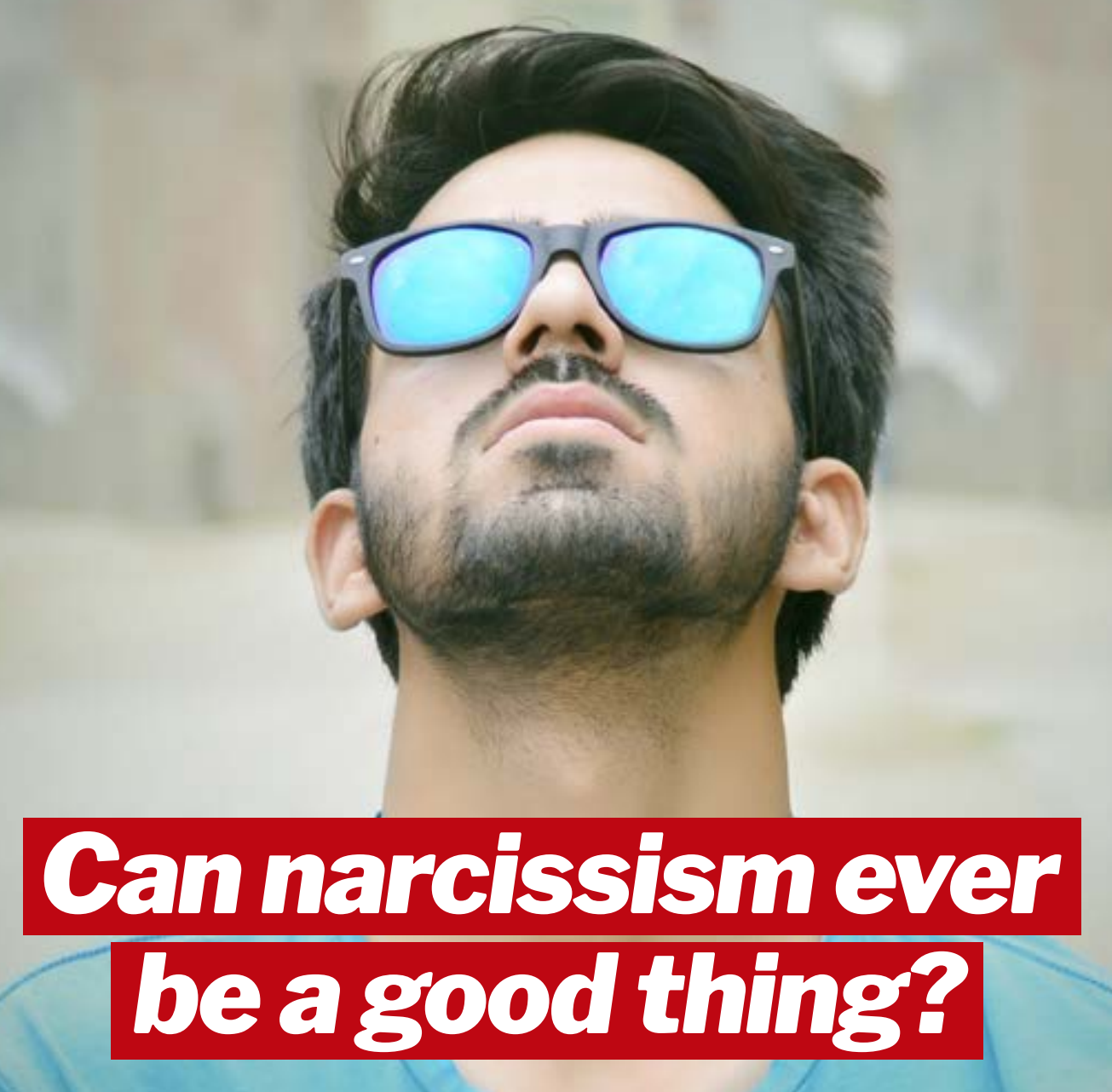

The he narcissism of young people is a favourite topic across the ages, from Plato to Mike Hosking. Indeed, studies show that young people are more narcissistic than older people on average.

Scientific theories about personality traits propose that if we have a personality trait, it is because it is useful to us in some way - we didn't evolve personality traits for nothing! This raises an intriguing question - is narcissism useful to us in some way when we are young?

In this research using NZAVS data from 2018, we looked at psychological entitlement (defined as a belief that you always deserve more than others) which typically has a very negative impact on a person's wellbeing and ability to maintain relationships.

Results showed that at every age, entitlement was linked with lower self-esteem, less satisfaction with life, and having less supportive people in life who you can depend on. However, the younger a person was, the weaker this link was. For example, the difference in self-esteem levels between an entitled 18-year-old and a non-entitled 18 -year-old was $1 \%$. But if you compared entitled and non-entitled 80 -year-olds, the entitled person would score $10 \%$ lower in self-esteem.

Why might this be? There are several theories to investigate further. Perhaps we don't judge young people for being entitled when they're still learning how to behave as an adult, while we judge older adults more harshly. Or maybe a little bit of entitlement is useful when we're navigating all the challenges of adulthood for the very first time - breakups, job interviews, and first mistakes in the workplace. Whatever the reason, the effect doesn't last forever!
This research was led by Dr. Samantha Stronge and was published in the Journal of Research in Personality.

This graph shows the average level of self-esteem at different ages. In blue, we see self-esteem levels for people who were less entitled than the average person, while in yellow, we see self-esteem levels for people who were more entitled than the average person. For under 25's, there is not much difference in self-esteem between the two different personalities, but the impact of entitlement grows with age. Similar results were found for life satisfaction and social support. These results are based on 47,487 people in 2018.

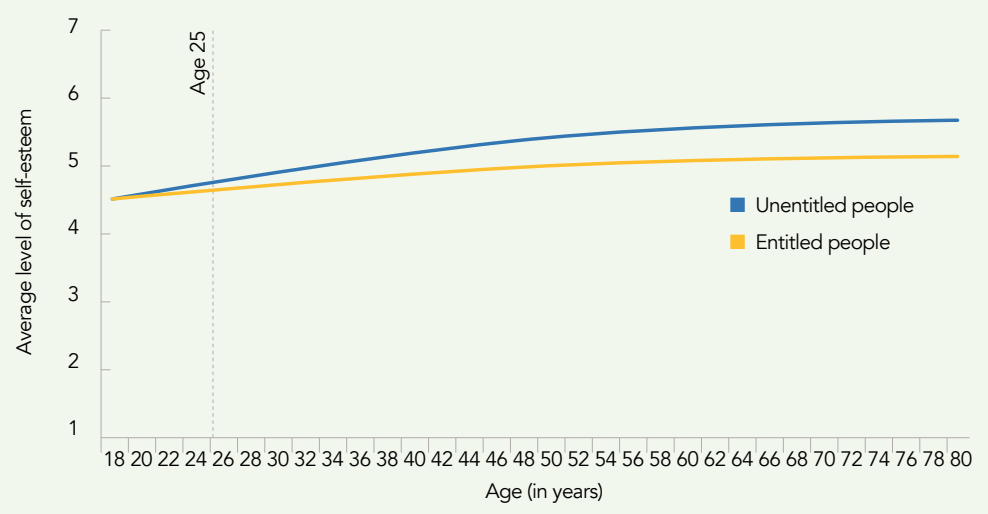




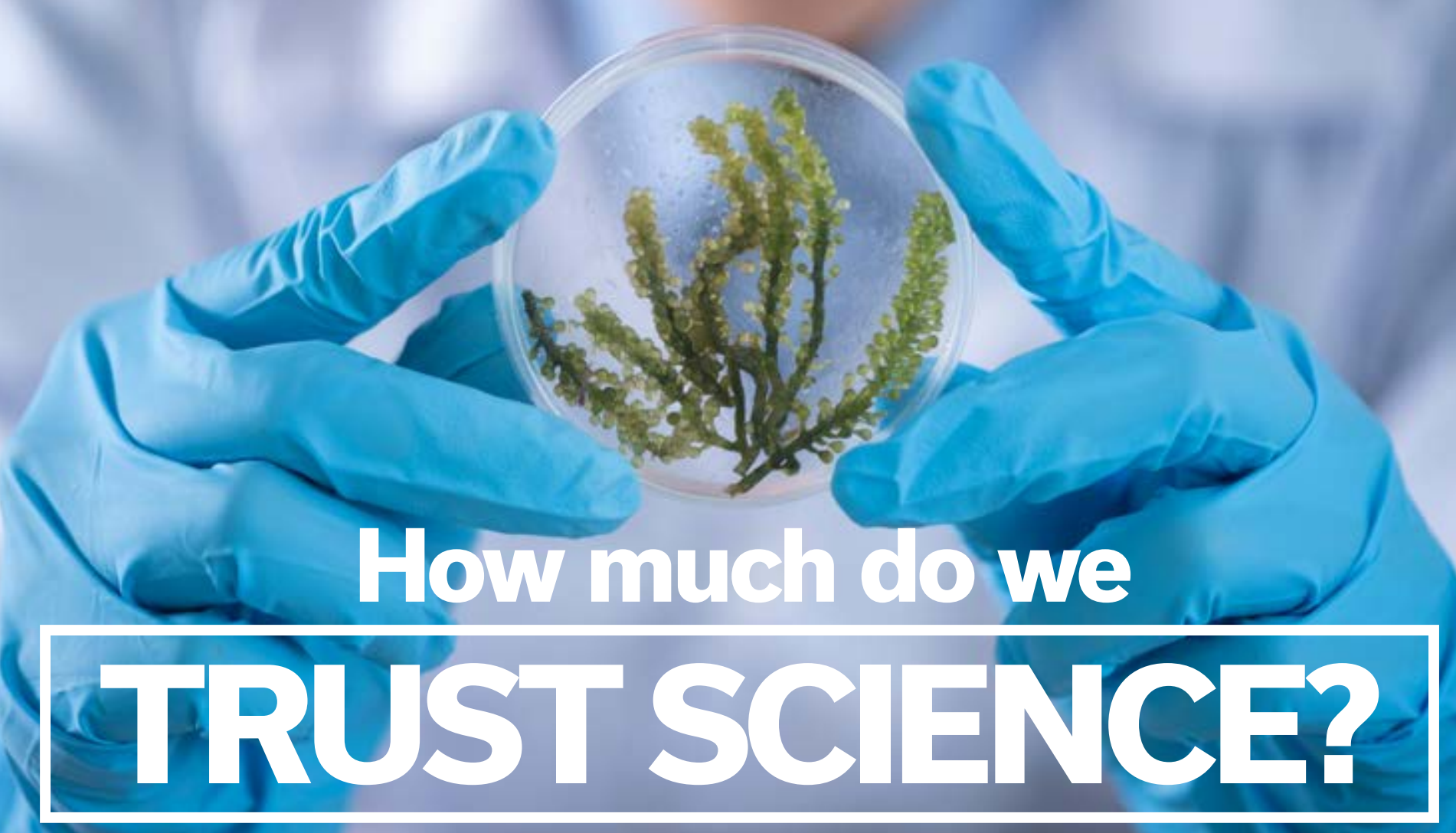

In 2019, we started to measure how much INZAVS participants trust science and the scientific community for the first time. Little did we know how important this question would become! We measured this by asking how much people agree with the statement "I have a high degree of confidence in the scientific community". On the flipside, we asked how much people agree that "Our society places too much emphasis on science".

Results show that trust in science is generally high, with over $50 \%$ reporting they were very confident in the scientific community. A further $34 \%$ were mostly confident in the scientific community. In addition, a large majority (3 out of 4 participants) disagreed that we place too much emphasis on science.

However, there was some room for doubt. While only a small group (3.5\%) of participants strongly agreed we place too much emphasis on science, a much larger group (21.8\%) somewhat agreed with that statement. Furthermore, over 1 in 10 participants disagreed they have confidence in the scientific community.

These results from pre-Covid times highlight the importance of tracking our attitudes over time, and will provide a very interesting baseline to compare to as we continue to analyse data from 2020 and beyond. Has trust in science increased or decreased over time? Who might have changed their mind and why? We will update you as the study progresses.
These charts show how much people agreed or disagreed with our two questions about trust in science, both measured on a scale from 1 (Strongly disagree) to 7 (Strongly agree). To help summarise the results, we collapsed people into three categories. If people answered 1, 2, or 3, they are in the 'Don't agree' section of the charts, if they answered 4 or 5 they are in the 'Moderately agree' section, and if they answered 6 or 7 they are in the 'Strongly agree' section. These results are based on 41,427 participants in 2019.
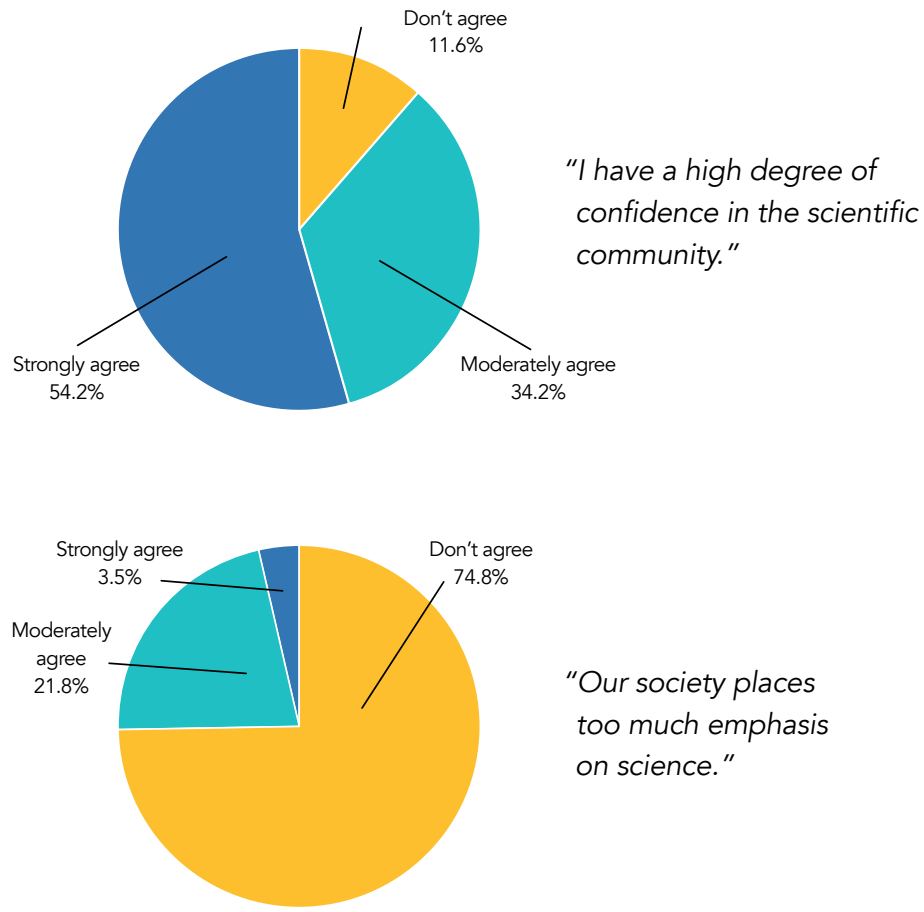

"Our society places too much emphasis on science." 


\section{Plant-based diets}

\section{in New Zealand}

International research has found that plant-based diets have seen a rapid rise in popularity over the last few years. Has the same change occurred in New Zealand? Using NZAVS questionnaires from 2017 and 2018, we investigated how many people changed their diet in the space of a year, and what kinds of people were likely to make the change.

We found that in $2018,94.1 \%$ of participants were omnivores (someone who eats meat), $4.6 \%$ were vegetarian, and $1.2 \%$ were vegan. Against expectations, vegetarian or vegan people were reasonably likely to start eating meat again from one year to the next, while omnivores were not very likely to stop eating meat (1.2\%). Furthermore, vegetarian people were more likely to become an omnivore than become vegan, while vegans were equally likely to become a vegetarian or an omnivore. For those people who did stop eating meat, they were more likely to be female and politically liberal. However, factors like health or caring about the environment did not seem to be related to changing one's diet.

While other research has suggested more people report they are mostly vegetarian, these findings show that less people are strictly vegetarian or vegan.

This research was led by Professor Taciano Milfont and was published in Appetite.

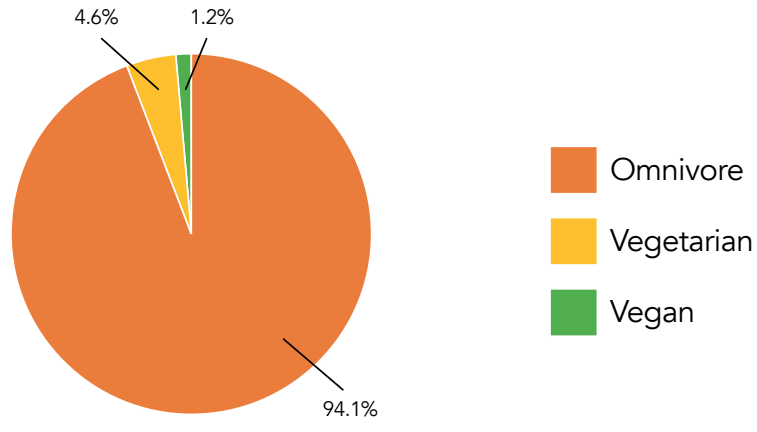

This chart represents the percentage of people who reported they were vegetarian, vegan, or an omnivore (someone who eats meat) in the NZAVS sample of 45,352 people in 2018.

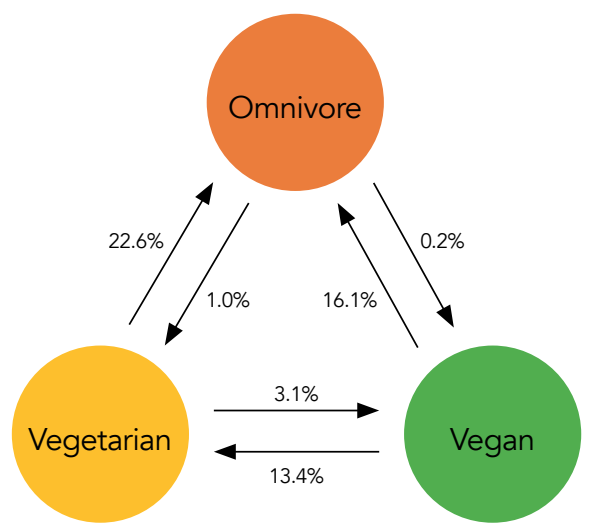

This diagram shows the probability that someone might change their diet over the course of a year (based on 12,259 people between 2017 and 2018). A vegetarian, for example, has a 3.1\% chance they will decide to become a vegan over the next year - but a $22.6 \%$ chance they will stop being vegetarian and start eating meat.

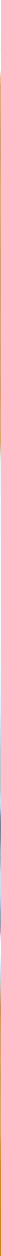




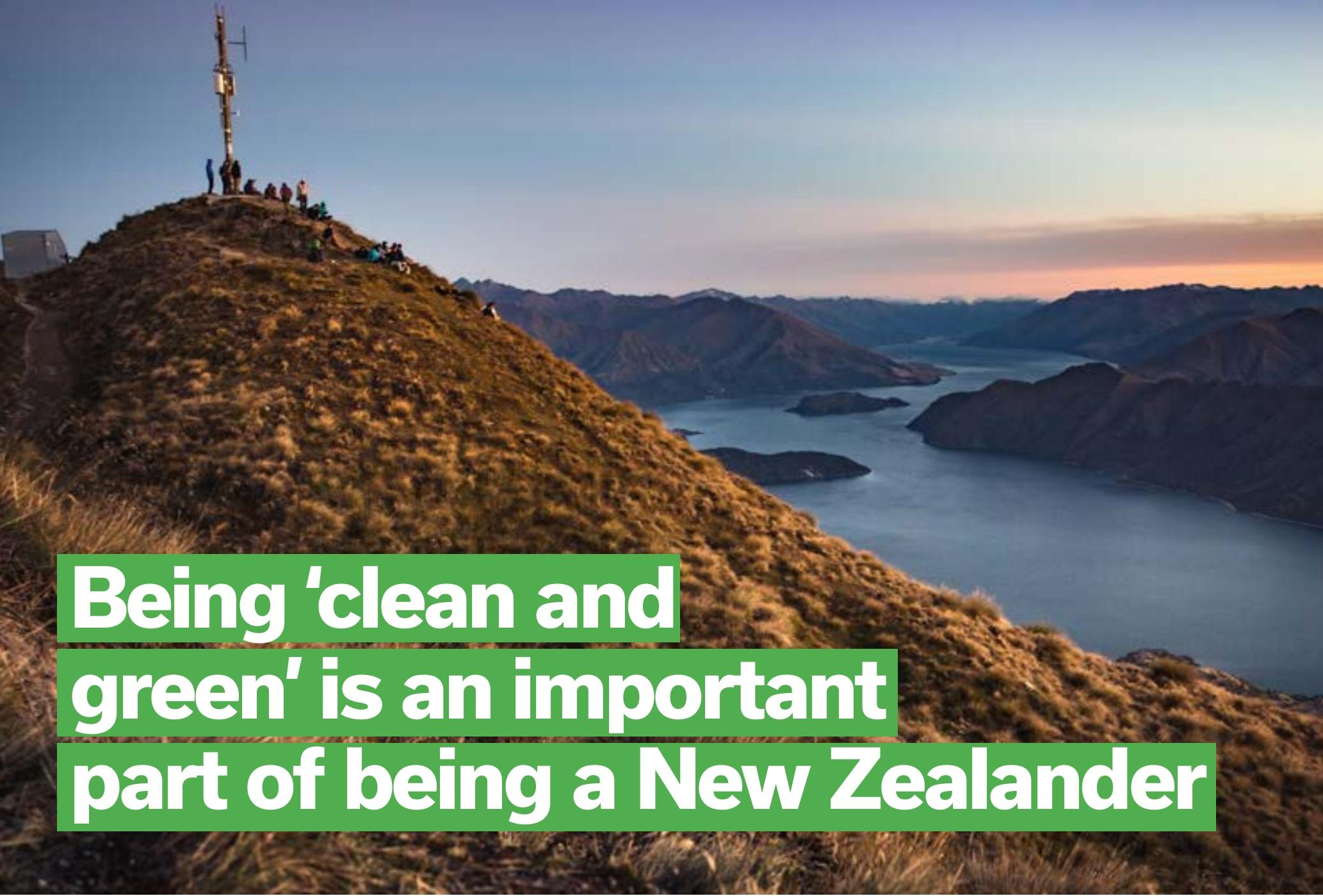

Research has shown that when people see environmentalism as part of their identity they are more likely to take actions to address climate change - but does that extend to our national identity? In this research led by Professor Taciano Milfont, we wondered whether having a 'clean and green' attitude is considered an important part of the New Zealand identity and whether this pro-environmental national identity influences people's environmental actions.

We investigated how 13,942 NZAVS participants define 'a true New Zealander' in terms of eight attributes, and identified five different groups with slightly different endorsements of those attributes. 'Local Egalitarians' (52.1\% of the sample) rated egalitarianism, clean and green, and respect for NZ's institutions and laws as being important qualities of being a true New Zealander. 'Global Egalitarians' (9.2\%) agreed with Local Egalitarians, but they also very clearly rated being able to speak English or having a NZ citizenship as not important. 'Nationalists' (22.8\%) similarly agreed with Local Egalitarians, but thought that having Māori or European ancestry, good knowledge about Māori culture, and liking rugby were also important aspects of being a New Zealander. 'Ethno-Nationalists' (5\%) were very similar to Nationalists but put even more emphasis on having Māori and European ancestry and liking rugby. Finally, 'AntiEgalitarians' (10.8\%) placed less emphasis on egalitarianism, Māori culture, or being 'clean and green' as qualities of true New Zealanders.

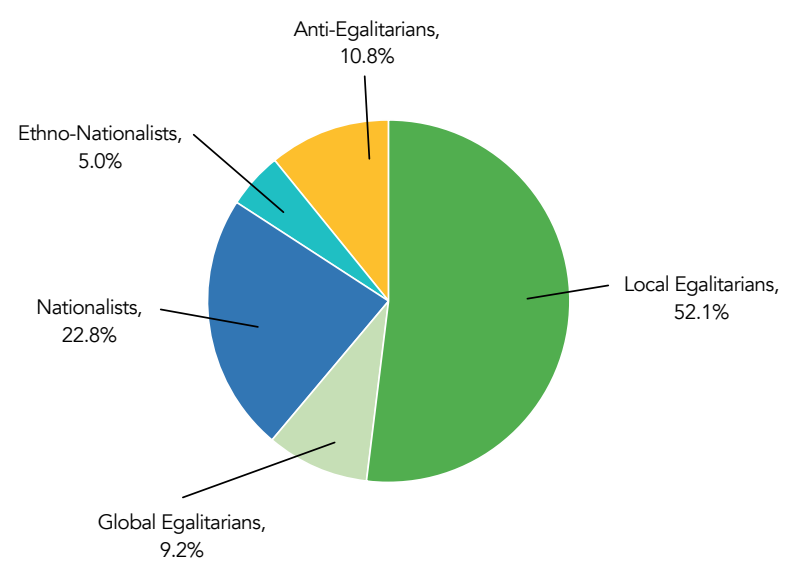

Being 'clean and green' was therefore rated as an important part of being a true New Zealander by the vast majority (89\%) of the participants. It wasn't just talk either - people who thought environmentalism defines New Zealanders were more likely to be concerned about climate change, make personal sacrifices for the good of the environment, and support policies such as regulating carbon emissions and making public transport more accessible.

These findings suggest environmentalism is a key part of the New Zealand identity, and that our shared identity as New Zealanders does indeed motivate us towards pro-environmental beliefs, policies, and actions.

This research was published in the Journal of Environmental Psychology. 



\section{How is body image changing over time?}

\section{Body image concerns among men and women}

are unfortunately very common, and some previous research suggests it has been getting worse over the last few decades. In this research led by Dr. Allanah Hockey, we investigated how New Zealanders' body image has been changing across seven years of the NZAVS (2010-2016) in 15,264 participants.

Our body image changes over time in two ways. Firstly, as we age and our body changes, the way we feel about it changes too. At the same time, our society changes, with different body types coming and going from fashion over the decades.

First, we looked at how body image changed with age. Results showed that, for men and younger women, body image stayed relatively the same as they aged. Although as we get older, we move further away from the young and fit people presented in the media, we also care less about how our body compares to others. Theories suggest these two things balance out and our body satisfaction stays mostly the same across the lifespan. However, for women aged approximately 60 and over, body image slowly improved with age.

Next, we looked at how body image changed over time. Results showed that younger women (below the age of 55) were reporting that their body image was improving over time - not as they age but as society changes. For example, results showed that a 39-year-old woman in 2016 would have better body image than a 39-year-old woman in 2010. The fact that only younger women's body image was improving over time may mean it is a result of recent fat acceptance and body positivity movements that largely take place on social media.

Only very small improvements were found in men's body image over time. However, men on average were much more satisfied with their bodies than women at every age. Women's body image was generally very low - it's not until the age of 60 that the average woman began to rate herself as satisfied with her body.

This research was published in Body Image.

\section{A romantic part
less time online}

\section{s we have relied on technology more and
more over the last two years, there is one} sure-fire way to cut down on screen time - be in a relationship.

Having a partner meant spending about an hour less a week playing video games or watching TV (or online streaming services), over an hour less using social media, and two hours less using the internet in general. The exception?

For people under 30 years old, being in a relationship didn't mean any less TV or social media compared to being single.

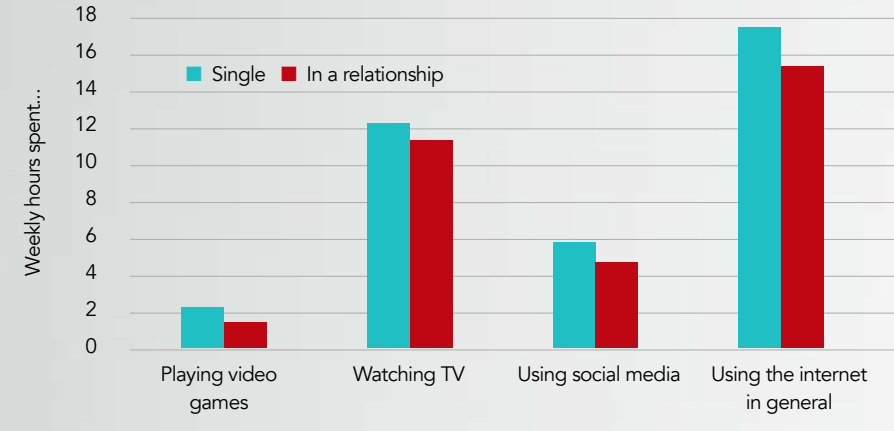

This chart shows the average number of hours per week people reported they spent doing each activity, for those who said they had a romantic partner and those who didn't. These data come from 39,208 participants in 2019. We account for differences between people with and without children.

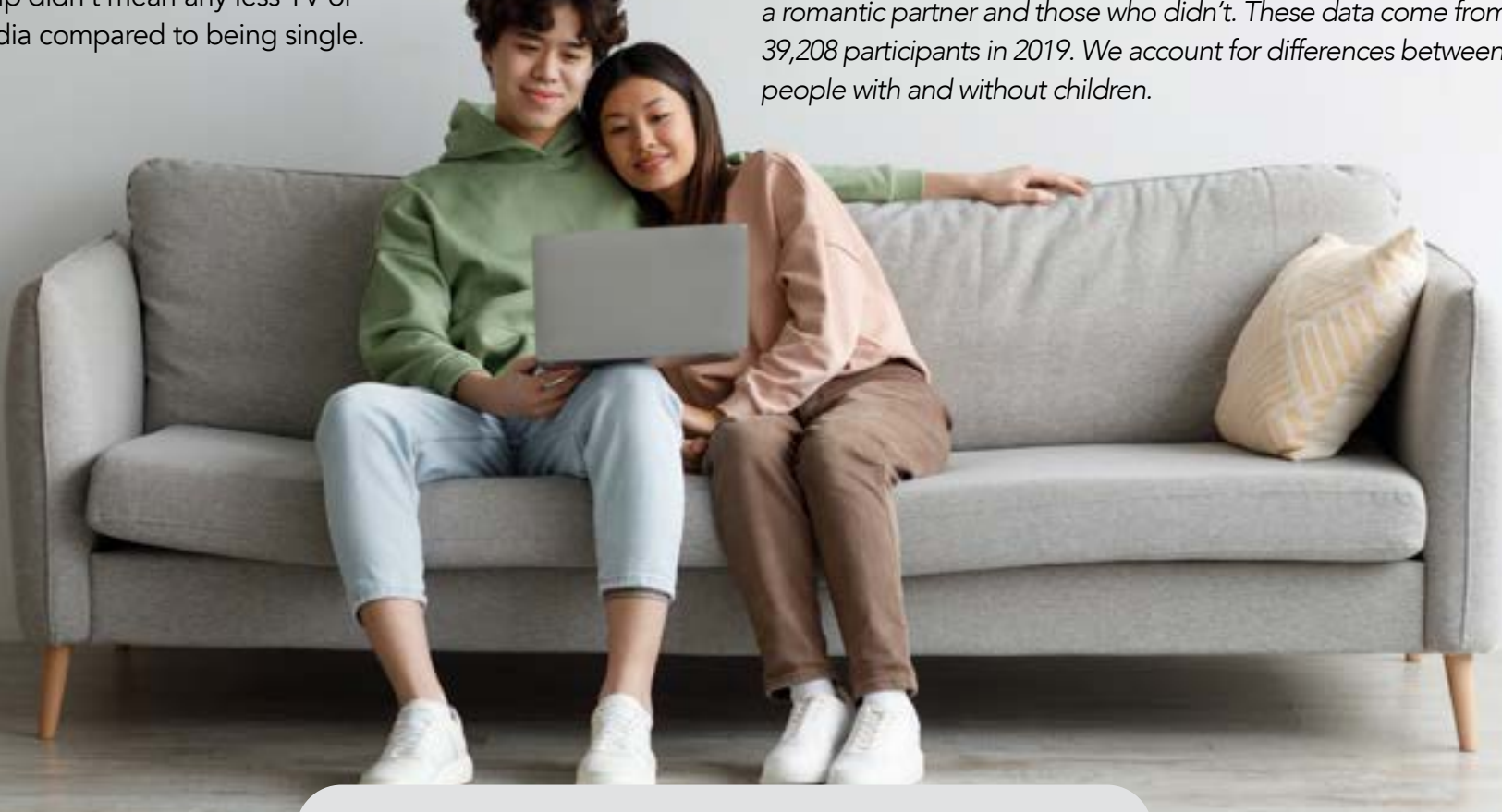




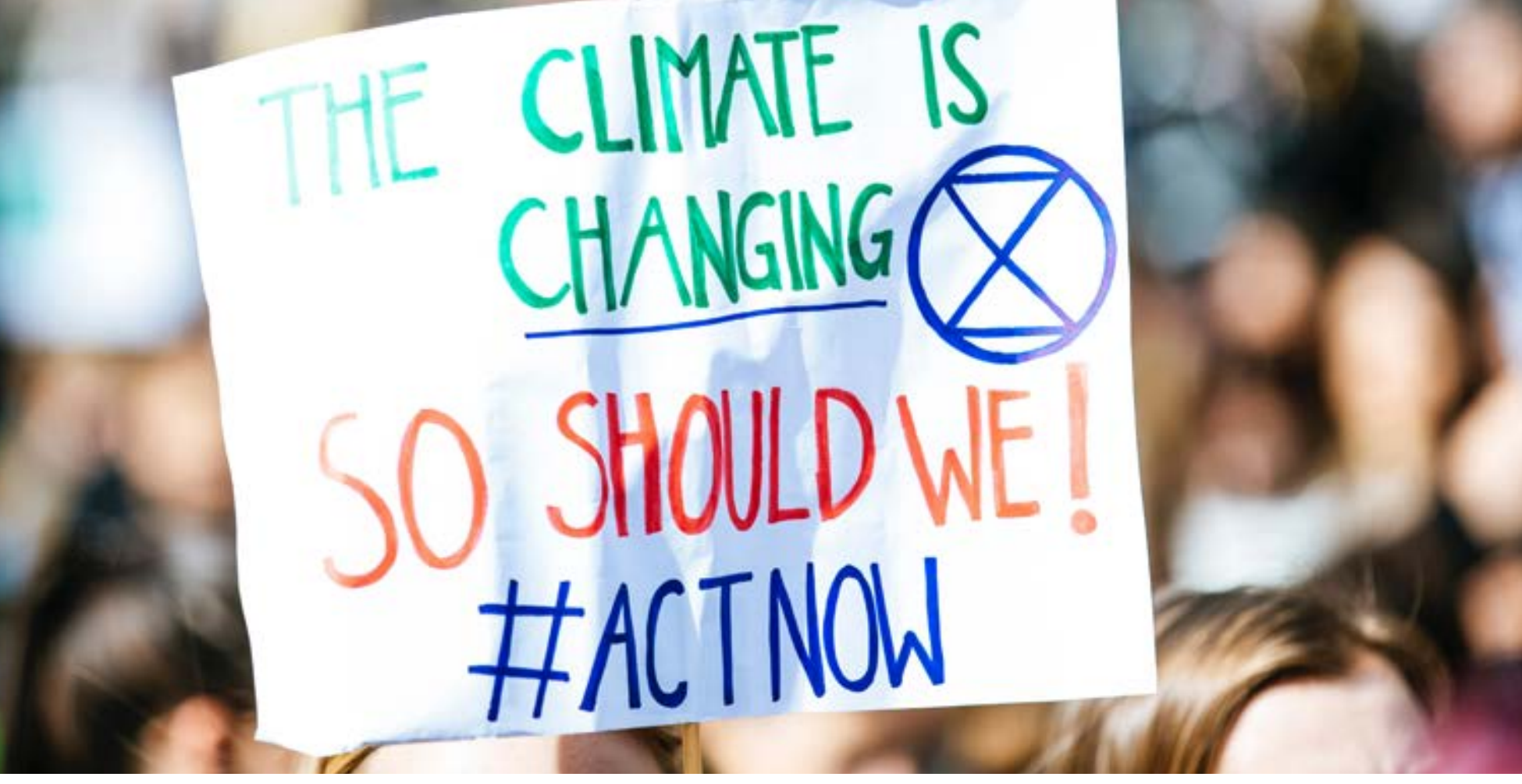

\section{Aging and climate change}

Concern about climate change is increasing worldwide, but is that true for everyone? Some commentators have pointed out that climate change is far more of a concern for younger generations than for older generations. Some people even argue that older generations don't care at all as they won't be directly impacted by climate change in their lifetime.

In this research led by Professor Taciano Milfont, we used ten years of data from the NZAVS and 56,513 participants to examine change over time in climate change beliefs. We found that there was a generation gap in how much people believe climate change is real and is caused by humans. Middle-aged adults believed in climate change the least, while younger and older adults had similarly high levels of belief in climate change.

However, there was no generation gap in how people were changing their views on climate change. Belief in climate change showed a similar increase over the ten years in every age group. Furthermore, belief in climate change was accelerating - not just growing but growing faster each year.

This research shows that while there were age differences in where people began in their belief in climate change, everyone is rapidly coming to the same conclusion. In fact, older generations' belief in climate change was growing the fastest. The generation gap exists, but is closing fast.

This research was published in Nature Communications.

\section{What did a 'normal' day used to look like? For some, long commutes}

\begin{abstract}
s we finalise the data collected from 2020 and 2021 , let's take a look back at how life used to be before lockdowns even existed.
\end{abstract}

For those in the workforce, New Zealanders spent an average of 4.89 hours commuting a week - which some of us may not miss. For a typical 9 to 5 job, that works out to be just under a half hour commute each way. $13.4 \%$ of employees already worked from home, reporting they spent no time commuting. On the other end of the spectrum, nearly one third of Kiwis had an hour-long (or longer!) commute per day.

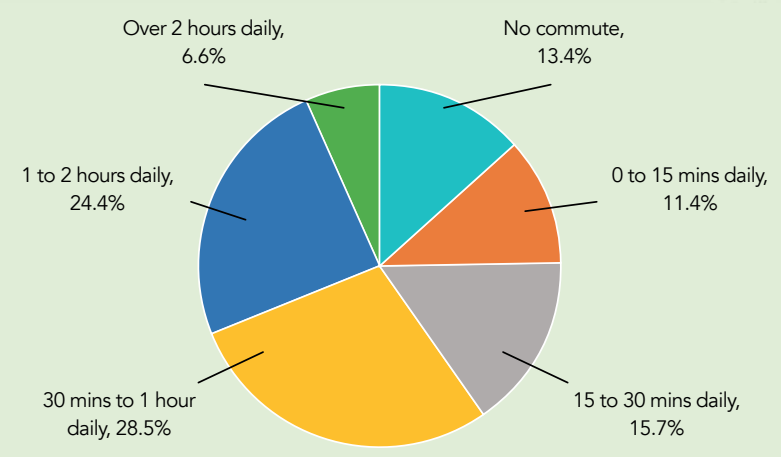

This graph shows the percentage of people with different commute times based on 29,957 participants in 2019. People reported on the weekly time they spent commuting, and we calculated the daily commute assuming 5 commutes per week. We only looked at people who said they had worked in paid employment that week. 
